

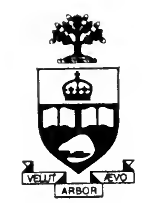

\author{
Presented to the \\ LIBRARIES of the \\ UNIVERSITY OF TORONTO
} by

Hugh Anson-Cartwright 
by

,
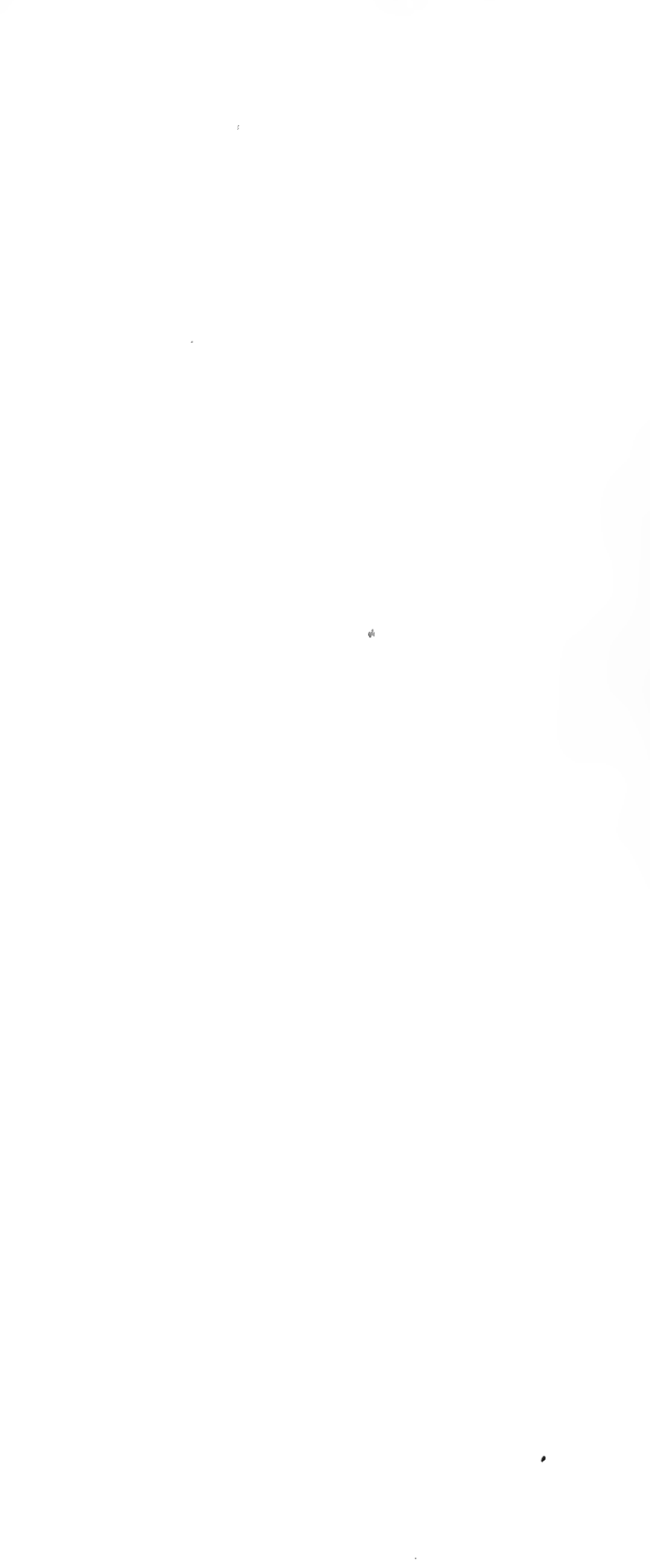


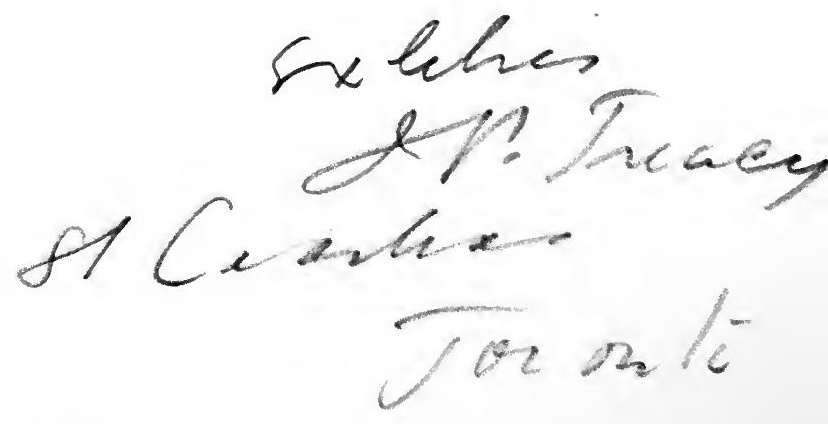

WORKS OF PASCAL。 



\title{
THI:
}

\section{THOUGHTS, LETTERS, AND OPUSCULES}

\author{
BLAISE PASCAL
}

TRANSLATED FROM THE FRENCH BY

O. W. WIGHT, A.

WITH INTRODUCTORY NOTICES

AND

NOTES FROM ALL THE COMLENTATORS

BOSTON

HOUGHTON, MIFFLIN AND COMPANY

Cbe Riverside Đress, $\mathbb{C}_{\text {ambriðge }}$

1890 


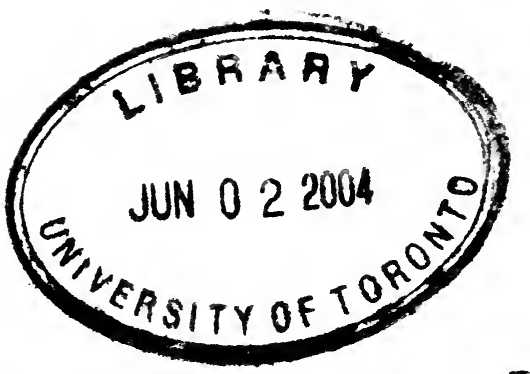

Copyright, 1859 and 1887. BY O. W. WIGHT. 


\section{0 N T' E N T S.}

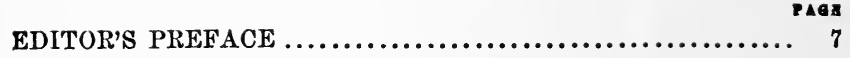

EDITIONS OF PASCAL'S THOUGHTS.................. 15

GENIUS AND WRITINGS OF PASCAL $\ldots \ldots \ldots \ldots \ldots \ldots \ldots . .38$

PASCAL AS A PHILOSOPHIC SKEPTIC ............... 85

PLAN OF THE THOUGHTS......................... 189

THOUGHTS OF PASCAL............................. 149

LETTERS OF PASCAL $. . . \ldots \ldots \ldots \ldots \ldots \ldots \ldots \ldots \ldots \ldots \ldots \ldots . \ldots 11$

OPUSCULES OF PASCAL ........................... 45 



\section{EDITOR'S PREFACE.}

This volume contains: 1st, an account of the " $\mathrm{Va}$. rious Editions of Pascal's Thoughts ;" 2d, an essay on the "Genius and Writings of Pascal;" 3d, "Pascal considered as a Philosophic Skeptic ;" 4th, the "Thoughts of Pascal ;" 5th, the "Letters of Pascal ;" 6th, the "Opuscules of Pascal."

The introductory paper, on the "Various Editions of Pascal," we have translated from M. Charles Louandre's lengthy preface to his edition of Pascal's Thoughts, etc. It gives a complete and interesting history of the earlier and later editions, and to it we refer for the considerations that have led us to lollow the arrangement adopted by him.

The "Essay on the Genius and Writings of Pascal" has been taken from the Edinburgh Review, for January, 1847, and is by Henry Rogers. We have used it because it contains the fairest and ablest discussion, from a religious point of view, of Pascal's philosophic skepticism.

"Pascal considered as a Philosophic Skeptic," is 
by the great French philosopher, M. Victor Cousin, and has been especially translated for this edition. When M. Cousin published, in 1849, a new edition of his "Blaise Pascal," he answered, in a lengthy preface, those who had, in the mean time, attacked him for bringing, in the first edition, a charge of philosophic skepticism against the ablest and most saintly of the Port-Royalists. It is this preface which we here reproduce. Henry Rogers, in his article on Pascal, especially attacks M. Cousin, and it is certainly fair to give the philosopher a chance to reply. These two polemics, thus brought face to face with each other, may be taken as able representatives of all that has been said on this question.

Of the Thoughts of Pascal we here give an entirely new version. After having carefully examined the editions of Faugère, Havet, Astié, and Louandre, we have adopted that of the last, because it contains all the Thoughts, and is neatest and most tasty in arrangement. It also contains judiciously selected notes from all the distinguished writers and commentators on Pascal, and these notes, together with M. Louandre's ôwn notes, we have transferred.

In translating the Thoughts, we have constantly aimed to express in English precisely what Pascal expressed in French. We fully agree with Pro. fessor Felton, that "we are not among those who 
think a pasaphrase is a translation. We do not think it the translator's duty to give us what he supposes his author would have written, had he writ ten in English, for this is precisely what the translator can never know. It is his plain duty, as we conceive, to let us know what his author has actually written, as a German, or a Frenchman, or whatever the case may be; not violating, of course, the genius of the language into which he translates, while doing so. We do not admit that the English language is incompetent to this task. It is rich enough to cope with the difficulties of any foreign author, who has a fund of solid thonght sufficient to sustain a faithful translation. Taking the whole range of the English language and literature, from the racy primeval expressions of Chaucer to the affluent harmonies of Spenser,-the all-embracing, all-describing, all-expressive forms of Shakspeare,- the majestic music of Milton, which made his mother tongue search her coffers round and round,- - to say nothing of the thousand-fold varieties of later prose-writers and poets, we have no doubt that all the phases of human thought, from the broadest farce up to the sublimest conceptions of benius, may be furnished with suitable expression from the store-houses of our mother-English speech." ${ }^{1}$

1 North American Keview, October, 1841, pp. 409-10. 
As to previous translations, but two need any attention here. The version of Edward Craig, A. M., Oxon., is now worthless, because the French edition from which he translated is now worthless The translation of George Pearce, Esq., published by the Longmans, in 1849, is at best a weak para. phrase of Pascal. $\mathrm{He}$ has constantly missed the meaning of the original, and has omitted every thing savoring of Catholicism in Pascal. "The very fow passages," he says (Introduction to Pascal's Miscellanies, p. xli.), "which incidentally occur among these papers, containing either direct advocacy, or tacit approval, of some of the doctrines of the Romish Church, are omitted." We can conscientiously say that our version is the first complete and honest translation of Pascal's immortal Thoughts into the English language. Not only have we adhered closely to the original, but have put in brackets any additional word or phrase necessary to complete the sense in another tongue. That, however, we have nowhere missed a shade of meaning, in Thoughts fragmentary at best, and sometimes so obscure as to be almost enigmatical; that we have nowhere, in a very literal rendering, used a form of expression peculiarly Gallic, is too much to hope, too much to be demanded. We devoutly pray Heaven that these sublime Thoughts of one of the greatest souls vouch- 
safed to earth, may inspire many a reader with humjie reverence for religious truth.

For a translation of the Letters of Pascal we are indebted to Miss Mary L. Booth, whose elegant version of M. Cousin's "Madame de Chevrense" is well known. In the arrangement of the Letters we have followed the edition of Astié. No French edition contains all the letters. In our edition we believe the collection is complete.

The Opuscules-among which are some of the finest productions of Pascal-have been translated from the text of Faugère. The arrangement is that of Louandre.

We take leave of Pascal with regret. Many holy hours we have spent in his company, and have thanked the Omniscient for such a revelation in man of moral and intellectual force. We regard Pascal not only as the greatest genius but as the holiest man that France has produced. To the young men of America we commend a writer in whom greatness snd rectitude of mind were combined in an equa degree.
O. W. WIGHT.

SkPTEMBER, 1859. 


$$
\bullet
$$




\section{EDITIONS OF PASCAL'S THOUGHTS,}

FROM THE

\section{INTRODUCTION TO THE "VARIORUM" EDITION OF M. CHARLES LOUANDRE.}

Tue history of these editions may be divided into three distinct periods, extending: $1^{\circ}$ From 1670 to $1779 ; 2^{\circ}$ From 1779 to $1842 ; 3^{\circ}$ From 1842 to 1854 .

I.

It is known that Pascal, on renouncing alike the world and science, formed the project of writing a great work on Christianity. ${ }^{1}$ He labored long upon it, but wholly within himself, and, if we may rely upon the testimony of his contem. poraries, it was only during the four last years of his life that he committed fragments of it to paper. "The greatest care and the principal occupation of those about him," it is said in the Preface of 1669 , "were to keep him from writing, and even from speaking of aught that required any struggle of mind, and to converse only of things indifferent and incapable of fatiguing him. . . . Nevertheless, when there occurred to him any new thoughts, any views, any ideas, or even any forms of expression that he foresaw might at some

1 It will be seen further ol, in the extract from the Preface of the edition of 1669 , how, a dozen or thirteen years before his death, Pascal developed pefore some friends the plan of this work. 
future time avail him in his design, since he was not then in a condition to apply himself so closely as when he was in good health, nor to impress them upon his mind and memory, he preferred to make some note of it in writing, in order not to forget it; and for this purpose he took the first piece of paper that he found at hand, on which he put down his thought in few words, and often even in abbreviation, for he wrote only for himself; for which reason he contented himself with doing it very slightly, in order not to fatigue his mind, and set down only the things necessary to recall his views and ideas.

"Such is the manner in which the Thoughts were written; and I believe no one will find any difficulty in judging by these slight beginnings and feeble essays of an invalid, which he had written only for himself, to recall trains of thoight that he feared to lose, which he had never reviewed or retouched, what the complete work would have been if he had been able to recover his health perfectly, and give to it the finishing touch,he who was so skilful in lucid exposition and clear arrangement, who gave such a peculiar, noble, and striking turn to every thing he wished to say, who intended to bestow more labor upon this work than upon all that he had ever made, who intended to devote to it all the strength of mind and all the talents that God had given him, and for the completion of which he often said that he needed ten years of health.

"As it was known that Pascal had the design of producing a work on religion, great care was taken after his death to collect all the writings he had made on this subject. They were found all filed together in different bundles, but without any order, without any sequence, because, as I have already remarked, they were only the first expressions of his thoughts which he wrote on bits of paper as they occurred to his mind.

"The first method that occurred to the mind, and that which was doubtless the easiest, was to have them printed just is they eame in the state in which they were found. But it was soon judged that by such a procedure nearly all the frui would be lost that might be hoped for from the work; because 
the most perfect, most coherent, the clearest and most extended thoughts were intermingled with, and, as it were, lost among so many others that were imperfect, obscure, half digested, and even at times unintelligible to any other than to him who had written them. Hence, there was every reason to believe that some would rebut others, and that the volume, uselessly swelled with so many imperfect thoughts, might be regarded only as a confused mass, without order, without sequence, and productive of no good.

"There was another way of giving these writings to the public, which was, to prepare them beforehand, to elucidate obscure thoughts, to complete those that were imperfect, and, taking the design of M. Pascal in all these fragments, to supply in some sort the work that he wished to produce. This way would certainly have been the most perfect; but it would also have been very difficult to execute it well. Nevertheless, the matter was a long time under consideration, and in fact the work was commenced. But it was finally resolved to reject it as well as the first, because it was considered almost impossible to enter fully into the thought and design of the author, and especially of an author deceased, and because it would not have been giving the work of Pascal, but a work quite different.

"Thus, to shun the inconveniences of both these methods of publishing these writings, an intermediate method has been chosen and followed in this collection. Among this great number of thoughts, only those have been chosen which have appeared the clearest and most complete, and they have been given as they were found, without any addition or change, except that, while they were without sequence, without connection, and confusedly scattered from side to side, they have been put in some sort of order, and those on the same subjects have been arranged under the same titles, and all the others that were too obscure or too imperfect have been suppressed."

We shall see further on what value is to be attached to the assertion, without any addition or change, and what were, for the most part, those thoughts either too obscure or too imperfect Fihich the severe criticism of the first editors had put aside. 
The princeps edition of 1669 was followed by two other editions, the last of which appeared in 1671. All three are, as to text, perfectly identical. In 1678 there was a fourth re-impression, to which were added a few new thoughts ; finally, in 1687, this last edition was reprinted, with a curious opuscule, whose publication had been delayed by the Jansenist controversy. This opuscule was the Life of Blaise Pascal, by his sister, Madame Périer.'

Save the unimportant additions made in 1678, the Thoughts remained, until the eighteenth century, what they were in the first edition. But in 1727, Colbert, Bishop of Montpellier, in a letter to the Bishop of Soissons, printed, in a very inexact manner however, some new fragments on the miracles. Finally, in 1728, Father Desmolets, of the Oratory, published under the title of Posthumous Works, or Sequel of Pascal's Thoughts, a considerable number of fragments till then unpublished; he also gave, in the Continuation des Mémoires de Litterrature, a morceau entitled Conversation of Pascal and Sacy $m$ the reading of Epictetus and Montaigne.

Thus, as time advaneed from the seventeenth century, the literary heritage of our author inereased, while by the successive publications that we have just indicated, the first editions were rendered more and more incomplete.

"The Thoughts," says M. Sainte-Beuve, "had remained unanimously accepted and unattacked, till Voltaire opened the breach in 1734. 'Would you counsel me,' wrote Voltaire at this date to Formont, 'to add to the Lettres philosophiques some detached reflections on the Thoughts of Paseal? I have long desired to combat this giant. There is no warrior so well armed that he may not be pierced in the weak point of his harness ; and I confess to you that if, in spite of my weakness, I could give some blows to this vanquisher of so many minds,

1 See for more ample details on the editions of 1678 and 1687, and on the sauses that delayed the impression of Madame Périer's Life, "Pensées, fragnerts et lettres de Blaise Pascal," par M. Prosper Faugère, Paris, 1844, in-8e t. i. Introduction, xxiii. et. seq. 
and break the yoke which he has imposed upon them, I should almost dare to say with Lucretius :

"Quare superstitio 1 pedibus subjecta vicissim
Obteritur, nos exæquat victoria cœlo."

w Moreover, I shall proceed with caution, and criticise no passages that are so connected with our holy religion that one cannot tear the skin of Pascal without making Christianity bleed.' This was the first signal of reaction, for we cannot honor with a serious appellation the chicaneries of the Archbishop of Embrun, M. de Tencin (1733), and the foolish accusation of Father Hardouin, who, in his book of Atheists unveiled (Athei detecti), ranked Pascal among them in excellent company."

Things remained in the same state till 1776 ; at this date, Condorcet undertook to unite in a new and general edition what the editors of 1670 , those of 1678 , the Bishop of Montpellier, and Father Desmolets, had in turn given to the public, adding to these scattered pieces some new fragments, among others the treatise entitled of the geometrical spirit, accompanying the whole with an Eloge. In spite of his elevation of mind, Condorcet forgot, in reprinting Pascal, a very common and simple thing-that the first obligation of an editor is to respect the text of a writer he publishes. In order to adapt himself to the taste of his times, and perhaps convinced that he was heightening the glory of Pascal, he suppressed a multitude of passages, and the finest, especially of those wherein the author of the Thoughts shows himself most eloquently, most profoundly Christian. Voltaire applauded this profanation, and, adopting in his turn this mutilated Pascal to varess and rend him at the same time, gave, in 1778, a new tdition, accompanied by a commentary, that is, for the most Dart, but a bitter and unjust criticism. ${ }^{2}$

1 Relligio in the text.

2 Voltaire comprehended that Paseal was the great rival who interfered with philosophy, and he attacked him faee to faee. Why did he attack Pascal rather than Bossuet, or any other? This is, in my opinion, a sin 
Thus, in a space of a hundred and eight years, that is, from 1670 to 1778 , Pascal had successively for editors Port-Royal and his own family, the Bishop of Montpellier and Father Desmolets, Condorcet and Voltaire; and between these two extreme dates, he was equally and pitilessly disfigured, corrected, and mutilated, in the name of Jansenist piety and philosophic skepticism.'

\section{II.}

In the year 1779 appeared a new edition of Pascal, that comprised at once the scientific and literary works, and may be regarded as an attempt at reaction, but a reaction still timid, against the spirit by which Voltaire and Condorcet had been inspired. This edition, made by the Abbé Bossut, reproduced, with the pieces previously published, the text of the edition of 1678 , and contained, besides, new thoughts and fragments hitherto unknown. It was, doubtless, the most complete and the most worthy of all the editions that had appeared up to that time; it became an authority, and served as a model for subsequent re-impressions, - in 1783, by Father André ; in 1803, by Renouard; in 1819, by Lefèvre; and yet the edition of Bossut, like the editions of 1669 and 1678, fails to give the true and authentic text of Pascal.

A modest scholar who lived at Dijon, occupied with literature, without seeking to make a noise and gain renown, first recognized, as early as the beginning of this century, that all the editions of Pascal left very much to be desired; and, without having recourse to the autograph manuscript, he nevertheless attempted to recover the primitive plan of Pascal. This editor, to whose efforts sufficient justice has not

gular honor, and proves that Pascal is at the very heart of Christianity.Sainte-Beuve.

1 Sainte-Beuve remarks the fact, that no one among the French clergy defended Pascal against Voltaire, and that the only champion who entered the lists in favor of the author of the Thoughts was a Protestant, son of the refugee Boullier, who ansvered Voltaire with vigor and gravity.--PortRoyal, t. iii. p. 322, et seq. 
been rendered, was M. Frantin, who published, in 1835, the Thoughts in a new order; and, in an excellent Preliminary Discourse, advanced just and sagacious ideas. The classification adopted by M. Frantin is in many respects questionable, and so much the more arbitrary, as the editor had not the indications of the manuscript to guide him ; moreover, as, for the first edition, he was not acquainted with the original text, he allowed faulty readings to remain; but we should none the less render this justice to him, that he first designated the necessity of a revision, and showed that there was something new to be tried. This is a merit which it would be unjust to contest.

What M. Frantin had quietly attempted in 1835 , M. Cousin accomplished with eclat in 1842, in his report to the French Academy, on the necessity of a new edition of Pascal's Thoughts.'

Guided by what might be called the piety of admiration, Cousin investigated the origin and source of the different pieces which the editors had successively given under the title of Thoughts. He established that those papers which had been found altogether, filed in different bundles, but without any order and sequence, collected and pasted on large sheets, had reached us under the form of a grand folio register composed of four hundred and ninety-one pages; that this precious register, falling as a heritage into the hands of the Abbé Périer, had been deposited by him, in 1711, in the abbey of Saint-Germain des Prés, as the following letter, which is found on the first page of the manuscript, witnesses:

" I, the undersigned, priest, canon of the church of Clermont, certify that the present volume, containing pages, the first of which begins in these words, and the last in these, is composed of small pieces of paper written on one side, or of loose leaves that have been found since the death of M. Pascal, my un-

1 This report, first printed in the Journal des Savants (April-November, 1342), was afterwards published in book form. Paris, 1843. There have neen soveral editions of it. $-E d$. 
cle, among his papers, and are the originals of the book of Pascal's Thoughts, printed by Desprez, at Paris, for the first time in the year, and are written in his hand, except certain that he dictated to persons that were with him; which volume I have deposited in the library of Saint-Germain-desPrés, to be preserved there among the other manuscripts which are there kept.

"Done at Paris, this twenty-fifth September, one thousand seven hundred and eleven.

\section{(Signed,) Perrer.”}

From the abbey Saint-Germain des Prés, where it remained during the eighteenth century, the legacy of the Abbé Périer was removed, at the period of the revolution, to the impcrial library ; moreover, M. Cousin has established that there exsst, in the same place, "two copies of the manuscript of the Thoughts, both belonging to the end of the seventeenth century or the beginning of the eighteenth ; . . . . that, as a sequel to the Thoughts, one of the copies contains a number of pieces relating to Pascal, and by Pascal himself;" finally, that there are also "two very precious manuscripts, one coming from the Oratory, the other from the collection called Supplément aux Manuscrits Français. The first is a folio entitled Manuscrit concernant M. Pascal, M. Arnoul, ets., Oratoire, No. 160 ; it contains a great number of important and little known pieces relating to Port-Royal, very many letters of those Messieurs, among others of Paseal. The other manuscript (Supplém. franc., No. 1485) contains the first part of the Memoirs of Mademoiselle Marguerite Périer, niece of Pascal, on all her family, with the same letters of Pascal which are found in the Oratory manuscript, and many other letters both of Pascal and of the most illustrious personages of Port-Royal."

There was here, it is perceived, a rich mine to explore; but It is a most astonishing fact, that the existence of the autograph manuscript, or copies of it, had long been known. Several editors had horrowed from the manuseript itself, and had $\mathbf{e x}$ 
tracted new Thoughts from it; and nevertheless no one, before Cousin, had thought of examining the original text, or of verifying the editions by this text. Honor, then, to M. Cousin! he has been the first to devote himself to this verification, and has thus restored to us the true Pascal.

\section{III.}

After having indicated the different collections to which it is indispensable to have recourse, M. Cousin set about demonstrating the necessity of a new edition. He first examines the publication of 1070, made by Pascal's friends, - Arnaud, Nicole, the Abbé Périer, and the Duc de Roannez. "Port-Royal," he says, "has treated Pascal as it had Saint-Cyran; and, after having often softened the Thoughts in order to render them more edifying, it has unscrupulously corrected the style to render it more exact, more regular, more natural, according to the model of a natural and tranquil style which it had formed for itself. Port-Royal had much esprit, and, sometimes, grandeur; it has therefore spared both the esprit and the grandeur of Pascal; but it has laid ruthless hands on every thing that revealed what was deepest in his thought and soul; and as this soul shines forth at every line traced by the dying hand of Pascal, Port-Royal was compelled to correct and alter every thing. I defy any one to invent a method of altering the style of a great writer to which the style of Pascal has not been subjected in the hands of Port-Royal. There was here no Jesuitical censorship to be feared; there was no other censorship than that of genius by mediocrity. I here allude to the Abbé P'irier and the Duc de Roannez; for there are, in truth, such alterations, that I have not the courage to impute them to Arnaud and Nicole . . . alterations of words, alterations of expression, alterations of phrases, suppressions, substitutions, additions, arbitrary and absurd compositions, sometimes of a paragraph, sometimes of an entire chapter, by the aid of phrases and paragraphs foreign to each other, and, what is worse, decompositions, still more arbitrary and truly inconceivable, of 
chapters which, in the manuscript of Pascal, were perfectly connected in all their parts, and profoundly elaborated."

Finally, Cousin sums up his opinion on the princeps edition in the following words: " 1 . It omits a great part of the 'Thoughts contained in the autograph manuscript, and it omits precisely the most original; 2 . It alters sometimes in their substance, it enervates almost always in their form, the Thoughts that it preserves."

The Port-Royal edition, once put aside as essentially defective, Cousin passes to the examination of that of Bossut, and he finds it with reason quite as faulty. "At first," he says, "it has been made, not according to the autograph manuscript, which Bossut appears not to have seen, but according to the copies of the Abbe Guerrier; that is its least defeet, for these copies are in general faithful. But, strange enough, Bossut, who, in comparing the edition of 1669 with the two manuscript copies, could recognize at a glance the differences and re-establish the true readings, has preserved all the alterations. There is still more : all the Thoughts of the first edition, that are neither in the autograph manuscript nor in the two copies, Bossut preserves, without suspecting, or at least without giving notice that they are not there, and without saying for what motive he retains them."

To these already grave reproaches, Cousin adds, and with iustice, a new reproach,--that Bossut has destroyed the very design of Pascal by dividing the Thoughts into two parts: one containing the Thoughts that relate to philosophy, to ethics, and to belles-lettres; the other, the Thoughts immediately relating to religion. "This distinction," says Cousin, "cannot be applied to thoughts that have all a common aim-the defence of the Christian religion; it gives to the work of Pascal a sort of literary physiognomy, unworthy of the serious obiect proposed to itself by this great mind. . . . . Every thing in Paseal tends to religion; he has not written moral and literary thoughts, like la Bruyère and Vauvenargues, and all his philosophy is but a demonstration of the vanity of phi losophy and of the neressity of religion." 
Here are already many criticisms, yet these are not all. Not content with having disfigured by unhappy and arbitrary divisions what might be called the generative idea of Paseal's immortal fragments, Bossut also introduces among them conversations collected by third persons; so that, instead of finding in his edition the Thoughts such as they really are, that is, fragments of a defence of Christianity, we find rather miscellanies collected almost at hazard from the complete works; sometimes even pieces collected from memory by third persons, and given as being written by Pascal himself.

We will not dwell longer on these details, but referring our readers, for the comparative study of the old editions and the autograph manuseript, to the fine work of M. Cousin, we will here give some phrases, taken at random, that will suffice to show, we think, what Pascal has become in the text of PortRoyal, of Bossut, and of all the editors who, until 1842, have copied each other:'

Pascal: "For, in fine, what is man in nature? A nothing in respect to the infinite, an all in respect to nothing; a mean between nothing and all. Infinitely far from comprehending the extremes, the end of things and their principle are for him inevitably concealed in an impenetrable secret. $\mathrm{He}$ is equally incapable of seeing the nothingness whence he is derived, and the infinite in which he is swallowed up."

Pascal: "Let man, having returned to himself, consider himself in comparison with all else that is; let him regard himself as strayed into this remote province of nature; and let him, from this narrow prison wherein he finds
Port-Royal: "For, in fine, what is man? .... a mean between nothing and all. Ile is infinitely removed from the two extremes; and his being is not less distant from the nothingness whence he is drawn than from the infinite wherein he is engulfed."

Port-Royal: "Let man, having returned to himself, consider himself in comparison with all else that is; let him regard himself as strayed into this remote province of nature; and let him, from what shall seem to him this narrow prison

- We borrow these eomparisons from M. Cousin. This great writer hav ng first made them, it is just to leave him all the eredit of them. 
himself dwelling (I mean the universe), learn to estimate the earth, kingdoms, cities, and himself at a proper value."

Pascal: "Who will blame, then, the Christians for not being able to render a reason for their belief, who profess a religion for which they cannot render a reason? They declare, in explaining it to the world, that it is foolishness, stultitiam, and then you complain that they do not prove it! If they proved it, they would not keep their word : it is in lacking proofs that they do not lack sense. Yes; but although this excuses those who offer it as such, and removes from them the blame of producing it without reason, it does not excuse those who receive it."

Pascal: "We know the truth not only by reason, but also by the heart."

Pascal: "Yes, but it is necessary to wager ; this is not voluntary ; vou are cmbarked; which will you ake, then? Let us see, since it is necessary to choose, let us see which interests you the least. You have two things to lose-the true and the good; and two things to regain-your reason and your will, your intelligence and your beatitude; and your nature has two things to shun-error and misery. wherein he finds himself dwelling. that is, this visible world, learn," etc.

Father Desmolets: "Who will blame, then, the Christians for not being able to render a reason for their belief, who profess a religion for which they cannot render a reason? They declare, on the contrary, in explaining it to the Gentiles, that it is a folly, stultitiam. And then you complain that they do not prove it! If they proved it, they would not keep their word: it is in lacking proofs that they do not lack sense. Yes; but al though this excuses those who offer it such as it is, and removes from them the blame of producing it without reason, this does not excuse those who, on the exposition they make of it, refuse to believe it. Recognize, then, the truth of religion in the obscurity of religion, in the little knowledge that we have of it, in the indifference that we have of knowing it."

Port-Royal: "We ninow the truth not only by reasoning, but also by sentiment, and by $a$ vivid and luminous intelligence."

Port-Royal: "Yes, but it is necessary to wager ; this is not voluntary; you are embarked, and not to wager that God is, is to wager that he is not. Which will you take then? 
Your reason is nt more wounded, since it is necessary to make a choice, in choosing the one than the other. Here is a point eliminated; but your beatitude?

"Let us weigh the gain and the loss : in taking 'heads' that God is, let us estimate these two cases; if you gain, you gain every thing; if you lose, you lose nothing. Wager then that he is, without hesitation. This is admirable. Yes, it is necessary to wager, but I wager perhaps too much."

"Let us weigh the gain and the loss in taking the part of believing that God is. If you gain, you gain every thing ; if you lose, you luse nothing. Bet then that he is, without hesitation. Yes, it is necessary to wager, but I wager per. haps too much."

Changes of this kind that often form real contradictions are met with at every line. It is the same with retrenchments and additions, and great indeed must have been the genius of Pascal if such profanations have allowed any thing of it to survive. But even this is not all. Port-Royal, Bossut, and the other editors, have, in many passages, inverted the very order of Pascal's thought, either by bringing together pieces that evidently should have remained separate, or by separating others that were found, as it were, connected by the very force of the idea; moreover, they have neglected to collect a great number of fragments quite as important as those they have published. It results, then, from all this, that we may justly regard as very faulty the editions of the Thoughts anterior to the report of M. Cousin, a report whose object is before all to demonstrate the necessity of a new edition.

M. Cousin's publication produced a very lively sensation, and raised an interesting polemic. M. Sainte-Beuve, while acknowledging how defective the old editions were, undertook nevertheless to lighten the gravity of the reproaches addressed to the editors of Port-Royal.

"There would be much to say in their faror," he wrote in $1844,{ }^{1}$ " for their acquittal, and on the score of extenuating sircumstances. The peace of the Church, it is known, had just 
been concluded; the Arnauds, the Nicoles, the Sacys, had scarcely left concealment or prison. It was proposed to them to occupy themselves with the papers of Pascal, who had been a few years dead, and to draw from them something useful, edifying, worthy of being offered to the Church of that time and to the faithful-a volume, in fine, that might be shown to friends and enemies. A committee of friends was formed; the Due de Roannez was the most zealous for the memory of his dear Paseal, but he took nothing upon himself, whatever may have been said; and it was M. Arnaud, M. Nicole, and other experts, who held the die. The Périer family was disposed to retrench, to modify, the least possible: family interest accorded in this instance with literary interest (what is so rare); but there were elsewhere powerful, insuperable considerations,- the censors to satisfy, the archbishop to manage, the peace of the Church to respect loyally. It is a marvel, in truth, that in the midst of all these breakers, in presence of this mass of almost illegible papers, from these Thoughts, often incolierent, often rugged, has been drawn, from the outset, a little volume so clear, so luminous, so complete in appearance, and which, even with one or two blunders (to conceal nothing), triumphed so incontestably with all. It is vain to talk afterwards about literary exactitude; there was here a far graver question of fidelity that ruled every thing, and this fidelity was respected by the first editors."

At the present time, now that the motives which guided the first editors exist no longer, the question of exactitude subsists in its integrity, and there remains as an acquisition to literary history: 1st, that the pieces of Pascal designated under the name of Thoughts, ought to be considered as the fragments of the defence of Christianity, of which this great writer developed the plan to his friends some years before his death; $2 \mathrm{~d}$. that in order to leave to these magnificent sketches their first signification, it is necessary to disengage them from a considerable number of fragments with which they have been long intermingled, and which are none the less foreign to the genera plan of the defence for being Pascal's ; $3 \mathrm{~d}$, that the only authen 
ric text of the Thoughts is that of the autograph manuscript. These are the incontestable principles that have guided the two last editors, Faugère and Havet.

The work of Faugère, the oldest in date, appeared in 1844, under the following title: Thoughts, Fragments, and Letters of Blaise Pascal, published for the first time conformably to the original manuscripts, in great part unpublished. To make Pascal known, such as he is in the autograph manuscript, is the end proposed by Faugère; and this end, so far as perfect exactitude of text is concerned, Faugère has completely attained. "We have wished," he says, "that our edition might hold the place of the manuscript texts of Pascal, and particularly of the autograph manuscript. We have read, or rather studied this manuscript, page by page, line by line, syllable by syllable, from beginning to end; and, save a certain number of words that we have taken care to indicate as illegible, it has passed entirely into our edition."

However little one may have studied the manuscript of Pascal, he comprehends how much patience and devotion it required to reproduce with the exactitude of a fac-simile that volume, the reading of which presents almost insuperable diffisulties, as well on account of the writing in itself, as on account of the references and interlineations with which it is filled; and, to be just, we must say that sufficient credit has not been given to Faugère for the eminent service he has rendered to letters; for if Cousin was the first to designate the defectiveness of the early text, it may also be said, with Sainte-Beuve, that the public has to thank Faugère for the re-conquest of the first Puscal.

The question of the text once settled, there remains the question of arrangement, and this, it must be acknowledged, will always leave something to be desired, since it will always be necessarily arbitrary. Faugère has wholly abandoned the order adopted either by Port-Royal or by Bossut, and he bas attempted, according to different indications of the antograph manuscript, to re-estahlish the Thoughts in the order that seemed to him most in accordance with the intentions of 
Pascal. In this essay of reconstruction, he has shown much sagacity; but the order that he has followed is so different from that of all the preceding editions, that the public has found itself, if we may use the expression, nonplussed by this wholly new arrangement. Accordingly Havet, who published, in 1852, a new edition of the Thoughts, has thought best to follow the classification of Bossut, that is, the classification to which the public has long been accustomed. This classification, moreover, when it has been disengaged from certain interpolations and certain arbitrary divisions, has seemed to us to approximate near enough to the general plan developed by Pascal to his friends, and we have thought best to retain it in many points, while fully aware that whatever arrangement is adopted, it is very diflicult, and, thus to speak, impossible, to be strictly methodical; for it is evident that if Pascal wrote certain pieces with the intention of attaching them to such or such a part of his plan, he wrote many others without any definitely preconceived idea of classification. We may now explain the course that we have pursued in the edition that we present to the public. First, in what concerns the Thoughts :

$1^{\circ}$ We have separated, as Cousin has demanded, and as Fangère and Havet have done, all the opuscules that do not form part of the autograph manuscript of the Thoughts, such as the Conversation with Sacy on Epictetus and Montaigne, and the Discourses on the Condition of the Great.

$2^{\circ}$ We have retrenched the Thoughts on Death, which the early editors had drawn from a letter of Pascal; but we have not therefore deprived the reader of them, for we have given in its original form the letter that contained them.

$3^{\circ}$ While avoiding an arbitrary reconstruction of the divisions, we have nevertheless made some transpositions that have seemed to us in accordance with the order indicated by Pascal himself before lis friends, on the subject of the defence of Christianity.

4" We have, at the head of the chapters, put in brackets ti. tles that are borrowed, sometimes from indications furnished by 
the manuscripts, sometimes from the editions of Port-Royal and Bossut, and form, we think, useful summaries, recalling, from point to point, the general idea of the book meditated by Pascal. Thus, in what touches the arrangement and order, we give, without any foreign addition, the Thoughts properly so called, prefacing them with a fragmert borrowed from the first edition, wherein is found a summary narrative of a conversation in which Pascal exposed the plan of his great work.

In what concerns the text, our course has been as follows:

We have caused all the alterations to which the text had been subjected by the early editors to disappear, and we have been able, thanks both to the excellent works of Cousin, Faugère, and Havet, and to the manuscripts, to restore it to its primitive purity; we have brought together what had been arbitrarily separated, separated what had been united without reason, and eliminated every thing that was not Pascal's.

We have not thought it best to reproduce, line by line and word for word, every thing contained either in the manuscripts or in the exact publication of M. Fangère, because however great may be our admiration for Pascal, we have thought that the public would be little interested in obscure or incomplete phrases that the author often jotted down on paper as a memorandum, and whose meaning he alone could know. We have given, in point of new thoughts, only those that are complete. But, except these suppressions, which can only render the reading more attractive and casy, we have omitted nothing, neglected nothing. We have even indicated, with great care, under the title of variations, all the passages that Pascal had erased, since these passages may offer some interest, either as a point of comparison with a definite text, or as the expression of the writer's temerity. As to the alterations, suppressions, or transpositions to which Port-Royal, Bossut, or the other editors, have subjected the Thoughts, we have not regarded it as necessary to dwell upon them, and have limited ourselves to an indication of some of them; for the existence of these slterations once established, it imports little to know what Pascal has been made to say, but much what Pascal has said. 
As to the annotation with which we have accompanied the text, we have endeavored to give only what is essential, apply. ing ourselves especially to elucidate, by extracts borrowed from Pascal's most accredited interpreters, important points of doctrine. Among the contemporary historians of Pascal and the Thoughts, Sainte-Benve and Cousin have furnished us important appreciations. We have also borrowed interesting commentaries or useful elucidations from Faugère, Havet, Nisard, Villemain, Maynard, etc. In fine, we have gathered from the early editors whatever could add any value to our'work. Placed between two contradictory opinions that are entertained in regard to Pascal,-one representing him as a skeptic, the other representing him as most irreproachably orthodox, we have limited ourselves to the part of exact and faithful reporters, fully persuaded that what interests the public, is not to know what such or such an editor thinks on this grave question, but to seize clearly, by some character istic extracts, the general sense of the most remarkable judgments of which Pascal has been the object on the part of philosophers, theologians, and men of letters. We will add that we have been sober in the use of notes; for, so far as we are able to judge from the impression upon ourselves, made by the reading of certain works, rendered obligatory by the labor of this edition, the writings to which Port-Royal, Jansenism, and Pascal himself, have given rise in these latter years, are not always exempt from ennui and fatigue. The minutice of research have been pushed to the extreme, and it must be acknowledged that such pedantry is not very pleasing to the public.

After the revolution that recent discoveries and the rectifcations of contemporaneous criticism have produced in the editions of Pascal, we could not limit ourselves to a reproduction of the Thoughts alone. It was at least necessary to give to the public, and this time isolating them and re-establishing them in the purity of their text, different opuscules that had been long confounded with them. It was moreover necessary to add to these opuscules, thus restored, the pieces recently discovered; and this we have done. 


\title{
GENIUS AND WRITINGS OF PASCAL,
}

\author{
BY HENRY ROGERS.
}

Pascal was born at Clermont, in Auvergne, in the year 1623 , and died in the year 1662 , at the early age of thirty. nine. When we think of the achievements which he crowded into that brief space, and which have made his name famous to all generations, we may well exclaim with Corneille: "A peine a-t-il vécu, quel nom il a laissé !"

It is well known that Pascal exhibited from the earliest childhood the most precocious proofs of inventive genius, especially in the department of mathematics. Having, if we may believe the universally received tradition, been willingly kept in ignorance of geome ry, lest his propensity in that direction should interfere with th $\circ$ prosecution of other branches of knowledge, his self-prompted genius discovered for itself the elementary truths of the forbidden science. At twelve years of age he was surprised by his father in the act of demonstrating, on the pavement of an old hall, where he used to play, and by means of a rude diagram, traced by a piece of coal, a proposition which corresponded to the thirty-second of the First Book of Euclid. At the age of sixteen, he composed a little tractate on the Conic Sections, which provoked the mingled incredulity and admiration of Descartes. At nineteen he invented his celebrated Arithmetical Machine; and at the age of six-andwenty he had composed the greater part of his mathematical works, and made those brilliant experiments in Hydrostatics 
and Pneumatics which have associated his name with those of Torricelli and Boyle, and ranked him among the first philosophers of his age. Yet, strange to say, he now suddenly renounced the splendid career to which his genius so unequivo cally invited him, and gave himself up to totally different studies. This was principally attributable to that strong reli. gious impulse which was imparted to his mind at this periodrendered deeper by early experience in the school of affliction. From the age of eighteen he was a perpetual sufferer. Ix 1647 , when only in his twenty-fourth year, he was attacked by paralysis. His ill-health was mainly, if not wholly, occasioned by his devotion to study; and of him it is literally true, that his mind consumed his body.

So complete was his abandonment of science, that he never returned to it but on one memorable occasion, and then only for a short interval. We allude, of course, to the remarkable problems which he solved respecting the curve called the $\mathrm{Cy}$ cloid. The accounts which have been transmitted to us by his sister, of the manner in which these investigations were suggested and completed-accounts which are authenticated by a letter of his own to Fermat-strongly impress us with the vigor and brilliancy of his genius. We are assured that, after long abandonment of mathematics, his attention was di. rected to this subject by a casual train of thought suggested in one of the many nights which pain made sleepless. The thoughts thus suddenly originated, his inventive mind rapidly pursued to all the brilliant results in which they terminated; and in the brief space of eight days the investigations were completed. Partly in compliance with the fashion of the age, and partly from the solicitation of his friend the Duke de Roannez, he concealed for a time the discoveries at which he had arrived, and offered the problems for solution to all the mathematicians of Europe, with a first and second prize to successfus candidates. If no solution were offered in three months, Pascal promised to furnish his own. Several were forwarded, but os none, in the estimation of the judges, completely fulfilled th s conditions of the challenge, Pascal redeemed his pledge by 
publishing his own, under the name of Amos Dettonville,-an anagram of Louis de Montalte, the name under which the "Provincial Letters" had appeared. This was in 1658-9, when he was thirty-six years of age.

With this brief exception, Pascal may be said to have prac tically abandoned science from the age of twenty-six. Yet $h$ did not at once become a religious recluse. For some years he lived a cheerful, and even gay, though never dissipated life, in Paris, in the centre of literary and polite society, loved and admired by a wide circle of friends, and especially by his patron, the Duke de Roannez. To the accomplished sister of this nobleman, M. Faugère conjectures (as we think plausibly) that Pascal was secretly attached, but, from timidity and humility, "never told his love." Perhaps, in part, from the melancholy which this hopeless attachment inspired, but certainly much more in consequence of the decper religious convictions, produced by a memorable escape from an appalling death, in 1654 , his indifference to the world increased; and he at length sought for solitude at Port-Royal, already endeared to him by the residence there of his sister Jacqueline.

Here it is well known he produced his immortal "Provincial Letters;" and, when death cut short his brief career, was meditating an extensive work on the fundamental truths of re. ligion,- - especially on the existence of God and the evidences of Christianity,--for the completion of which he would have required "ten years of health and leisure." $\Lambda \mathrm{n}$ outline of the work had been sometimes (and on one occasion somewhat 'ully) imparted in conversation to his friends, but no part of it was ever completed. Nothing was found after his death but detached "Thoughts" (interspersed with some on other subiects) on the principal topics appropriate to such a work. They were the stones of which the building was to have consisted, many of them unhewn, and some few such as the builder, had he lived, would no doubt have laid aside. The form in which the Thoughts were put together comported but too well with their fragmentary character. It appears that he did not even use a common-place book; but when, after profound 
meditation, any thought struck him as worth recording, he hastily noted it on any scrap of paper that came to hand, often on the backs of old letters; these he strung together on a file, or tied up in bundles, and left them till better health and untroubled leisure should permit him to evoke a new creation out of this chaos. It is a wonder, therefore, that the Pensées of Pascal have come down to us at all. Never, surely, was so precious a freight committed to so crazy a bark. The Sybil herself was not more careless about those leaves on which she inscribed her prophetic truths, than was Pascal about those which contained the results of his melitations. Of these results, however, we are in part defrauded, by something far worse than either the fragility of the materials on which they are inscribed, or their utter want of arrangement. Many of the "Thoughts" are themselves only half developed; other's, as given us in the literal copy of M. Faugère, break off in the middle of a sentence, even of a word. Some casual interruption-frequently, no doubt, some paroxysm of pain, to which the great author, in his latter years, was incessantly subjestbroke the thread of thought, and left the web imperfect forever.

It is humiliating to think of the casualties which, possibly in many cases, have robbed posterity of some of the most precious fruits of the meditations of the wise: perhaps arrested trains of thought which would have expanded into brilliant theories or grand discoveries;-trains which, when the genial moment of inspiration has passed, it has been found impossible to recall; or which, if recalled up to the point at which they were broken off, terminate only in a wall of rock, in which the mountain path, which had been before so clearly seen, exists no longer. It is humiliating to think that a fit of the toothache, or a twinge of the gout, might have thus arrested-no more to return - the opening germ of conjecture, which led on to the discovery of the Differential Calculus, or the Theory of Aravitation. The condition of man, in this respect, affords, inleed, one striking proof of that combined " greatness and misery" of lis uature, on which Pascal so profoundly meditated. 
It is wonderful that a being, such as he, should achieve sc much; it is humiliating that he must depend on such casualties for success. On the precarious control which even the greatest mer have over their own minds, Paseal himself strikingiy says: "The mind of this sovereign of the world is not so independent as not to be discomposed by the first tintamarre that may be made around him. It does not need the roar of artillery to hinder him from thinking; the creaking of a vane or a pulley will answer the purpose. Be not surprised that he reasons ill just now; a fly is buzzing in his ears-it is amply sufficient to render him incapable of sound deliberation. If you wish him to discover truth, be pleased to chase away that insect who holds his reason in check, and troubles that mighty intellect which governs cities and kingdoms! Le plaisant dieu que voilà! O ridicolosissimo eroe!

On the imperfect sentences and half-written words, which are now printed in the volumes of M. Faugère, we look with something like the feelings with which we pore on some halfdefaced inscription on an ancient monument-with a strange commixture of curiosity and veneration; and, while we wonder what the unfinished sentences may mean, we mourn over the malicious accident which has perhaps converted what might have been an aphorism of profoundest importanee into a series of unmeaning ciphers. One of the last things, assuredly, which we should think of doing with such fragments, would be to attempt to alter them in any way; least of all, to supplement them, and to divine and publish Pascal's meaning. There have been learned men, who have given us supplements to the lost pieces of some ancient historians;--erudite Freinsheimiuses, who hand us a huge bale of indifferent Latin, and beg us only to think it Livy's lost Decades. But what man would venture to supplement Paseal? Only such, it may be supposed, as would feel no scruple in scouring an antique medal, or a worthy successor of those monks who obliterated manuscript pieees of Cicero, that they might inscribe them with some edifying legend.

Alas! more noted people than these were scarcely more scru- 
pulous in the case of Pascal. His friends decided that the fragments which he had left behind him, imperfect as they were, were far too valuable to be consigned to oblivion; and so far all the world will agree with them. If, further, they had selected whatever appeared in any degree coherent, and printed these verbatim et literatim, in the best order they could devise, none would have censured, and all would have thanked them. But they did much more than this; or rather, thoy did both much more and much less. They deemed it not sufficient to give Pascal's Remains, with the statement that they were but Fragments; that many of the thoughts were very imperfectly developed; that none of them had had the advantage of the author's revision-apologies for any deficiencies with which the world would have been fully satisfied; but they ventured upon mutilations and alterations of a most unwarrantable description. In innumerable instances they changed words and phrases; in many others they left out whole paragraphs, and put a sentence or two of their own in the place of them; they supplemented what they deemed imperfect with a prefatory exordium or a prefatory conclusion, without any indication as to what were the respective ventures in this rare species of literary copartnery. It must have been odd to see this committee of critics sitting in judgment on Pascal's style, and deliberating with what alterations, additions, and expurgations it would be safe to permit the author of the Provincial Letters to appear in public. Arnauld, Nicole, and the Duke de Roannes were certainly no ordinary men; but they were no more capable of divining the thoughts which Pascal had not expressed, or of improving the style where he had expressed them, than of completing a sketch of Raphael.

It appears that, large as was the editorial discretion they assumed, or, rather, large as was their want of all discretion, they had contemplated an enterprise still more audacious: sothing less than that of completing the entire work which Pascal had projected; partly out of the materials he had left, and partly from what their own ingenuity might supply. It even appears that they had actually commenced this hetero 
geneous structure; and an amusing account has been left by M. l'érier, botb of the progress the builders of this Babel had made, and of the reasons for abandoning the design. " $\Delta \mathrm{t}$ last," says he, "it was resolved to reject the plan, because it was felt to be almost impossible thoroughly to enter into the thoughts and the plan of the author, and, above all, of an author who was no more; and because it would not have been the work of M. Pascal, but a work altogether different-un ouvrage tout different!" Very different indeed! If this naïve expression had been intended for irony, it would have been almost worthy of Pascal himself.

Subsequent editors have taken similar liberties, if not so flagrant. While the original editors left out many passages from fear of the Jesuits, Condorcet, in his edition, omitted many of the most derout sentiments and expressions, under the influence of a very different feeling. Infidelity, as well as superstition, has its bigots, who would be well pleased to have their index expurgatorius also. Unhappy Pascal! Between his old editors and his new he seemed to be in the conüition of the persecuted bigamist in the fable, whose elder wife would have robbed him of all his black hairs, and his younger of the gray. Under such opposite editing, it is hard to say what might not at last have disappeared.

It had, as we have stated, been long felt that no thoroughly trustworthy edition of Pascal's "Thoughts" had yet been published; that none knew what was precisely his, and what was not. M. Cousin demonstrated the necessity of a new edition founded upon a diligent collation of original manuscripts. This task M. Faugère has performed with incredible industry and exactitude . . . Every accessible source of informa tion has been carefully ransacked; every fragment of manu script, whether in Pascal's own hand or in that of members $O_{a}$ his family, has been diligently examined; and every pago offers indications of minute attention even to the most trivial ierbal differences. Speaking of the autograph MS. preserved in the Royal Library at Paris, a folio, into which the origina. loose leaves are pasted, or, when written on both sides, care. 
fully let into the page-encadrés-he says: "We have read, or rather studied this MS., page by page, line by line, syllable by syllable, from the beginning to the end; and with the exception of some words which are illegible, it has passed entirs into the present edition." As the public, in the former editions, did not exactly know what was Pascal's and what was not, M. Faugère has been compelled to do what, under other circumstances, it would not have been desirable, and indeed hardly just to do-what, indeed, any author of reputation would vehemently protest against in his own case. He has been obliged to give every fragment, however imperfect, literatim et verbatim. The extracts, as we have said, often terminate in the middle of a sentence, sometimes even of a word. As M. Vinet has justly observed in relation to this feature of $\mathbf{M}$. Faugère's labors, Pascal himself would hardly have been satisfied "with either his old editors or the new." " At the same time, it must be confessed, that, apart from this circumstance, it is deeply interesting to contemplate the first rude forms of profound or brilliant thought, as they presented themselves to the ardent mind of Pascal. This M. Faugère has often enabled us to do, more especially in the singular collection of the rough notes for the "Provincial Letters"-(Tom. i. p. 293-314). It is like looking at the first sketch of a great painting of Raphael; or, as M. Vinet observes, "we are taken into the great sculptor's studio, and behold him at work, chisel in hand."

M. Cousin, we should think, must be satisfied with the accuracy and completeness of this edition; and also of the insufficiency of his own argument that Pascal was, in fact, a " universal skeptic," who embraced the truths of religion not as a hypocrite, indeed, but in the exercise of a blind faith-in fact, in a sort of paroxysm of despair ; or because he believed that what he had proved false in physics was still true in morals : "that nature abhors a vacuum." M. Cousin, in part, founds

1 Our reasons for preferring the no less accurate and complete, but more nappily arranged edition of $M$. Louandre, have been fully stated in the preface. $-E d$. 
in thecry on the fact that the first editors had tamed down some of the more startling statements of Pascal, and omitted others; and that a new edition would reveal the skeptic in his full dimensions. He must now, we should think, see his crror. There is little or nothing which argues Pascal's abiding conviction of the sufficiency of the evidence for the fundamental truths of religion, or the divine origin of Christianity, to be found in the old editions, which does not reappear in the new, and with much new matter to confirm it. To this subject we shall return, after offering some observations on the genius and character of Pasca:.

In one respect, his genius strongly resembled that of a recent subject of our criticism-Leibnitz. His was one of the rare minds apparently adapted, almost in equal measure, to the successful pursuit of the most diverse departments of philosophy and science - of mathematics and physics - of metaphysies and criticism. Great as was his versatility, it may be doubted whether in that respect he did not yield somewhat to Leibnitz, as also in his powers of acquisition, and nost assuredly in tho extent of his knowledge. It is not, however, to be forgotten that he diea at little more than half the age of the veteran philosopher of Germany ; and that there can be no doubt that for his years, his attainments were very extensive. Still it is true that that periectly unique characteristic of Leibnitz-his equal aptituoic and appetite for reading and thinking, for the accumulation of knowledge, and for original speculation, could never have been in the same degree a characteristic of Pascal; and still less in such amazingly diversified directions. Pascal followea in this respect the predominant law of all very inventive minds. He was fonder of thought than of books-ot meditation than of acquisition. Even this tendency of mind manifested itself within a more restricted sphere, ample enough $t$ is true-that of philosophy and theology. To Leibnitz, risprudence, history, and antiquities were nearly as familiar is these.

But if the character of Pascal's genius was less excursire than that of Leibnitz, and the literary element in it far less 
active, these points of inferiority were amply compensated by a superiority in other qualities, in which there can be no com. parison between them. In inventiveness they may, perhaps. have been equal-but even here only in matnematies; in moral science-the science of man-we know of nothing out of Bacon, who may be said to set all comparison at defiance, certainly nothing in Liebnitz, that will oear comparison in depth, subtlety, and comprehensiveness with some of tho "Thoughts" of Paseal. But, in another sharacteristic of true genius - and which, for want of another name, we must call felicity - neither Leibnitz, nor, we might almost affirm, any one else, can, in the full import of the term, be sompared with Pascal. Endowed with originality the most active and various, all that he did was with grace. Full of depth, subtlety, biil. lianey, both his thoughts, and the manner in which he expresses them, are also full of beauty. His just image is that of the youthful athlete of Greece, in whom was seen the perfection of physical beauty and physical strength; in whom every musele was developed within the just limits calculated io secure a symmetrical development of all ; the result of the whole being the largest possible amount of power and flexibility in union.

In all the manifestations of Pascal's mind, this rare felicity is exuberantly displayed; in the happy methods by which he lighted on truth, and pursued scientific discovery; in the selection and arrangement of topies in all his compositions; in the peculiar delicacy of his wit-so strongly contrasted with all the ordinary exhibitions of that quality of mind with which his cuarse age was familiar; and, above all, in that indeseribab!o clegance of expression which uniformly characierizes his finished efforts, and often his most negligent utterances, and which even time can do nothing to impair. Let us be permitted to say a word or two further on these topics.

In his scientific writings, we seem to discern the traces $x$ ? this felicity almost equally in the matter and the form. In relation to the former, there is probably a little illusion prac. ised upon us. In reading his uniformly elegant and perspicuous exposition of his own scientific discoveries, we are apt tr 
under:ate the toil and intellectual struggles by which he achieved them. We know that they were, and must have been, attended with much of both-nay, that his shattered health was the penalty of the intensity of his studies. Still, it is hardly possible to read his expositions without having the impression that his discoveries resembled a species of inspiration; and that his mind followed out the first germinant thought to its consequences, with more ease and rapidity than is usually exemplified. We can scarcely imagine it would have been necessary for him to have undergone the frightful toils of Kepler, had he been led into the same track of discoveries. And, in fact, whatever illusion his ease and elegance of manner may produce, we know that his achievements were rapidly completea. It was so with the problems on the Cycloid; it was so with his discoveries in Pneumatics and Hydrostatics. In fact, though his ?'raité de l'Equilibre des $\mathrm{Li}$ queurs, and that De la Pesanteur te l'Air, were not composed till 1653 , they seem to have been only another form of the treatise he promised in his Nouvelles Expériences touchant le Vide, published in 1647 ; and of which that tract was avowedly an abridgment. Indeed, as already said, Paseal had nearly quitted these investigations before the completion of his twentysixth year.

There was no scientific subject which Pascal touched in which the felicity of his genius-the promptitude and brilliancy of his mind-did not shine forth. We see these qualities eminently displayed in his Traité du Triangle Arithmetique-in the invention and construction of his Arithmetical Machine-in the mode of solving the problems respecting the Cycloid, in which, while employing Cavalieri's "Method of Indivisibles," he proposes to remove the prineipal objection which had been made to it, by conceptions which bring him within a step of the Fluxions of Newton, and the Calculus of Leibnitz. The same qualities of mind are eminently displayed .n the manner in which he establishes the hydrostatic paradox; and generally in the experiments detailed in the Nouvelles Experiences, and the other connected pieces; most of all in 
that celebrated Crucial experiment on the Puy-de-Dòme, by which he lastingly decided the eause of the suspension of the mereury in the barometrical tube. As there are few things recorded in the history of seience more happily ingenious than the conception of this experiment, so never was there any thing more pleasantly naive than the manner in which he proposes it, in his letter to M. Perier. "You doubtless see," says he, "that this experiment is decisive of the question; and that it it happen that the mereury shall stand lower at the top than at the bottom of the mountain (as I have many reasons for thinking, although all those who have meditated on this subject are of a contrary opinion), it will necessarly follow that the weight and pressure of the air are the soie cause of this suspension of the mercury, and not the horror of a vacuum; since it is very certain, that there is much more air to press at the base than on the summit of the mountain; while, on the other hand, we surely eannot say, that nature abhors a vacuum more at the bottom of a mountain than on the top of it!"!

The usual felicity of his style is seen throughout his philosophical as well as his other works. They appear to us to

1 Descartes elaimed the suggestion of this brilliant experiment. All wa can say is, that Paseal, who was the very soul of honor, repeatedly declares, that he had meditated this experiment from the very time he had verified Torricelli's, and only waited the opportunity of performing it. Oy the other hand, Descartes was jealous of the discoveries of others, and, as I eibnitz truly observes, slow to give to them all the praise and admirations which were their due. With all his great powers, he had but iittle magnanimity. It is possible that he may have thought of a similar experiment, that he may have conferred upon the subject with Pascal; but, if the latter speaks truth, it is impossible that he should not already have determined upon it. Indeed, it is hardly probable that, had it been originally a conception of Descartes, he would not have made the experiment for himsel*, and thus gained the honor undisputed and undivided. Pascal was, in like manner, aceused of having appropriated the honor of Torricelli's exper1ments. Nothing can be more perfeetly beautiful than the manner in which he vindieates his integrity and eandor, in his letter to M. de Ribeyre on this subject. He shows triumphantly, that, in his original Nouvelles Experiences, he had not only not elaimed, but had most distinetly diselaimed. all credit for the experiments in question, and had been at mueh pains te give honor where honor was due. 
possess the highest merit which can belong to scientific com. position. It is true that, in his purely mathematical writingspartly from the defective notation of his age--itself a result of the want of that higher Calculus, which was reserved for Newton and Leibnitz-he is often compelled to adopt a more prolix style of demonstration than would have been subsequently necessary; but even here, and still more in all the fragments which relate to natural philosophy, his style is strikingly contrasted with the clumsy expression of the generality of contemporary writers. His Fragments abound in that perspicuous elegance which the French denominate by the expressive word netteté. The arrangement of thought and the turn of expression are alike beautiful. Probably no one ever knew so well when to stay his hand.

But it is, of course, in his writings on moral and critical subjects in which we should chiefly expect this felicity to appear; and here we may well say, in the eloquent language of $M$. Faugère, it is a "style grand sans exagération, partout rempli d'émotion et contenu, vif sans turbulence, personnel sans pé. lanterie et sans amour-propre, superbe et modeste tout-ensemble;" or, as he elsewhere expresses it, "tellement identifié avec l'àme de l'écrivain qu'il n'est que la pensée elle-même, parée de sa chaste nudité comme une statue antique." By the confession of the first French critics, the Lettres Provinciales did more than any other composition to fix the French language. On this point, the suffrages of all the most competent judgesof Voltaire and Bossuet, D'Alembert and Condorcet-are unanimous. "Not a single word occurs," says the first, "partaking of that vicissitude to which living languages are so subiect. Here, then, we may fix the epoch when our langt.age may be said to have assumed a settled form." "The French language," says D'Alembert, “was very far from being formed, as we may judge by the greater part of the works published at that time, and of which it is impossible to endure the read. ing. In the 'Provincial Letters,' there is not a single word that has become obsolete; and that book, though writtes ibove a century ago, secms as if it had beer. written but yes 
terday." And as these Letters were the first model of French prose, so they still remain the objects of unqualified admiration. The writings of Paseal have, indeed, a paradoxical destiny: "flourishing in immortai youth," all that time can do is to superadd to the charms of perpetual beauty the veneration which belongs to age. His style cannot grow old.

When we reflect on the condition of the language when he appeared, this is truly wonderful. It was but partially reclaimed from barbarism-it was still an imperfect instrument of genius. He had no adequate models-he was to create them. Thus to seize a language in its rude state, and compel it, in spite of its hardness and intractability, to become a malleable material of thought, is the peculiar characteristic of the highest species of mind: nothing but the intense fire of genius can fuse these heterogeneous elements, and mould them into forms of beauty. As a proof, it may be remarked, that none but the highest genius has ever been equal to this task. Genius of less than the first order will often make improvements in the existing state of a language, and give it a perceptible impulse; but none but the most creative and plastic power can at once mould a language into forms which cannot become obsolete;-which remain in perpetuity a part of the current literature, amid all the changes of time and the sudden caprices of fashion. Thus it required a Luther to mould the harsh German into the language of his still unrivalled translation of the Scriptures; in which, and in his vernacular compositions, he first fairly reclaimed his native language from its wild state, brought it under the yoke, and subjected it to the purposes of literature. Pascal was in a similar manner the creator of the French. Yet each performed his task in a mode as characteristic as the materials on which they operated were different. Energy was the predominant quality of Luther's genius; beauty of Pascal's. The rugged German; under the hand of Luther, is compelled to yield to an irresistible application of force; it is the lightning splitting oak and granite. The French, under that of Paseal, assumes forms of beauty by a still and noiseless movement, and as by a sort of enchantment; -it is " the 
west wind ungirding the bosom of the earth, and calling forth bud and flower at its bidding."

It may be thought strange by some that the orderly employment of an unformed language shou.d be represented, not only as so signal a triumph, but as an index of the highest genius. But it will not appear unphilosophical to those who duly consider the subject. If, even when language has reached its full development, we never see the full capacities of this delicate instrument put forth except by great genius, how can we expect it when the language is still imperfect? As used in this rude state, language resembles the harsh music of the Alpine horn, blown by the rude Swiss herd-boy: it is only when the lofty peaks around take it up that it is transmuted by their echoes into exquisite melody.

The scrcrely pure and simple taste which reigns in Pascal's style seems, when we reflect on those vices which more or less infected universal letters, little less than a miraculous felicity. One wonders by what privilege it was that he freed himself from the contagion of universal exaniple, and rose so superior to his age. Taste was yet almost unfelt; each writer affected extravagance of some kind or other,--strained metaphor, quaint conceits, far-fetched turns of thought, unnatural constructions. These were the vices of the day; not so much perhaps in France as in England, but to a great extent in both. From all these blemishes Pascal's style is perfectly frec; he anticipated all eriticism, and became a law to himself. Some of his observations, however, show how deeply he had revolved the true principles of taste in composition. His "thoughts" sur l'Eloquence et Style, are well worth the perusal of every writer and speaker. In one of them he profoundly says, "The very same sense is materially affected by the words that convey it. The sense receives its dignity from the words, rather than imparts it to them." In another, he says, "All the false beauties that we condemn in Cicero have their admirers in crowds." And, in the third, he admirably depicts the prerailing vice of strained antitheses: "Those," says he, "who frame antitheses by forcing the sense, are like men who make 
false windows for the sake of symmetry. Their rule is not to speak justly, but to make just figures." The time spent on his own compositions, however, shows that even such felicity as his own could not dispense with that toil, which is an essential tondition of all perfect writing-indeed of all human excellence; and is one other proof of the extreme shallowness of that theory which would have us believe that, to attain perfection, genius alone is all-sufficient. He is said, when engaged on his Lettres Provinciales, to have sometimes employed twenty days in perfecting a single letter.

Another circumstance which, as we have said, indicates Pascal's felicity of genius, is the peculiar delicacy and refinement of his wit. We say its delicacy and refinement, for the mere conjunction of great wit with great aptitude for science we do not consider as a felicity peculiar to Pascal. It is the character of that wit. As to the conjunction of distinguished wit in one or other of its many forms with elevated genius, it is far too common to be regarded as a peculiarity of his mind. Paraloxical as the statement may at first sight appear to many who have been accustomed to consider wisdom and wit as dwelling apart, we doubt whether there is any one attribute so common to the highest order of mind, whether scientific or imaginative, as some form or other of this quality. The names of Bacon, Shakspeare, Plato, Pascal, Johnson, Byron, Scott, and many more, will instantly occur to the reader. It is true that the history of the species reveals to us minds either really adapted so exclusively to the abstrusest branches of science, or so incessantly immersed in them, that, if they possess the faculty of wit at all, it is never developed. Aristotle and Newtonthough some of the few sayings of the former which tradition has preserved are not a little racy-may be named as examples. But, in general, and the whole history of science and literature will show, that this attribute, in one or other of its thousand varieties, has formed an almost perpetual accompaniment of the finest order of minds. And we may add, that, $\dot{a}$ priori, we should expect it to be so. That same activity of suggistion and aptitude for detecting resemblances, :nalogies, 
and differenees, which qualify genius for making diseoveries in seience, or, under different modifications, for evoking the creations of imagination, may well be supposed not to desert their possessor, when, for playful purposes, and in moments of relaxation, he exercises himself in the detection of the analogies on which wit and drollery are founded. Yet, clear as this truth seems to be, and strongly as it is corroborated by the history of genius, the opposite opinion has been, we believe, oftener expressed, and the highest order of mind pronounced ineompatible with such a eonjunction.

It is not, then, the activity, but the peculiar delicacy of Yascal's wit which renders this feature of his genius so truly worthy of admiration;- - the more admirable, when it is remembered that the wit of that age, and especially among polemies, so generally took the form of gross scurrility and buffoonery; and, even when it did not sink so low as that, was overgrown with every species of quaintness and affectation. Almost in no instance was it found pure from one or other of these debasements. The wit of Pascal, on the contrary, appears even now exquisitely chaste and natural-attired in a truly Attic simplicity of form and expression. In one quality-that of irony -nothing appears to us to approach it, exeept what we find in the pages of Plato, between whom and Pascal (different, and even opposite, as they were in many respects) it were easy to trace a resemblance in other points besides the elaracter of their wit. Both possessed surpassing aeuteness and subtlety of genius in the department of abstract seience-both delighted in exploring the depths of man's moral nature--both gazed enamored on the ideal forms of moral sublimity and loveliness -both were eharacterized by eminent beauty of intellect, and both were absolute masters of the art of representing thought -each with exquisite refinement of taste, and all the graces of language. The Grecian, indeed, possessed a far more opulent imagination, and indulged in a more gorgeous style than the Frenchman; or rather, Hlato may be said to have been a master of all kinds of style. His dramatic powers, however, in none of his Dialogues, ean be greater than those which Pas. 
cal has displayed in his Lettres Provinciales. Nothing could be happier for his purpose-that of throwing into strong light the monstrous errcrs of the system he opposed-than the machinery he has selected. The affected ignorance and näveté of M. Montalte, in quest of information respecting the theological disputes of the age, and especially the doctrines of the Jesuits - the frankness of the worthy Jesuit Father, of whom he seeks instruction, and who, in the boundless admiration of his Order, and the hope of making a convert, details without liesitation, or rather with triumph, the admirable contrivences by which their Casuists had, in fact, inverted every principle of morals, and eluded all the obligations of Christianity-the Ironical compliments of the supposed Novice, intermingled with objections and slightly expressed doubts, delivered with an air of modest ingenuousness which covets only further light - the arch simplicity with which he involves the good father in the most perplexing dilemmas--the expressions of unsophisticated astonishment, which but prompt his stolid guide eagerly to make good every assertion by a proper array of authorities - a device which, as Pascal has used it, converts what would have been in other hands only a dull catalogue of citations, into a source of perpetual amusement-the droll consequences which, with infinite affectation of simplicity, he draws from the worthy father's doctrines--the logical exigencies into which the latter is thrown in the attempt to solve them,--all these things managed as only Pascal could have managed themrender the book as amusing as any novel. The form of letters enables him at the same time to intersperse, amid the conversations they record, the most eloquent and glowing invectives against the doctrines he exposes. Voltaire's well-known panegyric does not exceed the truth-_" That Molière's best comedies do not excel them in wit, nor the compositions of Bossuet in sublimity." "This work," says d'Alembert, " is so much the more admirable, as Paseal, in composing it, seems to have theologized two things which seem not made for the theology of that time--language and pleasantry."

The success of the work is well known. By his inimitabl 
pleasantry, Pascal succeeded in making even the dullest mat. ters of scholastic theology and Jesuitical casuistry as interesting as a comedy; and, by his little volume, did more to render the formidable Society the contempt of Europe, than was ever done by all its other enemies put together.

The Jesuits had nothing for it but to inveigh against the letters as "the immortal liars"-les menteurs immortelles. To their charge of having garbled citations, and tampered with evidence to produce an unfair impression against the Society (practices, utterly abhorrent from all Pascal's habits of mind and dispositions of heart), he replies, with the characteristic boldness and frankness of his nature: "I was asked if I repented of having written Les Provinciales. I reply, that, far from having repented, if I had to write them now, I would write yet more strongly. I was asked why I have given the names of the authors from whom I have taken all the abominable propositions I have cited. I answer, that if I lived in a city where there were a dozen fountains, and that I certainly knew that there was one which was poisoned, I should be obliged to advertise all the world to draw no water from that fountain; and as they might think that it was a pure imagination on my part, I should be obliged to name him who had poisoned it, rather than expose all the city to the danger of being poisoned by it. I was asked why I had employed a pleasant, jocose, and diverting style. I reply, that if I had written in a dogmatical style, it would have been only the learned who would have read, and they would have had no necessity to do it, being at least as well acquainted with the subject as myself; thus, I thought it a duty to write so as to be comprehended by women and men of the world, that they might know the danger of those maxims and propositions which were then universally propagated, and of which they permitted themselves to be so easily persuaded. I was asked, lastly, if I had myself read all the books I have cited. I answer, No; for in that case it wonld have been necessary to have passed my life in reading ver: bad books; but I had read through the whole of Escobar twice, and, for the others, I 
carsed them to be read by my friends. But I have never nised a single passage without having myself read it in the rok cited, or without having examined the subject on which it is adduced, or without having read both what precedes and iphat follows it, in order that I might not run the risk of quiting what was, in fact, an objection, for a reply to it, which w. ould have been both censurable and unjust."

The moral aspects of Pascal's character are as inviting; as thosi of his intellect: here, too, he was truly great. Sime infirmities, indeed, he had, for he was no more than man; he is nevertheless one of the very few who as passionately pur ue the acquisition of moral excellence as the quest after spect la. tive truth; who, practically as well as theoretically, helit vo that the highest form of humanity is not intellect, but goc $d$. ness. Usually it is far otherwise; there is no sort of propcr. tion between the diligence and assiduity which men are ordinarily willing to expend on their own intellectual and mord culture. Even of those who are in a good degree under tho influence of moral and religious principles, and whose conduct in all the more important instances of life shows it, how few are there who make that comprehensive rectitude, the obliga. tion of which they acknowledge, and the ideal of which they admire, the study of their lives, the rule of their daily actions in little things as well as great; or who analyze their motives and school their hearts (in the habitual expressions of thought and feeling) in conscious obedience to it! Nor can it be regarded as other than an indication that there is something wrong about human nature, that of those three distinct orders of "greatness," which Pascal has so exquisitely discriminated in his Pensées-power, intellect, and goodness-the admiration inspired by the two flrst should be-so moth greater than that inspired by the last. The reverence for genius, in particular often degenerates into something like idolatry; so much so as to lead to the proverbial, but most culpable extenuation of grave faults on the part of biographers, who cannot bear to see a spot on the bright luminary they admire. Even if mora excellence he theoretically allowed to claim equal enthusiasm 
It, in fact, rarely receives it. How vivid, after all, is the sentiment which the intellect of a Bacon or a Shakspeare usually exeites in the young and ardent, compared with that with which they regard a Howard or a Martyn! Yet invineible patience, heroie constancy, that honesty of purpose which is proof against all flatteries and all menace, perfect candor, the spirit of unfeigned humility, benevolence, and charity, are surely not .ess worthy of our most enthusiastic admiration, than those qualities of mind which discover a new law of nature, or pour orth beautiful strains of poetry.

.$t$ is one of the proofs, according to Paley's ingenious resuark, of the originality of the Gospel, and one of the marks of the divinity of its origin, that it chiefly insists on the cultivation of an order of virtues which had been least applauded by man, and in which, notwithstanding, man was most deficient; of humility, meekness, patience, rather than of those opposite virtues to which the active principles of his nature would most readily prompt him, and which have been aceordingly the chief objects of eulture and admiration. We may extend the remark, and observe, that it is an equal indieation of the originality of the Gospel and of the divinity of its origin, that the ideal of greatness which it has presented to us is of a different character from that which has chiefly fixed the enthusiastic gaze of man. It is not one in which power and intellect constitute the predominant qualities, associated with just so much virtue as serves to make the pieture free from all grave re. proach; but the perfection of truth, reetitude, and love-to which even the attributes of superhuman power and superhuman wisdom, with which they are blended, are so wonderfully subor dinated, that they seem, as they are, intrinsically of inferior lustre. Glorious as is their light, it is absolutely quenched in the brighter effulgence of ineffable and supernal goodness. We think of Cæsar as the great warrior and the great statesman; of Shakspeare as the great poet; of Newton as the great philosopher: when the Christian thinks of his Master, though he believes nim to be possessed of immeasurably greater power and $w$ isdonn than theirs-his first, last thought is, that he is THe Good. 
The character of greatness in Christ, Pascal has beantifully tonched. "The distance between Matter and Mind typifies the infinitely greater distance between Mind and Love. . . . . All the éclat of external greatness has no listre for men pro. foundly engaged in intellectual researches. . . . . Their greatness, again, is invisible to the noble and the rich. . . . . Grest geniuses have their empire, their splendor, their victory, their renown. . . . . These are seen with the eyes of the mind, and that is sufficient. . . . Holy men, again, have their empire, their victory, and their renown. . . . A Archimedes would have been venerable even without rank. He gained no battles; but to the intellectual world he has bequeathed great discoveries. How illustrious does he look in their eyes! . . . . In like manner Jesus Christ, without external splendor, without the outward repute of science, is great in his own order of holiness. .... It had been idle in Archimedes to have insisted on his royal descent in his books of geometry. And it had been as useless for our Lord Jesus Christ to assume the state of a king for the purpose of giving splendor to his reign of holiness. But he came fully invested with the lustre of his own order."

Few men have ever dwelt on this ideal of moral perfection, or sought to realize its image in themselves, with more ardor than Pascal-not always, indeed, as regards the mode, with as much wisdom as ardor. Yet, upon all the great features of his moral character, one dwells with the serenest delight. Greatly as he is to be admired, he is yet more to be loved. His humility and simplicity, conspicuous as his genius and acquisitions, were those of a very child. The favorite of science-repeatedly crowned, as an old Greek might have said of some distinguished young hero at Olympia, with the fairest laurels of the successful mathematician and the unrivalled polemicmaking discoveries even in his youth which would have intox.cated many men even to madness-neither pride nor vanity lound admission to his heart. Philosophy and science produeed on him only their proper effect, and taught him--not how much he knew, but how little; not merely what he had attained, but of how much more he was ignorant. His perfec ${ }^{2}$ 
ove of truth was beautifully blended with the gentlest charity; and his contempt of fraud and sophistry never made him forget, while indignantly exposing them, the courtesies of the gentleman and the moderation of the Christian; and thus the severest raillery that probably ever fell from human lips, flows on in a stream undiscolored by one particle of malevolence, and unruffled by one expression of coarseness or bitterness. The transparency and integrity of his character not only shone conspicuous in all the transactions of his life, but seem even now to beam upon us as from an open ingenuous countenance, in the inimitable frankness and transparency of his style. It is impossible to read the passages in his philosophical writings, in which he notices or refutes the calumnies to which he had been exposed-by which it was sometimes sought to defraud him of the honor of the discoveries he had made, and in one instance to cover him with the infamy of appropriating discoveries which had been made by others-without being convinced of the perfect candor and integrity of his nature.' His generosity and benevolence were unbounded; so much so, indeed, as to become almost vices by excess; passing far beyond that rean in which the Stagyrite fixes the limits of all virtue. He even beggared himself by his prodigal benefactions; he did what few do--mortgaged even his expectancies to charity. To all which we may add, that he bore the prolonged and exruciating sufferings of his latter years with a patience and fortitude which astonished all who witnessed them.

The failings of Pascal-for to these we must advert-were the result partly of that system of faith in which he had been edlucated, and which, though he did so much to expose many of the worst enormities which had attached themselves to it, still exercised considerable influence over him. It is lament able to see such a mind as his surrendering itself to some or the worst extravagances of asceticism. Yet the fact cannot be denied; nor is it improbable that his life-brief perhaps at tho

1 See more partienlarly his letters to Father Noel, M. le Pail'eur, and M. de Ribeyre. 
.ongest, considering his intense study and his feeble constitu tion-was yet made briefer by these pernicious practices. We are told, not only that he lived on the plainest fare and performed the most menial offices for himself; not only that he practised the severest abstinenee and the most rigid devotions, but that he wore beneath his clothes a gircle of iron, with sharp points affixed to it: and that, whenever he found his mind disposed to wander from religious subjects, or take delight in things around him, he struck the girdle with his elbow, and forced the sharp points of the iron into his side. We even see but too clearly that his views of life, to a considerable extent, became perverted. He eherished mistrust even of its blessings, and acted, though he meant it not, as if the very gitts of God were to be received with suspicion-as the smiling tempters to evil-the secret enemies of our well-being. $\mathrm{He}$ often expresses himself as though he thought, not only that suffering is necessary to the moral discipline of man, but as though nothing but suffering is at present safe for aim. "I can approve," he says in one place, "only of those who seck in tears for happiness." "Disease," he declares in another place, " is the natural state of Christians." It is evident that the great and gracious Master, in whose school we all are, and whose various dispensations of goodness and severity are dictated by a wisdom greater than our own, does not thini so: if he did, health would be the exception and disease the rule. It is but too true, indeed, that not only is suffering necessary to teach us our feebleness and dependence, and to abate the pride and confidence of our nature, but that we are but too apt to forget, with the return of prosperity, all the wise reflections and purposes which we had made in sorrow. Jeremy Taylor likens us, in one of his many fanciful images, to the fabled lamps in the tomb of Terentia, which "burned under ground for many ages together," but which, as soon as ever they were brought into the air and saw a brighter light, went out in darkness. "So long as we are in the retirements of sorrow, of want, of fear, of sickness, we are burning and shining lamps but when (rod lifts us up from the gates of death, and carrie 
as abroad into the open air, to converse with. prosperity and temptations, we go out in darkness, and we cannot be preserved in light and heat but by still dwelling in the regions of sorrow."

There is beauty, and, to a certain extent, truth in the figure; but it by no means follows that continuous suffering would be good for man : on the contrary, it would be as remotc from producing the perfection of our moral nature as unmitigated prosperity. It would be apt to produce a morbid and ghastly piety; the "bright lamps" of which Taylor speaks, would still be irradiating-only a tomb. Since the end of suffering, as a moral discipline, is only to enable us at last to bear unclouded happiness, what guarantee can we now have of its beneficial effect on us, except by partial experiments of our capacity of recollecting and practising the lessons of adversity in intervals of prosperity? It is true that there is no more pcrilous ordeal through which man can pass-no greater curse which can be imposed on him, as he is at present constituted-than that of being condemned to walk his life long in the sunlight of unshaded prosperity. His eyes ache with that too untempered brilliance-he is apt to be smitten with a moral coup de soleil. But it as little follows that no sunshine is good for us. He who made us, and who tutors us, alone knows what is the exact measure of light and shade, sun and cloud, storm and calm, frost and heat, which will best tend to mature those flowers which are the object of this celestial husbandry, and which, when transplanted into the paradise of God, are to bloom there forever in amyranthine loveliness. Nor can it be without presumption that we essay to interfere with these processes; our highest wisdom is to fall in with them. And certain it is that every man will find by experience that he has enough to do, to bear with patience and fortitude the real afflictions with which God may visit him, without venturing to fill up the intervals in which He has left him ease, and even invites him to gladness, by a self-imposed and artificial sorrow. Vay, if his mind be well cunstituted, he will feel that the earning how to apply, in hours of happiness, the lessons which be has learned in the school of sorrow, is not one of the 
least difficult lessons which sorrow has to teach him; not to mention that the grateful reception of God's gifts is as true a part of duty-and eren a more neglected part of it - than a patient submission to his chastisements.

It is at our peril, then, that we seek to interfere with the discipline which is provided for us. He who acts as if God had mistaken the proportions in which prosperity and adversity should be allotted to us, and seeks by hair-shirts, prolonged abstinence, and self-imposed penance, to render more perfect the discipline of suffering, only enfeebles instead of invigorating his piety; and resembles one of those hypochondriacal patients - the plague and torment of physicians-who have sought advice, and being supposed to follow it, are found not only taking their physician's well-judged prescriptions, but secretly dosing themsclves in the intervals with some quackish nostrum. Thus it was even with a Pascal; and we cannot see that the experiment was attended in his case with any better effects.

It is indeed pitiable to read, that during his last days his perverted notions induced him to refrain from the natural expressions of fondness and gratitude towards his sisters anc attendants, lest that affection with which they regarded hin should become inordinate; lest they should transfer to an earthly creature the affection due only to the Supreme. Something like an attempted justification of such conduct, indeed, occurs in his Pensées. "Il est injuste qu'on s'attache à moi, quoiqu'on le fasse avec plaisir et volontairement. Je tromperais ceux à qui j'en ferais naître le désir ; car je ne suis la fin de personne, et n'ai pas de quoi les satisfaire. Ne suis-je pas prêt à mourir ? Et ainsi l'objet de leur attachement mourra donc. Comme je serais coupable de faire croire une fausseté, quoique je la persuadasse doucement et qu'on la crût avec plaisir, et qu'en cela on me fìt plaisir ; de même je suis coupable de me faire aimer."-(Tom. i. p. 198.) Madame Péric: has cited this passage in the Life of her brother, as accounting for his apparent coldness to herself.'

1 The plasaige of Madame Périer is deeply affeeting. "Meanwhilr. as 
It is wonderful that a mind so powerful as his should be misled by a pernicious asceticism to adopt such maxims : it is stili more wonderful that a heart so fond should have been able to act upon them. To restrain, even in his dying hours, expressions of tenderness towards those whom he so loved, and who so loved him-to simulate a coldness which his feelings belied-to repress the sensibilities of a grateful and confiding nature-to inflict a pang, by affected indifference, on hearts as fond as his own,--here was indeed a proof of the truth lie so passionately meditated upon, the "greatness and the misery" of man, of his strength and his weakness; - weakness in supposing that such perversion of all nature could ever be a dictate of duty - strength in performing without wincing, a task so hard. The American Indian, bearing unmoved the torture of his enemies, exhibits not, we may rest assured, greater fortitude than Pascal, when, with such a heart as his, he received in silence the last ministrations of his devoted friends, and even declined with cold and averted eye the assiduities of their zealous love.

That same melancholy temperament, which, united with a pernicious asceticism, made him avert his gaze even from innocent pleasures, and suspect a serpent lurking in every form of pleasure, also gave to his representations of the depravity of our nature an undue intensity and Rembrandt-like depth of coloring. His mode of expression is often such, that were it not for what we otherwise know of his character, it might almost be mistaken for an indication of misanthropy. With this vice, accordingly, Voltaire does not hesitate to tax him"Ce fameux écrivain, misanthrope sublime."

Nothing ean be more unjust. As to the substance of what

I was wholly a stranger to his sentiments on this point, I was quite surprised and discouraged at the rebuffs he would give me upon certain jecasions. I told my sister of it, and not without complaining, that my brother was unkind, and did not love me; and that it looked to me as if I put him in pain, even at the very moment I was studying to please him, end struving to perform the most affect:onate offices for him in his illness." - I'adanc Périer's Memoirs of I'ascub. 
Pascal has said of human frailty and infirmity, most of it is at once verified by the appeal to individual consciousness; and as to the manner, we are not to forget that he everywhere dwells as much upon the "greatness," as upon the "misery" of man. "It is the ruined archangel," says Hallam, with equal justness and beauty, "that Pascal delights to paint." It is equally evident that he is habitually inspired by a desire to lead man to truth and happiness; nor is there any thing more aflecting than the passage with which he closes one of his expostulations with infidelity, and which M. Cousin finally characterizes as "une citation glorieuse à Pascal." "This argument, you say, delights me. If this argument pleases you, and appears strong, know that it proceeds from one who, both before and after it, fell on his knees before that Infinite and Invisible Being to whom he has subjected his whole soul, to pray that he would also subject you to himself for your good and for his glory; and that thus Omnipotence might give efficacy to his feebleness."

Ir addition to this, it must be said, that in his most bitter reflections, this truly humble man is thinking as much of himself as of others, and regards Blaise Pascal as but a type of the race whose degeneracy he mourns. His most bitter sareasms often terminate with a special application to the writer. Thus he says, "Vanity is so rooted in the heart of man, that a common soldier, a scullion, will boast of himself, and will have his admirers. It is the same with the philosophers. Those who write would fain have the fame of having written well; and those who read it, would have the glory of having read it: and $I$, who am writing, probably feel the same desire, and not less those who shall read it."

It is true, indeed, that some of his reflections are as caustic and bitter as those of Rochefoucauld himself. For example: "Curiosity is but vanity. Often we wish to know more, only that we may talk of it. People would never traverse the sea if they were never to speak of it,-for the mere pleasure of secing, without the hope of ever communicating what they have seen." And again: "Man is so constituted, that, by merely telling 
him he is a fool, he will at length believe it; and, if he tells himself so, he will constrain himself to believe it. For man holds ar internal intercourse with himself, which ought to be well regulated, since even here 'Evil communications corrupt good manners.'"

It may not be without amusement, perhaps instruction, to cite one or two other specimens of this shrewd and caustic humor.

"Certain authors, speaking of their works, say, "My book, my commentary, my history.' It were better to say, 'Our book, our history, our commentary;' for generally there is more in it belonging to others than to themselves."

"I lay it down as a fact, that if all men knew what they say of one another, there would not be four friends in the world. This appears by the quarrels which are sometimes caused by indiscreet reports."

Still, as it is the motive which gives complexion to all our moral actions, so Pascal's bitter wisdom, or even his unjust satire, is something very different from misanthropy. Byron found an apology for his Cain in Milton's delineation of Satan; but few besides himself could ever see its force. With as little reason could a Timon plead the example of a Pascal. He who cannot see a deep benevolence in all this great man wrote respecting our corrupted nature, must indeed be blind. It is with no demoniacal chuckle, no smile of malicious triumph, that he publishes the results of his researches into the depths of man's moral nature. On the contrary, it is with profoundest pity. He gazes on the noble ruins of humanity as on those of some magnificent temple, and longs to see the fallen columns and the defaced sculpture restored. With what noble eloquence-with what deep sympathy and humanitydoes he rebuke the levity of those infidels who tell us, as if it were matter of triumph, that we are "the inhabitants of a fatherless and forsaken world;" and whe talk as if their vaunted demonstration of the vanity of our immortal hopes gave them a peculiar title to our gratitude and admiration! "What rdvantage is it to us to hear a man saying that he has thrown 
off the yoke; that he does not think there is any God who watehes over his actions; that he considers himself as the sole iudge of his conduct, and that he is accountable to none but himself? Does he imagine that we shall hereafter exereise special confidence in him, and expect from him consolation, advice, suceor in the exigencies of life? Do such men imagine that it is any matter of delight to us, to hear that they hold that our soul is but a little vapor or smoke, and that he can tell us this in an assured and self-sufficient tone of voice? Is this, then, a thing to say with gayety? Is it not rather a thing to be said with tears, as the saddest thing in the - world ?"

On the whole, in contemplating the richly diversified characteristies of this exalted genius in its different moods and phases-the combination of sublimity and depth with lightness and grace-of the noblest aptitudes for abstract speculation with the most exquisite delicacy of taste and the utmost sensibility of feeling-of profound melancholy with the happiest and the most refined humor and raillery-the grandeur of many aspects of his character, and the loveliness of others, we seem to be reminded of the contradictory features of Alpine scenery, where all forms of sublimity and beauty, of loveliness and terror, are found in singular proximity; where upland valleys of exquisite verdure and softness lie at the foot of the eternal glaciers; where spots of purest pastoral repose and beauty smile under the very shadow of huge snowy peaks, and form the entrance of those savage gorges, in which reign perpetual sterility and desolation-in which the very silence is appalling, broken only by the roar of the distant cataract and the lonely thunder of the avalanche.

We must now make some remarks on the projected treatise, of which the Pensées were designed to form the rude materials.

It is impossible to determine, from the undeveloped character of the Pensées, the precise form of this work, and which was to have treated of the primary truths of all religion, ana of the evidences of Christianity. It is clear, that about hal 
the thoughts which relate to theology at all, have reference to the former. In his time, however, both subjects might have teen naturally included in one work. The great deistical contri ersies of Europe had not yet commenced, and there had been little reason to discriminate very nicely the limits of the wo investigations. Pascal, himself, could hardly have anticipated the diversified forms which the subject of the evidences of Christianity alone would assume-so diversified, indeed, that probably they are insusceptible from their variety (externa) and internal) of being fully exhibited by one mind, or, consequently, in one volume. The evidenees of Christianity almosl form a science of themselves.

Fragmentary as the Pensées are, it is easy to see, both from their general tenor and from the character of the author's mind, where the principal strength of such a work would lie. His proofs of the truths of natural religion would have been drawn from within, rather than from without; and his proofs of the truths of Christianity, from its internal rather than ex ternal evidences;--including in this term "internal," not only the adaptation of the doctrines revealed to the moral nature of man, but whatsoever indications the fabric of Scripture itself may afford of the divinity of its origin.

It is evident that all these topics he had revolved profoundly. None had explored more diligently the depths of man's moral nature, or mused more profoundly on the "greatness and misery of man,"-or on the "contrarieties" which characterize his nature-or on the remedies for his infirmities and corruptions. And there are few, even since his time, who seem to have appreciated more fully the evidences of Christianity, arising from indications of truth in the genius, structure, and style of the Scriptures; or from the difficulties, not to say impossibilities, of supposing such a fiction as Christianity the probable product of any human artifice, much less of such an age, country, and, above all, such men as the problem limits us to. In one passage, he gives expression to a thought which has been expanded into the beautiful and eminently original work of Paley, entitled Horce Paulinar. He says, "The style of the 
Gospel is admirable in many respects, and, among others, in this-that there is not a single invective against the murderurs and enemies of Jesus Christ. . . . If the modesty of the evangelical historians had been affected, and, in common with so many other traits of so beautiful a character, had been afiectorl only that they might be observed, then, if they had not ventured to advert to it themselves, they would not have failed to get their friends to remark on it, to their advantage. But as they acted in this way without affectation, and from a principle altogether disinterested, they never provided any one to make such a criticism. And, in my judgment, there are many points of this character which have never been noticed hitherto; and this testifies to the simplicity with which the thing was done."

He has also, with characteristic comprehensiveness, condensed into a single paragraph the substance of the celebrated volume of "Bampton Leetures," on the contrasts between Mahometanism and Christianity. "Mahomet founded his system on slaughter; Jesus Christ by exposing his disciples to death : Mahomet by forbidding to read; the Apostles by commanding it. In a word, so opposite is the plan of one from that of the other, that if Mahomet took the way to succeed according to human calculation, Jesus Christ certainly took the way to fail; and instead of arguing, that since Mahomet succeeded, Jesus Christ might also succeed, we ought rather to say, that since Mahomet succeeded, it is impossible but that Jesus Christ should fail."

On the subject of the External Evidences, we doubt whether he would have been equally successful,--partly because the spirit of accurate historic investigation had not yet been developed, and partly from the character of his own mind. On the subject of Miracles, too, he searcely seems to have worked bis conceptions clear; and in relation to that of Prophecy, he was evidently often inclined to lay undue stress on analogies between events recorded in the Old Testament, and others recorded in the New, where Scripture itself is silent as to any zonnection between them;-analogies in one or two cases as 
anciful as any of those in which the Fathers saw so many types and prefigurations of undeveloped truths. This disposition to forget the limits between the analogies which may form the foundation of a logical argument, and those which, after all, can yield only poetical illustrations, has too often obtruded itself even into the domain of physical science, and is one from which the most philosophic minds, if they have much imaginativeness, are by no means exempt. Even Bacon, in several instances, has been the dupe of this delusion-one of the idola tribus which he was so anxious to expose.

There is one subject on which, after reading the Pensées, one would fain have seen a treatise from the hand of Pascal. If he had enjoyed leisure, health, and an unclouded mind, there is probably no man who could have written more profoundly or more wisely on the Prima Philosophia-the first principles of all knowledge-the limits within which man can hopefully speculate-and the condition and principles of belief. On all these subjects he had reflected much and deeply. His remarks on the position of man between "the two infinitudes," which he has so finally illustrated-on the Dogmatists and Pyrrhonists-on the influence of the affections and passions on the understanding - and his observations entitled, $D e$ l'Art de Persuader and De l'Esprit Géométrique, - these all show how deeply he had revolved the principal topics of such a work.

We have before alluded to the charge preferred against Pascal by M. Cousin, of no less than universal and hopeless skepticism,--from which, as is said, he took refuge in faith by a blind effort of will, without evidence, and in utter despair of obtaining it. M. Cousin even goes the length of saying that Pascal's religion "was not the solid and pleasant fruit which springs from the union of reason and feeling--de la raison et $d u$ coeur-in a soul well constituted and wisely cultivated; it : a bitter fruit, reared in a region desolated by doubt, under "he arid breath of despair." He also tells ns, that "the very depth of Pascal's soul was a universal skepticism, from which he conld find no refuge except in a voluntary blind credulity.' 
"Le fond même de l'âme de Pascal cst un scepticisme universel, contre lequel il ne trouve d'asîle que dans une foi volontairement aveugle."

These are certainly charges which, without the gravest and most decisive proof, ought not to be preferre? against any man, much less against one possessing so clear and powerful an intellect as Pascal. It is in fact the most degrading picture which can be presented of any mind; for what weakness can be inore pitiable, or what inconsistency more gross, than that of a man who, by a mere act of will-if indeed such a condition of mind be conceivable-surrenders himself to the belief of the most stupendous doctrines, while he at the same time acknowledges that he has no proof whatever of their certainty?

We have great respect for M. Cousin as a philosopher and historian of philosophy, and we willingly render him the homage of our thanks for his liberal and enlightened survey of the intellectual philosophy of Scotland; but he must excuse us for dissenting from, and freely examining, his startling view of the skepticism of Pascal. That charge we do not hesitate to pronounce unjust, for the following reasons :

1. It appears to us that M. Cousin has forgotten that Pascal by no means denies that there is sufficient evidence of the many great principles to which skepticism objects; he only maintains that we do not arrive at them by demonstration. $\mathrm{He}$ has powerfully vindicated the certainty of those intuitive principles which are not ascertained by reasoning, but are presupposed in every exercise of reasoning. Let us hear him : "The only strong point," says he, "of the Dogmatists is, that we cannot consistently with honesty and sincerity doubt our own intuitive principles. . . . We know the truth, not only by reasoning, but by feeling, and by a vivid and luminous power of direct comprehension; and it is by this last faculty that we discern first principles. It is vain for reasoning, which has no share in discovering these principles, to attempt subverting them. . . . The Pyrrhonists who attempt this enust try in vain. . . The knowledge of first principles, 
as the ideas of space, time, motion, number, matter, is as unequirocally certain as any that reasoning imparts. And, after all, it is on the perceptions of feeling and common-seuse that reason must at last sustain itself and base its argument. . . . Irinciples are perceived, propositions are deduced : each part of the process is certain, though in different modes. And it is as ridiculous that reason should require of feeling and perception proofs of these first principles before she assents to them, as it would be that perception should require from reason an intuitive impression of all the propositions at which she arrives. This weakness, therefore, ought only to humble that reason which would constitute herself the judge of all things, but not to invalidate the convictions of common-sense, as if reason' only could be our guide and teacher." Can he who thus speaks be a "universal skeptic," when it is the peculiar characteristic of Pyrrhonism-that is, universal skepticism-to controvert the certainty of principles perceived by intuition, and to plume itself upon having successfully done this, when it has shown that they cannot be demonstrated by reasoning?

But let us hear him still more expressly on the subject of Pyrrhonism. "Here, then, is open war proclaimed among men. Each must take a side; must necessarily range himself with the Pyrrhonists or the Dogmatists; for he who would think to remain neuter is a Pyrrhonist par excellence. He who is not against them is for them. What, then, must a person do in this alternative? Shall he doubt of every thing? Shall he doubt that he is awake, or that he is pinched, or burned? Shall he doubt that he doubts? Shall he doubt that he is? We cannot get so far as this; and I hold it to be a fact, that there never has been an absolute and perfect Pyrrhonist." M. Cousin must suppose Pascal to have made an exception in

1 It is true that, in these and many similar passages, Pascal, as M. Cousin rightly observes, often employs the word reason as if it were synonymous with reasoning, But this only respects the propriety of his expressiors n:s meaning is surely tolerably clear. 
favor of himself, if it be indeed true that he was an " univer sal skeptic."

2. It does not appear to us that M. Cousin has sufficiently reflected, that in those cases in which conclusions truly involve processes of reasoning, Pascal would not deny that the prepon. deranee of proof rested with the truths he believed, though he denied the demonstrative nature of that proof. And he applies this with perfeet fairness to the evidences of Christianity, as well as to the truths of natural theology. It may well be that minds so differently eonstituted as those of Pascal and Cousin may form different conclusions as to the degree of success which may attend the efforts of human reasoning; but a man is not to be straightway branded with the name of a universal skeptic, beeause he believes that there are rery few subjects on which evidence can be said to be demonstrative. The more deeply a man reflects, the fewer will he thinl: the subjects on which this species of certainty can be obtained; and the study neither of ancient nor of modern philosophy will convince him that he is far wrong in this conclusion. But he will not, for all that, deny that there is sufficient evidence on all the more important subjeets to form the belief and determine the conduet of man-evidence of precisely the same nature with that which does form the one, and does determine the other, in all the ordinary affairs of life. And this alone, where he rejects snch evidence, is sufficient to condemn him; for what right has he to decline, in the more important instances, a species and degree of evidence which he never hesitates to act upon in all other cases?

Now, that Pascal believed that there was sufficient evidence of this eharacter, for all the fundamental truths of religion, is manifest from many express declarations. "There is light enough," says he, "for those whose sincere wish is to see; and darkness enough to confound those of an opposite disposition." Of Christianity, he says-"It is impossible to see all the proofs of this religion combined in one view, without feeling that tiney have a force which no reasonable man can with "land." "The proofs of our religion are not of that kind that 
we can say they are geometrically convincing. . . . But their light is such that it outshines, or at the least equals, the strongest presumption to the contrary : so much so, that sound reason never can deterrsine not to accept the evidence, and probably it is only the corruption and depravity of the heart that do." It is not without reason that M. Faugère says, in reference to the charge of skepticism urged against Pascal"Faith and reason may equally claim him. If they sometimes appear to clash in his mind, it is because he wanted time not only to finish the work on which he was engaged, but even to complete that internal revision-son ouvre intérieure-which is a kind of second creation of genius, and to melt into one harmonious whole the diverse elements of his thoughts. . . . Among the inedited fragments of Pascal, we find these remarkable lines: "Il faut avoir ces trois qualités; Pyrrhonien, géomètre, Chrétien soumis; et elles s'accordent et se tempèrent en doutant où il faut, en assurant où il faut, en se soumettant où il faut." These bold words comprise the entire history of Pascal, and express in brief the state of his mind.

3. While we admit that the severely geometrical cast of Pascal's mind, as well as his gloomy temperament, have led him at times into extravagant expressions on this subject, so accomplished a critic as $M$. Cousin needs not to be told, that it is not fair to take such expressions alone, and in their utmost strictness, if they can be confronted with others which modify or explain them. The former, in common candor, are to be interpreted only in connection with the latter. This is the course we always pursue in interpreting the language of writers who have indulged in unlimited propositions; and if it be found even impossible to harmonize certain expressions-if they be absolutely contradictory-all we feel at liberty to do is to affirm the inconsistency of the writer; not to assume that he meant all that could possibly be implied in the one class of expressions, and nothing by the other. We know it is so natural for an author of much magination or sensibility to give an inordinately strong expression to a present thought or feeling, and to forget the judge in the advocate, that he must be taken 
in another mood, or rather in several, if we wish to ascertain the true mean of his sentiments. Paseal has, in one of his Pensées, indicated this only reasonable method of procedure.

Now, M. Cousin is surely aware oi the fact, that the expres. sions to which he has given such an unfavorable interpretation may be easily confronted with others of a different tendency. He himself, indeed, proclains it. He even says, no man ever contradicted himself more than Pascal. "Jamais homme ne s'est plus contredit." "Confounding," says he, "reasoning and reason, forgetting that he has himself judiciously discriminated primary and indemonstrable truths, discovered to us by that spontaneous intuition of reason-which we also with him call instinct, sentiment, feeling - from truths which are deduced from them by the method of reasoning, or which we draw from experience by induction;-forgetting that he has thus himselt replied beforehand to all the attacks of skepticism, Pascal demands all these principles from experience and reasoning, and by that means, without much trouble, confounds them all." Now, we do not stay to inquire here into the justness of the latter part of this representation; but we simply ask, why should all "the replies" which, as our author admits, "Paseal has himself made to skepticism," gro for nothing, and only the sentences in which he appears to favor it be remembered; and not only remembered, but taken as the sole exponents of his opinions? Surely a skeptic might as well take the opposite side, and say : "Alas! after Pascal seems in many expressions to have conceded much to skepticism, he forgets all he had said; and shows, by his whole talk of 'intuitive truths,' and 'sentiment,' and 'feeling,' that he is no better than a dogmatist." Might we not say to the two objectors, "Worthy friends ! you are the two knights in the fable; - one is looking on the golden, and the other on the silver side of the same shield."

4. Nor is it to be forgotten, that while such a mode of interpretation as that of M. Cousin would hardly be just in the ease of any work of any author, it is especially unfair to apply it to such a work, or rather mere materials of a work, as the Pen. 
sees. They were, we are to recollect, mere notes for $t$ ascal's own use, and were never intended to be published as they are. Many of them are altogether imperfect and undereloped; some scarcely intelligible. It is impossible to tell with what molifications, and in what connection, ther would hare stood in the matured form which the master-mind, hastily recording them for private reference, would have ultimately given them. Nar, there can scarcely be a doubt that many of them were mere objections which Pareal noted for refutation-not opinions to be maintained by him; and this in many places may be not obscurely inferred. Some, again, are mere quotations from Montaigne and other authors, extracted for some unknown purpose, but not distinguished in these private memoranda from the writers own expressions; so that the first editors of the Pensées actually printed them in some cases as his. And lastly, some were dictated, in moments of sickness and pain, to an old domestic, who has scrawled them in a fashion which sufficiently shows that it is rery possible that some errors may lie with the amanuensis.' Yet M. Cousin, while straining erery expression on which he founds his charge of skepticism to its utmost strictness of literary meaning, never seems to have adverted to one of these rery reasonable considerations.

j. The weight which any deliberate opinion of M. Cousin must reasonably possess, may in this case well be confronted with that of bayle, whose notorions skepticism would hare been but too glad to find an ally in so admired a genius as Pascal, had there been any plausible pretext on which to claim him. Yet that subtle and acute critic declares, that Pascal knew perfeetly well what to render to faith and what to reason.

6. In our judgment lascal's projected work is itself a suffcient confutation of M. Cousin's supposition. For, did erer man before meditate an elaborate work on the "eridences" of

1 Of one of these expressions, on which $\mathbf{Y}$. Consin has founded much, M. Fuagere says: "Tout ce morcean, dicté à une personne visiblement fort peu lettré, présente çà et là des obseurités qui vienuent sans doute de linexpérience du zecrétaire."-Tom. i, p. :It. 
truths for which he believed no evidence but a blind faith could be given?

7. We maintain, lastly, that even if it were proved (which is, doubtless, very true) that Pascal, at different periods and in different moods of mind, formed varying estimates of the evidence on behalf of the great truths in which he was so sincere a believer; or even (which may possibly be true) that for transient intervals he doubted the conclusiveness of that evidence altogether, these variations would be far from justifying a charge of "universal and habitual skerticism,"-such momentary differences of thought and mood having been notoriously experienced by many of the greatest minds. With some remarks on this subject, which may possibly be serviceable to minds peculiarly liable to attacks of skepticism, and calculated to teach all of us charity in judging of others, we shall close the present article.

We confess, then, that it by no means appears to us that a momentary invasion of doubt, or even of skepticism, is inconsistent with a prevailing and habitual faith, founded on an intelligent conviction of a preponderance of reasons to justify it; though those reasons may be felt to fall far short of absolute demonstration. There may be a profound impression that the reasons which justify habitual belief in any truth established only on moral evidence, or on a calculation of probabilities, are so varied and powerful-so vast is their zum-as to leave, in ordinary moods of mind, no doubt as to the conclusions to which they point, and the practical course of conduct which alone they can justify. And yet it is quite true, that from the infirmities of our nature-from the momentary strength which the most casual circumstances may give to opposing objections -from the depressing influence of sorrow-of a trivial indisposition-of a transient fit of melancholy - of impaired digestion-even of a variation of the weather (for on all these humiliating conditions does the boasted soundness of human reason depend) - a man shall for an hour or a day really duubt of that of which he never doubted before, and of which he would be ashamed to doubt to-morrow. And especially is this 
the case in those who, like Pascal, possess exquisite sensibility, or are liable to fits of profound depression. As they look upon truth through the medium of cheerful or gloomy feelings, truth herself varies like a landscape, as seen in a bright sunshine or on a cloudy day. Pascal himself, in those reveries in which he loved to indulge on the mingled "greatness and misery $o_{\text {. }}$ unan," has frequently depicted the dependence of the most powerful mind, even in the bare exercise of its exalted faculties, on the most insignificant circumstances. We have cited, in the early part of this article, one striking passage to this effect. In another place he says: "Place the greatest philosopher in the world on a plank, wider than is absolutely necessary for safety, and yet, if there is a precipice below him, though reason may convince him of his security, his imagination will prevail. There are many who could not even bear the thought of it without paleness and agitation." Another very powerful representation, to the same effect, may be found on the same page, where, after describing a "venerable judge," who may seem " under the control of a pure and dignified wisdom," and enumerating several petty trials "of his exemplary gravity," Pascal declares, that, let any one of these befall him, "and he will engage for the loss of the judge's self-possession!"

Nor are the causes which disturb the exercise of the reason merely physical : moral causes are yet more powerful; as we wish, hope, fear, humiliating as the fact is, so do we proceed to judge of evidence. Reason, that vaunted guide of life, nowhere exists as a pure and colorless light, but is perpetually tinctured by the medium through which it passes; it flows in upon us through painted windows. And thus it is, that perharps scarcely once in ten thousand times, probably never, does man deiiver a judgment on evidence simply and absolutely judicial. "The heart," says Pascal, with great truth, "has its reasons, which reason cannot apprehend." "The will," says be, in another place, "is one of the principal instruments of belief; not that it creates belief, but because things are true or false according to the aspect in which we regard them. The will, which is more inclined to one thing than another, turns 
away the mind from the consideration of those things which it loves not to contemplate; and thus the mind, moving with the will, stops to observe that which it approves, and forms its judgment by what it sees."

Most emphatically is this the ease where the moral state is habitually opposed to the conclusions to which the preponderance of evidence points. This is so notorious, in relation to the fundamental truths of morals and religion, that there are probably few who really disbelieve them, or profess to do so, who (if they examine themselves at all) are not conscious that the "wish is father to the thought." And what is true of habitual states of moral feeling, is also, in proportion, true of more transient states.

Certain, however, it is, that from one to the other of the above causes, or from a combination of several, neither has the understanding the absolute dominion in the formation of our judgments, nor does she occupy an "unshaken throne." A seditious rabble of doubts, from time to time, rise to dispute her empire. Even where the mind, in its habitual states, is unconscious of any remaining doubt,-where it reposes in a vast preponderance of evidence in favor of this or that conclusion,- - there may yet be, from one or other of the disturbing causes adverted to, a momentary eclipse of that light in which the soul seemed to dwell; a momentary vibration of that judgment which we so often flattered ourselves was poised forever. Yet this no more argues the want of habitual faith, than the variations of the compass argue the severance of the connection between the magnet and the pole; or, than the oscillations of the "rocking stone" argue that the solid mass can be heaved from its bed. A child may shake it, but a giant cannot overturn it.

And, as a matter of fact, there are, we appreherd, very few who have not been conscious of sudden and almost unaccountable disturbances of the intellectual atmosphere, unaccountable even after the equilibrium has been restored, and the air has again become serene and tranquil. In these momentary fluctuations, whether arising from moral or physical causes, or 
from causes of both kinds-from rervous depression, or a fit of melancholy, or an attack of pain, or harassing anxieties, or the loss of friends; or their misfortunes and calámities, or signal triumphs of baseness, or signal discomfitures of virtue, or, above all, from conscious neglect of duty-a man shall sometimes feel as if he had lost sight even of those primeval truths on which he has been accustomed to gaze as on the stars of the firmament-bright, serene, and unchangeable; even such truths as the existence of God, his paternal government of the world, and the divine origin of Christianity. In these moods, objections which he thought had long since been dead and buried, start again into sudden existence. They do more; like the escaped genius of the Arabian Nights, who rises from the little bottle in which he had been imprisoned in the shape of a thin smoke, which finally assumes gigantic outlines, and towers to the skies, these flimsy objections dilate into monstrous dimensions, and fill the whole sphere of mental vision. The arguments by which we have been accustomed to combat them seem to have vanished, or, if they appear at all, look diminished in force and vividness. If we may pursue the allusion we have just made, we even wonder how such mighty forms should ever have been compressed into so narrow a space. Bunyan tells us, that when his pilgrims, under the perturbation produced by previous terrible visions, turned the perspective glass towards the Celestial City from the summits of the Delectable Mountains, "their hands shook so that they could not steadily look through the instrument; yet they thought they saw something like the gate, and also some of the glory of the place." It is even so with many of the moods in which other "pilgrims" attempt to gaze in the same direction, a deep haze seems to have settled over the golden pinnacles anil the "gates of pearl ;" they, for a moment, doubt whether what others declare they have seen, and what they flatter themselves they have seen themselves, be any thing else than a gorgeous vision in the clouds; and "faith" is no longer "the substance of things hoped for, and the evidence of things not seen."

And as there are probably few who have profoundly inves 
tigated the evidences of truth, who have not felt themselves for a moment at least, and sometimes for a yet longer space, as if on the verge of universal skepticism, and about to be driven forth without star or compass on a boundless ocean of doubt and perplexity, so these states of feeling are peculiarly apt to infest the highest order of minds. For if, on the one hand, these can best discern and estimate the evidence which proves any truth, they, on the other, can see most clearly and feel most strongly the nature and extent of the objections which oppose it; while they are, at the same time, just as liable as the vulgar to the disturbing influences already adverted to. This liability is of course doubled, when its subject, as in the case of Pascal, labors under the disadvantage of a gloomy temperament.

A circumstanec which in these conflicts of mind often gives skeptical objections an undue advantage, is, that the great truths which it is more especially apt to assail, are generally the result of an accumulation of proof by induction, or are even dependent on quite separate trains of argument. The mind, therefore, sannot comprehend them at a glance, and feel at once their integrated force, but must examine them in detail by successive acts of mind,-just as we take the measurement of magnitudes too vast to be seen at once in successive small portions. The existence of God, the moral government of the world, the divine origin of Christianity, are all truths of this stamp. Pascal, in one of his Pensées, refers to this infirmity of the logical faculties. He justly observes: "To have a series of proofs incessantly before the mind is beyond our power." D'en avoir toujours les prevves présentes, c'est trop d'affaire.

From the inability of the mind to retain in perpetuity, or to - umprehend at a glance a long chain of evidence, or the total effect of various lines of argument, Pascal truly observes, that it is not sufficient for the security of our convictions, and their due influence over our belief and practice, that we have proved them onee for all by a process of reasoning; they must be, if possible, tinetured and colored by the imagination, informed and animated by feeling, and rendered vigorous and practica 
by habit. His words are well worth eiting: "Reason acts slowly, and with so many views upon so many principles which it is necessary should be always present, that it is perpetually dropping asleep, and is lost for want of having all its principles present to it. The affections do not act thus; they act instantaneously, and are always ready for action. It is necessary, therefore, to imbue our faith with feeling, otherwise it will be always vacillating."

It will not, of course, be imagined that, in the observations we have now made, we are disposed to be the apologists of skepticism; or even, so far as it is yielded to, of that transient doubt to which we affirm even the most powerful minds are not only liable, but liable in defiance of what are ordinarily their strong convictions. So far as such states of mind are involuntary, and for an instant they often are (till, in fact, the mind collects itself, and repels them), they are of course the object not of blame, but of pity. So far as they are dependent upon fluctuations of feeling, or upon physical causes which we can at all modify or control, it is our duty to summon the mind to resist the assault, and reflect on the nature of that evidence which has so often appeared to us little less than demonstrative.

We are not, then, the apologists of skepticism, or any thing approaching it; we are merely stating a psychological faet, for the proof of which we appeal to the recorded confessions of many great minds, and to the experience of those who have reflected deeply enough on any large and difficult subject, to know what ean be said for or against it.

The asserted fact is, that habitual belief of the sincerest and strongest character is sometimes checkered with transient fits of doubt and misgiving; and that even where there is no actual disbelief-no, not for a moment-the mind may, in some of its moods, form a very diminished estimate of the evidence on which belief is founded, and grievously understate it accordingly. We believe that both these states of mind were occa sionally experienced by Pascal-the latter, however, much more frequently than the former; and hence, as we apprehend, are we to account for those passages in which he speaks of the 
evidence for the existence of a God, or for the truth of Christianity, as less conclusive than he ordinarily believed, or than he has at other times declared them. Av such times, the clouds may be supposed to have hung low upon this lofty mind.

So little inconsistent with a habit of intelligent faith are such transient invasions of doubt, or such diminished perceptions of the evidence of truth, that it may even be said that it is only those who have in some measure experienced them, who can be said, in the highest sense, to believe at all. He who has never had a doubt, who believes what he believes for reasons which he thinks as irrefragable (if that be possible) as those of a mathematical demonstration, ought not to be said so much to believe as to know; his belief is to him knowledge, and his mind stands in the same relation to it, however erroneous and absurd that belief may be. It is rather he who believes-not indeed without the exercise of his reason, but without the full satisfaction of his reason-with a knowledge and appreciation of formidable objections-it is this man who unay most truly be said intelligently to believe.

While it is true that we are called upon to receive the great truths of Theology, whether natural or revealed, on evidence which is less than demonstrative, we are not to forget that no subjects out of the sciences of magnitude and number admit of any such demonstration. We are required to do no more in religion than we are in fact necessitated to do in all the affairs of common life-that is, to form our conclusions upon a sincere and diligent investigation of moral evidence. And, after all, such an arrangement is not only in harmonious analogy with all the conditions of our ordinary life, but, if the present world be indeed a state of moral probation-if it be designed to test our diligence and sincerity, to teach us what is so suitable in a finite and created being, a submissive and conniding posture of mind towards the Infinite Creator-such an qrrangement is essential to our course of moral discipline and education. If we are required to believe nothing but what it is impossible that we sl.ould dubt-that is, nothing but what 
it would be a contradietion to deny-where would be the prooi of our willingness to believe on the bare assurance of wisdom and knowledge superior to our own? Wise men assuredly consider it as a most important elcment in the education of their own children, not indeed that they should be taught to believe what they are told without any reason (and if they have been properly trained, a just confidence in the assurances of their superiors in knowledge will on many subjects be reason sufficient), yet upon evidence far less than demonstration; indeed upon evidence far less than they will be able to appreciate, when the lapse of a few brief ycars has transformed them from children into men. We certainly expect that they will believe many things as facts which as yet they cannot fully comprehend-nay, which they tell us are, in appearance, paradoxical; and to rest satisfied with the assurance, that it is in vain to attempt to explain the evidence till they get older and wiser. We are accustomed even to augur the worst results as to the future course and conduct of a youth who has not learned to exercise thus much of practical faith, and who flippantly rejects, on the score of his not being able to comprehend them, truths of which he yet has greater evidence, though not tirect evidence, of their being truths, than he has of the contrary. Now, "if we have had earthly fathers, and have given them reverence" after this fashion, and when we have become men have applauded our submission as appropriate to our condition of dependence, "shall we not much rather be subject to the Father of spirits, and live?" If, then, the present be a scene of moral education and discipline, it seems fit in itselt that the evidence of the truths we believe should be checkered with difficulties and liable to objections;-not strong enough zo force assent, nor so obscure as to elude sincere investigation. God, according to the memorable aphorism of Pascal already eited, has afforded sufficient light to those whose object is te sec, and left sufficient obscurity to perplex those who have no such wish. All that seems necessary or reasonable to expect is, that as we are certainly not called upon tc believe any thing without reason, nor without a preponderance of reason, so the 
evidence shall be such as our faculties are capable of dealing with; and that the objections shall be only such as equally bafle us upon any other hypothesis, or are insoluble only because they transcend altogether the limits of the human understanding: which last circumstance can be no valid reason, apart from other grounds, either for accepting or rejecting a given dogma. Now, we contend, that it is in this equitable way that God has dealt with us as moral agents, in relation to all the great truths which lie at the basis of religion and morals; and, we may add, in relation to the divine origin of Christianity. The evidence is all of such a nature as we are accustomed every day to deal with and to act upon; while the objections are either such as reappear in every other theory, or turn on difficulties absolutely beyond the limits of the human faculties. Take, for example, the principal argument which proves the existence of God; the argument which infers from the traces of intelligent design in the universe, the existence of a wise and powerful author. In applying this principle, man only acts as he acts every day of his life in other cases. IIe acts on a principle which, if he were to doubt, or even affect to doubt, he would be laughed at by his fellow-men as a ridiculons pedant or a crazy metaphysician. Whether indications of design, countless as they are inimitable, with which the whole universe is inscribed, are likely to be the result of chance, is a question which turns on principles of evidence with which man is so familiar that he cannot adopt the affirmative without contradicting all his judgments in every other analogous, or similar, or conceivable case. On the other hand, the objections to the conclusion that there is some Eternal Being of illimitable power and wisdom are precisely of the naure we have mentioned. A man makes a difficulty, we will buppose (as well he may), of conceiving that which has existed from eternity; but, as something certainly exists now, the denial of the existence of such a Being does not relieve from that difficulty, unless the objector plunges into another equally great,- - that of supposing it possible for the universe to have sprung into existence without a cause at all. This difficulty 
then, is one which reappears under any hypothesis. Again, wo will suppose him to make a difficulty of the ideas of selfsubsistenee, of omnipresence without extension of parts-of power which creates out of nothing, and which acts simply by volition - of a knowledge eognizant of each thing and of all its relations-actual and possible, past, present, and to come--tc every other thing, at every point of illimitable space, and it every moment of endless duration. But then these are difliculties, the solution of which clearly transcends the limits of the human understanding; and to deny the doctrines which seem established by evidenee which we can appreeiate, because we cannot solve difficulties which lie altogether beyond our capacities, seems like resolving that nothing shall be true but what we can fully comprehend-a prineiple again which, in numberless other cases, we neither ean nor pretend to act upon.

It is much the same with the evidenees of Christianity. Whether a certain amount and complexity of testimony are likely to be false; whether it is likely that not one but a number of men would endure ignominy, persecution, and the last extremities of torture, in support of an unprofitable lie; whether such an original fiction as Christianity-if it be fiction-is likely to have been the production of Galilean peasants; whether any thing so sublime was to be expected from fools, or any thing so holy from knaves; whether illiterate frand was likely to be equal to such a wonderful fabrication; whether infinite artifice may be expected from ignorance, or a perfectly natural and successful assumption of truth from inposture ;these and a multitude of the like questions are precisely of the same nature, however they may be decided, with those with which the historian and the advocate, judges and courts of law, are every day required to deal. On the other hand, whether miracles have ever been, or are ever likely to be admitted in the administration of the universe, is a question on which it would demand a far more comprehensive knowledge of that zdministration than we can possibly possess to justify an $\grave{a}$ priori decision. That they are possible is all that is required; and that, no consistent Theist can deny. Other difficulties of 
Christianity, as Bishop Butler has so clearly shown, baffle us on every other hypothesis; they meet us as much in the "constitution of nature" as in the pages of revelation, and cannot consistently be pleaded against Christianity without being equally fatal to Theism.

There are two thing philosophers of some future age will stand equallv stonished; the one is, that any man should have been called upon to believe any mystery, whether of philosophy or religion, without a preponderance of evidence of a nature which he can grasp, or on the mere ipse dixit of a fallible creature like himself; the other, that where there is such evidence, man should reject a mystery, merely because it is one. This last, perhaps, will be regarded as the more astonishing of the two. That man, who lives in a dwelling of clay, and looks out upon the illimitable universe through such tiny windows-who stands, as Pascal sublimely says, between "two infinitudes"--who is absolutely surrounded by mysteries, which he overlooks, only because he is so familiar with them, should doubt a proposition (otherwise well sustained) from its intrinsic difficulty, does not seem very reasonable. But when we further reflect that that very mind which erects itself into a standard of all things is, of all things, the most ignorant of that which it ought to know best-itself, and finds there the most inscrutable of all mysteries; when we reflect that when asked to declare what itself is, it is obliged to confess that it knows nothing about the matter-nothing either of its own essence or its mode of operation-that it is sometimes inclined to think itself material and sometimes immaterial-that it cannot quite come to a conclusion whether the body really exists or is a phantom, or In that way (if the body really exist) the intimate union between the two is maintained; when we see it perplexed beyond expression even to enceive how these phenomena car. be reconciled-proclaiming it to be an almost equal contradiction to suppose that matter can think, or the Soul be material, or a counection maintained between two totally different sub. stanees, and yet admitting that one of these must be true 


\section{GeNiUs AND WRithas OF PASCAL.}

though it cannot satisfactorily determine which; when we reflect on all this, surely we cannot but feel that the spectacle of so ignorant a being refusing to believe proposition merely becuuse it is above its comprehension, $i_{\sim}$ of all paradoxes the most paradoxical, snd of all absurdities the most ludicrous. 


\title{
PASCAL AS A PHILOSOPHIC SKEPTIC.
}

\author{
BY M. VICTOR COUSIN.
}

Already, in $1828,{ }^{1}$ we had found Pascal a skeptic, even in Port-Royal and Bossut; in 1842, we found him still more skeptical in the autograph manuscript, and in spite of the lively controversy that has been awakened on the subject, our conviction has not been for a single moment shaken-it has even been strengthened by new studies.

"What! Pascal a skeptic?" is the cry that is raised from almost every quarter. "What Pascal are you putting in the place of him who has hitherto been regarded as one of the stanchest defenders of the Christian religion ?" A truce, gentlemen; let us understand each other, I beg you. I have not said that Pascal was a skeptic in religion: that were, indeed, a little too absurd : far from that, Pascal believed in Christianity with all the powers of his soul. I will not go back and insist on the nature of his faith-a faith which I have not feared to call an unhappy one, such as I could not wish for any of my fellow-beings-but who could ever deny that this faith was sincere and profound? The question must be stated with clearness and precision:-Pascal was a skeptic in philosophy and not in religion; and because he was a skeptic in philosophy, he attached himself so much the more closely to religion, as to the last resource of humanity in the impotence o

1 Cours de l'Histoire de la Pdilosophie moderne, II Série, t. ii, lec. xii p. 338. 
rason, in the ruin of all natural truth among men. This is what I have said, what I maintain, and what it behooves me to prove for the last time beyond the possibility of refutation.

What is skepticism? A philosophic opinion that consists precisely in rejecting all philosophy as impossible, on the ground that man is incapable by himself of arriving at any truth, still less at those truths which corstitute what is called in philosophy Ethics and Natural Religion-that is, the free. dom of man, the law of duty, the distinction between just and unjust, between good and evil; the sanctity of virtue, the immateriality of the soul, and Divine Providence. All philosophers, worthy of the name, aspire to these truths. To reach them, one takes one course, another, another: processes differ; hence diverse methods and schools, less opposed to each other than one would at first sight believe, whose listory expresses the movement and progress of human intelligence and civilization. But the most different schools pursue a common end-the establishment of truth; and set out from a common principle--the firm conviction that man has received from God the power of attaining truths of the moral as well as of the physical order. This natural power, which they place in scnsation or reflection, in sentiment or intellect, is among themselves a subject of family quarrel; but they are all agreed upon the essential point that man possesses the power of arriving at truth; for upon this condition, and this alone, philosophy is not a chimera.

Skepticism is the adversary, not only of such or such a school, but of all schools of philosophy. We must not confound skepticism with doubt. Doubt has its legitimate use, its wisdom, its utility. It serves philosophy in its way, for it warns her of her aberrations, and reminds reason of its imperiections and limits. It may be applied to such a result, such a process, such a principle, even sach an order of cognitions; but as soon as it is applied to the faculty of knowing, if it contests with reason her power and her rights, from that moment it is no longer doubt but skepticism. Doubt does not Hec truth; it seeks it, and it is the better to attain it that it 
watches over and holds in check the often rash procedures o! reason. Skepticism does not seek truth, for it knows, or thinks it knows, that there is none and ean be none for man Doubt is to philosophy an inconvenient, often importmate always useful friend: skepticism is to it a mortal enemy Doult plays in some sort the part, in the empire of philosophy, of the constitutional opposition in the representative sys. tem; it acknowledges the principle of the government, only criticising its acts, and that too in the very interest of the government. Skepticism resembles an opposition that labors to ruin the established order, and exerts itself to destroy the principle itself in virtue of which it speaks. In days of peril, the constitutional opposition hastens to lend its support to the government, while the other opposition invokes dangers, and in them places its hopes of triumph. Thus, when the rights of philosophy are menaced, doubt, feeling itself menaced in her, rallies to her as to its own principle ; skepticism, on the contrary, then lifts the mask and openly betrays. Skepticism is of two kinds: it either remains its own end, resting tranquilly in the negation of all certainty; or it has a secret aim quite different from its apparent object, and plays a hidden game, holding back the cards, as we may say, of its most audacious designs. In the bosom of philosophy it has the air of combating for the unlimited liberty of the human mind, against the tyranny of what it calls philosophical dogmatism, while in reality it is conspiring in favor of a foreign tyranny.

Who does not remember, for instance, having seen in our times a famous writer preaching the most absclute skepticism in one volume of the Essay on Indifference, in order to lead as in the other volumes to the most absolute dogmatism that zver existed?

It remains to ascertain whether skepticism, such as we have ust defined it in general, is or is not in the book of Thouyhts.

According to us, it is thore, and breaks forth in every page, it every line. Pascal breathes skepticism; he is fuli of it; be proclaims its principle, accepts all its consequences ani 
pushes it at the outset to its furthest limits-the avowed contempt, and almost hatred, of all philosophy.

Yes, Pascal is a declared enemy of philosopiny : he believes in it neither much nor little; he rejects it absolutely.

Hear him, not in the weakened echo of Port-Royal and Bossut, but in his own manuscript, the incorruptible witness of his real thought.

At the close of the famous yet most unjust tirade against Descartes, Pascal has written these words : "We do not esteem the whole of Philosophy as worth a single hour of pains." And elsewhere : "To ridicule philosophy is truly to philosophize."

Is this language sufficiently clear? It is not such or such a philosophic school that is condemned, it is all philosophic study, it is philosophy itself. Idealists or empirists, diseiples of Plato or of Aristotle, of Locke or of Descartes, of Reid or of Kant, whoever you may be, if you are philosophers, Pascal declares war against you all.

In the same manner, in the whole history of philosophy, Pascal absolves nothing but skepticism. "Pyrrhonism. Pyrrhonism is truth." Mark well this decisive sentence. Pascal does not say: There is some truth in Pyrrhonism; but Pyrrhonism is truth. But Pyrrhonism is not doubt upon such or such a point of human knowledge; it is universal doubt, it is the radical negation of all natural power of knowing. Pascal explains his idea perfectly: "Pyrrhonism is truth; for, after all, before Jesus Christ, men neither knew where they stood, nor whether they were great or small; and those who asserted the one or the other knew nothing about it, but guessed without reason and through chance, and even constantly erred, whichever they excluded."

Thus, before Jesus Christ, the only sage in the world, is aeither Pythagoras nor Anaxagoras, neither Plato nor Arisotle, neither Zeno nor Epicurus, nor even thou, O Socrates, who hast died for the cause of truth and God. No; the only age is Pyrrho; as, since Jesus Christ, the least contemptible of all the philosophers is neither Locke nor Descartes, but Montaigne. 
Do you desire us to show you in Pascal the principle of all skepticism, the impotence of human reason? We are embarrassed only in the choice of passages.

"What is thought? How foolish it is!"

"Humiliate yourself, impotent reason; be silent, imbecile nature."

What mean these haughty invectives, if they do not spring fiom a deeply-rooted skepticism?

Notwithstanding, it is disputed, and this is the specious obiection which is made: You are mistaken, it is said, in - yard to Pascal's true thought. He is skeptical, we confess, on the side of reason; but what matters it, if he recognizes another natural principle of certainty? Now this principle, superior to reason, is sentiment, instinct, the heart. Let us clear up this interesting point.

Pascal has written a remarkable passage on the primary truths which reason cannot demonstrate, but which serve as the foundation of all demonstration.

"We know truth not only through the reason, but also through the heart; it is from the latter source that we know its first principles, and it is useless for reasoning, which has no share in them, to attempt to oppose them. The Pyrrhonists, who have this for their sole object, labor in vain. We know that we are not dreaming, however impotent we may be to prove it by reason-an impotence which merely demonstrates the weakness of our reason, but not the uneertainty of all our knowledge, as they pretend; for the knowledge of first principles, like that of space, time, motion, number, is as positive as that of any given us by our reasoning; and it is upon this knowledge of the heart and instinct that reason must rest and found all its conclusions. The heart feels that there are three dimensions in space, and that numbers are infinite; reason afterwards demonstrates that there are no two squares, one of which is double the other. Principles are felt, propositions eoncluded; both with certainty, though by different ways; and it is as useless and as ridiculons for the reason to demand of the heart proofs of its first principies before being willing to 
consent to them, as it would be absurd for the heart to demand of the reason a feeling of all the propositions which it demonstrates before being willing to receive them. This impotence should serve, therefore, only to humiliate reason, which would judge of every thing, but not to combat our certainty, as il there were nothing but reason capable of instructing us. Would to God, on the contrary, that we never had need of it, but that we knew all things by instinct and feeling!"'

We willingly adhere to this theory; but Pascal was not the inventor of it: it is common in philosophy, particularly in the Platonic and Cartesian school. Behold, therefore, this proud contemner of philosophy become a philosopher in turn-the disciple of Plato and Descartes. This is, in the first place, a very strange metamorphosis. And then, when one borrows from philosophy one of its most celebrated maxims, he should comprehend it well and express it faithfully.

There are assuredly some truths that spring from a faculty quite different from reasoning. What is this faculty? All the Cartesian and Platonic school call it reason-a very different thing from reasoning, as is well said by Molière:

"Et le raisonnement en bannit ia raison." 2

Reason is the very foundation of the human mind; it is the natural power of knowing, which manifests itself in very different ways, - sometimes by a sort of intuition, by a direct conception; and thus it is that it reveals to us primary truths. and those universal and necessary principles which constitute the patrimony of common sense,-sometimes by way of deduction, or of induction; and thus it is that it forms those

1 There are several similar passages in Pascal. "The mind and the heart are like doors by which truth is reseived into the soul." . . . "The heart has its order; so has the mind, which is by prineiples and demorstrations. But that of the heart is very different: we do not demonstrate that we ought to be loved by propounding in order the causes of love. This would be ricliculous." . . . "The heart has its reasons which tne eason does not know; we feel it in a thousand things." .... "lustim. - d reason, the marks of two natures."

And reasoning exiles reason 
ong chains of connected truths, termed the human sciences. All truths are not self-demonstrative: there are some which are clear from their own evidence, and which reason attains by her own virtue and by the energy which belongs to her; but in this case, as in all the rest, she is still the human reason : it may even be said that her natural power appears still more in this. In reproducing this theory, which is as old as philosophy $^{1}$ itself, but which he seems to regard as new, Pascal perveits it somewhat by the forms in which he clothes it. With due deference to the great geometrician-this consummate master of the art of speaking and of writing - can we approve this singular expression? The heart feels that there are three dimensions in space. Why this strange fashion of saying, with two or three hundred philosophers, the most common thing in the world, namely, that the notion of extent and space is not an acquisition of reasoning, but a direct conception of reason, of understanding, of intellect, as we may please to call it, commencing its functions in the train of sensation ? ${ }^{2}$

Pascal does worse: he turns against itself the theory of primary and undemonstrable truths, by the aid of a kind of play of words unworthy of his genius. What all the world calls reasoning, it suits Pascal to call reason; this would be well enough if, in conformity with the definition which he himself has established, he gave notice of the fact; but he does nothing of the sort, but argues in this manner at his ease. $\mathrm{He}$ addresses himself to reasoning, which he terms reason, and calls on it to justify the principles of human knowledge. This reasoning cannot do, for its function is not to demonstrate the principles from which it proceeds. Upon this, Pascal thunders forth: "Humiliate yourself, impotent reason; be silent, imbecile nature." But if, instead of reasoning, which is here alone arraigned, reason were suffered to take up the defencr

1 See our writings, passim, among othęrs, Cours de l'Histoire de he Phi. bosphie moderne, Ire Série, t. ii, lec. ix et x; Du Mysticisme, p. 193, t. iv lec. xiii ; Hutcheson, Esthétique, p. 104, loc. xiv, p. 140, lec. xxii ; Reid. Essais sur les Facultés intellentuelles, p. 502, et 3.

- Cours de l'Hist. de la Philos. moderne, II' Série, t. iii, lec. xvii. 
she would remind Paseal of his forgotten theory, and, in the name of this theory, would reply to him that, far from being impotent, she has the marvellous power of revealing truth to us without the aid of any reasoning - that, far from being imbecile in her nature, she rises by the power that is within herself to those first, eternal truths, which skepticism may deny with the lips, but which in reality it cannot but admit, and which its own arguments contain or suppose. She would say to Paseal : Either you abandon the theory which you just affirmed, or you maintain it; if you abandon it, what a paradox are you, in turn, to yourself! If you maintain it, then, in order to be faithful to your own maxims, abjure your inconsiderate disdain, and honor this light, at once human and divine, which illumines every man on his entrance into the world, and discovers to the herdsman as well as to yourself all necessary truths, without the often deceptive apparatus of scholastic demonstrations.

It appears to us that this answer should suffice; and yet it is necessary to carry it further-it is necessary to show that the skepticism of Pascal did not make the slightest reserve in favor of the truths of feeling and heart, and that it was too consequent not to have been without limits. In fact, as M. Royer-Collard says, "one does not take skepticism by halves ;" it is absolute, or it is not; it wholly triumphs, or perishes entire. If, under the name of feeling, reason legitimately farnishes us with sure first principles, reasoning, being based on these principles, will also legitimately draw from them sure conclusions, and science will raise itself entire on the smallest stone that is left to it. It is all over, then, with the design of Pascal. In order that faith (I mean here, with him, supernatural faith in Jesus Christ) should give every thing, it is necessary that natural reason should give nothing - that it should be able to give nothing, either under one name or another. Thus, hardly has Pascal finished this vaunted exposition of the truths of feeling, before he sets about depreciating them, diminishing sheir number and contesting their authority; he who has said, in a moment of distraction, that nature confounds Pyrrhonism, 
as Pyrrhorism confounds reason (always meaning reasoning) he who has just written the words, "We know that we are not drealning, however impotent we may be to prove it by reason," now takes up the arguments of Pyrrhonism, which he seemed to have broken forever, and turns them against feeling itself, to destroy all dogmatism which would agree as well with feeling as with reason, to decry all philosophy, and to crush human nature. Pascal proceeds with order in this enterprise; he goes on step by step, and only reaches by degrees his ultimate end.

In the first place, he studies to show that Pyrrhonism is far from being powerless against natural truths, and that it serves at least to entangle the matter ( $\grave{a}$ embrouiller la matière), which is something already. The passage is curious :

"We suppose that all men understand in the same manner, though we suppose it very gratuitously, since we have no proof of it. I know indeed that the same words are employed on the same occasions, and that whenever two men see a body changing place they both describe the sight of the same object by the same words, and both say that it is moving; and from this conformity of expression is drawn a strong conjecture of conformity of thought; but this is not an absolutely convincing proof of the latter conviction, although there may be good reason to incline to the affirmative, since it is well known that the same consequences often result from different suppositions.

"This suffices at least to entangle the matter, not that it absolutely extinguishes natural clearness, which assures us of these things, as the academicians would assert; but it darkens it and troubles the dogmatists, to the glory of the Pyrrhonian cabal, which consists of this ambiguous ambiguity, and of a a certain doubtful obscurity, from which our doubts cannot take away all the clearness, nor our natural light dispel all the darkness."

Behold natural light already obscured, and, thank heaven, the matter entangled; yet the principle of natural clearness, weak as it may be, is still existing; it is necessary tc extinguish it, and complete the chaos. Pascal goes, there 
fore, so far as to maintain that, without faith and revelation, fecling itself is impotent. What! ean fecling be so far impotent that, without revelation, man cannot legitimately know whether he is sleeping or waking? Just now, Pascal scoffed at the Pyrrhonism that pretended to go so far as this. But once more, if Pyrrhonism does not go thus far, it is lost; by degrees, feeling, instinct, and heart will win back from it, one by one, all the essential truths taken from reason. Pyrrbonism must, therefore, be resolutely followed in all its consequences in order that its principle shall remain, and Pascal dares no longer too positively affirm that man knows naturally whether he is sleeping or waking.

"The principal arguments of the Pyrrhonists (I leave the less important) are, that we have no certainty of the truth of principles, beyond faith and revelation, except the natural convietion of them which we feel within us. Now this natural feeling is not a convincing proof of their truth, since, having no certainty, except through faith, whether man was created by a good God, by an evil demon, or by chance, it is doubtful whether the prineiples thus given to us are true, false, or uncertain (according to our origin); furthermore, as ro one has the assurance, exeept through faith, whether he is sleeping or waking,--seeing that during sleep he believes himself awake as firmly as ourselves; thinks that he sees spaces, figures, and motions; realizes the lapse of time, measures it, and acts, in short, in the same manner as when awake; so that, half our life being passed in sleep, by our own confession or that which appears to us, we have not the least idea of truth. All our feelings being then illusions, who knows whether this other half of life, in which we think ourselves awake, be not another sleep, a little different from the first, from which we awaken when we think that we sleep, as one dreams often that he is dreaming, thus building one dream upon the other?

"'These are the chief arguments on both sides; I leave the !ess important ones, as the reasons that are urged in opposition no the Pyrrhonists, against the impressions of custom, education, manners, country; and other like things, which, although 
they carry away the greater portion of the common people, who dogmatize only upon such vain foundations, are overthrown by the slightest breath of the Pyrrhonists. One has only to see their books; if he is not already sufficiently persuaded, he will soon become so, and, perhaps, too firmly.

"I pause at the only stronghold of the dogmatists, which is that, speaking sincerely and in good faith, natural principles cannot be doubted; against which the Pyrrhonists oppose, in a word, the uncertainty of our origin, which comprehends that of our nature; and to this these dogmatists have still to reply, since the beginning of the world."

How! has no one been able to meet these objections, since the world began! But we have just heard Pascal himself reply to them by his theory of primary truths placed above all reasoning, and consequently inaccessible to all the attacks of Pyrrhonism. What! to know whether I am sleeping or waking -whether I see you or do not see you-whether two and two make four-whether I should keep pledged faith, be sincere, upright, temperate, charitable, etc., it is necessary that I should first have made an absolutely unassailable choice from among so many systems, more religious than philosophical, in respect to our origin and the essence of human nature! But these systems are precisely the subject of perpetual disputes, while the power of feeling, instinct, heart, that is, of natural reason,- -governs humanity since the world began!

Do you fancy Pascal become again wholly a Pyrrhonist? Not at all; he is about to abandon his Pyrrhonism anew, as he has just abandoned for Pyrrhonism the theory of feeling. After the fragment which we have just quoted, he adds :

"Behold an open war among men, in which each one $\mathrm{i}$ forced to take part, and range himself through necessity either with dogmatism or Pyrrhonism : for whoever thinks to remain neutral will be a Pyrrhonist par excellence: this neutrality is the essence of the cabal. Who is not against them is emphat. ieally for them; they are not for themselves,- they are neutral, indifferent, in suspense as to every thing, without exception. 
"What will man do, then, in this position? Will he doubt every thing-will he doubt whether he is waking, is pinched, or is burned-will he doubt whether he doubts-will he doubt his own existence? No one can go so far as this. I lay it down as a fact that there has never been a single effective, perfect Pyrrhonist. Nature sustains impotent reason, and hinders it from carrying extravagance to such a point."

Thus nature sustains reason; Pascal declares it himself: this nature, by his own confession, is, therefore, not impotent; natural feeling has, therefore, a power in which we may confide; it authorizes, therefore, the truths which it reveals to us; these truths, evolved by reflection, may, therefore, form a reliable and quite legitimate doctrine. Either the words, "nature sustains reason," signify nothing, or their scope extends as far as this.

But this conclusion cannot satisfy Pascal. He quickly retraces his steps, and, after having acknowledged that nature sustains impotent reason,- - that is, that there is a natural certainty anterior and superior to reasoning,-_exclaims: "Will man say, on the contrary, that he certainly possesses truth?" Yes, he will say it, after you and with you; he will say that he certainly possesses, not every species of truth, but a sufficiently large number, the first of which are the truths of feeling, instinct, and heart; or he will succumb to that absolute Pyrrhonism which you yourself declare impossible. "Will he say that he possesses truth certainly,-he who, pressed as little as he may be, fails to show any title to his claim, and is forced to loose his hold?" But he does not need to show any title to these first principles and truths of feeling ; for these principles and truths have their title within themselves, and are justified by their own virtue. Man is not forced, therefore, to loose his hold of them: far from this, he adheres immovably to these highest truths which nature reveals to him, and of which she persuades him in spite of all the arguments of Pyrrhonism. I do not, therefore, hesitate to say, that ail that follows in Pascal, admirable as it may be for its energy and magnificence of language, is after all nothing more than a piece 
of eloquence, which has not even the merit of perfect consistency.

Pyrrhonism has so fully taken possession of the mind of Pascal, that outside of this he perceives nothing but extravagance.

"Nothing strengthens Pyrrhonism more than the fact that there are soine that are not Pyrrhonists. If all were so, they would be in the wrong. . . . This sect derives strength from its enemies more than from its friends. For the weakness of mankind appears much more plainly in those who know it not than in those who know it. . . . It is fortunate that there are some in the world who are not Pyrrhonists, in order to show that man is really capable of the most extravagant opinions, since he is capable of believing that he is not in this state of natural and inevitable weakness."

In conclusion, according to Pascal, there can be no natural certainty for mankind, no more in feeling than in reason. His origin and nature condemn him to uncertainty. Revelation and grace alone can free him from this law.

The peremptory proof that skepticism is the principle of the book of Thoughts, is that it includes all its consequences, strangely enough, both in ethics and political science. In ethics, Pascal admits no natural justice. What we call by that name is only the result of custom and of fashion. Is it Pascal or Montaigne that writes these passages ?-

"What are our natural principles if not our habitual principles? in children, such as they have received from the customs of their fathers, like rapacity in animals.

"Fathers fear lest the natural love of their children may become extinct. What kind of a nature is this that is subject to extinctions? . . . I fear much that nature herself is a first habit, as habit is a second nature."

"As fashion makes comfort, so does she also make justice. If man had really had a knowledge of justice, he would not have laid down the maxim - the most general of all that are known among mankind-that every man should follow the customs of his own country. The lustre of true equity would 
have inthralled every nation; and legislators would r.ot have taken for their model, instead of this steadfast justice, the whims and caprices of the Persians and Germans-it would have been seen established in every government and in cvery age.

"They acknowledge that justice does not lie in these customs, but in natural laws common to all countries. This they would maintain with obstinacy, if the temerity of chance, which planted human laws, had made one at least to be universal. The jest of the matter is, that so diversified are the caprices of mankind that not a single one of this kind is to be found.

"We see scarcely any thing, just or unjust, that does not change its nature in ehanging its climate. Three degrees of higher latitude reverses all jurisprudence. A meridian determines a truth. Fundamental laws are changed by a few years' possession. Right has its eras. The entrance of Saturn into Leo marks the origin of such a crime. What ridiculous justice that is bounded by a river! Truth on this side the Pyrenees, error on that.

"This is my dog, that is my place in the sun, say these poor children,--herein lies the beginning and symbol of the usurpation of all the earth. ${ }^{1}$

"Nothing, according to pure reason, is just of itself. Custom makes equity; by this alone is it received; this is the mystic foundation of its authority. Whoever reduces it to its principle, destroys it. Nothing is so faulty as the laws for the redress of faults; he who obeys them because they are just, obeys the justice that he imagines in them, but not the essence of the law; it is wholly absorbed in itself-it is the law, and nothing more.

"Justice is subject to dispute; might is easily recognizable without dispute. .... Being unable to make justice might,

1 There is true and false property, but property is not a usurpation in itself; it has a natural and sound foundation. See Cours de l'Histoire de la Philosophie moderne, Ire Série, t. iii, p. 271. 
we have made might justice. . . . . We call that just which we are forced to observe. . . . . This is properly the definition of justice.

"Montaigne was wrong; custom should be followed only because it is custom, not because it may be reasonable or just."

But what avails it to multiply quotations? It would be necessary to transcribe a thousand passages of Montaigne, which Pascal calls up, condenses or elaborates, not, as has been said by some kindly disposed editors, in order to refute them at leisurc, but, on the contrary, to lean on them and make them scrve his design.

Do you wish to know the politics of Pascal? It is the worthy offspring of his ethics. It is the politics of slavery. Pascal, like Hobbes,' places the ultimate aim of human society in pcace, not justice: for the one, as for the other, right is might. But Hobbes has the advantage over Pascal of rigorous consistency. For example, he takes good care not to admit that the equality of property would be just in itself, in order to reach the admirable practical conclusion that it is necessary to maintain so much inequality that is destitute of all foundation. Can any thing be more false-I do not merely say more impracticable, but more unjust in itself-than the principle of equality of property? It is not in this that lies true equality. All men have an equal right to the free development of their faculties; they all have an equal right to the impartial protection of that sovereign justice which is called the State; but it is not true-it is contrary to all the laws of reason and of equity-it is contrary to the eternal nature of things-that the indolent man and the worker, the spendthrift and the economist, the thoughtless and the wise, should obtain and preserve an equal amount of property. Curiously enough, Pascal accepts the chimera of equality of property, and builds thereon the odious theory of the right of might in the interests of peace.

1 On the foundation and nature of ' 'ue equality, Cours de l' Historre de la Philosopliie moderne, Ire Série, t. ii, leç. xviii, p. 244 . On Hobbes, 1b., t. iii. 
"Withont doubt," says Pascal, "the equality of property is just; but being unable to compel might to obey justice, we have made it just to yield obedience to might; being unable to strengthen justice, we have justified might, that justice and might may go side by side, and peace result, which is the sovereign good.

"Thence comes the right of the sword; for the sword gives a true right; otherwise we should see violence on one side and justice on the other. . .."

But why, I pray you, should we voluntarily shut our eyes to this spectacle too often afforded us? Why not look violence in the face, and call it by its name? How ever reform that which we have never dared denounce as an abuse or a crime? Is this the philosophy which we should propose to humanity? What foundation has its dignity, what instrument its progress, what consolation its miseries, what limit its hopes? We do but little, incleed, when we promise it beyond this world a life which shall be the opposite of the one here below, and we have good reason to teach it the hatred of life and the love of death ;' for life, as men make it, is only a theatre for iniquity and folly. It remains to ascertain whether those are really the more religious who, in point of justice, refer mankind to another world, or those who strive to assimilate the always imperfect justice of men to the model of divine justice, and human society to the kingdom of God. If the object of religion be to reunite man to God and the earth to heaven, ought she to be contented to leave man on earth a prey to oppression, a slave to force, crushed down beneath immovable iniquities? No; to elevate his soul, she must also exalt his condition. For there is none but a free being, possessing, practising, and seeing the holy idea of justice and of love in some measure realized and shining about him, who could invoke, with some degree of intelligence, the infinite liberty, justice, and charity that made man, that guides him, and that will finally receive him. 
All great philosophies contain within themselves a natural theology, and also, as it is said, a theodicy which teaches what we have just recapitulated. Before and since Descartes and Leibnitz, with various processes, sometimes based even on different principles, every school that has not been divorced from common-sense has proclaimed the existence of a God, the first cause and invisible type of the perfections of the universe as well as of humanity. There is not a single philosopher of any authority, that does not draw the proof of an eternal geometrician from the admirable order of the world, and the hope, at least, of a moral order, better than our own, from the idea of order stamped within us, and which we carry, with more or less success, into every thing belonging to us,- our habits, our laws, our institutions, civil and political. But Pascal, who acknowledges no natural ethics, alike rejects all natural religion, and admits no proof of the existence of God.

And let it not be said that Pascal rejects only what are styled metaphysical truths. It is indeed true that he deems this kind of truth subtle and refined; but it is not true that he approves any other, or that he looks with favor on the physical proofs, so simple and so evident: even these he discards with disdain, as defeating their own end through excess of weakness.

But perhaps Pascal means to say nothing else than that man is incapable of penetrating the mysteries of the divine essence, and that at this height he meets more than one cloud which the Christian faith alone can dissipate. Vain explanation! Pascal declares openly, that man can neither know what .s God, nor even whether he is. These are the very words of Pascal which we have quoted.

But what! has Pascal then made a discovery of some argument, unknown hitherto, and whose unexpected omnipotence imposes silence on the unanimous voice of the human race, the cry of the heart, the authority of the sublimest and solidest geniuses? No: he negligently supports himself upon this commonplace of skepticism, that man, being but a part, cannot know the whole-as if, without knowing the whole, a part 
endowed with intelligence could not comprehend an $i$ feel that it lias not created itself, and that it springs from something quite different from itself; and also upon this other commonplace, that God, being infinite, and man finite, there can be no affinity between the two-as if man, wholly finite as he is, did not incontestibly possess the idea of the infinite; as if Pascal nad not proved, by natural enlightenment, that there are two species of the infinite-the one of greatness and the other of littleness; as if, in the face of infinite space, he had not himself placed, as better and of a more elevated nature, this think ing reed, this fragile and sublime being, which appears but for a day and an hour, yet in this day, in this hour, through thought, attains and embraces the infinite, measures the worlds that revolve above his head, and refers them to an author, allpowerful, all-knowing, and all-good! And then, when from the summit of this proud skepticism, you have decided that all relation between God, as the infinite, and man, as the finite, is radically impossible, by what charm, I pray you, will Christianity be able afterwards to lead man to God? A mediator is no longer possible here: for this mediator, to remain God, must preserve a portion of his infinity; by this infinity he must necessarily escape the grasp of man, and the insuperable abyss will subsist between man and God. Pascal does not perceive that, in overthrowing natural religion, he takes away the foundation of all revealed religion, or, rather, that he involves himself in contradictions which no logic can support. But let us establish the fact that Pascal rejects all natural proofs of the existence of a God.

"If man would first study himself, he would see how incapable he is of going further. How can a part comprebend the whole?

"Philosophers. A fine thing to cry to a man who knows not himself, to mount from himself to God! And a fine thing to tell this to a man who knows himself!

"Let us speak according to natural intelligence. If there is a God, he is infinitely incomprehensible, since, having neither parts nor bounds, he has no relation to us. We are, there 
fore, incapable of knowing either what he is or whether he is.

"I shall not undertake to prove, by natural reasons, either the existence of God, or the Trinity, or the immortality of the soul: not only because I do not feel myself strong enough to find in nature wherewith to convince obdurate atheists but ....

"The metaphysical proofs of God are so remote from the reasoning of man and so involved that they do not strike one; and even though they may avail with a few, it will be but for the moment in which they witness the demonstration; an hou. afterwards they will fear that they were mistaken.

"What! do you not say that the sky and the birds prove a God? No. And does not your religion affirm it? No; for though this is true in a manner to a few souls, on whom God has bestowed this light, nevertheless it is false in respect to the most.

"I admire the hardihood with which these people undertake to speak of God in addressing their discourse to the impious. Their first chapter is to prove divinity by the works of nature. i should not be astonished at their attempt, if they addressed their discourse to the faithful; for it is certain that those who have a lively faith within their hearts, incontinently see that all that is, is nothing else than the work of God whom they adore; but for those in whom this light is extinct, and in whom it is designed to revive it,-those persons destitute of faith and grace, who, investigating with all their ability all that they see in nature that may lead them to this knowledge, find only obscurity and darkness,-- to say to these, that they have only to observe the least of the things about them, and that they will see God revealed therein ; and to give them, for the sole proof of this vast and important subject, the course or the moon and stars, and to pretend to complete such a demonstration without trouble, is to give them reason to believe that the proofs of our religion are weak indeed; and I pereeive, by reason and experience, that nothing is better calculaterl to excite a contempt of it." 
We see how in this last passage Pascal treats the physical proofs themselves--proofs as old as the universe and human reason. I admit that his design, as well as ausolute Pyrrhonism, exacts this of him; but is it not both a gratuitous and an incomprehensible subversion of all received notions, to maintain in a serious tone that this kind of proofs, being only suited to excite contempt, no canonical author has ever made use of them?

"It is a marvellous thing, that no canonical author has ever availed himself of nature to prove the existence of a God: all strive to make this believed, but never have they said: There is no void; therefore there is a God: they must have been more able than the most able men that have come after them, who have all availed themselves of it. This is very remarkable."

No, indeed, this is not remarkable, for nothing is more obviously false. The Holy Scriptures are not a course of physics; they do not hold the language of scierice, much less that of any particular system; they do not say: There is no void; therefore there is a God,--a fantastic argument which is found nowhere except, perhaps, in the writings of some obscure Cartesian; but they teach, and this in every page and every way, that the heavens declare the glory of God.' And has not St. Paul, to whom, I hope, Pascal will not except, said : "That which may be known of God is known to them, God himself having made it manifest to them; for the invisible greatness of God, his eternal power, and his divinity, have been made visible in his works since the creation of the world." 2

Thus, to Pascal, there is no proof of the existence of a God. In the absolute impotence of reason, he invents a desperate aryument. We may set truth aside, but we must not set aside our interest,- - the interest of our eternal happiness. It is fromı

1 The Pralmist: "Cœli enarrant gloriam Dei. . . L Laudent illunı cool et terra . . . et annuntiabunt cœli justi."am ejus . . . confitcbuntur cœl: mirabilia t. a . . Laudate eum, cœli cœlorum . . . eonfessio ejus supa coelum et ter ram . . . interroga et volatilia coeli, indicabunt tibi . . . etc.

2 Epistlit to the Romans, i, 19-21. 
his stand-point, and not in the scale of reason, that we must astimate and weigh the problem of a divine providence. If God does not exist, no misfortune can happen to us for having believed in him; but if by chance he does exist, to have denied lim will be fraught for us with the most terrible consequences.

"Let us examine this point, and affirm: God is or he is not. But to which side shall we incline? Reason can here deternine nothing. A fathomless chaos separates us from the truth; on the other side of this infinite gulf a game of pitchand-toss is being played, in which heads or tails are sure to win. On which side will you stake? By reason, you could bet upon neither; by reason, you could defend neither of the two. ... The true way would be not to bet at all. Yes, but you must bet. . . . You have two things to lose,- - truth and good; and two things to redeem,-reason and will, knowledge and happiness; and your nature has two things to shun,error and misery. Your reason is none the more deeply wounded, since you are forced to choose, in choosing one than the other. This point is decided-but your happiness!"

It is upon this foundation, not of truth, but of interest, that Pascal institutes the celebrated calculus to which he applies the rule of chances. The conclusion is as follows: to the eyes of reason, to believe or not to believe in God, to be for him or against him, to wager on heads or tails - to use the simile of Paseal-is alike indifferent; but to the eyes of interest, the difference is infinite between the two, since by the hypothesis there is an infinity to gain. "This is demonstrative," says Pascal, "and if men are capable of any truth, it is this."

But this fine demonstration is, at the bottom, so far from being satisfactory, that after having thus reduced to silence the nterlocutor to whom it has been given, he cannot hinder him elf from saying:

"Yes, I confess it, I acknowledge it; but yet is there no w seans of seeing the trick in the game?"

And to appease this perverse curiosicy, to what does Pascal refor him? To the Iloly Scriptures-to the Christian re igion. 
"Very well," replies the groaning interlocutor, vanquished but not convincel; "but I am so constituted that I cannot believe. What would you have me do, then?"

"What would I have you do? Follow my example; take holy water, order masses to be said, etc. Naturally this will make you believe, and stultify you."

"But that is what I fear."- "And why? What have you to lose?"

We were the first to discover and publish this overwhelming passage,- the faithful summary of the entire book of Thoughts. When it appeared, it staggered for a moment the boldest partisans of Pascal; but they quickly set about twisting and subtilizing it in so many ways, that they ended by discovering in it the most beautiful meaning imaginable. It has, it can have but one meaning : it is necessary, in conformity with a precept of Pascal, which is now very clear, to renounce reason-to become a machine-to have recourse in ourselves, not to the mind, but to the machine-to succeed in believing in God by degrees through the insensible declivity of habit. This is true, or, rather, this alone is true, as soon as we seek God from the stand-point of Pyrrhonism. This is all the faith-I mean all the natural faith-allowed Pascal by his sombre philosophy. The master of Pascal, the Pyrrhonist Montaigne, has said before him: In order to become wise we must stultify ${ }^{1}$ ourselves. Pascal borrowed from him both the word and the idea. In order to make a man wise, in order to lead him to virtue and to God, Socrates and Marcus Aurelius knew other ways.

Let us anticipate a last objection. It will not fail to be said : The passage which has just been eited is simply a caprice, a yush of humor, a sort of geometric freak; but there are many other passages opposed to this, which attest that Pascal believed in the dignity of human reason. I answer honestly; that in fact there is a little of every thing in those diverse notes which are styled the Thoughts: what must be considered is

- Essais, 1. ii, chap. 12. 
them, is not a single passage taken by itself, separate from the rest, but the general, prevailing spirit of the whole. Now, this spirit we have faithfully expressed. And is it not also the condemnation of Pyrrhonism that in vain he watches over all his movements, all his words, that despite himself, there escape him continual contradictions of this absolute doubt, insupportable to nature and incompatible with all his instincts? More than once, the victorious sentiment of the grandeur of human thought breaks forth in Pascal, in energetic lines; but ere long philosophy imposes silence on the man, and the system resumes the ascendancy. Thus he repeats, several times; that all our dignity is in thought: here thought becomes again a thing of worth; but a moment after he exclaims: "How 'oolish is thought!"- that which makes of human dignity a folly, and of all certainty based on thought a chimera. Lastly, let us not forget that behind the Pyrrhonist is the Christian in Pascal. His faith, whatever may be its foundation and character, is, after all, the Christian faith: hence the strange brightness and the few rays which, evolved by grace, pierce at long intervals the darkness of Pyrrhonism. But when grace is withdrawn, Pyrrhonism alone remains.

At the risk of wearying the reader, I wish to present to him a last fragment, which completes the demonstration, lays bare the real thought of Pascal, and shows of what stuff, so to speak, bis religion itself was made.

"If nothing must be done except for the certain, nothing whould be done for religion, for this is not certain. But how many things are done for the uncertain,-as voyages on the sea, battles, etc. I affirm, therefore, that it would be unnecessary to do any thing at all, since nothing is certain, and that there is not more certainty in religion than that we shall see to-morrow's sun ; for it is not certain that we shall see the morrow, but it is certainly possible that we may not see it. We cannot say as much for religion. It is not certain that she is, but who will dare to say that it is certainly possible what she is not? Now when we work for the morrow and or the uncertain, we act with reason. For we should work 
tor the uncertain by the rule of chances, which is demon strated."'

Is this, I ask, the faith of St. Augustine, St. Anselm, St. Thomas, Fénelon, Bourdaloue, Bossuet ?

On the 23d of November, 1654, in a night full of anguish, soothed and charmed by mystic visions, Pascal, after having struggled for the last time with the fancies of the world-the troubles of his heart and thought-calls to his aid the true, the only comforter. He invokes God, but what God, I pray you? He has told us himself, in that strange writing ${ }^{2}$ which he traced with his own hand on that very night, which he always carried about him, and which was not discovered until after his death: "God of Abraham, Isaac, and Jacob, not of scholars and philosophers." He caught a glimpse of, and fancied lie found, certainty and peace; but where? "In entire submission to Jesus Christ and my spiritual director." The whole of Pascal is in this. Doubt has yielded, at last, to the omnipotence of grace, but vanquished doubt has borne away with it reason and philosophy!

Either we must renounce all historical criticism, or conclude from so many accumulated quotations that, with Pascal, skepticism is truth in the philosophic order, that natural intelligence is incapable of furnishing any certainty, that the only legitimate use of reason is that of renouncing reason, and that the only philosophy is the contempt of all philosophy.

This is what we have just established, regularly and methodically, with an elaborateness and rigor which, it appears to us, leaves nothing to be contested. We may, therefore, be permitted to consider the skepticism of Pascal in philosophy as a point demonstrated. But we may go still further. A more intimate acquaintance with Port-Royal, by enabling us to penetrate more deeply into the spirit of that illustrious society permits us to maintain, with the most assured conviction, that ot ouly was Pascal a skeptic in philosophy, but that he could

3 Bossut, second part, xvii, 197 . 2 Bossut, p. 549 ; man., p. r. 
not lut be so, for the conclusive reason that he was a Jansenist, and a consistent Jansenist.

What is Jansenism? An able pen' has undertaken the task of recounting its history: it suffices that we recapitulate its principles and trace its general character.

In our days, the whole truth may be spoken in respect to Jansenism. Fathers Annat and Letellier are no longer here t) listen to our words and carry them to the ears of Louis XIV. Port-Royal is no more. The plough has passed over the holy monastery ; its very ruins will ere long have perished. We visited it, a few days since, with a faithful map in hand, and it was with great difficulty that we could recognize a few of these venerable places. Nor has time shown more respect to the spirit which animated them. A dim tradition of it faintly exists in two humble societies devoted to the service of children and the poor. A few brothers of St. Anthony, a few sisters of St. Martha, are all that are left of that great people of Port-Royal, which formerly filled the religious orders, the parliaments, and the universities. At Paris, in a corner of the faubourg Saint-Jacques and the faubourg Saint-Marceau, three or four families cherish an obscure worship for these illustrious nemories; they talk among themselves, with meditative respect, of the virtues and misfortunes of Mother Angelique, of her sister and niece; they pronounce in low tones the illustrious names of Arnauld and Pascal; they put up prayers in secret for the good cause; they detest the Jesuits, and fear them most of all. Each day sweeps away some of this band, nevermore to be revived. Port-Royal is fallen into the domain of history. We can, therefore, judge it with respect, but with liberty. And besides, we too have learned in its school to prefer truth to all else; and since others are now arming themselves with this holy name to attack that which to us is truth, and the first of all truths-namely, the legitimate power of reason and the rights of philosophv-it is Port-Royal itself which, at need, will inspire us in the combat: in default of its

I The allusion here is to Saint-Beuve's Port-Royal.- Bh. 
doctrine, its example is with us in the struggle which we maintain.

Let us say it, then, without hesitation: Jansenism is an inmoderate and intemperate Christianity. By all its roots it clings doubtless to the Catholic Church; but in more than one point, without wishing or even knowing it, it inclines to Calvinism. It is especially based upon two dogmas, already of great weight in themselves, which it perverts and exaggerates: I mean the dogmas of original sin and of grace. In touching on this thorny matter, I shall endeavor to be as brief as attention to perspicuity will permit.

The dogma of grace is allied to that of original sin. It is because human nature suffered in its first representative a greater or less degree of corruption, that it stands in need of a reparation, and of a reparation proportioned to its corruption : for this vice of nature, the necessary remedy is the supernatural grace of Jesus Christ. These two dogmas being closely connected, neither ean be altered without changing the other in the like proportion. Let us suppose the corruption of nature to have been a trifle in the cradle of the world: the intervention of grace becomes almost superfluous. Let us suppose, on the contrary, the corruption to have been entire; the two essential parts of human nature-the reason and the will-to have been radically vitiated and made absolutely incapable, the former of perceiving the right and the latter of executing it: it becomes a vital necessity that grace should intervene, the more energetically, since it is in question, no longer to assist and strengthen the man, but in reality to create him anew, by substituting for reason a supernatural enlightenment, and for the will a foreign force. The Catholic Chureh, the guardian and interpreter of the Christian faith, is constantly placed between these two extremities. The Church has decided that human nature really fell through original sin; that reason and will thus lost the power which they had originally received-that incomparable power which made of Adam a sreature almost like unto an angel-perceiving all truths in their very source, and fulfilling the good freely, but without 
effort. The Church has, at the same time, decided that through original sin, nature did not fall to that point that reason became absolutely incapable of truth, and the will of good - at least, in the order of natural truths and virtues. The Church has thus anticipated the two opposite errors on the sabject of grace. And upon these, she has given these two decisions, conforming with the two first: 1st. That grace is necessary in order to reveal to man the truths and virtues of the supernatural order, without which there is no salvation; 2 d. That grace comes to the aid of nature, without destroying it-that it does not extinguish natural intelligence, but enlightens and increases it, and that human liberty subsists entire, with the works that are suited to it, under the influence of grace.'

Upon all these points Port-Royal has gone beyond the Catholic doctrine. In exaggerating the power of original sin, it has condemned itself to exaggerate that of redeeming grace.

The genius of Jansenism is the dominant feeling, not only of the weakness, but of the nothingness of human nature. In its sight, since the fall of Adam, reason and will have been in themselves radically impotent, for truth and good. Man possesses no other grandeur and preserves no other resource than the very feeling of his impotence, with that of the necessity of a supernatural aid. This supernatural aid is grace-not that universal grace which has been given to all mankind, and which is so often convicted of insufficiency, but that especial, chosen grace which, to be truly sufficient, must be efficacious through itself-that is, irresistible. This works in us by stifling natural intelligence beneath uncreated intelligence, and by putting its conquering influence in the place of the weakness of our will. It is this which makes us think and act, or, rather, it is this which thinks and acts in us; it excites the

1 For quotations, we content ourselves with referring to the Council of Trent, and the papal bulls and declarations condemnatory of the book $c$ Jansenius 
thought to action, communicates the strength which executes t, and our works are its works.'

Such is the Jansenist system-a mingling of truth and error. On its true side, it is the Catholic doctrine, which is not here in question; on its false side, it is simply a particular theory, which falls beneath our investigation. Port-Royal is a great party in the Church ; but, after all, it is only a party ; it is not the Church itself, for the Church has condemned it.

What is essentially false in the Jansenist grace is, that it takes away all power from the natural intellyence, and all efficacy from the will. The Christian grace adds its brightness and vivifying influence to reason and human liberty; it purifies and strengthens, but does not annililate them; far from denying, it supposes their existence; it fructifies, but does not create; it does not apply itself to nothingness, but to a germ of the Divine, which it evolves and develops. Its singular virtue lies in producing a faith which natural intelligence does not-the faith in supernatural truths. But it is not this alone that teaches man liberty, duty, the distinction between good and evil, just and unjust, the immortality of the soul, Divine Providence: without grace, natural intelligence can teach all this, and has taught it in every age. According to the Church, natural reason is a first revelation, possessing a power in itself. According to Jansenism, this first revelation remains absolutely sterile, without the aid of a new and especial revelation.

As all truths are contained in the Catholic doctrine, in the same manner are all errors linked together in the Jansenist theory. Grace should there be victorious and invincible, since there the corruption of human nature is entire-since such an evil demands a sovereign remedy-since, from the nothingness of nature, God alone can draw true justice and true virtue. This principle of the nothingness of human nature includes yet another consequence alike necessary,--the nothingness of the merit of our works. These belong to grace when they are

1 See the first Provinciales. 
good; $\sin$ alone is ours, since sin is the result of a corrupt Eature. Hence the perpetual trembling of the human creature, ancertain whether it is grace that is working in it, or its own mind and natural intelligence; hence excessive austerities, and an ardent and sombre asceticist., the world converted into a Thebais or Calvary, the flight of the most innocent pleasures, impatience of life and invocation of death, and, in anticipation, continual efforts to die to the life of nature, and only suffer siat of grace to subsist; hence inmense humility and immense pride-the one arising from the feeling of our nothingness, the other from the feeling of the working of God within us-with marvellous courage, capable of resisting, in the name of God, all the powers of earth, even the chief of all, that of the Holy See; hence, in a word, admirable greatness, with excess of every kind, in doctrine and in conduct-excess and greatness blending, sustaining each other, and falling together, since they hold to the same principle,- the nothingness of nature and the invincible power of grace. To separate, in Port-Royal, greatness from excess, good from evil, the true from the false, to cut off the one and retain the other-how vain the undertaking! All here proceeds from the same foundation. To temper Port-Royal is to destroy it. Let us leave it, then, its greatness and its faults. Let us acknowledge in Port-Royal the lofty qualities that commend it to the veneration of ages,rectitude, consistency, intrepidity, devotion; but let us also acknowledge that it has been lacking in two still more eminent qualities,-common-sense and moderation, that is, in true wisdom.

Jansenism thus defined, what could philosophy be to it? Indeed, after what precedes, it is hardly needful to say. Janenism and philosophy exclude each other. According to Jansenism, grace can do every thing, nature nothing; and natural reason, deprived of the light of grace, wanders in the midst of insuperable darkness. Philosophy, on the contrary, as we have said, is established on the foundation that man, even in his present state, possesses a faculty of knowing, limited yet :eal, and capable, if well directed, of attaining natural truths, of 
the moral order as well as truths of the physical order. As there is a science of geometry, physics, astronomy, etc., so, in the same manner and by the same right, there is, or there may be a science of psychology, logic, ethics, theodicy-in a word, of philosophy. The physical sciences rest on sensible experience; philosophy rests at the same time upon the senses and consciousness: the data, and, therefore, the processes differ; but the data are alike reliable, the processes alike rigorous, and the common principle acknowledged by the physical sciences and by philosophy is natural reason freely and methodically cultivated. According to Port-Royal, all the human sciences - the moral sciences in particular, with philosophy at their head-are but chimeras, the offspring of impotence and pride; the only true science is that of salvation, the imperious condition of which is the supernatural intervention of grace-a grace at once gratuitous and irresistible. Jansenism must go as far as this, or it has not its full scope; it can accept philosophy, therefore, only with manifest inconsistency.

And whence comes this inconsistency? From weakness, either of character or of logic. But the logic of Pascal was as lofty as his passionate and obstinate character. It was necessary to choose between Jansenism and philosophy. Pascal had chosen, and too firmly ever to turn aside from the goal or to waver on the road.

Pascal, as we have seen, was a declared skeptic in philosophy; it is now evident that he could not be otherwise. Examine anew, by the light of the Jansenist theory which has just been exposed, the passages in the book of Thoughts in which skcpticism appears, as it would seem, in its boldest form, and far from finding them paradoxical, you will recognize there the arowed principles and spirit of Port-Royal. Pascal affirms and repeats that there is no natural certainty. What is there surprising in this? The opposite would be to Pascal the mos! indefensible novelty. For what is there that could give him ecrtainty? A totally corrupt reason, which is radically powtrless without grace. There is no natural proof of the existence of God: God is neither revealed to us by the wonders $0^{f}$ 
rature nor of consciousness. Nothing can be more simple, if the senses and consciousness have been deceptive mirrors since the fall of Adam. Before Jesus Christ, man could not know whence he was. Assuredly not, for before Jesus Christ, he was condemned to error and vice. Since Jesus Christ, man, it is true, has been able to know both himself and his Creatorbut how? By grace, and by grace alone. If man, indeed, by natural means, could attain the knowledge of himself and God, grace-meaning always the Jansenist grace-would be superfluous. This must not be at any rate; it is necessary, therefore, to maintain, that without grace man would be unable to know of God, not only what he is, but that he is. This is neither the light of reason nor of feeling; it is the fire of grace which penetrates the heart of man with the idea of the greatness of the soul, and with the idea of God. The God who, then, appears to us, is not the God of scholars and philosophers, it is the God of Abraham, Isaac, and Jacob. Man is not capable of true virtue by the legitimate use of his natural liberty; but he may become so by the transfiguration of this liberty into a divine power, which acts within us, often despite ourselves, and the works of which do not belong to us. To destroy the natural man, to stultify him-that is, to deprive him of this reason and liberty which he vaunts as a privilege-to cast him blind and submissive into the hands of the grace of Jesus Christ and the spiritual guide who represents him,such is the sole means of conducting him to truth, virtue, peace, happiness. This being so, philosophy is evidently not worth a single hour of pains, and to despise it is truly to philosophize.

Pascal did go, and should have gone, as far as this; had he not carried the principles which he had embraced to this extremity, he would have fancied that he was abandoning them; he would have been in his own eyes a pusillanimous disciple of grace.

When we have thus penetrated to the heart of Jansenism: we cannot but smile on seeing the efforts of the modern partisans of Pascal to defend him against the aceusation of skepti 
cism. But this accusation is to his honor; it is your defence that would be to him an accusation of infidelity to the two great principles of the nothingness of human nature, and the omnipotence of grace. For these two principles, Pascal and his sister would willingly have given something more than all the systems of philosophy : they would have been happy to shed their blood. Weak minds, who comprehend neither Port-Royal nor the seventeenth century, you do not suspect that your injurious apologies take from Port-Royal its true character, and from the penitent of M. Singlin, the brother of Jacqueline, that singular feature of pride and irony in respect to reason and philosophy, and, at the same time, of absolute submission in the hands of grace, which made of Pascal a man of mark even in Port-Royal, and placed him, as regards Jansenism, far above Nicole, and even Arnauld!

Strange to say, in Port-Royal, Saint-Cyran excepted, the most rigid were not men, but women, not ecclesiastics, but laymen, not Nicole and Arnauld, but Domat and Pascal. In the important affair of the formulary, the women, with Jacqueline at their head, were of the opinion that it were better to brave every thing than to subscribe to the contrary of that which seemed to them the truth. They only signed it through deference to those who governed Port-Royal; and Jacqueline succumbed, three months after the fatal signature, beneath her scruples and anguish of conscience. In a meeting held at the house of Pascal, the latter proposed resistance. ${ }^{2}$ The Jansenist

1 The story of this affair is to be found everywhere. I have related the principal features of it in Jacqueline Pascal, and in the Documents inedils sur Domat, t. iii of this 4 th series.

2 Let us place before the eyes of the reader this scene, which so well depiets the soul of Pascal.-Ibid. "The majority of those present, led $\mathrm{ky}$ Nicole and Arnauld, gave their voice for the signature. 'Seeing which, says the Recueil d' Utrecht, ' after Mademoiselle Périer, M. Pascal, wlio loved truth above all things, and who, despite his weakness, had spoken very warmly to make the others feel what he felt himself, was so overcome by grief, that he fell into a swoon, and lost both speeeh and consciousness. Every bodv was surprised, and hastened to his assistance. These people afterwards withdrew, and no one was left but M. de Roannez, M. Domat and M. Périer, fils. When M. Pascal had quite recovered, M. Périer askeo 
grace had become the whole truth to him-the beginning and end of Christianity. For it, he advised that they should hazard every thing, even Port-Royal. But Port-Royal was not alone at stake: ecclesiastical discipline, and the unity of the Church, were also in question. Pascal and his sister did not recoil before this extremity. This young woman, not yet thirty-six years of age, dared say to a priest, a doctor, M. Ar nauld, with a loftiness and vehemence worthy of her brother, or of Demosthenes: "I can no longer disguise the grief which pierces me to the heart's core, on seeing that the only persons to whom it seemed that God had confided his truth, are so unfaithful to it as not to have the courage to expose themselves to suffering, even though it were death, in order to confess it openly.... I know well that it is said that it is not for women to defend the truth; but may it not be said, at this juncture of time, this subversion of order, that since bishops have the courage of women, women ought to have the courage of Jishops? But if it does not belong to us to defend the truth, it belongs to us to die for it. .... What is it that we fear! Banishment for the seculars, dispersion for the religious, the seizure of temporal goods, imprisonment,-death, if you will ? Yet is not this our glory, and should it not be our joy? Let us renounce the Gospel, or follow its maxims, and esteem ourselves happy in suffering something for justice. But perhaps we may be cut off from the Church? But who does not know that no one can be cut off without his own consent, and that the spirit of Jesus Christ being the only power that unites the members to him, and among themselves, we may, indeed, be Aeprived of the tokens, but never of the effects of this union, so long as we preserve charity."' And on these grounds, Pascal and his sister proposed to stand firm, to refuse the sig.

Lim what had eansed the aecident. 'When I saw all those people,' replied he, 'whom I regard as those t.? whom God has revealed the truth, and who onght to be the defenders of it stagger, I confess that I was seized with such grief that I could not support. it, but was forced to suecumb.'"

I Jacqueline Pascul, lctter on the signature of the formulary, t. ii, of that series. 
nature, and, if necessary, to disobey the canonical authority of the bishops and Holy See; a violent course, which would have openly separated Port-Royal from the Catholic Church, and nevertheless was but strict fidelity to the Jansenist doctrine of grace. Nicole and Arnauld did not pique themselves on so much rigor: they did not wish to carry consistency to schism; but for this, they were forced to waver a little between sincerity and prudence. The great Madame Angelique rejoiced at dying in this terrible juncture, in order neither to sign nor refuse to sign. The authority of Arnauld carried away PortRoyal; but, if Saint-Cyran had been there, logic would doubtless have vanquished policy, and God alone knows what would bave been the result.

It may be said that, in respect to philosophy, Port-Royal stood almost the same as in respect to the formula. The spirit of Port-Royal was contrary to philosophy ; but she influenced it through the habits and ascendency of two eminent men.

Turn over the works of these authors, the memoirs, narratives, letters, and all that remains of Port-Royal, and you will find everywhere the condemnation of all curiosity that turns aside from salvation, its only legitimate object, with a declared contempt of all the purely human sciences, particularly of philosophy. Sacy is not the highest representative of Port-Royal, but he is, to my mind, its calmest, purest, and truest expression. He exaggerates none of the principles of Jansenism, but he possesses and professes them all with the moderation of assurance, and with a sort of inflexible gentleness. Now, ask Fontaine for Sacy's opinion in respect to Cartesianism and philosophy. Fontaine will tell you that he blamed his two illustrious friends strongly for their attachment to the new philosophy.' "Smiling pleasantly when he was addressed on these matters, he seemed rather to pity those who dwelt on them, than to have the wish to dwell on them himself. .... He said that M. Descartes stood in respect to Aristotle like a thier who has just killed another thief, and despoiled him. God

1 Mémoires of Fontaine, t. ii, p. 53. 
created the world for two things," said he; "the one to give an exalted idea of himself, the other to portray things invisible in the visible. M. Descartes destroys both. Instead of recognizing the invisible in the visible, as in the sun, which is the god of nature, and of seeing in all its effects in plants the sym bol of grace, he pretends, on the eontrary, to give a reason for all by certain crotchets of his own imagination. I compare these philosophers to those ignorant persons who, on seeing a fine painting, instead of admiring the beauty of the work, pause at each color, and say, What is this red? Of what is it composed? It is of this thing or of that. . . . . These men seek truth by groping; it is a great chance whether they find it." Such were the real sentiments of Port-Royal towards Cartesianism and philosophy. Then, too, when M. Singlin sent his new penitent to Port-Royal-des-Champs, "it was," says Fontaine, " that M. Arnauld might try his strength in the sciences, and that M. de Sacy might teach him to despise them." Pascal quickly conformed himself to this school, and soon attained to the stand-point of Sacy; but with his temper, he could not content himself with setting philosophy aside : he trampled it under foot. And here again, the exact logician, the principles of Port-Royal admitted, was Pascal; Nicole and Arnauld were once more for common-sense and inconsistency. Why? For many reasons, which it would take too long to make known. Let us note a few of them briefly.

At first Pascal had all the ardor of a neophyte. Converted at the close of 1654, and dying in the middle of 1662, during this short interval, filled with the terrible conflicts of the Provinciales, with cruel ills and with a death-struggle of nearly two years, Pascal, born with a boiling temper, ${ }^{2}$ a strength and rigor of mind heightened by the habits of geometric method launched at once into the extremes of the Jansenist doctrine as soon as he had embraced the gace of Jesus Christ, he knew, be followed only this For this, he would have shed his blood

1 Mémoires of Fontaine, t. ii, p. 55.

- Jacqueline Pascal, letter of the 8th of December, 1654. 
on the question of the formulary : he did more, he made of his whole life a continued death; he died to all feelings of even the most innocent pleasure ${ }^{1}$ and when he felt his last hour approaching, the better to imitate the example of Christ, he begged with the most ardent entreaty to go into a hospital to yield up the ghost upon the pallet of a pauper. In practice as in theory, the peculiar characteristic of Paseal was that of in. flexible consistency towards others and himself; while at the same time he joined to this energy, a candid soul and the finest mind. He had in him the child, the wit, the hero, and the fanatic. He neither took nor did any thing by halves. Now when one carries attachment to a prineiple so far as to sacrifice to it all the sweets of life, it costs but little to add to this saerifice philosophy. And in truth, on the part of Pascal, this last sacrifice had no very great merit.

Philosophy at that time was styled Cartesianism. Pascal was perfectly master of the mathematical and physical part of this great philosophy, but here he stopped short. Partly through severity of spirit, partly through lack of breadth, Pascal did not aspire to universal views of nature. This was doubtless a sure means of avoiding many errors, but through this, he at the same time failed to attain the highest fame-to place his name side by side with those of Galileo, Deseartes, Newton, and Leibnitz. He formed part of a little cirele of people of wit and merit, in which it was the fashion to disparage Descartes and attack him on his weak points, such, for example, as the subtlety of matter and some other hypotheses, which was easy enough, without substituting any thing in their place, which was very eonvenient. From time to time, Deseartes administered rough lessons to the rashest of this little circle, the fiery and jealous Roberval. ${ }^{2}$ In the matter of the weight of the atmosphere, a quarrel took place between Paseal and Descartes, which has never yet been clearly explained, in which Pascal, who worshipped glory, was at least to blame in

- Vie de Pascal, by Madame Périer.

2 Montucla, Histwire des Mathimatiques, t. ii, pp. 55 and 144. 
too nearly forgetting the name of Descartes among thosie who bed put him on the way of his celebrated experiments.' These two geniuses were diametrically opposite and little calculated to comprehend each other. The one, essentially creative, unceasingly discovered new principles everywhere; he comprehended and ruled over every part of human knowledge; he aspired to the system of the universe and almost attained it. The other excelled in scientific processes and the complex solution of particular problems. Pascal perfected and fixed forever the language of reason, but it was Descartes that discovered it. The head of Pascal was not less strong than that of Descartes, but it was not so ample. Devoted at an early age to the study of mathematics and physics, it is not clear that Pascal ever gave great attention to philosophy, properly so called. No traces of any metaphysical studies appear either in his life or his works. He had read without doubt the Méthode and Méditations, and had retained from these the great principle of thought as the token and proof of existence. But Roberval himself had not dared to reject this principle ${ }^{3}$ it was found in St. Augustine, and, in admitting it, Pascal had only followed the general opinion. Logic alone had seriously occupied him, and of this logic, only definition, which belongs to mathematics as much as to philosophy. The only two philosophers whom he really knew, and with whose spirit he was evidently imbued, were Montaigne and his disciple Charronthat is, two skeptics. Skepticism paved the way admirably to the dogma of the nothingness of human nature, while, on the

1 Baillet, in the Vie des Descartes, demonstrates, by Descartes' own letters, how little justice was shown by Pascal towards his celebrated prerlecessor. Bossut, in his Discours sur ua vie et les ouvrages de Pascal, treats Baillet upon this point with much aisdain. Montucla, whose im partiality and information cannot be contested, gives almost the same iudgment as Baillet, Histoire des Mathématiques, t. ii, p. 205.

2 He was the first to enounce the problem which Newton resolved "Descartes was the first to reduce the cause of the motion of the heavenly jodies to science," says Laplace, Systeme du monde, liv. v, chap. v.

- See in our Fragments de Philosoplice cartésienne, the article entitled Robercal philosophe, p. 242. 
other hand, this dogma called for and confirmed skepticism. When grace, therefore, penetrated the mind of Pascal, tinding it void of all great philosophical doctrine, it easily took entire possession of it: the Jansenist faith surprised him in the abyss of Pyrrhonism, and, instead of extricating him, enchained him there.

It was not thus, it could not have been thus, with Nicole and Arnauld. Both possessed a foundation of philosophic study and knowledge which rendered them proof against Jansenism.

Nicole had studied philosophy with distinction at the University of Paris. He was admitted master of arts in 1644 . Checked in his theological and ecclesiastical career by the troubles excited by the celebrated five propositions of M. Cornet in the Sorbonne, and early allied with Port-Royal, where he had two aunts, nuns, one of whom, Mother Marie des Anges Suireau, had been abbess and reformer of Maubuisson, and died abbess of Port-Royal in 1658, he taught belles-lettres and philosophy several years at the Granges.' His course of logic is the foundation of the book which was afterwards composed in peculiar circumstances and published under the title of $L a$ Logique ou l'art de penser. This book is at once Arnauld's and Nicole's. It is fully imbued with Cartesianism. It opposes Pyrrhonism at every turn, as well as the philosophy based upon the maxim that all thought derives its origin from the senses. It professes the Cartesian principle that we have a natural, clear, and positive idea of the soul and of God. The two excellent preliminary discourses are from the hand of Nicole. ${ }^{2}$ The first and most important is almost entirely devoted to the refutation of skepticism and defence of philosophy. I am really very sorry for Pascal, but see how Nicole treats his beloved Pyrrhonists: "Pyrrhonism," says he, "is not a sect

1 Vie de Nicole, t. xiv, of the Essais de morale, p. 28: "He taught him Tillemont) philosophy, and gave him instructions in logic, all of which have since been given to the public."

I Ibid, p. 36. 
of men who are persuaded of what they say, but a sect of liars."' Montaigne is especially taken up and roughly handled. If I had to indicate the best reply to the book of Thoughts, I would designate the logic of Port-Royal. To this, I would add the admirable Discours contenant en abrégé les preuves natu. relles de l'existence de Dieu et de l'immortalité de l'âme. ${ }^{2}$ It appeared in 1670, shortly after the Thoughts, and one would say that Nicole had in view the skeptical arguments of Pascal when he wrote the following lines: "I am persuaded that these natural proofs do not cease to be sound. . . . There are some that are abstract and metaphysical, and I do not see that it is reasonable to take pleasure in decrying them; but there are also others that are more sensible, more in conformity with our reason, better suited to the majority of minds, and of such a nature that we must do violence to ourselves in order to resist them. ... Whatever effort atheists may make to efface the impression that the sight of this great world forms naturally in all men, that there is a God, the creator of it, they cannot entirely stifle it, so strongly and deeply is it rooted in our minds. We need not force ourselves to yield to it, but we must do violence to ourselves to contradict it. . . . Reason has only to follow its natural instinct to persuade itself that there is a God." A little later, in 1671, in the first volume of the Essais, when treating of the weakness of man, Nicole speaks of Descartes in terms that contrast strongly with those of Pascal and de Sacy: "The world had philosophized during three thousand years upon divers principles. A man now rises in a corner of the earth who changes the entire face of philosophy, and pretends to show that all who have gone before understood nothing of the principles of nature. And these are not idle promises alone; for it must be confessed that the newcomer throws more light upon the knowledge of natural things than all the rest have done together." Doubtless, when the

1 La Logique ou l'art de penser, edition of 1662 . Discours sur lo dessein de cette bogique, p. 13.

2 This was afterwards incorporated in the Essais, t. ii. 
beadstrong theologians applied Cartesianism at random to the explanation of the holy mysteries, the Eucharist among the rcst, Nicole, like Arnauld and even Bossuet himself, uttered a ery of alarm ' in the midst of his friends; but he therefore remained none the less faithful in public to the principles os his whole life. It may be imagined then, that, in the revision of the manuscript of Pascal, he strongly seconded the advice of Arnauld to suppress the arrogant insults everywhere addressed to Descartes and to natural reason, and as much as possible to efface the skepticism that prevails in the Thoughts. Yet, despite so much suppression, despite all the softening and even radical change, Nicole was never pleased with the Thoughts. As much as he admired and labored to circulate the Provincial Letters, so cold did he remain in respect to the Thoughts, interpreting in this the unanimous sentiments of his illustrious contemporaries. I have already made the observation that in the seventeenth century no philosopher, no celebrated theologian has praised or even quoted the Thoughts. We seek in vain for a single word in respect to this book in Fénelon, Malebranche, Bossuet,-even in the immense correspondence of Arnauld. As to Nicole, he concealed with a bad grace the slight value that he set on it. M. de Sévigné having shown him, one day, a letter from Madame de Lafayette, containing this singular eulogy of the Thoughts: "It is a bad sign in any one not to like this book," Nicole, timid as he was, had the courage to brave this anathema and confess his opinion. But first remark this enthusiasm for the Thoughts, coming from the circle of M. de Larochefoucauld, of which Madame de Lafayette is here but the secretary. The author of the Maximes indorses the author of the Thoughts. I believe it, indeed. When one has himself advanced, to the scandal of all

1 Nicole, Essais, t. viii, letters 82, 83, 84. Arnauld, letter of the 18 th of October, 1669. CEuvres complètes, t. i, p. 670. Bossuet, Lettre à un Dissiple du père Malebranche. Bossuet was the one of the three who least suf fered himself to be carried away by that very natural feeling produced in .he enlightened friends of a good eause by the exeesses which are com mitted in its name. 
honorakle men, that every thing in man may be reduced to self-love and egotism, and that all else is but hypocrisy, he must certainly congratulate himself on seeing a work appe:i: that comes to second this admirable principle by demonstrating that there is no such thing as ethics or natural religion, and that all law and virtue are based only upon caprice and fashion. This harmony between Larochefoucauld and Pascal is neither surprising nor very edifying; and in my opinion it is overwhelming to Pascal. After the disapproving silence of his equals, nothing more was wanting than the interested suffrage of this misanthropical personage, this melancholy wit, this disappointed and morbid courtier, who has not feared to give his own character and life of intrigue as a model for humanity. The reply of Nicole to M. de Sévigné is so little known, and serves so well our cause, that we give it abridged :'

"After this rigorous judgment of Madame de La F., that it is a bad sign in those that do not like this book, we are forced not to dare to express our sentiments, but to feign to find that admirable which we do not undesstand. She should at least have instructed us more particularly as to what we ought to admire in it, and not have contented herself with general praises, which serve only to convince us that we have not the mind to discover in it what she discovers, but avail nothing to enable us to find it. . . . To tell you the truth, I have hitherto had something of this bad sign myself. I have found indeed in it a great many stones tolerably well cut and fit to adorn a noble structure, but the rest has appeared to me a mass of confused material, nor could I see for what use it was designed. There are even some sentiments that do not appear to me to be quite exact, but which resemble chance thoughts written only to be examined with more care. What is said, for example, in tit. xxv, 15, that the title by which men possess their property has its origin only in imagination, concludes nothing of what it is designed to conclude, namely, the weak ness of mankind, and that we possess our property only by an

1 Essais, t. viii, first part, p. 245. 
imaginary title. . What is said in the same passage, No. 17, in respect to natural principles, appears to me too general. ... Fie supposes, in the whole chapter on amusement or the nisery of mankind, that ennui proceeds from what we see and think of ourselves, and that the good of amusement consists in that it distracts us from this thought. This, perhaps, is more subtle than sound. . . The pleasure of the mind consists in thinking, and in thinking vigorously and agreeably. It wearies as soon as its thoughts begin to languish. . . Hence those who are much occupied with themselves may grow sad, but not weary. Sadness and ennui are different emotions. . . M. Pascal confounds all this. I could make several other objections to his Thoughts, which sometimes appear to me a little too dogmatic, and thus disturb my self-love, which does not like to be taught so arrogantly."

And do you know the secret of this very indifferent liking of Nicole for the Thoughts? It is because this book is the strongest expression of Jansenism, and to tell the truth, Nicole was scarcely a Jansenist. He had suffered himself to be drawn into this controversy, somewhat through conviction, much through friendship, and most of all through a sincere and lasting antipathy to the Jesuits. He was much rather an adversary of the Jesuits than a true disciple of Port-Royal. He did not know Saint-Cyran; he had never felt the influence of that extraordinary man who dared to face Richelieu himself; who, from the depth of his dungeon at Vincennes, through a few billets, governed Port-Royal with sovereign power; who deeided the destiny of Arnauld, and exercised an irresistible ascendency over all that approached him; gentle and humble in outwarc appearance like his friend, St. François de Sales, but ardent, extreme, and inflexible at heart. The only strong influence to which Nicole was ever subjected was that of Arnauld. He admired and loved him, and willingly placed his elegant Latinity, and temperate, facile pen, at the service of his designs; but he took the liberty of choosing among the doctrines of his illustrious friend. Like him, he rejected the lax ethics of the Jesuits, falser incleed and far mor 
dangerous than the excessive austerity of Port-Royal; he had a horror of probabilism, that destroys all certainty and mural obligation; he detested most of all the intriguing and persecuting spirit of the Society, but he was a very lukewarm partisan of the Jansenist grace. His historian preserves an officious silence in respect to his conduct in the affair of the formulary. The truth is that he played an important part in it, opposing Pascal and Domat,' and warmly encouraging Arnauld in his resistance to the heroic madness into which Pascal wished to lead PortRoyal. From this moment, therefore, Nicole became suspected by the party. Following. Arnauld into exile, he soon became weary of the life of an émigré, and ended by declaring himself against special and in favor of universal grace. This was almost disowning Jansenism.

Arnauld was both more of a Jansenist and of a philosopher than was Nicole, and he remained true to both with equal constancy to the end of his long career.

In measuring this career, already so great, we may judge by what Arnauld did of what he would have done under more favorable circumstances, had it not been for that fatal meeting which first turned aside his destiny. It was Saint-Cyran who destroyed Port-Royal by introducing there a peculiar doctrine; it was Saint-Cyran who destroyed Arnauld by turning him 'rom the highway of the Gallican Church to cast him into a footpath environed with precipices. Nature had made him to be the equal of Bossuet, eloquence of course excepted, yet he became only the chief of a party. He had received all the attributes of genius, simplicity, strength, greatness, breadth of view, with inexhaustible fecundity of thought and facility of expression. Like Bossuet, he was lacking somewhat in invention; but, like him, he made up for this by almost unerring rectitude. In his youth, he had passed through those profound studies necessary to form a great geometrician, theologian,

1 A manuseript of the Bibliotreque Mcrarine, which we have often juoted, contains various inedited replies from Nieole to Domat and to Pascal himself. 
and philosopher. ${ }^{1}$ He even possessed several of the qualities of a great writer, rigid order, eminent perspicuity; no imagination, it is true, but wit and soul, often even elevated sentiment. But these many and rare qualities proved abortive, or ai least did not mature all their fruit for want of an equable and peaceful culture. Unceasingly occupied in directing a party, forgetting himself, despising glory, thinking only of truth and justice, constantly wandering from refuge to refuge without knowing where on the morrow he would lay his head, Arnauld passed his whole life sword in hand; he dissipated his strength in a thousand writings of the moment, instead of concentrating it upon some immortal work. He has strewn here and there lines and even pages worthy of admiration, but he was a stranger to that patient art of composition and style, that assiduous attention to beauty and form which alone can bring a book to perfection and posterity. Arnauld failed to attain the first rank in any thing, controversy excepted. In this, Bossuet himself was not his superior. It would too be unjust not to accord him a very elevated place in philosophy.

Arnauld, like Nicole, had studied philosophy in one of the colleges of the University of Paris. Entering the Sorbonne, he took all his degrees there in succession with great éclat. His favorite study was St. Augustine, whence he drew a foretaste of the principles of Descartes and of Port-Royal. As scon therefore as the Discours de la Méthode, with the three great corresponding works on physics and mathematics, appeared, in 1637, Arnauld recognized in some measure the philosophy that he was seeking, that was even already in his thought. From 1639 to 1641, during two consecutive ycars, he gave, at the Sorbonne, in the college of Mans, a regular and complete course of philosophy. It is affirmed that from this course arose several distinguished pupils

1 The Eléments de Géométrie of Y'ort-Roya are from the pen of Arnanl,l, and have served as the basis to all the works of this kind. See in the Vis 'Arnauld, p. 93, valuable details in respect to these Elements. I.eibuit speaks somewhere of the rare talent of Arnauld for mathonaties. 
who introduced the teachings of Arnauld into the University of Paris. ${ }^{\prime}$ But the surest trace that remains to us of these is the too little known thesis which he caused to be sustained in 1641 ; this contains more than one proposition well worthy af remark, and the spirit that prevails in it is found almost the same in the subsequent writings of Arnauld. ${ }^{2}$ At the same time, he wrote that celebrated opinion on the Méditations, in which the disciple of St. Augustine accepts without reserve the method and all the great principles of Descartes, the proof of personal existence derived from thought, the demonstration of the distinction between soul and body, and that of the existence of God by the idea of the Infinite. From this time, Arnauld never ceased to be, like Bossuet, an avowed Cartesian. There is indeed a striking analogy between the philosophic opinions of these two great men. Both are Cartesians, without prejudice as without weakness; at the height of the perse-

1 Preface historique of the tome xxxiii., p. 2.-Among these pupils is quoted Pierre Barbay, afterwards professor of philosophy, whose greatly mitigated Peripateticism serves as a connecting link between the old Peripatetic instructions and the teachings of the new school, that of Pcurehot, for example, in which Cartesianism appears already and well-nigh prevails.

2 Cuvres d'Arnauld, tome xxxviii., p. 1. Conclusiones philosophica. In logic, we meet with a certain conceptualism nearly allied to nominalism, which marvellously explains the antipathy of Arnauld to Malebranche's theory of ideas. Universals are to him but common notions and names: all reality lies in individuals. In mathematies, Arnauld criticises the el :ments of Euclid, the demonstrations of which do not appear to him always sufficiently luminous, thus preluding to his reflections on the fourth part of the Logique and to his Eléments de Géomitrie. From this epoch, that is from the year 1641, he attacks the Ptolemaic system in astronomy, and lares assert that the immobility of the earth rests on no proof either in astronomy or plysics, and that authority, not reason persuades us of it. Later, Paseal dared not go even so far as this. In ethics, Epicureanism, Stoicism, and Peripateticism are placed far beneath the Platonic ethies, culminating in Christianity. The liberty of man is admitted, but a few propositions already appear with wich Jansenism may harmonize. "He who eanuot $\sin$ is without doubt more free than he who ean sin." In physics, the opinion that extension is not distinct from things exten led, that is the space of bodies, is given as probable. In metaplysies, all eternal essence other than God is a chimera; all the entities are but being tself. Substantial forms are useless. To a mind free from prejudice, it is not less evident that God is, than that wo is as even number. 
cution,--let us speak plainly-, in the midst of the faults of Cartesianism, they had the courage to avow it while separating its principles from the daring applications that were made of them. Both set out from the fixed distinction between natural and supernatural truths, and philosophy appeared to them as legitimate and as certain in the natural order as the Christian faith in the order of revealed truths. They showed themselves the constant adversaries of the epicureanism of Gassendi and the skepticism of Montaigne and Huet. It was Arnauld that introduced and strove to bring Cartesianism in credit at Port-Royal. He was the author of of the fourth part of the Logique in which Descartes' method prevails. When, in 1633, the Roman censure placed the Méditations on the Index, he was not checked by this incredible injustice. In 1669, he expunged from the Thoughts all that was too openly in favor of skepticism and Montaigne and opposed to Descartes and philosophy. In 1675,' he composed an admirable address for the enlightenment of the Parliament of Paris, then about to issue a decree against the doctrine of Descartes. Lastly, in 1683, in his great controversy with Malebranche, he often recalled his brilliant but obstinate adversary to the sound methods and principles of their common master. ${ }^{2}$ Never did Jansenism warp philosophy or philosophy alter Jansenism in the mind of Arnauld. Grace and reason had early struck their roots so decply in it, that they stood, as it were, each by its own strength, side by side, meeting without being able to agree, and also without succeeding in destroying each other.

Arnauld occupied such a place in Port-Royal that what belonged to him alone was naturally extended to all the learned recluses. Because Arnauld was a Cartesian, it was thence con. cluded that all these gentlemen were Cartesians also. This conclusion has no foundation. If Port-Royal could not go the length of the Cartesianism of Arnauld, neither could Arnaula

1 Fragments philoscphique, série iii, t. iii, p. 7 .

- See that excellent volume, Des vraies et fausses idies. 
seduce Port-Royal to Cartesianism. It was in vain to present Descartes under the cloak of St. Augustine: the philosopher sonstantly appeared and terrified them. Arnauld brought over Nicole and the Duke de Luynes;' but all the rest remained cold or hostile. We must see in Fontaine what scandal was excited in the holy house by this new taste for philosophy. ${ }^{2}$ Sacy bewailed it, and all the world thought with Sacy. For some time, they dared not complain openly. Arnauld possessed immense authority; he was both priest and doctor; he had been the confessor of Port-Royal; he was the uncle and brother of its three most venerated personages, Mother Angelique, Mother Agnes, and Mother Angelique de Saint-Jean; His whole family in a manner peopled Port-Royal; he was the avowed chief, the light and the soul of the party. Yet signs of revolt burst forth from time to time. The Duke de Liancourt, in every respect an important personage, sometimes broke a lance on the visor of the illustrious doctor. Affairs came to such a pass that, about the year 1680 , the resolution was taken to make a final effort to win back Arnauld from philosophy. One of his most intimate friends, the theologal d'Aleth, M. du Vaucel, wrote a veritable manifesto entitled, Observations sur la Philosophie des Descartes. ${ }^{3}$ In this, du Vaucel complained that Arnauld compromised Port-Royal by giving reason to think it was Cartesian, whereas there were no Cartesians there but Arnauld and Nicole. He declared that instead of defending Descartes against the Jesuits, they must unite with the Jesuits against Descartes. He pronounced himself with strength and clearness in favor of the book that Father Valois, under the pseudonym of Delaville, had just published against Cartesianism in the name of the Society. SainteMarthe, one of the most thorough Jansenists, indorsed du Vaucel. Sacy was written to at Paris to procure his adhesion. It was obtained, but in terms comporting with the gen.

- The translator of the Méditations.

r. ii., p. 52, seq. ; and further on, p. 132.

- Préface historiqus of tome xxxviii of the works of Arnauld, p. 16. 
tleness and humility of that excellent man. He acknowledgell that he was not as much of a philosopher as his uncle, and entreated him to think less of philosophy and consecrate his pen to piety alone. In spite of these concerted efforts, Arnauld, like Bossuet, remained faithful to Descartes and philosophy to the end.

It is evident: Arnauld in philosophy does not represent Port-Royal; he contradicts it; he follows his own genius and the habits of his whole life. It is Sacy in 1650, it is Pascal in 1660 , it is du Vaucel in 1680, who are the true interpreters of Port-Royal. Pascal was the first to comprehend and openly express the absolute incompatibility of Jansenist grace with philosophy. The pious theologal d'Aleth, in repeating what had been said by the author of the Thoughts, obeyed an instinct quite as sure as genius itself, that instinct of party which must not be despised since it is often the inmost feeling of their principle. The whole party recognized their sentiments in du Vaucel and joined themselves to him. Arnauld remained alone, unshaken in his attachment to philosophy; and the adiniration with which his firmness inspires us is in the exact ratio of the serious opposition which he daily encountered, which he could not subdue, and which he resisted during forty years.

In conclusion, it is, I think, fully demonstrated that PortRoyal, founded on the double principle of the nothingness ot human nature and the invincible power of grace, could admit neither Cartesianism nor any other philosophy, and that therefore, as we at first asserted, Pascal, a Jansenist and a consistent Jansenist, must have been such as he is depicted by the Thoughts, a melancholy Christian, a skeptic of genius, who, rejecting all natural reason, all natural ethics, all natural religion, can find a shadow of certainty and peace nowhere but in the faith of a peculiar sect, which must not be confounded with the Church, of that sect so full of grandeur and misery, commencing, it is true, in Port-Royal and the Provinciales, but ending in the follies of Saint-Médard.

Pascal was really very obscure in the editions of Port-Roya 
and Bossut. We have thrown upon him the light of the autograph manuscript, and this light has revealed the most powerful enemy that philosophy has ever had.

Yes, Pascal was an enemy to philosophy : she is too loyal to conceal it, and too sure of herself to dread either Pascal or any other. Philosophy is established upon foundations whence she can brave alike Port-Royal and the Society of Jesus. She expresses in fact a necessary want and a sacred right of thought. Her cause is the great cause of the liberty of the world, reduced to its very principle, the liberty of the mind. Its strength is that of reason supported by two thousand years of progress and victory.

It looks well, indeed, at the present day, to treat natural reason with arrogant disdain. Assuredly, she is not infallible, neither is she convicted of error or of impotence. A thousand times has justice been done to the frivolous paralogism upon which rest all the inconsistent declamations, fulminated by reason against reason, from Pyrrho and Sextus to Pascal and his imitators. But let us leave logic and theories: let us adhere to facts. How emphatically they contradict the con. temners of philosophy!

From the earliest days of human communities to the coming of Jesus Christ, while a privileged nation in a corner of the world was guarding the deposit of revealed doctrine, who, I ask, taught men under the dominion of extravagant religions, and forms of worship often monstrous? Who taught them that they had a soul, and a free soul, capable of doing evil, but also capable of doing good? Who taught them, in the face of the triumphs of strength, and the almost universal oppression of weakness, that strength is not every thing, and that there are invisible but sacred rights, which the strong themselves must respect in the weak? From whom did men receive these noble principles: that it is more honorable to keep pledged faith than to betray it; that there is dignity in subduing one's passions, and in remaining temperate even in the midst of permitted pleasures? Who dictated to them the great maxims that a friend is another self; and that one should love his 
friends more than himself, his country more than his friends, and humanity more than his country? Who disclosed to them beyond the limits, and beneath the veil of the universe, a God concealed, but everywhere present, a God who created this world with weight and measure, and who ceases not to watch over his work, a God who made man because he was unwilling to retain his most august perfections within the inaccessible solitude of his own being, because he wishod to transmit and diffuse his intelligence, and, what is better, his justice, and, what is better still, his goodness? inspired them with the firm and touching hope that, this life ended, the immaterial, intelligent, and free soul will be received by its Maker? Who told them that, above all the uncertainties of life, there is one supreme certainty, a truth as sure as the truths of geometry: namely, that in death as in life, an all-powerful, all-just, and allgood God presides over the destiny of his creature, and that, beyond the shades of death, whatever may happen, all will be well, since all will be the work of infinite justice and goodness ?'

I ask, what power taught all this to so many millions of men in the old world, before the coming of Jesus Christ, if not that natural enlightenment which is treated to-day with such strange ingratitude? Let them deny it in the face of these irrefragable monuments of history, or let them confess that this natural enlightenment has not been tro weak to reveal to us all that gives value to life, the sure and necessary truths upon which are established the institutions of family and society, together with all the private and public virtues, and this through the pure ministry of the still unknown sages of the antique East, and of the better-known philosophers of Ancient Europe, admirable, simple, noble men, who, clothed in no sacerdotal garment, had no other mission than the zeal for truth, and the ove of their fellow-mortals, and who, to be called philosophers

1 'The texts that justify these assertions are numerous and incontestable Any man at all versed in ancient philosophy will feel them in some sor hrough this free translation. 
or frierids of wisdom, suffered persecution, exile, and death, sometimes on a throne, but oftener in chains; an Anaxagoras, a Socrates, a Plato, an Aristotle, an Epictetus, a Marcus Aurelius ! And that Roman legislation, which, for so many ages, gave to the world the most equitable government ever yet seen; what inspired and sustained it? Apparently, again, natural reason-that reason which it is sought to relegate to an obscure corner of our schools, or even to banish altogether, so useless or mischievous is it deemed!

Upon what basis rests the whole structure of French society? Of what elements is it formed-by whose hands has it been raised? Were the codes which, for the last fifty years, have presided over our public and private life, projected and deliberated upon in synods, like the capitularies of Charlemagne? No; they were the work of the Constituent Assembly, and ot the Council of State of the empire. The elements of the laws that govern us are the ideas that have everywhere been diffused by philosophy-ideas at once as sound as generous, which the French Revolution did not create, but proclaimed, and which she first defended with the sword, then engraved upon the bronze of our codes, for the example and instruction of the world. And in politics, what is the avowed principle of our government? The divine right of kings is to-day an extravagance which cannot even be recalled but with peril. The strength of constitutional royalty lies wholly in the recognition by p:I 5 . lic reason, of a permanent, inviolable power, as the surest support of order and liberty. The reciprocal rights and duties which form the woof, as it were, of the social life, especially the great duties of child and parent, of husband and wife, have been drawn by the civil law from the simple principles of honor and justice : in its sight, they rest upon their own evidence, the certainty and sanctity of natural justice. Like the civil, the penal code has no other foundation. Virtue merits a recompense in itself, and crime deserves a chastisement; this it receives in the torments of conscience, and also es public instruction in the presence of all mankind, in the name of that supreme, armed justice which is called the State. 
Let us thus glanee over all our codes of law; we meet everywhere the same spirit; we do not find a single principle that exceeds reason, and naturai ethies, and religion.

And this incontestible characteristic of French legislation and society is not a novelty, a miracle in our history ; for this history has been little more for the last three centuries than the continued progress of the secular spirit. Now, remark it well; all progress of secularization is homage rendered to the power of natural reason, and consequently to the power of philosophy. The mere existence of our society, such as time and the Revolution have made it, is therefore the triumph of philosophy, and so long as our society shall endure, philosophy has nothing to fear; for to rally to herself all the minds of the age, all at least who are not dreaming of a return to the society of the Middle Ages, philosophy has but to show them the sacred talisman of constitutional order and French law.

Let us go still forther : is it not evident to every impartial observer, that the principles of the French Revolution are penetrating by degrees all the European States and even extending beyond the ocean?

Such is the simple yet peremptory reply which we confine ourselves to making to all those who are now sheltering themselves under the revered name of Pascal to revive skepticism, to decry human reason, and to lull us into an individual mysticism without grandeur or solidity, or bring us again under the dominion once broken by our sires.

Is it said that we mean to contest the salutary authority of religion? God forbid! Religion and philosophy, as we a thousand times have shown, are based upon different yet not opposing truths. Each has a distinct and legitimate domain. To declare war against religion in the name of philosophy would be great folly, for philosophy cannot replace religion, and in such an enterprise would display but her ambition and impotence. On the other side, it would be no less folly to sleclare war against philosophy in the name of religion, and in order to attract to Christianity, to ealumniate reason, debase intellect, and stultify mankind. Religion and philosophy arc 
two equally necessary powers, which, thank God, can never destroy each other, but which may be easily united for the peace of the world and the service of the human race. The true courage, the true wisdom is to stand in turn by the one that is attacked by the other. We put the question to every henest man : which is now the assailant? Evidently, philosophy does not attack, but defends. Hence we are more than ever on her side; and, if we may be permitted to say it, we have shown clearly enough in evoking an adversary like Pascal, that we are little disposed to retreat before others. 


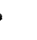




\section{PLAN OF THE THOUGHTS.}

ACCOUNT OF a CONVERSATION IN WHICH PASCAL EXPOSED THE PLAN AND MATTER OF HIS WORK ON RELIGION.'

[The following passage is an extract from the preface of the first edition of the Thoughts. It was written by Etienne Périer, and is of great importance, since it makes known how Pascal had conceived the plan of that defence of Christianity, of which the Thoughts are but scattered and incomplete fragments. "It is," to use the expression of M. Sainte-Beuve, "a luminous abridgment," that helps us penetrate the Thoughts more profoundly. See Port-Royal, 1. iii., c. xxi., p. 336 et seq., entitled : Conversation de Pascal._-Son plan ressaisi._-Préambule et méthode.-Opposée à celle de Descartes.-Entrée en matière.-L'homme devant la nature.-L'homme en lui-même.-Le moi.-L'homme dans la sociélé. -Oì est le droit naturel ?-Des opinions populaires.-Incertitude universelle. - Angoisse. $-2^{\circ} \mathrm{L}$ 'homme en quête du salut.-Les philosophies.-Les religions. - La religion.-Le peuple juif et l'Ecriture.-Les miracles et les prophéties. - JésusChrist.]

There happened an occasion, ten or twelve years ago, when Pascal was pressed, not to write what he had in his mind on this subject (religion), but to give some account of it viva voce $\mathrm{He}$ did it, therefore, in presence and at the instance of severa very eminent persons who were his friends. He developed to them in few words the plan of his whole work; he represented

1 This conversation must have taken place about 1658 . Who were those friends before whom Pascal explained himself? What was the place of the conversation? The too discreet prefaces have taken good care not to tell us; but certainly the élite of Port-Royal were there, and the place of meeting was perhaps no other than Port-Royal of Paris. (Sainte-Beuve.) 
to them what was to form its subject and matter; he gave them a résumé of its arguments and principles, and explained to them the order and sequence of things which he intended to treat of therein. And these persons, who wcre most capable of judging of such things, declare that they have never heard any thing finer, stronger, more touching, or more convincing; that they were charmed with them, and that what they saw of this project and this design in a discourse of two or three hours, delivered without premeditation or preparation, enabled them to judge what this work might at length become, if it were ever executed and perfected by a person whose ability and capacity they knew; who had been accustomed to bestow so much labor on all his works, that he scarcely ever was contented with his first thoughts, however good they might appear to others, and who has often rewritten, eight or ten times, pieces that any other than he would find admirable at first.

After having shown them what proofs make the greatest impression on the minds of men, and are best adapted to persuade them, he undertook to show that the Christian religion had as many marks of certainty and evidence as things that are received in the world as most indubitable.

In order to enter upon this design, he began by a delineation of man, in which he forgot nothing that could make him known both within and without himself, even to the most secret movements of his heart. He then supposed a man who, having always lived in general ignorance, and with indifference in regard to all things, especially in regard to himself, comes at length to consider himself in this picture and to examine what he is. He is surprised to discover therein an infinity of things on which he has never thought, and he could not notice without astonishment and wonder all that Pascal makes him feel of his greatness and his vileness, of his advantages and his weaknesses, of the little light that remains to him, and the darkness that surrounds him on almost every side, and, in fine, of all the astonishing contrarieties that are found in his nature. He can no longer remain in indifference, however feeble may we his reason, and however insensible he may have been hith. 
srto, he must wish, after having thus known what he is, to know also whence he comes and what he must become.

M. Pascal, having thus awakened in him the disposition tc inform himself in regard to a doubt so important, first directs him to the philosophers; and after having unfolded to him all that the greatest philosophers of all the sects have said on the subject of man, he makes him observe so many defects, so many weaknesses, so many contradictions, and so many falsehoods in all that they have advanced, that it is not difficult for this man to judge that it is not among the philosophers that he must find what he seeks.

He then carries him over the whole universe and through all ages, in order to point out to him an infinity of religions that are met with; but he shows him at the same time by reasons so strong and convincing that all these religions are only full of vanity, follies, errors, aberrations, and extravagances, that in them again he finds nothing that can satisfy him.

In fine, he directs his attention to the Jewish people, and points out in connection with them circumstances so extraordinary, that he easily engages his attention. 'After having represented to him all that is singular in this people, he especially directs his attention to a single book by which this people is governed, and which comprises at once its history, its law, and its religion. Scarcely hảs he opened this book when he learns that the world is the work of a God, and that this same God has created man in his own image, and endowed him with all the powers of body and mind that are adapted to this state of being. Although he has nothing yet that convinces him of this truth, it does not fail to please him; and reason alone suffices to discover to him more probability in the supposition that a God is the author of men and all that is in the universe, than in all that these same men have imagined by their own knowledge. What arrests his attention at this point is to perceive, by the delineation of man that has been given him, that he is very far from possessing all those advan tages that he must have had when he left the hands of hig Maker. But he does not remain long in this doubt; for, on 
reading further in this same book, he finds that after man had been created by God in a state of innocence and with all sorts of perfections, his first act was to revolt against his Creator, and to employ all the powers that he had received in offending him.

M. Paseal then made him comprehend that this crime being he greatest of all crimes in all its circumstances, it had been punished not only in this first man who, having fallen thereby from his state, sank at once into misery, weakness, error, and blindness, but also in all his descendants, to whom this same man has communicated and will still communicate his corruption in the whole course of time.

He shows him in course different passages of this book, wherein he has discovered this truth. He warns him that man is no longer spoken of in this book but in relation to this state of weakness and disorder; that it is often said therein that all flesh is corrupt, that men are abandoned to their senses, and that they are prone to evil from their birth. $\mathrm{He}$ shows him again that this first fall is the source not only of all that is most incomprehensible in the nature of man, but also of a multitude of effects that are external to him, and of which the cause is unknown to him. In fine, he represents to him man so well delineated in the whole of this book, that he no longer appears to him different from the first image of him that he has traced.

It is not enough to have made known to this man his state full of misery; M. Paseal teaches him furthermore that he will find in this same book wherewith to console himself. And in fact, it causes him to observe that it is therein said that the remedy is in the hands of God; that we must have recourse to him for the strength that we lack; that he will hare compassion and even send a deliverer to men, who will make satisfaction for them and repair their impotence.

After having explained a great number of very special remarks on the book of this people, he still makes him consider that it is the only book which has spoken worthily of the Supreme Being, and that has given the idea of a true 
religion. He makes him conceive its most evident marks, which he applies to what this book has taught; and he particularly directs his attention to the fact, that it makes the essence of its worship consist in the love of God whom it adores: which is a character wholly peculiar to it, and con spicuously distinguishes it from all other religions, whose false hood appears by the want of this essential mark.

Although M. Pascal, after having conducted so far this man whom he had proposed to persuade by insensible degrees, has not yet said any thing to him that might convince him of the truths which he has led him to discover, he has nevertheless put him in a disposition to receive them with pleasure, provided it could be shown him that he ought to yield to them, and even to desire with all his heart that they may be solid and well founded, since he finds in them advantages so great for his repose and for the enlightenment of his doubts. It is also the state in which every reasonable man ought to be, who has once fairly entered into the course of all those things that M. Pascal has just represented; and there is reason to believe that after this he would easily yield to all the proofs which he successively brought to confirm the certainty and evidence of all those important truths of which he had spoken, and which constitute the basis of the Christian religion, of whose truth it was his design to persuade.

In order to say something of these proofs in few words. after he had shown in general that the truths in question where contained in a book of whose certainty no man of good sense could doubt, he dwelt principally on the book of Moses, wherein these truths are peculiarly set forth; and showed by a great number of indubitable circumstances that it was equally impossible for Moses to have left a written account o false things, or for the people to whom he left them to have been deceived by them, even though Moses had been capable of being an impostor.

He also spoke of all the great miracles recorded in this book; and as they are of immense consequence for the religion therein taught, he proved that it was not possible 
that they should not be true, not only by the authority of tne book wherein they are contained, but also by all the circum stances that accompany them and render them indubitable.

He also showed in what manner the whole law of Moses was figurative; that all which had happened to the Iews was only the type of the truths accomplished at the coming of the Messiah; and that, the veil which covered these types having been removed, it was easy to see their complete accomplishment and perfect consummation in favor of those who have received Jesus Christ.

M. Pascal undertook in course to prove the truth of religion by the prophecies; and on this subject he dwelt much longer than on the others. As he had labored much on this subject, and had views in regard to it quite peculiar to himself, he explained them in a very intelligible manner; he showed their sense and sequence with marvellous felicity, and set them forth in all their brilliancy and power.

In finc, after having run through the books of the Old Testament, and having made several convincing observations to serve as foundations and proofs of the truth of religion, he undertook also to speak of the New Testament, and to draw his proofs of the truth itself from the Gospel.

He began with Jesus Christ; and although he had already invincibly proved his Messiahship by the prophecies and all the types of the law, whose perfect fulfilment was seen in him. he still adduced many proofs drawn from his person, from his miracles, from his doctrine, and the circumstances of his life. He then dwelt upon the Apostles; and in order to show the truth of the faith which they proclaimed everywhere, after having established that they could not be accused of falsehood but upon the supposition that they were either deceivers or themselves deceived, he cleariy showed that both of these suppositions were equally impossible.

In fine, he forgot nothing that could serve to establish th truth of the evangelical history, making very fine remarks on the Gospel itself, on the style of the Evangelists and their characters, on the Apostles in particular and their writings, on the 
prodigious number of miracles, on the martyrs, on the saintsin a word, on all the ways whereby the Christian religion has been completely established. And although he had not the leisure, in a simple discourse, to treat at length of so vast a matter as he designed to do in his work, he nevertheless said enough to carry the conviction that all this could not be the work of men, and that God alone could have guided the issue of so many different effects, which all equally concurred in proving in an irresistible manner the religion that he himsch came to establish among men.

Such in substance are the prineipal matters of which he undertook to speak in all this diseourse, which he proposed to those who heard him only as an abridgment of the great work that he meditated; and it is by means of one of those who were then present, that the little I have just reported has been since known.

The author of the preface, after haviny given the history of the publication of the Thoughts, and explained some fragments that may seem obscure, adds: "It is still it appears to me, quite proper. in order to undeceive some persons, that might, perhaps, expect to find here geometrical proofs and demonstrations of the existence of God, of the immortality of the soul, and of several other articles of Christian faith, to inform them that such was not the design of M. Pascal. He did not pretend to prove all these truths of religion by such demonstrations founded on evident principles, capable of convincing the obstinacy of the most hardened, nor by metaphysical arguments that often lead the mind more astray than they persuade it, nor by the common-places drawn from different effects of nature; but by moral proofs, which go to the heart rather than to the understanding ; that is, he would labor more to touch and dispose the heart than to convince and persuade the mind, since he knew that the passions and the vicious attachments which corrupt the heart and the will are the greatest obstacles, and the principal hindrances we have to faith; ath. that, provided these obstacles could be removed, it was not difficult ti make the mind receive the knowledge, and the reasons whereby it might be convinced.

" One will be easily persuaded of all this in reading thesn writings.' 



\section{THOUGHTS OF PASCAI.}




\section{TH OUGHTS OF PASCAL.}

\section{CHAPTER I. ${ }^{1}$}

\section{[AGAINST THE INDIFFERENCE OF THE ATHEISTS.]}

... LET them at least learn what the religion is which they oppuse before they oppose it. If this religion boasted of having a clear vision of God, and of possessing him directly, and without a veil, it would be indeed opposing it to declare that we see nothing in the world which discovers it with such evidence. But since religion says, on the contrary, that men are in darkness, and far from God, that he has hidden himself from their knowledge, that the very name which he gives himself in the Scriptures is, Deus absconditus; and, in fine, as religion equally labors to establish these two things, that God has established perceptible signs in the Church, in order to make himself knuwn to those who seek him sincerely, and that, nevertheless, he has so far concealed these signs that he will be found only by those who seek him with all their heart, what advantage do the opponents of religion gain when, professedly neglecting to search after the

1 This morceau, which was, according to all appearance, to serve as a general preface, is not found in the autograph manuscript, but only in the copies. It forms the first chapter of the edition of Port-Royal, where it is entitled: Against the Indifference of the Atheists. We have thought it best to reproduce this title, which appears to us exactly in accordance with the thought and intention of Pascal. 
truth, they cry out that nothing discovers it to them, since the very ubscurity in which they are, and which they bring as an objection to the Church, does but establish one of the things which she maintains, without affecting the other, and, far from ruining, confirms her doctrine?

The opponents of religion, in order to combat it, should be able to affirm that they have used their utmost endeavors in seeking it everywhere, and even in what the Church proposes for instruction, but without any satisfaction. If they could say. this, they would indeed combat one of her pretensions. But I hope to show here that no rational person can affirm this; and $I$ even venture to assert that no person ever did. We know very well how those act who are in this spirit. They think that they have made great efforts to instruct themselves, when they have spent a few hours in reading some book of Scripture, and have put a ferw questions to some ecclesiastic on the truths of the faith. After that, they boast of having made fruitless searches in books, and among men. But, in truth, I cannot help saying to them, what I have often said, that this negligence is insufferable. The question is not about the petty interest of some stranger, that it should be dealt with in such a manner; it is about ourselves, and our all.

The immortality of the soul is a thing which is of so much importance to us, which touches us so deeply, that we must have lost all feeling, if we are indifferent about knowing whether it is true or not. All our actions and thoughts must take such different directions, according as we have or have not the hope of eternal blessings, that it is impossible to take one step with sense and judgment, except in regulating it by kceping this point ever in view as our ultimate object.

Thus, our first interest and our first duty is to enlighten ourselves on this subject, upon which all our conduct depends. And therefore it is that, among those who are not convinced of its truth, I make an extreme difference between those who use every endeavor to instruct themselves in regard.to it, and those who live withcut troubling themselves about it, and without thinking of it. 
1 can feel only compassion for those who sincerely mourn in this doubt, who regard it as the last of misfortunes, and who, sparing no effort to free themselves from it, make this investigation their chief and most serious occupation.

But those who pass their lives without thinking of this ultimate end of existence, and who, for the sole reason that they cannot find in themselves the lights which persuade them, neglect to seek them elsewhere, and to examine fundamentally whether this opinion is one of those which the people receive through credulous simplicity, or one of those which, although obscure in themselves, have nevertheless a solid and impregna ble basis, I regard in a wholly different manner.

This negligence, in an affair wherein the question is concerning themselves, their eternity, and their all, irritates me much more than it excites my pity; it astonishes and overwhelms me: it is for me something monstrous. I do not say this through the pious zeal of a spiritual devotion. I mean, on the contrary, that one ought to have this sentiment by a principle of human interest and by an interest of self-love: it is only necessary for this to see what is seen by the least enlightened.

It is not necessary to have a very elevated soul in order to comprehend that there is here no true and solid enjoyment; that all our pleasures are but vanity; that our ills are infinite; and that, in fine, death which threatens us every instant must, in a few years, infallibly reduce us to the horrible necessity of eternal annihilation or misery.

There is nothing more real, more terrible, than this. We may put as brave a face on it as we will, this is the end that awaits the fairest worldly life. Let one reflect upon this, and then let him say whether it is not unquestionable that there is no good in this life but the hope of another life; that we are happy only in proportion as we attain this hope; and that as there remain no misfortunes for those who have a full assurance of eternity, so there is no happiness for those who, in 'egard to it, have no light.

It is then, assuredly, a gecat evil to be in dotbt concerning 
immortality; but it is at least an indispensable duty to seek, when we are in this doubt; and, therefore, he who doubts and neglects inquiry, is at once very unhappy and very perverse. But if he is calm and contented in his doubt, if he avows it, if he boasts of it, if he is even in such a state as to make it th subject of delight and vanity, I have no terms to characterize so extravagant a being.

Where can men get these sentiments? What subject of delight is found in expecting nothing but irremediable miseries? What subject of vanity is it to behold ourselves in the midst of impenetrable darkness? And how can it happen that a rational man reasons in this way?

"I know not who has put me in the world, nor what the world is, nor what I am myself. I am in terrible ignorance of all things. I know not what my body is, what my senses are, what my soul is, and that very part of me which thinks what I am saying, which reflects upon every thing and upon itself, and knows itself no more than the rest. I view 'these awful spaces of the universe that surround me, and I find myself fixed to a corner of this vast extent, without knowing wherefore I have been placed here rather than elsewhere, why this brief period of time that has been given me to live has been assigned to me now rather than at some other moment of the whole eternity that has preceded me, and of that which is to follow. I see nothing but infinities on every side, which inclose me like an atom, and like a shadow that appears but a moment and returns no more. All that I know is that I nust soon die; but what I am most ignorant of, is that very death which I am unable to avoid.

" $\Lambda$ s I know not whence I came, so I know not whither I go ; and I know only that in leaving this world I fall forever either into nothingness or into the hands of an angry God, without knowing which of these two conditions is to be my eternal lot. Such is my state-full of misery, weakness, ob. scurity. And from all this I conclude, that I ought to pass all the days of my life without thinking of what is to happen to me hereafter. Perliaps I might find some enlightenment 
in my doubts; but I am unwilling to take the trouble, or go a single step in search of it; and, treating with contempt those who give themselves up to such labor, I will go without forethought and without fear to try the great event, and will passively approach death, in uncertainty of the eternity of my future condition."

Who would desire to have for a friend a man who discourses in this manner? Who would select such a one for the confidant of his affairs? Who would have recourse to such a one in his afflictions? And, in fine, for what use of life could such a man be destined?

In truth it is the glory of religion to have for its enemies men so irrational; and their opposition is so little dangerous to religion, that it tends on the contrary to the establishment of her principal truths. For the Christian faith goes mainly to the establishment of these two things: The corruption of nature, and the redemption by Jesus Christ. Now if these persons do not serve to show the truth of redemption by the sanctity of their lives, they at least admirably serve to show the corruption of nature by sentiments so unnatural.

Nothing is so important to man as his condition; nothing is to him so fearful as eternity. It is, therefore, something wholly unnatural to find men indifferent to the loss of their being, and to the peril of an eternity of miseries. They are quite different in regard to all other things. They fear the merest trifles, anticipate them, feel them when they come; and that man who passes so many days and nights in rage and despair on account of the loss of an office, or some imaginary offence to his honor, is the very one who knows, without un. easiness or emotion, that he must lose every thing by death. It is something monstrous to see in the same heart, and at the same time, such sensibility for the least things, and such strange insensibility for the greatest. It is an incomprehensible delusion, and a supernatural supineness, that indicates an omnipotent force as its cause.

There must be a strange revulsion in the nature of man, to make him ylory in that state wherein it seems incredible that 
a single person should be found. Yet experience shows me so great a number of such, that this would be astonishing, if we knew not that most of those who are thus involved, counterfeit, and are not such in reality.' They are people who have heard that fine worldly manners consist in thus acting the abandoned. This is what they call throwing off the yoke, and what they try to imitate. But it would not be difficult to make them understand how much they deceive themselves in thus seeking esteem. This is not the means of acquiring it, I would say, even among persons of the world, who have a sound judgment of things, and know that the only way of gaining esteem is to show themselves honest, faithful, judicious, and capable of usefully serving their friends, because men naturally love only what can be uscful to them. Now, what advantage is it to us to hear a man say that he has thrown off the yoke, that he does not believe there is a God, who takes cognizance of his actions; that he regards himself as the sole master of his conduct, and that he expects to render an account of it to none but himself? Does he think thereby to induce us to have henceforth more confidence in lim, and to expect from him consolation, counsel, and aid in the various needs of life? Does he think to afford us satisfaction, by telling us that he regards the human soul only as a breath or a vapor, and that too, in a proud and self-sufficient tone? Is this, then, a thing to be gayly said? Is it not a thing to be said with sadness, on the contrary, as of all things the saddest?

If such persons thought of it seriously, they would see that this is so injudicious, so contrary to good sense, so opposed to integrity, and so remote in every way from that genteel air which they seek, that their conduct is rather calculated to

1 "L'atheïsme estant une proposition comme desnaturee et mulıtrueuse, lifficile aussi et malaysee d'establir en l'esprit humain, pour insolent et lesreglé qu'il puisse estre, il s'en est veu assez, par vanité, ci par tierté de concevivir des opinions non vulgai:es et reformatriees du mo.tde, en affreter la profission par eontenance; qa:, s'ils sort assez fols, ne sont pas assez forts pour l'avoir plantee en leu_ conscience. . . Hommes bien miserables et scervellez, qui taschent d'estre pures qu'ils ne peuvent."-Montaigne. 
repel than to corrupt those who might have some inclination to follow them. And, in fact, set them to rendering an account of their sentiments, and giving their reasons for doubting religion; they will say things so feeble and so base, that they will persuade you of the contrary. This is what a person once very aptly said to one of them: "If you continue to discourse in this manner, you will indeed soon convert me." And he was right; for who would not be horrified to find himself associated in his opinions with persons so despicable?

Thus, those who merely counterfeit these sentiments would be indeed unfortunate in contradicting their own nature, in order to render themselves the most absurd of men. If they are grieved to the bottom of their heart at not having more light, let them not disguise it: there will be no shame in confessing it. The only shame is that there is no shame. Nothing shows more an extreme weakness of mind than to know not what is the unhappiness of a man without God; nothing indicates more a bad disposition of heart than not to desire the truth of eternal promises; nothing is more cowardly than to brave God. Let them leave such impieties, then, to those who are so unhappily constituted as to be really capable of them: let them be at least honest men, if they cannot be Christians; and let them acknowledge, in fine, that there are but two sorts of persons who can be called rational,--either those that serve God with all their heart, because they know him; or those that seek him with all their heart, because they do not know him.

But as for those who live without knowing him and without s seking him, they show so little care for their own welfare, that they are not worthy of the care of others; and it requires all the love of the religion which they despise, not to despise them to such an extent as to abandon them in their folly. But, since this religion obliges us to regard them always, as long as they shall be in this life, as capable of receiving the grace that may enlighten them, and to believe that they may in a short time be more filled with faith than we are, and that we on the contrary may fall into the blindness in which they 
are, we must do for them what we would that they should do for us, if we were in their place, and entreat them to have pity on themselves, and to make at least some endeavors to find light. Let them give to this work some of those hours which they employ so uselessly elsewhere: whatever aversion they may bring to it, perhaps they will find something, or at least they will not lose much by it. But as for those who shall hring to it a perfect sincerity and a real desire to meet the truth, I hope they will find satisfaction in it, and be convinced cf the divinity of our religion, by the proofs which I have here brought together, and in which I have followed very nearly the following order.'

1. We see by the last lines that this fragment was designed to form the preface of a book that Pascal meditated.

After the fragment which eonstitutes this first chapter, the manuBcript copies contained what follows, which is doubtless a variation of the oreface :

"Before entering upon the proofs of the Christian religion, I think it neacssary to show the unreasonableness of men who live eareless of the truth of a thing that is so important to them and touches them so nearly.

"Of all their aberrations, this is doubtless that which most convicts them of folly and blindness, and wherein it is easiest to confound them by the simplest principles of common-sense and the sentiments of nature. Now it is unquestionable that the period of this life is but an instant; th at the state of death is eternal, whatever may be its nature; and that, thus, all our actions and thoughts must take such different directions according to the state of this eternity, that it is impossible to take a step with sense and judgment, but in regulating it by view of this point which must bo our ultimate object.

"Nctl ing is clearer than this, and therefore, accorling to the principles of reason, the conduct of men is wholly irrational, if they take no other course. By this rule, then, let those be judged who live careless of the close of life, who, giving themselves up to their inclinations and pleasures without reflection and solicitude, and as if they could annihilute etennity by turning away from it their thought, think only of rendering themselves lappy in this brief moment of existence.

"Yet this eternity subsists, and the death that must open it and threatons tlem every lour must soon infallibly place them in the terrible necesity ot eternal annihilation or misery, while they know not which of these : 'ulditions is eternally prepuree for them.

'This doubt, then, is of terrible consequenee. They are in peril of an elemity of miseries: and yet, as if the thing were not worth the pains, wey neglect to examine wlether tho opinion in question is one of these 
T Between us and hell or heaven, there is nothing but life, which of all things is the frailest.

A man in a prison, not knowing whether his sentence is passed, having but an hour longer to ascertain the fact, this hour sufficing, if he know that it is given, to procure its revocation,-it is against nature that he should employ this hour not in ascertaining whether his sentence is passed, but in play ing at piquet.' Thus it is unnatural that man .... It is an aftliction from the hand of God.

Thus not only the zeal of those who seek God proves his existence, but the blindness of those who seek him not.

- I am satisfied that they should not investigate the system of Copernicus; but this .... It is of the most vital importance to know whether the soul is mortal or immortal.

- We carelessly run off a precipicc, after having placed something before us to hinder us from seeing it.

that the mass receives with a too credulous facility, or one of those which, obscure in themselves, have a very solid although concealed basis. Thus, they know not whether there is truth or falsehood in the thing, whether there is strength or weakness in its proofs. They have the proofs before their eyes; they refuse to look at them, and in this state of ignorance, they take the part of doing whatever is necessary to fall into this evil, in case it exists, to await a solution of the problem by death, to be nevertheless very contented in this state, to make a profession of it, and, in fine, to tako pride in it. Is it possible to think seriously of the importance of this matter without being horrified at such extravagant conduct?

"Such tranquillity, in such ignorance, is something monstrous, the extravagance and stupidity of which it is necessary to make those feel who pass their lives thcrein, by showing them to themselves in order to confound them by the sight of their own folly. For these men, when they clinose to live in such ignorance of what they are, and withcut sceking enlightenment, reason in the following manner:

"I know not, they say, ....."

1 Port-Royal thus changes the end of this phrase: "To play and anuse himself." The following phrase, not being completed in the autograph manuscript, where it is found as given above, Port-Royal suppresses it and gives this in its place: "Such is the state in which those persons are found whom we are deseribing, with this difference, that the evils with which they are threatened are very different from the simple loss of life and a transient punishment, which the prisoner lias to dread " 


\section{CHAPTER II.}

[GREATNESS AND MISERY OF MAN.-ASTONISHING CONTRADICIIONS OF HIV NATURE.]

I.

Disproportion of man.'-Let man, then, contemplate entire nature in her height and full majesty; let him remove his view from the low objects which surround him; let him regard that shining luminary placed as an eternal lamp to give light to the universe; let him eonsider the earth as a point, in com parison with the vast eireuit described by that $\operatorname{star}^{2}$ [sun]; let him learn with wonder that this vast circuit itself is but a very minute point when compared with that embraced by the stars which roll in the firmament. But if our view stops there, let the imagination pass beyond: it will sooner be wearied with coneeiving than nature with supplying food for contemplation. All this visible world is but an impereeptible point in the ample bosom of nature. ${ }^{3}$ No idea approaches it. In vain we extend our coneeptions beyond imaginable spaces: we bring

1 VAr. of MS.: Incapacity.-At the head of this paragraph, we read in the MS. the following passage erased by Pascal: "Belıold whither we are led by natural knowledge. If these things are not true, there is no truth in man; and if they are, he finds in them much eause for humiliation, foreed to self-abasement in either case; and since he eannot subsist withont believing them, I desire, before entering upon the most important investigations of nature, that he should once eonsider her seriously and deliberately, that he sliould also regard himself and judge whether he has any proportion with her by the eomparison that he shall make of these 'wo objects."

2 VAR. OF MS.: Let the vast circuit which it describes make him regard ike earth as a point.-In effaeing this plırase, says M. Fangère, did Pascal wish to express no opinion on the systems of Copernieus and Galileo? This is vertain, and "that star" refers to the sun and not to the earth.

- Var. of MS.: Is only un atom in the immensity. Secund Var.: Is only in atom in the amplitude. 
Corth but atoms, in comparison with the reality of things. It is an infinite sphere, of which the centre is everywhere, the sircumference nowhere. ${ }^{1}$ In fine, it is the greatest discernible character of the omnipotence of God, that our imagination loses itself in this thought.

Let man, having returned to himself, consider what he $\mathrm{i}$ compared to what is; let him regard himself as a wanderer into this remote province of nature; and let him, from this narrow prison wherein he finds himself dwelling (I mean the universe), learn to estimate the earth, kingdoms, cities, and himself, at a proper value.

What is man in the midst of the infinite? But to show him another prodigy equally astonishing, let him seek in what he knows things the most minute; let a mite exhibit to him in the exceeding smallness of its body, parts incomparably smaller, limbs with joints, veins in these limbs, bloud in these veins, humors in this blood, globules in these humors, gases in these globules; let him, still dividing these last objects, exhaust his powers of conception, and let the ultimate object at which he can arrive now be the subject of our discourse; he will think, perhaps, that this is the minutest atom of nature. I will show him therein a new abyss. I will picture to him not only the visible universe, but the conceivable immensity of nature, in the compass of this abbreviation of an atom.?

1 This celebrated comparison does not belong to Pascal. It is found in Rabelais, Gerson, Saint Bonaventura, and Vincent de Beauvais. M. Havet, in a learned note, has investigated its origin, and the earliest indication which he has met with is that of Vincent de Beanvais, who attributes it to Empedocles, after the nonk Helinand, a poet and chronicler of the twelfth century. The text of Helinand having been lost, we are unable t' sscertain upon what authority he had himself attributed this definition $t$ Empedocles, whose poem on nature had been long lost. But every thing, .ndicates that there was preserved in the Middle Ages, in a Latin form, a collection of thoughts of the philosophers of antiquity, a colleetion of ancient origin, furnishing many traditions whose source is no longer found.

2 In the various editions we read imperceptible atom, instead of epitome o, an atom; and in this regard, M. Cousin says in h:s Report, page 126 "How often has been cited with admiration this expression already so 
Let him view therein an infinity of worlds, each of which has its firmament, its planets, its earth, in the same proportion as the visible world; and on this earth animals, and in fine mites, in which he will find again what the first have given; and still finding in the others the same thing, without end, and without epose, let him lose himself in these wonders, as astonishing in heir littleness as the others in their magnitude; for who will not marvel that our body, which just before was not perceptible in the universe, itself imperceptible in the bosom of the all, is now a colossus, a world, or rather an all, in comparison with the nothingness at which it is impossible to arrive?

Whoever shall thus consider himself, will be frightened at himself, and observing himself suspended in the mass of matter allotted to him by nature, between these two abysses of infinity and nothingness, will tremble at the sight of these wonders; and I believe that, his curiosity being changed into admiration, he will be more disposed to contemplate them in silence, than to investigate them with presumption.

For, in fine, what is man in the midst of nature? A nothing in comparison with the infinite, an all in comparison with nothingness: a mean between nothing and all. Infinitely far from comprehending the extremes, the end of things and their principle are for him inevitably concealed in an impenetrable secret; equally incapable of seeing the nothingness whence he is derived, and the infinity in which he is swallowed up.

What can he do, then, but perceive some appearance of the midst of things,' in eternal despair of knowing either their

fire: 'in the compass of this imperceptible atom!' What shall we say of this, which is the true reading of Pascal: 'in the compass of this epitome f the abyss?" "

This latter reading is found only in two copies : there is in the manucript an expression which has much more energy, and especially more jropriety, that of "epitome of an asom." The word atom, of which an crror of the copyist has made abyss, is legibly written in the autograph manuscript. $-P$. Faugère.

' We here find that Sir Wiliian Hamilton's doctrine of the Relatively Jouditioned had been distinctly grasped by the marvellous intellect of Pas. cal. Sir William attempted to show that Aristotle had anticipated him in 
principle or their end? All things have sprung from nothingness, and are carried onward to the infinite. Who shall follow this astonishing procession of things? The Author of these wonders comprehends them; no other can.

Through want of having contemplated these infinities, men are rashly borne to the investigation of nature, as if they had some proportion with it.

It is a strange thing that they have wished to comprehend the principles of things, and from thence even to reach a knowledge of all, by a presumption as infinite as their object. For it is unquestionable that such a design cannot be formed without a presumption or capacity infinite like nature.

When we are instructed, we comprehend that nature, having engraved her image and that of her Author upon all things, they almost all participate in her double infinity. Thus we see that all the sciences are infinite in the extent of their researches; for who doubts that geometry, for example, has an infinity of infinities of propositions to exhibit? They are also infinite in the multitude and delicacy of their principles; for who does not see that those which are proposed as the ultimate are not self-sustaining, and that they rest upon others which, having still others for a support, never admit an ultimate?

But we do with ultimates that appear to reason as we do in regard to material things, wherein we call that an indivisible point beyond which our senses perceive nothing more, although it is by its nature infinitely divisible.

Of these two infinites of science, that of magnitude is much more obvious, and therefore it has happened to few persons to pretend to a knowledge of all things. "I am about to speak of all things," said Democritus.'

we thought, although not in its explicit, still less in its differential statenent; but in this language of Pascal, there is a far clearer expression of $\mathrm{t}$; an unmistakable declaration that we can know only the conditioned (milieu des ,hoses), and the relatively conditioned (apparence du milieu des thoses.) $-E d$.

1 After this paragraph, we read in the MS. the following words erased. 
But the infinity ' in littleness is much less discernible. The philosophers have much sooner pretended to arrive at it; and here it is where they all have stumbled. It is what has given place to these very common titles, "Principles of things," "Principles of philosophy," and the like, as ostentatious in reality, although not in appearance, as this other which galls the eye, De omni scibili.

We naturally believe ourselves much more capable of reaching the centre of things than of embracing their circumference. The visible extent of the world obviously surpasses us; but as we surpass little things, we believe ourselves capable of possessing them ; and yet it requires no less capacity to reach nothingness than to reach the all. It requires infinite capacity for either; and it seems to me that whoever should have comprehended the ultimate principles of things might also arrive at a knowledge of the infinite. One depends upon the other, and the one leads to the other.

The extremes touch and unite, by reason of their remoteness from each other, and are found in God, and in God only.

Let us know then our range; we are something and not all. What we have of being deprives us of the knowledge of first principles, which spring from nothingness, and the little that we have of being conceals from us the view of the infinite.

Our intellect holds in the order of things intelligible the same rank as our body in the extent of nature.

Limited in every way, this state which holds the mean between two extremes is found in all our powers.

Our senses perceive nothing extreme. Too much noise deafens us; too much light dazzles us; too much distance or

\footnotetext{
"But besides that it is little to speak of these things simply, without demonstrating and knowing them, it is nevertheless impossible to do it, the infinite multitude of things being so concealed from us that all we can express by words or thoughts is but an invisible fraction of them. Hence it appears how foolish, vain, and ignorant is this title of certain booksle omni scibili."

1 Before these words--but the infinity, we read in the MS. this phrase erased: "We perceive at the first glance that arithmetic alone furnishes properties without number, and each sciance the same."
} 
too much proximity impedes vision; too much length or too much brevity of discourse obscures it; too much trutl astonishes us: I know those who cannot comprehend that when four are taken from nothing, nothing remains. First principles have too much evidence for us. Too much pleasure incommodes. Too much harmony in music displeases; too many benefits irritate': we wish to have wherewith to repay the $\mathrm{debt}^{2}$ : Beneficia eo usque loeta sunt dum videntur exsolvi posse; ubi multum antevenere, pro gratia odium redditur.

We feel neither extreme heat nor extreme cold. Excessive qualities are inimical to us, and not discernible: we no longer feel them, we suffer them. Too much youth and too much age obstruct the mind; too much or too little instruction ${ }^{3}$.... In fine, extreme things are for us as if they were not, and we are not in regard to them: they escape us, or we them.

Such is our true state. This is what renders us incapable of certain knowledge and absolute ignorance. We drift on a vast midst always uncertain and floating, driven from one extreme towards the other. Some term, whereat we think to fix ourselves and become settled, wavers and quits us ; and if we follow it, it escapes our grasp, slips from us, and flies with an eternal flight. Nothing stops for us. This is the state natural to us, and yet the most contrary to our inclination: we burn with desire to find a firm seat and an ultimate constant basis, in order to build upon it a tower that shall reach to the infinite; but our whole foundation cracks, and the earth opens to the abyss. ${ }^{4}$

1 VAR. of MS.: Render us ungrateful (erased).

2 After "the debt," the MS. adds: If it surpasses us, it wounds (erased;. This is a very laconie translation of the citation from Tacitus which follows (Ann., iv, 18).

3 Port-Royal terminates the phrase as follows: stupifies kim.

4 This remarkable passage has undergone many alterations in the edition of P'ort-Royal. We believe we shall afford the reader a pleasure by repeating here the earnest eritieism of M. Cousin. "Port-Royal," he says, "has spoiled this beautiful passage, by arranging it in the following manner which hitherto has been very much admired, and which can no longer be endured as soon as we know the true: "Such is our true state. This is 
Let us scek, then, no assurance, no certainty. Our reason is always deceived by the inconstancy of appearances; nothing can fix the finite between the two infinites that inclose and avoid it.

This being comprehended, I believe we shall be held in repose, each in the state wherein nature has placed him. This mean which has fallen to our lot being always distant from the extremes, what imports it that man may have a little more intelligence of things? If he has, he understands them a little higher. Is he not still infinitely far from the end, and is not the duration of our life, though lengthened by ten years, equally [far] from eternity?

In view of these infinites, all finites are equal; and I see not why we should fix the imagination rather upon one than upon the other. Any comparison that we make of ourselves with the finite gives us pain.

If man studied the first, he would see how incapable he is of passing beyond. How could it be that a part should know the whole? But he will aspire perhaps to know at least the parts with which he has some proportion. But the parts of the world have such a relation and such a connection with

what confines our knowledge within certain limits which we cannot pass, incapable of knowing every thing and of bcing absolutely ignorant of every thing (there is no question of total knowledge or ignorance, but of absolute ignorance or certain knowledge). We are on a vast midst, always uncertain and floating between ignorance and knowledge (this destroys the image commenced: ignorance and knowledge wcre the two extremes of the mean [midst] ) ; and if we think to go farther (there is no question of going further-farther than what?-but of attaching oursclves to a fixed point; Pascal does not speak of an object, but of a point, of a term to which wo attach ourselves), our object wavers and escapes our grasp; it disappeurs anc flies with an eternal flight: nothing can arrest it (Pascal says much more: Nothing stops for us). This is our natural condition, and yet the most contrary to our inclination. We burn with desire to fathom all things there is no question of fathoming all things, nor of going farther, etc., but rif finding a firm seat), and of building a tower that can reach to the infinite ( $f, r$ this it is neessary first to find a firm seat and an ultimate constant Dasis). But all our edifice cracks (not all our edifice, for we have not been able to build one, having no constant basis; it is the very foundatio which we have laid, that cracks), and the earth opens to the abyss." 
each other, that I believe it impossible to know the one without the other and the whole.

Man, for example, is related to whatever he knows. He has need of space to contain him, of time to endure, of motion to live, of elements to compose him, of warmth and aliment to nourish him, of air to breathe. He sees light, he feels borlies; in fine, every thing falls under his alliance.

It is necessary, then, in order to know man, to know whence it comes that he has need of air to subsist; and in order to know air, to know whereby it is related to the life of man, etc.

Flame subsists not without air: therefore to know one, we must know the other.

Hence all things being caused and causing, aided and aiding, mediate and immediate, and all inter-connected ${ }^{2}$ by a natural and imperceptible tie that unites the remotest and most diverse, I hold it impossible $e^{3}$ to know the parts without knowing the whole, any more than to know the whole without knowing the particular parts.

And what completes our impotence to know things is that they are simple in themselves, and that we are composed of two natures opposite and of different kinds-of soul and body. For it is impossible that the part which reasons in us should be other than spiritual; and should it be maintained that we are simply corporeal, this would exclude us much more from the knowledge of things, nothing being so inconceivable as the declaration that matter knows itself. It is impossible for us to know how matter could know itself. ${ }^{4}$

I VAR. of MS.: Under his investigations (crased). Seconv VAR.: Under his dependence (erased).

. Holding themselves together, being in relation.

s VAR. OF MS.: "I hold it impossible to know a single one of them withont all the others, that is purely and absolutely impossible" (erased). In continuation of this paragraph we find the following: "The eternity of things in themselves or in God must still astonish our brief duration. The fixed and constant immobility of nature, $[\mathrm{n}]$ comparison with the continual change that takes place in us, must produce the saine effect" (erased).

- VAR. OF MS.: "What completes our impotence is the simplicity of things compared with our double and composite state. There ar 
And thus, if we are simply material, we can know nothing at all; and if we are composed of mind and inatter, we can have no perfect knowledge of simple things, whether spiritual or corporeal.'

Hence it happens that almost all the philosophers confound the ideas of things, speaking of things corporeal spiritually and of things spiritual corporeally. For they boldly affirm that bodies tend downward, that they aspire to the centre, that they shun destruction, that they abhor a vacuum, that they have inclinations, sympathies, antipathies, - which are all things appertaining to minds. And in speaking of minds, they consider them as in a place, and attribute to them movement from one place to another,-which are things appertaining to bodies.

Instead of receiving ideas of these things in purity, we tinge them with our qualities, and stamp all the simple things that we contemplate [with] our own composite being.

Who, on seeing us compose all things of mind and body, would not believe that we have a clear comprehension of this compound? It is nevertheless the thing that we comprehend the least. Man is to himself the most marvellous object of nature; for he cannot conceive what body is, and still less what mind is, and least of all how a body can be united with a mind. This is the climax of his difficulties, and yet it is his own being: Modus quo corporibus adhoret spiritus comprehendi $a b$ hominibus non potest; et hoc tamen homo est. ${ }^{2}$ In fine, to

cible absurdities to combat this point; for it is as absurd as impious to deny that man is composed of two parts (of different natures), of soul and body. This renders us impotent to know all things; if one denies this composition and pretends that we are wholly corporeal, I leave it to be judged how incapable matter is of knowing matter. Nothing is more impossible than that. Let ns eoneeive, then, how this mixture of mind anel matter disproportions us"' (erased).

1 Vale. of MS. "Things simple; for how eould we know natter disinctly, since our agent. that acts in this knowledge, is in part spiritual and how could we clearly know spiritmal substances, having a budy tha: neighis us down and abases us towards the earth?" (erased).

2 St. Angustine, de Civit. Dei, xxi, 10. 
complete the proof of our weakness, I will finish by these twe considerations.'

II.

I can easily conceive of a man without hands, feet, head, for it is only experience that teaches us that the head is more necessary than the feet. But I cannot conceive of a man without thought,- -it would be a stone or a brute.

9 Greatness and Misery.-Misery being inferred from greatness, and greatness from misery, some have inferred nisery so much the more, as they have taken greatness for its proof; and others, inferring greatness so much the more strongly as they have inferred it from misery itself, all that the one class has been able to say to show greatness has only served as an argument to the other for inferring misery, since it is being so much the more miserable the greater the height is from which we have fallen; and vice versa. They oppose each other in a perpetual circle; being certain that, in proportion as men are enlightened, they find both greatness and misery in man. In a word, man knows that he is miserable: he is therefore miserable since he is so; but he is very great, since he knows it.

T ...If he exalts himself, I abase him; if he abases himself, I exalt him, and perpetually contradict him till he comprehends that he is an incomprehensible monster.

III.

Men, not having been able to cure death, misery, and ignorance, have imagined to make themselves happy by not thinking of these things.

1 VAR. OF MS.: "These are in part the causes that render man so im becile in knowing nature. She is infinite in two ways; he is finite and limited. She endures and perpetually maintains herself in her being; he passes away and is mortal. Individual things corrupt and ehange every moment: he sees them only in passing; they have their principle and end: he conceives neither the one nor the other. They are simple, and he is composed of two different natures; and in order to eonsummate the proof of our weakness, I will end by this refleetion on the state of our nature', (erased). 
IV.

Nature, rendering us always unhappy in onr conditions, ou desires figure to us a happy condition, because they join to the condition in which we are the pleasures of a condition in which we are not; and should we reach these pleasures, we should not be happy on that account, because we should have other desires in conformity with this new condition.

It is necessary to particularize this general proposition. . . .

\section{V.}

Let one imagine a number of men in chains, and all condemned to death, some of whom, being beheaded every day in the sight of the others, those who remain see their own condition in that of their fellows, and, regarding each other with grief, and without hope, await their turn : this is a picture of the condition of men.

\section{VI.}

Cromwell was abolit to ravage all Christendom; the royal family was lost, and his own forever powerful, had it not becn for a grain of sand that got into his ureter. Rome even was about to tremble under him; but this little gravel having got there, he died, his family was abased, peace restored, and the king re-established.

\section{VII.}

The greatness of man is great in that he knows himself miscrable. A tree does not know itself miserable. It is then to be miserable to know ourselves miserable; but it is to be great to know that we are miserable. All these miseries even prove man's greatness. They are miseries of a great lord miseries of a deposed king.

\section{VIII.}

The Greatness of Man.-The greatness of man is so obvious, that it is even deduced from his misery. For what nature is 
to animals, we call misery in man, whereby we recognize that, his nature being now similar to that of animals, he is fallen from a better nature, which was proper to him heretofore.

For who finds himself unhappy in not being a king, except a king dethroned? Was Paulus Emilius unhappy because he was no longer consul? On the eontrary, every one thought him happy in no longer being consul, for it was not his condition to be always consul. But Perseus was so unhappy in no longer being king, inasmuch as his permanent state was that of royalty, that men wondered how he could endure life. Who is unhappy in having but one mouth? and who would not be unhappy in having but one eye? We are, perhaps, never aflicted because we have not three eyes, but we should be inconsolable if we had none.

\section{IX.}

Greatness of Man.-We have such a grand idea of the soul of man, that we cannot endure to be despised by it, or even not to be esteemed by it; and the whole felieity of men consists in this esteem.

The greatest baseness of man is his seeking for glory : but even this is the greatest indication of his excellence ; for, whatever possession he may have on earth, whatever health and essential comfort he may have, he is not satisfied without the esteem of men. He esteems the reason of man so great, that whatever advantage he may have on earth, if he is not also advantageously situated in the reason of man, he is not content. This is the most beautiful situation in the world; nothing can turn him aside from this desire, and it is the most ineffaceable quality of man's heart.

And those who most despise men, and place them on a level with the brutes, still wish to be admired and believed by them, and contradict themselves by their own sentiment; their aature, which is stronger than all, more foreibly convincing them of man's greatness than reason eonvinces them of his baseness. 


\section{$\mathrm{X}$.}

Man is but a reed, the weakest in nature, but he is a thinking reed. It is not necessary that the entire universe arm itself to crush him. A breath of air, a drop of water, suffices to kill him. But were the universe to crush him, man would still be more noble than that which kills him, because he knows that he dies; and the universe knows nothing of the advantage it has over him.'

Our whole dignity consists, then, in thought. Our elevation must be derived from this, not from space and duration, which we cannot fill. Let us endeavor, then, to think well • this is the principle of ethics.

\section{XI.}

It is dangerous to make man see too clearly how nearly equal he is to the brutes, without showing him his greatness. It is also dangerous to make him see too clearly his greatness without his baseness. It is still more dangerous to leave him in ignorance of both. But it is very advantageous to represent to him both. ${ }^{2}$

\section{XII.}

Contrarieties. After having shown the baseness and the greatness of man:-Let man now rightly estimate himself.

1 Among Pascal's most admired passages, there is none more so than that wherein he compares man to a reed, but to a thinking reed. Nothing more complete or finely wrought out has escaped his pen. Pascal has returned twice to this thought; he has not left it till he has given it the last degree of pcrfection. It is curious to find the first and imperfect sketch of it on a corncr of a leaf of manuscript. Here it is with that title which contaius, at first, the entire thought (MS. p. 165): Thinking reed. "It is not in space that I an to seek my dignity, but in the regulation of my thought. I should have no advantage in possessing lands in space; the universe zouprehends me, and swallows me up like a point; by thought I comprebend it."-Cousin.

${ }^{2}$ As a continuation of this paragraph, we read in the copy: "Man mus" aot believe that he is equal with the brutes, nor that he is equal witb angels, nor must he be ignorant of either, but know both." 
Let hin love himself, for he has in him a nature capable of good; but let him not love for this reason what is base therein. Let him despise himself, since this capacity is void; but let him not, on this account, despise the natural capacity itself. Let him hate himself, let him love himself: he has in himself the capacity of knowing truth, and of being happy; but he has no truth, either constant or satisfying.

1 would therefore bring man to desire to find truth, to be ready, and free from passions, to follow it wherever he shall find it, knowing how much his knowledge is obscured by the passions; I would indeed that he hated in himself the concupiscence that determines him of itself, in order that it should not blind him in making his choice, and arrest him when he has chosen.

\section{XIII.}

I equally blame those who determine to praise man, those who determine to blame him, and those who determine to divert him; and I can approve only those who seek in sorrow.

T The stoics say: Enter into yourselves; there you will find your repose: and this is not true. Others say: Go out of yourselves; seek happiness in diverting yourselves: and this is not true. Diseases come: happiness is neither out of us, nor in us; it is in God, both out of, and in us.

\section{XIV.}

Man's nature may be considered in two ways : the one according to his end, and then he is great and incomparable; the other according to the crowd, as we judge of the nature of a horse or a dog, by the habit' of observing his course, et animum arcendi $;{ }^{2}$ and then man is abject and vile. These are the two ways that make philosophers judge diversely, and dispute so keenly. For one denies the assumption of another: one

1. Multitude in the original, for which Bossut substituted habitude.

2 That is, the game-instinct, in allusion to the hunting-dog. 
says, Man is not born for this end, for all his actions are opposed to it; another says, He wanders from the end of his being when he performs these base actions.

T Two things instruct man in regard to his whole natureinstinct and experience.

$X V$.

I feel that I might not have been : for the me consists in my thought; therefore the me that thinks would not have been, if my mother had been killed before I was animated. Therefore I am not a necessary being. Neither am I eternal, nor infinite ; but I see clearly that there is in nature a necessary, eternal, and infinite being.

1 After this first grand sketch of man placed and lost like a point in the bosom of the immensity and splendor of nature, and nevertheless superior to her because he possesses thought, . . . after having shaken as it were at random this thinking reed, and after having seen it floating on the bosom of things, Pascal takes man in himself, and lays bare to him in his mo the natural root of all action, which is a corrupt root.-Sainte-Beuve. 


\section{CHAPTER III.}

[VANITY OF MAN.-EFFECTS OF SELF-LOVE.-THE HUMAN ME.]

I.

$\mathrm{W}_{\mathbf{E}}$ are not contented with the life that we have in ourselves, and in our own being: we wish to live, in the idea of others, an imaginary life, and we constrain ourselves for this end to put on appearances. We labor incessantly to adorn and sustain this imaginary being, and neglect the real one. And if we have either tranquillity, or generosity, or fidelity, we strive to make it known, in order to attach these virtues to this being of imagination: we would sooner cast them off in reality than not to seem to have them; and we would willingly be cowards in order to acquire the reputation of being valiant. Striking mark of the nothingness of our own being,- - not to be satisfied with the one without the other, and often to renounce the one for the other! For, whoever would not die to preserve his honor would be infamous.

T So great is the sweetness of glory, that one loves whatever things it is attached to, even death.

II.

Contradiction.-Pride, counterbalancing all miseries. Either it conceals its miseries; or, if it discover them, it glorifies itself for knowing them.

T Of the desire of being esteemed by those with whom we irre.-Pride holds us with a possession so natural in the midst of our miseries, errors, etc. We even lose life with joy, provided people talk of it.

III.

Vanity is so anchored in the heart of man, that the lowest drudge of the camp, the street, or the kitchen, must boast anc 
have his admirers: and the philosophers themselves desire the same. And those who write controversially wish to have the glory of having written well.; and those who read would have the glory of having read; and I who write this, have, perhaps, this desire; and perhaps those who shall read it. . . .

IV.

Notwithstanding the sight of all our miseries, which touck us, which hold us by the throat, we have an instinct that we cannot repress, that exalts us.

\section{V.}

We are so presumptuous, that we would be known by the whole world, and even by those who shall come when we shall be no more; and we are so vain, that the esteem of five or six persons who surround us amuses and contents us.

VI.

Pride.-Curiosity is but vanity. Oftenest one wishes to know but to talk of it. Otherwise one would not go to sea, if he were never to say any thing about it, and for the sole pleasure of seeing, without hope of ever communicating what he has seen.

\section{VII.}

In the towns through which we pass we do not care to be estecmed; but when we are to remain some time in them, we do care. How long a time is necessary for this? A time preportioned to our vain and pitiful duration.

\section{VIII.}

' The nature of self-love and of this human $\mathrm{ME}$ is to love only self and to consider only self. But what will man do? He knows not how to prevent this object that he loves from

1 This paragraph is not found in the MS. of the Thoughts; most modern editors have nevertheless reproduced it, after a contemporaneous copy. I annot be doubted that it is Paseal's. 
being full of defects and miseries: he wishes to be gruat, and he sees himself small ; he wishes to be happy, and sees himself miserable; he wishes to be perfect, and sees himself full of imperfections; he wishes to be the object of the love and esteem of men, and he sees that his defects merit only their version and contempt. This embarrassment wherein he finds nimself produces in him the most unjust and most criminal passion that it is possible to imagine; for he conceives a mortal hatred of that truth which reproves him, and convinces him of his defects. He desires to annihilate it, and, not being able to destroy it in itself, he destroys it, as far as he can, in his own conscience and that of others: that is, he does his utmost to conceal his defects, both from others and himself, and cannot bear that they should be shown to him, or that they should be seen.

It is doubtless an evil to be full of defects; but it is a still greater evil to be full of them and to be unwilling to acknowledge them, since this is adding to them the farther evil of voluntary illusion. We are unwilling that others should deceive us; we do not regard it as just that they should wish to be esteemed by us more than they deserve: it is equally unust then that we should deceive them, and that we should wish them to esteem us more than we deserve.

Thus, when they manifest only the imperfections and vices that we have in fact, it is evident that they do us no wrong, since they are not the cause of them; and that they do us a good, since they aid us in delivering ourselves from an evil, which is ignorance of these imperfections. We ought not to be displeased that they know them, and that they despise us, it being just both that they should know us for what we are, and that they should despise us, if we are despicable.

Such are the sentiments that would spring from a heart full of equity and justice. What ought we to say then of ours, seeing in it a wholly contrary disposition? For. is it not true that we hate the truth and those who tell it to ns, and that we love to have nen deceive themselves in our favor, and that we wish to he esteemed by them as other than what we are in reality! 
And here is a proof of it that horrifies me. The Catholic religion does not oblige us to discover our sins indifferently to everybody: it allows us to remain concealed to all other men; but it excepts one alone, to whom it commands us to discover the bottom of our hearts, and to show ourselves as we are. To none in the world but this man does the Church order us to reveal ourselves, and she binds him to inviolabl secrecy, whereby this knowledge becomes in him as though it were not. Can any thing be imagined more charitable and more mild? And nevertheless the corruption of man is such, that he still finds severity in this law; and it is one of the principal reasons that has made a great part of Europe revolt against the Church.

How unjust and unreasonable is the heart of man, to be displeased with the obligation to do in regard to one man what it would be just, in some sort, he should do in regard to all men! For is it just that we should deceive them?

There are different degrees in this aversion to the truth: but it may be said that it is in all to a certain extent, since it is inseparable from self-love. It is this wretched delicacy that obliges those who are under the necessity of reproving others, to use so many circumlocutions and palliating expressions in order to avoid shocking them. It is necessary that they should diminish our defects, that they should seem to excuse them, that they should mix with them praises, and protestations of affection and esteem. Even then this medicine does not fail to be bitter to self-love. It takes as little as it can, wnd always with disgust, and often even with a secret spite against those by whom it is administered.

Hence it happens that, if any one has an interest in being esieemed by us, he shrinks from rendering us an office that he knows to be disagreeable to us; he treats us as we wish to be treated: we hate the truth, he conceals it from us; we wish to be flattered, he flatters us; we love to be deceived, he deceives us.

The reason why each degree of good fortune that elevates us in the world removes us farther from truth, is that men arf 
the more apprehensive of wounding those whose affection is more useful and whose aversion is more dangerous. A prince shall be the talk of all Europe, and he alone know nothing of it. I do not wonder at it: to speak the truth is useful to him to whom it is spoken, but disadvantageous to those who speak it, because they make themselves hated. Now, those who live with princes love their own interest more than that of the prince whom they serve; and thus they do not care to secure him an advantage at their own expense.

This evil is doubtless greater and more common in the highest fortunes; but the lowest are not exempt from it, because there is always some interest in making ourselves esteemed of men. Thus human life is but a perpetual illusion; men do nothing but mutually deceive and flatter each other. No one speaks of us in our presence as he speaks of us in our absence. The union that exists among men is founded upon this mutual deception; and few friendships would subsist if each one knew what his friend says of him when he is absent, although he then speaks of him sincerely and without passion. Man is therefore only dissimulation, only falsehood and hypocrisy, both in himself and in regard to others. He does not wish that the truth should be told him, he avoids telling it to others; and all these dispositions, so far removed from justice and reason, have a natural root in his heart. 


\section{CHAPTER IV.}

[IMAGINATION.-UNCERTAINTY OF MAN'S NATURAL KNOWLEDGE.-CUg1OM -PYRRHONISM.—ETHICS.]

Imagination.-It is that deceptive part in man, that mistress of error and falsehood, and so much the more deceitful as she is not always so ; for she would be an infallible rule of truth, if she were an infallible one of falsehood. But being most frequently false, she gives no mark of her quality, marking with the same character the true and the false.

I do not speak of fools, I speak of the wisest; and it.is among them that the imagination has the greatest power of persuading men. Reason eries out in vain, she cannot give to things their value.

This haughty power, the enemy of reason, which she delights in controlling and domineering, in order to show how much influence she has in all things, has established in man a second nature. She has her happy, her unhappy, her healthy, her sick, her rich, her poor; she causes belief, doubt, denial of reason; she suspends the senses, she makes them feel; she has her fools and her sages: and nothing distresses us more than to see that she fills her guests with a satisfaction far more full and complete than reason. The strongly imaginative are far more pleased with themselves than the prudent rationally can be. They regard people imperiously; they dispute with boldness and confidence; others, with fear and diffidence : and this gayety of visage often gives them the advantage in the opinions of the hearers, so much favor have the imaginary sages with judges of the same nature. Imagination cannot make fools wise; but she makes them happy, in emulation with reason, who can $\cdot$ only make her friends miserable, - the one covering her votaries with glory, the other with shame. 
Who dispenses reputation? who gives respect and veneration to persons, to works, to laws, to the great, except this faculty of the imagination? All the riches in the world are insufficient without its consent.

Would you not say that yonder magistrate, whose venerable old age imposes respect upon a whole people, is governed by a pure and sublime reason, and that he judges of things by their nature, without stopping at those vain circumstances which only wound the imagination of the weak? See him on his way to church, influenced alike by devotion and zeal; the solidity of his reason strengthened by the ardor of love. Behold him ready to listen with an exemplary respect. Let the preacher appear: if nature has given him a rough voice and a comic face, ill shaved by the barber; if furthermore he has by chance been bespattered, however great the truths that he announces, I wager that our senator will lose his gravity.

The greatest philosopher in the world, on a plank wider than necessary, 'if there is a precipice beneath him, although his reason convinces him of his safety, his imagination will prevail. Some could not bear the thought of it without turning pale and perspiring.

Who does not know that the sight of cats, of rats, the crushing of a coal, ete., unhinges the reason? The tone of voice imposes on the wisest, and alters the effect of a discourse or a poem.

Affection or hatred makes justice shift face; and how much more just does the advocate, well paid in advance, find the cause that he pleads! how much better does his bold gesture make it seem to the judges duped by this appearance! Ridiculous reason, turned by every wind, and in every direction!

I do not wish to refer to all its effects; I should refer to almost all the actions of men who are influenced by little else. For reason has been obliged to yeld, and the wisest takes for

'VAR. or MS.: "Wider than the road he usually occupies in walking" (erased). 
his principles those that the imagination of men has rashly introduced in each locality.'

Our magistrates have clearly understood this mystery. Their red robes, their ermine, with which they swathe themselves like furry cats, the paląces where they sit in judgment, the emblems of authority,-all this august apparel was very necessary; and if physicians had not had gowns and mules, and the doctors square hats and robes four times too ample, they never would have duped the world, which cannot resist such an authoritative parade. Soldiers alone are not disguised in this sort, because, in fact, their part is more essential : they establish themselves by force, the others by grimace.

Thus it is that our kings have not sought these disguises. They have not masked themselves in extraordinary habits in order to appear such $;^{2}$ but they have surrounded themselves with guards and halberds-those armed automatons that have hands and force only for them, the trumpets and drums that march before them, and those legions that encompass them, make the firmest tremble. They have not only the habit, they have the power. It would require a very unimpassioned reason to regard as an ordinary man the Grand Seignior surrounded, in his superb seraglio, by forty thousand janissaries.

If they had ${ }^{3}$ true justice, if physicians had the true art of healing, they would have nothing to do with square hats: the majesty of these sciences would be sufficiently venerable of itself. But having only imaginary sciences, they take these

1 As a continuation of this paragraph Paseal had put: "It is necessary -o toil all the day for goods acknowledged to be imaginary; and when 3lecp has restored the weary powers of reason, it is necessary straightway 0 arise and chase the shadows and efface the impressions of this mistress of the world."

2 Such, that is, Kings. Pascal has several times repeated this thought; ke says again at page 283 of the MS.: "The Chancellor is grave and clothed with ornaments, for his post is false, and not the king; he has power, but nothing to do with imagination. Judges, physicians, etc., have nothing brtt imagination."

3 It is evident that magistrates and not kings are meant. 
rain instruments that strike the imagination with which they have to do; and thereby, in fact, they attract respect.

We cannot even look upon an advocate in gown and square hat, without a favorable opinion of his merit.

The imagination disposes of every thing; it makes beanty, justice, happiness, which is every thing in the world. I should like much to see the Italian book, of which I know nothing but the title, which is alone worth many books : Della opinione regina del mondo. I indorse it without knowing it, save the evil, if there is any in it.

Such are very nearly the effects of this deceptive faculty which seems to have been given us expressly to lead us into necessary error. We have many other principles pertaining to it.

Old impressions are not the only ones capable of leading us astray: the charms of novelty have the same power. Hence arise all the disputes of men, who reproach each other eithc: with following false impressions from infancy, or with rashly running after new ones. Who holds the just mean? Let him appear, and let him prove it. There is no principle, however natural it may be, even from infancy, that could not be made to pass for a false impression, either of instructior, or of the senses. Because, it is said, you have supposed from infancy that a chest is empty when you see nothing in it, you have supposed a vacuum possible; it is an illusion of your senses, strengthened by custom, which science must correct. And others say: Because you have been told in the schools that there is no vacuum, your common-sense has been corrupted, which so clearly comprehended it before this false impression, which must be corrected by recurring to your primary nature, Which, then, has deceived? the senses or instruction?

We have another principle of error,--maladies. They spoil for us the judgment and the senses, and if great diseases sensibly change us, I doubt not that smal' ones make an impression proportioned to their magnitude.'

1 "Et ne fault pas doubter, encores que nous re le sentions pas, jue ai 
Our own interest, again, is a marvellous instrument for putting out our eyes agreeably. It is not permitted to the most equitable of men to be a judge in his own eause: I know men who, in order not to fall into this self-love, have been the most unjust by a contrary bias. The surest means of losing a really just cause was to get it recommended to them by their near relatives. Justice and truth are two points so subtile, that our instruments are too blunt to touch them with precision. If they are rightly aimed, they crush the point, and, also striking the surrounding surface, hit the false more than the true.

\section{II.}

The most important thing in life is the choice of an occupation : chance decides it. Custom makes masons, soldiers, tilers. That is an excellent tiler, men say; and, speaking of soldiers: They are indeed fools, they say. And others, on the contrary: There is nothing great but war; the rest of men are contemptible. By dint of hearing these oceupations praised in infancy, and all others contemned, a choice is made; for, naturally, we love virtue, and hate folly. These words influence us: onc errs only in the application of them. So great is the force of custom, that of those whom nature has made only men, arc made all conditions of men; for the inhabitants of some coun. tries are all masons, of others all soldiers, etc. Unquestionably nature is not so uniform. It is custom, then, that does this, for she constrains nature; and sometimes nature surmounts her, and retains man in his instinet, in spite of all custom. good or bad.'

\section{III.}

Our imagination so magnifies the present time, by continually reflecting upon it, and so diminishes eternity, by not re-

Ia fiebvre continue peult atterrer nostre ame que la tieree n'y apporte quelque alteration selon sa mesure et proportion."-Montaigne.

1 As a continuation of this paragraph we read in the MS.: "Men naturally tilers, and of all vocations except in-door ones." Although this phrase is not erased, we think it ought to be separated from the text, on sceount of its obscurity. 
flecting upon it, that we make a nothingness of etcr ity, and an eternity of nothingness, and all this has its roots so vital in us, that our reason cannot defend us from it, and that . . . .

\section{IV.}

... On what will he [man] found the economy of the world which he wishes to govern? Will it be on the caprice of each individual? What confusion! Will it be on justice? He is ignorant of it.

Certainly if he knew it, he would not have established this maxim, the most general of all that prevail among men, that each follow the customs of his country ${ }^{\prime}$ the splendor of true justice would have subjected all peoples, and legislators would not have taken as a model, instead of this constant justice, the fancies and eaprices of Persians and Germans. We should see it planted in all the States of the world and in all times, instead of which we see scarcely any thing just or unjust that does not change quality in changing climate. Three degrees of higher latitude overturn all jurisprudence. A meridian decides the truth; fundamental laws change in a few years; right has its epochs. The entrance of Saturn into the constellation of Leo marks for us the origin of such a crime. Pitiable justice, bounded by a river! ${ }^{2}$ Truth this side the Pyrenees, error that side.

1 "La droicture et la iustice, si l'homme en cognoissoit qui eust corps et veritable essence, il ne s'attacheroit pas à la condition des coustumes de cette contree ou de celle là." -Montaigne.

2 VAR. OF MS.: "Which the crossing of a river makes a erime." The idea is taken from Montaigne, who says: "Quelle verité est ce que ees montaignes bornent, mensonge au monde qui se tient au delà ?" The whole of this passage has evidently been inspired by the author of the $E_{\text {s- }}$ bays. " Montaigne," says Sainte-Beuve, "may be studied in Pascal. II was for him at eertain hours the fox of the Lacedemonian youth, the fox coneealed beneath the robe. Paseal was often scized, bitten, and devoured by him. In vain he erushes him; rejeets him; the sly old fox always returns. He is disturbed by him, eites him, sometimes transeribes him it the tissue of his own Though ${ }^{2} s$, of whieh his friends were unaware in theig ¿dition: phrases of Montaigne's have been left as being Paseal's." *

* Or at least we have the thought more briefly stated by Pascal_-Sainte-Beuva 
They confess that justice is not in these customs, but that it resides in natural laws, known in every country. Certainly they would maintain it obstinately, if the temerity of chanee that has sown human laws had encountered at least one that was universal; but such is the ridiculous pass, that the caprice of men has so well diversified itself, that there is none.

Theft, incest, infanticide, parricide, all have had their placc among virtuous actions. Can any thing be more ridieulous than that a man has a right to kill me because he dwells the other side of the water, and because his prince has a quarrel with mine, although I have none with him?

There are, doubtless, natural laws; but this fine corrupted reason has corrupted every thing: Nihil amplius nostrum est; quod nostrum dicimus, artis est.-Ex senatus consultis et plebiscitis crimina exercentur.-Ut olim vitiis, sic nunc legibus laboramus.

From this confusion it arises that one says that the essence of justice is the anthority of the legislator; another, the convenience of the sovereign; another, present custom, and this is the safest: nothing, if we follow reason alone, is just in itself; every thing gives way with time. Custom makes all equity, for the sole reason that it is received; it is the mystic foundation of its authority. Whoever traces it back to its principle annihilates it. Nothing is so faulty as those laws that redress faults; whoever obeys them because they are just, obeys the justice that he imagines, but not the essence of the law: it is wholly collected in itself; it is law, and nothing more. Whoever will examine its principle will find it so weak and frivolous, that, if he has not been aecustomed to contemplate the prodigies of the human imagination, he will wonder how an age ean have acquired for it so much pomp and roverenee. The art of revolutionizing, overturning States, is to undermine established customs, by going baek to their origin, in order to mark their want of justice. We must reenr, it is said, to the fundamental and primitive laws of the State, which an unjust eustom has abolished. It is a game where you are sure to lose every thing; nothing will be just at this rate. Nevertheless 
people lend a willing ear to such discourses. They throw off the yoke as soon as they perceive it; and the great profit by it to ruin them and these curious examiners of received customs. But, by an opposite error, men sometimes think they are able to do with justice whatever is not without precedent. This is why the wisest of legislators said that, for the good of men, it is often necessary to deceive them ;' and another, ${ }^{2}$ very politic: Quum veritatem qua liberetur ignoret, expedit quod fallatur. It is not necessary that he feel the truth of the usurpation; it was formerly introduced without reason, and has become reasonable; it is necessary to make it regarded as authentic, eternal, and to conceal its commencement, if we do not wish it soon to come to an end.

\section{V.}

The mind of the supreme judge of the world ${ }^{3}$ is not so independent as not to be liable to be disturbed by the least uproar that is made about him. It does not need the report of a canl. non $t s$ disturb his thoughts: the creaking of a vane or pulley is quite enough. ${ }^{4}$ Do not wonder that he reasons ill just now ; a fly is buzzing in his ear: it is enough to render him incapable of sound judgment. If you are desirous that he should find the truth, drive away that insect, which suspends his reasoning powers, and frets that mighty mind which governs cities and kingdoms. Here is a pretty god, indeed! $O$ ridicolosissimo eroe!

1 " Platon triacte ce mystere d'un ieu assez descouvert ..... Il dict tout destrousseement, en sa Republique; Que pour le proufit des hommes, il est nouuent besoing de les piper."-Montaigne.

2 Varro, eited by Saint Augustine, De Civ. Dei, iv, 27. Here is the entire phrase: "Praclara religio, quo confugiat liberandus infirmus, et quum veritatem, etc.-A fine religion for a sick man to go to in search of his health, and that while he demands a truth that will cure him, is told that it is to his advantage to be deceived!"-Huvet.

3 VAr. of MS.: "The sovereign inte"ligence of this monarch of the universe" (erased).

4 "Ce ne sont pas seulement . . . les grands aceidents qui renversent nosre ingemont, les moindres choses du n.Jnde le tournevirent."-Mortatiyne. 


\section{VI.}

Montaigne is wrong ${ }^{1}$ in declaring that custom ought to be followed simply becanse it is custom, and not because it is reasonable or just; but the people follow it for the sole reason that they believe it just: otherwise, they would not follow it, although it were custom; for men wish to be subject only to reason or justice. Custom, were not this the case, would pass for tyranny; but the empire of reason and justice is not more tyrannical than that of pleasure: these are principles natural to man.

It would be good, then, that we should obey the laws and customs, because they are laws; that we should know that there is none true and just to be introduced; that we know nothing of them, and that thus it is.only necessary to follow the received; by this means, we would never quit them. But the people are not susceptible of this doctrine; and thus, as they suppose the truth may be found, and that it is in laws and customs, they have faith in them, and take their antiquity as a proof of their truth, and not simply of their authority without truth. Thus they obey them; but they are liable to revolt as soon as they are shown that laws and customs are worth

1 "Is wrong" is the text of the MS. Montaigne, who is very ineonsistent, eontinually wavers in his skepticism, and he says sometimes that eustom is right, and that this is why we follow it. Pascal rectifies Montaigne here; he reproaches him for this concession, and maintains that the foree of enstom springs from itself, that is, from the nere weakness of man. We have seen that Arnanld eites this thought, or some other of the same kind, as an example of those that require to be modified, and aro indefensible; we have also seen Marguerite Périer submitting to her brother the Abbé Périer, the difficulties provoked by this passage, as well as the new reading proposed by Arnanld: "Montaigne is not wrong when he says that enstom ought to be followed beeause it is custom, ete., provided it is understood of things not opposed to natural and divine right. It is true shat, etc..." Bossut again modifies the reading of Port-Royal (1 ${ }^{\text {re }}$, part. ix, 43). "Montaigne $i$; right: custom ought to be followed, becanse it is eustom, and because it is found established, without examining whether it is reasonable or not; it being always understood that it is nob sontrary to natural or divine right."-Cousin. 
nothing; as all may be shown to be, by regarding them on a certain side.

T Iniustice.-It is dangerous to tell the people that laws are not just; for they obey only for the reason that they think them just. Hence they must be told at the same time that they must obey them because they are laws, as they must obcy superiors, not because they are just, but because they are superiors. All sedition is prevented, then, if we can make this understood, and it is, properly speaking, the definition of justice.

\section{VII.}

There is a universal and essential difference between actions of will and all others.

Will is one of the principal organs of belief; not that it forms belief, but because things are true or false, according to the side on which we look at them. The will, that is more pleased with one than with another, hinders the mind from considering the qualities of those that it dislikes to see; and thus the mind, keeping pace with the will, fixes its attention upon the side that it likes, and thus it judges by what it sees in that.

\section{VIII.}

The imagination magnifies little objects till they fill the soul, by a fantastic estimation; and, by an insolent temerity, it diminishes great objects to its own measure, as in speaking of God.

\section{IX.}

Weakness.-All the occupations of men are for the getting of property; and it would be impossible for them to show that they possess it justly, for they have only the fancy of men;

1 Nicole severely condemned this thought, and he was right. In saying that, only the fancy of men has established the right of property, Paseal completely loses sight of the Christian law which forbids not only the taking of the goods of others, but even the eoveting of them, which certainly does not imply that, according to this holy law, to possess is an injustice. We say it with regret, but however great our respeet for Pascal, it appear 
nor have they the power to possess it securely. It is the same with science, for disease takes it away. We are incapable both of truth and of good.'

$\mathrm{X}$.

What are our natural principles except our accustomed principles? And in children, those that they have received from the custom of their fathers, as the chase in animals.

A different custom will-give other natural principles. This i: seen by experience; and if there are natural principles ineffaceable by custom, there are also those of custom contrary to nature, ineffaceable by nature, and a second custom. This depends on the disposition.

T Fathers fear lest the natural love of children should be effaced? What is, then, this nature liable to be effaced? Custom is a second nature that destroys the first. Why is not custom itself natural? I am very much afraid that this nature is itself but a first custom, as custom is a second nature.

\section{XI.}

If we dreamed every night the same thing, it would affect us as much as the objects that we see every day; and if an artisan were sure of dreaming every night, during twelve hours, that he is a king, I believe he would be almost as happy as a king who should dream every night, during twelve hours, that he is an artisan.

If we dreamed every night that we were pursued by enemies, and agitated by these painful fancies, and were our days passed in different occupations, as on a journey, we should suffer almost as much as if this were true, and we should apprehend sleep as we apprehend waking when we fear to enter upon

\footnotetext{
" us that, from this maxim, Men do not possess by justice, to this other naxim, Property is theft, the distance is not very great.

1 Here, again, it appears to us that Paseal is entirely out of the way. fcr, if nian is really ineapable of good, wherefor should God have com. manded lim to do good? and whereunto would serve the preects of reli -ion? whereunto would serve grace itself?
} 
such misfortunes in reality. And, in fact, it would produce nearly the same ills as the reality. But inasmuch as dreams are different, and the same dream is varied, what we see in them affects us less than what we sce waking, on account of the continuity, which, nevertheless, is not so continuous and equal that it does not also change, but less abruptly, except rarely, as when we are journeying, and then one says, it seems to me that I am dreaming, for life is a somewhat less inconstant dream.

\section{XII.}

'Against Pyrrhonism.-... We suppose that all conceive them in the same manner; but this is a very gratuitous supposition, for we have no proof of it. I see clearly that these words are applied on the same occasions, and that, whenever two men see a body change place, they both express the view of the same object by the same word, both saying that it has moved; and from this conformity of application is deduced a strong conjecture of a conformity of idea; but this is not absolutely convincing, with the last degree of conviction, although there is a stroug presumption in the affirmative; since we know that the same consequences are often deduced from different suppositions.

This is sufficient for at least entangling the matter; not that this absolutely extinguishes the natural clearness which assures us of these things (the academicians ${ }^{2}$ would then have been in the right); but this tarnishes it, and troubles the dogmatists, to the glory of the Pyrrhonist cabal, which consists in this double ambiguity, and in a certain doubtful obscurity, of which

1 This passage began in these words: "It is then a strange thing that we cannot define these things without obscuring them" (erased).

2 There are some philosophers who have made denying their profession, and who have even established on that foundation the whole of their philosorlyy; and among these philosophers some are satisfied with denying certainty, admitting at the same time probability, and these are the New Academics: the others, who are the Fyrrhonists, have denied even this probability, and have maintained that all things ase equally certain and uncertain.-(Port-Royal Logic, part iv, chap. i.) - Ed. 
our doubts cannot remove all the clearness, nor our natural light dispel all the darkness.

\section{XIII.}

Spongia solis.'-When we see an effect always taking place in the same manner, we conclude that there is a natural necessity for it, as, that the sun will rise to-morrow, etc.; but nature often deceives us, and does not bow to her own laws.

\section{XIV.}

Contradiction is a bad mark of trutt:

Many things that are certain are comradicted, many that are false pass without contradiction: neither is contradiction a mark of falschood, nor non-contradiction a mark of truth.

XV.

The world judges well of things, for it is in natural ignorance, which is the true state of man. The sciences have two extremes that meet: the first is the pure natural ignorance wherein all men are found at birth. The other extreme is that reached by great souls, who, having run over all that men can know, find that they know nothing, and meet again in that same ignorance whence they set out. ${ }^{2}$ But it is a learned ignorance that knows itself. Those between the two, who have left natural ignorance, and have not been able to reach a learned ignorance, have some tincture of this sufficient science, and

1 Spots on the Sun. Pascal doubtless meant by this strange title to express the idea that we are perhaps wrong in believing that the sun will rise to-morrow, as it rose to-day, since the spots on it might extinguish its lighi, and thus nature might deceive us.

2 '"Il se peult dire, aveeques apparence, qu'il y a ignoranee abecedaire, qui va devant la science, aultre doctorale, qui vient aprez la science, ete. Les païsans simples sont honnestes gents, et honnestes gents les philosophes, ou selon que nostre temps les nomme, des natures fortes et claires, enrichies d'une large instruction de scienees ntiles: les mestis, qui on desdaigné le prennier siege de l'ignorance des lettres, et n'ont pu ioindro l'aultre (le cul entre deux selles, desquels ie suis et tant d'aultres), sont langere $\mathrm{ix}$, inejtes, importuns ; ceulx-cy troublent le monde."-Montaigne. 
constitute the class of the conceited. These trouble the world, and judge ill of every thing. The people and the capable, keep the world going; the conceited despise it, and are despised. They judge ill of all things, and the world judges rightly of them. ${ }^{1}$

1 There are two sorts of Ignorance: we philosophize to eseape ignorance, and the consummation of our philosophy is ignorance; we start from the one, we repose in the other; they are the goals from which, and to which, we tend; and the pursuit of knowledge is but a course between two ignorances, as human life is itself only a wayfaring from grave to grave. Wo never can emerge from ignorance. If, as living creatures,

"We are such stuff

As dreams are made of, and our little lifo

Is rounded with a sleep ;"

Bo, as cognizant intelligenees, our dream of knowledge is a little light, rounded with a darkness. Cire mortal, one nation or generation of mortals, may flare a flambeau, and ancther twinkle a taber; still the sphere of human enlightenment is at best a point, con. ared with the boundless universe of night surrounding it. Seienec is a drop; nescience is the ocean in which that drop is whelmed.

The highest reach of human science is indeed the scientific recognition of human ignoranee: "Qui neseit ignorare, ignorat scire." This "learned ignorance" is the rational conviction by the human mind of its inability to transcend certain limits; it is the knowledge of ourselves,--the seienee of man. This is accomplished by a demonstration of the disproportion between what is to be known, and our faculties of knowing,--the disproportion, to wit, between the infinite and the finite. In fact, the recognition of human ignorance, is not only the one highest, but the one true, knowledge; and its first fruit, as has been said, is-humility. Simple nescience is not proud; consummated science is positively humble. For this knowledge it is not which "puffeth up;" but its opposite, the conceit of false knowledge,-the conceit, in truth, as the Apostle notices (1 Cor. viii. 2), of an ignorance of the very nature of knowledge:

"Nam nesciens quid scire sit,
Te scire cuncta jactitas."

But as our knowledge stands to Ignoranee, so stands it also to Doubt Doubt is the beginning and the end of our efforts to know ; for as it is true,-_"Alte dubitat qui atius credit," so it is likewise true,-" Quo magis quærimus magis dubitamus."-Doubt is even divinely enjoined on us as a duty. For the eommand of the Apostle,_- "Prove (test) all things," involves the correlative injunetion, $-D_{0}=3 \mathrm{t}$ all things. And Bacon (or Church Controversies) truly says :- "There cannot be a 'quod bonum est tenete,' without an 'omnia probate' going before."

The grand result of human wislom, is thus only a consciousness that 
XVI.

Man is but a being filled with error. This error is natural, and, without grace, ineffaceable. Nothing shows him the truth: every thing deceives him. These two principles of truth, reason and the senses, besides lacking sincerity, reciprocally deceive each other. The senses deceive reason by false appearanees; and just as they cheat reason they are clieated by her in turn: she has her revenge. Passions of the soul trouble the senses, and give them false impressions. They emulously lie and deceive each other. ${ }^{1}$

\section{XVII.}

What most astonishes me is to sce that all men are not astonished at their weakness. Men art seriously, and each follows his calling (not because it is good in reality to follow it), since such is the fashion; but as if each one knew certainly where reason and justice lie. Men find themselves deceived at every hour: and, by a ridiculous humility, believe that it is their fault, and not that of the art they always boast of possessing. But it is guod that there are so many of these people in the world, who are not Pyrrhonists, for the glory of Pyrrhonism, to the end of showing that man is very capable of the most exiravagant opinions, since he is capable of believing that he is not in this natural and inevitable weakness, and of believing that he is, on the contrary, in natural wisdom.

Nothing strengthens Pyrrhonism more than what is Pyrrhonic in those who are not Pyrrhonists: if all were Pyrrhonists, they would be wrong.

what we know is as nothing to what we know not ("Quantum est quod nescimus !") -an articulate confession, in fact, by our natural reason, of the truth declared in revelation,-_ "that now we see through a glass, darkly." -(Sir Wm. Hamilton, Discussions, Socond London Edition, pp. 634, (i3) 5.$)-E d$.

1 " 'ttte mesme piperie que les sens apportent à nostre entendment, ils he recoivent à leur tour; nostre ame parfois s'en revenche de mesme: its "uentent et se trompent à l'envy."-Montaigne. 


\section{XVIII.}

This sect is strengthened more by its enemies than by its friends; for the weakness of man is much more manifest in those who are ignorant of it, than in those who know it.

- If one is too young, he does not judge well; too old, the same; if one does not give the matter sufficient thought... ; if one thinks upon it too much, he becomes dogmatic, and makes a hobby of it. If one considers his work immediately after having performed it, he is still wholly preoccupied with it; if too long afterwards, he no longer enters into its spirit. So with pictures, seen too far off or too near; there is only an indivisible point that is the true place: other points are too near, too far off, too high, or too low. Perspective assigns it in the art of painting; but in truth and ethics, who shall assign it?

\section{XIX.}

Those who lead irregular lives say to those that are living orderly, that it is they who abandon nature and believe they are following her: as those who are on a ship believe that those on shore are receding. The language is the same on both sides. It is necessary to have a fixed point in order to judge. The port judges those who are on the ship; but wherr shall we find a stand-point in ethics? 


\section{SiAPTER V.}

[INQUIETUDE OF MAN.—OCCUPATIONS AND AMUSEMENTS.]

I.

We never confine nurselves to the present time. We anticupate the future as too slow in coming, as it were, to hasten its course; or we recall the past, in order to stop it as too ready to go: so imprudent, that we wander into times that are not ours, and do not think on that alone which belongs to us; and so vain, that we meditate upon those periods that have vanished, and allow the sole moment that subsists to escape without reflecting upon it. It is only the present time that ordinarily wounds us. We conceal it from our view, because it afflicts us; and if it is agreeable to us, we regret to see it escape. We strive to prolong it by the future, and think to dispose of things that are not in our power, for a time at which we have no assurance of arriving.

Let each one examine his own thoughts; he will find them always occupied with the past and the future. We scarcely think of the present; and if we do think of it, it is only to take its light in order to dispose of the future. The present is never our end; the past and the present are our means; the futurs alone is our end. Thus we never live, but we hope to live; and always disposing ourselves to be happy, ${ }^{1}$ it is inevitable that we never become so.

\section{II.}

Men are charged, from their infancy, with the care of their honor, of their property, of their friends, and also with the

1 We are reminded of Pope's line:

"Man never is, but always to be blessed."-Ed. 
property and honor of their friends. They are overwhelmed with affairs, with apprenticeship to languages and sciences, and are taught that they cannot be happy unless their health, their honor, their own and their friends' fortunes, are in a good con dition, and that the failure of any one of these things would render them unhappy. Thus they are given cares and occupa tions that keep them busy from morning till night. This, you will say, is a strange way of rendering them happy! What more could be done to render them unhappy? How! what could be done? It would only be necessary to take from them all these cares; for then they would see themselves, they would think on what they are, whence they come, whither they go; and thus they cannot be too much occupied and distracted; and accordingly, after having been provided with so many affairs, if they have some time for relaxation, they are counselled to employ it in diverting themselves, in playing, and in occupying themselves constantly and wholly.'

T Amusement. ${ }^{2}$-When I have sometimes set myself to consider the various agitations of men, and the perils and pains to which they expose themselves, in the court, in war, whence spring so many quarrels, passions, bold and often criminal enterprises, I have often said that all the unhappiness of men comes from a single thing, which is, that they have not the wisdom to remain in tranquillity at home. A man who has property enough to live, if he could remain at home with pleasure, would not go abroad for adventures on the sea or at a siege. A man purchases a post in the army at a high price only because he finds it insupportable not to leave the town; and conversation and the distractions of play are sought only because people cannot remain at home with pleasure.

1 On the margin of the MS.: How hollow and full of ordure is the heart of man!

2 By this'word, amusement, which is found ir. the MS. repeated at the head of several fragments, Paseal makes allusion to the need felt by men of occupying or amusing themselves, ir order not to think of the problem of the present life, and the mysteries of the life to come. This is the meaning of this paragraph and all thos that $b$ ar the samo title. 
But when I have thought more closely on the matter, and, after having found the more obvious cause of our ills, have endeavored to discover their reason, I have found that there is a very effective one, which consists in the natural evil of our feeble and mortal condition, - a condition so miserable that nothing can console us when we consider it closely.

Whatever condition one imagines for himself, if one collects all the goods that car belong to us, royalty is the finest position in the world, and nevertheless let one imagine to himsel. [a king] accompanied by all the satisfactions his state can furnish ; if he is without amusement, and is left to consider and reflect upon what he is, this languishing felicity will not sustain him; he will fall by necessity into various forebodings, as of revolts that may happen, in short, of death and maladies that are inevitable; so that, if he is without what is called amusement, he is unhappy, and more unhappy than the least of his subjects who plays and diverts himself.

Hence it comes that play, and the conversation of women, war, high employments, are so much sought after. Not that there is in fact happiness in them, nor that one imagines true happiness to be in the money that may be gained by play, or in the hare that is chased. Nothing of this kind would be accepted were it offered. It is not this quiet effeminate life allowing us to think on our unfortunate condition, that we seek, nor the dangers of war, nor the pain of employments, but the confusion which keeps us from thinking on our condition and diverts us.'

Hence it comes that men are so fond of noise and commotion; hence it comes that imprisonment is such a horrible punishment; hence it comes that the pleasure of solitude is something incomprehensible. And it is, in short, the main source of felicity in the condition of kings, that those about them unceasingly strive to divert them, and procure them all sorts of pleasures.

\footnotetext{
jame.

1 On the margin of the MS.: Reason why we love the chase more than the
} 
A king is surrounded by people who think only of tiverting him, and hirder him from thinking on himself. For he is un happy, king as he is, if he thinks on his own condition.

This is all that men have been able to invent to make them selves happy. And those who philosophize upon the matter, and believe that the world is very irrational to spend a whole day in running after a hare that they would not have purchased, know but little of our nature. This hare would not secure us from the view of death and the miseries that turn us aside from it,' but the chase does secure us from them. And thus, when they are reproached for seeking with so much ardor what can give them no satisfaction, if they responded, as they should do if they considered the matter well, that they seek in this only a violent and impetuous occupation which keeps them from thinking on themselres, and that in this they propose to themselves an attractive object which charms and attracts them with ardor, they would leave their adversaries without reply. ${ }^{2}$ But they do not respond thus, because they know not themselves ${ }^{3}$ they know not that it is only the chase, and not the taking of the game, that they seek.

T They imagine that, if they had obtained this post, they would then settle down in content, and do not feel the insatiable nature of their cupidity. They believe they are sincerely seeking repose, and are seeking in reality only agitation.

They have a secret instinct that leads them to seek external distraction and occupation, which springs from the sense of their continual miseries; and they have another secret instinet,

1 These words, "that turn us aside from it," are found in the MS. We thought it our duty to reproduee them, notwithstanding their obseurity. We think, howeva, they may be understood thus: "This hare sceures us : either from the view of death, Lor the chagrins (the miseries) of thinking if death, but the enase does secure us from them. Thus we are distracted rom the thoughts of death, and from the misuries that turn us aside from this thought, by the ehase."

2 On the margin of the MS.: The dance. We onust mind where we put nur feet.

3 On the margin of the MS.: The gentleman really believes that the shase is a high and royal amusement; but his huntsman does not think so 
which remains from the greatness of our first nature. which tells them that happiness is, in fact, only in repose, and not in tumult; and of these two contrary instincts there is formed in them a confused project, which is eoneealed from their view in the depths of their soul, which leads them to seek repose through agitation, and always to imagine that the satisfaction which they have not will come to them, if, surmounting a few difficulties that they face, they can thereby open for themselves the gate to repose.

Thus glides all life away. We seek repose in combating a few obstacles; and if we have surmounted them, the repose becomes insupportable; for, we either think on the miseries that we have, or on those that threaten us. And even were we sufficiently protected on all sides, ennui, deprived of its authority, would not fail to come out from the depths of the heart, where it has its natural roots, and fill the mind with its venom.

The counsel given to Pyrrhus, to take the repose that he was about to seek with so much fatigue, admits of many difficulties.

Thus man is so unhappy, that he is even wearied without any cause of weariness, by the peculiar eondition of his constitution; and he is so vain that, filled with a thousand essential causes of weariness, the least thing, as a game of billiards,' suflices to divert him.

But, you will say, what object has he in all this? That of boasting to-morrow among his friends that he has played better than another. Thus others sweat in their closets in order to show to the learned that they have resolved an algebraical problem for the first time; and so many others expose themselves to extreme perils in order to boast afterwards of having taken a place, and as foolishly, in my opinion. And, in fine, (thers wear themselves out in studying all these things, not in order to become more wise, but simply to show that they know them; and these are the most foolish of all, since they are

1 VAR. OF MS.: "As a d^g, a ball, a hare" (crascd). 
consciously foolish, while we may suppose that others would no longer be foolish if they were conscious of it.

Such a man spends his life without weariness, by playing every day for. a small stake. Give him every morning th money that he may gain during the day, on condition that $h$ does not play-you will make him unhappy. It will perhap be said that what he seeks is the amusement of play, not gain Let him play then for nothing; he will lose his interest and te wearied. It is not then amusement alone that he seeks: a languishing and passionless amusement will weary him. He must be warmed by it and cheat himself, by imagining that he will be happy by gaining what he would not care to have given him on condition of not playing, to the end that passion may be excited, that he may arouse his desire, his anger, his fear, for the object that he has set before him, as children' are frightened at the faces they have daubed.

Whence comes it that that man, who lost his only son a few months ago, and who, overwhelmed with litigation and contention, was so troubled this morning, no longer thinks of these things now? Do not be surprised at it: he is wholly occupied in watching the course of that boar which the dogs lave been pursuing so fiercely for six hours. He wants nothing more. ${ }^{2}$

1 "C'est pitié que nous nous pipons de nos propres singeries et inventions.... comme les enfants qui s'effroient de ce mesme visage qu'ils ont barbouillé et noircy à leur compaignon."-Montaigne.

2 VAR OF MS.: "That man so afflicted by the death of his wife and only son, who has a great quarrel which torments him,-whence comes it chat at this moment he is not sad, and is seen to be so free from all his painful and disquieting thoughts? We need not wonder at it; a ball has just been thrown to him, and he must throw it back to his companion. IIe is oceupied in eatehing it as it falls from the roof in order to win a run how do you suppose that he can think of his affairs, having this othe affair to attend to? This is a care worthy of occupying that great soul and of taking from it every other thought of the mind. That man, born to know the universe, to judge of all things, to rule an entire State,-behold him occupied and wholly filled with the eare of taking a hare. And $v^{\prime}$ he does not lower himself to this, and would keep his powers ever or the stretch, he would only be the more foolish, because he would elevate imself above humanity, and is, at the end of the account, only a man, that is, capable of little and of much, of every thing and of nothing. He 
Man, however full of grief he may be, if he can be prevailed upon to engage in some amusement, is for the time happy. And man, however happy he may be, if he is not diverted and occupied by some passion or some amusement that shields him from the approach of weariness, will soon be troubled and unhappy. Without diversion there is no joy; with diversion there is no sadness. And this is also what makes the happiness of persons of high condition,- that they have a number of persons about them who divert them, and have the power of keeping them in this state.

Just consider: What else is it to be superintendent, chancellor, high president, than to be in a condition that brings from morning till night a great number of people from all quarters, who leave such dignitaries not a single hour of the day wherein they can think of themselves? And when they are in disgrace and are sent to their country houses, where they lack neither goods nor domestics to assist them in their needs, they cease not to be wretehed and desolate, beeause no one hinders them from thinking of themselves.

T Amusement.--Is not royal dignity sufficiently great of itself for him who possesses it, to make him happy by the mere contemplation of what he is? Must he be diverted from this thought the same as ordinary men? I see clearly that it makes a man happy to divert him from the contemplation of his domestic miseries in order to fill his whole mind with the care of dancing well. But will it be the same with the king, and will he be more happy in attaching himself to these vain anusements than in the contemplation of his greatuess? And what more satisfying object could be given to his mind? Would it not then be marring his joy, to occupy his soul ir. thinking how to adjust his steps to the cadence of an air, or adroitly to place a billiard-ball, instead of leaving him to pnjoy in tranquillity the meditation of the glory and majesty

s neither angel nor beast, but man. A single thought occupies us, we rannot think of two things at once. Of all which may good betide us according to the world, not according to God" (erased). 
which surround him $\hat{\varepsilon}$ Let the experiment be tried: let a king be left wholly alone, without any satisfaction from his senses, without any care on his mind, without company, to think quite at leisure on himself, and it will be seen that a king without amusement is a man full of miseries. Hence this is carefully avoided, and there is never wanting about the persons of kings a great number of people on the watch to provide amusement when business is over, and to fill up every interval of leisure with pleasures and games, so that there may be no void; that is, they are surrounded by persons who take wonderful care that the king shall not be left alone and in a situation to think of himself,--knowing well that he would be miserable, king as he is, if he does.

I do not speak in all this of Christian kings as Christians, but simply as kings.

T Misery.-The only thing that consoles us for our miseries is amusement, and nevertheless, it is the greatest of our miseries. For it is this which principally keeps us from thinking of ourselves, and leads us insensibly to perdition. Without this, we should be left in weariness, and this weariness would impel us to seek more effectual means of deliverance. But diversion amuses us, and leads us insensibly on to death.'

Amusement.-If man were happy, he would be so much the more so as he were less diverted, like the saints and God.

True, but is it not to be happy to be able to be rejoiced by amusement? No, for it is adventitious and external; and thus it is dependent, and therefore liable to be troubled by a thousand accidents, which make unavoidable afflictions.

1 Nicole in the Traité de la connaissunce de soi-même, chap. 1st, and in the Lettre au Marquis de Sévigné, has given a profound examịnation of the ideas developed by Pascal in the precedir 3 pages. 


\section{CHAPTER VI.}

[ON CERTain Opinions AND CERTAin usages.]

\section{I.}

Pyrrhonism.-I will here write my thoughts without order and not perhaps in a confusion without design: it is the true order, the order that will always indicate my object even by disorder.

I should honor my subject too much were I to treat it with order, since I wish to show that it is incapable of it.

II.

Aeason of Effects.-Gradation. The people honor persons of high birth. The semi-cultivated despise them, saying that birth is not an advantage of the person, but of chance. The cultivated honor them, not by the thought of the people, but by after-thought. The devotees who have more zeal than knowledge despise them, in spite of the consideration that makes them honored by the cultivated, since they form a judgment by a new light which is given them by piety. But perfect Christians honor them by another light which is higher. Hence opinions, pro and con, succeed each other, according to the degree of light men have.

T Reason of Effects.-Perpetual revolution of pro and con.

We have therefore shown that man is vain by his esteem. for things that are not essential. $\Lambda$ nd all these opinions have been destroyed. We have then shown that all these opinions zre very sound, and that henee, all these vanities having a good foundation, the people are not so vain as it is said. And thus we have destroyed the opinion that destroys that of the people.

But it is now necessary to destroy this last proposition, and 
to show that it is always true that the people are vain, although their opinions may be sound, since they do not feel the truth where it is, and since, placing it where it is not, their opinions are always very false and unsound.

Reason of effects.- It is, then, true to say that the whole world is in illusion: for even though the opinions of the people may be sound, they are not so in their heads, for they think that the truth is where it is not. The truth is indeed in their opinions, but not at the point they imagine. For example, it is true that gentlemen must be honored, but not because birth is an effective advantage, etc.

\section{III}

Opinions of the people sound.-Civil wars are the greatest of evils. They are inevitable, if we wish to reward merit, for all will say that they are meritorious. The evil to be feared from a fool, who succeeds by right of birth, is neither so great, nor so inevitable.

\section{IV.}

Why do we follow the majority? Is it because they have more reason? No, but more force. Why do we follow ancient laws and ancient opinions? Is it because they are sounder? No, but they are exclusive, and rid us of the root of diversity.

$$
\text { V. }
$$

The dominion founded on opinion and imagination lasts a considerable period, and this dominion is mild and voluntary : that of force lasts always. Thus opinion' is, as it were, the queen of the world, but force is its tyrant.

1 Man is by nature a social animal. "He is more political," says Aristotle, "than any bee or ant." (Epist. xeiv.) But the existence of soeiety, from a family to a state, supposes a eertain harmony of sentinient among its members; and nature has, aecordingly, wisely implanted in us a tendency to assimilate in opinions and habits of thought to those with whom we live and act. There is thus, in every soeiety, great or small, a certain gravitation of opinions towards a common eentre. As in our natural body, zvery part has a necessary sympatly with every other, and all together 


\section{VI.}

How proper has it been to distinguish men by the exterior, rather than by internal qualities! Which of us two shall take

form, by their harmonious conspiration, a healthy whole; so, in the social body, there is always a strong predisposition, in each of its members, to act and think in unison with the rest. This universal sympathy, or fellowfecling, of our social nature, is the principle of the different spirit dominant in different ages, countries, ranks, sexes, and periods of life. It is the eause why fashions, why political and religious enthusiasm, why moral example, either for good or evil, spread so rapidly, and exert so powerfui an influence. As men are naturally prone to imitate others, they consequently regard, as important or insignificant, as lionorable or disgraecful, as true or falsc, as good or bad, what those around them eonsider in the same light. They love and hate what they sce others desire and eschew. This is not to be regretted; it is natural, and, consequently, it is right. Indeed, were it otherwise, society could not subsist, for nothing ean be more apparent than that mankind in general, destined as they are to oceupations incompatible with intellectual eultivation, are wholly incapable of forming opinions for themselves on many of the most important objeets of humin consideration. If such, however, be the intentions of nature with respect to the unenlightened elasses, it is manifest that a heavier obligation is thereby laid on those who enjoy the advantages of intellectual eultivation, to examine with diligence and impartiality the foundation of those opinions whieh have any eonnection with the welfare of mankind. If the multitude must be led, it is of consequenee that it be led by enlightened conductors. That the great multitude of mankind are, by natural disposition, only what others are, is a fict at all times so obtrusive, that it could not eseape observation from the moment a reflective eye was first turned upon man. "The whole eonduct of Cambyses," says Herodotus, (Lib. iii, 37, 38), the father of history, "towards the Egyptian gods, sanecuaries, and priests, convinces me that this king was in the highest degree insane, for otherwise he would not have insulted the worship and holy things of the Egyptians. If any one should aceord to all men the permission to make free choice of the best among all eustoms, undoubtedly each would choose his own. That this would eertainly happen can be slown by many examples, and, among others, by the following: The King Darius once asked the Greeks, who were resident in his court, at what jrice they could be indueed to devour their dead parents. The Greeks answered that to this no price conld bribe them. Thereupon the king asked some Indians who were in the habit of eating their dead parents, what they would take not to eat but to burn them; and the Indians answered even as the Greeks had done." Horodotus concludes this narraive with the observation, that "Pindar had justly entitled Custom-the Queen of the World."

The ancient skepties, from the sonformity of men in every country, their 'abits of thinking, feeling, and acting, and from the diversity of differen 
whe precedence? which shall give place to the other? The least cultivated? but $I$ am as cultivated as he is; it will be necessary to fight on this point. He has four lackeys, and I have but one: that is perfectly obvious; there is nothing to

nations in these habits, inferred that nothing was by nature beautiful or deformed, true or false, good or bad, but that these distinetions originated solely in custom. The modern skepticism of Montaigne terminates in the same assertion; and the sublime misanthropy of Pascal has almost carried hill to a similar exaggeration....

Nor is this influence of man on man less unambiguous in times of social tranquillity, than in erises of social eonvulsion. In seasons of political and religicue revolution, there arises a struggle between the resisting force of ancient habits and the eontagious sympathy of new modes of feeling and thought. In one portion of society, the inveterate influence of custom prevails over the contagion of example; in others, the eontagion of example prevails over the conservative foree of antiquity and habit. In either case, however, we think and act always in sympathy with others. "We remain," says an illustrious philosopher, "submissive so long as the world continues to set the example. As we follow the herd in forming our conceptions or what is respectable, so we are ready to follow the multitude also, when such conceptions come to be questioned or rejected; and are no less vehement reforniers, when the current of opinion has turned against former establishments, than we were zealons abettors while that current continued to set in a different direction." (Ferguson's Moral and Political Science, vol. i, part i, chap. ii, $\$ 11$, p. 135.)

Thus it is that no revolution in publie opinion is the work of an indiviclual, of a single cause, or of a day. When the crisis has arrived, the eatastrophe must ensue; but the agents through whom it is apparently accomplished, though they may aecelerate, eannot originate its oecurrenee. Who believes that but for Luther or Zwingli the Reformation would not have been? Their individual, their personal energy and zeal, perhaps, bastened by a year or two the event; but had the public mind not been ilready ripe for their revolt, the fate of Luther and Zwingli, in the sixteenth eentury, would have been that of Huss and Jerome of Prague, in the fifteentl. Woe to the revolutionist who is not himself a creature of the revolution! If he anticipate, he is lost; for it requires what no individual can supply, a long and powerful counter-sympathy in a nation, to untwine the ties of custom which bind a people to the established and the old. ...

"Almost every opinion we have," says the pious Charron, "we have but by anthority; we believe, judge, act, live. and die on trust, as common eustom teaehes us; and rightly, for we are too weak to decide and ehoose of ourselves. But the wise do not act thus." (De la Sagesse, liv. i, elıap. xvi.) "Every opinion," says Montaigne, "is strong enough to have had its martyrs." (Essais, liv. i, ehap. xl.) And Sir W. Raleigh,-"It is opinion, not truth, that travelleth the world without paisport." (Prefaco 
do but to count; it belongs to me to yield, and I am a fool if I contest the matter. We are by this means in peace, which is the greatest of goods. ${ }^{1}$

\section{VII.}

The habit of seeing kings accompanied by guards, drums, officers, and all the machinery for inspiring respect and terror, is the reason why their visage, when they are sometimes alone and unaccompanied, impresses their subjects with respect and terror, because men do not separate in thought their person from their retinue, with which they are usually attended. And the world, which does not know that this effect has its origin in this custom, believes that it comes from a natural force; and hence come these words: The character of the Divinity is stamped upon his countenance, etc.

- The power of kings is founded on reason and the peoples' folly, and much more on the folly. The greatest and most important thing in the world has weakness for its basis: and this basis is marvellously certain; for there is nothing more certain than this-that the people will be weak. What is founded on sound reason is ill founded, as the esteem of wisdom.

\section{VIII.}

The Swiss are offended at being called gentlemen, and prove themselves plebeians in order to be judged worthy of great employments.

to his History of the World.) "Opinion," says Heraclitus, is a falling sickness." (Diog. Laert. lib. ix, § 7.) And Luther,-- "O doxa! doxa! "quam es communis noxa." In a word, as Hommel has it, "An ouncs of cuscom ontweighs a ton of reason." (Alex. V. Joch [Hommel], Uber Beluhrung und Strafe, p. 111. Sec Krug, Philosophisches Lexikon, vol. v, p. 467, art. Gewohnheit.)-(Sir William Hamilton's Lectures on Metaphysics, vol. i, p). 84-89.)--Ed.

1 This thought is not in the MS.; we find there only this isolated lme: lhe has four lackeys. There has been, however, a very strong inclinatior vo attribute to Pascal this developınent, the form of which is lively, familiar dramatic. Perhaps the cditors reproduced it from memory, after a conver sation with Pascal. - Havet. 


\section{IX.}

Men do not choose among navigators the one who is of highest birth to command a ship.'

T Saint Augustine saw that men labor for the uncertain, at sea, in battle, etc.; he did not see the rule of chance which demonstrates that this ought to be done. Montaigne saw that we are offended at a crippled mind, and that custom can do every thing; but he did not see the reason of this effect. All these persons saw the effects, but they did not see the canses; they are, in comparison with those who have discovered causes, like those who have eyes only, in comparison with those who have mind; for effects are, as it were, sensible, and causes are visible only to the mind. And although these effects are seen by the mind, this mind is, in comparison with the mind that sees causes, like the corporeal senses, in comparison with the mind.

\section{$\mathrm{X}$.}

Whence comes it that a cripple does not irritate us, and a crippled mind does irritate us? Because a cripple recognizes that we go straight, and a crippled spirit says that it is we who limp; were it not for this we should have pity for him and not anger.

Epictetus much more forcibly asks why we are not displeased if we are told that we have a headache, and are displeased to

1 M. Faugère gives this thought with the following amplification: "The most unreasonable things in the world become the most reasonable, on account of the irregularity of men. What is less reasonable than to choose the first son of a queen to govern a state? Men do not choose among navigators the one who is of highest birth to command a ship; this law would bo ridiculous and unjust. But beeause they are and always will be [ridiculous and unjust], it becomes reasonable and just. For whom shall we choose? The most virtuous and the most capable? We are then straightway in difficulty: each one pretends to ve the most virtuous and the most capable. Let us, then, attach this quality to something incontestable. It is he eldest son of the king; this is clear, there is no dispute about it. Reason cannot do better, for civil war is the greatest of evils." M. Faugere found this text in the note-book of the physician Vallant. This note-book, entitled Pensées de M. Pascal, is preserved is. the Biblipthèque Impériale. 
be told that we reason ill, or make a bad choice. What causes this is, that we are very sure that we have not a headache, and that we are not lame: but we are not so certain that we have made a true choice. So that, having no other ground of cer tainty than that we see it with our whole sight, when another sees the contrary with his whole sight, this puts us in suspense and astonishes us, and still more when a thousand others laugh at our choice; for we must prefer our intelligence to that of so many others, and this is bold and difficult. There is never this contradiction in the senses respecting a cripple.

\section{XI.}

Respect is, ${ }^{\prime}$ Incommode yourself. This is vain in appearance, but very just; for it is saying: I would willingly incommode myself if you were in need of it, for I do so when it can do you no service. Besides this, respect is the mark by which we distinguish the great: now, if respect were to cost us no trouble, we should respect everybody, and thus make no distinctions : but being incommoded, we make these distinctions very well.

\section{XII.}

Opinions of the people sound.-To be well dressed is not over vain; for it is showing that a great number of people labor for you; it is showing by the hair that one has a valet-deshambre, a perfumer, etc.; by the band, frill, lace, etc.

Now it is not simply superficial, nor mere harness, to have several arms. The more arms one has, the stronger he is. To be well dressed is to show one's force.

\section{XIII.}

Reason of effects.-This is marvellous: one would not have me honor a man clothed in silk, and followed by seven or eight lackeys! Indeed! he will have the lash applied to me, if I do

1 That is, "In order to testify our deference towards a person, it is vecessary to incommode ourselves, to put ourselves to trouble for him." 
not salute him. This custom is a compulsion. It is quite the same as a well-caparisoned horse, in comparison with another! Montaigne is ridiculous in not seeing what difference there is, in wondering that any is found, and in asking the cause of it. In truth, says he, whence comes....

\section{XIV.}

The people have very sound opinions; for example: $1^{\circ}$. In having chosen amusement and the chase rather than poetry. The half-learned ridicule their ehoice, and triumph in showing therein the world's folly; but, by a reason that they do not penetrate, the people are right. $2^{\circ}$. In having distinguished men by externals, as nobility or property : the world triumphs again in showing how unreasonable this is; but this is very reasonable. $3^{\circ}$. In being offended at receiving a blow, or desiring glory so much. But this is very desirable, on account of other essential goods that are connected with it. And a man who has received a blow without resenting it, is overwhelued with abuse and necessities. $4^{\circ}$. In laboring for the uncertain; going to sea; crossing on a plank.

\section{XV.}

A great advantage is rank which, at eighteen or twenty, puts a man under way, makes him known and respected, as another might have merited at fifty : it is thirty years gained without trouble.

\section{XVI.}

Have you never seen people who, by way of complaining of the little regard you have for them, parade the example of people of quality who esteem them? I would answer them hus: Show me the merit by which you have charmed these persons, and I will esteem you the same.

\section{XVII.}

A man who stations himself at the window to see the passers-by,-if I pass that way, can I say that he stationed dimself there to see me? No; for he does not think of me in 
particular. But he who loves a person on account of that person's beauty, does he love the person? No; for the smallpox, which kills the beauty without killing the person, wilt destroy the love. And if one loves me for my judgment, for my memory, does he love me? No; for I may lose those faculties without losing myself. Where, then, is this $\mathrm{ME}$, if it is neither in the body nor in the soul; and how love the body or the soul, except for these endowments, which are not what constitute the $\mathrm{ME}$, since they are perishable? For could we love the substance of a person's soul abstractly, and without reference to its qualities? This is impossible, and would be unjust. One never loves the person, then, but only the qualities. Let us, then, no longer ridicule those who claim honor for their place and office, for we love no one but for adventitious qualities.

\section{XVIII.}

Things that influence us most, as concealing the smallness of our possessions, are often scarcely any thing. It is a nothing that our imagination magnifies into a mountain. Another turn of the imagination enables us to discover it without troulle.

\section{XIX.}

... It is the effect of force, not of eustom; for those who are capable of invention are rare; the stronger in number wish only to follow, and refuse glory to those inventors who seek it by their inventions. And if they are obstinate in wishing to obtain it, and despise those who do not invent, others will give them ridiculous names, would give them blows with a stick. Let no one pique himself, then, on account of this inventive slutility, or let him be contented in himself. 


\section{CHAPTER VII.}

[ON INEQUality of CONDITIONS, LAWS, JUSTICE, FORCE, POLITICAL POWER.]

I.

Mine, thine.-That dog is mine, said those poor children; that place in the sun is mine. Such is the beginning and type of usurpation throughout the earth.

II.

It is necessary that there be inequality among men; this is true; but this being granted, we see the door opened not only to the highest domination, but to the highest tyranny. It is necessary to relax the mind somewhat; but this opens the door to the greatest excesses. Let us mark the limits of these things. There are no limits in things themselves; laws endeavor to fix such limits, and the mind cannot endure them.

\section{III.}

Reason commands us much more imperiously than a master; for in disobeying the one we are unhappy, and in disobeying the other we are foolish.

\section{IV.}

Wherefore do you kill me? What! do you not dwell on the opposite side of the water? My friend, if you dwelt on this side, I should be an assassin, it would be unjust to kill you thus; but since you dwell on the other side, I am courageous, and it is just.

\section{V.}

Justice.-As fashion makes attraction, even so it makes ustice. 
VI.

Justice is what is established; and thus, all our establishec laws will be regarded as just, without being examined, since they are established.

\section{VII.}

The only universal rules are the laws of a country for ordinary things; and the majority for others. Whenee comes this? From the force there is in them.

Hence it comes that kings, who have force from other sourees, do not follow the majority of their ministers.

T Doubtless equality of goods is just;' but men, not being able to make force obedient to justice, have made justice obedient to foree ; and not being able to fortify justice, have justified foree, to the end that justice and force might be together, and that peace might be attained, which is the sovereign good.

\section{VIII.}

Summum jus, summa injuria.-The majority is the better way, because it is palpable, and has the force to make itself obeyed; yet it is the opinion of the less capable.

If it had been possible, force would have been put in the hands of justice; but as force does not allow itself to be managed as we like, since it is a palpable quality, while justice is a spiritual quality, of which we dispose as we wish, justice has been put in the hands of force, and thus we call just what we are forced to observe.

1 Nothing is falser, I do not simply say more impracticable, but more unjust in itself, than equality of goods. This is not the true equality. All men have an equal right to the free development of their faculties; they have an equal right to the impartial protection of that sovereign justice which is called the State; but it is not true, it is against all the laws of reason and equity, it is against the eternal nature of things, that the indolent man and the laborious man, the spendthrift and the economist. the imprudent and the wise, should obtain and preserve an equal amount of goods. - crusirs. 
Hence comes the right of the sword, for the sword gives a veritable right.

Otherwise, we should see violence on the one side, and justice on the other.

Hence comes the injustice of the Fronde, which sets up its pretended justice against force.

It is not the same in the Church; for there is a veritable justice, and no violence.

\section{IX.}

The cords that bind the respect of some towards others, in general, are cords of necessity ; for there must be different degrees, all men wishing to rule, and all not being able to do it, but some being able.

Let us imagine then that we are witnessing the commencement of the formation of society. It is indubitable that there would be a general conflict till the stronger oppress the weaker, till, in short, there is a dominant party. But when this is once determined, then the masters, who do not wish that war should continue, ordain that the power which is in their hands shall be transmitted as they please; some remitting it to the election of the people, others to the succession of birth, etc.

And here the inagination begins to play its part. Hitherto force controls the fact : here power is held by the imagination in a certain party, the party of gentlemen in France, of plebeians in Switzerland, ete.

These cords, then, that bind respect to such or such a class in particular, are cords of the imagination.

\section{$\mathrm{X}$.}

Justice, force.-It is just that what is just be followed. It is necessary that what is strongest be followed. Justice without foree is powerless : force without justice is tyrannical. Justice without force is contradicted, because there are always men sriminally inclined: force without justice is accused. It is herefore necessary to put justice and force together; and for 
this end to make what is just strong, and what is strong just.

Justice is subject to dispute: force is very recognizable and without dispute. Thus men have not been able to give force to justice, because force has contradicted justice and has said that she was unjust, and has said that it was she herself who was just: and thus, not being able to make what is just strong, men have made what is strong just.'

\section{XI.}

When there is a question of judging whether we ought to make war and kill so many men, to condemn so many Spaniards to death, it is one man alone who judges, and even he is interested: it should be a disinterested third party.

\section{XII.}

As duchies, and royalties, and magistracies are real and necessary, because force rules every thing, there are such everywhere and always; but since the existence of such or such a one depends upon fancy alone, it is not constant, but subject to variation.

\section{XIII.}

Tyranny.-Hence the following remarks are false and tyrannical : I am beautiful, therefore people ought to fear me; I am powerful, therefore people ought to love me; I am .... Tyranny is the desire of having by one means what we can have only by another. We render different duties to different merits: the duty of love to attraction; the duty of fear to

1 Pascal appears here to approach the ideas of Hobbes, and the greatest devotee among the philosophers of this eentury, is, on the nature of justiee and injustiee, of the same opinion as the most irreligious.-Condorcet.

- In attacking IIobbes and his adherents the Christian does not conound himself with them. Rigorously admitting the same overwhelming fact, he admits it only for fallen man, and deduces from it but a stronge? enson for pressing ever on to deliverance.-Sainte-Beuve. 
force; the duty of belief to science. We ought to render these duties; we are unjust in refusing them, and unjust in demanding them from others. It is equally false and tyrannical to say: He is not strong, therefore I will not esteem him; be is not capable, therefore I will not fear him. 


\section{CHAPTER VIII.}

\section{[ON DIFFERENT SUBJECTS OF ETHICS.]}

Pyrrhonism.-An extreme measure of intelligence is accused of folly, as well as extreme deficiency. Nothing but mediocrity is good. The generality have laid down this rule, and carp at whoever deviates from it into either extreme. I shall not insist upon it, for my part; I shall readily consent to be thus limited, and refuse to be of the lower extreme, not because it is low, but because it is the extreme; for I would refuse to be placed even at the higher extreme. It is quitting humanity to quit the mean course: the greatness of the human soul consists in knowing how to keep in it; so far is greatness from cousisting in quitting it, that it consists in not quitting it at all.

\section{II.}

One does not get credit in the world for talent in poetry, if he has not hung out his sign of poet, of mathematician, ${ }^{2}$ etc. But universal people wish no sign, and make but little difference between the trade of a poet and that of an embroiderer.

1 Paseal pursues in this chapter the ideas developed in the preceding chapter, to wit, that the human mind abandoned to its own light offers only darkness and contradiction, that most opinions in the world are erroneous, and that man is almost always astray from truth, when he is out of faith.

2 The MS. gives a second version of this thought, as follows: "There should be no occasion to say, He is a mathematician, a preacher, eloquent; but, He is an honest man. This universal quality alone pleases me. It is a bad sign when, on seeing a man, we are reminded of his book; I would that no quality should be pereeived but by the eneounter and occasion of its nse. Ne guid nimis, lest he be carried away by a quality, and be thristened with its name. Let it not be thought that he speaks well, ex. eept when there is a question of speaking well, then let us be reminded of t to some purpose." 
Universal people are called neither poets nor geometers, ctc.; but they are all that, and judge of all those. One does not divine them. They will speak of what one is speaking when they entered. Men do not perceive in them one quality rather than another, except as necessity calls it forth; but they are then equal to the occasion: for it is all the same with such characters that it should not be said of them that they speak well, when there is no question of language; and that it should be said of them that they speak well, when there is a question of it. It is therefore a false praise that is given a man when it is said of him, as he comes in, that he is very capable in poetry; and it is a bad indication, when we have not recourse to a man when judging verses is the question.

\section{III.}

Man is full of needs: he loves only those that can supply them. This is a good mathematician, it will be said. But I have nothing to do with mathematics; he would take me for a proposition. This is a good warrior. He would take me for a place besieged. An honest man is requisite, then, who could accommodate himself to all my needs in general.

\section{IV.}

When we are well, we wonder how we should act if we weru sick; when we are sick, we.take medicine cheerfully. The disease brings us to this resolution. We have no longer the passion and desire for amusements and promenades, which health gave, and which are incompatible with the exigencies of the disease. Nature, then, gives passions and desires, conformed to the present state. It is only the fears that originate with ourselves, and not with nature, that trouble us; for they join to the state in which we are the passions of the state in which we are not.

\section{V.}

Discourses of humility are matter of pride to the proud, and of humility to the humble. Thus discourses of Pyrrhonism 
are matter of affirmation to the affirming. Few speak of humility humbly; few of chastity, chastely; few of Yyrrhonism, doubtingly. We are only falsehood, duplicity, contradiction, and we conceal and disguise to ourselves.

\section{VI.}

Good actions concealed are the most estimable. When I discover such in history, they please me much. But, in short they have not been wholly concealed since they have been recorded: and although every thing possible has been done to conceal them, the little whereby they have come to light spoils all ; for the finest thing about them, is the wish to conceal them.

\section{VII.}

Sayer of bons mots, bad character.

\section{VIII.}

The ME is hateful: you, Miton, ${ }^{1}$ cover it, you do not thereby renounce it; you are therefore always hateful.-By no means, [you say], for in acting, as we do, obligingly towards all men, they have no longer cause to hate us.-That is true, if we hated in the $\mathrm{ME}$ only the displeasure that comes to us from it. But if $I$ hate it because it is unjust, because it makes itselt the centre of every thing, I shall hate it always. In a word, the $\mathrm{ME}$ has two qualities: it is unjust in itself, in that it makes itself the centre of every thing; it is troublesome to others, because it wishes to bring them into subjection: for each $\mathrm{ME}$ is the enemy, and would be the tyrant of all others. You take away the annoyance arising from it, but not the injus tice; and thus you do not make it acceptable to those who hate the injustice: you make it acceptable only to the unjust,

1 Miton was a fashionable man, friend of the Chevalier de Méré, by whom he appears to have been brought into relation with Pascal.- Haves 
who no longer find in it their enemy; and thus ycu remain unjust, and can please only the unjust.

\section{IX.}

I do not admire excess of one virtue, as of valor, if I dc not discover at the same time excess of the opposite virtue, as in Epaminondas, who had extreme valor and extreme benignity ; for otherwise it is not exalting, but debasing. One does not show his greatness by being at one extreme, but in touching both extremes at once, and filling all the intermediate space. But it may be that this is only a sudden movement of the soul from one of these extremes to the other, and that the soul is never, in fact, in but one point, like a fire-brand [whirled around]. It may be so, but this at least indicates the agility of the soul, if it does not indicate its extent

\section{$\mathrm{X}$.}

In omnibus requiem qucesivi.-If our condition were really happy, it would not be necessary to divert us from thinking of it in order to make us happy.

T A little consoles us, because a little afflicts us.

T We are so unhappy that we can take pleasure in a thing only on condition of being vexed if it turn out ill; which may be the case, and is the case, with a thousand things, at every hour. Whoever should find the secret of being rejoiced at good without being vexed at the opposite evil, would find the point. It is perpetual motion.

\section{XI.}

I spent much time in the study of abstract sciences; and the little communication that we can have on such subjects disgusted me with them. When I began the study of man, I perceived that these abstract sciences are not suited to him, and that I should wander farther from my condition by advancing in them than others by remaining in ignorance of them; and I pardoned others for krowing little of them. 
But I expected to find at least many companions in the study of man, and that this is the true study which is suited to him. I was deceived. There are still fewer who study man than who study geometry. It is only because we know not how to study man that we seek any other subjects of study. But is it not true that this is not yet the science that man ought to have, and that it is better for him to be ignorant of it in order to be happy?

\section{XII.}

When every thing moves equally, nothing moves apparently: as on a ship. When all things go towards disorder, nothing seems to go thither. He who stips, causes, like a fixed point, the recession of others to be remarked.

\section{XIII.}

Order.-Why should I assume in my ethics a fourfold rather than a sixfold division? Why should I rather estahlish virtue into four sorts, two sorts, one sort? Why into Abstine and sustine, ratlier than into Follow nature, or, Pay attention to your own particular affairs without injustice, like Plate, or any thing else? But, you will say, every thing is here reduced to a single word. Yes, but that is useless, if it is not explained; and when we come to explain it, as soon as we develop this precept which contains all the others, they issue in the same confusion that you at first wish to avoid. Thus, when they are all contained in one, they are hidden in it and useless, as in a box, and never appear but in their natural confusion. Nature has established them all without including one in the other.

T Nature has put all these truths each in itself. Our art includes some in others, but this is $n$ tt natural. Each holds its place.

\section{XIV}

When we wish to reprove with profit, and show another that he is mistaken, we must observe on what side he looks 
at the thing, for it is usually true on that side, and to adınit to him that truth, but to diseover to him the side whereon it it is false. He is pleased with this, for he perceives that he was not mistaken, and that he only failed to look on all sides. Now, one is not vexed at not seeing every thing. But one does not like to be mistaken; and perhaps this arises from the fact that man naturally eannot see every thing, and that naturally he eannot be deceived in regard to the side that he looks at; as the apprehensions of the senses are always true.

\section{$\mathrm{XV}$.}

The power of a man's virtue should not be measured by his special efforts, but by his ordinary doing.

\section{XVI.}

Great and small have the same accidents, and the same vexations, and the same passions; but one is at the circumference of the wheel, and the other near the eentre, and thus less agitated by the same movements.

\section{XVII.}

Although persons may have no interest in what they are saying, we must not thence conclude absolutely that they are not lying; for there are people who lie simply for the sake of lying.

\section{XVIII.}

The example of Alexander's chastity has not made so many continent as that of his drunkenness has made intemperate It is not shameful not to be as virtuous as he, and it seem excusable to be no more vicious than he. One thinks he is not altogether in the vices of the crowd of men, and he perceives himself in the vices of these great men; and yet he does not remember that in th's respect they are of the crowd. $\mathrm{He}$ is connected with them by the same extreme whereby 
they are connected with the people; for, howerer elevated they may be, yet are they united with the least of men at some point. They are not suspended in the air, wholly abstracted from our society. No, no; if they are greater than we, it is because their heads are higher; but their feet are as low as ours. They are all on the same level, in this respect, and stand on the same earth; and by this extreme they are as abased as we, as the smallest, as children, as brutes.

\section{XIX.}

The combat alone pleases us, not the victory. We love to see the combats of animals, not the vanquisher let loose on the vanquished. What would we see but the crisis of victory? And as soon as it comes, we are satisfied. Thus in play, thus in the search after truth. We like to see in disputes the combat of opinions; but to contemplate truth discovered, not at all. To remark it with pleasure, we must see it emerging from dispute. Just so in the passions, there is a pleasure in secing two contending passions in conflict; but when one is mistress, it is no longer any thing but brutality. We never seek things, but the search after them. Thus, in the drama, tranquil scenes without fear are worthless; just so, extreme miseries without hope, brutal loves, and harsh severities.

\section{$\mathrm{XX}$.}

Men are not taught to be honest, but they are taught every thing else; and they never pique themselves so much on knowing any thing else, as on knowing how to be honest men. 'They pique themselses on knowing the only thing they do not learn.

\section{XXI.}

Prefuce of the first part.-... To speak of those who have treated of the knowledge of self, of the divisions of Charon, which sadden and weary, of the confusion of Montaigne; that 
he had very sensibly felt the defect of strictness of method, that he shunned it by leaping from topic to topic, that he sought an aristocratic air. The foolish project that he has of painting himself! and this not incidentally, and contrary to his maxims, as shortcoming happens to everybody; but by his own maxims, and by his first and principal design. For to utter follies by hazard and weakness is a common ill; but to utter them by design is insufferable.'

\section{XXII.}

To pity the unhappy is not contrary to selfish desire; on the other hand, we are glad of the occasion to thus testify friendship, and attract to ourselves the reputation of tenderness, without giving any thing.

\section{XXIII.}

Would he who possessed the friendship of the King of England, of the King of Poland, and of the Queen of Sweden," have believed it possible that he might be without a retreat and an asylum in the world?

\section{XXIV.}

Inconstancy.-Things have different qualities, and the soul has different inclinations: for nothing of what is offered to the soul is simple, and the soul nerer offers itself simple to any subject. Hence it comes that we sometimes weep and laugh on account of the same thing.

1 After "is insufferable," we read in the MS.: "and to say such as these...." Paseal not having finished this phrase, we have thrown into a note these last words, which leave the paragraph in an unfinisherl state.

2 Reference is here made to Charles 1 , who died on the scaffold, in 1649 ; to John Casimir, who, for a time, was expelled from his kingdom, in 1656 by the king of Sweden, Charles Gustavus; and to queen Christina, who ablicated in 1654. 


\section{$\mathrm{XXV}$.}

Ferox gens, nullam esse vitam sine armis rati.'-They prefer death to peace; others prefer death to war. Every opinion may be preferable to life, the love of which appears so strong and so natural.

\section{XXVI.}

How difficult it is to propose a thing for the judgment of another, without corrupting his judgment by the manner of proposing it to him! If it is said : I find it beautiful, I find it obscure, or something else similar, imagination is enlisted in favor of this judgment, or irritated to opposition. It is better to say nothing, and then he judges according to what it is, that is, according to what it is then, and according as the other circumstances over which we have no control may influence him; but at least we shall not influence him, unless our silence has its effect, according to the interpretation which he is in the humor to give it, or according to his conjectures from the expression of the countenance, or from the tone of voice, according as he is a physiognomist; so difficult is it not to bias a judgment from its natural conclusion, or rather, so few there are firm and stable!

\section{XXVII.}

Vanity of the sciences.-The science of external things will console me for ignorance of ethics in times of affliction; but the science of morals will always console me for ignorance of external sciences.

\section{XXVIII.}

Time cures griefs and strifes, because one changes, and is no longer the same person. Neither the offending nor the offended remains the same. It is like a nation irritated and 
revisited after two generations. They are still the French, but not the same.

\section{XXIX.}

Condition of man : inconstancy, weariness, disquiet.

- Whoever would fully know the vanity ${ }^{1}$ of man, has only to consider the causes and effects of love. The cause of it is "an I-know-not-what;" and its effects are frightful. This "I-know-not-what," so insignificant a thing that we can scarcely recognize it, moves the whole earth, prinees, armies, the entire world. If the nose of Cleopatra had been shorter, the whole face of the earth would have been changed. ${ }^{2}$

\section{XXX.}

Cæsar was too old, it seems to me, to amuse himself with conquering the world. This amusement was well enough for Augustus or Alexander; they were young people whom it is difficult to stop; but Cæsar ought to have been more mature.

\section{XXXI.}

The feeling of the falseness of present pleasures, and the ignorance of the vanity of absent pleasures, cause inconstaney.

\section{XXXII.}

Continued eloquence wearies.

Princes and kings sometimes play. They are not always on their thrones; they become tired of it. Greatness needs to be abandoned in order to be felt. Continuity disgusts in every thing. Cold is agreeable for the sake of warming ourselves.

1 Vanity in the sense of nothingness, weakness.

2 The thought on the effects of love, and on Cleopatra's nose, has been eproduced three times. First draught: "( $A s$ a title). Vanity. The inuses and the effects of love. Cleopatra." Second draught: "Nothing shows better the vanity of men than to consider the cause and the effects of love ; for the whole universe is changed by it: Cleopatra's nose." This cecond draught was erased by Pascal's own hand.-Cousin. 


\section{XXXIII.}

Lustravit lampade terras. The weather and my humors have little connection.'-My humor depends but little on the weather: I have my fogs and my fair weather within me. The good and ill of my affairs even make but little difference: I sometimes rouse myself against fortune; the glory of overcom. ing it makes me overcome it gayly; while I sometimes feel disgust in good fortune.

\section{XXXIV.}

My thought sometimes escapes me while I write it; but that reminds me of my weakness, which I am always forgetting; and this instruets me as much as my forgotten thought; for I strive only to know my nothingness.

- Thought escaped: I wished to write it; I write, instead, that it has escaped me.

\section{XXXV.}

It is an amusing thing to consider, that there are men in the world who, having renouneed all the laws of God and nature, have made laws for themselves which they strictly obey, as, for example, the soldiers of Mohammed, thieves, heretics, ctc. And thus logicians .... It seems that their license ought to be without limit or barrier, seeing that they have overleapt so many that are so just and so holy.

\section{XXXVI.}

"You are not polished, excuse me, if you please." Without this excuse, I should not have perceived that any harm was done. "To speak with deference ...."-There is nothing bad but their excuse.

1 Here Pascal responds to this passage of Montaigne: "L'air mesme et la screnité du ciel nous apporte quelque mutation, comme dit ce vers grec en Cicero: Tales sunt hominum mentes quali pater ipse Jupiter auctifera lus. travit lampaile territs." (A versc translated from the Odyssey, $\sigma, 135$, anpreserved by St. Angustine, de Civitate Dei, v, 8.)-Havet. 


\section{XXXVII.}

We always imagine Plato and Aristotle with the long robes of pedants. They were well-bred men, and, like others, laughing with their friends: and when they diverted themselves in making their laws and politics they did it playfully. It was the least philosophic and least serious part of their lives. The most philosophic was living simply and tranquilly.

If they wrote politics, it was to regulate a hospital of fools. If they made a show of speaking of politics as of something great, it was because they knew that the fools to whom they were speaking thought themselves kings and emperors. They entered into their principles in order to moderate their folly to the least possible degree of evil.

\section{XXXVIII.}

Epigrams of Martial. Man loves malignity : but it is not against the one-eyed, nor against the unfortunate, but against the fortunate who are proud; otherwise we are mistaken. For desire is the source of all our movements, and humanity .... It is necessary to please those who have humane and tender sentiments.

That on the two one-eyed ' is worthless, because it does not console them, and does nothing but give a point to the author's glory. All that is merely for the author is worthless. Ambitiosa recidet ornamenta.

\section{XXXIX.}

I am not pleased with these compliments: "I have given you much trouble;" "I fear to weary you ;" "I fear that is soo long." They either captivate or they irritate.

\section{XL.}

A true friend is so advantageous a thing, ever. for the greatest lords, in order that he may speak well of them, and defend

1 Epigram of Martial.-Ed.

${ }^{2}$ Hor. : de Arte poet., 447. 
them even in their absence, that they should do every thing to get one. But let them choose carefully; for, if they spend all their efforts on fools, this will be useless for them, whatever goud they may speak of them: and they will not even speak well of them, if they find themselves the weaker, for they have no authority; and thus they will speak ill through companion ship.

\section{XLI.}

Do you wish to be thought well of? do not speak of it.

\section{XLII.}

I lay it down as a fact that, if all men knew what others say of them, there would not be four friends in the world. This appears from the quarrels to which indiscreet reports occasion. ally give rise.

\section{XLIII.}

Diversion.-Death is easier to bear without thinking of $t$, than the thought of death without peril.

\section{XLIV.}

Vanity.-It is wonderful that a thing so obvious as the vanity of the world is so little known, and that it is a strange and surprising thing to say that seeking its honors is a folly!

I Who sees not the vanity of the world is himself vain indeed. In fact who sees it not, except young people who give themselves up to the din of life, to diversion, and to thoughts of the future? But take away their diversion, and you will sec them wither with ennui; they then feel their nothingness without knowing it: for it is being wretched indeed to be overwhelmed with sadness as soon as we are reduced to consider ourselves, and cease to be diverted.

\section{XLV.}

Pyrrhonism.-Every thing here is true in part, false in part. Essential truth is not thus: it is all pure and all true. 
This mixture dishonors it and annihilates it. Nothing is purely true; and thus nothing is true, understood in relation to pure truth. It will be said, it is true that homicide is bad ; certainly, for we indeed know the evil and the false. But what shall we say is good? Celibacy? I say no; for the world would come to an end. Marriage? No; continence is better. Not to kill? No ; for disorders would be horrible, and the wicked would kill the good. To kill? No; for that destroys nature. We have neither the true nor the good but in part, and mixed with the evil and the false. 


\section{CHAPTER IX.}

[ON DIFFERENT KINDS Ü MIND. -ON REASON AND BEN: IMENT.-VARICUE THOUGHTS.']

I.

ThE more mind we have, the more original men do we discover there are. Common people find no difference between men.

II.

Different sorts of right sense; some in a certain order of things, and not in other orders, wherein they are extravagant. Some draw conclusions well from few principles, and this is exactness of sense. Others draw eonclusions well where there are many principles. For example, some clearly comprehend the effects of water, in which there are few principles; the conclusions are so fine, that nothing but extreme exactness of mind could reach them; and yet these men would not perhaps be great geometricians, because geometry comprises a great number of principles, and the nature of a mind may be such that it can penetrate well a few principles to the very bottom, and cannot penetrate in the least things containing many principles.

There are, then, two sorts of minds : the one penetrates rapidly and profoundly the consequences of principles, and this is the accurate mind; the other comprehends a great number of principles without confounding them, and this is the geometrical mind. The one is foree and exactness of mind, the other

1 Pascal still continues in this chapter the study of man, directing his analysis more particularly to the intellectual faculties,-which naturally eads him to speak of style, of eloquence, of poetic beauty. Those editory are wrong, then, who separate the literary thoughts from their connection with the rest. 
is amplitude of mind. Now one may exist without the other; the mind may be strong and narrow, or wide and weak.

DIFFERENCE BETWEEN THE GEOMETRIC MIND AND THE ACUTE MIND.

T In the one, the principles are palpable, but remote from cummon usage; so that it is difficult to turn the attention in that direction, through want of habit: but so far as the attention is turned in that direction, the principles are fully seen; and a mind wholly false would be required to reason ill on principles so obvious that it is almost impossible that they should escape.

But in the acute mind, the principles are in common use and before the eyes of everybody. It is only necessary to look in that direction; painful attention is not required. The only requisite is good sight, but it must be good; for the principles are so interwoven and so many in number, that it is almost impossible that some of them should not escape. Now, the omission of one principle leads to error: thus, the sight must be very clear in order to see all the principles, and the mind must also be very accurate not to reason falsely on known principles.

All geometricians would, therefore, be acute if they had clearness of sight, for they do not reason falsely on the principles that they know; and acute minds would be geometrical if they could bend their vision towards the unaccustomed principles of geometry.

The reason, then, why certain acute minds are not geometrical, is that they cannot at all be directed towards the principles of geometry; but the reason why geometrical minds are not acute, is that they do not see what is before them; and that being accustomed to the clear and palpable principles of zeometry, and to reason only after having clearly seen and handled their principles, they are lost in matters of acuteness, but the principles do not allow themselves thus to be handled; they are scarcely seen, they are rather felt than seen; infinite pains are required to make them felt by those who do not fee 
them of themselves: they are things so delicate and so numerous, that a very delicate and very clear sense is necessary in order to feel them, and to judge rightly and exactly according to this feeling, without being able generally to demonstrate them in order as in geometry, because these principles are not thus possessed, and because it would be an endless matter to undertake it. It is neeessary to see the matter all at once by a single glance, and not by a process of reasoning, at least to a certain degree. And thus it is rare that geometricians are acute, and that the acute are geometrieians, because geometricians wish to treat these acute matter's geometrically, and make themselves ridiculous, wishing to begin with definitions and then with prineiples, which is not the manner of procedure in this sort of reasoning. Not that the mind does not do this; but it does it tacitly, naturally, and without art, for the expression of it is beyond all men, and the feeling of it pertains to but few.

And acute minds, on the contrary, thus accustomed to judge at a single glance, are so astonished when one presents to them propositions in which they comprehend nothing, and in order to enter into which they must pass through such sterile definitions and principles, which they have not been aceustomed to view thus in detail, that they are diseouraged and disgusted. But false minds are never either aeute or geometrical. Geometricians who are merely geometricians, have therefore exact Ininds, provided all things are clearly explained to them by definitions and prineiples; otherwise they are false and insupportable, for they are exact only in regard to clearly elucidated principles. And the acute who are merely acute, cannot have the patience to deseend to first prineiples in matters of speculation and imagination, which they have never seen in the world, which are wholly beyond their experience.

\section{III.}

The examples which we take to prove other things, if we wish to prove the examples, we should take the other thing 
to be their examples; for, as we always believe that the diffculty is in what we wish to prove, we find the examples more clear, and they aid us in proving it. Thus when we wish to illustrate a general principle, we must exhibit the particular rule of a case : but if we wish to illustrate a particular case, we must begin with the general rule. For we always find the thing to be proved obscure, but that which we employ as the medium of proof, clear: for, when we propose to prove a thing, we are immediately filled with the idea that it is obscure, and, on the contrary, that that which ought to prove it is clear, and thus we understand it easily.

IV.

All our reasoning is compelled to yield to feeling. But the fancy is similar and contrary to feeling, so that we cannot distinguish between these contraries. One says that my feeling is fancy, the other that his fancy is feeling. We must have a rule. Reason offers herself, but she is pliable in any direction; and thus we have no rule.

\section{V.}

Those who judge of a work by rule, are, with regard to others, as those who have a watch, with regard to those who have not. The one says: "It is two o'clock;" the other says : "It is only a quarter to one." I look at my watch; I say to one: "You are getting weary ;" and to the other: "Time flies fast with you;" for it is half-past one, and I laugh at those who say that the time lingers with me, and that I judge of it by my fancy: they do not know that I judge by my watch.

\section{VI.}

There are those who speak well, and do not write well. It is because the place, the audience, warms them, and elicits from their mind more than they find in it without this warmtl. 


\section{VII.}

What is good in Montaigne can be acquired only with difficulty. What is bad in him (I except his morals) might have been corrected in a moment, if he had been told that he was telling too many stories, and that he spoke too much of himself.

\section{VIII.}

Miracles.-It is annoying to be in the exception to the rule. It is necessary to be even severe, and against the exception. But, nevertheless, as it is certain that there are exceptions to the rule, we must judge them severely, but justly.

\section{IX.}

Let it not be said that I have said nothing new; the disposition of the matter is new. When men play at tennis, two play with the same ball; but one places it better. I would as lieve they should say that I have used old words. And as if the same thoughts, by a different disposition, would not form a different body of discourse, just as the same words differently arranged would express different thoughts.

\section{X.}

We are more forcibly persuaded, in general, by the reasons that we ourselves discover, than by those that come from the minds of others.

\section{XI.}

The mind believes naturally, and the will loves naturally; so that, in default of true objects, they must attach themselves to false ones.

\section{XII.}

Those grand efforts of mind which the soul occasionally eaches, are such as it cannot sustain. It reaches them only

- This appears to be an allusion to the miracle of the IIoly Thorn. 
by a bound, not as on the throne, continuously, but for an instant only.

\section{XIII.}

Man is neither angel nor brute; and the nisfortune is, tha those who would play the angel, play the brute.'

\section{XIV.}

In knowing the dominant passion of any man, we are sure of pleasing him; and nevertheless, each one has his fancies, contrary to his own good, in the very idea that he has of good; and this is an eccentricity that disconcerts.

\section{$\mathrm{XV}$.}

Glory.-Brutes do not admire each other. A horse does not admire his companion. Not that there is no emulation among them on the course, but it is of no consequence; for, being in the stable the heaviest and worst made does not give up his oats to another, as men wish we should do to them. Their virtue is satisfied with itself.

\section{XVI.}

As we injure the mind, we injure also the feelings. The mind and the feelings are formed by conversations. We injure the mind and the feelings by conversations. Thus good or bad conversations form the mind or injure it. It is of importance, then, to know how to choose well, in order to form, and not to injure the mind; and we cannot make this choice, if we have not already formed and not injured it. Thus we have a circle, from which happy are those who escape.

\section{XVII.}

When we do not know the truth of a thing, it is good that there is a common error which fixes the mind of men, as, for

1 "Ils veulent se mettre hors d'eulx ot eschapper à l'homme, e'est folie a lieu de se transformer en anges, ils se transforment en bestes; au lieu do se haulser, ils s'abattent."-Montaigne. 
example, the moon, to which we attribute the change of seasons, the progress of diseases, ete. For the principal disease of man is a restless curiosity after things which he cannot know; and it is not so bad for him to be in error, as to have this useless euriosity.

- The manner of writing adopted by Epictetus, Montaigne, and Solomon de Tultie ${ }^{1}$ is most in use, is most insinuating, dwells longest in the memory, and is oftenest quoted, beeause it is composed altogether of thoughts springing from the ordinary conversations of life; as when we speak of the vulgar error that obtains in the world, that the moon is the cause of every thing, we never fail to say that Solomon de Tultie says that, when we do not know the truth of a thing, it is good that there is a common error, etc., which is the thought mentioned above.

\section{XVIII.}

If the thunderbolt fell on low places, etc., poets, and those that know not how to reason but on things of this nature, would lack proofs.

\section{XIX.}

The heart has its reasons, which the reason knows nothing about; we know it in a thousand things. I say that the heart loves the universal Being naturally, and it loves itself naturally, according to its inclination; and it hardens itself against the one or the other at its choice. You have rejected the one and preserved the other: is it through reason that you love? It is the heart that feels God, and not the reason. This is faith : God sensible to the heart, not to the reason.

\section{$\mathrm{XX}$.}

The heart has its order; the mind has its own order, which is by prineiples and demonstrations; the heart has

1 The editors of Pascal have sought in vain who Solomon de Tultie miglit be. It is evidently a pseudonym. 
another.' We do not prove that we ought to be loved by making a systematic exposition of the causes of love: this would be ridiculous.

Jesus Christ, and St. Paul have the order of charity, not of the mind; for they wished to warn, not to instruct. St. Augustine the same. This order consists, principally, in a digression on each point that has a relation to the end, so as to show it always.

\section{XXI.}

To mask nature and disguise her. No longer king, pope, bishops; but august monarch, etc. : no Paris; but the capital of the kingdom. There are places where we must call Paris Paris, and others where we must call it the capital of the kingdom.

\section{XXII.}

When in a composition we find words repeated, and when endeavoring to correct them we find them so suitable that a change would spoil the composition, it is necessary to let them stand; this is an indication of their fitness, and to erase them is the part of envy, which is blind, and knows not that this repetition is not a fault in this place; for there is no general rule.

\section{XXIII.}

Miscell[anea]. Language.-Those who make antitheses by forcing the sense, are like those who make false windows for

1 The design of Pascal, in his new apology, was to show that Christianity is amiable, and, this important point once gained, to establish that it is as true as any thing in the world: he wished to insinuate it in some sort into reason through the heart. This thought is everywhere in Pascal. In order to prepare the way for this new apclogy, he advanees a theory which he thinks he is inventing, but which is too true to be new, to wit, the distinction between two orders of truths, - the one, demonstrable, the nther, indemonstrable, because they are primary truths; the former are nroved, the latter are felt; these emerge from reason, from reasoning, frcm initlligence, from mind; tnose from sentiment, from instinct, from the beart.-Cousin. 
the sake of symmetry. Their rule is not to speak accurately but to make accurate figures.

\section{XXIV.}

Languages are ciphers, wherein the letters are not changed nto letters, but the words into words; so that an unknown ongue can be deciphered.

\section{XXV.}

There is a certain model of agreement and beauty which consists in a certain relation between our nature, feeble or strong, such as it is, and the thing that pleases us. Every thing that is formed according to this model delights us : houses, songs, compositions, verse, prose, women, birds, rivers, trees, rooms, elothes, etc. Every thing that is not made according to this model displeases those who have good taste. And as there is a perfect relation between a song and a house that are made according to the good model, because they resemble this unique model, though each according to its kind, so there is a perfect relation between things made according to the bad model. It is not that the bad model is unique, for there is an infinity of them. But each bad sonnet, for example, according to whatever false model it may have been made, perfectly resembles a woman dressed according to this model.Nothing makes us understand better how ridiculous a false sonnet is than to consider its nature and the model, and then to imagine a woman or a house made according to this model.

\section{XXVI.}

Poetic beauty.-As we say poetic beauty, we ought also to say, geometrical beauty, and medicinal beauty. However, we do not say this: and the reason of it is, that we know very well what is the object of geometry, and that it consists in proofs, and what is the object of medicine, and that it consists in bealing; but we do not know in what consists, the eharn that is the object of poetry. We do not know what this 
natural model is, which must be imitated; and, in default of this knowledge, we have invented certain extravagant terms : "golden age," "marvel of our days," "fatal," etc.; and we call this jargon, poetic beauty. But whoever shall imagine a woman according to this modfl, that consists in saying littlo things with big words, will see a pretty maiden covered witl mirrors and chains, at which he will laugh, because we know better in what consists the charm of a woman, than the charm of verses. But those who are not skilled in these matters might admire her in this dress ; and there are many villages where she would be taken for the queen: and this is the reason why we call sonnets made after this model, "village queens."

\section{XXVII.}

When a natural discourse paints a passion or an effect, we find in ourselyes the truth of what we hear, of the existence of which within us we were unaware, so that we are induced to love him who discovers it to us; for he has not shown us his possession, but ours; and thus this benefit makes him loveable to us: besides, this community of intelligence we have with him, necessarily inclines the heart to love him.

\section{XXVIII.}

Eloquence.-The agreeable and the real are requisite; but this agreeable must itself be found in the truth.

\section{XXIX.}

When we see the natural style, we are quite astonishe and delighted; for we expected to see an author, and we find a man. Whilst those of good taste, who look into a book expecting to find a man, are quite surprised to find an author : Plus poetice quam humane locutus es. They indecd honor nature, who teach her that she can speak of all things, even of heology. 


\section{XXX.}

The last thing that we find in making a book is to know what we must put first.

XXXI.

Language. - We must not divert the mind, except to relax it, but at the proper time; to relax it when it is necessary, and not otherwise; for whoever relaxes inappropriately wearies; and whoever wearies inappropriately relaxes, for people then withdraw attention altogether: so pleased is the malice of desire to do just the opposite of what one wishes to obtain from us without giving us pleasure, which is the change for which we give all that is desired.

\section{XXXII.}

What vanity is painting, which attracts admiration by the resemblance of things which in the original we do not admire!

\section{XXXIII.}

The same sense changes according to the words that express it. The sense receives dignity from words, instead of giving it to them. Examples of this must be sought....

\section{XXXIV.}

Those who are accustomed to judge $b$ - sentiment understand nothing of matters of reasoning; for they wish at first to penetrate with one view, and are not accustomed to search for principles. And others, on the contrary, who are accustomcd to reason by principles, comprehend nothing of matters of sentiment, seeking therein principles, and not being able to sce them at one view.

\section{$\mathrm{XXXV}$.}

Geometry, acuteness.-True eloquence scorns eloquence, true r.orality scorns morality; that is, the morality of the judgment 
scorns the morality of the mind, which is without rules. For it is judgment that sentiment appertains to, as the sciences appertain to the mind. Acuteness is a part of the judgment, geometry is a part of the mind.

To scorn philosophy is truly to philnsophize.'

\section{XXXVI.}

All the false beauties that we blame in Cicero have admirers, and in great number.

\section{XXXVII.}

There are many people who understand the sermon in the same manner as they understand vespers.

\section{XXXVIII.}

Rivers are highways that move on, and bear us whither we wish to go.

\section{XXXIX.}

Two similar faces, neither of which alone causes laughter, cause laughter when they are together, by their resemblance.

\section{XL.}

Probability. ${ }^{2}$-They have some principles, but they abuse them. Now, the abuse of truths ought to be punished as much as the introduction of falsehood.

1 "Un ancien à qui on reprochoit qu'il faisoit profession de la philosc phie de laquelle pourtant en son iugement il ne tenoit pas grand compte, respondit que cela c'estoit vrayement philosopher."-Mon'aigne.

2 Port-Royal, as usual, omits the title, and says that astrologers and alchemists "have some principles." Pascal refers to the Jesuits, wino: his earliest editors had reasons for not wishing to mention. 


\section{CHAPTER X.}

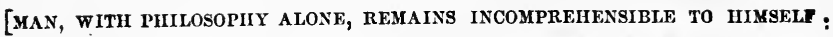
HE ONLY KNOWS HIMSELF BY THE MYSTERY OF THE TRANSMISSI'ON OF SIN, AND CAN FIND ONLY BY FAITH THE TRUE GOOD AND JUSTICE.]

'...The principal arguments of the Pyrrhonists (I omit the least important) are, that we have no certainty of the truth of these principles, aside from faith and revelation, except that we feel them naturally in us: now, this natural feeling is not a convineing proof of their truth, since there being, aside from faith, no certainty whether man has been created by a good God, by a wicked demon, or by chance, it is doubtful whether these principles have been given to us as true, false, or uncertain, according to our origin. Moreover, as no one has any assurance, except from faith, whether he wakes or sleeps, seeing that, during sleep, the man believes he is awake as firmly as we do; he thinks he sees spaces, figures, movements; he feels the lapse of time, measures it, and, in short, acts the same as when awake ; so that, the half of life being passed in sleep, by our own confession, in which, however it may appear to us, we have no idea of the true, all our sentiments being then illusions, who knows whether this other half of life in which we

1 At the head of this chapter, Port-Royal placed the following preamble: "Nothing is stranger, in the nature of man, than the contrarieties therein discovered in regard to all things. He is made to know the truth; he ardently desires it, seeks it; and, nevertheless, when he strives to grasp it, he is so dazzled and confounded that he gives occasion to doubt whether he has attained it. This has given rise to the two sects of Pyrrhonisti ard dogmatists, of which the one has wished to rob man of all knowledge of the truth, and the other strives to assure him of it; but each with rea. sons so improbable, that they augment the confusion and embarrassment of man, when he has no other light than that which he finds in his own nature." 
think we are awake, is not another sleep a little different from the first, from which we awake when we think we go to sleep?'

Such are the principal arguments on both sides.

I leave the least, such as the discourses that the Pyrrhonists make against the impressions of custom, education, manners, countries, and other similar things, which, though they carry away the majority of common men, who dogmatize only on these vain foundations, are overturned by the least breath of the Pyrrhonists. We have but to see their books; if we are not sufficiently persuaded of it, we shall become so very quickly, and perhaps too quickly.

I pause at the only strong point of the dogmatists, which is, that we cannot, speaking sincerely and in good faith, doubt natural principles.

Against which the Pyrrhonists oppose, in a word, the uncertainty of our origin, which includes that of our nature; and this the dogmatists have not yet answered since the world began.

Here is open war between men, in which each must take part, and must, necessarily, range himself on the side of dogmatism, or on that of Pyrrhonism ; for, whoever thinks of remaining neutral will be a Pyrrhonist par excellence. This neutrality is the essence of the cabal $:^{2}$ whoever is not against them is necessarily for them. They are not for themselves; they are neutral, indifferent, in suspense about every thing, not excepting themselves.

1 As a continuation of this paragraph, Pascal had written: "And who doubts that, if we dreamed in company, and dreams by chance accorded with each other, as is common enough, and we were awake in soitude, we should not believe matters reversed? In fine, as we often dream that we dream, piling one dream upon another, it is also quite possible that this life is itself only a dream, on whi.h others are grafted, from which we awake at death, during which we have the principles of the true and the good as little as during the natural slecp; these thoughts that agitate us being, perhaps, only illusions, similar to the lanse of time, and to the vain fancies of onr dreams" (crased).

2 VAR. OF MS.: "For neutrality, which is the part of the wise, is the most ancient dogma of the Pyrrhonian cabal" (erased). 
What shall man do, then, in this state? Shall he donbt of every thing? shall he doubt that he is awake, if we pinch him or burn him? shall he doubt that he doubts? shall he doubt that he is? We cannot go so far as this; and I state it as a fact, that there never has been an absolute and perfect Pyrrhonist. Nature sustains impotent reason, and prevents her from reaching this point of extravagance.

Shall he say, then, on the contrary, that he possesses truth with certainty; he who, if you press him ever so little, can show no title to it whatever, and is forced to give up his hold?

What a chimera, then, is man! what a novelty, what a monster, what a chaos, what a subject of contradiction, what a prodigy! A judge of all things, feeble worm of the earth, depositary of the truth, cloaca of uncurtainty and error, the glory and the shame of the universe!

Who shall unravel this entanglement. ${ }^{1}$ Nature confounds the Pyrrhonists, ${ }^{2}$ and reason confounds the dogmatists. What shall become of you, then, $\mathrm{O}$ man! you who search out what is your true condition by your natural reason? You cannot avoid $^{3}$ one of these sects, nor subsist in either.

Know, then, ${ }^{4}$ haughty man, what a paradox you are to yourself. Humble yourself, impotent reason; be silent, imbecile nature; learn that man infinitely surpasses man, and hear

1 VAR. OF MS.: "Who shall unravel this entanglement? Certainly, this surpasses dognuatism, and Pyrrhonism, and all human philosopliy. Man surpasses man. Let us aceord, then, to the Pyrrhonists what they have so often proclaimed: that truth is not within our reach, and is not our game, that it does not dwell on earth, that it inhabits heaven, that it lodges in the bosom of God, and that we can know no more of it than what he is pleased to reveal to us. Let us learn, then, of the uncreated and incarnate truth our true nature" (erased).

2 VAr. of MS.: "One cannot be a Pyrrhonist without stifling nature; one cannot be a dogmatist without renouncing reason" (erased).

3 "You cannot avoid one of these sects." That is, you cannot avoid lalling into one or the other of these seets ; for, if you are not a dogmatist, you are a Pyrrhonist, and vice versa. And you cannot, notwithstanding remain steadfast in either.-Havet.

"VAR. uf MS. : "Let us lcarn then" (erased). 
from your master your true condition, which you are ignorant of. Listen to God.

For, in fine, if man had never been corrupted, he would enjoy in his innocence both truth and happiness with assurance. And if man had never been any thing more than a corrupted being, he would have no idea either of truth or of leatitude. But, unhappy as we are, and more than if there were no grandeur in our condition, we have an iclea of happiness, and we cannot reach it; we feel an image of the truth, and possess but falsehood: incapable of absolute ignorance, and of certain knowledge, so manifest is it that we have been in a degree of perfection from which we are unfortunately fallen!

It is an astonishing thing, nevertheless, that the mystery most remote from our knowledge, which is that of the transmission of sin, is a thing without which we can have no knowledge whatever of ourselves! For there is, without doubt, nothing that shocks our reason more than to say that the sin of the first man has rendered those guilty who, being so far removed from this source, seem incapable of participating in it. This inference appears to us not only impossible, it seems to us even very unjust; for what is there more contrary to the rules of our miserable justice than to damn eternally a child incapable of will, for a sin in which he appears to have so little part, that it was committed six thousand years before he was in being?

Certainly, nothing strikes us more rudely than this doctrine; and yet, without this mystery, the most incomprehensible of all, we are incomprehensible to ourselves. The knot of our condition takes its twists and turns in this abyss; so that mar is more inconceivable without this mystery, than this mystery is inconceivable to man.'

1 Here Pascal had added these lines: "Whence it appears that God, wishing to render the problem of our own being unintelligible to ourselves, vas hidden the solution of it so high, or, more properly speaking, so low, that we are altogether incapable of eoming at it; so that it is not by the lianghty perturbations of our reason, put by the simple submission of the -eason, that we can truly know ourselves. 
T Second part. That man without faith can know neither the true good nor justice.-All men seek to be happy; this is without exception. Whatever different means they may employ, they all tend to this end. This is why some go to war, and why others do not, that both parties have the same desire. accompanied by different views. The will never takes the least step but towards this object. It is the motive of all the actions of all men, even of those who hang themselves.

And yet, after the lapse of so many years, no one has erer reached, except by faith, this point upon which all keep their eyes continually fixed. All complain: princes, subjects; nobles, plebeians ; old, young ; strong, weak ; learned, ignorant; healthy, unhealthy; of all countries, of all times, of all ages, and of all conditions.

An experience so lengthened, so continued, and so uniform, ought to convince us of our inability to arrive at the good by our own efforts; but the example does not instruct us. It is never so perfectly similar, that there is not some slight difference; hence it is that we expect our hope will not be deceived on this occasion as on the other. And thus the present never satisfying us, hope cheats us, and from evil to evil leads us in to death, which is an eternal consummation of ill.

What then is this cry of avidity and impotency, except that there was formerly in man a true happiness, of which there remains to him now only a mark, a trace wholly void, which

"These foundations, solidly established on the inviolable authority of religion, teach us that there are two truths of faith equally constant: one, that man, in the state of ereation, or in that of grace, is raised above all tature, made like unto God, and participating in his divinity; the other, that in the state of corruption and sin, he is fallen from this state, and made like unto the brutes. These two propositions are equally constant and certain. The Scripture manifestly declares them to us, when it says in some places: 'Delicia mea esse cum filiis hominum. Effundam spiritum meum super omnem carnem. Dii estis,' ete.; and when it says in other places: 'Omnis caro fcenum. Homo assimilatus est jumentis insipientibus 't similis factus est illis. Dixi in corde meo de filiis hominum'... (Eceles. iii); whence it clearly appears that man, by grace, is become like unte God, and participating in his divinity, and that, without grace, he is like into the brute beasts" (erased). 
he vainly tries to fill with all that surroun ds him, seeking from things absent the succor which he cannot obtain from things present, but which are incapable of it, because this infinite abyss cannot be filled but by an infinite and immuiable object, that is, but by God himself.

He alone is man's true good; and since man has left God it is a strange thing, that there is nothing in nature that has been able to fill his place: stars, heaven, earth, elements, plants, cabbages, pears, animals, insects, calves, serpents, fevers, plagues, war, famine, vices, adultery, incest.' And since he has lost the true good, every thing may equally appear to him such, even his own destruction, although so contrary to God, reason, and nature combined.

Some seek it in authority, others in curiosities and science, others in voluptuous pleasures. Others, who have in fact approached nearer to it, have considered that the universal good, which all men desire, necessarily cannot be in any particular thing which can be possessed only by one, and which, being divided, afflicts its possessor more, by the lack of the part which he has not, than it contents him by the enjoyment of that which he has. They have understood that the true good ought to be such, that all might possess it at once, without diminution and without envy, and that no one might lose it against his will.

And their reason is that this desire being natural to man, since it is necessarily in all, and that he cannot but have it, they conclude ....2

q Philosophers.-We are full of things that impel us to the outward.

Our instinct makes us feel that we must seek our happinese

1 "Des crimes les plus noirs vous souillez tous vos dieux;

Vous n'en pupissez point qui n'ait son maître aux cicux:

La prostitution, l'adultère, l'inceste,

Le vol, l'assassinat, et tout ce qu'on déteste,

C'est l'exemple qu'à suivre offrent vos inmortels.

Corneilze, Polyeucte, V, iii.

- Pascal did not finish this sentence. 
in ourselves. Our passions drive us to the outward, even when there are no objects to excite them. Outward objects tempt us of themselves and call us, even when we are not thinking of them. And thus philosophers have vainly said: Return into yourselves, you will there find your good; men do not believe them, and those who do believe them are the most empty and the greatest fools.

- Stoics. - . . They conclude that we ean do always what we ean do sometimes, and that, sinee the desire of glory prompts some to do a thing well, others can do so also. These are feverish movements, which health cannot imitate. Epictetus concluded that sinee there are steadfast Christians, each may become such.

- The three desires' have made three sects, and the philosophers have done nothing else than follow one of the three.

- We know the truth, not only by the reason, but also by the heart; it is by the heart that we know first prineiples, and it is in vain that reasoning, which has no part in it, tries to combat them. The Pyrrhonists, whose only object this is, strive for it in vain. We know that we do not dream, however impotent we may be to prove it by reason; this impotence proves nothing more than the feebleness of our reason, but not the uncertainty of all our knowledge, as they pretend. For the knowledge of first principles, as of space, time, movement, numbers, is as certain as any of those that our reasonings give us. And it is on this knowledge of the heart and instinct that reason must support herself, and on this she founds her whole procedure. 'The heart feels that there are three dimensions in space, and that numbers are infinite; and the reason demonstrates in course, that there are no two square numbers of which one is double the other. Principles are felt, iropositions are proved; and all with certainty, although in different ways. And it is as ridiculous for the reason to demand of the heart proofs of its first principles, in order to be

1 Voluptuonsuess, which made the Epicureans; pride, which made the Stoics; curiosity, libido sciendi, which made the Dogmatic philosophers. 
willing to consent to them, as it would be for the heart to demand of the reason a feeling of all the propositions that it demonstrates in order to be willing to receive them.

This impotency ought to serve, then, only to humble the eason, that would judge of every thing, but not to combat our certainty, as if there were nothing but reason eapable of nstrecting us. Would to God, that, on the contrary, we never had need of it, and that we knew all things by instinct and sentiment! But nature has refused us this good, and she has given us, on the contrary, but very little knowledge of this kind; all other knowledge can be acquired only by reasoning.

Hence it is that those to whom God has given religion by sentiment of heart are very happy and very legitimately persuaded. But to those who have it not we ean give it only by reasoning, until God gives it to them by sentiment of heart, without which faith is but human, and useless for salvation.

II.

... This internal war of the reason against the passions has been the cause why those who wished for peace, have separated into two sects.' Some have wished to renounce the passions, and become gods; others have wished to renounce reason, and become brute beasts (Des Barreaux). But neither party has been able to do this, and reason always remains to accuse the baseness and the injustice of passion, and to trouble the repose of those who abandon themselves to it; and the passions are sways alive in those even who wish to renounce them.

\section{III.}

Instinct, Reason.-We cannot become invincible to all dog matism; we have an idea of the truth, invincible to all Pyrrhonism.

T We desire truth, and find in ourselves only uncertainty

2 "Into two sects." The Stoics and the Epicurcans.--Havet. 
We seek happiness, and find only misery and death. We are incapable of not desiring truth and happiness, and are incapable either of certainty or lappiness. This desire is left us, as much for our punishment, as to make us feel whence we have fallen.

\section{IV.}

If man is not mado for God, why is he happy only in God? If man is made for God, why is he opposed to God?

\section{V.}

Man knows not in what rank to place himself. He is obviously astray, and fallen from his true place without being able to find it again. He seeks it everywhere with uneasines and without swecess in impenetrable darkness. 


\section{CHAPTER XI.}

[OF THE FINITE AND THE INFINITE.-THAT MAN, IN WAGERING THAT GOD EXISTS, WAGERS WITH CERTAINTY AND HAS EVERY THING TO GAIN.ON THE KNOWLEDGE OF GOD.]

INFinite, Nothing.-Our soul is thrown into the body, wherein it finds number, time, dimension. It reasons thereon, and calls this nature, necessity, and cannot believe any thing else.

Unity joined to the infinite augments it in nothing any more than a foot added to an infinite measure. The finite is annihilated in the presence of the infinite, and becomes a pure nothing. Thus our mind before God; thus our justice before the divine justice.

There is not so great a disproportion between our justice and God's, as between unity and infinity.

The justice of God must be great as his mercy: now, the justice toward the reprobates is not so great, and ought to shock us less, than the mercy toward the elect.

We know that there is an infinite, and know not its nature. As we know that it is false that numbers are finite, then it is true that there is an infinite in number: but we know not what it is. It is not true that it is even, it is not true that it is odd; for, in adding unity to it, it does not change its nature; yet it is a number, and every number is odd or even: it is true that this is understood of all finite numbers.

Thus we may easily know that there is a God without knowing what he is.

We know, then, the existence and the nature of the finite, because we are finite and extended as it is.

We know the existence of the infinite, and know not its uature, because it has extent like us, but it has no limits jke us. 
But we know neither the existence nor the nature of God, because he has neither extent nor limits.

But by faith we know his existence; by glory' we shall know his nature. Now, I have already shown that we may easily know the existence of a thing without knowing its nature.

Let us speak now according to the light of nature.

If there is a God he is infinitely incomprehensible, since, having neither parts nor limits, he has no proportion to us : we are then, incapable of knowing either what he is, or whether he is. This being true, who will dare to undertake to resolve this question? It is not we, who have no proportion to him.

Who, then, shall blame, as not being able to give a reason for their belief, those Christians, men who profess a religion for which they ean give no reason? They declare, in exposing it to the world, that it is a folly, stultitiam $;^{2}$ and then you complain that they do not prove it! If they proved it, they would not keep their word: it is in lacking proofs, that they do not lack sense. Yes; but though this may excuse those who offer it such, and take away the blame for producing it without reason, this does not excuse those who receive it. Let us examine this point then, and say: God is, or he is not. But to which side shall we incline? Reason cannot decide it at all. There is an infinite chaos that separates us. A game is being played, at the extremity of this infinite distance, in which heads or tails must come up. Which will you take? By reason you can wager on neither; by reason you can hinder neither from winning. ${ }^{3}$

Do not, then, charge with falsehood those who have made a choice; for you know nothing about it.-No: but I blame

: Glory, in the Christian language, means the glorious state of the tect m heaven.-Ilavet.

Saint Paul, 1 Cor. i, 18.

3 Rousseau determined his own destiny by the falling of a stiek; Fichte created God, for some long-haired German students, in a lecture; Pasca here determines the existenee of the Deity by a game of pitch-penny

"Heads, I win; tails, you lose."-Ed. 
them for having made, not this choice, but a cnoice; for, although he who takes heads, and the other, are in the same fault, they are both in fault: the proper way is not to wager.

Yes, but you must wager: this is not voluntary, you are cmbarked. Which will you take then? Let us see. Since a choice must be made, let us see which interests you the least. You have two things to lose, the true and the good; and two things to stake, your reason and your will, your knowledge and your beatitude; and your nature has two things to shun, error and misery. Your reason is not more wounded, since a choice must necessarily be made, in choosing one rather than the other. Here is a point eliminated; but your beatitude? Let us weigh the gain and the loss, in taking heads that God exists. Let us weigh these two cases : if you gain, you gain all; if you lose, you lose nothing. Wager then that he is, without hesitation.-This is admirable: yes, it is necessary to wager; but perhaps I wager too much.-Let us see. Since there is equal hazard of gaining or losing, if you had to gain but two lives for one, still you might wager. But if there were three to gain, it would be requisite to play (since you are under the necessity of playing), and you would be imprudent, when you are forced to play, not to hazard your life in order to gain three in a play where there is equal hazard of loss and gain. But there is an eternity of life and happiness. And this being true, even were there an infinity of chances, only one of which might be for you, you would still be right in wagering one in order to have two, and you would act foolishly, being obliged to play, to refuse to play one life against three in a game where among an infinity of chances there is one for you, if there was an infinity of life infinitely happy to gain. But there is here an infinity of life infinitely happy to gain, a chance of gain against a finite number of chances of loss, and what you play is finite. This is quite settled $:^{1}$ wherever the infinite is, and where there is not an infinity of chances of loss against

1 That is, as M. Havet explains it, the balance of gain or loss is quito sottled. 
the chance of gain, there is nothing to balance, we must give all. And thus, when we are foreed to play, we must renounce reason in order to keep life rather than to hazard it for the infinite gain, as ready to come as the loss of nothingness.

For there is no use in saying that it is uncertain whether we shall gain, and that it is certain that we hazard; and that the infinite distance between the certainty of what we risk, and the uncertainty of what we shall gain, raises the finite good which we risk with certainty, to an equality with the infinite which is uncertain. It is not so : every player hazards with certainty to gain with uncertainty, and nevertheless he hazards certainly the finite to gain uncertainly the finite, without sinning against reason. The distance is not infinite between this certainty of what we risk and the uncertainty of gain; this is false. There is, in truth, an infinity between the certainty of gaining and the certainty of losing. But the uncertainty of gaining is proportioned to the certainty of what we hazard, aceording to the proportion of the chances of gain and loss; whence it comes that, if there are as many chances on one side as there are on the other, the game is playing even; and then the certainty of what we hazard is equal to the uncertainty of the gain: so far is it from being infinitely distant. And thus our proposition is of infinite foree, when there is the finite to hazard in a play where the chances of gain and loss are equal, and the infinite to gain. This is demonstrative; and if men are capable of any truths, this is one of them.

I confess it, I admit it. But, still, are there no means of seeing the trick of the game?-Yes, the Scripture, and the rest, etc.

Yes; but my hands are tied and my mouth is dumb: I am forcel to wager, and I am not at liberty: I am not unfettered, and so constituted that I cannot believe. What will you havo me do then?

It is true. But learn, at least, your inability to believe, since reason brings you to it, and yet yor cannot believe; try then to convince yourself, not by the augmentation of proofs of the 
existence of God, but by the diminution of your own passions. You would have recourse to faith, but you know not the way: you wish to be cured of infidelity, and you ask for the remedy: learn it from those who have been bound like yourself, and who would wager now all their goods; these know the road that you wish to follow, and are cured of a disease that you wish to be cured of. Follow their course, then, from its beginning; it consisted in doing all things as if they believed in them, in using holy water, in having masses said, etc. Naturally this will make you believe and stupefy you at the same time.-But this is what I fear.-And why? what have you to lose?'

1 "What language! Is this, then, the last word of human wislom? Has reason been given to man only to be sacrificed, and is the only means of believing in a Supreme Intelligence, as Paseal desires and says, that of stupefying ourselves? This terrible sentence pronouneed by snch a genius, and by a genius naturally so proud, would overwhelm humanity, if there were not something above genius itself, common-sense. 'This same reason that Paseal wishes, but in vain, to stifle, which has been given to erery man, and which no man lacks, in any conntry or at any time, and which persuades all, without the assistance of a positive revelation, or that of arbitrary demonstrations, of the existence of a spiritual soul, of the distinc. tion between good and evil, of duty and equity, of liberty and the responsibility of actions, of an eterual justice, of' a divine Providenee wlic has made every thing with weight and measure, who possesses in an infinite degree all the attributes that manifest themselves in his works, not only power and grandeur, but liberty, intelligenee, and life. All these grand beliefs, for which Pascal thirsts like the entire human race, common-sense has revealed, more or less impertectly, from the first day, to all men; and, while some wandering geniuses have had the misfortune to forget them, the most exalted geniuses have made it their glory to establish and diffuse them. They are the patrimony of the human race, its treasure in the midst of all its miseries. It is serving the human race very ill to undertake to rob it of these things with one hand, withont being very sure of returning them with the other. As if, moreover, when we brutalize mar, he were on that aecount any nearer to God!"-Cousin. We see, by th? above passage, that M. Cousin takes the word stupefy in its most rigororis acceptation. MM. Faugère and Maynard do not understand it in the same way.

Saint Paul: "Nemo se sedueat: si quis videtur inter vos sapiens esse in hoc sæculo, stultus fiat ut sit sapiens.--Sapientia enim hujus mundi, stultitia est apud Deum."-1 Cor. iii, 18, 19.

"In Pascal as in St. Panl, stupefy ought not to be taken literally, but in the profundity of the Christian sense."-Faugère.

"According to the excellent observation which I heard M. Ballaceh 
But to show you that this leads to it, this will diminish the passions, which are your great obstacles, etc.

Now, what harm will come to you in taking this course? You would be faithful, virtuous, humble, grateful, beneficent, a sincere friend, truthful. Truly, you would not be given up to infections pleasures, to false glory, or false joys; but would you not have other pleasures?

I say to you that you will gain by it in this life; and that at cach step you take in this direction, you will see so much ot the ecrtainty of gain, and so much of the nothingness of what you hazard, that you will acknowledge in the end that you have wagered for something certain, infinite, for which you have given nothing.

Oh! this discourse transports me, delights me, ete.

If this discourse pleases you and appears to you strong, know that it is made by a man who has put himself on his knees, before and after, to pray that Being, who is infinite and without parts, and to whom he entirely submits himself, that he would also subject you to himself for your good and his glory; and that thus power accords with this weakness.

Those who hope for salvation are happy in that, but they. have a counterpoise in the fear of hell.-Who has the most reason to fear hell, he who is ignorant that there is a hell, and who is certain of damnation, if there is one; or he who is surely persuaded that there is a hell, and has hope of being saved, if there is?

T I would very soon abandon these pleasures, they say, if I had faith. And I answer: You would very soon have faith, if you had abandoned these pleasures. Now, it is for you to begin. If I could, I would give you faith. I cannot do it;

make, many of these astonishing and exaggerated words that surprise us in the scraps of Paseal (such as this will stupefy you) may well be, in his ialpid stenography, only a sort of meemonic for securing his thought more callily and finding it again more ecrtainly. These words would not have "peared in public, and the thought would have been elothed at onee with more propriety and truth, in perfect harmony with the subject."-SainteBeuve. 
and, consequently I cannot prove the truth of what you say. But you may easily quit your pleasures, and experience whether what I say is true.

Thoever, having but a week to live, shall nut find that the way is to believe that all this is but a stroke of chance....

Now, if the passions do not hold us, a week and a hundred years are the same.

\section{II.}

The metaphysical proofs of God are so remote from the reasoning of men, and so complicated, that they make but little inipression; and even were this to serve some persons, it would be only during the instant of their seeing the demonstration, and an hour afterwards they would fear they had been deceived.

Quod curiositate cognoverint superbia amiserunt.

This is what produces the knowledge of God, which is deduced without Jesus Christ, which is to communicate without mediator, with the God whom we have known without mediator. Whilst those who have known God by a mediator know their misery.

Jesus Christ is the object of all, and the centre whither all tends. Whoever knows him knows the reason of all things.

Those who go astray, go astray only because they do not see one of these two things. We can then indeed know God without knowing our misery, and our misery withont knowing God; but we cannot know Jesus Christ without knowing both God and our misery.

And this is why I will not undertake here to prove by natural reasons, either the existence of God, the 'Trinity, or the immortality of the soul, or any thing else of this nature; not snly because I should not feel myself strong enough to find in nature wherewith to convince hardened atheists, but also beeause this knowledge, without Jesus Curist, is useless and iarren. Even were a man persuaded that the proportions of numbers are truths immaterial, eternal, and dependent on a 
primary truth in which they subsist, and which we call God, I should not find him much advanced towards his salvation.

\section{III.}

It is a surprising thing that no canonical author has ever made use of nature to prove the existence of God. They al. tend to establish the belief of this truth: David, Solomon, etc., have never said: There is no void, therefore there is a God. They must have been more able than the ablest of those who have come after them, who have all made use of it. This is very considerable.'

-... If it is a mark of weakness to prove the existence of God by nature, do not despise the Scripture for it: if it is a mark of strength to have known these contrarieties, esteem the Scripture for il.

\section{IV.}

... For we must not mistake ourselves, we are automaton" as much as mind; and hence it comes that the instrument by

1 "No, truly, this is not very eonsiderable; for nothing is more manifestly false. The holy Seriptures are not a course of physies: they do not employ the language of science, and still less that of any particular system; they do not say: There is no void, therefore there is a God, a whimsical argument which is to be found nowhere, exeept perhaps in some obseure Cartesian; but they teach, and this on every page, and in every way, that the Heavens declare his glory... Does not St. Paul say: 'That whieh may be known of God is manifest in them; for God hath slowed it unto them. For the invisible things of him from the ereation of the world are clearly seen, being understood by the things that are made, even his eternal power and Godhead." "-Cousin.

2 "M. Pascal spoke little of the seienees; nevertheless, when the oecasion presented itself, he gave his opinion on things of which people were speaking. For example, in regard to the philosophy of M. Descartes, he said without hesitation what he thought; he was of his opinion in regard to the automaton, and was not of his op.nion in regard to subtile matter, whieh he ridienled very mueh; but he conld not endure his manner of explaining the formation of all things, and he very often said: 'I cannot pardon Descartes; he would very much like, in all his philosophy, to dispensw 7ith God; but he has not been able to eseape aecording him a fillip to put the world in motion; after that he has nothing more to do with God."' -Mademoiselle Périer. 
which persuasion is made, is not the only demonstration. How few things are demonstrated! Proofs convince only the mind. Custom makes our strongest and hardest proofs; it influences the automaton, which carries along the mind without its being aware of it. Who has demonstrated that there will be a tomorrow, and that we shall die? and what is more believed? It is custom, then, that persuades us of these things; it is custom that makes so many Christians, it is custom that makes Turks, pagans, trades, soldiers, etc. In fine, we must have recourse to custom when once the mind has seen where the truth is, in order to drench and dye ourselves in this belief, which escapes us at every hour: for to have the proofs always present would be impossible. We must acquire a more easy belief, which is that of habit, which, without violence, without art, without argument, makes us believe things, and inclines all our powers to this belief, so that our soul falls into it naturally. When we believe only from the force of conviction, and the automaton is inclined to believe the contrary, it is not enough. Both our powers must be made to believe: the mind, by reason, which suffices to have examined but once; and the automaton, by custom, which does not permit it to incline to the contrary. Inclina cor meum, Deus. 


\section{CHAPTER XII.}

[THE MARKS BY WHICH WE MAY KNOW THAT A RELIGION IS TRUE, AND IOW THE CHRISTIAN ReLIGION CARRIES IN ITSELF the PROOFS OF its TRUTH].

\section{I.}

True religion should be marked by the obligation to love God. This is very just. And yet no other than ours has ever enjoined it; ours has. It ought also to have recognized the concupiscence and the impotency of man; ours has. It ought to have brought us remedies; one is prayer. No religion has asked of God to love and follow him.

II.

The true nature of man, his true good, and true virtue, and true religion, are things the knowledge of which is inseparable.

T After having understood the nature of man.-A religion, to be true, must have known our nature. It should have known its greatness and its littleness, and the reason of both. What religion has known this but the Christian?

\section{III.}

Other religions, as those of the pagans, are more popular, for they are external; but they are not for people of capacity A religion purely intellectual would be better adapted to the capable; but it would be of no use to the people. The Christian religion alone is adapted to all, being a mixture of the 3xternal and the internal. It elevates the people internally, and abases the proud externally; and is not perfect without both, for it is necessary that the people should understand the spirit of the letter, and that the learned should submit their spirit to the letter. 
The external must be joined to the internal to cbtain of God, that is, that we bend the knee, pray with the lips, etc., in order that proud man, who has been unwilling to submit himself to God, may now be submitted to the creature. To ex pect relief from the external is superstition; not to be willing to join it to the internal is to be proud.

\section{IV.}

No other religion has proposed to us to hate ourselves. No other religion, then, can please those who hate themselves, and who are seeking a truly amiable being. And they, if they had never heard of the religion of a humiliated God, would embrace it incontinently.

T ... No other has recognized man to be the most excellent creature. Some who have known well the reality of his excellence have taken for cowardice and ingratitude the low sentiments that men naturally have of themselves; others, who have known well how effective is this baseness, have treated as supremely ridiculous those sentiments of greatness which are also natural to man.

Raise your eyes toward God, say some; consider him whom you resemble, and who made you to adore him. You may become like him; wisdom will make you equal to him, if you will follow it. Others say: Bend your eyes to the ground, miserable worm that you are, and regard the brutes, whose companion you are.

What, then, shall become of man? Shall he be equal tc God, or to the brutes? What a frightful distance! What shall we be, then? Who does not see by all this that man is astray, that he is fallen from his place, that he seeks it with anxiety, that he can never find it again? And who, then, will direct him to it? The greatest men have not been able to do it.

To religion but ours has taught that man is born in sin; wo sect of philosophers has evcr taught it; none, then, has spoken the truth. 


\section{V.}

That God wished to be concealed.-If there were but one religion, God would be very manifest. If there were no mar tyrs but in our religion, the same.

... Thus, God being concealed, every religion that does not say that God is eoncealed is not true; and every religion which does not render a reason for this, is not instructive. Ours does all this: Vere tu es Deus absconditus.

- Perpetuity.-This religion, which consists in the belief of man's fall from a state of glory and communication with God, into a state of sorrow, penitence, and estrangement from God, but that after this life we shall be re-established by a Messiah who is to come, has always been in the world. All things have passed away, but this has remained, for which all other things exist.

Men in the first age of the world were led into all kinds of disorders, but there were, nevertheless, saints, such as Enoch, Lamech, and others, who waited in patience for Christ, prom ised from the beginning of the world. Noah saw the malice of men in its highest degree; and he merited to save the world in his own person, by the hope of the Messiah, of whom he was the figure. Abraham was surrounded with idolators, when God made known to him the mystery of the Messiah, whom he saluted a long way off. In the days of Isaac and Jacob, abomination was spread over the whole earth; but these saints lived in faith ; and Jacob, dying, and blessing his children, exclaims, in a transport that interrupts his discourse, "I wait, O my God, the Saviour whom thou hast promised: Salutare tuum exspectabo, Domine."

The Egyptians were infected both with idolatry and magic; the people of God, even, were carried away by their example. But, nevertheless, Moses and others believed in him whom they saw not, and adored him, regarding the eternal gifts that be prepared for them.

Then the Greeks and the Latins enthroned false deities the poets made a hundred different theologies; the philosophers 
were divided into a thousand different sects : and yet there were always in the heart of Judæa some chosen men, who foretold the coming of this Messiah, who was known to them alone.

At length, in the fulness of time, he came: and since, we have seen so many schisms and heresies spring up, so many States overturned, so many changes in all things; and this Church, which adores him who has always been adored, has sulsisted without interruption. And what is wonderful, incomparable; and altogether divine is, that this religion, which has always endured, has always been combated. A thousand times has it been on the eve of universal destruction; and every time that it has been in this condition, God has raised it up by some extraordinary stroke of his power. It is astonishing that it has maintained itself without yielding or submitting to the will of tyrants. For it is not strange that a State subsists even when its laws are sometimes made to yield to necessity, but that....

T Figures.-God, wishing to form to himself a holy people, whom he would separate from all other nations, whom he would deliver from their enemies, whom he would put in a place of rest, promised to do it, and foretold by his prophets the time and the manner of his coming. And, in the mean while, to confirm the hope of his elect in all time, he exhibited to them the image of it, without ever leaving them without some assurances of his power and of his will for their salvation. For, in the creation of man, Adam was the witness of it, and the depositary of the promise of the Saviour, who was to be born of the woman. When men were still so near to the creation that they could not have forgotten their creation and their fall, when those who had seen Adam were no longer in the world, God sent Noah, whom he saved, and drowned the whole world by a miracle which sufficiently indicated ooth his power to save the world, and his intention to do so, aud raise up from the seed of the woman him whom he had promised. This miracle is sufficient to confirm the hope of men.... 
The memory of the deluge being still so fresh among inen, while Noah still lived,' God made his promises to Abraham, and while Shem still lived, God sent Moses, ete....

\section{VI.}

States would perish if their laws did not often yield to no. cessity. But religion has never suffered this, and it has never made use of it. But it must have such compliances or miracles. It is not strange that States preserve themselves by yielding, and this is not, properly speaking, maintaining themselves; and still they would perish, at last : there is not one of them that has endured for a thousand years. ${ }^{2}$ But that this religion has always maintained itself inflexible,-this is divine.

\section{VII.}

There would be too much obscurity, if truth had not some visible signs. It is a wonderful sign that it has always been preserved in a Church and visible assembly. There would be too much light if there were but one opinion in this Church; but to know which is the true, we have only to see that which has always existed in the Church; for it is certain that the true has always existed in it, and that no false opinion has always existed in it.

Perpetuity.-Thus, the Messiah has always been believed. The tradition of Adam was still new in Noah, and in Moses. The prophets subsequently foretold him, at the same time predicting other things, which, being fulfilled from time to time, before the eyes of men, showed the truth of their mission, and, consequently, that of their promises touching the Messiah. Jesus Christ wrought miracles; so did the Apostles, who con. verted all the Gentiles; and all the prophecies being thus ful. filled, the Messiah is forever established.

1 Here Paseal is mistaken; Noah and Shem no longer lived at the mo ment spoken of in this paragraph.

2 VAR. of Port-Royal: "Fifteen hundred years." 


\section{VIII.}

In sceing the blindness and the misery of man, in beholding the whole universe dumb, and man without light, abandoned to himself, and, as it were, strayed into this nook of the univer'se, not knowing who placed him here, what he came to do, what shall become of him at death, I am affirighted like a man' who should be carried sleeping into a frightful desert island, and awakened without knowing where he is, and without means of escape. And for this reason I wonder how one does not go into despair at so miserable a state. I see other persons near me of like nature: I ask them whether they are better informed than I, they answer me no; and, thereupon, these miserable wanderers, having looked around them, and having seen a few pleasant objects, have given themselves up to them, and have become attached to them. For myself, I have not been able to become attached to them, and, considering how much more there is of appearance than any thing else than what I see, I have sought to discover whether God has not left some signs of himself.

I see many contrary religions, consequently they are all false, except one. Each wishes to be believed on its own authority, and threatens the incredulous. I do not therefore believe them on this account; any one can say this, any one can say he is a prophet. But I behold the Christian religion where I find prophecies, and these every one cannot make.

\section{IX.}

The only religion against nature, against common-sense. against our pleasures, is the only one that has always existed.

X.

The whole conduct of things ought to have for its object the establishment and the grandeur of religion; men ought to

I VAR. of MS.: "Like a child" (erased). 
have in themselves sentiments in conformity with what it teaches; and, in fine, religion ought so to be the object and the centre to which all things tend, that whoever shall know its principles will be able to give a reason both of the whole nature of man in particular, and of the whole conduct of the world in general.

9 ... They blaspheme what they know not. The Christian religion consists in two points. It is equally important for men to know them, and it is equally dangerous to be ignorant of them. And it is equally indicative of God's mercy to have shown signs of both.

And nevertheless they take as a ground for inferring that one of these points is not, what should make them infer the other. The sages who have said that there is a God have been persecuted, the Jews hated, the Christians still more. They have seen by the light of nature that, if there is a true religion on earth, the conduct of all things ought to tend thither as to their centre. And on this foundation, they undertake to blaspheme the Christian religion, because they understand it ill. They imagine that it consists simply in the adoration of a God considered as great, and powerful, and eternal; which is properly deism, almost as far from the Christian religion as atheism, which is wholly contrary to it. And thence they conclude that this religion is not true, because they do not see that all things concur in the establishment of this point,- - that God does not manifest himself to men with all the evidence that he might manifest.

But let them infer from this what they will against deism, they will infer nothing against the Christian religion, which properly consists in the mystery of the Redeeiner, who, uniting in himself the two natures, human and divine, has drawn men from the corruption of $\sin$ to reconcile them to God in his divine person.

It therefore teaches men these two truths: that there is a God whom men are capable of knowing, and that there is a corruption in their nature which renders them unworthy of it. It is equally important for men to know both of these points 
and it is equally dangerous for man to know God without knowing his misery, and to know his misery without knowing the Redeemer, who can cure him of it. One alone of these knowledges causes either the pride of the philosophers, who have known God and not their misery, or the despair of th atheists, who know their misery without the Redeemer. And thus, as it is equally necessary for man to know these two points, it is also equally merciful in God to have shown them to us. The Christian religion does it; it is in this that it consists. Let one examine the order of the world in regard to this point, and let one see whether all things do not tend to the establishment of the two fundamental principles of this religion.

\section{XI.}

If one does not know himself to be full of pride, ambition, concupiscence, weakness, misery, and injustice, he is blind indeed. And if, knowing this, one does not desire to be delivered from it, what can be said of a man? .... What can one have then but esteem for a religion which knows the defects of man so well, and desire for the truth of a religion which promises for him remedies so desirable?

\section{XII.}

Proof.- $1^{\circ}$. The Christian religion by its establishment: by itself establishes so strongly, so mildly, being so contrary to nature. $-2^{\circ}$. The holiness, the loftiness, and the humility of a Christian soul. $-3^{\circ}$. The wonders of the holy Scripture $-4^{\circ}$. Jesus Chirist in particular.- $5^{\circ}$. The apostles in particular. $-6^{\circ}$. Moses and the prophets in particular.- $7^{\circ}$. The Jewish people. $-8^{\circ}$. The prophecies. $-9^{\circ}$. Perpetuity. No religion has perpetuity. $-10^{\circ}$. The doctrine that renders a reason for every thing. $-11^{\circ}$. The holiness of this law. $-12^{\circ}$. By the conduct of the world.

It is indubitable that after this we ought not to refuse, considering what life is, and this religion, to follow the inclination of following it, if it comes in our heart; and it is certain that there is no occasion of laughing at those who follow it. 


\section{CHAPTER XIII.}

[TIIAT TIIE CHRISTIAN RELIGION IS THE ONLY ONE THAT MAKES MAN UNDERSTAND TIE CONTRADICTION OF HIS MISERY AND IIIS GREATNESS ; AND TIIAT TIE PHILOSOPHIC SECTS ARE UNABLE TO GIVE IHIS KNOWLEDGE.]

I.

After having explained the incomprehensibility.'-The greatness and the misery of man are so visible, that the true religion must, necessarily, teach us both that there is some great principle of greatness in man, and that there is a great prineiple of misery. It must, therefore, give us a reason for these astonishing contrarieties.

In order to make man happy, religion must show him that there is a God; that we are obliged to love him; that our true felicity is to be in him, and our only evil to be separated from him; that it recognizes that we are full of darkness, which prevents us from knowing him and loving him; and that thus our duties obliging us to love God, and our passions turning us from it, we are full of injustice. Religion must render us a reason for this opposition which we have to God and to our own good; she must teach us the remedies for these impotencies, and the means of obtaining these remedies, Let us examine on this subject all the religions in the world, and let us see whether there is one of them other than the Christian that would satisfy us in this respect.

Shall it be the philosophers, who offer us as the chief good the goods that are in us? Is this the true good? Have they found the remedy for our ills? Is it to cure the presumption of man to make him equal to God? Those who have made us equal with the brutes, and the Mahometans who have given

1 'That is: After having shown that man is incomprehensible. 
as the pleasures of the world for the chief good, even in eternity,-have they given us a remedy for our passions?

What religion will teach us then to cure our pride and consupiscence? What religion, in a word, will teach us our good, our duties, the weaknesses that turn us from them, the eanse of these weaknesses, the remedies that can cure them, and the means of obtaining these remedies? All the other religions lave not been able to do it. Let us see what the Wisdom of God will do.

Do not, it says, expect either truth or consolation from men. I am that which formed you, and which alone can tell you who you are. But you are now no longer in the state in which I formed you. I created man holy, innocent, perfect; I filled him with light and intelligence; I communicated to him my glory and my wonders. Then the eye of man saw the majesty of God. Then he was not in the darkness that blinds him, nor in the mortality and the miseries that afflict him. But he could not endure so much glory without falling into presumption. He wished to render himself the centre of himself, and independent of my aid. He withdrew himself from my dominion, and, making himself equal to me, by the desire of finding his felicity in himself, I abandoned him to himself; and, causing the creatures to revolt against him, which had been subjected to him, I rendered them his enemies: so that to-day man has become like unto the brutes, and in such estrangement from me, that he has hardly a confused glimmering of his author: to such a degree have his powers been extinguished or disturbed! The senses, independent of the reason, and often masters of the reason, have carried him away in the search after pleasures. All creatures either afflict or tempt him, and rule over him, either subjecting him by their foree, or charming him by their blandishments, which is a domination still more terrible and more imperious. Such is the state in which men now are. There remains to them a powerful instinct of the happiness of their primitive nature, and they are plunged into the miseries of their blindness and desire, which have become their second nature. 
From this principle which I am explaining to you, you may recognize the cause of so many contrarieties which have astonished all men, and which have divided them into such dif ferent sentiments. Observe all the emotions of greatness and glory which the trial of so many miseries cannot stifle, and see whether the cause must not be in another nature.

Prosopopceia.-...It is in vain, $\mathrm{O}$ men! that you seek in yourselves the remedy for your miseries. All the light you kave only shows you that it is not in yourselves that you will find either truth or good. The philosophers have promised you both, and they have not been able to give you either. They know not either what is your veritable good, or what is your veritable state.' How should they give you remedies for your ills, when they have not even known them? Your principal maladies are pride, which separates you from God, concupiscenee, which attaches you to earth; and they have done nothing else than foster, at least one of these maladies. If they have given you God for your object, it has only been to exereise your pride: they have made you think that you are similar to him by your nature. And those who have seen the vanity of this pretension have hurled you over the other precipice, in teaching you that your nature was similar to that of brutes, and have led you to seek your good in the desires that you have in common with animals. This is not the way of euring you of your iniquities, which these sages have not known. I alone can teach you who you are .... .

- If you are united to God, it must be by graee, not by nature. If you are humbled, it must be by penitence, not by nature.

1 After these words Paseal had written at first: "I am the only me that can teach you these things; I teach them to those who listen to me. The books that $I$ have put in the hands of men diseover them very elearly. But I have not wished that this knowledge should be so open. I teach men what ean render them happy; why do you refuse to hear me? Seck no satisfaction on the eartl : hope nothing from men. Your good is only in God, and the sovereign felieity consists in knowing God, in uniting ourselves to him in eternity. Your duty is to love him with all your heart He has ereated you...." (erased). 
T ... These two states being explained, it is impossible that you should not recognize them. Trace your own emotions, observe yourselves, and see whether you will not find the living characters of these two natures. Would so many contradictions be found in a simple subject?

T...I do not mean that you should submit your belief to me without reason, and do not pretend to subject you with tyranny. Neither do I pretend to give you a reason for all things; and in order to reconcile these contrarieties, I mean to show you clearly, by convincing proofs, divine marks in myself, which shall convince you of what $I$ am, and clothe me with authority by marvels and proofs which you cannot refuse; and that, in course, you may surely believe the things that $I$ teach you, when you shall find in them no cause for rejecting them, except that you may be unable by yourselves to know whether they are or not.'

T If there is a single principle of every thing, a single end of every thing: every thing thereby, every thing therefor True religion must teach us then to adore only him, and to love only him. But, as we find ourselves incapable of adoring what we do not know, of loving any other thing than ourselves, religion, which instructs us in these duties, must also instruct us in regard to this inability, and must teach us also the remedies. She apprises us that by one man ${ }^{2}$ every thing was lost, and the connection broken between God and us, and that by one $\operatorname{man}^{3}$ the connection has been restored.

We are born so adverse to this love of God, and it is so necessary, that it must be we are born guilty, or God would be unjust.

\section{II.}

Original $\sin$ is foolishness to men, but it is given out as such. You should not reproach me with the want of reason in this doctrine, since $\mathrm{I}$ give it out as being without reason. But this foolishness is wiser than all the wisdom of men, sapi-

1 The reader will observe that the divine Wisdom, mentioned abcve, it still speaking.

${ }^{2}$ Adam.

3 Jesus Christ. 
entius est hominibus.' For, without this, what will it be said that man is? His whole condition depends upon this imperceptible point. And how could he have discovered this by his reason, seeing that it is a thing above his reason, and that his reason, very far from discovering it by itself, revolts from it when it is presented to it?

\section{III.}

This duplieity of man is so obvious, that some have thought that we possess two souls: ${ }^{2}$ a simple subject appearing to them incapable of such great and so sudden varieties, from an immeasurable presumption, to a horrible dejection of heart.

- All these contrarieties, which seemed the most to lead me away from the knowledge of religion, are what have soonest led me to the true.

For myself, I confess that as soon as the Christian religion discovers the principle that human nature is corrupted and fallen from God, this opens our eyes to see everywhere the cliaracter of this truth: for nature is such, that it everywhere indicates a God lost, both in man and out of man, and a corrupt nature.

- Without this divine knowledge, what have men been able to do, except, either to elevate themselves by the internal sentiments which remains to them of their past greatness, or to a'base themselves in view of their present weakness ${ }^{3}$ For, not seeing the entire truth, they have not been able to arrive at perfect virtue. Some considering nature as uncorrupted, others

1 "The foolishness of God is wiser than men."-1 Cor., i, 25.

2 "Cette variation et contradietion qui se veoid en nous, si souple, a faict ( . ie aulcuns nous songent deux ames, d'aultres deux puissances, qui nous w'compaignent et agitent chaseune à sa mode, vers le bien l'une, l'aultre vers le mal: une si brusque diversité ne se pouvant bien assortir à un subiect simple,"-Montaigne.

s VAR. OF MS.: "In this impotency of seeing the entire truth, if they knew the dignity of our condition, they were ignorant of its corruption or if they knew its infirmity, they were ignorant of its exeelleney; and ollowing the one or the other of these routes, which made them see nature sither as uneorrupted, or as irreparable, they lost themselves either in pride or in despair" (erased). 
as irreparable, they have not been able to shun either pride or sloth, which are the two sources of all vices; since they cannot, except, either in abandoning themselves through cowardice, or in escaping from them through pride. For, if they knew the excellence of man, they were ignorant of his corrup tion; so that they indeed avoided sloth, but they lost them selves in pride. And if they recognized the infirmity of nature, they were ignorant of its dignity: so that they were, indeed, able to shun vanity, but it was by precipitating themselves into despair.

Whence comes the different sects of Stoics and Epicureans, of dogmatists and academics, etc. The Christian religion alone has been able to cure these two vices, not in expelling the one by the other, by the wisdom of the earth, but in expelling them both by the simplicity of the Gospel. For it teaches the just, that it exalts even to the participation of Divinity itself, that in this sublime state they still bear the source of all corruption, which renders them, during their whole life, subject to error, to misery, to death, to sin; and it proclaims to the most impious that they are capable of the grace of their Redeemer. Thus, making those tremble whom it justifies, and consoling those whom it condemns, it so justly tempers fear with hope, by this double capacity of grace and sin, which is common to all, that it humbles infinitely more than reason alone can, but without driving to despair; and that it exalts infinitely more than the pride of nature, but without puffing up: thereby showing that being alone exempt from error and vice, it belongs only to it both to instruct and to correct mankind.

Who, then, can refuse either to believe or to adore these celestial lights? For is it not clearer than the day that w fec, in ourselves the unalterable characters of excellence. And is it not equally veritable that we experience every hour the effects of our deplorable condition? What, then, do this thaos and this monstrous confusion proclaim to us, except she truth of these two states, with a voice so powerful that if is impossible to resist? 
IV.

We have no conception either of the glorious state of Adam, of the nature of his sin, or the transmission of it to ourselves.

These are things which took place in a state of nature altogether different from ours, and which exceed our present capacity. A knowledge of all this is of no utility for our deliverance; and all that is of importance for us to know is, that we are miserable, corrupted, scparated from fod, but redeemed by Jesus Chist; and of this we have admirable proofs in this world. Thus the two proofs of corruption and of redemption are drawn from the impious, who live in indifference to religion, and from the Jews, who are its irreconcilable enemies.

\section{V.}

Christianity is strange! It orders man to recognize that he is vile, and even abominable; and it orders hın to wish to be like unto God. Without such a counterpoise, this elevation would render him horribly vain, or this abasement would render him horribly abject.

- Misery leads to despair, pride leads to presumption. The incarnation discovers to man the greatness of his misery, by the greatness of the remedy that has been necessary.

\section{VI.}

... Not an abasement that renders us incapable of good, nor a holiness exempt from evil.

T No doctrine is better adapted to man than that which mforms him of his double capacity of receiving and losing trase, because of the doub's danger to which he is always exposed, of despair or pride.

\section{VII.}

Philosophers prescribe no sentiments adapted to the two itatrs. They inspire emotions of unalloyed greatness, and this 's not the state of man. They inspire emotions of unalloyed 
baseness, and this is not the state of man. We must liave emotions of baseness, not of nature, but of penitence; not to dwell therein, but to advance to greatness. We must have emotions of greatness, not of merit, but of grace, and after having passed through baseness.

\section{VIII.}

None is so happy, rational, virtuous, amiable, as a truo Christian.

T With how little pride does a Christian believe himself united to God! with how little abjection does he compar. himself to the worms of the earth! A fine manner of receiv ing life and death, good and evil!

\section{IX.}

Incomprehensible.-Not every thing that is incomprehensi ble lacks being. Infinite number. An infinite space equal to the finite.

Incredible that God should unite himself to us.-This con sideration is drawn only from the view of our baseness. But if you are sincere in this consideration, follow it out as far as I do, and acknowledge that we are in fact so base, that we are by ourselves incapable of knowing whether his mercy can render us capable of him. For I would indeed know whence this animal, which is avowedly so weak, has the right of measuring God's mercy, and of limiting it according to the suggestions of his fancy. Man knows so little what God is, that he knows not what he is himself : and, all troubled at the view of his swn state, he dares to say that God cannot render him capable of communion with him! But I would ask him whether God demands any thing else of him, than that he love him while knowing him; and why he believes that God cannot make himself the object of knowledge and love to him, since he is naturally capable of love and knowledge? It is unquestionable that he knows at least that he is, and that he loves something. Therefore, if he sees something in the darkness wherein be is, 
and if he finds some object of love among the things of earth. why, if God gives him some rays of his essence, shall he not be capable of knowing him and loving lim in the manner that it shall please him to communicate himself to us? There is, then, without doubt, an insufferable presumption in these sorts of reasonings, although they seem founded on an apparent humility, which is neither sincere nor rational, if it does not make us confess that, not knowing of ourselves who we 8.re. we can learn it only from God. 


\title{
CH A P TER XIV.
}

\author{
[OF REASON AND FAITH.]
}

\section{I.}

Trie last attainment of reason is to know that there is an infinity of things that surpass it. It is but feeble if it has not gone so far as to know this. If natural things surpass it, what shall we say of those that are supernatural?

T Submission. - It is necessary to know where to doubt, where to be assured, and where to submit. ${ }^{2}$ Who does not thus, understands not the force of reason. There are those who offend against these three principles, either affirming every thing as demonstrative, for want of a knowledge of demonstration; or doubting every thing, for want of knowing where

1 Pascal sometimes doubts, or seems to doubt; he conceives and expresses his doubt in a terrible manner; but he has also, or he believes he has, the remedy. His faith, I think, was anterior to his doubt; when this doubt supervened, it found a place only in the interval of what has been called his two conversions, and it was quickly recovered. If it be said that it returned to the charge, and always lodged itself, more or less, in the bosom of his faith, this was only a manner, after all, of being badly lodged and badly off; and Pascal would not leave it day or night, in peace or in rest. M. Vinct admirably says of a young man of this period: "... Skepticism by a thousand means sought to penetrate into his mind; but his faith fortified itself, imperturbably increased in the midst of the storms of his thought. It may be said that doubt and living faith, the one transient, the other immutable, were born for him the same day; as if God, in allowing the enemy to make breaches in the outworks, had wished to fortify the heart of the place with an impregnable rampart." This fino sentence, which so well expresses one of the mysteries of the inward Christian life, may be applied with much verisimilitude to the true Pascal -Sainte-Beuve.

2 VAr. of MS. : "It is neessary to have these three qualities: Pyrrhonist, Geometrician, submissive Christian; and they accord with each sther, and temper each other, in doubting where it is necessary, in assurng where it is necessary, in submitting where it is necessary" (erased). 
it is necessary to submit; or submitting to every thing, for want of knowing where it is necessary to judge.

\section{II.}

If we submit every thing to reason, our religion will have nothing in it mysterious or supernatural. If we violate the principles of reason, our religion will be absurd and ridiculous,

T Saint Augustine. The reason would never submit, if it did not judge that there are occasions when it ought to submit. It is right, then, that it submit, when it judges that it ought to submit.

\section{III.}

Piety is different from superstition. To carry piety to the extent of superstition is to destroy it. The heretics reproach us with this superstitious submission. It is doing what they reproach us with....'

\section{IV.}

There are two ways of inculcating the truths of our religion : one by the force of reason, the other by the authority of him who speaks. We do not use the last, but the first. We do not say: We must believe this; for the Scripture, which says it, is divine ; but we say, it must be believed for this or that reason, which are feeble arguments, reason being pliable to every thing.

T ... But those even who seem the most opposed to the glory of religion will not be useless to it for others. We will adduce as the first argument that there is something supernatural; for a blindness of this sort is not a natural thing; and if their folly renders them so opposed to their own good, it will serve to assure others by the horror of an example so deplorable and of a folly so worthy of compassion.

T This will be one of the confusions of the damned-to

1 Port-Royal thus completes the sentence: "to exact this submissior in things that are not matter of submission." 
see that they are condemned by their own reason, by which they pretended to condemn the Christian religion.

T There is nothing so in conformity with reason as this disavowal of reason.

Two excesses : to exclude reason, to admit only reason.

T It is not a rare thing that the world must be chided for too much docility. It is a natural vice, like incredulity, and as pernicious.

\section{V.}

Faith, indeed, affirms what the senses do not affirm, but not the contrary of what they perceive. It is above, and not contrary to.

\section{VI.}

If I had seen a miracle, they say, I should have been converted. How are they sure that they would do what they are ignorant of? They imagine that this conversion consists in an adoration of God like an intercourse and conversation such as they fancy. The conversion consists in annihilating ourselves before that universal Being who has been so often offended, and who can at any hour justly cast you away; in acknowledging that we are powerless without him, and that we have merited nothing from him but his displeasure. It eonsists in knowing that there is an invincible opposition between God and us; and that, without a mediator, there is no possibility of intercourse.

\section{VII.}

Be not astonished to see simple persons believe without reasoning. God gives them love of himself and hatred of themselves. They incline their heart to belief. One will never believe with a useful belief and with faith, if God does not incline the heart; and one will believe as soon as he shall incline it. This is what David knew well, when he said: Inrlina cor meum, Deus, in testimonia tua.'

1 Incline my heart, o Lord, unto thy testimonies. 


\section{VIII.}

Those who believe without having read the Testanents, bejieve because they have a quite holy internal disposition, and becanse what they hear said of our religion is in conformity with it. They feel that God has made them. They wish to love only God; they wish to hate only themselves. They feel that they have not the strungth by themselves; that they are incapable of going to God; and that, if God does not come to them, they can have no communication with him. And they hear it said in our religion that we must love only God, and hate only ourselves: but that, being wholly corrupt and inca pable of God, God has made himself man in order to unite himself to us. Nothing more is requisite in order to persuade men who have this disposition in therr hearts, and who have this knowledge of their duty and of their incapacity.

\section{IX.}

Those whom we see Christians without the knowledge of prophecies and proofs, do not fail to be as good judges of religion as those who have this knowledge. They judge of it by the heart, as the others judge of it by the mind. It is God limself who inclines them to believe; and thus they are very efficaciously persuaded.'

I admit indeed that one of these Christians who believes without proofs, will not have perhaps wherewith to convince an infidel who will say as much of himself. But those who know the proofs of religion will prove without difficulty that this infidel is really inspired of God, although he might not be able to prove it himself. For God having said in his prophets (who

1 VAR. of MS.: "It will be responded that the infidels would say the Bame thing; but I respond to this that we have proofs that God veritably inclines those whom he loves to believe the Cliristian religion, and that intilels have no proof of what they say; and thus our propositions being similar in terms, they differ in this-that one is without any proof, and the other is solidly proved" (erased). 
are unquestionably prophets), that in the reign of Jesus Christ he wonld pour out his spirit among all nations, and that the sons, the daughters, and the children of the Church should prophesy, it is indubitable that the spirit of God is upon them, and that it is not upon others. 


\section{CHAPTER X}

[TIIAT MAN, CONVINCED OF IIIS MISERY AND TORMENTED BY DOUBT, FINDS NOTHING EFFECTIVE OUT OF TIIE CHRISTIAN RELIGION; AND TIIAT TIIF HISTORY OF THE JEWS IS ONE OF THE INDUBITABLE FOUNDATIONS OF THIS RELIGION.]

\section{I.}

$\mathrm{W}_{\mathrm{E}}$ are ridiculous in seeking repose in the society of our fellows. Miserable like us, impotent like us, they cannot aid us ; we must die alone; we must act, then, as if we were alone ; and then, would we build magnificent houses, etc.? We should seek truth without hesitation; and if we refuse it, we testify that we regard the esteem of men, more than the search after truth.

T ... This is what I see and what troubles me. I look all around me, and see everywhere nothing but obseurity. Nature offers me nothing that is not a matter of doubt and disquietude. If I saw nothing in nature that indicated a Divinity, I should be determined to believe nothing of her. If $\mathbf{I}$ saw everywhere the signs of a Creator, I should peaceably repose in the Faith. But, seeing too much to deny, and too little to assure me, I am in a pitiable condition, and wherein I have a hundred times wished that, if God sustains her, she should show it without equivocation; and that, if the signs that she gives of it are deceptive, she would suppress them entirely; that she would say every thing or nothing, in order that I might see which course I ought to pursue. Whilst in the state in which I am, ignorant of what I am and of what I ought to do, I know neither my condition nor my duty. My whole heart inclines to know where is the true good, in order to follow it. Nothing would be to me too dear for eternity. ... 
9 I see the Christian religion founded on a former religion,' and the following is what I find effective in it. I do not speak here of the miracles of Moses, of Jesus Christ, and of the apostles, because they do not at first appear to be convincing, and because I wish to put in evidence here only those fundamental proofs of the Christian religion that are indubitable, and which cannot be doubted by any person whatever. . . .

I see, then, many religions in several quarters of the world, and in all times. But they have neither the morals that can please me, nor the proofs that ean arrest me. And thus I would have equally refused the religion of Mahomet, and that of China, and that of the ancient Romans, and that of the Egyptians, for this single reason-that one having no more marks of truth than another, and nothing that would necessarily lead to determination, reason cannot incline towards one rather than towards another.

But, in thus considering this inconstant and strange variety of manners and beliefs, in different periods, I find in a corner of the world a peculiar people, ${ }^{2}$ separated from all other nations of the earth, the most ancient of all, and whose histories precede, by several ages, the most ancient that we possess. I find, then, this great and numerous people, deseended from one man, who adore one God, and who are governed by one law which they profess to have received from his hand. They maintain that they are the only people in the world to whom God has revealed his mysteries; that all men are corrupt, and under the Divine displeasure; that they are all abandoned to their senses, and to their own understanding; and that hence come the strange irregularities and continual changes that take place among them, both in religions and customs; whilst they remain immovable in their conduct: but that God will not leave eternally the other peoples in this state of darkness; that a Liberator will come for all; that they are in the world to announce him; that they are expressly prepared to be the forerunners and heralds of this great advent. and to summon all 
nations to unite themselves with them in the expectation of this Liberator.

The meeting with this people astonishes me, and seems to me worthy of attention. I consider this law that they boast of having received from God, and I find it admirable. It is the first law of all, and of such a kind, that before even the word law was used among the Greeks, they had received and observed it, without interruption, for more than a thousand years. Thus I find it strange that the first law of the world should be also the most perfect, so that the greatest legislators have borrowed theirs from it, as it would appear by the law of the Twelve Tables of Athens, which was afterwards taken by the Romans, and as it would be easy to show, if Josephus and others had not treated this matter sufficiently.

- Advantages of the Jewish People.-In this inquiry the Jewish People attracts at first my attention by a number of remarkable and singular things that appear among them.

I see at first that this is a people wholly composed of brethren: and, whilst all others are formed by the assemblage of an infinite number of families, this, although so strangely populous, is sprung entirely from one man; and, thus all being one flesh, and members one of another, they compose a powerful state of one single family. This is unexampled.

This family, or this people, is the most aucient within the knowledge of men; a cireumstance which, it appears to me, entitles them to peculiar veneration, and particularly in the inquiry that we are now making; since, if God has from all time communicated himself to men, it is to them we must have recourse, in order to know the tradition of it.

This people is not only important by its antiquity; but it is still inore singular on account of its duration, which has always subsisted since its origin until the present time: for, whilst the peoples of Greece, and of Italy, of Lacedæmon, of Athens, of home, and others which came such a long time afterwards, have long since passed away, the Jews always remain; and in spite of the enterprises of so many powerful kings, who have a hundred times endeavored to destroy them, as the his 
torians testity, and as it is easy for us to judge by the natural order of things, during such a great number of years they have, nevertheless, always been preserved, and extending from the earliest times to the latest, their history comprises in its duration that of all our histories.

The law by which this people is governed is at the same time the most ancient law of the world, the most perfect, and the only one that has always been preserved without interruption in a State. This is what Josephus admirably maintains against Apion, and Philo, the Jew, in several places, where they show that it is so ancient, that even the name of law was not known to the most ancient nations for more than a thousand years after, so that Homer, who has treated of the history of so many States, has never used it. And it is easy to judge of its perfection by a simple perusal, in which we see that they have provided for all things with so much wisdom, so much equity, so much judgment, that the most ancient Greek and Roman legislators, having had some light from it, have borrowed from it their principal laws; which appears by what they call the Twelve Tables, and by the other proofs that Josephus gives of it. But this law is, at the same time, the most severe and the most rigorous of all in every thing regarding the worship of their religion, obligating this people, in order to retain them in their duty, to a thousand peculiar and painful observances, on pain of death. So that it is a very astonishing thing that this law should always be preserved, during so many ages, by a people so rebelious and impatient; whilst all other States have, from time to time, changed their laws, although they were much more easy of observance. The book which contains this law, the first of all, is itself the most ancient book in the world, those of Homer, of Hesiod, and others, not having made their appearance until six or seven hundred years afterwards.

\section{II.}

Sincerity of the Jews. - ... They preserve with affection and fidelity the book wherein Moses declares that they have been 
ungrateful towards God during their whole life, and that ne knows they would be still more so after his death; but that he calls heaven and earth to witness against them, and that he has taught them sufficiently: he declares that at length God, being irritated against them, will disperse them among all the nations of the earth : that, as they have irritated him in adoring gods that were not their God, so he will provoke them in ealling a people that is not his people; and desires that all his words be everlastingly preserved, and that his book be deposited in the Ark of the Covenant, to serve as a witness against them forever. Isaiah says the same thing, $\mathrm{xxx}, 8$. Yet this book, which dishonors them in so many ways, they preserve at the expense of their lives. This is an instance of sincerity without example in the world, and which has no root in nature.

There is much difference between a book which is made by an individual, and which he gives to a people, and a book which is made by a people itself. It cannot be doubted that the book is as old as the people.

All history that is not contemporary is suspicious; as the books of the Sibyls and of Trismegistus, and so many others that have obtained credence in the world, are false, and will be found to be false to the end of time. It is not thus with contemporary authors.

\section{III.}

What a difference there is between one book and another! I am not surprised that the Greeks had their Iliad, and the Egyptians and Chinese their histories. It is necessary only to see how this originated.

These fabulous historians were not contemporary with the events of which they wrote. Homer composed a romance, which he gave as such; for nobody doubted that Troy and Agamemnon had no more existed than the Golden Apple. He did not contemplate making a history of them, but merely a book of amusement. It was the only book of his time : the beauty of the work made the thing endure: everybody learnea 
It and spoke of it: it was necessary to know it; and every one knew it by heart. Four hundred years after the witnesses of the events were no longer living, no one knew, by his own knowledge, whether it was a fable or a history: they had merely learned it from their ancestors, this might pass for the truth.

\section{IV.}

That the law of Moses was figurative.-The creation and the deluge being past, and God having determined not again to destroy the world, nor to recreate it, nor to give such great manifestations of limself, began to establish a people on the earth, formed expressly, who was to endure until the coming of the people whom the Messiah would form by his spirit.

\section{V.}

God, wishing to show that he could form a holy people, possessing an invisible sanctity, and fill them with an eternal glory, has wrought visible wonders. As nature is an image of grace, he has done in the things of nature what he was to do in those of grace, in order that we might judge that he was able to do the invisible, since he easily achieved the visible. He saved, then, this people from the deluge; he caused them to be born of Abraham, he redeemed them from their enemies, and brought them into a place of rest.

The object of God was not to save from the deluge, and to cause a whole people to spring from Abraham, merely to introduce them into a fruitful land.' And even grace is but the figure of glory, for it is not the final object. It has been typified by the law, and itself typifies glory; but it is its type and principle, or cause.

The ordinary life of men is like that of the saints. They all seek their own satisfaction, and differ only in the object in whick ther place it. They cali those their enemies who ob-

1 The promised land. 
struct them, etc. God then has shown the power he has of giving invisible benefits, by that which he has shown that he had over visible things.

VI.

Figures.-God wishing to deprive his own of perishable goods, in order to show that it was not through impotency, created the Jewish people.

T The Jews had grown old in these earthly thoughts, that God loved their father Abraham, and all his flesh, that descended from it; that, for this reason, he had multiplied and distinguished them above all other nations, not suffering them to intermingle with them; that, when they languished in Egypt, he led them out of it with signal manifestations in their favor; that he fed them with manna in the wildernoss; that he brought them into a very fruitful land; that he gave them kings and a well-built temple for the offering of victims, that by the effusion of their blood they might be purified, and that he designed, at last, to send them the Messiah, in order to render them masters of the whole world. And he predicted the time of his coming.

The world having grown old in these carnal errors, Jesus Christ came in the time predicted, but not indeed with that splendor which was expected; and therefore, they did not believe that it was he. After his death, St. Paul came to teach men that all these things had been prefigured; that the kingdom of God was not carnal but spiritual; that the enemies of man were not the Babylonians, but his own passions; that God took no pleasure in temples built with hands, but in a pure and humble heart; that the cireumcision of the body was useliss, but that of the heart necessary; that Moses had not given them bread from heaven, etc.

But God, not having wished to discover these things to this people, which was unworthy of them, and, having wished, nevertheless, to predict them in order that they might be believed, had foretold the time clearly, and he had sometimes even expressed them clearly, but with many figures, in order 
that those who loved figurative things ${ }^{1}$ might rest in them, and that those who loved prefigured ${ }^{2}$ things might see thens.

\section{VII.}

The carnal Jews understood neither the greatness nor the lowliness of the Messiah, foretold in their prophecies. They misapprehended him in his greatness, as when it is said that the Messiah will be David's Lord, although his son; that he was before Abraham, and had seen him. They did not believe that he was so great, that he was eternal: and they equally misunderstood him in his humiliation and his death. The Messiah, they said, lives forever, and this man says that he will die. They did not, therefore, believe him to be either mortal or eternal: they sought in him only a carnal greatness.

\section{VIII.}

The Jews so loved figurative things, and were in such expectation of them, that they knew not the reality when it came at the time and in the manner predicted.

\section{IX.}

Those who have difficulty in believing, seek an argument in the fact that the Jews did not believe. If the truth was so clear, they say, why did they not believe? And half wished that they might believe, in order not to be stopped by the example of their refusal. But it is their very refusal that is the foundation of our belief. We should be much less disposed to believe, if they were of our faith. We should then have a more ample pretext. This is marvellous, - to have

1 "Figurative things." Port-Royal wrote on the margin: "That is, carnal things which served for figures."

2 "Prefigured things." Port-Royal wrote on the margin: "That is, spiritual truths prefigured by carnal things." Here Pascal interlined the words: "I do not express myself well." In fact, though we understand his thought, it is not here expressed with that admirable persficuity which is the gift and the necessity of his mind. Havet. 
rendered the Jews great lovers of the things predieted, and great enemies of their fulfilment.

\section{$\mathrm{X}$.}

It was necessary that, to give faith to the Messiah, there should have been preceding prophecies, and that they should have been proclaimed by men altogether unsuspected, and of extraordinary diligence and fidelity and zeal, known to the whole world.

To accomplish all this, God chose this carnal people, with whom he deposited the prophecies which foretell the Messiah, as a deliverer and dispenser of those earthly goods which this people loved; thus they had an extraordinary ardor for their prophets, and exhibited to the view of the whole world those books which foretell their Messiah, assuring all nations that he would come, and in the manner predicted in their books, which they laid open to the whole world. And thus this people, deceived by the poor and ignominious advent of the Messiah, has been his most cruel enemy. So that here is a people the least suspected of favoring us, and the most exact of all for their law and their prophets, who keep them uncorrupted.

Hence it is that the prophecies have a hidden sense, the spiritual, of which this people was an enemy, under the carnal, of which it was a friend. If the spiritual sense had been manifest, they were not capable of loving it; and, not being able to bear it, they would not have had the zeal for the preservation of their books and of their ceremonies. And if they had loved these spiritual promises, and had preserved them incorruptible until the coming of the Messiah, their testimony would not have had weight, since they would have been his friends. This is why it was good that the spiritual sense should be concealed. But, on the other hand, if this sense had been so concealed that it would not have appeared at all, it could not have served as a proof of the Messial. What, then, has been done? It has been concealed under the temporal sense in a great many passages, and has been disclosed very clearly in a 
few : besides, the time and the state of the world were so clearly predicted, that the sun itself is not so clear. Anc this spiritual sense is so clearly explained in some places, that a blindness like that which the flesh brings upon the spirit when it is subjected to it, was necessary in order not to know it.

This, then, was the way which God has taken. This sense is hidden by another in a multitude of passages, and in some, though rarely, it is discovered, but in such a manner, nevertheless, that the places where it is hidden are equivocal, and may admit both senses; while the places where it is disclosed are unequivocal, and can admit only the spiritual sense.

So that this could not lead into error, and that none but a people as carnal as they could have misunderstood it.

For when good things are promised in abundance, what hindered them from understanding the veritable goods, except their cupidity, which restricted this sense to earthly goods? But those who had no goods but in God referred them exclusively to God. For there are two principles that divide the wills of men, cupidity and charity. Not that cupidity may not exist with faith in God, or that charity may not exist with the goods of this world. But cupidity makes use of God, and enjoys the world; and charity, the contrary.'

Now, it is the ultimate end which gives names to things. Whatever hinders us from arriving at this end is called an enemy. Thus creatures, though good in themselves, are enemies to the just when they turn them away from God, and God himself is the enemy of those whose lusts he disturbs.

Thus the word enemy depending on the ultimate end, the just understand by it their passions, and the carnal, the Babylonians: and thus these terms were obscure only to the unjust. And this is what Isaiah says: Signa legem in electis meis, and that Jesus Christ would be a stone of stumbling. But, "Blessed are they who shall not be offended at him!" Hosea,

1 "The contrary." Port-Royal thus e^mpletes the phrase: nsos the coorld and enjoys God. 'That is, inakes use of the goods of the world only to do the will of God, and thus to optain his grace.-Havet.

Seal the law among my disciples. 
in his last ehapter, expresses this perfectly: "Who is wise, and he shall understand these things? prudent, and he shall know them? for the ways of the Lord are right, and the just shall walk in them: but the transgressors shall fall therein."

T... So that those who have rejected and crucified Jesus Christ, who has been to them a scandal, are the very persons who preserve the books which testify of him, and which predict that he will be rejected and a scandal; so that they have shown that it was he by refusing him, and that he has been equally proved, both by the just Jews who have received him, and by the unjust who have rejected him, both having been predicted.

\section{XI.}

The time of the first advent is predicted; the time of the second is not, because the first was to be concealed; the second is to be glorious, and so manifest that even his enemies would recognize him. But, as he was to come only in obscurity, and to be known to those only who searched the Scriptures....

T What could his enemies, the Jews, do? If they receive him, they prove him by their reception, for the depositaries of the promise of the Messiah receive him; and if they renounce him, they prove him by their renunciation.

\section{XII.}

Fac secundum exemplar ${ }^{1}$ quod tibi ostensum est in monte. The religion of the Jews has, then, been formed on the resemblance of the truth of the Messiah, and the truth of the Messiah has been recognized by the religion of the Jews, which was the type of him.

Among the Jews, truth was only prefigured. In heaven it is revealed. In the Church it is concealed, and recognized by its relation to the figure. The figure was made by the truth, and the truth was recognized by the figure. 


\section{XIII.}

Whoever judges of the Jewish religion by its externals knows but little of it. It is visible in the holy books, and in the tradition of the prophets, who have made it sufficiently understood that they did not understand the law literally Thus our religion is divine in the Gospel, the apostles, and tradition; but it is ridiculous in those who treat it ill.

The Messiah, according to the carnal Jews, was to be a great temporal prince. Jesus Christ, according to the carnal Christians, came to dispense with the obligation of loving God, and to give us sacraments, which effect all without our coneurrence. Neither is the Christian religion, nor the Jewish. The true Jews and the true Christians have always expected a Messiah who would make them love God, and, by this love, triumph over their enemies.

T Two sorts of men in every religion.-Among the pagans, the worshippers of beasts, and the others, the worshippers of one God in natural religion. Among the Jews, the carnal, and the spiritual, who were the Christians of the old law. Among the Christians, the sensual, who are the Jews of the new law. The carnal Jews expected a carnal Messiah, and the sensual Christians thought that the Messiah dispensed with the obligation of loving God. The true Jews and the true Christians adore a Messiah who makes them love God.

T The carnal Jews and the pagans have their miseries, and the Christians also. There is no Redeemer for the pagans, for they do not even hope for one. There is no Redeemer for the Jews, they hope for one in vain. There is a Redeemer only for the Christians.

\section{XIV.}

The veil that is over the books of the Scripture for the Jews, is there also for bad Christians, and for all those who do not hate themselves. But how well-disposed we are to understand them and to know Jesus Christ, when we truly hate ourselves! 


\section{$\mathrm{XV}$.}

The earnal Jews hold a middle plaee between the Christians and the pagans. The pagans do not know God, and love only the earth. The Jews know the true God, and love only the earth. The Christians know the true God, and do not love the earth. The Jews and the pagans love the same goods. The Jews and the Christians know the same God. The Jews were of two sorts: some had only pagan affeetions, others had Christian affections.

\section{XVI.}

Evidently, this people was formed expressly to serve as witnesses to the Messiah: Is. xliii, $9 ;$ xliv, 8 . They have the books, and love them, but do not understand them. And all this is foretold: that the oraeles of God are committed to them, but as a book that is sealed.

- While the prophets remained to maintain the law, the people were negligent. But since there have been no more prophets, zeal has succeeded. The devil troubled the zeal of the Jews before Jesus Christ, because it might have been salutary to them, but not after.

\section{XVII.}

The ereation of the world beginning to be a remote event, God provided a single contemporary historian, and committed his book to the keeping of a wltole people, in order that this history might be the most authentic in the world, and that all men might learn a thing so necessary to know, and that it might be known only by this.

\section{XVIII.}

Prineiple: Moses was an able man; if, therefore, he was governed by his understanding, he said nothing plainly which was directly against the understanding. Thus all very apparent weaknesses are forees. As, for example, the two genealogies 
of St. Matthew and of St. Luke: what is there more clear, than that they were not made in concert?

T Proof of Moses.-Why has Moses made the lives of men so long, and the generations so few? for it is not the length of years, but the multitude of generations that make things obscure.

For truth is altered only by change of men. And yet he places two events, the most memorable that were ever imagined, namely, the creation and the deluge, so near, that they are tangible.

T Shem, who saw Lamech, who saw Adam, saw also Jacob, who saw those who saw Moses. Therefore, the deluge and the creation are true. This is conclusive among certain people who understand it well.

T The length of the patriarchal life, instead of causing the histories of past events to be lost, served, on the contrary, to preserve them. For the reason that we are not, sometimes, sufficiently instructed in the history of our ancestors, is, that we have but seldom lived with them, and that they have died often before we had attained the age of reason. But, when men lived so long, children lived a long time with their fathers, and conversed a long time with them. Now, what would they have conversed about, if not the history of their forefathers, since all history was reduced to that, and they had no studies, no sciences, no arts, which occupy a great part of the discourses of life? We see also, that in those days, the people took especial care to preserve their genealogies.

\section{XIX.}

... Hence I refuse all other religions: by this $I$ find an answer to all objections. It is just that a God so pure should reveal himself only to those whose hearts have been purified. Hence this religion is to me amiable, and already I find it sufficiently authorized by such a divine morality ; but I find more

1 "Saw also Jacub." This is an crror which Port-Royal ccrrects in writing: saw at least Abraham, and Abruham saw Jacob.-Havet. 
in it. . . . I find it true that since the world began, it has been constantly announced to men that they are in a state of universal corruption; but that a Restorer shall come. That it is not one man who says it, but an infinite number of men, and an entire people, during four thousand years, prophesying and made expressly. . . . Thus I extend my arms to my Liberator, who, having been foretold for four thousand years, came to suffer and to die for me on the earth, at the time and with all the circumstances which had been predicted; and, by his grace, I await death in peace, in the hope of being eternally united to him ; and I live, nevertheless, with joy, either in the blessings which it may please him to give me, or in the ills which he may send me for my good, and that he has taught me to endure by his example.

T...The more I examine them, the more truths I find in them: in what preceded and in what followed; in fine, the Jews, without idols or king, and that synagogue which was predicted, and those miserable creatures who follow it, and who, being our enemies, are admirable witnesses of the truth of those prophecies, wherein their misery and evon their blindness is predicted. I find this concatenation, this religion, altogether divine in its authority, in its duration, in its perpetuity, in its morality, in its government, in its doctrine, in its effects, and the darkness of the Jews frightful and predicted : Eris palpans in meridie. Dabitur liber scienti litteras, et dicet, non possum legere. 


\section{CHAPTER XVI.}

THAT THE JEWISI RELIGION, LIKE THE CHRISTIAN. RECOMMENDS THE LOVZ oF GoD.]

Tire religion of the Jews seemed to consist essentially in the paternity of Abraham, in circumcision, in sacrifices, in ceremonies, in the ark, in the temple of Jerusalem, and finally, in the law and covenant of Moses.

I say that it did not consist in any of these things, but simply in the love of God, and that God rejected all the rest.

That God did not accept the posterity of Abraham.

That the Jews shall be punished by God like the Gentiles, if they offend. Deut. viii, 19: "If thou forget the Lord thy God, and walk after other gods, and serve them, and worship them ; I testify against you this day, that you shall surely perish ; as the nations which the Lord destroyeth before your face, so shall you perish."

That the Gentiles shall be received of God, even as the Jews, if they love him. Is. lvi, 3 : "Let not the Gentiles say: The Lord will not receive me. The strangers that attach themselves to God will serve and love him : I shall lead them to my holy mountain, and shall receive sacrifices from them, for my house is a house of prayer."

That the true Jews ascribed their merit to God, and not to Abraham. Is. lxiii, 16 : "Doubtless thou art our father, though Abraham be ignorant of us, and Israel acknowledge us not thou, O Lord, art our Father, our Redeemer."

Moses even told them that God would not regard persons. Deut. x, 17 : God, said he, "regards not persons, neither taketh he reward."

That the circumcision of the heart is enjoined. Deut. $x, 16$; ner. iv, 4 : "Circumcise, therefore, the foreskin of your heart 
and be no more stiff-necked. For the Lord your God is God of gods, and Lord of lords, a great God, a mighty, a terrible, which regards not persons."

That God said he would do this at some future day. Deut. $\mathrm{xxx}, 6$ : "And the Lord thy God will circumcise thy heart, and the heart of thy seed, to love the Lord thy God with all thy heart."

That the uncircumeised in heart shall be judged. Jer. ix, 26 : "For God will punish them which are eireumeised with the uncireumeised; for all these nations are uneireumeised, and all the house of Israel are uncireumeised in heart."

That the exterior avails naught without the interior. Joei ii, 13 : Scindite corda vestra, ete. Is. lviii, 3,4 , etc.

The love of God is enjoined throughcut the whole of Deuteronomy. Deut. xxx, 19: "I eall heaven and earth to record this day against you, that I have set before you life and death, blessing and cursing; therefore choose life, that both thou and thy seed may live; that thou mayest love the Lord thy God, and that thou mayest obey his voice, and that thou mayest cleave unto him, for he is thy life."

That the Jews, for want of this love, would be rejected for their crimes, and the Gentiles elected in their place. Hos. i, [10]; Deut. xxxii, 20: "I will hide my face from them, for they are a very froward nation, and unbelieving. They have moved me to jealousy with that which is not God; and I will move them to jealousy with those which are not a people. I will provoke them to anger with a foolish nation." Is. lxv, [1].

That temporal goods are false, and that the true good is to be united to God. Ps. cxliii, 15 .

That their feasts are displeasing to God. Amos v, 21.

That the sacrifices of the Jews are displeasing to God. Is. Ixvi, [1-3]; i, 11; Jer. vi, 2) ; David, Miserere, [18].-Even on the part of the good. Exspectans. Ps. xlix, 8-14. That he has established them only on account of their hardness. Mich., admirably, vi, [6-8]; I. R. [first book of Kings], xv, 22 . Hosea vi, 6.

That the sacrifices of the Gentiles shall be accepted of God. 
and that the sacrifices of the Jews were not acceptakle to him. Mal. i, 11.

That God will make a new covenant by the Messiah, and that the old one shall be abolished. Jer. xxxi, 31. Mantata non bona. Ezek.

'That the former things shall be forgotten. ${ }^{\circ}$ Is. xliii, 18, 19 ; lxr, $17,18$.

That the ark shall be no more remembered. Jer. iii, 15, 16. That the temple shall be rejected. Jer. vii, 12-14.

That the sacrifices should be rejected, and a purer sacrifice established. Mal. i, 11.

That the order of the Aaronic priesthood would be rejected, and that of Melchisedek introduced by the Messiah. Dixit Lominus.

That this priesthood should be everlasting. Ibid.

That Jerusalem would be rejected, and Rome admitted. That the name of the Jews would be rejected and a new name given. $I s .1 \mathrm{xv}, 15$.

That this last name would be better than that of the Jews, and eternal. Is. Ivi, 5 .

That the Jews shall be without prophets (Amos), kinga, princes, sacrifices, idols.

That, nevertheless, the Jews should always subsist as a people. Jer. xxxi, 36. 


\section{CHAPTER XVII.}

[THAT THE OLD LAW WAS Figurative, AND THAT THE OLD TESTAMEN1 CONTAINS THE FIGURE OF TRUTHS FULFILLED BY THE COMING OF THA Messiah.]

\section{I.}

Some figures are elear and demonstrative; but there are others which seem forced, and which convince those only who have been persuaded by other means. These latter are like those of the Apocalypse. But the difference is, that they have none that are unquestionable. So that there is nothing so unjust as when they attempt to show that theirs are as well founded as some of ours; for they have none that are demonstrative like some of ours. The cases, then, are not parallel. Men should not compare and confound these things because they appear to be alike in one respect, being so different in another. It is the lucidities that merit, if they are divine, that we should revere the obscurities.

\section{II.}

Jesus Christ, prefigured by Joseph, the well beloved of his father, sent by his father to see his brethren, etc., innocent, sold by his brethren for twenty pieces of silver, and, by this means, become their lord, their saviour, and the saviour of strangers, and the saviour of the world; which would not have come to pass without the design of destroying him, without the sale and the abandonment they made of him.

In prison, Joseph, who was innocent, was placed between riminals : Jesus Christ on the cross was placed between two thieves. Joseph predicted salvation to one and death to the other, on the same appearances: Jesus Christ saves the eleet and damns the reprobate, though both are guilty of the same crime. Joseph only predicted: Jesus Christ fulfilled 
Joscph asked the one who was to be saved to remember him when he was restored to his prosperity; and he whom Jesus Christ saved prayed that he would remember him when he came in his kingdom.

\section{III.}

The synagogue did not perish because it was the figure, but, because it was only the figure, it has fallen into servitude. The figure subsisted until the truth came, in order that the Chureh might be always visible, either in the image that promised it, or in the reality.

\section{IV.}

Proof of both Testaments at once.-To prove at once the two Testaments, it is only necessary to see whether the prophecies of the one have been fulfilled in the other. To examine the prophecies, it is necessary to understand them : for if we believe that they have but one meaning, it is certain that the Messiah has not come; but, if they have a double meaning, it is certain that he has come in the person of Jesus Cirrist.

The whole question, then, is to know whether they have two meanings....

\section{V.}

Figures.-In order to show that the Old Testament is only figurative, and that the prophets understood by temporal goods other goods, we have only to notice, first, that this would be anworthy of God; secondly, that their language expresses very clearly the promise of temporal goods, and that they say, nevertheless, that their language is obscure, and that their meaning will not be understood. Whence it appears that the meaning was not that which they expressed openly, and that, consequently, they intended to speak of other sacrifices, of another liberator, etc. They say that it will not be understood till the end of time. Jerem. xxx, 24.

The third proof is, that their discourses are contradictory, and destroy each other, so that, if we believe them to have intended by the words law and sacrifice something different 
from the law and sacrifice of Moses, there is a manifest and gross eontradiction. Then they understood something alse, contradicting themselves sometimes even in the same chapter...

\section{VI.}

Figures.-If the law and the sacrifices are the truth, they must be pleasing to God, and not displeasing. If they are figures, they must please and displease. Now, in all Scripture they please and displease.

It is said that the law shall be ehanged; that the sacrifice shall be changed; that they shall be without a king, without a prince, and without sacrifiees; that a new eovenant shall be made; that the law shall be renewed; that the precepts which they have received are not good; that their sacrifices are abominable; that God has not required them.

It is said, on the contrary, that the law shall endure forever; that this covenant shall be eternal; that the sacrifice shall be eternal; that the sceptre shall never leave them, since it eannot leave them until the arrival of the Eternal King. Do all these passages indicate that this is the reality? No. Do they indieate either that this is a figure? No: but that it is reality or figure. But the first, excluding the reality, indicate that it is only figure.

All these passages together eannot mean the reality; all may mean the figure; therefore, they do not indicate the reality, but the figure. Agnus occisus est ab origine mundi.

\section{VII.}

Figures.-A portrait bears absence and presence, pleasure and displeasure. The reality excludes absenee and displeasure.

In order to aseertain whether the law and the saerifices are reality or figure, we must observe whether the prophets, in speaking of these things, terminated their view and their thought therein, so that they saw only this ancient covenant; or whether they saw therein some other thing, of which this might be the image; for in a portrait we see the thing 
imaged. It is necessary for this only to examine what they say of these things.

When they say that this covenant shall be eternal, atc they anderstood to speak of the covenant, of which they say that it shall be changed; and the same of the sacrifices, etc.?

A cipher has two meanings.-When we intercept a letter of importance wherein we find a clear meaning, and in which it is said, nevertheless, that its sense is veiled and obscured; that it is hidden, so that we shall see this letter without perceiving it, and we shall hear it without understanding it; what ought we to think, except that it is a cipher of double signification; and much more so when we find in it manifest contradictions in the literal sense? How much, then, ought we to esteem those who discover to us the cipher, and teach us to know the hidden meaning; and particularly when the principles which they take from it are quite natural and clear! This is what Jesus Christ has done, and the apostles also. He has broken the seal, he has rent the reil, and disclosed the spirit. They have taught us that the enemies of man are his passions; that the Redeemer would be spiritual; that there should be two advents, the one in misery, to abase prond man, the other in glory, to exalt man humiliated; that Jesus Crrrist should be God and man. The prophets have clearly said that Israel would always be loved by God, and that the law would be eternal; and they have said that they would not understand their meaning, and that it was veiled.

\section{VIII.}

Jesus Christ has done nothing else than to teach men that they loved themselves, and that they were slaves, blind, sick, unhappy, and sinners; that it was necessary that he should deliver, enlighten, sanctify, and heal them; that this would be accomplished in hating themselves, and following him through the misery and death of the cross.

That the law was figurative.-This is the eipher that St. Paul gives us. The letter kills. All things came in fig ures. It was necessary that Christ should suffer. A God is 
humiliation. Circumcision of the heart, a true fast, a true sacrifice, a true temple. The prophets have indicated that it was necessary that all these things should be spiritual.

q Figures.-Double law, double tables of the law, double temple, double captivity.

\section{IX.}

... And yet this Testament, made to blind some and enlighten others, showed even to those whom it blinded, that truth which must have been known to the others. For the visible blessings which they received from God were so great and so divine that it appeared clearly that he was able to give thein those invisible and a Messiah.

For nature is an image of grace, and visible miracles are images of the invisible. Ut sciatis, tibi dico, Surge.

Isaiah, ch. li, says that the Red Sea is a type of redemption.

God has shown, then, in the deliverance from Egypt, from the sea, in the defeat of the kings, in the manna, in the whole genealogy of Abraham, that he had power to save, to make bread descend from heaven, etc.; so that a hostile people is the type and representation of the very Messiah of whom they are ignorant.

He has then, in fine, taught us that all these things were but figures, and also what is the truly free, the true Israelite, the true circumcision, the true bread from heaven, etc.

In these promises, every one finds what is in the bottom of his heart, temporal blessings or spiritual blessings, God or the creature; but with this difference, that those who seek in them the creature find it, but with many contradictions, with the prohibition to love it, with the command to adore God alone, and to love only him, which is the same thing, and that, finally, no Messiah has come for them; while those who seek God in them find him, and without any contradictions, with the command to love only him, that a Messiah came in the time predicted to give them the blessings which they ask.

And thus the Jews had miracles, prophecies, which they saw fulfilled; and the doctrine of their law was to adore and 
love only one God: this doctrine was perpetual, too. Thes, it had all the signs of the true religion: so it was. But we must distinguish the doctrine of the Jews from the doctrine of the Jewish law. Now, the doctrine of the Jews was not true, although it had its miracles, its prophecies, and perpetuity, becauso it had not this other point to adore and love only God.

$\mathrm{X}$.

Source of contrarieties.-A God humiliated, and even to the death of the cross: a Messiah triumphant over death by his death. Two natures in Jesus Christ, two advents, two states of the nature of man.

- Contradiction.-We cannot make a good physiognomy' but in harmonizing all our contrarieties; it is not sufficient to follow one series of accordant qualities, without conciliating the contrary. To understand the sense of an author, it is necessary to reconcile all the contradictory passages.

Thus, to understand the Scripture, it is necessary to have a sense in which all the contradictory passages agree. It is not sufficient to have one which agrees with several analogous passages; but there must be one which makes even contradictory passages agree.

Every author has a meaning with which all the contradictory passages agree, or he has no meaning at all. This cannot be said of the Scripture and of the prophets. They had assuredly too much good sense. We must then seek a meaning in them which will harmonize all contrarieties.

The veritable sense, then, is not that of the Jews; but in Jesus Christ all the contradietions are reconciled.

The Jews could not reconcile the termination of royalty and principality, predicted by Hosen, with the prophecy of Jacob.

If we take the law, the sacrifices, and the kingdom for realities, we cannot make all the passages agree. They must, then,

1 'That is, we cannot make a good portrait but by representing the liverse expressions of the countenanee, even the most opposite. This ex plunition is hy M. Havet, and we ent:-ely subscribe to it. 
necessarily be only figures. We could not reconcile eve. the passages of the same author, of the same book, sometimes of the same chapter. This more than sufficiently indicates what was the sense of the author. As when Ezekiel, ch. xx, says, they shall live in the commandments of God; and, they shall not live in them.

\section{XI.}

It was not permitted to sacrifice out of Jerusalem, which was the place that the Lord had chosen, nor even to eat the tithes elsewhere. Deut., xii, 5, etc. ; xiv, 23, etc.; xv, 20; xvi, 2, $7,11,15$.

Hosea predicted that they would be without a king, without a prince, without sacrifices, and without idols; which is now accomplished, not being able to make a legitimate sacrifice out of Jerusalem.

\section{XII.}

When the word of God, which is veritable, is literally false, it is spiritually true. Sede a dextris meis. ${ }^{1}$ Literally, this is false; therefore, spiritually it is true. In these expressions, God is spoken of after the manner of men; and this means no more than that God has the same intention as men have, when they eause another to sit at their right hand. This is, then, an indication of the intention of God, not of his manner of executing it.

So when it is said: God has received the odor of your incense, and will recompense you with a fruitful land; the intention is the same as a man would have, who, accepting your incense, would recompense you by giving you a fruitful land. God will have the same intention for you, because you have had the same intention with respect to him, as a man has for him to whom he gives incense. Thus, iratus est, "A jealous God," etc. For the things of God being unutterable, they cannot be otherwise expressed, and the Church to-day still uses: Quia confortavit seras. 


\section{XIII.}

All that tends not to charity is figure.

The only object of the Scripture is charity. Whatever tends not to this exclusive end is but its figure: for, since there is but one end, every thing that does not tend to it in literal words, is figure.

God thus diversifies this one precept of charity, in order to satisfy our curiosity, which seeks diversity, by this diversity, whick leads us ever towards the one thing needful. For one thing only is necessary, and we love variety; and God satisfies both by these diversities, which lead to the one thing needful.

\section{XIV.}

The Rabbins interpret figuratively the breasts of the Spouse,' and every thing which does not express their only object,temporal good. And Christians interpret even the Eucharist as a figure of the glory to which they are tending.

\section{$\mathrm{XV}$.}

There are those who see clearly that the only enemy of man is concupiscence, which turns him from God, and that it is not God who withdraws himself from man; nor any other good but God and not a fruitful land. Those who believe that the good of man is in the flesh, and the evil in that which turns him from the pleasures of the senses, let them thus defile themselves and let them die therein. But those who seek God with all their heart, who have no sorrow but in being deprived of his presence, who have no desire but to possess him, and no enemies but those who turn them from him; who are afflicted in seeing themselves surrounded and oppressed by such enenies; let them be comforted, I bring them good news; there is a Liberator for them, I shall cause them to see him; I shall show them that there is a God for them; I shall show him to

1 The Spouse of the So $\mathrm{g}$ of Solomon. 
no others. I shall show that a Messiah was promised who would deliver them from their enemies; and that one has come to deliver from iniquities, but not from enemies.

\section{XVI.}

When David prediets that the Messiah shall deliver his people from his enemies, we might think, carnally, that it was from the Egyptians; and then I could not show that the prophecy was fulfilled. But we can easily believe that it was from their iniquities: for, in truth, the Egyptians were not enemies, but the iniquities were. This word, enemies, is, then, equirocal.

But if he says elsewhere, as he does in common with Isaiah and others, that he shall deliver his people from their sins, the equivocation is removed, and the double sense of the word enemies is reduced to the simple sense of iniquities : for, if he had the sins in his mind, he might easily denote them by the word enemies; but if he were thinking of the enemies, he could not designate them by the word iniquities.

Now, Moses and David and Isaiah employed the same terms. Who shall say, then, that they had not the same sense, and that the meaning of David, which is manifestly that of iniquities when he is speaking of enemies, was not the same as that of Moses when he is speaking of enemies?

Daniel, ch.ix, prays for the deliverance of the people from the eaptivity of their enemies; but he was thinking of their sins: and, in order to show it, he said that Gabriel came to assure him that his prayer was heard, and that he had only seventy weeks to wait; after which period the people would be delivered from iniquity, and sin would come to an end; and the Liberator, the Holy of holies, would bring everlasting justice, not the legal, but the eternal.

T Figures.-As soon as we have once opened this seıret, it is impossible not to perceive it. Let us read the Old Testament with this view, and let us see whether the sacrifices were true, whether the parentage of Abraham was the true cause of 
the friendship of God, whether the promised land was the veritable place of rest. No. Then they were figures. Let us see, in the same way, all the ordained ceremonies, all the commandments which have not for their end charity, we shall find them all figurative.

T All these sacrifices and ceremonies were then figurative or meaningless. Now there are clear things too exalted to be regarded as meaningless. 


\section{CHAPTER XVIII.}

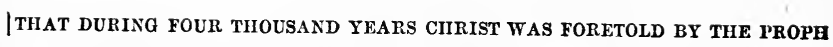
ECIES, AND THAT HE IIAS BEEN PROVED BY THEIR FULFILMENT.]

I.

The greatest of the proofs of Jesus Christ are the prophecies. They are also what God has the most provided for; for the event which has fulfilled them is a miracle which has subsisted from the birth of the Church even to the end. During sixteen hundred years therefore God raised up a succession of prophets; and, in the four hundred years that succeeded, he dispersed all these prophecies, with the Jews who bore them, into all parts of the world. This, then, was the preparation for the birth of Jesus Christ, whose Gospel was to be believed by the whole world, it was necessary, not only that there should be prophecies, to make him be believed, but that these prophecies should be everywhere in the workl, in order to cause him to be embraced by the whole world.

T Prophecies.-Even if one man had made a book of predictions of Jesus Christ,' both of the time and the manner of his coming, and if Jesus Cirrist had come in conformity with these prophecies, this would be of infinite weight. But there is much more here. There is a succession of men, who come, during four thousand years, constantly and without variation, one after another, predicting the same event. A whole people announce him, and subsist during four thousand years, in order to render as a body testimony of the assurances which they have of him, and from which they can be turned by no menaces and persecutions: this is much more important.

1 That is, predictions announcing Jesus Christ. 


\section{II.}

Prophecies.-The time was predicted by the state of the Jewish people, by the state of the heathen peuple, by the state of the temple, by the number of years. There must have been great boldness to predict the same thing in so many ways.

It was necessary that the four idolatrous or pagan monarchies, the end of the reign of Judah and the seventy weeks should have come to pass at the same time, and all before the second temple should be destroyed.

9 Predictions. - ... That in the fourth monarchy, before the destruction of the second temple, before the dominion of the Jews should be taken away, in the seventietl week of Daniel, pending the duration of the second temple, the heathen should be instructed, and led to the knowledge of the God worshipped by the Jews; that those who loved him should be delivered from their enemies, and filled with his fear and his love.

And it happened that in the fourth monarchy, before the destruction of the second temple, etc., the heathen in multitudes worshipped God, and led angelic lives; the maidens consecrated their virginity and their life to God; the men renounced all pleasure. What Plato could not persuade a few chosen and enlightened men to receive, a secret power, by the virtue of a few words, persuaded a hundred thousand ignorant men to receive.

The rich forsook their possessions, the children forsook the delicate homes of their parents to plunge into the austerities of a desert, ete. (See Philo Judæus.) Whence eomes all this. It is what has been predicted so long before. For two thousand years no heathen had worshipped the God of the Jews; and in the time predicted, the multitude of the heathen adored this only God. The temples were destroyed, the kings submitted themselves to the cross. What means all this? It is the Spirit of God that is poured out over the earth.

If Effundam spiritum meum.- All nations were in infidelity and concupiseence; the whole earth was burning with charity The princes forsook their splendors; girls suffered martyrdom 
Whence comes this power? It is because the Messiah has come. Behold the effect and the signs of his arrival.

T Prediction.-It is predicted that at the time of the Messiah, a new covenant would be established by him, which would make them forget their departure from Egypt [.Jerem. xxiii, $5 ; I s$. xliii, 16]; that he would write his law, not externally, but in their hearts; that JESUs Cinist would put his fear, which had been only external, into the midst of their hearts. Who does not see the Christian law in all this?

- Prophecy. - That the Jews would reject Jesus Cirist, and that they would be rejected by God, for the reason that the chosen vine would give only sour grapes. That the chosen people would be unfaithful, ungrateful, and ineredulous : populum non credentem et contradicentem. That God would smite them with blindness, and that they would grope as the blind at noon-day. [Deut. xxriii, 28.]

-... That Jesus Cunist would be little in his commencement, but would grow in his progress. The little stone of Daniel.

- ... That their idolatry would be overthrown; that the Messiah would destroy all the idols, and would make men enter into the worship of the true God.

That the temples of idolatry would be destroyed, and that, among all nations and in all places in the world, a pure victim would be offered to him, and not animals.

T... That he would teach men the perfect way.

And never has there appeared, either before or since, any man who has taught any divine thing approaching this.

T ... That he would be the king of the Jews and the Gentiles. And behold this king of the Jews and the Gentiles, oppressed by both, who conspire together for his death, ruling over both, and destroying both the worship of Moses in Jerusalem, which was its centre, and where he founded his first chureh and the worship of idols in Rome, which was its centre, and where he established his principal church.

T ... Jesus Christ came to tell men that they have nc other enemies than themselves; that it is their passions which separate thein from God; that he came to destroy them, anc 
to give them his grace, in order to make of them ali one holy Church; that he came to gather into this Church botl Gentiles and Jews; that he came to destroy the idols of the one, and the superstition of the other.

To this all men were opposed, not only by the natural antipathy of their concupiseence; but, above all, the kings of the earth united themselves in order to abolish this nascent religion, as it had been predicted (Quare tremuerunt gentes. Reges terrae adversus Christum). All who were great on the earth united, the learned, the wise, the kings.

Some wrote, others condemned, others killed. And, notwithstanding all these oppositions, these simple and powerless people resisted all these powers, and even overcame these kings, these philosophers, these sages, and removed idolatry from the whole earth. And all this was wrought by the power that predicted it.

T ... The Jews, in killing him in order not to receive him as the Messiah, gave him the last proof of his Messiahship. And, in continuing to deny him, they rendered themselves irrefragable witnesses: both in killing him and in continuing to deny him, they fulfilled the prophecies. Is. $\mathrm{lv},[5] ; 1 \mathrm{x},[4$, ete.]; Ps. lxxi, [11, 18, etc.].

9. ... Enigmatis, Ezek. xvii, [2].

His forerunner. Malach. iii, [1].

A child shall be born. Is. ix, [6].

He shall be born in the town of Bethlehem. Mic. v, [2]. He shall appear principally in Jerusalem, and shall spring from the family of Judah and of David.

He shall confound the wise and the learned (Is. vi, [10], viii, $[14,15]$, xxix, $[10$, etc.]), and preach the Gospel to the poor and humble (Is. xxix, $[18,19])$, open the eyes of the blind, give health to the sick, and lead those to the light who languished in darkness. Is. lxi, [1].

He shall teach the perfect way, and be the instructor of the Gentiles. Is. Iv, [4]; xlii, [1-7].

... That he shall be the vietim offered for the sins of the world. Is. xxxix, liii, [5], etc. 
He shall be the precious foundation-stone. Is. xxviii, [16]. He shall be the stone of stumbling and of offence. Is. viii, [14]. Jerusalem shall dash against this stone.

The builders shall reject this stone. Ps. cxvii, [22].

God shall make of this stone the head of the corner.

And this stone shall grow unto a mountain, and shall fill the whole earth. Dan. ii, [35].

That thus he shall be rejected (Ps. cviii, [8]), disowned, betrayed, sold (Zach. xi, [12]); spit upon, buffeted, mocked, aftlicted in numberless ways, given gall to drink ( $P s$. lxviii, [22]), pierced (Zach. xii, [10]), his feet and his hands pierced, himself killed, and his garments divided by lot.

That he shall rise again $(P s . \times x,[10])$, the third day. Hosea vi, [3].

That he shall ascend to heaven to sit at the right hand of God. Ps. cix, [1].

That kings shall arm themselves against him. Ps. ii, [2].

That being at the right hand of the Father, he shall be victorious over his enemies.

That the kings of the earth, and all nations shall adore him. Is. lx, [14].

That the Jews shall always subsist as a nation. Jerem.

That they shall be wanderers, without kings, etc. (Hosea iii, [4]), without prophets (Amos); looking for deliverance, and finding it not. Is. lix, [9].

The calling of the Gentiles by Jesus Christ. Is. lii, [15]; lv, [5]; lx, [4, etc. $;$ Ps. lxxxi, [11, 18, etc. $]$.

\section{III.}

Figures.-... Saviour, Father, Sacrificer, Victim, Sustenance, King, Sage, Legislator, Afflicted, Poor, destined to produce a people, which he was to lead, and nourish and introduce into the earth ....

T Jesus Christ, offices.'-He was to form to himself a great people, elect, holy, and chosen; to lead them, to nourish them.

1 That is, the mission which Jesus Christ came to fulfil in the world. 
W bring them into a place of rest and holiness; to make them holy to God; to make them the temple of God, to reconcile them to God, to save them from the wrath of God, to deliver them from the bondage of sin, which visibly reigns in man; to give laws to this people, to engrave these laws in their hearts, to offer himself to God for them, to sacrifice himself for them, to be a victim without spot, and to be himself the sacrificer: he was to offer himself, his body and his blood, and nevertheless to offer bread and wine to God ....

9. ... That he was to come as a deliverer, who should bruise the serpent's head, who should deliver his people from their sins, ex omnibus iniquitatibus; that there should be a New Testament which would be eternal; that there should be a new priesthood after the order of Melchisedek; that this should be eternal; that the Christ should be glorious, powerful, mighty, and yet so miserable that he would not be recognized; that he would not be esteemed for what he was; that he would be rejected; that he should be killed; that his people who denied him, should no longer be his people; that the idolatrous would receive him, and would have recourse to him; that he would abandon Zion, to reign in the centre of idolatry; that, nevertheless, the Jews should always subsist; that he should spring from the tribe of Judah, and when it had no longer a king.

\section{IV.}

Perpetuity.-Let us consider that, from the commencement of the world, the expectation or the adoration of the Messiah has subsisted without interruption; that men were found who affirmed that God had revealed to them that a Redeemer should be born who would save his people; that then Abraham came to say that he had had a revelation that he would descend from him by a son that would be born to him; that Jacob declared that, of his twelve children, he would be born of Judah; that then Moses and the prophets came to declare the time and the manner of his coming; that they declared that the law which they possessed was only in expectation of that of the Messiah; that until he came, it would be perper ral, but that the other 
would be eternal; that thus their law, or that of the Messiah. of which it was the promise, would always exist in the world that, in fact, it had always existed; that, finally, Jesus CHrist did come, in conformity with all the circumstances predicted. This is wonderful.

- If this was so clearly forctold to the Jews, why did they not believe; or why were they not exterminated, for resisting a thing which was so clear?

I answer: first, that it had been predicted, both that they would not believe a thing which was so clear, and that they would not be exterminated. And nothing is more glorious for the Messiah; for it was not sufficient that there should be prophecies; it was necessary that their prophecies might be preserved without suspicion. Now, etc.

V.

The prophets mixed particular prophecies with those of the Messiah, in order that the prophecies of the Messiah might not be without proofs, and that the particular prophecies might not be without fruit.

T Non habemus regem nisi Ccesarem.-Then Jesus Christ was the Messiah, since they had no king but a stranger, and would have no other.

9. Prophecies.-The seventy weeks of Daniel are equivocal as to the point of commencement, on account of the terms of prophecy; and as to their termination, on account of the diversities of chronologists. But all this difference is not more than two hundred years.

9 The prophecies ought to be unintelligible to the impious (Dan. xii, [10]; Hosea xiv, [9]), but intelligible to those who arc properly instructed.

... The prophecies that represent him as poor, represent him as master of nations. Is. lii, [14, etc.], liii; Zach. ix, [9]. ... The prophecies that predict the time, predict him only as master of the Gentiles, and as suffering, and not as coming in the clouds of heaven, nor as a judge. And those that represent him as judging and in glory, do not indicate the time. 


\section{CHAPTER XIX.}

[PROOFS OF JESUS CHRIST, DEDUCED FROM HIS BIRTH AND HIS DEATH.]

I.

Tire infinite distance between body and mind represents the infinitely more infinite distance between mind and charity, for it is supernatural.

All the splendor of external show has no lustre for those who are engaged in intellectual research. The greatness of intellectual men is imperceptible to kings, to the rich, to captains, to all those carnally great. The greatness of Wisdom, which is nowhere but in God, is imperceptible both to the carnal and to the intellectual. These are three orders, differing in kind.

Great geniuses have their empire, their renown, their greatness, their victory, and their lustre, and have no need of material grandeurs, with which they have no relation. They are seen not with the eyes, but with the mind; that is enough. The saints have their empire, their renown, their victory, their ustre, and have no need of material or intellectual grandeurs, with which they have no relation, for they neither add to them nor take from them. They are seen of God and angels, and not by body and curious intellect: God is sufficient for them.

Archimedes, without material splendor, would be held in the same veneration. He gained no battles for the satisfaction of the carnal eye, but he furnished all minds with his inventions. Oh! what splendor he had for minds! Jesus Christ, withont wealth, and without any outward production of science, is in his order of holiness. He gave ne inventions, he did not reign; but he was humble, patient, holy, holy, holy to God, errible to demons, without any sin. Oh, with what great 
pomp, and with what prodigious magnificence did he come to the eyes of the heart and the eyes which see Wisdom!

It would have been useless for Arehimedes to affect the prince in his books of geometry, although he might have done this. It would have been useless for our Lord Jesus Crinist, in order to appear with splendor in his reign of holiness, tc come as a king: but with what a splendor of his own order has he indeed come!

It is very ridiculous to be scandalized at the lowliness of Jesus Christ, as if this lowliness were of the same order as the greatness which he came to manifest. Let us consider this greatness in his life, in his passion, in his obscurity, in his death, in the election of his own, in their abandonment of him, in his secret resurrection, and in the rest; we shall see it so great, that we shall have no cause to be scandalized at a lowliness that is not there. But there are some who can admire only material grandeurs, as if there were no intellectual grandeurs; and others who admire only the intellectual, as if there were none infinitely higher in Wisdom.

All bodies, the firmament, the stars, the earth and its kingdoms, are not worth the least of minds; for it knows all this, and itself; and bodies know nothing. All bodies together, and all minds together, and all their productions, are not worth the least emotion of charity; this is of an order infinitely more exalted.

From all bodies together could never be obtained the smallest thought; this is impossible, and of a different order. From all bodies and minds could be extracted no emotion of true charity: this is impossible, and of a different order, the supernatural.

\section{II.}

... Jesus Christ in an obscurity (according to what the world calls obscurity) such, that historians, writing only the important things of States, have scarcely perceived him.

1 We here recognize the threefold division of Dr. Hickok's murvellow philosophy. $-E d$. 


\section{III.}

What man erer had more rerown! The whole Jewish people predict him, before his coming. The Gentile people adore him, after his coming. The two peoples, the Gentile and the Jewish, regard him as their eentre. And nevertheless what man enjoys such renown less! Of thirty-three years, he lives thirty without appearing. During three years, he passes for an impostor; priests and princes reject him; his friends and his kindred despise him. In fine, he dies betrayed by one of his own, denied by another, and abandoned by all.

What part has he, then, in this renown? Never has a man had so much renown; never has a man had more ignominy. All this renown has served only us, in order to make him recognizable to us; and has had nothing for him.

\section{IV.}

Proofs of Jesus Christ.-Jesus Christ has said great things so simply, that it seems that he has not thought of them; and so precisely, nevertheless, that we see elearly what he thought of them. This clearness, joined to this simplicity, is admirable.

T Who taught the evangelists the qualities of a perfectly heroic soul, that they should paint it so perfectly in Jesus Cnrist? Why do they make him so weak in his agony? Do they not know how to paint a constant death? Yes, without doubt ; for the same St. Luke paints that of St. Stephen as more resolute than that of Jesus Christ. They make him, then, capable of fear before the necessity of death is come, and then altogether strong. But when they make him so troubled, it is when his aftliction proceeds from himself; but when men aftlict him, he is all strength.

- The Church has had as much trouble to show that Jesus Cirrist was man, against those who denied it, as to show that ne was God; and the appearances were as great.

T Jesus Christ is a God whom we approach without pride, and under whom we humble ourselves without despair. 
V.

The conversion of the pagans was reserved for the grace of the Messiah alone. The Jews were so long combating them without success : all that Solomon and the prophets said of them was useless. Sages like Plato and Socrates were unable to inculcate it.

T The Gospels speak of the virginity of the Virgin only until the birth of Jesus Christ. Every thing has relation to Jesus Cirrist.

T ... Jesus Christ, whom both the Testaments regard, the Old as its expectation, the New as its exemplar, both as their centre.

T The prophets predicted, and were not predicted. The saints are then predicted, but do not predict. Jesus Christ is predicted and predicts.

- Jesus Christ for all, Moses for one people.

The Jews were blessed in Abraham: "I will bless them that bless thee." Gen. xii, [3]. But, "All nations are blessed in his seed." Gen. xxii, [18].

Lumen ad revelationem gentium.

Non fecit taliter omni nationi, said David, in speaking of the law. But in speaking of Jesus Christ, it is necessary to say: Fecit taliter omni nationi.

Parum est ut, etc. Isaiah xlix, [6]. So it is for Jesus Christ to be universal. Even the Church offers sacrifices only for the faithful: Jesus Christ has offered that of the cross for all, 


\section{CHAPTER $\mathrm{X} X$.}

SOF THE TRUTH OF THE GOSPEL HISTORY.-PROOFS OF JESUS CHRIST DRAWN FROM HIS MIRACLES.-DIFFERENCE BETWEEN THE MESSIAH AND MAпомет.]

I.

The apostles were deceived, or deceivers. Either is difficult. For it is not possible to take a man as raised from the dead ....

While Jesus Christ was with them, he could sustain them; but after that, if he did not appear to them, who caused them to act?

T Proof of Jesus Christ.-The hypothesis of deceptive apostles is very absurd. Let one follow it throughout; let one imagine these twelve men, assembled after the death of Jesus CHrist, conspiring together to say that he was raised from the dead : they attack thereby all powers. The heart of man is strangely inclined to levity, to change, to promises, to possessions. However little one of them might have been shaken by these attractions, and-what is more-by prisons, tortures, and death, they had been lost. Let one follow this out.

\section{II.}

The style of the Gospel is admirable in so many ways, and, among others, in never using any invective against the executioners and enemies of Jesus Christ. For there is none in the historians against Judas, Pilate, or any of the Jews.

If this modesty of the Gospel historians had been affected, as well as many other traits of a character so beautiful, and it they had affected it only to make it remarked; if they had not dared to remark it themselves, they would not have failed to procure friends, who would have made these remarks to their ic vantage. But as they have acted thus without affectation: 
and by a wholly disinterested impulse, they have caused it tc be remarked by no one. And I believe that several of these things have not hitherto been remarked; and this evinees the coldness with which the thing has been done.

\section{III.}

Jesus Christ wrought miracles, and then the apostles, anc. the first saints in great number; because, the propheeies not yet being fulfilled, and their fulfilment taking place by them, nothing testified it but miracles. It was predicted that the Messiah would convert the nations. How could this prophecy be fulfilled without the conversion of the nations? And how could the nations be converted to the Messiah, without seeing this final effort of prophecies that prove him? All was not fulfilled, then, before his death, resurrection, and conversion of the nations; and thus miracles were neeessary during the whole of this time. Now no more are required against the Jews, for the prophecies fulfilled are a standing miracle ....

\section{IV.}

It is an astonishing thing, and one worthy of peculiar attention, to see the Jewish people subsisting so many years, and to see them always so miserable : it being necessary for the proof of Jesus Christ, both that they should subsist to prove him, and that they should be miserable, since they crucified him: and, although to be miserable and to subsist may be contradictory, they nevertheless perpetually subsist, in spite of their nisery.

T When Nebuchadnezzar led the people captive, lest it might be believed that the seeptre had departed from Judah, it was said to them beforehand that they should be there but a short time, and that they should be re-established. They were still consoled by their prophets, their kings continued. But the second destruction is without promise of re-establish. ment, without prophets, without kings, without consolation without hope, because the sceptre has departed forever. 
9 Proofs of Jesus Christ.-It is not to have been captive to have been so with the assurance of being delivered in seventy years. But now they are so without any hope.

God promised them that althuugh he should scatter them to the ends of the world, nevertheless, if they were faithful to his law, he would bring them together again. They are very faithful to it, and remain oppressed....

\section{V.}

If the Jews had all been converted by Jesus Christ, we should no longer have any but suspected witnesses; and if they had been exterminated, we should have none at all.

T The Jews reject him, but not all of them: the holy receive him, and not the carnal. And so far is this from being against his glory, that it is the last feature of its completion. As the reason they have of it, and the only one that is found in all their writings, in the Talmud and the Rabbins, is only because Jesus Cirrist did not overcome the nations with an armed hand, gladium tuum, potentissime. Have they nothing but this to say? Jesus Christ has been killed, they say; he has succumbed; he has not overcome the pagans by his force; he has not given us their spoils; he gives no riches. Have they nothing but this to say? It is in this that he is to me worthy of love. I would not have him whom they imagine. It is evident that it is only his life that has hindered them from receiving him; and by this refusal, they are irreproachable witnesses, and, what is more, they fulfil thereby the prophecies.

\section{VI.}

How beautiful it is to see, with the eyes of faith, Darius and Cyrus, Alexander, the Romans, Pompey, and Herod, acting without knowing it, for the glory of the Gospel!

1 When Pascal interprets the propheus, and breaks the seals of the Old Testament, when he explains the mission of the Apostles among the Gentiles, and the marvellous economy of the designs of God, he eonspicuously 


\section{VII.}

The pagan religion is without foundation.'

The Mahometan religion is founded on the Koran and Mahomet. But was this prophet, who should have been the final expectation of the world, predicted? What sign has he, that any man who would be called a prophet has not also? What miracles does he claim to have performed? What mystery has he taught, according to his own tradition even? What morality and what felicity?

The Jewish religion must be differently regarded in the tradition of the holy books, and in the tradition of the people. ${ }^{2}$ Its morality and felicity are ridiculous in the tradition of the people, but admirable, in that of their saints. The foundatior of it is admirable; it is the oldest book in the world, and the most authentic; and while Mahomet, in order to cause the subsistence of his, has prohibited its reading, Moses, to make his subsist, has commanded everybody to read it.

Our religion is so divine, that another divine religion is only its foundation.

- Mahomet, without authority. ${ }^{3}$ His reasons should then be very strong, having only their own force. What does he say then? That it is necessary to believe.

precedes Bossuet, the Bossuet of the Universal History; he opens many vistas which the other will survey and fill up.... Bossuct had read the Thoughts, he had met with the passage: How beautiful it is to see, ete. It is a complete programme, that his impetuous genius must have instantly embraced, as the eagle eye of the great Condé surveyed the battle-field.Saint-Beuve.

1 VAR. OF MS. Pascal had first written: "Without foundation at present. It is said that it formerly had a foundation, by the oracles that spoke. But what books give us assurance of this? Are they so worthy of faith by the virtue of their authors? Have they been preserved with so much eare that one may be certain they are not corrupt?" (erased).

2 The following note is in the MS.: "And every religion is the same, for Christianity is very different in the holy books and in the easuists."

s That is, Mahomet has no authority to invoke in suprort of his pro tended mission. 


\section{VIII.}

Two persons tell each a foolish story,-one a story with a double meaning, understood by the initiated,--the other a story simply foolish; if any one, not in the secret, were to liear the two discoursing in this sort, he would form the same judgment of both. But if, subsequently, in their other discourses, one said angelic things, and the other, things always flat and common-place, he would judge that one spoke with mystery, and the other not: one having abundantly shown that he is incapable of such stupidities, and capable of being mysterious; and the other that he is incapable of mystery, and capable of stupidities.

IX.

It is not by what is obscure in Mahomet, and what may be taken in a mysterious sense, that I mean he should be judged, but by what is clear in him, by his paradise, and the rest. It is in this that he is ridiculous. And therefore it is not proper to take his obscurities for mysteries, seeing that his luciditics are ridiculous. It is not the same with Scripture. I mean that there are obscurities as strange as those of Mahomet; but there are admirable lucidities, and manifest prophecies fulfilled. The cases are not parallel, then. Things must not be confounded and made equal, that are similar only by obseurity, and not by the clearness that entitles obscurities to reverence.

T Against Mahomet.-The Koran is no more from Mahomet, than the Gospel from St. Matthew, for it is cited by several authors from age to age. Even enemies, Celsus and Porphyry, have never disavowed it.

The Koran says that St. Matthew was a good man. Therefore, Mahomet was a false prophet, either in calling good people bad, or in not remaining in accordance with what they have said of Jesus Christ.

$\mathrm{X}$.

Every man can do what Mahomet did; for he wrought no 
miracles, he was not foretold. No man can do what Jesus Christ did.

T Difference between Jesus Christ and Mahomet.-Mahomet, not foretold; Jesus Christ, foretold. Mahomet, killing; JEsus Christ, causing his own to be slain. Mahomet, prohibiting to read; the apostles, commanding to read. Finally, this is so opposite-that, if Mahomet took the way of succeeding according to human calculation, JESUs CHRIST took that of perishing according to human calculation. And instead of concluding that, since Mahomet succeeded, Jesus Christ was surely able to succeed, it must be said that, since Mahomet succeeded, Jesus Christ should have failed.'

1 Jerome Savonarola, in a treatise entitled, The Triumph of the Cross, institutes, like Pascal, a eomparison between Jesus Christ and Mahomet. This point of relation, which has not yet been pointed out, is not the only one that exists between the two anthors. The Triumph of the Cross, published in 1497, is, like the Thoughts, a work in defence of Christianity, and es it has often been reprinted, it does not appear impossible that Paseal might have had some knowledge of it. See the luminous analysis of $\mathbf{M}$. Perrens in Jerome Savonarole, sa Vie, ses Ecrits, etc. Paris, 1858, 8\% , t. ii, p. 210 ef esq. 


\section{CHAPTER XXI.}

'IIIAT GOD NEITIER CONCEALS NOR REVEALS HIMSELF ENTIRELY ; THAT IHH MESSIAII IS COGNIZABLE TO THE GOOD, AND INCOGNIZABLE TO THE WICKED, AND THAT IT IS NECESSARY TO RECOGNIZE THE TRUTH OF THE CHRISTIAN RELIGION EVEN IN THE OBSCURITY OF CERTAIN TRUTHS.]

I.

GoD has desired to redeem mankind, and to open salvation to those who should seek it. But men render themselves so unworthy of it, that it is just that God should refuse to some, because of their hardness of heart, what he accords to others by a mercy to which they have no claim. If he had chosen to overcome the obstinacy of the most hardened, he could have done so, in revealing himself so manifestly to them, that they could not have doubted of the truth of his essence; as he shall so appear on the last day, in the lightnings of heaven, and with convulsions of nature, that the dead shall arise and the blindest shall see him.

It is not in this manner that he wished to appear in his advent of mildness; because so many men rendering themselves unworthy of his clemency, he determined to leave them in destitution of the 1 blessing which they did not desire. It was not just then that he should appear in a manner manifestly divine, and absolutely capable of convincing all men; but it was not just either that he should come in a manner so hidden that he could not be recognized by those who should seek him sincerely. He wished to render himself perfectly recognizable to those; and thus, willing to be revealed to those who seek him with their whole heart, and hidden from those who shun him with all their heart, he so regulates the means of knowing him, that he has given signs of himself which are visible to hose who seek lim and obscure to those who seek him not 
There is light enough for those who desire only to see him, and obscurity enough for those who have a contrary disposition. There is sufficient light to enlighten the elect, and suffcient obscurity to humiliate them. There is sufficient obscurity to blind the reprobate, and sufficient light to condemn them, and render them inexcusable.

\section{II.}

If the world subsisted for the purpose of instructing man ir regard to God, his divinity would shine forth from every part of it in an incontestable manner; but, as it subsists only by Jesus Cinist and for Jesus Christ, and to instruct men in regard to their corruption and their redemption, every thing in it abounds with the proofs of these two truths. What appears in it indicates neither a total exclusion, nor a manifest presence of divinity, but the presence of a God who conceals himself : every thing bears this character.

If nothing had ever appeared of God, this eternal privation would be equirocal, and might equally relate to the absence of all divinity, or to the unworthiness of man to know him. But since he has appeared sometimes, and not always, this removes the equirocation. If he has appeared once, he is always; and thus we cannot conclude, but that there is a God, and that men are unworthy of him.

\section{III.}

God wishes to dispose the will rather than the mind. Perfect clearness would serve the mind and injure the will. To abase the proud.

TI If there were no obscurity, man would not feel his corruption; if there were no light, man would not hope for a remedy. Thus, it is not only just, but useful for us, that God hould be concealed in part and revealed in part, since it is equally dangerous for man to know God without knowing his misery, and to know his misery without knowing God. 


\section{IV.}

... It is true, then, that all things inform man of his condition, but it is necessary to understand them: for it is not true that all things reveal God, and it is not true that all things conceal God. But it is altogether true that he conceals bimself from those who tempt him, and that he reveals himrelf to those who seek him, because men are altogether unworthy of God, and capable of God; unworthy by their corruption, tapable by their original nature.

\section{V.}

There is nothing on earth that does not show, either the misery of man or the mercy of God; either the impotence of man without God, or the power of man with God.

T... Thus, the whole universe teaches man, either that he is corrupt, or that he is redeemed; every thing teaches him his greatness or his misery. The abandonment of God appeared in the pagans; the protection of God appeared in the Jews.

\section{VI.}

All things work for good to the elect, even the obscurities of Scripture; for they honor these obscurities, on account of the divine light of Seripture: and all things work for ill to others, even this light; for they blaspheme it, on account of the obscurities which they do not understand.

\section{VII.}

If Jesus Christ had come only to sanctify, all Scripture ar.d all things would tend to this object, and it would be very easy o convince the infidels. If Jesus Christ had come only to blind, all his corduct would be confused, and we should have no means of convincing the infidels. But as he came in sinctificationem et in scandalum, as Isaiah says, we cannot convince the infidels, and they carnot convince us; but by this even, we convince them, since we say that there is no conviction in his whole conduct throughout. 
T Jesus Christ came to blind those who see clearly, and to give sight to the blind; to heal the sick, and let the whole perish; to call sinners to repentance and justification, and to leave the just in their sins; to fill the poor, and to leave the rich empty.

T What say the prophets of Jesus Christ? That he shall manifestly be God? No: but that he is a God veritably concealed; that he shall be unrecognized; that men shall not think that this is he; that he shall be a stone of stumbling, on which many shall fall, etc. Let us then be reproached no more for the want of light, since we profess to have it.

T... But, they say, there are obscurities.-And without this men would not be offended at Jesus Curisr, and it is one of the formal designs of the prophets : Excaca, ${ }^{1}$...

T God, in order to make the Messiah cognizable to the good and incognizable to the wicked, caused him to be predieted in this way. If the manner of the Messiah had been clearly predicted, there would have been no obscurity, even for the wicked. If the time had been obscurely predicted, there would have been obscurity, even for the good; for the goodness of their hearts would not have made them under. stand that the mem close, ${ }^{2}$ for example, means six hundred years. But the time has been predicted clearly, and the manner figuratively.

In this way, the wicked, taking the promised goods for material goods, went astray, notwithstanding the time was clearly predicted, and the good did not go astray: for the understanding of the promised goods depends on the heart, which calls that good which it loves; but the understanding of the promised time does not depend on the heart; and thus the clear prediction of the time, and the obscure prediction of the goods, deceive only the wicked.

1 Excaca cor populi hujus. Isaiah vi, 10.

2 The mem, a letter of the IIebrew alplabet. Hebrew letters, like the Greek, are numerals as well as letters. The mem open is equivalent to 40 , the mem close is equivalent to 600 ; which has made the Rabbins say tha: Christ would come at the end of six hundred years. 


\section{VIII.}

How was it necessary that he should be the Messiah, sineo by him the sceptre was to be eternally in Judah, and that at his coming the sceptre was to be taken away from Judah?

... Nothing could be more effectual to bring it to pass that seeing, they might not see; and that hearing, they might not understand.

\section{IX.}

The genealogy of Jesus Christ in the Old Testament is mixed with so many others which are useless, that it cannot be discerned. If Moses had kept only a register of the ancestors of JesUS Christ, this would have been too obvious. If he had not indicated that of JESUs Christ, it would not have been obvious erough. But, after all, whoever looks closely, will see that of Jesus Cirrist clearly traced through Tamar, Ruth, etc.

\section{$\mathrm{X}$.}

... Recognize then the truth of our religion in its very obscurity, in the little light that we have of it, in the indifference that we feel with respect to knowing it.

T Jesus Christ does not say that he is not of Nazareth, nor that he is not the son of Joseph, in order to leave the wicked in blindness.

\section{XI.}

As Jesus Christ remained unknown among men, so his truth remains among common opinions, without difference as to exterior: thus the Eucharist among common bread.

- If the mercy of God is so great that it instructs us unto salvation, even when he conceals himself, what light should we not expect from him when he discovers himself?

- We know nothing of the works of God, if we do not take it as a principle that he has wished to blind some and enlight en others. 


\section{CHAPTER XXII.}

[THAT MAN CAN KNOW GOD AND KNOW HIMSELF ONLY THROUGH JESUg CHRIST, AND TIIAT OUT OF JESUS CHRIST, MEDIATOR AND RESIORER, THERE IS NOTIING BUT SIN, MISERY, ERROR, DARKNESS, DEATH, DESPAIR.-TIIE MYSTERY OF JESUS.]

\section{I.}

Finst part: Misery of man without God. Second part: Felicity of man with God. Otherwise, First part: That nature is corrupt. By nature even.

Second part: That there is a restorer. By Scripture.

T Preface of the second part: To speak of those who have treated of this matter.

I wonder at the boldness with which these persons undertake to speak of God, in addressing their discourses to the impious. Their first chapter is to prove the Divinity by the works of nature.

I should not be astonished at their undertaking, if they addressed their discourses to the faithful, for it is certain that those who have a lively faith in their hearts incontinently see that all that is, is nothing else than the work of God whom they adore. But as for those in whom this light is extinguished, and in whom it is designed to rekindle it, these persons destitute of faith and grace, who, seeking with all their light every thing they see in nature that may lead them to this knowledge, find only obscurity and darkness; to say to them .hat they have only to observe the least of the things that surround them, and they will see God without veil, and to give them, as the whole proof of this great and important subject, the course of the moon and planets, and to pretend to have completed this proof with such a discussion, is to give them grounds for believing that the proofs of our religion are vers 
weak, and I see by reason and experience that nothing is better calculated to produce in them contempt of it.

It is not in this wise that Scripture, which understands better the things that are God's, speaks of it. It says, on the contrary, that God is a God concealed; and that, since the corruption of nature, he has left them in a blindness from which they can escape only through Jesus Christ, except hy whom any communication with God is impossible: Nemo novit Putrem, nisi Filius, et cui voluerit Filius revelare.'

This is what Scripture indicates to us, when it says, in so many passages, that those who seek God find him. It is not said of this light that it is clear as noon-day. It is not said that those who seek light at noon-day, or water in the sea, shall find it; and thus it is very certain that the evidence of God is not such in nature. Scripture also says to us elsewhere: Vere tu es Deus absconditus. ${ }^{2}$

T The God of Christians does not consist in a God simply author of geometric truths and of the order of the elements; this is the belief of pagans and Epicureans. He does not consist simply in a God who watches providentially over the lives and goods of men, in order to give a happy course of years to those who worship him; this is the belief of the Jews. But the God of Abraham, the God of Isaac, the God of Jacob, the God of Christians, is a God of love and consolation: he is a God who fills the soul and the heart that he possesses: he is a God who makes them feel within them their misery, and his infinite mercy; who unites himself to their inmost soul; who fills it with humility, joy, confidence, love; who renders them incapable of any end but him.

T The God of Christians is a God that makes the soul feel that he is its only good; that its only repose is in him, and that it shall have no joy but in loving him; and who makes it at the same time abhor the obstacles that restrain it, and hinder it from loving God with all its strength. Self-love and

1 No man knoweth the Father, but the Son, and he tc whom the Son will reveal him.

Truly thou art o God, that hideth himself. 
concupiscence, that arrest it, are to it insupportable. This God makes the soul feel that it has in itself this destroying root of self-love, and that he alone ean heal it.

- The knowledge of God without that of our misery produees pride. The knowledge of our misery without that or God gives despair. The knowledge of Jesus Christ is intermediate, because therein we find God and our misery.

- All those who seek God, except through Jesus CHrist, and stop in nature, either find no light that satisfies them, or they finally form to themselves a means of knowing God and serving him without a mediator; and thereby they fall, either into atheism, or into deism, which are two things almost equally abhorred by the Christian religion.

- God through Jesus Christ.-We know Gol only through Jesus Christ. Without this mediator, is taken away all communication with God; through Jesus Christ we know God. All those who have pretended to know God, and to prove him without Jesus Christ, have had only impotent proofs. But, to prove Jesus Christ, we have the prophecies, which are good and valid proofs. And these prophecies, being fulfilled, and truly proved by the event, indicate the certainty of these truths, and therefore the proof of the divinity of JESUS CHRIST. In him and by him, then, we know God. Otherwise and without Seripture, without original sin, without a necessary mediator, promised and come, we cannot absolutely prove God, nor teach a good doctrine and sound morals. But by Jesus Cirrist and in Jesus Christ, we prove God, and teach doctrine and morals. Jesus Cirrist is, then, the true God of men.

But we know, at the same time, our misery, for this God is nothing else than the repairer of our misery. Thus we can properly know God, only in knowing our iniquities.

Those, too, who have known God without knowing their misery, have not glorified him, but have glorified themselves. Quia non cognovit per sapientiam, placuit Deo per stultitiam predicationis salvos facere.

- Not only do we know God only through Jesus CiIrist but we know ourselves only through Jesus Chris'r. We know. 
life, death, only through Jesus Cririst. Except by Jesus Cnnist we know not what our life is, what our death is, what God is, what we are ourselves.

Thus, without Scripture, which has only JeSus Christ for its object, we know nothing, and we see only obscurity and confusion in the nature of God, and in nature herself.

T Without Jesus Christ, man must be in sin and misery; with Jesus Christ, man is exempt from sin and misery. In him is all our virtue and all our felicity. Out of him, there is notling but sin, misery, error, darkness, death, despair.

- Without Jesus Cirist, the world would not subsist, for it would be necessary either that it should be destroyed, or should be like a hell.

\section{THE MYSTERY OF JESUS CHRIST.1}

I.

Jesus suffers in his passion the torments inflicted upon him by men; but in his agony he suffers the torments that ho gives himself : turbavit semetipsum. It is a punishment from a hand not human, but omnipotent, and it is necessary to be omnipotent, in order to endure it.

JESUS seeks some consolation, at least in his three most cherished friends, and they sleep. He entreats them to abide a little while with him, and they leave him with an entire negligenec, having so little compassion that it could not even hinder them from sleeping one moment. Thus Jesus was left alone to the wrath of God.

JEsus is alone in the earth, that not only feels and shares his pain, but knows it: heaven and it are alone in this knowledge. Jesus is in a garden, not of delights, like the first Adam, where he ruins himself and the whole human race, but in one

1 This fragment was first published by M. Faugère. It is found at p. 87 of the autograph MS. We have from Jaequeline Pascal a meditation of the same kind, entitled The Mystery of the Death of our Lord Jesus Christ. This piece was published by M. Cousin, Jacqueline Pascal, p. 122 et sed : and by M. Faugère, Lettres, Opuscules, p. 157 et seq. 
of punishment, where he saves himself, and the vhole human race.

He suffers this pain and abandonment amid the horrors of night.

I believe Jesus never complained but this once; but then be complains as if he could no longer contain his excessive. rief : My soul is exceedingly sorrowful, even unto death!

JESUs seeks companionship and consolation on the part of men. This is the only time in his whole life, it seems to me. But he does not receive it, for his disciples sleep.

JESus will be in agony, even unto the end of the world : during this time there must be no sleep.

Jesus, in the midst of this universal abandonment, even by his friends chosen to watch with him, finding them sleeping, is grieved on account of the peril to which they expose, not him, but themselves; and he warns them with respect to their own safety and good with a cordial tenderness for them during their ingratitude; and reminds them that the spirit is willing, but the flesh is weak.

JESUs, finding them still sleeping, restrained neither by consideration for him nor for themselves, has the goodness not to wake them, and to leave them in their slumber.

Jesus prays in uncertainty of the Father's will, and fears death ; but having ascertained the Father's will, he hastens to offer himself to death: Eamus. Processit. (Joannes.)

JESus has prayed men, and has not been heard.

JESUS, while his disciples were sleeping, wrought their salvation. He did the same for each of the justified while they were sleeping, both in nothingness before their birth, and iv sins since their birth.

He prays only once that the cup may pass from him, and then with submission; and twice that it may come if it be necessary.

$J_{\text {ESUS }}$ in weariness. JESUS seeing all his friends sleeping, and all his enemies vigilant, betakes himself wholly to the Father.

JESUS does not regard in Judas his enmity, but the order o xod, which he lores and . . . . since he calls him friend. 
Jesus tears himself away from his disciples, in order to enter into his agnny; we must tear ourselves away from those nealest and dearest, in order to imitate him.

JEsus being in his agony and the greatest pain, let us the longer pray.

\section{II}

Console thyself : thou wouldst not seek me, if thou harlst not found me.

I thought on thee in my agony; such drops of blood I shed for thee.

It is tempting me rather than proving thee, to think whether absent thou wouldst do such or such a thing: I will do it in thee if it come.

Let thyself be guided by my rules; see how well I have guided the Virgin and the saints, who have allowed me to act in them.

The Father loves all that $I$ do.

Wishest thou that I always shed the blood of my humanity, while thou dost not shed even tears?

Conversion is my work : fear not, and pray with confidence in me.

I am present to thee by my word in the Scripture; by my spirit in the Church, and by inspirations; by my power in the priests; by my prayer in the faithful.

Physicians will not heal thee; for thou shalt finally die. But it is I who heal and render the body immortal.

Suffer chains and corporeal servitude; I deliver thee at present only from spiritual servitude.

I am more of a friend to thee than such or such a one; for $\mathrm{l}$ have done for thee more than they, and they would not suffer what I have suffered from thee, and would not die for thee in the time of thy infidelities and cruelties, as I have done, as I am ready to do, and do with my elect.

If thou knewest thy sins thou wouldst lose heart.-I shall lose heart, then, Lord, for I believe their malignancy on thy assurance.-No, for I, through whom thou dost learn this, can weal thee, and what I say to thee, is a sign that I wish to heal 
thee. Just so far as thou shalt expiate thy sins, thou shalt know them, and it shall be said to thee: Behold the sins that are forgiven thee! Do penance then for thy concealed sins, and for the hidden malignity of those that thou knowest.

Lord, I give thee all.

I love thee more ardently than thou hast loved thy impurities. Ut immundus pro luto.

Mine be the glory and not thine, worm and earth [as thou art]. Ask thy director, when my own words are to thee an occasion of evil, and vanity or curiosity.

\section{III.}

I see my abyss of pride, of curiosity, of concupiscence. There is no relation between me and God, nor between me and Jesus Curist the just. But he has been made sin for me; all thy scourges have fallen on him. He is more abominable than I, and, far from abhorring me, he deems himself honored that I go to him and aid him.

But he has healed himself, and for a still stronger reason will he heal me.

My wounds must be added to his, and I must be joined to him, and he will save me in saving himself.

But none must be added in the future.

$$
\text { IV. }
$$

Console yourself : it is not of yourselves that you ought to expect him ; but, on the contrary, in expecting nothing of yourselves, you ought to expect him.

\section{V.}

Sepulchre of Jesus Christ.-Jesus Christ died visibly on the cross. He died and was hidden in the sepulchre.

JESUS Christ was buried only by saints.

Jesus Christ wrought no miracle in the sepulchre.

Saints alone enter it.

It is there that Jesus Christ assumes a new life, not upor the cross. 
This is the final mystery of the passion and the redemption. Jesus Cirist had not where to lay his head upon the earth, but in the sepulchre.

His enemies ceased to persecute him only in the sepulchre.

VI.

I speak to thee and counsel thee often, because thy guide cannot speak to thee, for I do not wish thee to be without a guide. And perhaps I do it for his prayers, and thus he guides thee without thy knowledge.-Thou wouldst not seek me, if thou possessedest me not; do not disquiet thyself then.

\section{VII.}

I do not compare thee to others, but to myself. If thou findest me not in those with whom thou comparest thyself, thou comparest thyself with a reprobate. If thou findest me not in any one, then compare thyself with him. But what wilt thou compare? thyself, or me in thee? If it is thyself, it is a reprobate. If it is I, thou comparest me to myself. Now I am God in all.

\section{VIII.}

It seems to me that Jesus Christ let only his wounds be touched, after his resurrection: Noli me tangere. It is necessary to unite ourselves only to his sufferings.

IX.

... He administered the communion as a mortal in the Last Supper, as one raised from the dead to the disciples of Emmaus, as one ascended to heaven to the whole Church.

$\mathrm{X}$.

"Pray, lest ye enter into temptation." It is perilous to be tempted; and those who are, are tempted because they pray not.

Et tu conversus confirma fratres tuos But first, conversu" Jesus respexit Petrum. 
Saint Peter asks permission to strike Malchus, and strikes before hearing the response; and Jesus Christ responds afterwards.

\section{XI.}

Jesus Christ did not wish to be put to death without the forms of justice; for it is much more ignominious to die by justice than by an unlawful sedition.

\section{XII.}

The false justice of Pilate only serves to make Jesus Christ suffer; for he causes him to be scourged by his false justice, and then puts him to deatl. He had better have put him to death at first. Thus the false just. They do good works and wicked to please the world, and to show that they are not wholly for Jesus Cinrist; for they are ashamed of him. In fine, under great temptations and on great occasions, they put him to death. 


\section{CHAPTER XXIII.}

[ON MIRACLES.]

Miracle.-It is an effect which exceeds the natural force of the means employed for it; and a non-miracle is an effect which does not exceed the natural force of the means employed for it. Thus, those who cure by the intervention of the devil, do not work a miracle; for this does not exceed the power of the devil.'

T Miracles prove the power which God has over the heart by that which he exercises over the body.

I.

Miracles test doctrine, and doctrine tests miracles.

There are false and true [miracles]. We must have some mark whereby to know them; otherwise they would be useless. Now, they are not useless, and are, on the contrary, a foundation. Now it is necessary that the rule which they give us be such, that it destroy not the proof which the true miraales give of the truth, which is the principal object of miracles.

Moses has given two: that the prediction should not be fulfilled (Deut. xviii, [22]); and that they should not lead to idolatry (Deut. xiii, [4]); and Jesus Christ one.

If doctrine regulates miracles, miracles are useless for doc-

1 "Si quelquesfois la Providence divine a passé par dessus les regleś ausquelles elles nous a necessairement astreinets, ce n'est pas pour nous en dispenser: ee sont coups de sa main divine, qu'il nous fault nen pas imiter, mais admirer; et exemples extraordinaires, marquez d'un exprez et particulier adveu, du genre des miraeles, qu'elle nous offre pour tesmoignage de sa tonte puissanee, an dessus de nos ordres et de nos forees, qu'il est folie et impiété d'essayer à representer, et que nous ne debvons pas suyvre, mais contempler avee estonnement; aetes de son personnage, nor pas du nostre."-Montaigne. 
trine. If miracles regulate doctrine, could we enforce all doctrine? No; for this would not happen.'

-... In the Old Testament, when they turn you away from God. In the New, when they turn you away from Jeses Cin ists. Here are the occasions of exclusion to the faith of miracles, indicated. It is not necessary to give other occasions of exclusion.

Does it follow from this that they would have the right to exclude all the prophets who came to them? No. They would have sinned in not excluding those who denied God, and they would also have sinned in excluding those who did not deny God.

As soon as we see a miracle, then, we must either submit to it, or have striking indications of the contrary. We must see whether they deny either God, or Jesus Christ, or the Church.

If there were no false miracles, there would be certainty. If there were no rule for testing them, miracles would be useless, and there would be no reason for believing. Now, humanly speaking, there is no human certainty but reason.

T A miracle, they say, should strengthen my belief. They say this when they do not see it. The reasons which, being seen from a distance, appear to limit our view, but when we have arrived there, we begin to see still further. Nothing stops the quick working of our mind. There is no rule, it is said, that is without exception, no truth so general that it has no aspect in which it is deficient. It is sufficient that it be not absolutely universal, in order to give us grounds for applying the exception to the present subject, and to say: This is not always true; therefore, there are cases wherein this is not true It only remains to show that this is one of them; and we are very awkward or very unfortunate if we do not find this to be true some day.

II.

Every religion is false which, in its faith, does not adore a

1 This phrase which completes Pascal's thought, is found in the MS., a pago 475 . 
God as the principle of all things, and which, in its morals, does not love one only God as the object of all things.

- The Jews had a doctrine from God as we have one from JESUS Christ, and eonfirmed by miracles; and forbidden tc believe in all workers of miracles, and, moreover, ordered to have recourse to the high priests, and to adhere to them. And thus all the reasons which we have for refusing to believe the workers of miracles, they had in regard to their prophets. And yet, they were very guilty in refusing the prophets, because of their miracles, and Jesus Christ; and would not have been guilty if they had not seen the miracles. Nisi fecissem, peccatum non haberent. Then all belief is founded on miracles.

T The proofs which Jesus Christ and the apostles draw from Scripture are not demonstrative; for they merely affirm that Moses has said that a prophet would come, but they do not prove thereby that it is he, and this was the whole question. These passages serve, then, only to show that they are not contrary to Scripture, and that no repugnance appears, but not that there is accordance. Now this suffices, exclusion of repugnance, with miracles.

\section{III.}

Jesus Christ says that the Scriptures testify of him, but he does not show in what.

Even the propheeies could not prove Jesus Christ during his life. And thus one would not have been culpable in not believing in him before his death, if the miracles had not been sufficient without the doctrine. Now those who did not believe on him while he was still living were sinners, as he himself says, and without excuse. Therefore it was necessary that they should have a demonstration which they might resist. Now they had not ... but simply miracles; therefore they are sufficient, when the doctrine is not contrary, and we should believe in him.

9 Jesus Christ has verified that he was the Messiah, never in verifying his doctrine by the Seripture and the prophecies 
but always by his miracles. He proves that he forgives sins by a miracle.

Nicodemus knew by his miracles that his doctrine was from God: Scimus quia a Deo venisti, magister; nemo enim potest hace signa facere quce tu facis, nisi fucrit Deus cum eo. ${ }^{1} \mathrm{He}$ does not judge of the miracles by doctrine, but of doctrine by miracles.

T There is a reciprocal duty between God and man ... Quid debui? "Accuse me," says God in Isaiah. "God should fulfil his promises," etc.

Men owe it to God to receive the religion which he sends them. God owes it to men not to lead them into error. Now, they would be led into error if the workers of miracles announced a doctrine that did not appear manifestly false to the apprehension of common-sense, and if a greater worker of miracles had not already warned them not to believe them. Thus, if there were division in the Church, and if the Arians, for example, who declared themselves founded upon the Scripture like the Catholies, had wrought miracles, and not the Catholics, Inen would have been led into error. For, as a man who professes to make known to us the secrets of God is not worthy of being believed on his own private authority; and as it is for this that the impious doubt: so a man, who, in proof of the communication which he has with God, raises the dead, predicts future events, removes seas, heals the sick,-there is none so impious as not to yield to these things, and the incredulity of Pharaoh and the Pharisees is the effect of a supernatural hardness of heart. When, therefore, we see the mirales, and the doctrine without suspicion, altogether on one side, there is no difficulty. But when we sce the miracles and the suspected doctrine on the same side, then we must ascertain which is the clearest. Jesus Christ was suspected.

T There is much difference between tempting and leading into error. God tempts, but he does not lead into error. To

1 "We know that thou art a teacher come from God; for no man ean do he things that thou doest, except God be with him."-John iii, 2. 
tempt is to procurc the occasions, which imposing no necessity, if we do not love God, we will do a certain thing. To lead into error is to put a man under the necessity of assuming and following a falsehood.

- The justice of God renders it impossible that a man, concealing his bad doctrine, and exhibiting only a good one, and proclaiming himself in conformity with God and the Church, should work miracles in order insensibly to insinuate a false and subtile doctrine: that cannot be. And still less that God, who knows hearts, should work miracles in favor of such a one.

\section{IV.}

There is much difference between not being for Jesus Curist, and saying so; and not being for Jesus Cirrist, and pretending to be so. The former can work miracles, not the latter; for it is clear that the former are opposed to the truth, not the latter; and thus the miracles are clearer.

T Miracles are a test in doubtful things : between the Jewish people and the Heathen; the Jew and the Christian; the Catholies and the heretics; the calumniated and the calumniators ; between the two crosses.' But to the heretics miracles would be useless, for the Church, authorized by the miracles which have anticipated the belief, informs us that they do not possess the true faith. There is no doubt that they are not in the true faith, for the first miracles of the Church exclude their laith. There is thus miracle against miracle, and the first and greatest on the side of the Church.

Abel, Cain, Moses, magicians. Elijah, the false prophets. Jeremiah, Ananias. Micah, the false prophets. Jesus Christ, Pharisees. St. Paul, Elymas. Apostles, exorcists. The Chrisians and the infidels. The Catholies, the heretics. Elijah, Enoch, Antichrist. The truth always prevails in miracles. The two crosses. ${ }^{2}$

2 The Saviour's aross, and the thief's eross

2 This last paragrapl is an explanation, by examples, of the words: niracles against miracles. Pascal opposes truth to error; he opposes Mo 
Never, in the contention' of the true God, and of the truth of religion, has a miracle been wrought on the side of error and not on that of truth.

- John vii, 40. Contestation among the Jews, as among the Christians to-day. Some believed in Jesus Christ, others did not, because of the prophecies which said that he should be born in Bethlehem. They should rather have examined whether he was not born there. For these miracles being convincing, they should have made themselves certain in regard to these pretended contradictions of his doctrine to the Scripture; and this obscurity did not excuse them, but blinded them. So those who refuse to believe the miracles of the present day, on account of a pretended chimerical contradiction, are not justifiable.

Jesus Christ healed the born-blind, and wrought a number miracles on the Sabbath-day. By which he blinded the Pharisees, who said the miracles should be judged by the doctrine.

"We have Moses: but this man, we know not whence he is." This is marvellous that you know not whence he is, and yet he works such miracles.

Jesus Crrrist spoke neither against God, nor against Moses. The Antichrist and the false prophets, predicted by both the Testaments, will speak openly against God and against JEsus Christ. Whoever should be a concealed enemy, God would not permit that he should work miracles openly.

- If there is a God, the faith of God must have been in the world. Now the miracles of Jesus Christ are not predicted by Antichrist, but the miracles of Antichrist are predicted by Jesus Christ : and thus if Jesus Christ was not the Messiah, he would certainly have led into error; but Antichrist cannot well lead into error. When Jesus Cinist predicted the miracles of Antichrist, did he think to destroy faith in his own miracles? Moses foretold Jesus Cririst and commanded

ses to the magicians, Christ to the Pharisee, the Catholies to the hercties, etc.

1 The contention of the true God, etc. That is, the debates, of which Gos was the object, and the quarrels wherein religion was in question. 
to follow him; Jesus Chirist foretold the Antichrist and forbade to follow him.

It was impossible that, in the time of Moses, men should reserve their belief in the Antichrist, who was unknown to them; but it is very easy, in the time of the Antichrist, to believe in Jesus Christ, already known.

There is no reason to believe in Antichrist, that there is not for believing in Jesus Christ; but there are reasons for be. lieving in JESUs Christ, which there are not for believing in the other.

\section{V.}

Miracies are more important than you think: they have served 'for the foundation, and will serve for the continuation, of the Church, to the time of Antichrist, even to the end.

T God has either overthrown false miracles, or he has foretold them; and by both he has elevated himself above that which is supernatural as respects ourselves, and has raised us to the same elevation.

9 Miracles have such a force, that it was necessary that God should warn men not to suppose them against himself, however clear it may be that there is a God; without which they might have been capable of troubling us.

And thus so far from these passages (Deut. xiii) being agains the authority of miracles, nothing marks more strongly their force. And so with Antichrist: "and seduce, if it were possible, the very elect."

\section{VI.}

Reasons why we do not believe.-The reason why we do not believe true miracles is the want of love. John. Sed vos non creditis quia non estis ex ovibus.' The reason why the false are believed, is the want of love. 2 Thess. ii, [10].

T Having considered how it is that men place so much faith

2 Ye believe not because ye are not of my sheep. 
in so many impostors, who profess to have certain remedies, often even to the putting their lives in their hands, it has appeared to me that the true reason is that there are some real remedies; for it could not be possible that there should be so many false ones, and that they should obtain so much credit, if there were none true. If there never had been a remedy for any ill, and if all our diseases had been incurable, it is impossible that men could have imagined that they were able to cure; and still more that so many others should have given credit to those who have boasted of having effected cures: just as, if a man boasted of being able to prevent us from dying, no one would believe him, because there is not a single example of this. But as there has been a number of remedics which have been found real by the knowledge even of the greatest men, the belief of men has been warped by them; and this having been known to be possible, they have thence concluded that it was. For the people ordinarily reason thus : A thing is possible, therefore, it is; because the thing cannot be denied in general, since there are particular effects which are true, the people, who cannot discern which among these particular effects are true, believe them all. In like manner, the reason why so many false effects of the moon are believed is, that some are true, as the flux of the sea.

It is the same with prophecies, miracles, divinations by dreams, sorceries, etc. For, if in all this there never had been any truth, none of them would ever have been believed: and thus instead of concluding that there are no true miracles because there are so many that are false, we must say, on the sontrary, there are certainly true miracles, since there are so many that are false, and that there are false miracles only for the reason that there are true ones.

We must reason in the same way in regard to religion; for t would not be possible that men should have imagined so many false religions, if there were not a true one. The objec: on to this is, that the savages have a religion: but the answer to this is, that they have heard it spoken of, as it wonld appear by the deluge, circumcision, St. Andrew's cross, etc. 


\section{VII.}

It is said, Believe in the Church, but it is not said, Believe in miracles, because the latter is natural, and not the former. The one required a precept, not the other.

\section{VIII.}

... These ladies,' astonished at its being said that they are on the road to perdition; that their confessors are leading them to Genera ${ }^{2}$ that they inspire them with the idea that Jesus Christ is not in the Eucharist, nor on the right hand of the Father; they know that all this is false; they, thereforc, offer themselves to God in this state: Vide si via iniquitatis in me est. What happens thereupon? This place, which is said to be the devil's temple, God makes his own temple. It is said that the children ought to be taken out of it: God heals them there. It is called the arsenal of hell : God makes it the sanctuary of his grace. In fine, they are menaced with all the fury and all the vengeance of heaven; and God loads them with his favors. We must have lost our senses to conclude from this that they are on the road to perdition.

- In order to weaken your adversaries, you disarm the whole Cliurch.

- If they say ${ }^{3}$ that our salvation depends on God, they are heretics. If they say that they are submissive to the pope, it is hypocrisy. They are ready to subscribe all his constitutions, but that is not sufficient. If they say that we must not kill for an apple, ${ }^{4}$ they combat the ethics of the Catholics. If miracles are wrought among them, it is not a mark of holiness, but, on the contrary, a suspicion of heresy.

9... The three marks of religion : perpetuity, a good life, miracles. They destroy ${ }^{5}$ perpetuitv by probability, good life

1 The nuns of Port-Royal.

2 That is, to the doctrines professed at Geneva, to Calvinism.

3 If they say, that is, the Jansenists, to whom the paragraph refers.

" "Kill for an apple." An allusion to the ethice of the Casr.ists.

s They destroy, that is, the Jesuits. 
by their ethies; miracles, by denying either their truth, us their consequence.

If we believe them, the Church will have nothing to do witt perpetuity, a holy life, or miracles. The heretics deny them, or deny their consequence; so do they. But one must be without sineerity to deny them, or must have lost his senses to deny their consequence.

T... However this may be, the Church is without proofs, if they are right.

The Chureh has three kinds of enemies: the Jews, who never have been of its body; the hereties, who have withdrawn themselves from it; and bad Christians, who rend it within.

These three different kinds of adversaries generally oppose the Chureh in different ways. But here they oppose it in the same way. As they are all without miracles,' and as the Church has always had miracles against them, they have all had the same interest in eluding them, and have all made use of this evasion-that we must not judge of the doctrine by the miracles, but of the miracles by the doctrine. There were two parties among those who heard Jesus Cirrist: one that followed his doctrine, because of the miracles; the other that said ... There were two parties in the time of Calvin.... There are now the Jesuits, etc.

- This is not the country of truth: she wanders unknown among men. God has covered her with a veil, which prevents her from being known by those who do not understand her voice. The way is open to blasphemy, and even in regard to truths that are at least very apparent. If the truths of the Gospel are published, their contraries are published, and the questions are obscured, so that the people cannot discriminate. And it is asked: "What have you more than the others to make yourselves believed? What $\operatorname{sign}^{2}$ do you work? You have only words, and we also. If you had miracles, well."

1 "As they are all without miracles." When Paseal says this of the Jews, he means only the Jews since the advent of the Messiah, the Iew opprised to Jesus Christ.-Havet.

s Sign, in the sense of miracle. 
This is a truth, that the doctrine ought to be sustained by the miracles, which are perverted in order to blaspheme the doctrine. And if miracles are wrought, they say that the miracles are not sufficient without the doctrine; and this is another truth, in order to blaspheme the miracles.

T How glad you are to know the general rules, thinking stereby to east away trouble, and render every thing useless! You will be prevented from doing this, my father: truth is one and constant.

\section{IX.}

A miracle among the schismatics is not so much to be feared: for schism, which is more manifest than a miracle, manifestly indicates their error. But when there is no sehism, and when there is a question of error, miracle affords a test.

- John ix : Non est hic homo a Deo, qui sabbatum non custodit. Alii: Quomodo potest homo peccator hocc signa facere? Which is the clearest?

"This house is not of God, for it does not believe that the five propositions are in Jansenius." The others say: "This house is of God; for strange miracles are wrought in it." Which is the clearest?

Tu quid dicis? Dico quia propheta est.-Nisi esset hic a Deo, non poterat facer' quidquam.

I "If you do not believe in me, believe at least in the miracles." He sent them, as it were, to the strongest.

T It had been told the Jews, as wall as the Christians, that they would not always believe the prophets. But, nevertheless, the Pharisees and the Scribes make much ado about the miracles, and try to show that they are false, or wrought liy the deril: being under the necessity of being convineed, $\mathrm{i}$ they acknowledge them to be from God.

We are not now at the trouble of making this distinction. It is, however, very easy to do: those who deny neither God nor Jesus Christ work no miracles that are sure: Nemo faciat virtutem in nomine meo, et cito possit de me male loqui. But we have not to make this distinction. Here is a sacred 
relic. Here is a thorn of the crown of the Saviour of the world, over whom the prince of this world' has no power, who works miracles by the power of that blood which was shed for us. Here is a house ${ }^{2}$ chosen by God himself, wherein to make manifest his power.

It is not men who work these miracles by an unknown and doubtful virtue, which obliges us to make a difficult distinction. It is God himself; it is the instrument of the passion of his only Son, who, being in several places, chooses this one, and causes men to come from all quarters, to receive in it these miraculous consolations in their languor.

- Miracles are no longer necessary, but when tradition is no longer listened to, when nothing but the pope is any longer proposed, when he has been circumvented, and the true source of truth, which is tradition, having thus been excluded, and the pope, who is the depositary of truth, having been prepossessed, when truth has no longer the liberty to appear: then, men no longer speaking the truth, the truth ought herself to speak to men. This is what happened in the time of Arius.

John vi, [26] : Non quia vidistis signa, sed saturati estis. ${ }^{3}$

Those who follow Jesus Curist because of his miracles, nonor his power in all the miracles which it produces; but those who, in professing to follow him on account of his miracles, follow him in fact only because he consoles them, and fills them with the goods of this world, they dishonor his miracles, when they are contrary to their convenience.

- Unjust judges, ${ }^{4}$ make not laws for the occasion; judge by those that are established, and established by yourselves: Voc qui conditis leges iniquas.

T The manner in which the Church has subsisted is, that he truth has been without contestation; or, if it has been con-

1 "The prinee of this world." The devil (John xii, 31, ctc.)

2 Port-Royal.

s Ye seek me, not beeause ye saw the miracles, but bccause ye did eal of the loaves, and were filled.

4 This is addressed to the Jcsuits. 
tested, there has keen the pope, and if not, there has been the Church.

q It is important to kings, to princes, that they should be esteemed for piety, and for this end, it is necessary that they hould confess to you.

T The Jansenists resemble the heretics by their reformation $f$ morals, but you resemble them in evil. 


\section{CHAPTER XXIV.}

[ON REason, Grace, Faith, TIIE CHURCh, AND DIfFerent poinis of DOCTRINE AND MORALS.]

I.

Pyrnhonism is true ; for, after all, men, before Jesus Christ, knew not where they were, nor whether they were great or small. And those who have said either, knew nothing of it, and divined, without reason, and by chance; and they even always erred in excluding either. Quod ergo ignorantes quaritis, religio annunitat vobis.

- The only license that is against the common-sense and nature of men, is the only one that has always subsisted among men.

II.

Do you believe it is impossible that God should be infinite, without parts? Yes. I wish, then, to show you an infinite and indivisible thing; it is a point moving everywhere with an infinite swiftness; for it is in all places, and is entire in every place.

Let this effect of nature, which at first seemed to you impossible, teach you that there may be others which you do sot yet know. Do not draw this conclusion from your apprenticeship - that nothing remains for you to know; but that an infinity of things remains for you to know.

\section{III.}

The providence of God, which disposes of all things sweetly, is to put religion in the mind by reasons, and in the heart by grace. But to undertake to put it in the mind and heart by force and threats, is not to put religion there, but terror 'errorem potius quam religionem. 
T To begin by pitying the incredulous; they are unfortu. nate enough by their condition. We should not abuse them, except when this might serve them; but this injures them.

\section{IV.}

The whole of faith consists in Jesus Christ and Adam; an 211 morals, in concupiscence and grace.

$\mathrm{V}$.

The world subsists for the exercise of mercy and judgment, not as if men were there leaving the hands of God, but as cnemies of God, to whom he gives, by grace, sufficient light to return, if they wish to seek and follow him; but to punish them, if they refuse to seek and to follow him.

\section{VI.}

Let people say what they will, it must be confessed that the Christian religion has something astonishing in it. It is because you were born in it, it will be said. So far from it, I gird myself against it, for this very reason, lest this prejudice suborn me. But, although I have been born in it, I do not fail to find it thus.

\section{VII.}

Shall he alone who knows nature know it only to be miserable? Shall he alone who knows it, be alone unhappy?

... It is not necessary that he see nothing at all; neither is it necessary that he see enough of it to believe that he possesses it; but that he see enough of it to know that he has lost it: for, to know that we have lost, it is necessary to see and not to see; it is precisely the state in which nature is.

- It would be necessary that the true religion should teach greatness, misery, should lead to esteem and contempt of self. to love and hatred.

\section{VIII.}

Religion is a thing so great, that $t t$ is just that those who would not take the pains to seek it if it is obscure, should be 
deprived of it. What do they complain of, then, if it is such that they could find it by seeking it?

- Pride counterbalances and outweighs all miseries. Behold a strange monster, and a very obvious aberration. Behold him fallen from his place, which he seeks with dis. quietude. This is what all men do. Let us see who has found it.

ब When it is said that Jesus Christ did not die for all, you abuse a vice of men, who immediately apply this exception to themselves, which is to favor despair, instead of turning them from it, in order to favor hope. For we aceustom oureelves thus to the interior virtues by these external habits.

\section{IX.}

The dignity of man consisted in his innocence, in using and having dominion over the creatures, but now it consists in avoiding and subduing them.

\section{$\mathrm{X}$.}

The Church has always been combated by contrary errors ; but never, perhaps, at the same time, as at present. If she suffers more because of the multiplicity of errors, she receives this advantage from them-that they destroy each other.

It complains of both, but much more of the Calvinists, on account of schism.

It is certain that several of the two contrary sects are mistaken. It is necessary to disabuse them.

Faith embraces several truths which seem to contradict each other. Time to laugh, to weep, etc. Responde. Ne respon. deas, etc.

The source of this is the union of the two natures in JEsus Cirrist.

And also the two worlds. The creation of a new heaver

1 'These two errors are: $1^{\circ}$. That which sacrifices free will to grace; this ts the error of Calvin; $2^{\circ}$. That which sacrifices grace to free will; this is the error of the Jesuits. 
nnd a new earth; new life, new death; all things doubly, and the same names remaining.

And, in fine, the two men who are among the just, for they are the two worlds, and a member and image of JESUS CnRIST. And thus all names suit them: just, sinners; dead, living: living, dead; elect, reprobate, etc.

There is then a great number of truths, both of faith and cthics, which seem repugnant, and which all subsist in an admirable order.

The source of all heresies, is the exclusion of some one or other of these truths; and the source of all the objections which the heretics bring against us, is the ignorance of some of these truths.

And, generally, it happens that, not being able to conceive the relation between two opposite truths, and believing that the adoption of one involves the exclusion of the other, they attach themselves to one, they exclude the other, and think that we do the contrary. Now, the exclusion is the cause of their heresy; and ignorance that we hold the other, causes their objections.

1st Example: Jesus Christ is God and man. The Arians not being able to reconcile these things, which they believe to be incompatible, say that he is man; in this they are Catholies. But they deny that he is God: in this they are heretics. They pretend that we deny his humanity; in this they are ignorant.

2d Example, on the subject of the holy sacrament: We believe that the substance of the bread being changed, and consubstantially into that of the body of Our Lord, Jesus Christ is really present therein. This is a truth. Another is, that this sacrament is also one of the figures of the cross and of the glory, and a commemoration of both. This is the Catholic faith, which comprehends these two truths, which seem to be contradictory.

The heresy of the day, not corserving that this sacrament 
eontains, at the same time, both the presence of Jesus Christ, and his type, and that he is the saerifiee and the comnemoration of the saerifice, thinks, for this reason, that it cannot admit one of these truths without exeluding the other.

They adhere to this single point, that this saerament is fig urative; and in this they are not hereties. They think that we exelude this truth; and from this it eomes that they make so many objections to us, founded upon the passages of the Fathers who assert it. Finally, they deny the presence; and in this they are heretics.

3d Example: Indulgenees.

Henee the shortest way to prevent heresy, is to teach all the truths; and the surest way to refute heresy is to declare them all. For what will the hereties say?

All err so much the more dangerously as they each follow a truth. Their fault is not that of following a falsehood, but in not following another truth.

- Grace will always be in the world (and also nature), so that it is, in some sort, natural. And thus there will always be Pelagians, and always Catholies, and always confliets.

Because the first birth makes the former, and the grace of the second birth makes the latter.

\section{XI.}

There is this in common between the ordinary life of men and that of saints, that they all aspire to felieity; and they differ only in the object wherein they place it. Both call those their enemies who prevent them from obtaining it.

We ought to judge of what is good or bad by the will of God, who san be neither unjust nor blind; and not by our own will, which is always full of malice and error.

\section{XII.}

When St. Peter and the apostles were deliberating in regard to abolishing eireumcision, where the point in question was whether to act against the law of God, they did not consult the orophets, but simply the reeeption of the Holy Spirit in the 
persons of the uncircumcised. They judged it more sure that God approves those whom he fills with his Spirit, than that it is necessary to observe the law; they knew that the object of the law was only the Holy Spirit; and that thus, since they certainly had it without circumcision, circumeision was no necessary.

\section{XIII.}

Two laws are sufficient to rule the whole Christian republic, better than all political laws.'

T Religion is proportioned to all kinds of minds. 'The first stop at its establishment alone; and this religion is such that its establishment alone is sufficient to prove its truth. Others go as far as the apostles. The most learned go as far as the commencement of the world. The angels see it still better, and farther.

T God, in order to reserve to hirnself alone the right of instructing us, and to render the problem of our being unintelligible to us, has hidden the solution of it so high, or, to speak more correctly, so low, that we were incapable of finding it: so that it is not by the agitations of our reason, but by the simple submission of the reason that we can truly know ourselves.

\section{XIV.}

The impious, who profess to follow reason, ought to be wonderfully strong in reason. What do they say then? Do we not see, say they, that brutes die and live like men, and Turks like Christians? They have their ceremonies, their prophets, their doctors, their saints, their religious, like us, etc.-Is this contrary to Scripture? does it not assert all this? If you care but little to know the truth, here is enough to leave you in repose. But if you desire with all your heart to know the truth, it is not enough; examine minutely. It would be Plough for a question of philosophy; but here where every

1 Ilere Port-Royal adds, and acecrding to us, with reason: "the love of God and that of our neighbor." 
thing is at stake.... And yet, after a superficial reflection of this sort, people will amuse themselves, etc. Let them inform themselves of this very religion, whether it does not render a reason for this obscurity; perhaps it will instruct us on this point.

It is a horrible thing to feel all that we possess gliding way.

- Partis.-It is necessary to live differently in the world according to these different suppositions: $\mathbf{1}^{\circ}$. Whether we could be here always; $2^{\circ}$. Whether it is sure that we shall not long be here, and uncertain whether we shall be here an hour. This last supposition is ours.

\section{$\mathrm{XV}$.}

By the partis you ought to put yourself to trouble to discover the truth : for if you die without adoring the true principle, you are lost. But, you say, if he had wished that I should adore him, he would have left me some signs of his will. So he has; but you neglect them. Seek them, then; it is well worth it.

\section{XVI.}

The prophecies, the miracles even, and the proofs of our religion, are not of such a nature that we can say they are absolutely convincing. But they are also of such a kind that we can say that it is not without reason that they are believed. So there is evidence and obscurity, to enlighten some and to obscure others. But the evidence is such, that it surpasses, or equals at least, the evidence of the contrary; so that it is not the reason that can determine us not to follow it; and thus it can be only the concupiscence and wickedness of the heart. And by this means there is sufficient evidence to condemn, and not sufficient to convince; in order that it might appear that in those who follow it, it is grace and not reason, that makes it followed; and that in those who shun it, it is concupiscence and not reason, that makes it shunned.

- Who can help admiring and embracing a religion, which 
knows thoroughly what we recognize the more, the more light we have?

T ... It is an heir who finds the titles of his house. Will he say: Perhaps they are false? and will he neglect to examine them?

\section{XVII.}

Two sorts of persons know : those whose hearts are humbled, and who love lowliness, whatever degree of mind they may have, high or low; or those who have sufficient mind to perceive the truth, whatever opposition they may have in it.

T The sages who have said that there is a God, have been persecuted, the Jews hated, the Christians still more.

T Atheists.-What reason have they for saying that we cannot rise again? which is the more difficult, to be born, or to rise again? that what has never been, should be, or that what has been, should be again? Is it more difficult to come into being, than to return to it? Custom makes the one easy to us; the want of custom renders the other impossible. The popular way of judging.

\section{XVIII.}

What have they to say against the resurrection, and against the Virgin bringing forth? Is it more difficult to produce u man, or an animal, than to reproduce it? And if they had never seen a species of animals, could they divine whether they were produced without the company of one another?'

\section{XIX.}

... But is it probable that probability gives assurance?Difference between repose and surety of censcience. Nothing gives assurance but truth. Nothing gives repose but sincere search after truth.

1 Hcre Pascal adds: "Why cannot a virgin bring forth? Does not a hen lay eggs without a cock? who can distinguish them, outwardly, frcm tho others? and who has told us that the hen cannot form this germ as well as the cock?" 


\section{$\mathrm{XX}$.}

The examples of the heroic deaths of the Lacedemonians and others, scarcely touch us; for what does that bring us! But the example of the death of the martyrs touches us; for they are our members. We have a common bond with them: their resolution may form ours, not only by the example, but because it has, perhaps, merited ours. There is nothing of this in the examples of the pagans: we have no connection with them; as people do not become rich by contemplating a wealthy stranger, but indeed by seeing a wealthy father, or spouse.

\section{XXI.}

The elect will be ignorant of their virtues, and the reprobate of the greatness of their crimes: "Lord, when have we seen thee hungry, thirsty, etc.?"

T Jesus Christ did not wish the testimony of demons, nor of those who were not called; but of God, and John the Baptist.

\section{XXII.}

What spoils us for comparing what formerly took place in the Church with what we see in it now, is that ordinarily we regard St. Athanasius, St. Teresa, and the others, as crowned with glory, and . . . . like gods. Now that time has cleared up these matters, it appears thus. But in the days of his persecution, this great saint was a man who was called Athanasius, and St. Teresa, a nun. "Elias was a man subject to like passions as we are," said St. James [v, 17], in order to disabuse the Christians of this false idea which makes us reject the example of the saints, as disproportioned to our state. They were saints, we say, they were not like us. What happened at that time, then? St. Athanasius was a man called Athanasius, accused of several crimes, condemned in such and such a council, for such and such a crime. All the bishops consented to it, and finally the pope. What do we say to those who resist him? That they break the peace, that they cartse schism, etc. 
Four sorts of persons: zeal without knowledge; knowledge without zeal; neither knowledge nor zeal; zeal and knowledge. The three former eondemn him, and the latter absolve him, and are exeommunicated from the Church, and nevertheless save the Chureh.

\section{XXIII.}

Men have contempt for religion, they have a hatred of it, and fear that it is true. To eure this it is necessary to eommence by showing that religion is not contrary to reason; then that it is venerable, and worthy of respect; next to make it amiable, and make the good wish that it were true; and finally to show that it is true. ${ }^{\prime}$

Venerable, beeause it has known men well; amiable, because it promises the true good.

- A word from David, or from Moses, as God will eireumcise your hearts [Deut. xxx, 6], makes us judge of their mind. Let all the other discourses be equivocal, and doubtful whether they are Philosophic or Christian, a word of this nature determines all the others, as a word of Epietetus determines all the rest to the contrary. Thus far ambiguity eontinues and ro farther.

1 "That it is true." Here is what Louis Racine says in the preface to his poem entitled Religion: "Such is the plan of this work which I have framed on this short thought of M. Pascal: To those who have a repugnance for religion, it is necessary to begin by showing them that it is not contrary to reason; then, that it is venerable; next, render it amiable, and make it to be wished that it were true, show that it is true, and finally that it is amiable; and this thought is the abridgment of this whole poem, in the composition of which I have often made use of other thoughts of the saine author."-Ilavet.

"It is by ethics that Paseal was brought back to religion, as being itselt the most perfect of all ethics, and the only ethics that has known all and harmonized all. From this time truth was for him entirely in revelation, und he undertook to prove it, not indeed as an authority transmitted by testimony or as an establishment founded by ages, but as an evident truth. We see, an unheard of thing, the method of Descartes applied to the demmstration of faith ; the rigor of the geometric mind, which advances only by evidences, employed in proving the religion of miracles; the instrument even of science serving to confound science, and reasoning directed against the resistance of the reason to faith." -Nisard 
- I should have much more fear of being mistaken, and of finding that the Christian religion is true, than of not being mistaken in believing it true.

\section{XXIV.}

The conditions the easiest to live in, according to the world, are the most difficult, according to God; and vice versa. Nothing is so difficult according to the world as the religious life; nothing is easier according to God. Nothing is more easy than to live in a high position, and to have great wealth according to the world; nothing is more difficult than to live in them according to God, and without taking part and pleasure in them.

\section{XXV.}

The Old Testament contained the figures of the future joy, and the New contains the means of reaching it. The figures were of joy; the means of penitence; and nevertheless the pasehal lamb was eaten with wild herbs, cum amaritudinibus.

\section{XXVI.}

The word Galilee, which the Jewish crowd pronounced as by chance, in accusing Jesus Christ before Pilate, caused Pilate to send Jesus Christ to Herod; by which was accomplished the mystery, that he should be judged by the Jews and the Gentiles:- The apparent chance was the cause of the acsomplishment of the mystery.

\section{XXVII.}

A person said to me one day that he had great joy and confidence in coming out of the confessional: another said that he remained in fear. I thought thereupon that of these two a good one might be made, and that each wanted something, inasmuch as he had not the feeling of the other. This often happens in the same way in other things. 


\section{XXVIII.}

There is pleasure in being on a vessel tost by the storm when we are certain that we shall not perish. The persecu tions which trouble the Church are of this nature.

T The History of the Church ought properly to be called the History of the truth.

\section{XXIX.}

As the two sources of our sins are pride and sloth, God has discovered to us two qualities in himself in order to cure them: his mercy and his justice. The property of justice is to abase pride, however holy the works may be, et non intres in judicium; and the property of mercy is to combat sloth by inviting to good works, according to this passage: "The mercy of God leadeth thee to repentance;" and this other of the Ninevites: "Who can tell if God will return and repent, and turn away from his fierce anger, that we perish not." And thus so far from mercy authorizing remissness, it is, on the contrary, the quality which formally combats it; so that instead of saying, If there was no mercy in God, it would be necessary to make all sorts of efforts for virtue; we must say, on the contrary, that it is because there is mercy in God, that we must make all sorts ot efforts.

\section{XXX.}

All that is in the world is the lust of the flesh, or lust of the eyes, or pride of life : libido sentiendi, libido sciendi, libido dominandi. Unhappy the land of malediction which these three rivers of fire embrace rather than water! Happy those who, being upon these rivers, not engulfed, not carried away, but immovably established; not standing, but sitting in a low and sure seat, from which they never rise before the light, but, after having reposed in it in peace, stretch out the hand to him who will raise them again, in order to make them stand erect and firm within the porches of the holy Jerusalem, where pride ean no more combat and abase them; and who nevertheless weep, not indeed at seeing glide past all the perishable things 
which the torrents carry away, but at the remembrance of their dear country, the heavenly Jerusalem, which they remember without ceasing during the length of their exile!

\section{XXXI.}

Charity is not a figurative precept. To say that Jesus CnRist, who has come to take away figures in order to establish the truth, has come only to establish the figure of charity, in order to take away the reality which was before; this is horrible. If the light is darkness, what will the darkness be ?

\section{XXXII.}

IIow many existences have our glasses discovered which were not for our philosophers formerly! They wickedly ridieuled the holy Scripture in regard to the great number of the stars, saying: There are but a thousand and twenty-two,' we know it.

\section{XXXIII.}

Man is so made, that by dint of telling him that he is a fool, he believes it; and, by dint of telling himself so, he makes bimself believe it. For man holds an inward conversation with himself, which ought to be well regulated: Corrumpunt mres bonos colloquia prava. ${ }^{2}$ We ought to keep silence as miclı as possible, and hold converse only with God, whom we know to be the trutl, and thus we shall persuade ourselves or it.

\section{XXXIV.}

What difference is there between a soldier and a Carthusian, as to obedience? For they are equally obedient and depend-

1 "One thousand and twenty-two." This is the number of stars eom. prised in Ptolemy's Catalogue, from the observations of Hippareus. But wo read in the Cosmos: "The number of stars that ean be distinguished by the use of the telescope in the milky-way, is estimated at eighteen millions. In order to give us an idea of the magaitude of this number, or rather to aid ns with a term of comparison, it is sufficient to say that we eannot see with the naked eye, on the whole suriace of the heavens, more than eight thouand stars; such is in fact the number of stars comprised between the first ond the sixth magnitude."-Havet.

Evil communications corrupt good manners. 
ent, and their discipline is equally painful. But the soldier always hopes to become master, and never becomes such (for the captains, and princes even, are always slaves and dependants); but he always hopes it, and always works for it. Whilst the Carthusian makes a vow never to be any thing but dependent. Thus they do not differ in their perpetual seiviturle, in which state both are always, but in hope, which the one has always, and the other never.

\section{XXXV.}

Our own will can never be satisfied, even if it should havo power over every thing it wishes; but we are satisfied from the instant that we renounce it. Without it we cannot be discontented; with it we cannot be contented.

T... The true and only virtue is, then, to hate ourselves, for we are hateful by our concupiscence, and to seek a truly amiable being, in order to love him. But, as we cannot love what is out of us, we must love a being who is in us, and who is not us, and this is true of each and all men. Now, there is only the universal being who is such. The kingdom of God is within us; the universal good is in ourselves, and it is not us.

T It is unjust that people should become attached to me, although they may do so voluntarily and with pleasure. I should deceive those in whom I should create the desire; for I am the end of nobody, and have nothing wherewith to satisfy them. Am I not ready to die ?' And so the object of their

1 Pascal had made this thought the rule of his inward life; and in order ro have it always present he wrote it with his own hand on a separate picee of paper, as Madame Périer informs us, who, in her life of her brother, quotes this passage without changing it in the least. Port-Royal did not to like Madame Périer; it has removed the first person singular, which is sublime here; it has extinguished in the frosts of abstraction the ardent melancholy of this passage, which seems to have been written in the desert by the burning pen of St. ' erome, or by the author of the Initation in his cell.

Port-Royal: "It is unjust that people should become attached to us elthough they may do so voluntarily and with pleasure; we shall deceive 
attachment will die then. As I should be guilty in making a falsehood believed, although I should persuade to it mildly, and although it should be believed with pleasure, and although in this I should receive pleasure: so I am culpable in making myself loved, and if I attract people to become attached to me. I ought to warn those who may be ready to consent to a lie, that they should not believe it, whatever advantage miglit come to me from it; and so, that they should not become attached to me; for it is necessary that they spend their life and efforts in pleasing God, or in seeking him.

\section{XXXVI.}

It is to be superstitious to put our hope in formalities; but it is to be proud not to be willing to submit to them.

\section{XXXVII.}

All the religions and sects of the world have had natural reason for their guile. The Christians alone have been eompelled to take their rules from without, and to inform themselves of those which Jesus Curist left to the early Christians in order to be transmitted to the faithful. This constraint tires these good fathers. They wish to have, like other people, the liberty of following their imaginations. It is in vain that we cry to them, as the prophets said formerly to the Jews : Stand ye in the way, and ask for the old paths, where is the good way, and walk therein. They have answered like the Jews: IVe will not walk therein; but we will certainly do according to the thoughts of our own heart, like the nations round about us.

\section{XXXVIII.}

There are three means of believing: reason, custom, and inspiration. The Christian religion, which alone has reason, does not admit as its true children, those who believe without

those in whom we shall create the desire; for we are the end of robody and have rot wherewith to satisfy them. (To what does they refer?) Are we not ready to die, and so the object of their attachment would die." Dousin. 
inspiration : not that it excludes reason and custom; on the contrary, but it is necessary to open the mind to proofs, and confirm ourselves therein by custom; but offer ourselves by humiliations to inspirations, which alone can give the true and salutary effect: Ne evacuetur crux Christi.

\section{XXXIX.}

We never do evil so fully and so gayly as when we do it consciously.

\section{$\mathrm{XL}$.}

The Jews, who were called to subdue nations and kings, were slaves to $\sin$; and Christians, whose vocation was to serve, and be subject, are the children that are free.

\section{XLI.}

Is it courage in a dying man to go, in weakness and in agony, to affront an almighty and eternal God?

\section{XLII.}

History of China.-I believe only those histories whose witnesses would shed their blood in their support.

There is no question of seeing this in general. I tell you that there is wherewith to blind and wherewith to enlighten. By this single word I ruin all your reasonings. But China darkens, you say; and I answer: China darkens, but there is light to be found there; seek it. Thus all you say favors one, and does not oppose the other. Therefore this serves, and hurts not. We must then look at this in detail, we must have the documents.

\section{XLIII.}

Superstition and concupiscence. Scruples, improper desires. Improper fear.

Fear, not that which comes irom believing in God, but that which comes from doubting whether he is or not. Proper fear comes from faitl, false faith comes from doubt. Proper fear is allied to hope, because it is born of faith, and because 
we hope in the God in whom we believe: improper fear is allied to despair, because we fear the God in whom we have no faith. The former fear to lose him, the latter fear to find him.

\section{XLIV.}

Solomon and Job have best known and best spoken of the misery of man: the former is the most fortunate, the latter the most unfortunate; the one knowing the vanity of pleasures by experience, the other the reality of evils.

\section{XLV.}

Heretics.-Ezek[iel]. All the pagans spoke evil of Israel, and the prophet also; and so far from the Israelites having a right to say to him, "You speak like the pagans," he made it his strongest argument that the pagans spoke like him.

\section{XLVI.}

There are only three sorts of persons: those who serve God, having found him; those who are employed in seeking him, not having found him; those who live without seeking him, or having found him. The first are reasonable and happy; the last are fools and unhappy; those of the middle class are unhappy and reasonable.

\section{XLVII.}

Men often take their imaginations for their hearts; and they think they are converted as soon as they think of being converted.

\section{XLVIII.}

Reason auts with slowness, and with so many views, on so many principles, which it is necessary to have always present, that at every hour it becomes drowsy, and goes astray, for the want of having all its principles present. Fecling does not act thus; it acts in an instant, and is always ready to act. It is necessary, then, to put our faith in feeling, otherwise it wil always be wavering. 


\section{XLIX.}

Man is manifestly made for thinking; it is all his dignity and all his merit; and his whole duty is to think correctly; and the order of thought is to begin with himself, with his author, and his end. ${ }^{1}$ Now, what does the world think of? Never of this; but of dancing, of playing the lute, of singing, of making verses, of running at the ring, etc., of fighting, of becoming a king, without thinking what it is to become a king, and what it is to be a man.

T The whole dignity of man is in thought. But what is this thought? how foolish it is!?

\section{L.}

If there is a God, we ought to love only him, and not his transitory creatures. The reasoning of the impious in Wis$d o m,{ }^{3}$ is founded only on the supposition that there is no God. This being granted, they say, let us then enjoy the creature. This is the last shift. But if there was a God to love, they would not have concluded thus, but the contrary. And it is the conclusion of the wise: there is a God; therefore, let us not enjoy the creature. Therefore, every thing

1 "It is in the solitude of Port-Royal, in the midst of those deep philosophic and literary studies that were made there, that Pascal concentrated all his thoughts on this living subject, on man, all of whose greatnesses and niseries he experieneed in himself: not man such as Montaigne paints him, coming by universal doubt to believe only in himself; nor man, according to Deseartes, who is satisfied to know that there is a God, and that there is a soul which exists distinct from the body, and who disposes himnelf in such a way as to live the most agreeably, and for as long a time as cossible in the world; but man such as Christianity has described him; nan, of whom Montaigne has not seen all the greatness, nor Deseartes all the littleness."-Nisard.

2 VAr. of MS.: "The whole digrity of man is in thought. Thought is, therefore, something admirable and incomparable in its nature. It would be necessary that it should have strange faults to be despicable. But it has such funlts, that nothing is more ridiculous. How high it is by ts nature! how low it is by its faults!" (erasell).

3 That is, in the Jook of Wisdom. This book is, we know, attributed to Bolomon. 
that incites us to attach ourselves to the creature is barl, since this hinders us either from serving God, if we know him, or from seeking him, if we are ignorant of him. Now, we are full of concupiscence: therefore, we are full of evil; therefore, we ought to hate ourselves, and every thing which excites us to any other attachment than God alone.

\section{LI.}

When we wish to think of God, is there nothing that turns us from it, that tempts us to think of something else? All this is bad, and born with us.

\section{LII.}

It is false that we are worthy of being loved by others; it is unjust that we should wish it. If we were born reasonable and indifferent, and knowing ourselves and others, we should not give this inclination to our will. We are born, however, with it: we are, therefore, born unjust; for every thing tends to self. This is against all order: it is necessary to tend to the general good; and the inclination towards self is the commencement of all disorder, in war, in government, in economy, in the human body. The will is then depraved.

If the members of natural and civil communities seek the good of the body, the communities themselves should seek the good of another more general body, of which they are members. We ought, then, to seek the general good. We are, therefore, born unjust and depraved.

- Whoever does not hate on himself his self-love, and that instinct which leads him to make himself a God, is blind indeed. Who does not see that nothing is so opposed to justice and truth? For it is false that we merit this; and it is unjust and impossible to attain it, since all demand the same thing. This is, then, a manifest injustice in which we are born, from which we cannot free ourselves, and from which it is necessary to free ourselves.

Nevertheless no religion has remarked that this was a $\sin$ 
or that we were born in it, or that we were obliged to resist it, or has thought to give us remedies for it.

\section{LIII.}

Civil war in man between reason and the passions. If he hall only reason without passions .... If he had only passicns without reason .... But having both, he cannot be without war, not being able to have peace with the one without baving war with the other. Thus he is always divided, and contrary to himself.

T If it is a supernatural blindness to live without seeking to know what we are, it is terrible to live badly, while believing in God.

\section{LIV.}

It is unquestionable that, let the soul be mortal or immortal, this must make an entire difference in morals; and yet the philosophers have managed morals independently of all this. They deliberate how to pass an hour. ${ }^{1}$ Plato $^{2}$ to dispose to Christianity.

व The last act is bloody, however beautiful the play may be in every other respect. At last some earth is thrown over him, and there he is forever.

\section{LV.}

Morals.-God having made heaven and earth, which do not feel the happiness of their existence, wished to make beings who should know him, and who should compose a body of thinking members. For our members do not feel the happiness of their union, of their admirable harmony, of the care which nature takes to influence the vital spirits, and to inrease and preserve them. How happy they would be if they celt it, if they saw it! But it would be necessary for this that they should have the intelligerce to know it, and the good will

1 That is: They debate in order to know how they shall pass this lif., wohich endures but an instant.

2 Understood: is a suitable author to dispose. 
to consent to that of the universal soul. If, having received intelligence, they should make use of it to retain in them. selves the nourishment, without allowing it to pass to the other members, they would be not only unjust, but miserable also, and they would hate, rather than love each other: their beatitude, as well as their duty, consists in consenting to the government of the all-embracing soul, to whom they belong, who loves them better than they love themselves.

- To be a member is to have no life, being, or motion, but by the spirit of the body, and for the body. A separated member, secing no longer the body to which it belongs, has only a perishing and dying existence.

Yet it thinks it is a whole, and seeing no body to which it belongs, it thinks it belongs only to itself, and wishes to make itself a centre and body. But having in itself no principle of life, it only wanders, and wonders at the uneertainty of its existence; distinctly feeling that it is not a body, and yet not seeing that it is a member of a body. Finally, when it comes to know itself, it is, as it were, returned home, and loves itself no more but for the body; it bemoans its past wanderings.

It could not by its nature love any thing else, except for itself and in order to subject it, because every thing loves itself better than all. But in loving the body it loves itself, because it has no being but in it, by it, and for it: qui adhcret Deo unus spiritus est.

T The body loves the hand; and the hand, if it had a will, would love itself in the same way that the soul loves it. All love which exceeds this is unjust.

Adhcerens Deo unus spiritus est. We love ourselves because we are members of Jesus Christ. We love Jests Cririst because he is the body of which we are members. All is one, one is the other, like the three persons.

9 Members.-In order to regulate the love which we owe to ourselves, it is necessary to imagine a body full of thinking members, for we are members of the whole body, and to see how each member ought to love itself, etc.

If the feet and hands had a private will, they would never 
be in their place but in submitting this private will to the primary will which governs the entire body. Otherwise, they are in disorder and misfortune; but in wishing only the good of the body, they consult their own good.

- It is necessary to love only God, and hate only ourselves If the foot had always been ignorant that it belonged to th boly, and that there was a body on which it depended, if it had had only the knowledge and love of self, and had come to know that it belongs to a body on which it depends, what regret, what confusion for its past life, to have been useless to the body, which has influenced its life, which would have annihilated it, if it had rejected and separated it from itself, as it separated itself from the body! What praycrs for its preservation! and with what submission it would let itself be governed by the will which regulates the body, even to consent to be cut off, if it were necessary! Or it would lose its quality of member; for it is necessary that every member should be willing to perish for the body, which is the only thing for which all exist.

T In order that the members may be happy, it is necessary that they have a will, and that they conform it to the body.

T Reason of effects.-Concupiscence and compulsion are the sources of all our actions: concupiscence gives rise to voluntary actions : compulsion to those that are involuntary.

LVI.

Philosophers.-They believe that God alone is worthy of being loved and admired, and yet they desire to be loved and admired of men, not knowing their own corruption. If they feel themselves full of sentiments of love and adoration for him, and if they find their chicf joy in him, very well, I do not object that they deem themselves good. But if they find themselves averse to this, if they have no inclination but to wish to establish themselves in the esteem of men, and if their whole perfection consists, merely in making men, without compulsion, find their happiness in loving them, I shall say that this perfection is horrible. What! they have known God, and not exclusively 
desired that men should love him, [but] that men should stop at them; they have wished to be the object of the voluntary happiness of men!

\section{LVII.}

It is true that there is difficulty in entering into piety. But this difficulty does not eome from the piety that begins to exist in us, but from the impiety which still remains there. If our senses were not opposed to penitence, and if our corruption was not opposed to the purity of God, there would be in this nothing painful for us. We suffer only in proportion as viee, which is natural to us, resists supernatural grace. Our heart feels itself torn between these contrary efforts. But it would be very unjust to impute this violence to God, who draws us to himself, instead of attributing it to the world, which holds us back. As a child, snatched by its mother from the arms of robbers, ought to love, even in the pain that it suffers, the affectionate and legitimate violence of her who procures its liberty, and to detest only the fieree and tyrannical violence of those who unjustly retain it. The most cruel war that God can wage against men in this life is, to leave them without that war which he came to bring. "I am come to bring war," he said; and, to inform us what this war is: "I am eome to bring fire and sword." Before him, the world lived in a false peace.

\section{LVIII.}

On confessions and absolutions without signs of regret.-God looks only at the interior: the Chureh judges only by the exserior. God absolves as soon as he sees penitence in the heart; the Church when she sees it in works. God will make a Church which is pure within, which confounds by its internal and wholly spiritual sanctity the internal impiety of proud sages and pharisees : and the Church will form an assembly of men, whose outward manners shall be so pure, that they will eonfound the manners of pagans. If there are hypocrites among them, but so well disguised that she does not perceive their venom, she suffers them to remain; for, although they are 
not received by God, whom they cannot deceive, they are reeeived by men, whom they deceive. And thus she is not dishonored by their conduct, which appears holy. But you wish the Chureh to judge neither of the interior because that belongs only to God, nor of the exterior, because God stops only at the interior ; and thus, taking from her all choice of men, you retain in the Chureh the most dissolute, and those who dishonor her so much that the synagogues of the Jews, and the sects of the philosophers would have exiled them as unworthy, and would have abhorred them as impious.

\section{LIX.}

The law has not destroyed nature; but it has instrueted nature: grace has not destroyed the law; but has fulfilled it. The faith received at baptism is the source of the whole life of the Christian and the converted.

T We make an idol of truth itself; for truth, apart from charity, is not God, it is his image, and an idol, that we ought neither to love nor adore, and still less ought we to love and adore its contrary, which is falsehood.

T I could very well love total darkness; but if God places me in a state which is half dark, the little darkness that there is displeases me, and beeause I do not see the merit of an entire darkness, it does not please me. It is a fault, and a sign that I make an idol of darkness, separated from the order of God. Now we ought to adore only his order.

\section{LX.}

All great amusements are dangerous for the Christian life; but, among all those that the world has invented, there is none that is more to be feared than the drama. It is a representa tion of the passions, so natural and so delicate, that it awaken them and gives birth to them in our hearts, and especially that of love: principally when it is represented as eminently thaste and virtuous. For the more innocent it appears to innoeent minds, the more they are eapable of being moved by it. Its violenee pleases our self-love, which soon forms a desire to 
cause the same effects, which we see so well represented; and we at the same time appease our conscience by the honorable nature of the sentiments which we see in it, which calms the fear of pure minds, which imagine that it is not wound ng purity to love with an affection which appears to them to be so rational. Thus we leave the theatre with the heart so filled with all the charms and all the delights of love, the heart and the mind so well persuaded of its innocence, that we are fully prepared to receive its first impressions, or rather, to seek the opportunity of giving birth to them in the heart of another, in order to receive the same pleasures and the same sacrifices which we saw so well depicted on the stage.

\section{LXI.}

... Loose opinions please men so well, that it is strange that theirs are displeasing. It is because they have exceeded all bounds. And, moreover, there are many people who see the truth, and who cannot reach it. But there are few who do not know that the purity of religion is contrary to our corruptions. Ridiculous to say that an eternal recompense is offered to Escobartine' manners.

\section{LXII.}

Silence is the greatest persecution: never have the saints held their peace. It is true there should be a call to speak, but it is not from the decrees of the Council ${ }^{2}$ that we ought to learn whether we are called, it is from the necessity of speaking. Now, after Rome has spoken, and we think that she has condemned truth, and that they have written it; and that the books which have affirmed the contrary are censured, it is necessary to cry the londer the more unjustly we are censured,

1 Pascal here makes an adjeetive of Escobar,-in regard to whom see The Provincial Letters, passim.--Ed.

2 An allusion to the decree of the $23 \mathrm{~d}$ September, 1660, which condem ned the Latin translation of the Provinciales, by Nicole, to be burred. The lecree was executed the 14th Oetober of the same year. 
and the more violently they wish to suppress the word, until a pope will come who will hear both parties, and who will consult antiquity in order to do justice. Truly the good popes will still find the Church in clamors.

... The Inquisition and the Society, ${ }^{1}$ the two scourges of truth.

... Why do you not accuse them of Arianism? For they have said that Jesus CHRIst is God: perhaps they understand it, not by nature, but as it is said, Dii estis.

T If my letters are condemned at Rome, what I condemn in them is condemned in heaven : Ad tuum, Domine Jesu, tribunal appello.

... You are yourself corruptible.

... I am afraid that I may have written erroneously, secing myself condemned; but the example of so many pious writings makes me think otherwise. It is no longer permitted to write the truth, so corrupt or ignorant is the Inquisition!

... It is better to obey God than men. I fear nothing, I hope for nothing. The bishops are not thus. Port-Royal fears, and it is bad policy to separate them; for they will fear no longer, and will no longer make themselves feared.

... I do not fear even your censures, if they are not founded on those of tradition. Do you censure every thing? what? even my respect? No. Then say what, or you will do nothing, if you do not designate the evil, and why it is evil. And it is what they would have much difficulty in doing.

\section{LXIII.}

Nature has some perfections, to show that she is the image of God; and some defects, to show that she is only his image.

\section{LXIV.}

Men are so necessarily fools, that it would be being a fool in a higher strain of folly, not to be a fool. 


\section{LXV.}

Take away probability, we can please the world no longer Give the world probability, we can no longer displease it.

\section{LXVI.}

The ardor of the saints in seeking and practising the good, was useless, if probability is sure.

\section{LXVII.}

To make a man a saint, it must mdeed be by grace; and whoever doubts this, does not know what a saint is, or a man.

\section{LXVIII.}

We love certainty. We like the pope to be infallible in faith, and the grave doctors to be infallible in morals, in order to have assurance.

\section{LXIX.}

We must not judge of what the pope is by some words of the Fathers, as the Greeks said in a council (important rule), but by the actions of the Church and the Fathers, and by the canons.

\section{LXX.}

The pope is first. What other is known by all ?. What other is recognized by all? having the power to insinuate into all bodies, because he holds the chief branch which insinuates itself everywhere? How easy it was to make this degenerate into tyranny! Therefore Jesus Christ has laid down for them this precept: Vos autem non sic.

Unity and multitude: Duo aut tres in unum. It is to err to exclude one of the two, as the papists do, who exclude multitude, or the huguenots, who exclude unity.

\section{LXXI.}

There is heresy in always explaining omnes by all, and heresy in not explaining it sometimes by all. Bibite ex hoc 
omnes: the huguenots, heretics, in explaining it by all. In quo omnes peccaverunt: the huguenots, heretics, in excepting the children of the faithful. It is necessary, therefore, to follow the Fathers and tradition in order to know when, sine there is heresy to be feared on both sides.

\section{LXXII.}

Every thing may be mortal to us, even the things made to serve us, as, in nature, the walls may kill us, and the stairs may kill us, if we do not walk carefully.

The least motion is of importance to all nature; the entire sea changes for a stone. So, in grace, the least action is of importance in its consequences to all. Therefore, every thing is important.

In every action, we ought to consider, besides the action, the present, past, and future state of ourselves, and of others to whom it is of importance, and to see the connection of all these things. And then we shall be very prudent.

\section{LXXIII.}

All men naturally hate each other. Men have used as they could, human passion, in order to make it subserve the public good. But this is only dissimulation, and a false image of charity; for at bottom it is only hatred.

T This vile substratum of man, this figmentum malum, is only covered, it is not removed.

\section{LXXIV.}

Those who say that man is too insignificant to merit com. munion with God, should be very great to judge of it.

\section{LXXV.}

Man is not worthy of God, but he is not incapable of being made worthy of him. It is unworthy of God to unite himself to miserable man; but it is not unworthy of God to bring man out of his misery. 


\section{LXXVI.}

The wretches who have obliged me to speak of the basis of religion!... Sinners purified without penitence, the just justified without charity, all Christians without the grace of Jesus Cinist, God without power over the wills of men, a predestination without mystery, a Redemption without certainty!

\section{LXXVII.}

The Church, the Pope--Unity, multitude. In considering the Church as a unity, the pope, whoever he is, is the head, is as it were the whole. In considering it as a multitude, the pope is only a part of it. The Fathers have considered it sometimes in one manner, sometimes in the other. And thus they have spoken differently of the pope. Saint Cyprian: Sacerdos Dei. But in establishing one of these two truths they have not excluded the other. The multitude which is not reduced to the unity is confusion; the unity which does not depend on the multitude is tyranny. There is scarcely any country but France where it is permitted to say that the council is above the pope.

\section{LXXVIII.}

God works no miracles in the ordinary government of his Church. It would be a strange miracle indeed, if infallibility were in one; but that it may be in the multitude appears very natural, since the government of God is concealed under nature, as in all his other works.

\section{LXXIX.}

That the Christian religion is not the only one.-So far from this being a reason for believing that it is not the true nne, on the contrary, it is what makes us see that it is.

\section{LXXX.}

If it were necessary to do nothing but for the ccrtain, we should do nothing for religion; for it is not certain. But how many things we do for the uncertain, as sea-voyages, battles 
I say, therefore, that it would be necessary to do nothing at all ; for nothing is certain ; and that there is more certainty in religion than that we shall see to-morrow: for it is not certain that we shall see to-morrow, but it is certainly possible that we may not see it. We cannot say as much of religion. It is not certain that it is; but who will dare to say that it is certainly possible that it is not? Now, when we work for tomorrow, and for the uncertain, we act with reason. For we ought to work for the uncertain, by the rule of chance which has been demonstrated.

\section{LXXXI.}

All good maxims are in the world: we need only to apply them. For example, we do not doubt that we should expose our lives for the defence of the public good, and many do it; but for religion, not one.

\section{LXXXII.}

There are some vices which adhere to us only because or others, and which, when the trunk is removed, fall away like branches.

\section{LXXXIII.}

When malignity has reason on its side, it becomes proud, and displays reason in all its lustre: when austerity, or a severe choice, has not succeeded in obtaining the true good, and when it is necessary to return to nature, she becomes proud because of this return.

\section{LXXXIV.}

Evil is easy, there is an infinity of evils; good, almost alone. But a certain kind of evil is almost as difficult to find as what we call good; and, on this account, this particular evil often passes for good. It is necessary to have even an extraordinary greatness of soul to reach it, as well as the good.

\section{LXXXV.}

The nature of man is not to go always; it has its goings and its comings. Fever has its cold and its hot fits, and the 
cold shows as well the great ardor of the fever, as the heat itself. Just so men's inventions advance from age to age. The goodness and the wickedness of the world in general remain the same: Plerumque grato principibus vices.

\section{LXXXVI.}

$\mathrm{He}$ is made a priest who wishes to be, as under Jeroboam. It is a horrible thing to propose to us the discipline of the Church of to-day, as so good that it is made a crime to wish to change it. Formerly, she was infallibly good, and we find that she might be changed without sin; and now, such as she is, we cannot desire to change her! It has indeed been permitted to change the custom of making priests only with so much circumspection, that there were scarcely any who were worthy of being priests; and it is not permitted to complain of the custom which makes so many that are unworthy!

\section{LXXXVII.}

Children who are scared at the face which they have themselves bedaubed, are children; but how is it that he who is so weak as a child is so strong in maturer years? We only change our fancy.

\section{LXXXVIII.}

It is incomprehensible that God is, and incomprehensible ${ }^{1}$ that he is not; that the soul is in the body, that we have no soul; that the world is created, that it is not created, etc.; that original sin is, and that it is not.

\section{LXXXIX.}

The atheists ought to say things perfectly clear; now, it is not perfectly clear that the soul is material.

1 "We can only justly eoneeive God," says St. Cyprian, "in reeognizing hum to be inconceivable."-_"Si enim comprehendis," says St. Augustine (Sermo elxv), "non est Deus. Sit pia confessio ignorantiæ magis quam temeraria professio scientiæ. Adtingere aliquantum mente Deum, magna leatitudo est; comprehendere autem, omnino impossibile."- $E d$. 
$\mathrm{XC}$.

Unbelievers, the most credulous. They believe the miracles of Vespasian, in order not to believe those of Moses.

\section{XCI.}

To write against those who examine the sciences too much. Descartes.

9 [It should be said in general: This is made by figuro and motion, for this is true. But to say which, and to compose the machine, this is ridiculous; for this is useless, and uncertain and laborious. And even if this were true, we do not esteem all philosophy as worth an hour's trouble.]

\section{XCII.}

Atheism indicates ${ }^{1}$ force of mind, but to a certain degree only.

\section{XCIII.}

The faults of Montaigne are great. Lascivious words. This is worth nothing, notwithstanding Mademoiselle de Gournay. Credulous (people without eyes). Ignorant (quadrature of the circle, a larger world). His sentiments on voluntary homicide, on death. He inspires an indifference in regard to salvation, "without fear and without repentance." His book not being made to inculcate piety, he was not obliged to do it: but we are always under obligation not to lead men away from piety. We can excuse his somewhat liberal and voluptuous sentiments in relation to some of the accidents of life; but we cannot excuse his wholly pagan sentiments in relation to death; for we must renounce all piety, if we do not wish to die at least in a Christian manner: now, throughout his whole book, he thinks only of dying basely and effeminately.

1 All the editions made before the Report of M. Cousin read: lacks force of mind. Here, as in many other passages, the editors make Pascal say preeisely the contrary of what he wrote.

2 Pascal surpassed Montaigne neither in frankness nor in imagination. He surpassed him in depth, in fivesse, in sublimity, in vehemence. He 


\section{XCIV.}

The arithmetical machine produces results which approarb nearer to thought than all that animals do ; but it does nothing that could lead us to suppose that it has a will, like the animals.

\section{$\mathrm{XCV}$.}

Certain authors, speaking of their works, say: My book, my commentary, my history, etc. They betray their vulgarity who have just got a house over their heads, and have always "my house" at their tongue's end. It would be better to say : Our book, our commentary, our history, etc., seeing that, ordinarily, there is more in it that belongs to others than to themselves.

\section{XCVI.}

Eloquence is an art of saying things in such a manner that, $1^{\circ}$. Those to whom we speak may hear them without pain, and with pleasure; $2^{\circ}$. That they may feel interested in them, so that self-love may make them more willing to reflect on them. It consists then, in a correspondence which we endeavor to establish between the mind and the heart of those to whom we speak on the one side, and the thoughts and expressions of which we make use, on the other; which supposes that we have studied well the human heart in order to know all its springs, and then to find the just proportions of the discourses that we wish to adapt to this end. We must put ourselves in the place of those who are to hear us, and make trial on our own heart of the turn that we give to our discourse, in order to see whether the one is made for the other, and whether we can be certain that the hearer will, as it were, be compelled to

carried to perfection the eloquence of art, of which Montaigne was alinost entirely ignorant, and he has not been equalled in that vigor of genius by which the points of a discourse are brought together and summed up: bat the warmth and vivacity of his mind could lead him into errors, of which the firm and modcrate genius of Montaigne was not as susceptible.-Vauvenargues. 
surrender. We ought to confine ourselves, as much as possible, to the simple and natural; not making great what is little, nor little what is great. It is not sufficient that a thing be beautiful, it must be adapted to the subject, there must be nothing superfluous, nothing wanting.

- Eloquence is a painting of thought; and thus, those who, after having painted it, still add to it, make a picture, instead of a portrait.

\section{XCVII.}

It is necessary to have a reserved thought, and to judge of every thing by that, while speaking however like the people.'

\section{XCVIII.}

Force is the queen of the world, and not opinion; but opinion is that which uses force.

T Men consult only the ear, because they lack heart.

T We ought, in every dialogue or discourse, to be able to say to those who take offence at it: Of what do you complain?

1 This means, simply, that it is necessary to have a profound and dislinct reason for that of which the people have a confused good sense, and in speaking like the people, to know better than they why we say it.Sainte-Bewoe. 


\section{CHAPTER XXV.}

THOUGHTS PUBLISIED SINCE 1843.

I.

WIIEN our passions lead us to do any thing, we forgut our duty. As one having a book reads it, when he should be doing something else. But, in order to be mindful of duty, it is requisite that one should propose to himself to do something that he dislikes; and then he excuses himself upon the ground that he has something else to do, and is reminded of his duty by this means.

\section{II.}

What irregularity of judgment, by which there is no person who does not put himself above all the rest of the world, and who does not love more his own good, and the continuance of his happiness, and of his life, than that of all the rest of the world!

\section{III.}

There are plants on the earth; we see them; from the moon they would not be seen. And on these plants, down; and in this down, minute animals : but after that, nothing more.-O presumptuous!-The mixed are composed of elements; the elements not. $O$ presumptuous! Here is a delicate feature. It is not necessary to say that there is something that is not seen; it is therefore necessary to speak like others, but not to think like them.

\section{IV.}

... Not only do we look at things on other sides, but with. other eyes: we do not take care to find them similar. 
V.

Sneezing absorbs all the faculties of the soul, as well as begetting; but we do not draw the same consequences from it against the greatness of man, because it is against his will. And although he does it himself, yet, it is against his will that he does it; it is not in view of the thing itself, it is for another object; and therefore it is not an indication of the weakness of man, and of his subjection under this action.

\section{VI.}

It is not shameful for man to succumb under pain, and it is shameful for him to succumb under pleasure. This does not arise from the fact that pain comes to us from without and that we seek pleasure; for we may seek pain and succumb to it designedly, without this kind of baseness. Whence comes it, then, that it is glorious for the reason to succumb under the effort of pain, and that it is shameful for it to succumb under the effort of pleasure? The reason is, that it is not pain that tempts us and attracts us. It is ourselves who voluntarily choose it and wish it to have dominion over us; so that we are masters of the thing; and in this it is man that succumbs to himself : but in pleasure, it is man who succumbs to pleasure. Now it is only freedom and empire that give glory, and only servitude that gives shame.

\section{VII.}

Those who, in troublesome affairs, have always good hope, and are rejoiced at happy adventures, if they are not equally afflicted at unhappy ones, are suspected of being very glad at the loss of the affair, and are delighted to find these pretexts of hope, in order to show that they are interested therein, and to cover by the joy that they feign to feel that which they really have at secing the affair lost.

\section{VIII.}

Our nature is in movement; entire repose is death. 


\section{IX.}

We know ourselves so little that many think they are going to die, when they are well, and many think they are well, when they are near dying, not feeling the fever near, or the abscess ready to form.

\section{$\mathrm{X}$.}

Nature always begins again the same things, years, days, hours; just so space touches space, and number follows number without break. Thus is made a species of infinite and eternal. Not that there is in all this any thing that is infinite and eternal, but these determinate beings are infinitely multiplied; thus it seems to me, there is nothing infinite but the number that multiplies them.

\section{XI.}

When it is said that heat is only the motion of some globules, and light the conatus recedendi that we feel, this astonishes us. What? that pleasure is nothing else than the dance of the spirits? What a different idea we have conceived of it! and these sentiments seem to us so far from those others which we affirm to be the same as those that we compare with them: The feeling of fire, that heat which affects us in quite another inanner than touch, the reception of sound, and light,-all this appears to us mysterious, and yet this is as palpable as a blow from a stone. It is true that the littleness of the spirits which cnter the pores touch other nerves, but they are always nerves touched.

\section{XII.}

If an animal did by mind what it does by instinct, and if $\mathrm{t}$ spoke by mind what it speaks by instinct, for the chase, and for iuforming its comrades that the prey is found or lost it would speak also of things wherein it has more affection, as to say: Gnaw this rope that wounds me, and which I cannot reach. 


\section{XIII.}

We do not maintain ourselves in virtue by our own strength, but by the counterpoise of two opposing vices, as we remain standing between two contrary winds: remove one of thes $\theta$ vices, we fall into the other.

\section{XIV.}

They say that eclipses presage misfortune, because misfortunes are common; so that evil happens so often, that they divine often; whilst if they said that they presage happiness, they would lie often. They ascribe happiness only to rare conjunctions in the heavens; thus they very seldom fail to divine.

\section{$\mathrm{XV}$.}

Memory is necessary for all the operations of the mind.

\section{XVI.}

Instinct and reason, marks of two natures.

\section{XVII.}

When I consider the brief duration of my life, absorbed in the eternity preceding and following; the small space that ! fill, and even that I see, swallowed up in the infinite immensity of spaces that I am ignorant of, and which are ignorant of me, I am frightened, and astonished at seeing myself here rather than there; for there is no reason why here rather than there, why at present rather than then. Who has put me here? by the order and government of whom has this place and time been destined for me?-Memoria hospitis unius diei prete"euntis.

\section{XVIII.}

How many kingdoms are ignorant of us!

T The eternal silence of these infinite spaces terrifies me. 


\section{XIX.}

I envy those whom I see in the faith live with so much neg. ligence, who use so badly a gift, of which it seems to me I would make a very different use.

\section{XX.}

Each is a whole to himself, for he keing dead, the whole is dead for him. Hence it comes that each believes himself to be a whole to all. We must not judge of nature according to ourselves, but according to her.

\section{XXI.}

The ordinary world has the power of not thinking about what it does not wish to think about. Do not think of the passages of the Messiah, said the Jew to his son. Thus often do ours. Thus are the false religions preserved; and even the true, with respect to many people. But there are those who have not the power thus to refrain from thinking, and who think the more, the more they are forbidden to think. These rid themselves of false religions; and of the true even, if they find no solid arguments in its favor.

\section{XXII.}

What a distance there is between the knowledge of God and loving him!

\section{XXIII.}

Art thou less a slave for being loved and flattered than thy master? Thou art well off, slave: thy master flatters thec. He will beat thee presently.

\section{XXIV.}

It is not in Montaigne, but in myself, that I find what I see in him.'

1 Paseal does not always treat Montaigne as greatly as 11 the interview with M. de Sacy: he insults him and repeats him; he would fain make im contemptible: "He is full of filthy and discourteous words . . . . The foulish project that Montaigre had of painting limself! . . ." Then, 


\section{XXV.}

Ennui.-Nothing is so insupportable to man as to be in complete repose, without passion, without occupation, without diversion, without application. He then feels his nothingness, his abandonment, his insufficiency, his impotence, his vacuity. Incontinently will issue from the bottom of his soul ennui, baseness, saảness, chagrin, spite, despair.

- Agitation.-When a soldier complains of his painful toil, or a laborer, etc., let him be left without any thing to do.

\section{XXVI.}

Man does not act by reason, which makes his being.

\section{XXVII.}

Baseness of man even to submitting himself to the brutes, even to adoring them.

\section{XXVIII.}

All their principles are true, Pyrrhonists, Stoics, Atheists, etc. But their conclusions are false, because the opposite principles are also true.

\section{XXIX.}

Philosophers have consecrated the vices, by putting them in God himself; Christians have consecrated the virtues.

\section{XXX.}

Immateriality of the soul. The philosophers who have ruled their passions, - what matter has been able to do this?

almost immediately, he returns to him: "Custom ouglit to be followed . . . ." Or again, what is more formal and escapes him: "What Montaigne has of good ean be acquired only with difficulty; what he has of bad (except in morals) might have been eorrected in a moment, if he had been warned that he was telling too many stories and was speaking too much of himsclf." And elsewhere he all at onee speaks of lim as the incomparable zuthor of the art of discussing . . . . It miglit be said that Paseal, during his whole life, did, and wished to do, but two t_lings-relentlessly combat the Jesuits in the Provinciales, ruin and anzihilate Montaigne in the Thoughte - Sainte-Beuve. 


\section{XXXI.}

A fine thing to proclaim to a man that knows not himself, that he go from himself to God! And a fine thing to tell this to a man who does know himself!

\section{XXXII.}

Search for the true good. - The commonalty of men put the good in fortune and external goods, or at least in diversion. Philosophers have shown the vanity of all this, and have put it where they could.

T For the philosophers ${ }^{1} 288$ sovereign goods.

- Ut sis contentus temetipso et ex te nascentibus bonis. There is contradiction, for, in fine, they counsel the killing of one another. Oh! what a happy life, from which one delivers himself as from a plague!

TI It good to be wearied and fatigued by uselessly seeking the true good, in order to extend the arms to the liberator.

\section{XXXIII.}

Good heavens! what foolish speeches are these: "Would God have made the world in order to damn it? would he demand so many weak people?" etc. Pyrrhonism is a remedy for this evil, and will beat down this vanity.

\section{XXXIV.}

Will it be affirmed that, because it is said that justice is a part of the earth, men have known original sin? Nemo ante olitum beatus est. Is this saying that they have known that at death the eternal and essential beatitude begins?

\section{XXXV.}

Good sense.-They are constrained to say: You do not act in good faith; we ought not, ete. How I love to see this

1 "There is no combat so violent among the philosophers, and so bitter as that in regard to the question of the sovereign good of man; from which, by the calculation of Varro, sprang two hundred and eighty-eigh. sects.' -Montaigne. 
proud reason humbled and suppliant! For this is not the language of a man whose right is contested, and who defends it by force of arms. He does not amuse himself by saying that we do not act in good faith, but he punishes this bad faith by force.

\section{XXXVI.}

Ecclesiastes shows that man without God is in ignorance of every thing, and in inevitable misery. For it is to be miserable to wish and be powerless. Now, he wishes to be happy and assured of some truth, and yet he can neither know nor desire not to know. He cannot even doubt.

\section{XXXVII.}

We are under much obligation to those who tell us of our faults, for they mortify. They teach us that we have been despised; they do not prevent us from being despised in the future, for we have many other faults to make us despised They prepare for the exercise of correction, and exemption from fault.

\section{XXXVIII.}

No sect or religion but the Christian has always been on the earth.

T There is only the Christian religion that renders a man at the same time amiable and happy. In virtue, we cannot be at the same time amiable and happy.

\section{XXXIX.}

Faith is a gift of God. Do not think that we said that it is a gift of reasoning. Other religions do not say this of their faith; they give only reasoning as the means of reashing it, which nevertheless does not lead to it.

\section{XL.}

The figures of the totality of redemption, as that the sun shines for all, indicate only one totality; but the figures of ex- 
slusions, as of the Jews elected to the exclusion of the Gen. tiles, indicate the exclusion.

"Jesus Christ, the Saviour of all."-Yes, for he has made an offering for all; as a man who has redeemed all those who are willing to eome to him. Those who die un the way, it is their misfortune; but as for him, he offered them redemption. This is good in this example, where he who redeems, and he who preserves us from death are two, but not indeed in JEsus Cnnist, who does both. No, for Jesus Christ, in the quality of redeemer, is not, perhaps, master of all; and thus, in so far as it is in him, he is the redeemer of all.

\section{XLI.}

The prophecies cited in the Gospel you think are reported in order to make you believe. No, it is to make you averse to believing.

T Miracles do not serve to convert but to condemn.

\section{XLII.}

Even had Epictetus seen the way perfectly well, he would have said to men: You follow a false way; he shows that there is another, but he does not lead to it. That way is to will what God wills; Jesus Christ alone leads to it: Via, veritas.

\section{XLIII.}

I regard Jesus Christ in all persons, and in ourselves. iesus Christ as father in his Father, Jesus Curist as brother in his brethren, Jesus Christ as poor in the poor, Jesus Christ as rich in the rich, JESUS Christ as doctor and priest in the priests, Jesus Christ as sovereign in princes, etc. For, being God, all his greatness is by his own glory, and all that is miserable and abject in him is by his mortal life; therefore, he has taken this pitiable condition, in order to be able to be ir. all persons, and to be a model of all conditions. 


\section{XLIV.}

The psalms sung by the whole earth.

Who testifies of Mahomet? Himself. Jesus Christ wishes that his testimony may be nothing.

The quality of witnesses makes it necessary that they should be always and everywhere, and, miserable wretch, he is alone.'

\section{XLV.}

It is not seldom that it is necessary to chide the world for too much docility; it is a natural vice like incredulity, and as pernici us. Superstition.

\section{XLVI.}

There are few true Christians, I say, even in faith. There are many who believe, but through superstition; there are many who do not believe, but through free-thinking: there are few between the two.

I do not mean to include those who are in real piety of living, and those who believe through a sentiment of the heart.

\section{XLVII.}

Those who do not love the truth make a pretext of the contestation of the multitude of those who deny it, and thus their error comes only from the fact that they do not love truth or 'harity; and, therefore, they are not excused.

\section{XLVIII.}

So far from the having heard a thing said being the rule of rour belief, you ought to believe nothing without putting rourself in the condition as if you never had heard it. It is the consent of yourself to yourself, and the constant voice of your reason, and not of others, that ought to make you believe.

"He is alone."-Mahomet. 
To believe is so important! A hundred contradictions might be true.

If antiquity was the rule of belief, the ancients were there fore without a rule. If the general consent; if men had pershed?

False humility, pride. Raise the curtain. It is in vain; we nust either believe, or deny, or doubt. Shall we then have no rule? We judge of animals that they do well whatever they do: shall there be no rule whereby to judge men? To deny, to believe, and to doubt well, are to man what running is to the horse.

\section{XLIX.}

Our religion is wise and foolish. Wise, because it is the most learned, and the most firmly founded in miracles, prophecies, etc. Foolish, because it is not all this that makes us be of it; this certainly condemns those who are not of it, but it does not make those believe who are. What makes them believe is the cross, ne evacuata sit crux. And thus St. Paul, who came in wisdom and signs, said that he came neither in wisdom nor in signs, for he came to convert. But those who come only to convince may say that they come in wisdom and signs.

\section{L.}

The law obligated to what it did not give. Grace gives that to which it does not obligate.

\section{LI.}

What men, by their greatest learning had been able to know, this religion taught to their children.

\section{LII.}

How I hate these stupidities, not to believe in the Eucharist, vtc. ...! If the Gospel is true, if Jesus Cirist is Gorl, what difficulty is there in it? 


\section{LIII.}

The just man acts by faith in the smallest things: when he reprimands his servants he wishes their conversion by the spirit of God, and prays God to correct them, and expects as much from God as from his reprimands, and prays God to bless his corrections. And thus in other actions.

- Of all that is on the earth, he takes part only in the sorrows, not in the pleasures. He loves his neighbors, but his charity does not confine itself to these limits, but extends itself to his enemies, and then to those of God.

\section{LIV.}

Why God has established prayer.- $1^{\circ}$. In order to communicate to his creatures the dignity of causality. $2^{\circ}$. In order to inform us from whom we have virtue. $3^{\circ}$. In order to make us merit the other virtues by labor.-Objection. But one would think that we are indebted for prayer to ourselves.This is absurd, for since, having faith, we cannot have the virtues, how could we have faith? Is there a greater distance from infidelity to faith, than from faith to virtue?

T God should do only according to his promises. He has promised io accord justice to prayer: he has never promised prayer but to the children of the promise.

\section{LV.}

M. de Roannez said: The reasons come to me afterwards, but at first the thing pleases me or displeases me without snowing the cause, and yet this displeases me for the reason that I discover it only afterwards. But I think, not that the thing displeased for the reasons that we find afterwards, bu that we find the reasons only because the thing displeases.

\section{LVI.}

He no longer loves the person that he loved ten years ago. - believe it; she is no longer the same, nor he either. He 
was young and she also; she is altogether different. He would love her perhaps still, such as she was then

\section{LVII.}

Fear death out of danger, and not in danger, for it is neces. ary to be a man.

- Sudden death alone to be feared, and hence confessors kept by the great.

\section{LVIII.}

We should know ourselves: even if this did not serve to discover the true, it, at least, serves to regulate our lives, and nothing is more just.

\section{LIX.}

How I hate those who set up for doubters of miracles! Montaigne speaks as he should of them in two places. We see in one how prudent he is, and yet in the other he believes, and laughs at the incredulous.

\section{LX.}

When we wish to pursue the virtues to extremes on every side, vices appear, and insensibly insinuate themselves, in their insensible courses, from the side of the infinitely little; and they appear, too, in crowds from the side of the infinitely great, so that we lose ourselves in the vices, and no longer see the virtues.

\section{LXI.}

Diversity.-Theology is a science, but at the same time how many sciences are there! A man is an instrument: but if we anatomize him, shall it be the head, the heart, the stomach, the veins, each vein, each portion of a vein, the blood, cach humor of the blood?

A town, a country, seen from a distance is a town and coun. try; but in proportion as we approach, they become houses 
trees, tiles, leaves, grass, ants, the legs of ants, ad infinitum. All this is comprehended under the name of country.

\section{LXII.}

Two sorts of people compare things, as the holidays to the working days, the Christians to the priests, all the sins among themselves, etc. And hence some conclude that what is therefore bad in priests is also bad in Christians; and others, that what is bad in Christians is permitted in priests.

\section{LXIII.}

Nature imitates herself. A seed, thrown into good ground, produces. A principle, thrown into a good mind, produces. Numbers imitate space, which are of such a different nature. All is made and governed by the same Master : root, branch, fruits; principles, consequences.

\section{LXIV.}

Admiration spoils everybody from childhood. Oh! how well that is said! how handsome he is! how good he is! etc. The children at Port-Royal, to whom this incitement to envy and glory is not given, fall into nonchalance.

\section{LXV.}

Experience makes us see a wonderful difference between devotion and goodness.

\section{LXVI.}

We do not weary of eating and sleeping every day, for hunger and sleep revive: without this we should weary of them. Thus, without the hunger after spiritual things, we weary os them. Hunger after justice; eighth beatitude.

\section{LXVII.}

There are only two sorts of men : the one the just, who be lieve themselves sinners; the other sinners, who believe them selves just. 


\section{LXVIII.}

It is not good to be too free. It is not good to have all that is necessary.

\section{LXIX.}

The hope that Christians have of possessing an infinite good, is mixed with joy as well as fear; for they are not like those who hope for a kingdom, of which they could have nothing (being subjects); but they hope for holiness, exemption from injustice, and they have something of these.

\section{LXX.}

Comminutum cor. St. PAul. Here is the Christian character. "Albe has named you, I know you no more."-CorNEILLE. Here is the inhuman character. The human character is the contrary.

\section{LXXI.}

Symmetry is what we see at one view. Founded on thisthat there is no reason for doing otherwise. And founded also on the figure of man, whence it comes that we wish to see symmetry only in breadth, not in height or depth.

\section{LXXII.}

Morals and language are special sciences, but universal.

\section{LXXIII.}

... But it is impossible that God should ever be the end, if he is not the principle. We direct our view above, but we rest on the sand: and the earth will melt and we shall fall looking at the heavens.

\section{LXXIV.}

What weariness we have in quitting the occupations to which we have become attached! A man lives with pleasure in his own house: let him see a woman that pleases him, let bim play five or six days with pleasure; how miserable he is 
if he returns to his first occupation. Nothing is more common than this.

\section{LXXV.}

It is deplorable to see all men deliberating only in regard to means, and not in regard to the end. Each thinks how he will acquit himself in his condition; but as for the choice of esndition and country, lot determines it for us. It is a pitiable thing to see so many Turks, heretics, infidels, following in the track of their fathers, for this single reason that they have been each prepossessed with the idea, that it is the best. And this is what determines each to each calling, as that of a locksmith, soldier, ete. This is why the savages have nothing to do with Provence.

\section{LXXVI.}

Description of man. Dependence, the desire of independence, need.

\section{LXXVII.}

One is not miserable without feeling. A ruined house is not. Man alone is miserable. Ego vir videns.

\section{LXXVIII.}

The nature of man is all nature, omne animal. There is nothing that we make natural; we destroy the natural in every thing.

q The true nature being lost, every thing becomes his nature; as, the true good being lost, every thing becomes his true good.

\section{LXXIX.}

Jurisdiction is not given for [the] judge but for the judged. It is dangerous to tell it to the people: but the people have too much faith in you; this will not hurt them, and may serve you. It ought then to be published. Pasce oves meas, not tuas. You owe me food. 


\section{LXXX.}

Wisdom sends us to childhood: nisi effici mini sicut parvul.

\section{LXXXI.}

The true religion teaches our duties, our impotences (pride and concupiscence), and the remedies (humility, mortification).

\section{LXXXII.}

The Scripture has provided passages to console all conditions, and to intimidate all conditions.

Nature seems to have done the same thing by its two infinities, natural and moral: for we shall always have something of the superior and the inferior, of the most able and the least able, of the most exalted and the most miserable, in order to abase our pride and to raise our abjection.

\section{LXXXIII.}

The eternal Being is forever, if he is at all.

\section{LXXXIV.}

The corruption of the reason appears by so many different and extravagant manners. It was necessary that the truth should come, in order that man should no longer live in himself.

\section{LXXXV.}

Custom is our nature. Whoever accustoms himself to his faith, believes it, and believes nothing else, and can no longer fear hell. Whoever accustoms himself to believe that the king is terrible ...., etc. Who doubts, then, that our soul, being accustomed to see number, space, motion, believes this and nothing but this?

\section{LXXXVI.}

Falsity of other religions. They have no witnesses, these have. God defies other religions to produce such marks • Isaiah xliii, 9; xliv, 8. 


\section{LXXXVII.}

The two oldest books in the world are Moses and Job, the one a Jew, the other a pagan, who both regard Jesus CHrist as their conimon centre and object: Moses, in referring the promises of God to Abraham, Jacob, etc., and his prophecies; and Job: Quis mihi det ut, etc. Scio enim quod redemptor meus vivit, etc.

\section{LXXXVIII.}

I should not be a Christian without the miracles, said St. Augustine.

9 We should not have sinned in not believing Jesus Christ without the miracles: Vide an mentiar.

T It is not possible to believe reasonably against the miracles.

T Ubi est Deus tuus? The miracles show it, and are an elucidation.

\section{LXXXIX.}

For religions, it is necessary to be sincere; true pagans, true Jews, true Christians.

\section{XC.}

... The true Christians obey follies nevertheless, not that they respect follies, but the order of God, who, for the punishment of men, has subjected them to these follies. Omnis creatura subjecta est vanitati, Liberabitur.

Thus St. Thomas explains the passage of St. James in regard to the preference of the rich, that, if they do it not in the sight of God, they forsake the order of religion.

\section{XCI.}

Abraham took nothing for himself, but only for his servants; thus the just man takes nothing in the world for himseli, nor the world's applause; out only for his passions, of which he serves himself as a master, saying to the one, Go, and [to another], Come. Sul te erit appetitus tuus. The pas- 
sions thus ruled are virtues. Avarice, jealonsy, anger,--God himself attributes them [to himself]; they are virtues as well as clemency, pity, constancy, which are also passions. We must make use of them as slaves, leaving them their food, taking care that the soul does not partake of it; for when the passions are masters, they are vices, and then they give to the coul their food, on which the soul feeds and is poisoned.

\section{XCII.}

We forsake [God] only in forsaking charity. Our prayers are abomination before God, if they are not the prayers and the virtues of Jesus Christ. And our sins shall never be the object of God's mercy, but of his justive, if they are not those of Jesus Chri-T. IIe has adopted our sins, and has admitted us to his alliance; for the virtues are peculiar to him, and sins foreign to lim; and the virtues are foreign to us, and our sins are peculiar to us.

Let us change the rule that we have taken hitherto to judge of what is good. We had our will for a rule, let us now take the will of God: whatever he wills is for us good and just, whatever he does not will is bad for us.

Whatever God does not will is prohibited. The sins have been prohibited by the general declaration made by God that they are contrary to his will. Other things that he has left without general prohibition, and for this reason are said to be permitted, are nevertheless not always permitted. For, when God removes any thing from us, and by the event, which is a manifestation of God's will, it appears that God docs not wish that we should have a thing, it is then forbidden us like sin, sinee the will of God is that we should have the one no more than the other. There is this sole difference between these two things, - that it is certain that God would never allow sin, whilst it is not certain that he would not allow the other. But as long as God does not will it, we should regard it as sin; as long as the absence of God's will, which alone is the whole of goodness and justice, renders it unjust and bad. 


\section{XCIII.}

"I have reserved to myself seven thousand."' I love the worshippers that are unknown to the world, and even to the prophets.

\section{XCIV.}

Men not having been accustomed to form morit, but only to 1eward it when they find it already formed, judge of God by themselves.

\section{$\mathrm{XCV}$.}

.. I should certainly have taken this discourse of order as the following: to show the vanity of all sorts of conditions, to show the vanity of common lives, and then the vanity of philosophic lives (Pyrrhonists, Stoics); but order would not be preserved. I know a little what it is, and how few people understand it. No human scienee can preserve it. St. Thomas has not preserved it. The mathematics preserve it, but they are useless in their profundity.

\section{XCVI.}

My friend, you have been born on this side of the mountain; it is therefore just that your elder brother have every thing.

\section{XCVII.}

We implore the mercy of God, not that he may leave us in our sins, but that he may deliver us from them.

\section{XCVIII.}

If God gave us masters from his own hand, oh! with what good heart should we obey them! Necessity and events are such infallibly.

1 "I have reserved to myself seven thousand men in Israel, who have not bi)wed the knee to Baal." 


\section{XCIX.}

Eritis sicut dii, scientes bonum et malum. All the world plays the god in judging. This is good or bad; and being afllicted or rejoicing too much at events.

\section{C.}

To do little things like great ones, on account of the majesty of Jesus Cirrist who does them in us, and who lives our life; and great things like things little and easy, on account of his omnipotence. 
LETTERS AND OPUSCULES. 


\section{LETTERS OF PASCAL.}

From Pascal to his Sister Jacqueline.

JANUARY 26, 1648.

\section{My dear Sister,}

We have reeeived your letters. I intended to reply to the first that you wrote me more than four months since, but my indisposition and some other things prevented me. Since then I have not been in a condition to write, either on aecount of my illness, for want of leisure, or for some other reason. I have few hours of leisure and health together; I shall however endeavor to finish this letter without forcing myself; I know not whether it will be long or short. My prineipal design is to make you understand the truth of the visits which you know of, in which I hoped to have wherewith to satisfy you and to reply to your last letters. I can commenee with nothing else than the expression of the pleasure which they have given me; I have received satisfactions so sensible from them that I eannot tell them to you by word of mouth. I entreat you to believe that, though I may not have written to you, there has not been an hour in which you have not been present to me, in which I have not made wishes for the eontinuation of the great designs with which Heaven has inspired you.' I have felt new transports of joy at all the letters which bore testimony of it, and I have been delighted to see the con-

1 An allusion to the design of Jacqueline to hecome a nun. 
tinuance of it without your receiving any news on our part. This has made me judge that there was a more than human support, since there was no need of human means to sustain it. I should be glad nevertheless to contribute something to it; but I have none of the capacities necessary for that purpose. My weakness is so great that, if I should undertake it, I should do an act of temerity rather than of charity, and I should have a right to fear for us both the calanity that menaces the blind led by the biind. I have felt my incapacity incomparably more since the visits which are in question; and far from having brought back enough of light for others, I have brought nothing but confusion and trouble for myself, which God alone can ralm, and in which I shall work with care, but without impaiience and disquietude, knowing well that both would remove me from it. I repeat that God alone can calm it, and that I shall work for this, since I find nothing but occasions for making it spring up and increase in those from whom I had expected its dissipation; so that, seeing myself reduced to myself alone, it remains to me only to pray to God that he may bless it with success. For this I shall have need of the aid of scholars and disinterested persons: the first will not afford it; I seek no longer but for the latter; and hence I desire infinitely to see you, for letters are long, inconvenient, and almost useless on such occasions. Nevertheless I will write you something of it.

The first time I saw M. Rebours, ${ }^{1}$ I made myself known to him and was received with as much civility as I could wish. This was due to my father, since I received it on his account. After the first compliments, I asked permission to see him again from time to time; he granted it to me: thus I was at liberty to see him, so that I do not account this first sight as a visit, since it was only the permission for such. I was there for some time, and among other conversation, I told him with ury usual frankness and naïveté, that we had seen their books

1 One of the confessors of Port-Royal. See the Necrologe de Port-Ruyal p. 333 . 
and those of their adversaries, which was sufficient to make him understand that we were of their sentiments. He expressed some pleasure at this. I then teld him that I thought that many things could be demonstrated upon the mere principles of common-sense that their adversaries said were contrary to it, and that well-directed reasoning led to a belief in them, although it was necessary to believe in them without the aid of reasoning. These were my own words, in which I think there was not wherewith to wound the most severe modesty. But as you know that all actions may have two sources, and that such language might proceed from a principle of vanity and of confidence in reasoning, this suspicion, which was increased by the knowledge that he had of my studies in geometry, sufficed to make him find this language strange, and he expressed it to me by a repartee so full of humility and gentleness that it would doubtless have confounded the pride that he wished to refute. Still I endeavored to make him understand my motive; but my justification increased his suspicions and he took my excuses for obstinacy. I acknowledge that his discourse was so beautiful that if I had been in the state in which he believed me, he would have drawn me from it; but as I did not think myself in this disease, I opposed the remedy which he presented me; but he insisted on it the more, the more I seemed to evade it, because he took my refusal for obstinacy; and the more he strove to continue, the more my thanks testified to him that I did not consider it necessary; so that the whole of this interview passed in this equivocation and in an embarrassment which continued in all the rest, and which could not be unavelled. I shall not relate the others word for word, sinee it would not be necessary to my purpose; I shall only tell you ${ }^{1}$ in substance the purport of what was said on them, or rather, the principle of their restraint.

But I entreat you before all things to draw no conclusions from what I write, for things may zscape me without sufficient

3 We have not the letter that seems here to be announced.-Faugire. 
precision; and this may cause some suspicion to spring up in you as disadvantageous as unjust. For indeed, after having reflected on it carefully, I find in it only an obseurity which it would be diffieult and dangerous to decide, and for myself, I suspend my judgment entirely, as much from my weakness as from my want of knowledge.

\section{Letter from Pascal and his sister Jacqueline to their sister, Madame Périer.}

April 1, 1648.

We do not know whether this letter will be interminable, like the rest, but we know that we would gladly write to you without end. We have here the letter of M. de Saint-Cyran, de la Vocation, lately published without approbation or privilege, which has shocked many. We are reading it; we will send it afterwards to you. We should be glad to know your opinion of it, and that of my father. It takes high ground.

We have several times begun to write to you, but I have been deterred from it by the example and the speeches, or, if you like, the rebuffs of which you know; but, since we have been enlightened upon the matter as much as possible, I believe that it is necessary to use some circumspection in it, and if there are oceasions in which we ought not to speak of these things, we may now dispense with them; for we do not doubt each other, and as we are, as it were, mutually assured that we have, in all these discourses, nothing but the glory of God for our cbject, and searcely any communication outside of our selves, I do not see that we should have any scruple, so long is he shall give us these sentiments. If we add to these considerations that of the union which nature has made between us, and to this last that which grace has made, I think that, far from finding a prohibition, we shall find an obligation to it; for I find that our happiness has been so great in being united in the latter way, that we ought to unite tr acknowledge 
and to rejoice at it. For it must be confessed that it is properly since this time (which M. de Saint-Cyran wishes should be called the commencement of life), that we should consider ourselves as truly related, and that it has pleased God to join us in his new world by the spirit, as he had done in the terrestrial world by the flesh.

We beg you that there may not be a day in which you do not revolve this in memory, and often acknowledge the way which God has used in this conjunction, in which he has not only made us brothers of each other, but children of the same father; for you know that my father has foreseen us all, and, as it were, conceived us in this design. It is in this that we should marvel, that God has given us both the type and the reality of this union; for, as we have often said among ourselves, corporeal things are nothing but an image of spiritual, and God has represented invisible things in the visible. This thought is so general and so useful that we ought not to let much time pass without thinking of it with attention. We have discoursed particularly enough of the relation of these two surts of things, for which reason we shall not speak of it here; for it is too long to write, and too beautiful not to have remained in your memory, and, what is more, is absolutely necessary, according to my opinion. For, as our sins hold us wrapped in things corporeal and terrestrial, and as these are not only the penalty of our sins, but also the occasion of committing new ones, and the cause of the first, it is necessary that we should make use of the same position into which we have fallen to raise us from our overthrow. For this reason, we should use arefully the advantage which the goodness of God bestows -pon us in having always before our eyes an image of the pood that we have lost, and in surrounding us in the very baptivity to which his justice has reduced us, with so many objects that serve to us as an ever-present lesson.

So that we should consider ourselves as criminals in a prison filled with images of their liberator, and instructions necessary to escape from their bondage; but it must be acknowledged that we cannot perceive these sacred characters without a 
supernatural light; for as all things speak of God to those who know him, and as they reveal him to all those who love him, these same things conceal him from all those who know him not. Thus it is seen, that in the darkness of the world men follow them in a brutal blindness, and eling to them, and make of them the final end of their desires, which they cannot do without sacrilege, for there is nothing but God that should be the final end, as he alone is the principle. For whatever resemblance created nature may have to its Creator, and although the most trifling things, and the smallest and the vilest por tions of the world represent at least by their unity the perfect unity that is found only in God, we cannot legitimately bear to them sovereign respect, since there is nothing so abominable in the eyes of God and man as idolatry, because it renders to the creature the honor that is due to none but the Creator. The Scripture is full of the vengeance that God executes on all those who have been guilty of it, and the first commandment of the Decalogue, which includes all the rest, prohibits above every thing the adoration of his images. But as he is much more jealous of our affections than our respect, it is evident that there is no crime more injurious or more detestable to him than to bestow sovereign love upon created things, although they represent him.

This is why those to whom God has made known these great truths ought to use these images to enjoy that which they represent, and not remain eternally in that carnal and Judaical blindness which causes the type to be taken for the reality. And those whom God, by regeneration, has drawn freely from $\sin$ (which is the veritable nothingness, since it is opposed to God, who is the veritable being) to give them a place in his Church, which is his real temple, after having drawn them freely from nothingness to the point of their creation, in order to give them a place in the universe, have a double obligation to honor him and serve him; since as created beings they should remain in the order of created beings, and not profane the place that they fill, and as Christians they. should aspire without ceasing to render themselves worthy ts 
form part of the body of Jesus Christ. But as whilst the created things that compose the world acquit themselves of their obligation by remaining within a limited perfection, because the perfection of the world is also limited, the children of God should set no bounds to their purity and their perfection, bezause they form part of a body wholly divine, and infinitely perfect; as it is evident that Jesus Christ does not limit the commandment of perfection, and that he proposes it to us as a model wherein it exists infinite when he says: "Be ye also perfect as your Father in heaven is perfect." Thus it is a very prejudicial and very common error among Christians, and even among those who make a profession of piety, to persuade themselves that there may be a degree of perfection in which they can be with assurance, and which it is not necessary to pass, since there is none at which it will not be wrong to stop, and from which we can only avoid falling by mounting still higher.

Letter from Pascal and his Sister Jacqueline to their Sister, Madame Périer.

Paris, November 5, afternoon, 1648.

My dear Sister,

Your letter has recalled to us a misunderstanding of which we had lost recollection, so absolutely had it passed from us. The somewhat too diffuse explanations that we have received have brought to light the general and former subject of our complaints, and the satisfaction that we have given has softened the harshness which my father had conceived for them. We said what you had already said, without knowing that you had said it, and then we excused verbally what you had afterwards excused in writing, without knowing that you had done so; and we knew not what you had done until after we had acted ourselves; for as we have hidden nothing from my father, he has revealed every thing, and thus cured all our suspicions. You know how much such troubles disturb the peace of the 
family both within and without, and what need we have in these junctures of the warnings which you have given us a little too late.

We have some to give you on the subject of your own. The first is in respect to what you say, that we have instructed you as to what you should write to us. $1^{\circ}$. I do not remember to have spoken to you of it, so that this was a novelty to me; and, besides, even though this were true, I should fear that you had not retained this humanly, if you had not forgotten the person of whom you learned it to remember only God, who alone could have truly instructed you in it. If you remember it as a good thing, you cannot think to hold it from any other, since neither you nor the others can learn it except from God alone. For, although in this kind of gratitude, we do not stop at the men whom we address as though they were the authors of the good that we receive through their means, this nevertheless forms a partial opposition to the views of God, and cliefly in the persons who are not entirely divested of the carnal impressions which make them consider as the source of good the objects that transmit it.

Not that we ought not to remember those persons from whom we have reeeived any instructions, when these persons have been authorized to make them, as fathers, bishops, and sonfessors, because they are the masters of whom others are the disciples. But as to us, it is different; for as the angel refused the adoration of a holy servant like himself, we tell you, in entreating you no longer to use these terms of human gratitude, to refrain from paying us such compliments, since we are disciples like yourself.

The second is in respect to what you say of its being unnecessary to repeat these things to us, since we know them per fectly already; which causes us to fear that you do not distin guish clearly enough here between the things of which you speak and those of which the world speaks, since it is doubtless quite enough to have learned the latter once and retained them well to be no further instructed in them, while it does not suffice to have comprehended once those of the other kind, and to 
bave known them well, that is, by the internal impulse of God, to preserve the knowledge of them in the same degree, although we may retain the memory. Not that we may not remember and as easily retain an epistle of St. Paul as a book of Virgil; but the knowledge that we aequire in this manner, as well as its continuation, is only an effect of memory, while to understand this secret language, unknown to those who are not of Heaven, it is necessary that the same grace, which alone ean give the first knowledge of it, shall continue and render it ever present by retracing it without ceasing in the hearts of the faithful to keep it constantly existing there; as God continually renews their beatitude in the blessed, which is an effect and a consequence of grace; as likewise the Church holds that the Father perpetually produces the Son and maintains the eternity of this essence by an effusion of his substanee, which is without interruption as well as without end.

Thus the continuation of the justice of the faithful is nothing else than the continuation of the infusion of grace, and not a single grace that subsists continually ; and this it is that teaches us perfectly our perpetual dependence on the mercy of God, since if he suspends the course of it ever so slightly, barrenness necessarily becomes the result. In this necessity, it is easy to see that it is necessary to make new efforts continually to acquire this continual newness of spirit, since we can only preserve the former grace by the acquisition of a new grace, and sinee otherwise we shall lose what we think to retain, as those who wish to shut in the light shut in nothing but darkness. Thus we should wateh unceasingly to purify the interior, which is constantly sullied by new spots while retaining the old ones, since without this assiduous renovation we shall be incapable of receiving that new wine that eannot be put into old bottles.

For this reason you should not fear to place before our eyes the things which we have in cur memory, and which it is necessary to eause to enter into the neart, since it is unquestionable that your discourse can better serve as the instrument of grace than can the impression of it that remains in our 
meinory, since grace is especially accorded to prayer, and since this charity that you have had for us is among those prayers that ought never to be interrupted. Thus we never should refuse to read or to hear holy things, however common or well-known they may be; for our memory as well as the instructions which it contains, is only an inanimate and Juclaical body without the spirit that should vivify them. And it often happens that God avails himself of these exterior means tc make them understood and to leave so much the less food for the vanity of men when they thus receive grace in themselves. Thus, a book or a sermon, however common it may be, brings much more profit to him who hears or reads it with better disposition than does the excellence of the most elevated discourses which usually bring more pleasure than instruction; and it is sometimes seen that those who listen as they ought, although ignorant and almost stupid, are touched by the simple name of God and the words that menace them with hell, although these may be all that they comprehend and although they knew it as well before.

The third is in respect to what you say about only writing things to make us understand that you share the same feeling. We have equally to praise and to thank you on this subject; we praise you for your perseverance and thank you for the testimony that you give us of it. We had already drawn this confession from M. Périer, and the things that we induced him to say had assured us of it: we can only tell you how much we are pleased by representing to you the joy which you would receive if you should hear the same thing of us.

We have nothing in particular to tell you, except touching the design of your house.' We know that M. Périer is too earnest in what he undertakes to fully think of two things at once, and that the entire design is of such magnitude that, in order to complete it, he must remain a long time without thinking of any thing else. We know, too, that his project is

1 A country house built by $\mathrm{M}$. Périer, which is still standing, at Bien ussis, near the gates of Clermont.-Faugère. 
only for a part of the building; but this, besides being unly too large alone, engages for the completion of the rest as soon as there shall be no farther obstacles to it, however deternined he may be to the contrary, especially if he employs the time in building that it would take to undeceive him of the secret pleasure that he finds in it. Thus we have counselled him to $b$ iild much less than he intended, and only what is actually necessary, although according to the same design, in order that he may not have cause to become absorbed in it, nor yet de. prive himself of the opportunity of doing so. We entreat you to think seriously of it, and to resolve to counsel him likewise, lest it may happen that he may be far more prudent and bestow much more care and pains in the building of an earthly house than he is obliged to bestow on that mystic tower, of which you know St. Augustine speaks in one of his letters, which he has promised to finish in his conversations. Adieu. B. P.-J. P.

Postscript of Jacqueline.-I hope shortly to write you the particulars of my own affair, of which I shall send you the details; meanwhile, pray to God for the result.

If you know any pious soul, let him pray to God for me also.'

\section{Letter to Madame Perier and her husband, ${ }^{2}$ on the death of M. Pascal, Père.}

October 17, 1651.

As you are both now informed of our common misfortune, and as the letter which we commenced has given you some consolation by the recital of the happy circumstances that

1 This last sentence is in the handwriting of Pascal: usually Jacqueline wrote under the dictation of her brother.

2 Fragments of this letter have figured in a great number of the editions af Pascal, under the title of: Thougtts upon Death, extracted from a letter vritten by $M$. Pascal upon the subject of the death of his father. M. Cousin, upon this indiration, sought for and found tne letter, such as we pub- 
accompanied the subject of our aftliction, I cannot refuse to you those which remain in my mind, and which I pray God to give me, and to recall to me several which we formerly received from his grace, and which have been newly given to us by our friends on this occasion.

I know not now where my first letter ended. My sister sent it away without noticing that it was not finished. It only seems to me that it contained in substance some particulars of the conduct of God over life and sickness, which I would repeat to you here, so deeply are they engraven in my heart, and so solid is the consolation that they bring me, if you could not have seen them yourselves in the preceding letter, and if $\mathrm{my}$ sister did not intend to make to you a more exact recital of them at her earliest convenience. I shall, therefore, only speak to you here of the conclusion which I draw from them, which is that, except those who are interested by the feelings of nature, there is not a Christian who should not rejoice at it.

Upon this great foundation, I shall commence what I have to say to you by a remark that is very consoling to those who have sufficient liberty of spirit to conceive it in the midst of

lish it here.* "Compared with the published thouglits on death," says M. Cousin, "this letter furmishes passages entirely new, and different read. ings, that mark, in the most striking manner, how much the style of a medioere man, like the Duke de Roannez, or even the style of an estimable writer, like Arnauld, differs from that of a writer of genius, like Pascal. ... We see that, at the moment in which Pascal wrote this letter, at the end of 1651 , he had not yet arrived at that absolute retrenehment of the most legitimate natural affections that he imposed upen himself in the closing years of his life, through an exeess contrary to haman wisclom, and even to the Divine Wisdom, who also loved during his asssage over the earth. Here Paseal is still a man, a son, a brotlier. This letter, which depiets his soul at this epoch of his life, should be inte grally restored."

The father of Paseal died on the 24th of Deeember; the letter is dated the 17 th of Oetober.

* See Des Pensées de Pascal, 1843, in 8vo, p. 49 and following, and 308 and fol lowing. 
grief. It is that we should seek consolation in our ills, not in ourselves, not in men, not in any thing that is created; but in God. And the reason is, that all creatures are not the first cause of the accidents that we call evils; but that the providence of God being the only and veritable cause, the arbiter and the sov ereign of them, it is indubitable that we must resort directly tc the source, and go back to the origin to find a solid alleriation. If we follow this precept, and if we regard this event, not as an effect of chance, not as a fatal necessity of nature, not as the play of the elements and parts of which man is composed (for God has not abandoned his elect to caprice and chance), but as a result indispensable, inevitable, just, holy, useful to the good of the Church, and to the exaltation of the name and the greatness of God, of a decree of his providence conceived from all eternity to be executed in the plenitude of its time in such a year, such a day, such an hour, such a place, such a manner; and, in short, that all that has happened has been from all time foreknown and foreordained of God; if, I say, through a transport of grace, we regard this accident, not in itself and apart from God, but apart from itself, and in the inmost part of the will of God, in the justice of his decree, in the order of his providence, which is the true cause of it, without which it.would not have happened, through which alone it has happened, and in the manner in which it has happened; we shall adore in humble silence the impenetrable loftiness of his secrets, we shall venerate the sanctity of his decrees, we shall bless the acts of his providence, and, uniting our will to that of God himself, we shall wish with him, in him, and for him, the thing that he has willed in us and for us from all eternity.

Let us regard it, then, in this manner, and let us practice this precept, which I learned of a great man in the time of our teepest attliction, that there is no consolation except in truth nlone. It is certain that Socrates and Seneca have nothing consolatory on such an occasion as this. They have been in the error that has blinded all men in the heginning: they have all taken death as natural to man; and all the discourses whick. 
they have founded upon this false principle are so futile that they only serve to demonstrate by their inutility how weak man is in general, since the most elevated productions of the greatest among men are so weak and puerile. It is not the same with Jesus Christ, it is not thus in the eanonical books the truth is there revealed, and consolation is also as infallibly ioined with it as it is infallibly separated from error.

Let us, then, consider death in the truth which the Holy Spirit has taught us. We have this admirable advantage, of knowing that death is really and actually a penalty of sin imposed on man in order to expiate his crime, necessary to man to purge him from sin; that it is the only one that can deliver the soul from the concupiscence of the members, without which saints come not into the world. We know that life, and the life of Christians, is a continual sacrifice, that can only be completed by death; we know that as Jesus Christ, being in the world, regarded and offered himself to God as a sacrifice, and a veritable victim; as his birth, his life, his death, his resurrection, his ascension, his presence in the Eucharist, and his eternal seat at the right hand, are only a sole and single sacrifice; we know that what has been accomplished in Jesus Christ should be accomplished also in all his members.

Let us, then, consider life as a sacrifice; and let the accidents of life make no impression upon the minds of Christians, except in proportion as they interrupt or accomplish this sacrifice. Let us only call that evil which renders the victim of God the victim of the devil, but let us call that good which renders the victim of the devil in Adam the victim of God; and by this rule let us examine the nature of death.

For this consideration it is necessary to have recourse to the person of Jesus Christ for all that is in men is abominable, and as God looks upon men only through the mediator Jesus Christ, men should also look neither upon others nor themselves except mediately through Jesus Christ. For if we de rot take this course, we shall find in ourselves nothing but veritable misfortunes, or abominable pleasures; but if we 
regard all things in Jesus Christ, we shall find full consolation. full satisfaction, and full edification.

Let us, then, consider death in Jesus Christ, and not with out Jesus Christ. Without Jesus Christ it is horrible, detestable, the horror of nature. In Jesus Christ it is altogether different; it is benignant, holy, the joy of the faithful. Every thing s sweet in Jesus Christ, even to death: and this is why he suffered and died to sanctify death and suffering; and, in common with God and man, he has been all that was great, and all that was abject, in order to sanetify in himself all things except sin, and to be the model of every condition.

To consider the nature of death, and of death in Jesus Christ, it is necessary to see what rank it holds in his continual and uninterrupted sacrifice, and for this to remark that in sacrifices the most important part is the death of the victim. The oblation and sanctification which precede are the details; but the accomplishment is the death, in which, by the annihilation of life, the creature renders to God all the homage of which it is capable, in annihilating itself before the face of his majesty, and in adoring his sovereign existence, which alone exists in reality. It is true that there is another part, after the death of the victim, without which its death would be useless, that is, God's acceptance of the sacrifice. This is what is said in the Scripture: Et odoratus est Dominus suavitatem. "And the Lord smelled a sweet sacrifice." This it is that really consummates the oblation; but it is rather an action of God towards the creature than of the creature towards God, and does not hinder the last act of the creature from being death.

All these things have been accomplished in Jesus Christ. In entering the world, he offered himself: Obtulit semetipsum per Spiritum Sanctum. Ingrediens mundum, dixit: Hostiam, noluisti... Tunc dixi: Ecce venio. In capite, etc. "Through the Eternal Spirit he offered himself. When he cometh into the world, he saith, sacrifice and offering thou wouldst not. Ihen said I, Lo, I coine." This is his oblation. His sanetification was immediate upon his oblativr. This sacrifice lested 
all his life, and was accomplished by his death. "Ought he not to have suffered these things, and to enter into his glory ?" "Though he were a son, yet learned he obedience by the things which he suffered." But " in the days of his Hesh, when he had offered up prayers and supplications, with strong cries and tears unto him that was able to save, he was heard in that he feared:" and God raised him from the dead, and sent him his glory, prefigured formerly by the fire from heaven that fell upon the victim to burn and consume his body, and to make it live the spiritual life of glory. This is what Jesus Christ has obtained, and what has been accomplished through his resurrection.

Thus this sacrifice being perfected by the death of Christ, and consummated even in his body by his resurrection, in which the image of sinful flesh was absorbed by glory, Jesus Christ had wholly finished his part; it remained only that the sacrifice should be accepted of God, that, as the smoke ascended and carried the odor to the throne of God, thus Jesus Christ was, in this state of perfect immolation, offered, carried to, and accepted at the throne of God himself: and this it is that has been accomplished in the ascension, in which he mounted on high and by his own power and by the power of his Holy Spirit, which surrounded him on every side, was carried away; as the smoke of the victims, the emblem of Jesus Christ, was earried on high by the air that sustained it, the type of the Holy Spirit: and the Acts of the Apostles indicate to us exorcssly that he was received up into heaven, in order to assure -s that this holy sacrifice accomplished on earth was welcome and acceptable to God, and was received into the bosom of God, to shine in glory through ages upon ages.

This is the state of things as regards our sovereign Lord. Let us consider them now in ourselves. From the moment we enter the Church, which is the world of the Faithful and especially of the elect, into which Jesus Christ entered at the moment of his incarnation by a privilege peculiar to the only Son of God, we are offered and sacrificed. This sacrifice is sontinued by life and completed at death, in which the sou.' 
truly quitting all vices, and the love of the world, with the contagion of which it is always infected throughout life, achieves its immolation and is received into the bosom of God.

Let us not grieve then like the heathen who have no hope. We did not lose our father at the moment of his death: we lost him, so to say, when he entered the Church through bap. tism. From that time, he belonged to God; his life was devoted to God; his actions regarded the world only for God. In his death, he became totally separated from sin, and it was at that moment that he was accepted by God, and that his sacrifice received its accomplishment and its consummation. He has performed therefore what he had rowed: he has finished the work that God had given him to do; he has accomplished the only thing for which he was created. The will of God is accomplished in him, and his will is absorbed in God. Let not our will then separate what God has joined together; and let us stifle or moderate, by the understanding of truth, the feelings of a corrupt and fallen nature which has only false images, and which troubles by its illusions the sanctity of the feelings which truth and the Gospel should give us.

Let us then no longer look upon death like the heathen, but like Christians, that is with hope, as St. Paul commands, since this is the especial privilege of Christians. Let us no longer regard a corpse as putrid carrion because deceitful nature figures it thus; but as the inviolable and eternal temple of the Holy Spirit, as faith teaches. For we know that sainted bodies are inhabited by the Holy Spirit until the resurrection, which will be caused by virtue of this spirit which dwells in them for this effect. It is for this reason that we honor the relics of the dead, and it was on this true principle that the Eucharist was formerly placed in the mouth of the dead, since, as it was known that they were the temple of the Holy Spirit, it was believed that they also merited to be united to this holy sacrament. But the Chureh has changed this custom, not in order that these bodies shall not be holy, but for the reason what the Eucharist being the bread of life and of the living, it sught not to be given to the dear. 
Let us no longer regard a man as having ceased to live although nature suggests it; but as beginning to live, as trutb assures. Let us no longer regard his soul as perished and reduced to nothingness, but as quickened and united to the sovereign life; and let us thus correct, by attention to these truths, the sentiments of error so deeply imprinted in ourselves and those emotions of honor so natural to mankind.

To subdue this dread more effectually, it is necessary fully to comprehend its origin ; and to paint it to you in a few words, I am forced to tell you in general what is the source of all vice and all sin. This I have learned from two very great and holy yersonages. The truth covered by this mystery is that God clas created man with two loves, the one for God, the other for himself; but with this law, that the love for God shall be infinite, that is without any other limits than God him self; and that the love for self shall be finite and relating to God.

Man in this state not only loves himself without sin, but could not do otherwise than love himself without $\sin$.

Sinee, sin being come, man has lost the first of these loves; and the love for himself being left alone in this great soul capable of an infinite love, this self-love has extended and overflowed in the empty space which the love of God has quitted; and thus he loves himself alone, and all things for himself, that is, infinitely. This is the origin of self-love. It was natural to Adam and just in his innocence; but it became criminal and immoderate after his sin.

Here is the source of this love, and the cause of its defect and of its excess. It is the same with the passion of ruling, of indolence, and others. The application is easy. Let us come to our single subject. The dread of death was natural to innocent Adam, because, his life being pleasing to God, it must have been pleasing to man: and death was terrible when it ended a life conformed to the will of God. Since, man having sinned, his life has become corrupt, his body and soul enemies to each other, and both to God. This horrible change having infected so holy a life, the love of life has nevertheless re 
mained; and the dread of death being equally felt, that which was just in Adam is unjust and criminal in us.

Such is the origin of the dread of death and the cause of its faultiness. Let us then illumine the error of nature by the light of faith. The dread of death is natural, but it is in the state of innocence; death in truth is terrible, but it is when it puts an end to a pure life. It was just to hate it when it separated a holy soul from a holy body; but it is just to love it when it separates a holy soul from an impure body. It was just to flee it, when it broke the peace between the body and the soul; but not when it calms the irreconcilable dissension between them. In short, when it aftlicted an innocent body, when it took away from the body the liberty of honoring God, when it separated from the soul a body submissive to and co-operative with its will, when it put an end to all the good of which man is capable, it was just to abhor it; but when it puts an end to an impure life, when it takes away from the body the liberty of sinning, when it delivers the soul from a powerful rebel that contradicts all the motives for its salvation, it is very unjust to preserve the same feelings.

Let us not therefore relinquish this love for life which nature has given us, since we have received it from God; but let this be for the same life for which God has given it to us and not for a contrary object. In consenting to the love that Adam had for his innocent life and that Jesus Christ himself had for his own, let us bring ourselves to hate a life contrary to that which Jesus Christ has loved, and only to fear the death which Jesus Christ has feared, which comes to a body pleasing to God; but not to fear a death that, punishing a guilty body, and purging a vicious body, ought to give us quite contrary feclings, if we have any thing of faith, of hope, and of charity.

It is one of the great principles of Christianity that every thing that happened to Jesus Christ should take place in the soul and the body of each Christian : that as Jesus Christ suffered during his mortal life, died to this mortal life, was raised to a new life, ascended to heaven, and sitteth at the right hand of the Father; so the body and soul should suffer, die, be 
raised from the dead, ascend to heaven, and sit at the right hand of God. All these things are accomplished in the soui during life, but not in the body. The soul suffers and clies to sin in penitence and in baptism; the soul is raised again to a new life in the same baptism; the soul quits the earth and ascends to heaven at death, and takes its seat at the right hand of God at the time that he appoints. None of these things happen to the body during this life; but the same things befall it afterwards. For at death the body dies to its mortal life; at the judgment it will rise to a new life; after the judgment, it will ascend to heaven and will sit at the right hand of God. Thus the same things happen to the body and the soul, but at different times; and the changes of the body come only when those of the soul are accomplished, that is at the hour of death : so that death is the consummation of the beatitude of the soul and the commencement of the beatitude of the body.

These are the admirable ways of the wisdom of God for the salvation of his saints, and St. Augustine teaches us on this subject, that God has arranged them in this wise for fear that if the body of man should die and rise again forever at baptism, men would only enter into the obedience of the Gospel through the love of life; whilst the grandeur of faith shines forth far more when it tends to immortality through the shades of death.

This is, certainly, our belief and the faith that we profess, and I believe that there is in this more than is needed to aid your consolations by my small efforts. I should not undertake to carry you this aid of myself; but as these are only repetitions of what I have learned, I give them with assurance, praying God to bless these seeds, and to give them growth, for without him we can do nothing, and his most holy words will not take root in us, as he himself has said.

It is not that I wish that you should be without feeling; the blow is too sensible; it would be even insupportable without supernatural aid. It is not therefore right that we should be without grief, like the angels who have no sentiment of na. ture; neither is it right that we should be without consolation, 
likn the heathen whe have no sentiment of grace: but it is right that we should be afflicted and consoled like Christians, and that the consolations of grace should orercome the feelings of nature; that we should say with the apostles: "We are afflicted but not cast down," in order that grace may not only be in us but victorious in us; that thus, in sanctifying the name of our Father, his will may be made ours; that his grace may reign and prevail over nature, and that our aftlictions may be as the substance of a sacrifice which his grace perfects and annihi. lates for the glory of God; and that these individual sacrifices may honor and precede the universal sacrifice wherein all nature should be perfected by the power of Jesus Christ. Thus we derive advantage from our own imperfections, since they serve as material for this sacrifice; for it is the aim of true Christians to profit by their own imperfections, because "all things work together for good to the elect."

And if we pay close attention to this, we shall find great advantages for our edification, in considering the thing truly as we said just now. For, since it is true that the death of the body is only the type of that of the soul, and since we build upon the principle that in this chance we liave all possible reason to hope for its sure salvation, it is certain that if we cannot arrest the progress of grief, we should derive this benefit, that since the death of the body is so terrible that it causes in us such emotions, that of the soul ought to cause in us those far more inconsolable. God sends us the first, God turns away the second. Let us then consider the greatness of our blessings in the greatness of our ills, and let the excess of our grief be in proportion to that of our joy.

There is nothing that can moderate it, except the fear that he may languish for some time in the pains which are destined to purge the remains of the sin of this life, and we ought carefully to apply ourselves to appease the anger of God towards him. Prayer and sacrifices are a sovereign remedy for his pains. But I have learned of a holy man in our aftliction that one of the most solid and useful charities towards the dead is to do the things that they would command were they 
still in the world, to practise the holy advice which they have given us, and put ourselves, for their sakes, in the condition in which they would wish us at present. By this practice, we shall in some sort revive them in ourselves, since their counsels are still living and acting within us; and as heresiarchs are punished in the other life for the sins into which they have drawn their votaries, in whom their venom is still living, so the dead are recompensed, exclusive of their own merit, for those to whom they have given succession by their counsels and their example.

Let us strive then with all our power to revive him in us before God; and let us console ourselves in the union of our hearts, in which it seems to me that he still lives, and that our reunion in some sort restores to us his presence, as Jesus Christ makes himself present in the assembly of his faithful.

I pray God to form and to maintain these sentiments in us, and to continue those which it appears to me he has given me, of having more tenderness than ever for you and for my sister; for it seems to me that the love that we had for my father ought not to be lost, and that we should make a division of it among ourselves, and that we should chiefly inherit the affection which he bore to us, to love each other still more cordially if possible.

I pray God to strengthen us in these resolutions, and in this hope I entreat you to permit me to give you a counsel which indeed you could take without me; but I shall not refrain from giving it. It is that after having found grounds of consolation for him, we shall not come to lack them for ourselves by dwelling upon the need and the utility that we shall have of his presence.

It is I who am the most interested in it. If I had lost him six years ago, I should have lost myself, and although I believe my necessity of him at present to be less absolute, I know that he would still have been necessary to me ten years and useful all my life. But we should hope that God having ordered it in such a time, such a place and such a manner, it is doubtless the most expedient for his glory and for our salvation. 
However strange this may appear, I believe that we should regard all events in the same manner, and that, however sinister they may appear to us, we should hope that God would draw from them a source of joy to us if we will but intrust the direction of them to him. We know of persons of condition who have feared the death of relatives which God has perhaps averted at their prayer, who have caused or been the occasion of so much misery that there was reason to wish that the prayers had not been granted.

Man is assuredly too weak to judge soundly of the result of future things. Let us therefore hope in God, and let us not weary ourselves by rash and indiscreet forecasts. Let us commit ourselves then to God for the direction of our lives, and that grief may not prevail within us.

St. Augustine teaches us that there is in every man a serpent, an Eve and an Adam. The serpent is the senses and our nature, the Eve is the concupiscible appetite, and the Adam is the reason. Nature tempts us continually, concupiscible appetite often fills us with desires, but the sin is not consummated if reason does not consent. Let the serpent and the Eve therefore act if we cannot hinder it; but let us pray to God that his grace may so strengthen our Adam that he may remain victorious; and that Jesus Christ may be the conqueror over him and may reign eternally in us. Amen.

\section{Extract from a Letter of M. Pascal to M. Périer.}

$$
\text { Paris, Friday, Jume 6, } 1658 .
$$

I have just received your letter, inclosing that of my sister, which I have not had leisure to read, and moreover believe that this would be useless.

My sister made her profession yesterday, Thursday, the 5th of June, 1653. It was impossible for me to delay her: the Messieurs of Port Royal feared that a slight delay might bring on a greater one, and wished to hasten it for the reason that 
they hope ere long to put her in office; and consequently, it was necessary to hasten, because for this several years of profession are yeeded. This is the way they paid me. In fine, I could not, ete.

\section{Extract from a Letter to Madame Périer, upon the pro. Jected Marriage of Mademoiselle Jacqueline Périer.}

1659.

In general, their advice was that you could in no way, without mortally wounding charity and your conscience, and ren. dering yourself guilty of one of the greatest crimes, pledge a child of her age and innocence, and even of her piety, to the most perilous and lowest of the conditions of Christianity. That indeed, according to the world, the affair had no difficulty, and she was to conclude it without hesitation; but that according to God, she had less difficulty in it, and she was to reject it without hesitation, beeause the condition of an advantageous marriage is as desirable in the opinion of the world as it is vile and prejudicial in the sight of God. That not knowing to what she may be called, nor whether her temperament may not be so tranquil that she can support her virginity with piety, it were little to know the value of it to pledge her to lose this good so desirable to every one in himself, and so desirable to fathers and mothers for their children, since as they can no longer desire it for themselves, it is in them that they should strive to render to God what they have lost in general for other causes than for God.

Besides, that husbands, although rich and wise in the opinion of the world, are in truth complete pagans in the sight of God; so that the last words of these gentlemen are that to pledge a child to an ordinary man is a species of homicide and a deicide as it were in their own persons.'

1 Upon what revolves all human life? upon marriage and society. Now Pascal declares marriage a homicide and almost a deicide, and absolute so'tude is to him the imperative condition of salvation. . . . Sublime but 


\section{Note from Pascal to the Marchioness de Sable.'}

December, 1660.

Although I am much embarrassed, I can no longer defer rendering you a thousand thanks for having procured me the acquaintance of M. Menjot; for it is doubtless to you, Madame, that I owe it; and as I esteemed him highly already from the things which my sister had told me of him, I cannot tell you with how much joy I have received the favor which he has wished to render me. It is only necessary to read his letter to see how much intellect and judgment he possesses; and although I may not be capable of understanding the depth of the matters which he treats in his book, ${ }^{2}$ I will tell you, nevertheless, Madame, that I have learned much from the manner in which he reconciles in a few words the immateriality of the soul with the pewer of matter to change its functions and to cause delirium. I am very impatient to have the honor to converse with you on it.

\section{Fragment of a Letter to M. Périer. ${ }^{3}$}

1661.

You give me pleasure by sending me all the details of your controversies, and chiefly because you are interested therein;

but marifest folly! Plato inclines to it in some passages, but Socrates and the Graees restrain him, while Paseal precipitates liimself into it entire with the impetuosity of logic and of passion.-Cousin.

1 Portfolio of Doctor Valant, the physician of Madame de Sablé, t. ii, No. 28s. This billet has neither date nor signature. It is novertheless sertainly from Pascal; for No. 299 is a letter of acknowledgment from he physician Menjot to Madame de Sablé for the billet of Pascal which - he had transmitted to him through Doctor Valant.

2 Is this the Historia et Curatio febrium malignarum of 1662 ? This would fix the date of this billet in the same year as the death of Paseal.

3 Bossut was the first to publish the fragment of a letter of Paseal, beginning with the words: "We avail ourselves badly, as it appears to me, of the advantage, ete.," without saying where he had procused the fragment. We find it in the Recueil of M. Périer, with a begimirg which seems to indieate that this letter was addressed to M. Périer, who also had a quarrel with the Jesuits of Clermont.- Jousin. 
for I imagine that you do not imitate our controversialists of this country, who avail themselves so badly, at least so it seems to me, of the advantage which God offers them of suffering something for the establishment of his truths. For, if this were for the establishment of their truths, they would not act differently; and it seems that they are ignorant that the same Providence that has inspired some with light, has refused it to others; and it seems that in laboring to persuade them of it they are serving another God than the one who permits the obstacles that oppose their progress. They think to render service to God by murmuring against the hindranees, as if this were another power that should excite their piety, and another that should give vigor to those. who oppose them.

This is what comes of self-will. When we wish by our own efforts that something shall sueceed, we beeome irritated with obstacles, because we feel in these hindrances that the motive that makes us act has not placed them there, and we find things in them which the self-will that makes us aet has not formed there.

But when God inspires our actions, we never feel any thing outside that does not come from the same principle that eauses us to act; there is no opposition in the motive that impels us; the same motive power which leads us to act, leads others to resist us, or permits them at least; so that as we find no dif. ference in this, and as it is not our own will that combats external events, but the same will that produces the good and permits the evil, this uniformity does not trouble the peace of the soul, and is one of the best tokens that we are acting by the will of God, since it is much more eertain that God permits the evil, however great it may be, than that God eauses the good in us (and not some secret motive), however great it may "npear to us; so that in order really to pereeive whether it is God that makes us act, it is much better to test ourselves by our deportment without than by our motives within, since if we only examine ourselves within, although we may find nothIng but good there, we cannot assure ourselves that this good comes truly from God. But when we examine ourselves with. 
out, that is when we consider whether we suffer external hindrances with patience, this signifies that there is a uniformity of will between the motive power that inspires our passions and the one that permits the resistance to them; and as there is no doubt that it is God who permits the one, we have a right humbly to hope that it is God who produces the other.

But what! we act as if it were our mission to make truth triumph whilst it is only our mission to combat for it. The desire to conquer is so natural that when it is covered by the desire of making the truth triumph, we often take the one for the other, and think that we are seeking the glory of God when in truth we are seeking our own. It seems to me that the way in which we support these hindrances is the surest token of it, for in fine if we wish only the order established by God, it is certain that we wish the triumph of his justice as much as that of his mercy, and that when it does not come of our negligence, we shall be in an equal mood, whether the truth be known or whether it be combated, since in the one the mercy of God triumphs, and in the other, his justice.

Pater juste, mundus te non cognovit. Righteous father, the world has not known thee. Upon which St. Augustine says that it is through his justice that the world has not known him. Let us pray, labor, and rejoice evermore, as St. Paul says.

If you had reproved me in nyy first faults, $I$ should not have been guilty of this, and should have been moderate. But I shall not suppress this any more than the other; you can suppress it yourself if you wish I could not refrain, so argry am I against those who insist absolutely that the truth shall be believed when they demonstrate it, which Jesus Christ did not do in his created humanity. It is a mockery, and it seems to we treating .... I am grieved on account of the malady of I. de Laporte. I assure you that I ho:sor him with all my heart. I, etc. 


\section{Letter to Madame Périer.}

(Addressed : A Mademoiselle Périer la Conseillère.)

\section{My Dear Sister,}

Roven, Saturday, the last of January, 1643.

I doubt not that you have been greatly troubled at the length of time in which you have reeeived no news from these parts. But I think that you must have suspeeted that the journey of the Élus has been the cause, as in fact it was. Had it not been for this, I should not have failed to write to you oftener. I have to tell you that Messieurs the commissioners being at Gizors, my father made me take a tour to Paris, where I found a letter which you had written, in which you say that you are surprised that I reproach you that you do not write often enough, and in which you tell me that you write to Rouen once every week. It is very certain, if this is so, that the letters are lost, for I do not reeeive one once in three weeks. On my return to Rouen, I found a letter from M. Périer, who writes that you are ill. He does not write whether your sickness is dangerous or whether you are better; and an unusual length of time has passed since without having receivec any letter, so that we are in an anxiety from which I pray you to relieve us as soon as possible; but I think the prayer I make you will be useless, for before you shall have reeeived this letter, I hope that we shall have received letters from you or from M. Périer. The department is finished, God be praised. If I knew of any thing new, I would let you know it. I am, my dear sister, ete.

Postscript in the handwriting of Etienne Pascal, the father • "My dear daughter will excuse me if I do not write to her as I wished, having no leisure for it; for I have never been in a tenth part the perplexity that I am at present. I could not be more so without being overwhelmed; for the last four months I have not been in bed six times hefore two o'clock in the morning. 
"I lately eommenced a jesting letter upon the subject of your last, eoncerning the marriage of M. Desjeux, but I have never had leisure to finish it. For news, the daughter of $\mathrm{ML}$. de Paris, maitre des comptes, the wife of M. de Neufirlle, also maitre des comptes, is dead, as well as the daughter of Belair the wife of young Lambert. Your little boy slept here last night. He is very well, thank God.

"I am ever your true and affectionate friend, Pascal."

Your very humble and affectionate servant and brother, Pascal.

\section{Note from Pascal to ins sister, Madame Périer.'}

(Superscribed, To Mademoiselle ${ }^{2}$ Périer, at Clermont, in Auvergne.)

\section{My Dear Sister,}

I do not believe that it is quite right that you should be vexed; for, if you are not so because we have forgotten you, then you ought not to be at all. I tell you no news, for there is too much that is general, and there must always be too much that is private. I should have mueh to tell you that happens in eomplete secreey, ${ }^{3}$ but I regard it as useless to send it to you; all that I pray you is, to mingle acts of grace with the prayers which you make for me, and which I entreat you to multiply at this time. I carried your letter myself with the aid of God, in order that it might be forwarded to Madame de Maubuisson. They gave me a little

1 This note comes from the fumily papers of M. Hecquet-d'Orval, of Abbeville, a deseendant of M. Hecquet, a eelebrated Jansenist physieian of the seventeenth eentury. It is without signature or date. But as the neetings are in question in it that were held for the signature of the formuary, it may be placed, like the preeeding, about the year 1660 or 1661.

2 The title of Madame was only applied to women of elevated condition.

3 "M. Paseal refers here to what was discussed at Paris in the meeting shat were held respecting the signature of the formulary. See the Supple uent au Nécrologe de Port-Royal, p. $460 . "$-(Old note written in the mar gin of the letter by a member of the family of M. Ileequet-l'()rval.) 
book, in which this sentence was written with the hand.' 1 know not whether it is in the little book of sentences, but it is beautiful. I am so much hurried that I can say no more. Do not fail in your fasts. Adieu.

\title{
Letters to Mademoiselle de Roannez.
}

\begin{abstract}
I.
In order to answer all the points upon which you address me, and, indeed, to write, although my time is limited.
\end{abstract}

1 It is wanting here.

2 Cliarlotte Gouftier de Roannez, sister of the duke of this name, the friend of Paseal, and one of the editors of the Thoughts. Mlle. de Roannez may be regarded as one of the vietims, most to be lamented, of the proselytism of Port-Royal. Reeeived as a novice in this celebrated house in 1657 , after having escaped by stealth from her mother, she took simple vows of virginity, but she did not assume the veil, because she was eonstrained by a lettre de cachet to return to her family. She lived there a long time in retreat, sustained and exalted in her devotion by Paseal, Madame Périer, and M. Singlin. But, some years after her leaving Port-Royal, she espoused the Duke de Feuillade, in 1667, after a couneil of eonscienee, that authorized her to put off the vows of virginity which she had taken on entering Port-Royal. There was nothing unnatural in all this; but the Jansenists thought quite otherwise; they reproaehed with extreme severity the Duehess de la Feuillade with what they ealled her fall, and this noble woman, worthy in every respeet of a treatment less severe, "and vhom a fieree zeal," says M. Cousin, "disputed so long with the most legitimate ties of nature and of the world, and who, divided with herself in this terrible confliet, finally died a miserable death, charged with the anathemas of Port-Royal, unhappy and in despair for having been an obedient daughter, and an irreproaehable wife "' this noble woman eorsecrated the rest of her life to penitenee, often saying that she would have been more happy in living a paralytie at Port-Royal than as she lived in her exalted fortune. She died of a eancer in the breast in 1683, after having given birth to four ehildren, of whom "the first," says the Recueil d'Utrecht, "did not reeeive baptism; the seeond came into the world quito Aeformed; the third was a female dwarf, who died at the age of nineteen; the fourth was M. de la Feuillade, who died in 1725 without issue."-See on the Düchess de la Feuillade, the neerology of Port-Royal of 13th of February, and a Notice of Marguerite Périer, published by M. Lisisin, in the Biblisthèque de l'Ecole des Chartes, September and Oetober, 1843. An 
I am delighted that yon like the book of M. de Laval, ${ }^{1}$ and the Meditations on Grace; I draw from this important conclusions for what I desire.

I send the details of this condemnation which had fright. ened $^{2}$ you : it is nothing at all, thank God, and it is a miracle that nothing worse is done, since the enemies of truth have the power and the will to oppress him. Perhaps you are of those who merit not to be abandoned by God, and removed from an undeserving world, and he is assured that you will serve the Church by your prayers, if the Church has served you by hers. For it is the Church that merits with Jesus Christ, who is inseparable from her, the conversion of all those who are not in the truth; and it is in turn these converted persons who succor the mother who has delivered them. I praise with all my heart the little zeal that I have recognized in your letter for the union with the pope. The body is not more living withcut the head, than the head without the body. Whoever separates himself from the one or the other is no longer of the body, and belongs no more to Jesus Christ. I know not whether there are persons in the Church more attached to this unity of body than those that you call ours. We know that all the virtues, martyrdom, the austerities and all good works are useless out of the Church, and out of communion with the head of the Church, which is the pope. I will never separate

extract from this notice has also been published by M. Faugère, in his Densées de Pascal, t. i, p. 381 et sequens.

The letters of Paseal to Mlle. de Roannez are nine in number; they are of eonsiderable length, and make more than thirty pages of the edition of Port-Royal. They paint to us Paseal, no longer, as in 1651, retaining the natural affections in the midst of the progress of a piety still rational hut Paseal, under the discipline of the Abté Singlin, engaged in the sub the littlenesses of Port-Royal, eharmed and almost puffed up with th niracles of the holy thorn, plunging each day deeper, and preeipitating sthers into the extremes of an exaggerated devotion.-Cousin.

1 Pseudonym under which the Duke do Luynes published different works of picty, among others, Sentences draun from Holy Scripture and tho Fathers.

2 The allusion is probably to the censure of the Sorbonne against Arnauld, in 1656 . 
myself from his communion, at least I pray God to give me this grace, without which I should be lost forever.

I make to you a sort of profession of faith, and I know not wherefore; but I would neither efface it nor commence it again.

M. Du Gas has spoken to me this morning of your letter, with as much astonishment and joy as it is possible to have: he knows not where you have taken what he has reported to me of your words; he has said to me surprising things, that no longer surprise me so much. I begin to accustom myself to you and to the grace that God gives you, and nevertheless I avow to you that it is to me always new, as it is always new in reality.

For it is a continual flow of graces that the Scripture compares to a river, and to the light which the sun continually emits from itself, and is always new, so that if it ceased an instant to emit them, all that we have received would disappear, and we should remain in darkness.

$\mathrm{He}$ has said to me that he had begun a response to you, und that he would transcribe it to render it more legible, and that, at the same time, he would extend it. But he has just sent it to me with a little note, wherein he informs me that he has been able neither to transcribe it nor to extend it; this makes me think that it will be ill-written. But I am a witness of his want of leisure, and of his desire that he had leisure for your sake.

I take part in the joy that the affair of the...' will afford you, for I see clearly that you are interested for the Church : you are indeed under obligations to her. For sixteen hundred years she has groaned for you. It is time to groan for her and for us altogether, and to give her all that remains to us of life since Jesus Christ has assumed life only to lose it for her anci for us.

1 In the manuscript of the Cratory: of the Nuns.-Faugèro 


\section{II.}

Остовеr, 1636.

It seems to me that you take sufficient interest in the mirasle to send you particular notice that its verification is consummated by the Church, as you will see by the sentence of the grand vicar.

There are so few persons to whom God would manifest himself by these extraordinary acts, that we ought indeed to profit by these occasions, since he does not leave the secrecy of the nature that covers him but to excite our faith to serve him with so much the more ardor as we know him with the more certainty.

If God discovered himself continually to men, there would be no merit in believing him; and, if he never discovered himself, there would be little faith. But he conceals himself ordinarily and discovers himself rarely to those whom he wishes to engage in his service. This strange secrecy, in which God is impenetrably withdrawn from the sight of men, is a great lesson to betake ourselves to solitude far from the sight of men. He remained concealed under the veil of the nature that covers him till the Incarnation; and when it was necessary that he should appear, he coneealed himself still the more in covering himself with humanity. He was much more recognizable when he was invisible than when he rendered himself visible. And in fine, when he wished to fulfil the promise that he made to his apostles to remain with men until his final coming, he chose to remain in the strangest and nost obscure secret of all, which are the species of the Encharist. It is this sacrament that St. John calls in the Apoc. alypse a concealed manner; and I believe that Isaiah saw it in that state, when he said in the spirit of prophecy: T'ruly thou r.t a God concealed. This is the last secrecy wherein he can ve. The veil of nature that covers God has been penetrated by some of the unbelieving, who, as St. Paul says, have reeognized an invisible God in visible nature. Heretical Christians have recognized him through his humanity and adored Jesus Lhrist God and man. But to recognize him under the species 
of bread is peculiar to Catholics alone: none but us are thus enlightened by God. We may add to these considerations the secrecy of the spirit of God concealed still in the Scripture. For there are two perfeet senses, the literal and the mystical; and the Jews, stopping at the one, do not even think that there is another, and take no thought for searching it out, iust as the impious, seeing natural effects, attribute them to nature, without thinking that there is another author, and, as the Jews, seeing a perfect man in Jesus Christ, have not thought to seek in him another nature: We had not thought that it was he, again says Isaiah : and just as, in fine, the heretics, secing the perfect appearances of bread in the Eucharist, do not think to see in it another substance. All things cover some mystery; all things have veils that cover God. Christians ought to recognize him in every thing. Temporal afflictions cover eternal goods to which they lead. Temporal joys cover eternal ills that they cause. Let us pray God to make us recognize and serve him in every thing; let us give him countless thanks that, having concealed himself in all things for others, he has discovered himself in all things and in so many ways for us.

\section{III.}

I know not how you have taken the loss of your letters. I could wish indeed that you may have taken it as you ought. It is time to begin to judge of what is good or bad by the will of God, who can be neither unjust nor blind, and not by our own, which is always full of malice and error. If you have had these sentiments, I shall be greatly pleased, inasmueh as you will have received consolation for a more valid reason than that which I have to communicate to you, which is that I hope that they are found again. That of the 5th has already been brought to me; and although it is not the most important (for that of M. du Gas is more so), nevertheless this makes me hope to recover the otleer.

I know not why you complain that I have written nothing for you,-I do not separate you two, and continually think of 
both. You see plainly that my other letters, and this also, re. fer sufficiently to. you. In truth, I cannot refrain from telling. you that I could wish to be infallible in my judgments; you would not be badly off if that were the case, for I am very much pleased with you ; but my judgment is nothing. I say this with reference to the manner in which I see you speak of that good persecuted friar, and of what ** does. I am not surprised tu see NI. N. interested in the matter, I am accustomed to his zeal, but yours is wholly new ; this new language is usually the product of a new heart. Jesus Christ has given in the Church this sign whereby to recognize those who have faith,- that they shall speak a new language; and in fact the renewal of thoughts and desires causes that of discourse. What you say of days passed in solitude, and the consolation afforded you by reading, are things that M. N. will be extremely happy to know when I shall make him acquainted with them, and my sister also. These certainly are new things, but they must be unceasingly renewed, for this newness, which cannot be displeasing to God as the old man cannot be pleasing to him, is different from earthly novelties, inasmuch as worldly things, however new they may be, grow old as they endure; whilst this new spirit is renewed the more, the longer it endures. Our old man perishes, says St. Paul, and is renewed day by day, and will be perfectly new only in eternity, when shall be sung without ceasing that new song of which David speaks in the Psalms; that is the song that springs from the new spirit of love.

I will tell you for news, of what eoncerns these two persons, that I clearly perceive their zeal does not grow cold; this surprises me, for it is much more rare to see continuation in piety than to see entrance upon it. I have them always in mind, especially her of the miracle, because there is something in her case more extraordinary, although the other may be also very extraordinary and almost without example. It is vertain that the graces conferred by God in this life are the neasure of the glory prepared by him for the other. Thus when I foresee the end and crown of this work by the com. 
mencements that appear in pious persons, I feel a veneration that overcomes me with respect towards those whom he seems to have chosen for his elect. I confess to you that it seems to me that I see them already on one of those thrones where those who shall have left all will judge the world with Jesus Christ, according to the promise that he has made. But when I come to think that these same persons may fall, and be cn the contrary, of the unfortunate number of the judged, and that there will be so many of them who will fall from glory and leave to others by their negligence the crown that God had offered them, I cannot bear the thought; and the distress that I should feel in seeing them in this eternal state of misery, after having imagined them with so much reason in the other state, makes me turn my mind from the idea and recur to God in order to pray him not to abandon the weak creatures that he has acquired, and to say to him for the two persons whom you know what the Church says to-day with St. Paul : O Lord, do thou complete that work which thou thyself hast commenced. St. Paul often regarded himself in these two states, and it is what makes him say elsewhere: I keep under my body, and bring it into subjection; lest when $I$ have preached to others, I myself be a castaway. I end therefore with these words of Job : I have always feared the Lord like the waves of a raging sea and swollen to engulf me. And elsewhere: Happy is the man that feareth always!

\section{IV.}

It is very certain that separation never takes place without pam. We do not feel our bond when we voluntarily follow the object that leads us, as St. Augustine says; but when we begin to resist and draw back, we suffer; the bond stretehes and suffers violence; and this bond is our body, which is oroken but by death. Our Lord has said that since the coming of John the Baptist, that is, since his coming in each of the faithful, the kingdom of heaven suffers violence and the violent take it by storm. Before we are touched by the spirit we feel nothing but the burden of concupiscence that presses us 
to the earth. When God draws us on high, these two opposing efforts cause that violence which he alone can enable us to overcome. But we can do all things, says St. Leon, with him, without whom we can do nothing. We must then resolve to endure this warfare all our lives; for here there is no peace. Christ came not to bring peace, but a sword. Nevertheless, it must be acknowledged that, as Seripture says, the wisdom of this world is foolishness with God; so it may be said that this warfare which appears hard to men is peace with God, for it is the peace which Jesus Christ himself has brought us. Yet it will not be perfeeted until the body shall be destroyed; and this it is which makes us wish for death, while we nevertheless cheerfully endure life for the love of him who has suffered both life and death for us, and who is able to give us more than we ean ask or think, as says St. Paul in the Epistle of to-day.

\section{V.}

God be praised, I have no more fears for you, but am full of hope! These are consoling words indeed of Jesus Christ: To him that hath shall be given. By this promise, those who have received much have the right to hope for more, and those who have received extraordinarily should hope extraordinarily. I try as much as I can to let nothing distress me, and to take every thing that happens as for the best. I believe that this is a duty, and that we sin in not doing so. For, in short, the reason why sins are sins is only because they are contrary to the will of God: and the essence of sin thus consisting in having a will opposed to that which we know to be of God, it is plain, it appears to me, that when he diseovers his will to us by events, it would be a sin not to conform ourselves to it. I have learned that in every thing that happens there is something worthy of admiration, since the will of God is manifest in it. I praise him with all my heart for the continzation of his favors, for I see plainly that they do not diminish. The affair of *** does not go on very well: it is a thing that makes those tremble who are truly the children of God to vee the persecution which 's in preparation, not only against 
individuals (this would be little) but against the Tr.ıth. To speak truly, God is indeed abandoned. It appears to me that this is a time in which the service that we render him is very pleasing to him. He desires that we should judge of grace by nature, and thus we may be allowed to suppose that as a prince driven from his country by his subjects feels extreme tenderness for those who remain faithful to him amidst the public revolt, in the same manner, God looks with especial favor upon those who are at this time defending the purity of religion and morals, so warmly assailed. But there is this difference between the kings of the earth and the King of kings, that the princes do not render their subjects faithful, but find them so; whilst God never finds men other than unfaithful, and renders them faithful when they are so. So that while the kings of the earth are under signal obligations to those who adhere to their allegiance, it happens, on the contrary, that those who subsist in the service of God are themselves infinitely indebted to him. Let us continue then to praise him for this grace, if he has bestowed it upon us, for which we shall praise him throughout eternity, and let us pray that he may give us still more of it, and that he may look with pity upon us and upon the whole Church, ontside of which there is nothing but malediction.

I am interested in the victim of persecution of whom you speak. I see plainly that God has reserved to himself some liilden servants, as he said to Elijah. I pray him that we may be of the number, and that in spirit, in sincerity, and in truth.

\section{VI.}

Whatever may come of the affair of ***, enough, thank Gol, has already been done to draw an admirable advantage from it against these accursed precepts. There is need that those who have taken any part in this should render great thanks to God, and that their relatives and friends should pray to God for them that they may not fall from the great happiness and honor which he has bestowed on them. All the nonors of the world are but the image of this; this alone is 
solid and real, and nevertheless it is useless without the right frame of heart. It is not bodily austerities nor mental exercises, but good impulses of the heart, which are of merit and which sustain the sufferings of the body and the mind. For in short two things are necessary for sanctification-sufferings and joys. St. Paul says that we must through much tribulation enter into the kingdom of God. This should console those who experience tribulation, since, being warned that the path to heaven which they seek is filled with it, they should rejoice at meeting tokens that they are in the right way. But these very sufferings are not without joys, and are never surmounted but by pleasure. For as those who forsake God to return to the world do it only because they find more enjoyment in the pleasures of the world than in those of a union with God, and because this conquering charm leads them away and, making them repent of their first choice, renders them penitents of the devil, according to the saying of Tertullian; so none would ever quit the pleasures of the world to embrace the cross of Jesus Christ, did he not find more enjoyment in contempt, in poverty, in destitution, and in the scorn of men, than in the delights of sin. And thus, says Tertullian, it must not be supposed that the Christian's life is a life of sadness. We forsake pleasures only for others which are greater. Pray without ceasing, sayss St. Paul, in every thing give thanks, rejoice evermore. It is the joy of having found God that is the principle of the sorrow for having offended him, and of the whole change of life. He that finds a treasure in a field, according to Jesus Christ, has such joy that he goes directly and sells all that he has to purchase the field. The people of the world know nothing of this joy, which the world can nither give nor take away, as is said by Jesus Christ. The blessed have this joy without sorrow; the people of the world have .heir sorrows without this joy, and Christians have this joy mingled with the sorrow of having pursued other pleasures and the fear of losing it by the allurements of these same pleasures which tempt us without ceasing. And thus we should labor unceasingly to cherish this joy which moderates 
our fear, and to preserve this fear which preserres our joy, so that on feeling ourselves too much carried away by the one we may incline towards the other, and thus remain poised between the two. In the day of prosperity be joyful; but in the day of adversity consider, says the Scripture, and so it shall be till the promise of Jesus Christ shall be accomplished in us that our joy shall be full. Let us not then le cast down by sadness, nor believe that piety consists only in bitterness without consolation. The true piety, which is found perfect only in heaven, is so full of satisfactions that it overflows with them in its beginning, its progress, and its consummation. Its light is so shining that it is reflected on all about it; and if there is sadhess mingled with it, especially at the outset, this comes from ourselves and not from virtue; for it is not the effect of the piety that is springing up in us, but of the impiety that still is there. Remove the impiety and the joy will be unalloyed. Let us not ascribe this then to devotion, but to ourselves, and seek relief from it only through our correction.

\section{VII.}

I am very glad of the hope which you give me of the success of the affair which you fear may make you vain. There is something to fear in any case ; for, were it successful, I should fear from it that evil sorrow of which St. Paul says that it leads to death, instead of that different one that leads to life.

It is certain that the matter was a thorny one, and that, if the person should be extricated from it, the result would give reason for some vanity, were it not that we had entreated it of God, and should therefore believe the good that comes of it his work. But if it should not succeed well, we ought not thereore to fall into despondency, for the same reason that having prayed to God in the affair, it is evident that he has taken it into his own hand; thus he must be regarded as the author of all good and of all evil, with the exception of sin. Thereupor I would repeat to the person the passage of Scripture to which I have before referred: In the day of prosperity rejoice, but in the day of adversity consider. Nevertheless, I must say to you 
in respect to the other person whom you know, who sends word that she has many things on her mind that trouble her, that I am very sorry to see her in this state. I am deeply gricred at her troubles, and should be glad to be able to relieve them I entreat her not to anticipate the future, and to remembe that, as our Lord has said, Sufficient unto the day is the evi thereof.

The past ought not to trouble us, since we have only to feel regret for our faults; but the future ought to concern us still less, since it is wholly beyond our control, and since perhaps we may not reach it at all. The present is the only time that is truly our own, and this we ought to employ according to the will of God. It is in this that our thoughts ought chiefly to be centred. Yet the world is so restless that men scarcely ever think of the present life and of the moment in which they are living, but of that in which they will live. In this manner we are always living in the future, and never in the present. Our Lord has willed that our foresight should not extend beyond the present day. These are the bounds within which we must keep both for our safety and for our own repose. For in truth, the Christian precepts are those fullest of consolation, exceeding, I affirm, the maxims of the world.

I also foresee many troubles, both for that person, for others, and for myself. But I pray to God, when I find myself absorbed in these forebodings, to restrain me within my prescribed course. I call myself to an account, and I find that I am neglecting to do many things that I ought at present, in order to escape from useless thoughts of the future on which, far from being obliged to dwell, it is on the contrary my duty not to dwell at all. It is only for want of not understanding how to know and study the present that we undertake to study the future. What I say here, I say for myself, and not for that person who has assuredly more virtue and reflection than I; put I show him my defect to hinder him from falling into it: wc sometimes correct ourselves better by the sight of evil than by the example of good; and it is well to accustom ourselres to profit by evil, since this is so cummon while goodness is sc rare. 


\section{VIII.}

I pity the person whom you know in the disquietude in which I know she is, and in which I am not surprised to see her. It is a little day of judgment which cannot come without a universal emotion of the person, as the general judgment will cause a general emotion in the world, those excepted who shall have already judged themselves, as she pretends to have done. This temporal suffering would guarantee her from the eternal, through the infinite merits of Jesus Christ, who has endured it and rendered it his own; this it is that should console her. Our yoke is also his own; without this it would be insupportable.

Take my yoke upon you, says he. It is not our yoke; it is his, and he also bears it. Know, says he, that my yoke is easy and light. It is light only to him and to his divine power. I would say to her that she should remember that these dis.quietudes come not from the good that is springing up in her, but from the evil which is still remaining and must be continually diminished; that she must do like a child that is being torn by robbers from the arms of its mother who will not let it go; for it should not charge the mother that fondly holds it back with the violence that it suffers, but its unjust ravishers. The whole office of Advent is well fitted to give courage to the weak; these words of Scripture: T'ake courage, ye fearful and unbelieving, behold, your Redeemer cometh, are often repeated there, and in the vesper service of to-day it is said: "Take courage and fear not; for your God shall come to save and deliver you."

\section{IX.}

Your letter has given me the greatest joy. I confess that I was beginning to fear, or at least to be astonished. I know not what was the beginning of the trouble of which you speak; bit I know that trouble must come. I was reading the thirteenth chapter of St. Mark. I was thinking of writing you; and I will tell you therefore what I found in it. Jesus Christ 
is there addressing a solemn discourse to his disciples on his second coming; and as whatever happens to the Chureh happens also to each individual Christian, it is certain that this whole chapter predicts the state of each person in whom on conversion the old man is destroyed, as well as that of the whole universe which shall be destroyed to give place to a new heaven and a new earth, as the Scripture says. And thus I should think that the overthrow of the reprobate temple, which prefigures the overthrow of the reprobate man within us, and of which it is said that there shall not be one stone left upon another, indicates that no passion of the old man shall remain ${ }^{1}$ and these fierce contentions, both civil and domestic, represent so well the internal conflicts experienced by those who give themselves up to God, that nothing can be better depicted.

But very striking are these words: When ye shall see the abomination of desolation in the holy place, let not him that is on the house-top go into the house. It seems to me that this perfectly predicts the times in which we live, in which moral corruption is in the houses of sanctity and in the books of theologians and ecclesiastics, in whirh we should least expect it. We must shun such disorder; and woe to those with child and to those that give suck in those days, that is to those that are held back by worldly ties! The words of a sainted woman are applicable here: "We are not to consider whether we are called to quit the world, but solely whether we are called to remain in it, as we should not deliberate whether we were salled to fly a house infected with plague or on fire."

This chapier of the Evangelist, which I should like to read with you entire, concludes with an exhortation to watch and pray in order to shun all these misfortunes, and in truth, it is proper indeed that when the danger is continual the prayer should be continual also.

For this purpose I send the prayers which were asked of me; it is now three in the afternoon. Since your departure, a

${ }^{1}$ The two MSS. of the Biblic théque Inp. say : "no passion in us."Faugère. 
miracle has been performed upon a nun of Pontoise, who, with. out leaving her convent, has been cured of an extraordinary headache by an act of devotion to the holy Thorn. I will tell you more about it another time. But I must quote to you, in respect to this, an excellent saying of St. Augustine, very consoling to certain persons, that those alone really see miracles whom the miracles benefit; for they are not seen at all if they do not benefit.

I am under obligations that I cannot sufficiently exprese for the present which you have made me; I did not know what it could be, for I unfolded it before reading your letter, and $I$ afterwards repented for not having rendered to it at first the respect that was due to it. It is a truth that the Holy Spirit reposes invisibly in the relies of those who have died in the grace of God, until they shall appear visibly in the resurrection, and this it is that renders the relies of the saints so worthy of veneration. For God never abandons his own, even in the sepulchre in which their bodies, though dead to the eyes of men, are more than ever living in the sight of God, since $\sin$ is no more in them; whilst it constantly resides in them during life, at least in its root, for the fruits of sin are not always in them; and this fatal root, which is inseparable from them in life, causes it to be forbidden us during life to honor them, since they are rather worthy of detestation. It is for this that death becomes necessary to mortify entirely this fatal root, and this it is that renders it desirable. But it is of no use' to tell you what you know so well; it would be better to tell it to the other persons of whom you speak, but they would not listen to it.

1 The MSS. of the Bibliothéque Imp. say : " $\mathrm{Br} t$ it is not nevessary . . . ' The MS. of Troyes agrees with ours.-Faugère. 
Leftrer from Pascal to Queen Ciristina, on sending her the Arithmetical Machine, 1650.

Madame,

If I had as much health as zeal, I should go myself te present to Your Majesty a work of several years which I dare offer you from so far; and I should not suffer any other hands than mine to have the honor of bearing it to the feet of the greatest princess in the world. This work, Madame, is a machine for making arithmetical calculations without pen or counters. Your Majesty is not ignorant of the cost of time and pains of new productions, above all when the inventors wish to bring them themselves to their highest perfection; this is why it would be useless to say how much I have labored upon this one, and I cannot better express myself than by saying that $I$ have devoted myself to it with as mueh ardor as though I had foreseen that it would one day appear before so august a person. But, Madame, if this honor has not been the veritable motive of my work, it will be at least its recompense; and I shall esteem myself too happy if, after so many vigils, it can give Your Majesty a few moments' satisfaction. I shall not importune Your Majesty with the details of the parts which compose this machine; if you have any curiosity in respect to it, you can satisfy yourself in a discourse which I have addressed to M. de Bourdelot $;^{\prime}$ in which I have sketched in a few words the whole history of this work, the object of its invention, the occasion that led to its investigation, the utility of its applications, the difficulty of its execution, the degree of its progress, the success of its accomplishment, and the rules for its use. I shall

1 Physician to Queen Christina. He had first been physician to the great Condé, to whom he nad introauced Paseal in 1644, that the latter might show to the prince the arithmetical machine, as we learn from an anpublished note from Bourdelot to Paseal, MS. 397, Suppl. fr., p. 22, and MS. of Mazarin, p. 33.-Cousin. 
therefore only speak here of the motive that led me to offer it to Your Majesty, which I consider as the consummation and happiest fortune of its destiny. I know, Madame, that I may be suspected of having sought honor in presenting it to Your Majesty, since it can pass only for something extraordinary when it is seen that it is addressed to you : and that whilst it should only be offered to you through the consideration of its excellence, it will be judged that it is excellent for the sole reason that it is offered to you. It is not this hope, however, that has inspired me with such a design. It is too great, Madame, to have any other object than Your Majesty yourself. What has really determined me to this is the union that I find in your sacred person of two things that equally overwhelm me with admiration and respect-which are, sovereign authority and solid science; for I have an especial veneration for those who are elevated to the supreme degree either of power or of knowledge. The latter may, if I am not mistaken, as well as the former, pass for sovereigns. The same gradations are found in genius as in condition; and the power of kings over their subjects is, it seems to me, only an image of the power of minds over inferior minds, over whom they exercise the right of persuasion, which is with them what the right of command is in political government. This second empire even appears to me of an order so much the more elevated, as minds are of an order more elevated than bodies; and so much the more just, as it can be shared and preserved only by merit, whilst the other can be shared and preserved by birth and fortune. It must be acknowledged then that each of these empires is great in itself; but, Madame, let Your Majesty, who is not wounded by it, permit me to say, the one without the other appears to me defective. Ilowever powerful a monarch may be, something is wanting to his glory if he has not pre-eminence of mind; and however enlightened a subject may be, his condition is always lowered by dependence. Men who naturally desire what is most perfect, have hitherto continually aspired to meet this 
sovereign par excellence. All kings and scholars have hitherto been but faint outlines of it, only half performing their endeavor; this masterpiece has been leserved for our own times. And that this great marvel might appear accompanied with all possible subjects of wonder, the position that men could not attain is filled by a youthful queen, in whom are found combined the advantage of experience with the tenderness of youth, the leisure of study with the occupation of royal birth, and the eminence of science with the feebleness of sex. It is Your Majesty, Madame, that furnishes to the world this unique example that was wanting to it. You it is in whom power is dispensed by the light of science, and science exalted by the lustre of authority. It is from this marvellous union that, as Your Majesty sees nothing beneath your power, you also see nothing above your mind, and that you will be the admiration of every age. Reign then, incomparable princess, in a manner wholly new; let your genius subdue every thing that is not submissive to your arms; reign by right of birth during a long course of years over so many triumphant provinces; but reign continually by the force of your merit over the whole extent of the earth. As for me, not having been born under the former of your empires, I wish all the world to know that I glory in living under the latter; and it is to bear witness to this that I dare to raise my eyes to my queen, in giving her this first proof of my dependence.

This, Madame, is what leads me to make to Your Majesty this present, although unworthy of you. My weakness has not checked my ambition. I have figured to myself that although the name alone of Your Majesty seems to put away from you every thing that is disproportioned to your greatness, you will not however reject every thing that is inferior to yourself; as your greatness would thus be without homage and your glory without praise. You will be contented to receive a great mental effort, without sxacting that it should be the effort of a mind as great as your own. It is by this condescension that you will deign to enter into communication 
with the rest of mankind; and all these joint considerations make me protest, with all the submission of which one of the greatest admirers of your heroic qualities is capable, that I desire nothing with so much ardor as to be able to be adopted, Madame, by Your Majesty, as your most humble, most obe lient, and most faithful servant.

Blaisf yagcal. 


\section{P U S C U L E S.}

\section{EPITAPH OF M. PASCAL, PERE.}

Here lies, etc.

Illustrious for his great knowledge, which was recognized by the scholars of all Europe; more illustrious still for the great probity which he exercised in the offices and employments with which he was honored; but much more illustrious for his exemplary piety. He tasted good and bad fortune, that he might be known in every thing for what he was. He was seen temperate in prosperity and patient in adversity. He sought the aid of God in misfortune, and rendered him thanks in happiness. His heart was devoted to his God, his king, his family, and his friends. He had respect for the great and love for the small; it pleased God to crown all the graces of nature that he had bestowed on him with a divine grace which made his great love for God the foundation, the stay, and the consummation of all his other virtues.

Thou, who seest in this epitome the only thing that remains to us of so beautiful a life, admire the fragility of all present things, weep the loss that we have suffered; render thanks to God for having left for a time to earth the enjoyment of such a treasure; and pray his goodness to crown with his eternal glory him whom he crowned here below with more graces and sirtues than the limits of an epitaph permit us to relate.

His grief-stricken children have placed this epitaph on this spot, which they have composed from the fulness of their 
hearts, in order to render homage to the truth and not to ap. pear ingrates in the sight of God.

MSS. of the Bibliothèque Imp., Oratoire, No. 160.-Faugére, Lettres, etc., Appendice, No. 5.

\section{PRAYER}

TO ASK OF GOD THE PROPER USE OF SICKNESS.

I. Lord, whose spirit is so good and so gentle in all things, and who art so merciful that not only the prosperity but the very disgrace that happens to thy elect is the effect of thy mercy, grant me the favor not to act towards me as towards a heathen in the condition to which thy justice has reduced me: that like a true Christian I may recognize thee for my Father and my God, in whatever condition I may find myself, since the change of my condition brings none to thine; as thou art always the same, however subject I may be to change, and as thou art none the less God when thou afflictest and punishest, than when thou comfortest and showest indulgence.

II. Thou gavest me health to serve thee, and I made a profane use of it. Thou sendest me siekness now to correct me; suffer not that I use it to irritate thee by my impatience. I made a bad use of my health, and thou hast justly punished me for it. Suffer not that I make a bad use of my punishment. And since the corruption of my nature is such that it renders thy favors pernicious to me, grant, $\mathrm{O}$ my God! that thy all-powerful grace may render thy chastisements salutary. If my heart was full of affection for the world while it retained its vigor, destroy this vigor for my salvation; and render me inLapable of enjoying the world, either through weakness of body or through zeal of charity, that I may enjoy but thee alone.

III. O God, before whom I must render an exact account of all my actions at the end of my life and at the end of the sorld! $O$ God, who lettest the world and all the things 0 . 
the world subsist but to train thy elect or to punish sinners! $\mathrm{O}$ God, who allowest sinners hardened in the pleasurable and criminal use of the world! O God, who makest our bodies to die, and who at the hour of death separatest our soul from all that it loved in the world! O God, who wilt snatch me, at this last moment of my life, from all the things to which I am attached and on which I have set my heart! O God, who wilt consume at the last day the heavens and the earth with all the creatures they contain, to show to all mankind that nothing subsists save thee, and that thus nothing is worthy of love save thee, since nothing is durable save thee! O God, who wilt destroy all these vain idols and all these fatal objects of our passions! I praise thee, my God, and I will bless thee all the days of my life, that it has pleased thee to anticipate in my favor this terrible day, by destroying all things in respect to me through the weakness to which thou hast reduced me. I praise thee, my God, and I will bless thee all the days of my life, that it has pleased thee to reduce me to the incapacity of enjoying the sweets of health and the pleasures of the world, and that thou hast destroyed in some sort, for my advantage, the deceitful idols that thou wilt destroy effectively, for the confusion of the wicked, in the day of thy wrath. Grant, Lord, that I may judge myself, after the destruction that thou hast made with respect to me, that thou mayest not judge me thyself, after the entire destruction that thou wilt make of my life and of the world. For, Lord, as at the instant of my death I shall find myself separated from the world, stripped of all things, alone in thy presence, to answer to thy justice for all the emotions of my heart, grant that I may consider myself in this siekness as in a species of death, separated from the world, stripped of all the objects of my attachment, alone in thy presence, to implore of thy mercy the conversion of my heart; und that thus I may have extreme consolation in knowing that thou sendest me now a partial death in order to exercise thy merey, before thou sendest me death effectively in order tc excreise thy judgment. Grant then, O my God, that as thou hast anticipated my death, I may anticipate the rigor of thy 
sentence, and that I may examine myself before thy jurlgment, so that I may find mercy in thy presence.

IV. Grant, O my God! that I may adore in silence the order of thy adorable providence in the direction of my life; that this scourge may console me; and that, having lived during peace in the bitterness of my sins, I may taste the heavenly sweets of thy grace during the salutary evils with which thou aflictest me. But I perceive, my God, that my heart is so obdurate and full of the thoughts, the cares, the anxieties, and the attachments of the world, that sickness no more than health, nor discourses, nor books, nor thy sacred Scriptures, nor thy Gospel, nor thy most holy mysteries, nor alms, nor fasts, nor mortifications, nor miracles, nor the use of sacraments, nor the sacrifice of thy body, nor all my efforts, nor those of all the world together, can do any thing at all for the commencement of my conversion, if thou dost not accompany all these things with an extraordinary assistance of thy grace. It is for this that I address myself to thee, all-powerful God, to ask of thee a gift which all created things together cannot accord to me. I should not have the boldness to address to thee my cries, if any other had power to grant them. But, my God, as the conversion of my heart, which I ask of thee, is a work which surpasses all the efforts of nature, I can only address myself to the all-powerful Author and Master of nature and of my heart. To whom shall I cry, O Lord, to whom shall I have recourse, if not to thee? Nothing that is less than God can fulfil my expectation. It is God himself that I ask and seek; and it is to thee alone, my God, that I address myself to obtain thee. Open my heart, O Lord; enter into the rebellious place which has been occupied by vices. They hold it subject. Enter into it as into the strong man's house; but first bind the strong and powerful enemy that has possession of it, and then take the treasures which are there. Lord, take my affections, which the world had stolen; take this treasure thyself, or rather retake it, since it beiongs to thee as a tribute that I owe thee, since thy image is imprinted in it. Thou formedst it, O Lord, at the moment of my bap. 
tism, which was my second birth; but it is wholly effaced. The image of the world is so deeply engraven there that thine is no longer to be recognized. Thou alone couldst create my soul, thou alone canst ereate it anew; thou alone couldst form thy image, thou alone canst reform and reimprint thy effaced portrait, that is, my Saviour, Jesus Christ, who is thy image, and the expression of thy substance.

V. O my God! how happy is a heart that can love so charming an object, that does not dishonor it, and the attachment of which is so salutary to it! I feel that I cannot love the world without displeasing thee, and destroying and dishonoring myself; yet the world is still the object of my delight. O my God! how happy is the soul of which thou art the delight, since it can abandon itself to loving thee, not only without scruple, but also with merit! How firm and durable is its happiness, since its expectation will never be frustrated, because thou wilt never be destroyed, and neither life nor death will ever separate it from the object of its desires; and since the same moment that will plunge the wicked with their idols into a common ruin, will unite the just with thee in a common glory; and since, as the former will perish with the perishable objects to which they are attached, the latter will subsist eternally in the eternal and self-subsistent object to which they are closely bound! Oh! how happy are those who with an entire liberty, and irresistible inclination of their will, love perfectly and freely that which they are obliged to love necessarily!

VI. Perfect, O my God, the good impulses that thou givest me. Be their end as thou art their principle. Crown thy own gifts, for I recognize that they are from thee. Yes, my God, and far from pretending that my prayers may have some merit that forces thee to accord them of necessity, I humbly acknowledge that, having given to created things my heart, which thou hadst formed snly for thyself, and not for the world, nor for myself, I can expect no grace except from thy mercy, since I have nothing in me that can oblige thee to it. and since all the natural impulses of my heart, whether tend- 
ing towards created things, or towards myself, can only irritate thee. I, therefore, render thee thanks, my God, for the good impulses which thou givest me, and for the very one that thou bast given me to render thanks for them.

VII. Move my heart to repent of my faults, since, without this internal sorrow, the external ills with which thou affectest my body will be to me a new occasion of sin. Make me truly to know that the ills of the body are nothing else than the punishment and the symbol combined of the ills of the soul. But, Lord, grant also that they may be their remedy, by making me consider, in the pains which I feel, those that I did not fecl in my soul, although wholly diseased, and covered with sores. For, Lord, the greatest of its diseases is this insensibility and extreme weakness, which had taken away from it all feeling of its own sufferings. Make me to feel them acutely, and grant that the portion of life that remains to me may be a continual penitence to wash away the offences that I have committed.

VIII. Lord, although my past life may have been exempt from great crimes, of which thon hast removed from me the occasions, it has nevertheless been most odious to thee by its continual negligence, by the bad use of thy most august sacraments, by the contempt of thy word and of thy inspirations, by the indolence and total uselessness of my actions and my thoughts, by the complete loss of the time which thou hadst given me only to adore thee, to seek in all my occupations the means of pleasing thee, and to repent of faults that are committed every day, and are even common to the most just; so that their life should be a continnal penitence, without which they are in danger of falling from their justice. Thus, my God, I have always been opposed to thee.

IX. Yes, Lord, hitherto I have always been deaf to thy inspirations, I have despised thy oracles; I have judged the contrary of that which thou hast judged; I have contradicted the holy maxims which thou hast-brought to the world from the bosom of thy eternal Father, and conformably to which thou wilt judge the world. Thon sayest: Blessed are those 
that mourn, and woe to those that are comforted! And I have said: Woe to those that mourn, and blessed are those that are comforted! I have said: Blessed are those that enjoy an affluent fortune, a glorious reputation, and robust health! And why have I reputed them blessed, if not because all these advantages furnished them ample facility for enjoying created things, that is for offending thee! Yes, Lord, I confess that I have esteemed health a blessing, not because it is an easy means for serving thee with utility, for accomplishing more cares and vigils in thy service, and for the assistance of my neighbor; but because by its aid I could abandon myself with less restraint to the abundance of the delights of life, and better relish fatal pleasures. Grant me the favor, Lord, to reform my corrupt reason and to conform my sentiments to thine. Let me esteem myself happy in affliction, and, in the impotence of acting externally, purify my sentiments so that they may no longer be repugnant to thine; and let me thus find thee within myself, since I cannot seek thee without because of my weakness. For, Lord, thy kingdom is within thy faithful; and I shall find it within myself, if I find there thy spirit and thy sentiments.

X. But, Lord, what shall I do to force thee to diffuse thy spirit over this miserable earth? All that I am is odious to thee, and I find nothing in myself that can be pleasing to thee. I see nothing therein, Lord, but my sufferings, which bear some resemblance to thine. Consider then the ills that I suffer and those that menace me. Look with an eye of mercy upon the wounds that thy hand has made, $O$ my Saviour, who lovedst thy sufferings in death! O God, who wert made man only to suffer more than any other man for the salvation of mankind! O God, who wert not incarnated until after the sin of mankind, and who only tookest upon thyself a body in order to suffer therein all the ills which our sins had nerited! $O$ God, who lovedst so much these suf zring bodies that thou hast chosen for thyself a body more oppressed with suffering than any that has ever appeared on earth! Look with favor upon my body, not for itself, nor for all that it contains, for $20^{\circ}$ 
every thing therein is deserving of thy anger, but for the ills that it endures, which alone can be worthy of thy love. Love my sufferings, Lord, and let my ills invite thee to visit me. But to finish the preparation for thy abode, grant, O my Saviour, that if my body has this in common with thine-that it suffers for my offences, my soul may also have this in common with thine-that it may be plunged in sorrow for the same offences; and that thus I may suffer with thee, and like thee, both in my body and in my soul, for the sins that I have committed.

XI. Grant me the favor, Lord, to join thy consolations to my sufferings, that I may suffer like a Christian. I ask not to be exempt from sorrow, for this is the recompense of the saints; but I ask that I may not be abandoned to the sorrows of nature without the consolations of thy spirit; for this is the curse of the Jews and the heathen. I ask not to have a fulness of consolation without any suffering; for this is the life of glory. Neither do I ask to be in the fulness of evils without consolation; for this is the state of Judaism. But I ask, Lord, to feel at the same time both the sorrows of nature for my sins, and the consolations of thy spirit through thy grace; for this is the true condition of Christianity. Let me not feel sorrow without consolation; but let me feel sorrow and consolation together, that I may come at last to feel thy consolation withcut any sorrow. For, Lord, thou lettest the world languish in natural suffering without consolation, before the coming of thy only Son: now thou consolest and assuagest the sufferings of thy faithful through the grace of thy only Son: and thou crownest thy saints with a pure beatitude in the glory of thy only Son. Such are the admirable degrees through which thou conductest thy work. Thou hast drawn me from the first: make me pass through the second, to arrive at the third. Lord, this is the favor that $I$ ask of thee.

XII. Suffer me not to be so far removed from thee, that I zan consider thy soul sorrowful unto death, and thy body a prey to death for my own sins, without rejoicing to suffer both in my body and in my soul. For what is there mors elameful, and yet mere common in Christians and in my 
self, than that, whilst thou sweatest blood for the expiation of our offences, we live in delights; and that those Chris tians who profess to belong to thee, that those who by baptism have renouneed the world to follow thee, that those who have sworn solemnly in the presence of the Church to live and die for thee, that those who profess to believe that the world has persecuted and crucified thee, that those who believe that thou wert exposed to the wrath of God and the cruelty of men to ransom them from their crimes; that those, I say, who believe all these truths, who consider thy body as the victim that was yielded up for their salvation, who consider the pleasures and the sins of the world as the only cause of thy sufferings, and the world itself as thy executioner, seek to flatter their bodies by these very pleasures, in this very world; and that those who cannot, without shuddering with horror, see a man caress and cherish the murderer of his father who would devote himself to give him life, can live as I have done, with full joy, in the world that I know to have been veritably the murderer of him whom I acknowledge for my God and my Father, who has delivered himself up for my own salvation, and who has borne in his person the penalty of my iniquities? It is just, Lord, that thou shouldst have interrupted a joy so criminal as that in which $I$ was reposing in the shadow of death.

XIII. Remove from me then, Lord, the sadness that the love of self might give me for my own sufferings and for the things of the world that do not succeed to the satisfaction of the inclinations of my heart, and that do not regard thy glory; but create in me a sadness in conformity with thine. Let my sufferings serve to appease thy wrath. Make of them an occasion for my salvation and my conversion. Let me henceforth desire health and life only to employ them and end them for thee, with thee, and in thee. I ask of thee neither health, nor sickness, nor life, nor death; but that thou wilt dispose of my health and my sickness, my life and iny death, for thy slory, for my salvation, and for the utility of the Church and of thy saints, of whom I hope by thy grace to form a part 
Thou alone knowest what is most expedient for me : thou art the sovereign master, do what thou wilt. Give to me, take from me; but conform my will to thine; and grant that in humble and perfect submission and in holy confidence, I may be disposed to receive the orders of thy eternal providence, and that I may adore alike all that comes to me from thee.

XIV. Grant, my God, that in a constantly equal uniformity of spirit I may receive all kinds of events, since we know not what we should ask, and since I cannot desire one more than another without presumption, and withont rendering myself the judge of and responsible for the results that thy wisdom has rightly been pleased to hide from me. Lord, I know only that I know but one thing, that it is good to follow thee and that it is evil to offend thee. After this, I know not which is the better or worse of any thing; I know not which is more profitable to me, health or sickness, wealth or poverty, nor of all the things of the world. This is a discernment that exceeds the power of men or of angels, and that is hidden in the secrets of thy providence which I adore, and which I wish not to fathom.

$X V$. Grant then, Lord, that such as I am I may conform myself to thy will; and that being sick as I am, I may g.orify thee in my sufferings. Without them I could not arrive at glory; and thou, too, my Saviour, hast only wished to attain it through them. It was by the tokens of thy sufferings what thou wert recognized by thy disciples; and it is by suffer:ngs also that thou wilt recognize thy disciples. Acknowledge we then for thy disciple in the evils which I endure both in my body and my mind, for the offences that I have committed. And since nothing is pleasing to God if it be not offered llrough thee, unite my will to thine, and my sorrows to those which thou hast suffered. Grant that mine may become thine. Unite me to thee; fill me with thyself and with thy Holy Spirit. Enter into my heart and soul, to bear in them my sufferings, and to continue to endure in me what remains to thee to suffer of thy passion, that thou mayest complete in thy members even the perfect consummation of thy body, so that 
being full of thee, it may no longer be I that live and suffer, but that it may be thou that livest and sufferest in me, $\mathrm{O}$ my Saviour! And that thus having some small part in thy sufferings thou wilt fill me entirely with the glory that they have acquired for thee, in which thou wilt live with the Father and the Holy Spirit through ages upon ages. So be it.

\section{COMPARISON BETWEEN CHRISTIANS}

OF EARLY TIMES AND THOSE OF TO-DAY.

In early times, Christians were perfectly instructed in all the points necessary to salvation; whilst we see to-day so gross an ignorance of them, that it makes all those mourn who have sentiments of tenderness for the Church.

Men only entered then into the Church after great labors and long desires; they find their way into it now without any trouble, without care, and without labor.

They were only dmitted to it after a strict examinatior. They are received into it now before they are in a condition to be examined.

They were not received then until after having abjured their past life, until after having renounced the world, the flesh, and the devil. They enter it now before they are in a condition to do any of these things.

In short, it was necessary formerly to forsake the world in order to be received into the Church; whilst men enter now into the Church at the same time as into the world. By this process, an essential distinction was then known between the world and the Church. They were considered as two opposites, as two irreconcilable enemies, of which the one persecuted the other without cessation, and of which the weaker in appearance should one day trimpli over the stronger; so that of these two antagonistic parties men quitted the one to enter he other; they abandoned the maxims of the one to embrace 
the maxims of the other; they put off the sentiments of the one to put on the sentiments of the other; in fine, they quitted. they renounced, they abjured this world in which they had re ceived their first birth, to devote themselves entirely to th Church in which they received as it were their second birth and thus they conceived a terrible difference between the two; whilst they now find themselves almost at the same time in both; and the same moment that brings us forth into the world makes us acknowledged by the Church, so that the reason supervening, no longer makes a difference between these two opposite worlds. It is developed in both together. Men frequent the Sacraments, and enjoy the pleasures of the world; and thus whilst formerly they saw an essential difference betwcen the two, they see them now confounded and blended together, so that they can no longer discriminate between them.

IIence it is that formerly none but well-instructed persons were to be seen among the Christians, whilst they are now in an ignorance that inspires one with horror; hence it is that those who had formerly been regenerated by bartism, and had forsaken the vices of the world to enter into the piety of the Church, fell back so rarely from the Church into the world; whilst nothing more common is to be seen at this time than the vices of the world in the hearts of Christians. The Church of the Saints is found defiled by the mingling of the wicked; and her children, whom she has conceived and nourished from childhood in her bosom, are the rery ones who carry into her heart, that is to the participation n her most august mysteries, the most cruel of her enemies, the spirit of the world, the spirit of ambition, the spirit of vengeance, the spirit of impurity, the spirit of concupiscence; and the love that she has for her children obliges her to admit into her very bowels the most cruel of her persecutors.

But it is not to the Church that should be imputed the mis fortunes which have followed a change in such salutary disci pline, for she has not changed in spirit, however she may have shanged in conduct. IIaving therefore seen that the deferring of baptism left a great number of children in the curse o 
Adam, she wished to deliver them from this mass of perdition by hastening the aid which she could give them; and this good mother sees only with extreme regret that what she devised for the salvation of these children has become the occasion for the destruction of adults. Her true spirit is that those whom she withdraws at so tender an age from the contagion of the world, shall adopt sentiments wholly opposed to those of the world. She anticipates the use of reason to anticipate the vices into which corrupt reason will allure them; and before their mind has power to act, she fills them with her spirit, that they may live in ignorance of the world and in a condition so much the more remote from vice as they will never have known it. This appears from the ceremonies of baptism; for she does not accord baptism to children until after they have declared, by the mouth of sponsors, that they desire it, that they believe, that they renounce the world and Satan. And as she wishes that they should preserve these intentions throughout the whole course of their lives, she commands them expressly to keep them inviolate, and orders the sponsors, by an indispensable commandment, to instruct the children in all these things; for she does not wish that those whom she has nourished in her bosom should to-day be less instructed and less zealous than the adults whom she admitted in former times to the number of her own; she does not desire a less perfection in those whom she nourishes than in those whom she receives. . . . . Yet men use it in a manner so contrary to the intention of the Church, that one cannot think of it without horror. They scarcely reflect any longer upon so great a benefit, because they have never wished it, because they have never asked it, because they do not even remember having re-

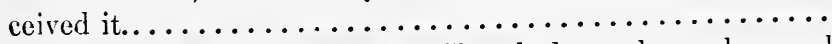

But as it is evident that the Church demands no less zeal in those who have been brought up servants of the faith than in those who aspire to become such, it is necessary to place before their eyes the example or the catechumens, to consider their ardor, their devotion, their horror of the world, their generous renunciation of the world; and if they were not 
deemed worthy of receiving baptism without this disposition, those who do not find it in themselves................. They must therefore submit to receive the instruction that they would have had if they had begun to enter into the communion of the Church; they must moreover submit to a continual penitence, and have less aversion for the austerity of their mortification than pleasure in the use of delights poi-

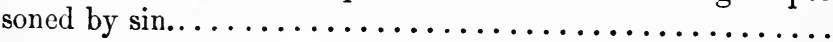

To dispose them to be instructed, they must be made to understand the difference of the customs that have been prac tised in the Church in conformity with the diversity of the

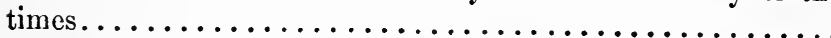

As in the infant Church they taught the catechumens, that is those who aspired to baptism, before conferring it upon them; and only admitted them to it after full instruction in the mysteries of religion, after a penitence for their past lives, after profound knowledge of the greatness and excellence of the profession of the faith and of the Christian maxims into which they desired to enter forever, after eminent tokens of a genuine conversion of the heart, and after an extreme desire of baptism. These things being known to all the Church, the sacrament of incorporation was conferred upon them by which they became members of the Church; whilst in these times, baptism having been accorded to children before the use of reason, through very important considerations, it happens that the negligence of parents suffers Christians to grow old without any knowledge of the greatness of our religion.

When instruction preceded baptism, all were instructed; but now that baptism precedes instruction, the instruction that was necessary has become voluntary, and then neglected and almost abolished. The true reason of this conduct is that men are persuaded of the necessity of baptism, and they are not persuaded of the necessity of instruction. So that when instruction preceded baptism, the necessity of the one caused men to hava recourse to the other necessarily; whilst baptism at the present time preceding instruction, as men have been made Christians without having been instructed, they believe 
that they can remain Christians without seeking instruction... And whilst the early Christians testified so much gratitude towards the Church for the favor which she accorded only to their long prayers, they testify to-day so much ingratitude for this same favor, which she accords to them even before they are in a condition to ask it. And if she detested so strongly the lapses of the former, although so rare, how much must she hold in abomination the continual lapses and relapses of the latter, although they are much more indebted to her, since she has drawn them much sooner and much more unsparingly from the damnation to which they were bound by their first birth. She cannot, without mourning, see the greatest of her favors abused, and what she has done to secure their salvation becomes the almost certain occasion of their destruction.'....

\section{DISCOURSES}

\section{ON THE CONDITION OF TIE GREAT.2}

I.

Is order to enter into a real knowledge of your condition, consider it in this image :

A man was cast by a tempest upon an unknown island, the inhabitants of which were in trouble to find their king, who

1 'This fragment was first published by Bossut. M. Faugère has given a more exact text after the MSS. of Father Guerrier.

2 These diseourses, published for the first time in 1670 , are found in the Essuis of Nicole, who prefaces them with the following explanations:

"One of the things upon whieh the late M. Paseal had thought the most, was the instruetion of a prinee who should be edueated in the manner unost in conformity with the condition to which God had ealled him, and best suited to render him eapable of fultilling all its duties and of shunning all its dangers. Ile has often been heard to say, that there was nothing to whieh he should desire more to contribute if he were engaged in it, end that he would willingly saerifice his life for so important an objeet. And as he was aceustomed to write down the thonghts that oceurred to tim upon subjects witl which his mind was oceupied, those who have 
was lost; and having a strong resemblance both in form and face to this king, he was taken for'him, and acknowledged in this capacity by all the people. At first he knew not what course to take; but finally he resolved to give himself up to his good fortune. He received all the homage that they chose to render him, and suffered himself to be treated as a king.

But as he could not forget his real condition, he was conscious, at the same time that he was receiving this homage, that he was not the king whom this people had sought, and that this kingdom did not belong to him. Thus he had a double thought: the one by which he acted as king, the other by which he recognized his true state, and that it was accident alone that had placed him in his present condition. He concealed the latter thought, and revealed the other. It was by the former that he treated with the people, and by the latter that he treated with himself.

known him are astonished at having found nothing among his remaining thoughts regarding this matter expressly, though it may be said in one sense that they all regard it, there being few books that ean better serve to fo:m the mind of a prinee than the eollection which has been made of them.

"It must be, then, either that what he had written on the subjeet has been lost, or that having these thoughts well fixed in his memory, he reglected to write them. And as by either eause the publie finds itself equally deprived of them, it has come into the mind of a person who was present at three short diseourses which he delivered to a child of elevated eondition, and whose mind, which was extremely precocious, was already eapable of the strongest truths, to write nine or ten years afterwards what he had retained of them. Now although after so long a time he cannot say that these are the very words which $M$. Pascal used at the time, notwithstanding all that he said made so lively an impression upon his mind that it was not poible for him to forget it. And thus he ean affirm that these are at least his thoughts and his sentiments."

It is evident that the person who heard and collected the three discourses is no other than Nicole himself. As to the ehild to whom they were addressed, it is said that it was the Duke de Roannez, but this opinion has been disearded for plausible reasons. M. Havet thinks that it might have been the Prince de Guémenée, admitting nevertheless that the prince was very young for so grave a eonversation, since he was scareely seven year old at the death of Pascal. It matters little, after all, to whom Pasia mpoke, provided that we know what he said. 
Do not imagine that it is less an accident by which you find yourself master of the wealth which you possess, than that by which this man found himself king. You have no right to it of yourself and by your own nature any more than he: and not only do you find yourself the son of a duke, but also do you find yourself in the world at all, only through an infinity of chanees. Your birth depends on a marriage, or rather on the marriages of all those from whom you descend. But upon what do these marriages depend? A visit made by chance, an idle word, a thousand unforeseen oceasions.

You hold, you say, your wealth from your aneestors; but was it not by a thousand accidents that your aneestors acquired it and that they preserved it? A thousand others, as capable as they, have either been unable to aequire it, or have lost it after having gained it. Do you imagine, too, that it may have lieen by some natural way that this wealth has passed from your ancestors to you? This is not true. This order is founded only upon the mere will of legislators who may have had good reasons, but none of which was drawn from a natural right that you have over these things. If it had pleased them to order that this wealth, after having been possessed by fathers during their life, should return to the republic after their death, you would have no reason to eomplain of it.

Thus the whole title by which you possess your property, is not a title of nature but of a human institution. Another turn of imagination in those who made the laws would have rendered you poor; and it is only this concurrence of chance which caused your birth with the caprice of laws favorable in your behalf, that puts you in possession of all this property.

I will not say that it does not legitimately belong to you, and that it is permissible for another to wrest it from you ; for God, who is its master, has permitted communities to make laws for its division, and when these laws are onee established, it is unjust to violate them. This it is that distinguishes you somewhat from the man who possessed his kingdom only through the error of the people; because God did not authorize this possession, and required him to renounce it, whilst ho 
authorizes yours. But what you have wholly in common with him is, that this right which you have, is not founded any more than his upon any quality or any merit in yourself which renders you worthy of it. Your soul and your body are, of themselves, indifferent to the state of boatman or that of duke; and there is no natural bond that attaches them to one condition rather than to another.

What follows from this? that you should have a double thought, like the man of whom we have spoken, and that, if you act externally with men in conformity with your rank, you should recognize, by a more secret but truer thought, that you have nothing naturally superior to them. If the public thought clevates you above the generality of men, let the other humble you, and hold you in a perfect equality with all mankind, for this is your natural condition.

The populace that admires you knows not, perhaps, this secret. It believes that nobility is real greatness, and it almost considers the great as being of a different nature from others. Do not discover to them this error, unless you choose; but do not abuse this elevation with insolence, and, above all, do not mistake yourself by believing that your being has something in it more exalted than that of others.

What would you say of that man who was made king by the error of the people, if he had so far forgotten his natural condition as to imagine that this kingdom was due to him, that he deserved it, and that it belonged to him of right? You would marvel at his stupidity and folly. But is there less in the people of rank who live in so strange a forgetfulness of their natural condition?

How important is this advice! For all the excesses, all the violence, and all the vanity of great men, come from the fact that they know not what they are: it being difficult for those who regard themselves at heart as equal with all men, and who are fully persuaded that they have nothing within themselves that merits these trifling advantages which God has given them over cthers, to treat them with insolence. For this it is neces. Bary "or one to forget himself, and to believe that he has some 
real excellence above them, in which consists this illusior that I am endeavoring to discover to you.

\section{II.}

It is well, sir, that you should know what is due to yon, that you may not pretend to exact from men that which is not due to you; for this is an obvious injustice; and nevertheless it is very common to those of your condition, because they are ignorant of the nature of it.

There is in the world two kinds of greatness: for there is greatness of institution, and natural greatness. Greatness of institution depends upon the will of men who have with reason thought it right to honor certain positions, and to attach to them certain marks of respect. Dignities and nobility are of this class. In one country the nobles are honored, in another the plebeians; in this the eldest, in the other the youngest. Why is this? because thus it has been pleasing to men. The thing was indifferent before the institution; since the institution it becomes just, because it is unjust to disturb it.

Natural greatness is that which is independent of the caprice of men, because it consists in the real and effective qualities of the soul or the body, which render the one or the other more estimable, as the sciences, the enlightenment of the mind, virtue, health, strength.

We owe something to both these kinds of greatness; but as they are of a different nature, we owe them likewise different respect. To the greatness of institution we owe the respect of institution, that is, certain external ceremonies which should be nevertheless accompanied, in conformity with reason, with an internal recognition of the justice of this order, but which do not make us conceive any real quality in those whom we honor after this manner. It is necessary to speak to kings on the bended knee, to remain standing in the presence-chamber of princes. It is a folly and baseness of spirit to refuse to them these duties.

But as for the natural homage whuh consists in esteem, we 
owe it only to natural greatness; and we owe, on the contrary, contempt and aversion to qualities eontrary to this natural greatness. It is not necessary, because you are a duke, that I should esteem you; but it is neecssary that I should salute you. If you are a duke and a gentleman, I shall render what I owe to both these qualities. I shall not refuse you the ceremonies that are neerited by your quality of duke, nor the esteem that is merited by that of a gentleman. But if you were a duke without being a gentleman, I should still do you justice; for in rendering you the external homage which the order of men has attached to your birth, I should not fail to have for you the internal contempt that would be merited by your baseness of mind.

Therein eonsists the justice of these duties. And the injustice consists in attaching natural respeet to greatness of condicion, or in exacting respeet of condition for natural greatness. M. N.... is a greater geometrician than I; in this quality, he wishes to take precedenee of me: I will tell him that he understands nothing of the matter. Geometry is a natural greatness; it demands a preference of esteem; but men have not attached to it any external preferenee. I shall, there. fore, take precedence of him, and shall esteem him greater than I in the quality of geometrician. In the same manner, if, being duke and peer, you would not be contented with my standing uncovered before you, but should also wish that I should esteem you, I should ask you to show me the qualities that merit my esteem. If you did this, you would gain it, and I could not refuse it to you with justice; but if you did not do it, you would be unjust to demand it of me; and assuredly you would not succeed, were you the greatest prince in the world.

\section{III.}

I wish, sir, to make known to you your true condition; for nis is the thing of all others of which persons of your elass are the most ignorant. What is $\mathrm{it}$, in your opinion, to be a great nobleman? It is to be master of several objects that 
men covet, and thus to be able to satisfy the wants and the desires of many. It is these wants and these desires that attract them towards you, and that make them submit to you : were it not for these, they would not even look at you; but they hope, by these services, and this deference which they render you, to obtain from you some part of the good which they desire, and of which they see that you have the disposal. God is surrounded with people full of love who demand of him the benefits of love which are in his pawer: thus he is properly the king of love. You are in the same manner surrounded with a small circle of persons, over whom you reign in your way. These men are full of desire. They demand of you the benefits of desire; it is desire that binds them to you. You are therefore properly the king of desire. Your kingdom is of small extent; but you are equal in this to the greatest kings of the earth : they are like you the sovereigns of desire. It is desire that constitutes their power; that is the possession of things that men covet.

But while knowing your natural eondition, avail yourself of the means that it gives you, and do not pretend to rule by a different power than by that which makes you king. It is not your strength and your natural power that subjects all these people to you. Do not pretend then to rule them by force or to treat them with harshness. Satisfy their reasonable desires; alleviate their necessities; let your pleasure consist in being beneficent; adrance them as much as you can, and you will act like the true king of desire.

What I tell you does not go very far; and if you stop there you will not save yourself from being lost; but at least you will be lost like an honest man. There are some nen who expose themselves to damnation so foolishly by avarice, by brutality, by debauches, by violence, by excesses, by blasphemies ! The way which I open to you is doubtless the most honorable; but in truth it is always a great folly for a man to expose himself to damnation; and therefore he must not stop at this. He must despise desire and its kingdom, and aspire to that kingdom of !:ve in which all the subjects breathe nothing but love, 
and desire nothing but the benefits of love. Others than I will show you the way to this; it is sufficient for me to have turned you from those gross ways into which I see many persons of your condition suffer themselves to be led, for want of knowing the true state of this condition.

\section{ON THE CONVERSION OF THE SINNER.'}

TIIE first thing with which God inspires the soul that he deigus to touch truly, is a knowledge and most extraordinary insight by which the soul considers things and herself in a manner wholly new.

This new light gives her fear, and brings her a trouble that

1 Father Guerrier, who has preserved to us this fragment, says that he knows not whose this writing $i s$. In another collection, it is attributed to Jaequeline Pascal. Bossut, who was the first to publish it, aseribes it to the author of the Thoughts. MM. Faugère and Havet are of the opinion of Bossut.

"It is indeed," says M. Faugère, "the thought and style of Pascal, not, it is true, in his most mature and loftiest manner, but in that already so powerful before the Provinciales; for this fragment must have been coun posed in 1647 or 1648, when Pascal had just entered, at the age of twentythree or twenty-four, that phase of his life that may be called his first conversion ; these pages express the peculiar sentiments of his soul."

M. Havet is not, in respect to the date at which this fragment was written, of the opinion of M. Faugère: "It seems to me that Pascal o $\mathbf{-}$ presses here what passed in his soul during that eritical time of his lite in which was laboriously accomplished his great and last conversion, that is during the year $1654 \ldots$.

"There is a letter from Jacqueline to Madame Périer, of January 25, 1655 , in which she gives the history of the conversion of her brother, and this is what this letter contains: "He came to see me [about the end of September, 1654] and in this visit he opened himself to me in a manner that moved me to pity, confessing to me that in the midst of his occupations, which were grear, and among all the things that could contribute to make him love the world, and to which there was reason to believe him strongly attached, he was to such a degree solicited to quit all these, both by the extreme aversion that lie had to the follies and amusements of the world, and by the continual reproach that his conscience made him, that he tound himself detached from every thing to a degree that he had never been before, or any thing approaching to it; but that he was besides so greath 
penetrates the repose which she found in the things that made her delights.

She can no longer relish with tranquillity the things that charmed her. A continual scruple opposes her in this enjoyment, and this internal sight causes her to find no longer this accustomed sweetness among the things to which she abandoned herself with a full effusion of heart.

But she finds still more bitterness in the exercises of piety than in the vanities of the world. On one side, the vanity of the visible objects interests her more than the hope of the invisible, and on the other the solidity of the invisible interests her more than the vanity of the visible. And thus the presence of the one and the solidity of the other dispute her affection, and the vanity of the one and the absence of the other excite her aversion; so that a disorder and confusion spring up

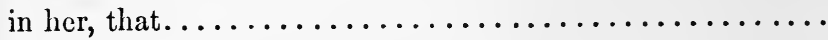

She considers perishable things as perishable and even already perished; and in the certain prospect of the annihilation of every thing that she loves, she is terrified by this consideration, in seeing that each moment snatches from her the enjoyment of her good, and that what is most dear to her glides away at every moment, and that finally a certain day will come in which she will find herself stripped of all the things in which she had placed her hope. So that she comprehends perfectly that her heart being attached only to vain

estranged from the side of God that he felt no attraction to it; etc. Is not what Jacqueline relates precisely the same that is depicted by Pascal ?"

As to M. Cousin, he is of an opinion contrary to MM. Faugère and Havet: "Bossut," says he "was the first to publish a fragment on the con version of the sinver. This fragment is found in the Mémoires of Mi.demoiselle Périer with the following ncte: "This writing has been transcribed from a copy which is among the papers left by Mademoiselle Périer. The blanks are found in it as they are marked. The name of the author is not there. I believe it to have been by Mademoiselle Pascal before she became a nun.' We meline to the opinion of the author of this note. The style of the fragment is very fine; it has elevation, and even strength, but not that internal velemence that marks the most trifling words of Pascal." 
and fragile things, her soul must be left alone and forsaken on quitting this life, since she has not taken care to unite herself to a true and self-subsisting good which could sustain her both during and after this life.

Thence it comes that she begins to consider as nothingness all that must return to nothingness, - the heavens, the earth, her spirit, her body, her relatives, her friends, her enemies, wealth, poverty, disgrace, prosperity, honor, ignominy, esteem, contempt, authority, indigence, health, sickness, life itself. In fine, all that is less durable than her soul is incapable of satisfying the desire of this soul, which seeks carnestly to establish itself in a felicity as durable as herself.

She begins to be astonished at the blindness in which she has lived, and when she considers, on the one hand, the long time that she has lived without making these reflections, and the great number of people who live in the same way, and, on the other hand, how certain it is that the soul, being immortal as she is, cannot find her felicity among perishable things which will be taken away from her, at all events, by death, she enters into a holy confusion and an astonishment that brings to her a most salutary trouble.

For she considers that, however great may be the number of those who grow old in the maxims of the world, and whatever may be the authority of this multitude of examples of those who place their felicity in this world, it is nevertheless certain that, even though the things of the world should have some solid pleasure, which is recognized as false by an infinite number of fearful and continual examples, it is inevitable that we shall lose these things, or that death at last will deprive us of them; so that the soul having amassed treasures of temporal goods, of whatever nature they may be, whether gold, or science, or reputation, it is an indispensable necessity that she shall find herself stripped of all these objects of her felicity; and that thus, if they have had wherewith to satisfy her, they will not always have wherewith to satisfy her; and that, if it is to procure her. solf a real happiness, it is not to promise herself a very durable happiness, since it must be limited to the course of this life. 
So that, by a holy humility which God exalts above pride, she begins to exalt herself above the generality of mankind: she condemns their conduct, she detests their maxims, she bewails their blindness; she devotes herself to the search for the true good; she comprehends that it is necessary that it should have the two following qualities : the one that it shall last as long as herself, and that it cannot be taken away from her except by her consent, and the other that there shall be nothing more lovely.

She sees that in the love she has had for the world, she found in it this second quality in her blindness; for she perceived nothing more lovely. But as she docs not see the first in it, she knows that it is not the sovereign good. She secks it, therefore, elsewhere, and knowing by a pure light that it is not in the things that are within her, or without her, or before her (in nothing, therefore, within or around her), she begins to soek it above her.

This elevation is so eminent and so transcendant that sho does not stop at the heavens, - - they have not wherewith to satisfy her,-nor above the heavens, nor at the angels, nor at the most perfect beings. She passes throngh all created things, and cannot stop her heart until she has rendered herself up at the throne of God, in which she begins to find her repose and that good which is such that there is nothing more lovely, and which cannot be taken away from her exeept by her own consent.

For although she does not feel those charms with which God recompenses continuance in piety, she comprehends, nevertheless, that created things cannot be more lovely than their Creator; and her reason, aided by the light of grace, makes her understand that there is nothing more lovely than God, and that he can only be taken away from those who reject him, since to possess him is only to desire him, and to refuse him is to lose him.

Thus she rejoices at having found a good which cannot be wrested from her so long as she shal' desire it, and which has nothing above it. 
And in these new reflections she enters into sight of the grandeur of her Creator, and into humiliations and profound adorations. She becomes, in consequence, reduced to nothing and being unable to form a base enough idea of herself, or to conceive an exalted enough idea of this sovereign good, she makes new efforts to abase herself to the lowest abysses of nothingness, in considering God in the immensities which she multiplies without ceasing. In fine, in this conception, which exhausts her strength, she adores him in silence, she considers hersel: as his vile and useless creature, and by her reiterated homage adores and blesses him, and wishes to bless and to adore him forever. Then she acknowledges the grace which he has granted her in manifesting his infinite majesty to so vile a worm; and after a firm resolution to be eternally grateful for it, she becomes confused for having preferred so many vanities to this divine master; and in a spirit of compunction and penitence she has recourse to his pity to arrest his anger, the effect of which appears terrible to her. In the sight of these immensities ............................

"She makes ardent prayers to God to obtain of his mercy that, as it has pleased him to discover himself to her, it may please him to conduct her to him, and to show her the means of arriving there. For as it is to God that she aspires, she aspires also only to reach him by means that come from God himself, because she wishes that he himself should be her path, her object, and her final end. After these prayers, she begins to act, and seeks among these .....................

She begins to know God, and to desire to reach him; but as she is ignorant of the means of attaining this, if her desire is sincere and true, she does the same as a person who, desiring to reach some place, having lost his way, and knowing his aberration, would have recourse to those who knew this way

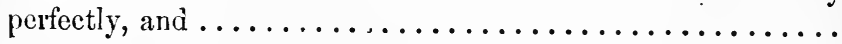

She resolves to conform to his will during the remainder of her life; but as her natural weakness, with the habit that she has of the sins in which she has lived, have reduced her to the 
Impotence of attaining this felicity, she implores of his mercy the means of reaching him, of attaching herself to him, of

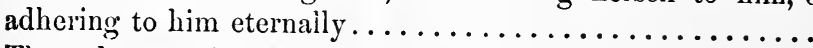
Thus she perceives that she should adore God as a creature, render thanks to him as a debtor, satisfy him as a criminal, and pray to him as one poor and needy.

\section{CONVERSATION OF PASCAL}

WITH M. DE SACI

\section{ON EPICTETUS AND MONTAIGNE.1}

"M. Pascal came, too, at this time, to live at Port-Royal des Champs. I do not stop to tell who this man was, whom not only all France, but all Europe admired; his mind always acute, always active, was of an extent, an elcvation, a firmness,

1 This chapter, says M. Cousin, is a debris of a conversation that took place at Port-Royal between Saci and Paseal several years before the Provinciales. The secretary of Saei, Fontaine, who was present at this conversation, recounts it in tome ii, of his Mémoires, printed at Utrecht in 1730. Before the appearanee of these mémoires, Father Desmolets, librarian of the Oratoire, had aceess to them, and extracted from them this conversation, which he published in the Mémoires de littérature et d'histoire, t. v, 1728 .

"' 'It must be,' wrote the Abbé d'Etemare to Margnerite Périer, in 1731, "that this conversation of M. Paseal with M. de Saei was put in writing" on the spot by M. Fontaine. It is indubitably M. Fontaine's in style, but it bears, in substanee, the charaeter of M. Pascal to a point that If. Fonaine eould not imitate.' Bossut has had the mistaken idea of putting this conversation, like the Discourses on the Condition of the Great, among the Thoughts, which it preceded several years, since it was anterior to the Provincial Letters themselves; and to introdnce it there, he has mutilated and disfigured it; he has suppressed the form of a dialogue, taken away all that Saei said, and only retained what was spoken by Paseal; then, to bind together these disjointed fragments and make of them a whole, he was foreed to put in links of his own composition. Still more: Bossut finds that Pascal speaks sometimes a little too much at length through the mouth of the good Fontaine, and then he suppresses all that appears to him 'anguishing; sometimes, on the contrary he adds to Fontaine and elaborates him; oftenest, he breaks up and decomposes his long scntences, and 
a penctration, and a clearness exceeding any thing that can be believed. . . . This admirable man, being finally moved by God, submitted this lofty mind to the yoke of Jesus Christ, and this great and noble heart embraced penitence with humility. He came to Paris to throw himself into the arms of M. Singlin, resolved to do all that he should order him. M. Singlin thought, on seeing this great genius, that he should do well to send him to Port-Royal des Champs, where M. Arniuld would cope with him in the scienees, and where M. de Saci would teach him to despise them. He came therefore to live at Port-Foyal. M. de Saci conld not courteously aroid seeing him, especially having been urged to it by M. Singlin; but the holy enlightenment which he found in the Scripture and in the Fathers made him hope that he would not be dazzled by all the brillianey of M. Pascal, which nevertheless charmed and carried away all the world. IIe found in fact all that he said very just. He acknowledged with pleasure the strength of his mind and conversation. All that M. Pascal said to inim that was remarkable he had seen before in St. Augustine, and doing justice to every one, he said: 'M. Pascal is extremely estimable in that, not having read the Fathers of the Church, he has of himself, by the penetration of his mind, found the same truths that they had found. $\mathrm{He}$ finds them surprising, he says, because he has not found them in any place; but for us, we are accustomed to see them on every side in our books.' Thus, this wise ecclesiastic, finding that the ancients had not less light than the moderns, held to

Ifraces the logical and argumentative forms of the language of the seveneenth century."

As a matter of course, we give here the conversation in all its integrity. Only we do not follow the text of Fontaine, but that of Father Desmolets, which appears to ns, as is also the opinion of Havet, the most preferable; this is explained by the cireumstance that Father Desmolets, in 1728, reproduced almost integrally the MS. of Fontaine, whilst the editors of the latter, on printing this MS. in 1736, made numerous changes therein. [See on this fragment, Sainte-Benve, Port-Royal, t. ii, p. 369.-Cousin, Des Pensées de Pascal, Paris, 1843, in 8vo, p. 29 and follcwing.--Havet cxxiii.] 
them, and esteemed M. Pascal greatly because he agreea in all things with St. Augustine.

"The usual way of M. de Saci, in conversing with people, was to adapt his conversation to those with whom he was talking. If he met, for example, M. Champagne, he talked with him of painting. If he met M. Hamon, he talked with him of medicine. If he met the surgeon of the place, he questioned him on surgery. Those who cultivated the vine, or trees, or grain, told him all that was remarkable about them. Every thing served to lead him speedily to God and to lead other there with him. He thought it his duty therefore to put M. Pascal in his province, and to talk with him of the philosophical readings with which he had been most occupied. He led him to this subject in the first conversations that they had together. M. Pascal told him that his two most familiar books had been Epictetus and Montaigne, and highly enlogized these two minds. M. de Saci, who had always thought it a duty to read but little of these two authors, entreated M. Paseal to speak of them to him at length."

"Epictetus," says he, "is among the philosophers of the world who have best understood the duties of man. IIe requires, before all things, that he should regard God as his principal object; that he should be persuaded that he governs every thing with justice; that he should submit to him checrfully, and that he should follow him voluntarily in every thing, as doing nothing except with the utmost wisdom: as thus this disposition will check all complaints and murmurs, and will prepare his mind to suffer tranquilly the most vexatious events. Never say, says he, I have lost this; say rather, I have restored it. My son is dead, I have restored him. My wife is dead, I have restored her. So with property and with every thing else. But he who has deprived me of it is a wicked man, you say. Why does it trouble you by whom the one who has lent it to you demands it of you again? While he permits you the use of it, take care of it as property belonging to another, as a man who is travelling would do in an inn. You ought not, says he, to desire that things sliculd be done as you wish, but 
you ought to wish that they should be done as they are done. Remember, says he elsewhere, that you are here as an actor. and that you play the part in a drama that it pleases the manager to give you. If he gives you a short one, play a short one; if he gives you a long one, play a long one; if he wishes you to feign the beggar, you should do it with all the simplicity possible to you; and so with the rest. It is your business to play well the part that is given you ; but to choose it is the business of another. Have every day before your eyes death and the evils which seem the most intolerable; and you will never think of any thing lower and will desire nothing with excess.

"Ile shows, too, in a thousand ways what man should do. He requires that he should be humble, that he should conceal his good resolutions, especially in the beginning, and that he should accomplish them in secret: nothing destroys them more than to reveal them. He never tires of repeating that the whole study and desire of man should be to perceive the will of God and to pursue it.

"Such, sir, said M. Paseal to M. de Saci, was the enlightenment of this great mind that so well understood the duties of man. I dare say that he would have merited to be adored if he had also known his impotence as well, since it is necessary to be a god to teach both to men. Thus as he was clay and ashes, after having so well eomprehended what was due, behold how he destroys himself in the presumption of what ean be done. He says that God has given to every man the means of acquitting himself of all his obligations; that these means are always in our power; that we must seek felicity through the things that are in our power, since God has given them to us for this end: we must see what there is in us that is free; that wealth, life, esteem, are not in our power, and therefore do not lead to God; but that the mind eannot be forced to believe what it knows to be false, nor the will to love what it knows will render it unhappy; that these two powers are therefore free, and that it is through them that we cap render ourselves perfect; that man can by these powers ver. 
fectly know God, love him, obey him, please him, cure himself of all his vices, acquire all the virtues, render himself holy, and thus the companion of God. These principles of a diabolic pride lead him to other errors, as that the soul is a portion of the divine substance; that sorrow and death are not evils; that one may kill himself when he is persecuted to such a degree that he has reason to believe that God calls him, and others.

"As for Montaigne, of whom you wish too, sir, that I should speak to you, being born in a Christian State, he made profession of the Catholic religion, and in this there was nothing peculiar. But as he wished to discorer what morals reason would dictate without the light of faith, he based his principles upon this supposition; and thus, considering man as destitute of all revelation, he discourses in this wise. IIe puts all things in a universal doubt, so generai that this doubt bears away itself, that is whether he doubts, and even doubtirg this latter proposition, his uncertainty revolves upon itself in a perpetual and restless cirele, alike opposed to those who affirm that every thing is uncertain and to those who affirm that every thing is not so, because he will affirm nothing.' It is in this doubt which doubts itself, and in this ignorance which is ignorant of itself, and which he calls his master-form, that

1 Does not Pascal abuse here the power of his imagination, to impose on our weakness by the energy of words? What is this phantom of incredulity which he takes pleasure in eonjuring up in order to crush it easily beneath the weight of his invincible eloquence? where ean he then find in the avowals of so ingenious and so modest a philosopher, that incorrigible Pyrrhonist, pursued by doubt even into his doubt itself, and exclianging follies without being able to eure them. Montaigne never doubted either of God or of virtue ... . Hc finds in the nature of man terrible difliculties and inserutable mysteries; he looks with pity upon the error of our reason, the weakness and the uncertainty of our understanding he affects sometimes to level us with the brutes; ond then Paseal approves him ... Why then, Pareal, did you exculpate yourself just now to a sage for distrusting this reason which you yourselt acknowledge as so weak and so deecitful? Do you now wish to .ead him through impotence of thinking to the necessity of belicving, and does it seem to you that there is need of snatehing from him the torch of reason in order to precipitate him into faith?-Villemain. 
lies the essence of his opinion, which he was unable to ex. press by any positive term. For if he says that he doubts, he betrays himself in affirming at least that he doubts; which being formally against his intention, he could only explain it by interrogation; so that, not wishing to say: "I do not know," he says: "What do I know?" Of this he makes his device, placing it under the scales which, weighing contradictories, are found in perfect equilibrium : that is, it is pure Pyrrhonism. Upon this principle revolve all his discourses and all his essays; and it is the only thing that he pretends really to establish, although he does not always point out his intention. He destroys in them insensibly all that passes for the most certain among men, not indeed to establish the contrary with a certainty to which alone he is the enemy, but merely to show that, appearances being equal on both sides, one knows not where to fix his belief.

"In this spirit he jests at all affirmations; for example, he combats those who have thought to establish in France a great remedy against lawsuits by the multitude and the pretended justice of the laws: as if one could cut off the root of the doubts whence arise these lawsuits, and as if there were dikes that could arrest the torrent of uncertainty and take conjectures captive! Thus it is that, when he says that he would as soon submit his cause to the first passer-by as to judges armed with such a number of ordinances, he does not pretend that we should change the order of the State,- -he has not so much ambition; nor that lis advice may be better,- he believes none good. It is only to prove the vanity of the most received opinions; showing that the exclusion of all laws would rather diminish the number of disputants whilst the multiplicity of laws serves only to increase them, since difficulties grow in proportion as they are weighed; since obscurities are multiplied by commentaries; and since the surest way to understand the meaning of a discourse is not to examine it, and to take it on the first appearance: as soon as it is serutin. ized, all its clearness becomes dissipated. In the like manner be judges by chance of all the acts of men and the points o' 
history, sometimes in one way, sometimes in another, freely following his first impression, and, without constraining his thought by the rules of reason, which has only false measures, he delights to show, by his example, the eontrarieties of the same mind." In this free genius, it is alike equal to him to get the better or not in the dispute, having always, by either example, a means of showing the weakness of opinions; being sustained with so mueh advantage in this universal doubt, that he is strengthened in it alike by his triumph and his defeat.

"It is from this position, floating and wavering as it is, that he combats with an invincible firmness the heretics of his times in respect to their affirmation of alone knowing the true sense of the Seripture; and it is also from this that he thunders forth most vigorously against the horrible impiety of those who dare to affirm that God is not. He attacks them especially in the apology of Raimond de Sebonde; and finding them voluntarily destitute of all revelation, and abandoned to their natural intelligence, all faith set aside, he demands of them upon what authority they undertake to judge of this sovereign Being who is infinite by his own definition, they who know truly none of the things of nature! He asks them upon what principles they rest; he presses them to show them. He examines all that they can produce; and penetrates them so deeply, by the talent in which he excels, that he demonstrates the vanity of all those that pass for the firftest and the most natural. He asks whether the soul knows any thing; whether she knows herself; whether she is sub. stance or accident, body or spirit, what is each of these things, and whether there is any thing that does not belong to one of these orders; whether she knows her own body, what is matter, and whether she can discern among the innumerable variety of bodies from which it is produced; how she can reason if she is material; and how she ean be united to a par. tieular body and feel its passir'ns if she is spiritual: when she commenced to be? with the body or before? and whether she will end with it or not; whether she is never mistaken; whether she knows when she errs, seeing that the essence of 
contempt consists in not knowing it; whether in her obscurity she does not believe as firmly that two and three make six as she knows afterwards that they make five; whether animals reason, think, talk; and who can determine what is time, what is space or extent, what is motion, what is unity, what are all the things that surround us and are wholly inexplicable to us; what is health, sickness, life, death, good, evil, justice, sin, of which we constantly speak; whether we have within us the principles of truth, and whether those which we believe, and which are called axioms or common notions, because they are common to all men, are in conformity with the essential truth. And since we know but by faith alone that an all-good Being has given them to us truly in creating us to know the truth, who can know without this light whether, being formed by clianec, they are not uncertain, or whether, being formed by a lying and malicious being, he has not given them to us falsely in order to lead us astray? Showing by this that God and truth are inseparable, and that if the one is or is not, if it is certain or uncertain, the other is necessarily the same. Who knows then whether the common-sense, that we take for the judge of truth, can be the judge of that which has created it? Besides, who knows what truth is, and how can we be sure of having it without understanding it? Who knows even what is being, which it is impossible to define, since there is nothing more general, and sinee it would be necessary at first, to explain it, to use the word itself: It is being ...? And since we know not what is soul, body, time, space, motion, truth, good, nor even being, nor how to explain the idea that we form within ourselves, how can we assure ourselves that it is the same in all men, seeing that we have no other token than the uniformity of consequences, which is not always a sign of that of principles; for they may indeed be very different, and lead nevertheless to the same conclusions, every one knowing that the true is often inferred from the false.

"Lastly, he examines thus profoundly the sciences, both geometry, of which he shows the uncertainty in the axioms and the terms that she does not define, as centre, motion, etc. 
physics in many more ways, and medicine in an infinity of methods; history, polities, etkics, jurisprudence, and the rest. So that we remain convinced that we think no better at present than in a dream from which we shall wake only at death, and during which we have the principles of truth as little as during natural sleep. It is thus that he reproaches reason divested of faith so strongly and so cruelly that, making her doubt whether she is rational, and whether animals are so or not, or in a greater or less degree, he makes her descend from the excellence which she has attributed to herself, and places her through grace on a level with the brutes, without permitting her to quit this order until she shall have been instructed by her Creator himself in respect to her rank, of which she is ignorant; threatening, if she grumbles, to place her beneath every thing, which is as easy as the opposite, and nevertheless giving her power to act only in order to remark her weakness with sincere humility, instead of exalting herself by a foolish insolence."

"M. de Saci, fancying himself living in a new country, and listening to a new language, repeated to himself the words of St. Augustine: O God of truth! are those who know these subtleties of reasoning therefore more pleasing to thee? He pitied this philosopher who pricked and tore himself on every side with the thorns that he formed, as St. Augustine said of bimself when he was in this state. After some meditation, he said to M. Pascal :

"I thank you, sir; I am sure that if I had read Montaigno a long time, I should not know him so well as I do, since the conversation that I have just had with you. This man should wish that he might never be known, except by the recitals that you make of his writings; and he might say with St. Augustine: Ibi me vide, attende. I believe assuredly that this man had talent; but I know not whether you do not lend to Sim a little more than he had, by the logical chain that you make of his principles. You can judge that, having passed my life as I have done, I have had little counsel to read this nuthor, the works of whom had nothing of that which we 
ought chiefly to seek in our reading, according to the rule of St. Augustine, because his works do not appear to proceed from a solid basis of humility and piety. We should forgive those philosophers of former times who styled themselves academicians, for putting every thing in doubt. But what need had Montaigne to divert the mind by reviving a doctrine which passes now in the eyes of Christians for a folly? This is the judgment that St. Augustine passes on these persons. For we can say after him of Montaigne: He sets faith aside in every thing that he says; therefore we, who have faith, should set aside every thing that he says. I do not blame the talent of this author, which was a great gift from God; but he might have used it better, and made a sacrifice of it to God rather than to the devil. What avails a blessing when one uses it so ill ? Quid proderat, etc., said this holy doctor of him before his conversion. You are fortunate, sir, in having raised yourself above these people, who are called doctors, who are plunged in drunkenness, but whose hearts are void of truth. God has poured out into your heart other sweets and other attractions than those which you find in Montaigne. He has recalled you from that dangerous pleasure, a jucunditate pestifera, says St. Augustine, who renders thanks to God that he has forgiven him the sins which he had committed in delighting too much in vanity. St. Augustine is so much the more credible in this that he held formerly the same sentiments; and as you say of Montaigne that it is through universal doubt that he combats the hereties of his times, so through this same doubt of the academicians, St. Augustine forsook the heresy of the Manicheans. As soon as he belonged to God, he renounced these vanities, which he calls sacrileges. He perceived with what wisdom St. Paul warned us not to suffer ourselves to be seduced by these discourses. For he acknowledges that there is in them a certain harmony which fascinates: we sometimes believe things true only because they are narrated eloquently. Those are dangerous viands, says he, that are served up in fine dishes; but these viands, instead of nourishing the heart, starve st. We then resemble men who sleep, and who fancy that 
they eat while sleeping: these imaginary viands leave them as enipty as they were before.

“M. de Saci made several similar remarks to M. Pascal : whereupon M. Pascal said to him, that if he omplimented bim on thoroughly possessing Montaigne, and of knowing how to construe him well, he could tell him without flattery that he understood St. Augustine mueh better, and that he knew how to construe him much better, though little to the advantage of poor Montaigne. He expressed himself as being extremely edified by the solidity of all that he had just represented to him; nevertheless, being full of his author, he could not contain himself, and thus continued:

"I acknowledge, sir, that I cannot see without joy in this author proud reason so irresistibly baftled by its own weapons, and that fierce contention of man with man, which, from the companionship with God, to which he had exalted himself by maxims, hurls him down to the nature of brutes; and I should have loved with all my heart the minister of so great a vengeance, if, being a disciple of the Church by faith, he had followed the rules of ethics, in bringing men whom he had so usefully humiliated, not to irritate by new crimes him who alone can draw them from the crimes which he has convicted them of not being able even to know.

"But he acts on the contrary like a heathen in this wise. On this principle, says he, outside of faith every thing is in uncertainty, and considering how much men seek the true and the good without making any progress towards tranquillity, he concludes that one should leave the care of them to others; and remain nevertheless in repose, skimming lightly over sucjects for fear of going beyond one's depth in them; and take the true and the good on first appearances, without dwelling on them, for they are so far from being solid that if one grasps them ever so lightly, they will s'ip through his fingers and leave them empty. For this reas on he follows the evidence of the senses and common-sense, because he would be obliged to do violence to himself to contradict them, and because he knows not whether he would gain by it, ignorant as to where 
the truth is. So he shuns pain and death, because his instinct impels him to it, and because he will not resist for the same reason, but without concluding thence that these may be the real evils, not confiding too much in these natural emotions of fear, seeing that we feel others of pleasure which are accused of being wrong, although nature speaks to the contrary. Thus there is nothing extravagant in his conduct; he acts like the rest of mankind, and all that they do in the foolish idea that they are pursuing the true good, he does from another principle, which is that probabilities being equan on either side, ex ample and convenience are the counterpoises that decide him.

"IIe mounts his horse like a man that is not a philosopher, because he suffers it, but without believing that this is his right, not knowing whether this animal has not, on the contrary, the right to make use of him. IIe also does some violence to himself to avoid certain vices; and he even preserves fidelity to marriage on account of the penalty that follows irregularities; but if the trouble that he takes exceeds that which he avoids, it does not disturb him, the rule of this action being convenience and tranquillity. He utterly rejects therefore that stoical virtue which is depicted with a severe mien, fierce glance, bristling locks, and wrinkled and moist brow, in a painful and distorted posture, far from men, in a gloomy silence, alone upon the summit of a rock : a phantom, he says, fit to frighten children, and which does nothing else with continual effort than to seek the repose which it never attains. His own is simple, familiar, pleasant, playful, and as we may say sportive: she follows whatever charms her, and toys negligently with good and bad accidents, reclining effeminately in the bosom of a tranquil indolence, from which she slows to those who seek felicity with so much toil that it is only there where she is reposing, and that ignorance and incuriosity are soft pillows for a well-balanced head, as he himrelf has said.

"I cannot conceal from you, sir, that in reading this author and comparing him with Epictetus, I have found that they are assuredly the two greatest defenders of the two most celebrated 
sects of the world, and the only ones conformable to reason, since we can only follow one of these two roads, namely: either that there is a God, and then we place in him the sovereign good; or that he is uncertain, aud that then the true good is also uncertain, since he is incapable of it. I have taken extreme pleasure in remarking in these different reasonings wherein both have reached some conformity with the true wisdom which they have essayed to understand. For it it is pleasing to observe in nature her desire to paint God in all his works, in which we see some traces of him because they are his images, how much more just is it to consider in the productions of minds the efforts which they make to imitate the essential truth, even in shumning it, and to remark wherein they attain it and wherein they wander from it, as I have endeavored to do in this study.

"It is true, sir, that you have just shown me, in an admirable manner, the little ntility that Christians can draw from these philosophic studies. I shall not refrain however, with your permission, from telling you still further my thoughts on the subject, ready, however, to renounce all light that does not come from you, in which I shall have the advantage either of having encountered truth by good fortune or of receiving it from you with certainty. It appears to me that the source of the errors of these two sects, is in not having known that the state of man at the present time differs from that of his creation; so that the one, remarking some traces of his first greatness and being ignorant of his corruption, has treated nature as sound and without need of redemption, which leads him to the height of pride; whilst the other, feeling the present wretchedness and being ignorant of the original dignity, treats nature as necessarily infirm and irreparable, which precipitates it into despair of arriving at real good, and thence into extreme laxity. Thus these two states which it is necessary to know together in order to see the whole truth, being known separately, lead necessarily to one of these two vices, pride or indolence, in which all men are invariably before grace, since if they do not remain in their disorders 
through laxity, they forsake them through vanity, so true is that which you have just repeated to me from St. Augustine, and which I find to a great extent; for in fact homage is rendered to them in many ways.

"It is therefore from this imperfect enlightenment that it happens that the one, knowing the duties of man and being ignorant of his impotence, is lost in presumption, and that the other, knowing the impotence and being ignorant of the duty, falls into laxity; whence it seems that since the one leads to truth, the other to error, there would be formed from their alliance a perfect system of morals. But instead of this peace, nothing but war and a general ruin would result from their union ; for the one establishing certainty, the other doubt, the one the greatness of man, the other his weakness, they would destroy the truths as well as the falsehoods of each other. So that they cannot subsist alone because of their defects, nor unite because of their opposition, and thus they break and destroy each other to give place to the truth of the Gospel. This it is that harmonizes the contrarieties by a wholly divine act, and uniting all that is true and expelling all that is false, thus makes of them a truly celestial wisdom in which those opposites accord that were incompatible in human doctrines. And the reason of this is, that these philosophers of the world place contrarieties in the same subject; for the one attributed greatness to nature and the other weakness to this same nature, which could not subsist; whilst faith teaches us to place them in different subjects: all that is infirm belonging to nature, all that is powerful belonging to grace. Such is the marvellous and novel union which God alone could teach, and which he alone could make, and which is only a type and an effect of the ineffable union of two natures in the single person of a Man-God.

si I ask your pardon, sir, said M. Paseal to M. de Saci, for bcing thus carried away in your presence into theology, instead of remaining in philosophy, which alone was my subject; but I was led to it insensibly; and it is difficult not to enter upon It whatever truth may be discussed, because it is the centre of 
all the truths; which appears here perfectly, since it so obviously includes all those that are found in these opinions. Thus I do not see how any of them could refuse to follow it. For if they are full of the idea of the greatness of man, what have they imagined that does not yield to the promises of the Gospel, which are nothing else than the worthy price of the death of a God? And if they delighted in viewing the infirmities of nature, their ideas do not equal those of the rcal weakness of sin, of which the same death has been the remedy. Thus all find in it more than they have desired; and what is marvellous, they who could not harmonize in an infinitely inferior degree, then find themselves in unison!"

"M. de Saci could not refrain from testifying to M. Pascal that he was surprised to see how well he knew how to interpret things; but he acknowledged at the same time that every one had not the secret of making on these readings such wise and elevated reflections. He told him that he was like those skilful physicians, who by an adroit method of preparing the most deadly poisons knew how to extract from them the most efficacious remedies. He added, that though he saw clearly, from what he had just said, that these readings were useful to him, he could not beiieve however that they would be advantageous to many people of slow intellect, who would not have elevation of mind enough to read these authors and judge of them, and to know how to draw pearls from the midst of the dunghill, aurum ex stercore, as said one of the Fathers. This could be much better said of these philosophers, the dunghill of whom, by its black fumes, might obscure the wavering faith of those who read them. For this reason he would always counsel such persons not to expose themselves lightly to these readings, for fear of being destroyed with these philosophers, and of becoming the prey of demons and the food of worms, according to the language of the Scripture, as these philosophers have been."

" $A$ s to the utility of these readings, said M. Pascal, I will tell you simply my tho'aght. I find in Epictetus an incomqarable art for troubling the repose of those who seek it in ex. 
ternal things, and for forcing them to acknowledge that they are veritable slaves and miserable blind men; that it is impossible that they should find any thing else than the error and pain which they fly, unless they give themselves without reserve to God alone. Montaigne is incomparable for confounding the pricle of those who, outside of faith, pique themselves in a genuine justice; for disabusing those who cling to their opinions, and who think to find in the sciences impregnable truths; and for so effectually convicting reason of its want of light and its aberrations, that it is difficult, when one makes a good use of its principles, to be tempted to find repugnance in mysteries; for the mind is so overwhelmed by him, that it is far from wishing to judge whether the Incarnation or the inystery of the Eucharist are possible; which the generality of mankind discuss but too often.

"But if Epictetus combats indolence, he leads to pride, so that he may be very injurious to those who are not persuaded of the corruption of the most perfect justice which is not from faith. And Montaigne is absolutely pernicious to those who have any leaning to impiety or vice. For this reason these readings should be regulated with much care, discretion, and regard to the condition and disposition of those to whom they re counselled. It seems to me only that by joining them together they would not succeed ill, since the one is opposed to the evil of the other : not that they could bestow virtue but only disturb vice; the soul finding itself combated by contrarieties, the one of which expels pride and the other indolence, and being unable to be tranquil in any of these vices by their reasonings, or to shun them all."

"It was thus that these two persons of so fine an intellect agreed at last upon the subject of the reading of these philosophers, and met at the same goal, which they reached however by a somewhat different method; M. de Saci arriving there at once through the clear views of Christianity, and M. Pascal reaching it only after many turns by clinging to the principles of these philosophers." 


\section{THE ART OF PERSUASION.'}

TuE art of persuasion has a necessary relation to the manner in which men are led to consent to that which is proposed to them, and to the conditions of things which it is sought to make them believe.

No one is ignorant that there are two avenues by which opinions are reeeived into the soul, which are its two principal powers: the understanding and the will. The more natural is that of the understanding, for we should never consent to nny but demonstrated truths; but the more eommon, though the one contrary to nature, is that of the will; for all men are almost always led to believe not by proof, but by attraction This way is base, ignoble, and irrelevant : every one therefore disavows it. Each one professes to believe and even to love nothing but what he knows to be worthy of belief and love.

I do not speak here of divine truths, which I shall take eare not to comprise under the art of persuasion, because they are,

1 The Art of Persuasion, says M. Faugère, like the treatise on the Geometrical Spirit, has for its object the application of the method of geometricians to the art of reasoning in general. There is even every reason to believe that this writing was only the reproduetion of the latter in a briefer and more didactic form. The authors of the Logique de Port-Royal, although they make no mention of it, have evidently made use of it for their chapter On the Method of Composition.

"As to the date of this fragment, we do not think that it belongs to the youth of Pascal, to the time that may be called lis first epoch, because: 1st, It bears the stamp of naturity; $2 \mathrm{~d}$, Pascal, after having said that there may be as certain rules for pleasing as for demonstrating, adds that if any one is capable of teaching them, he knows that it is those persons with whom he is acquainted, and that no sther's have such clear and abundint light on this subject. Paseal means here most probably Arnauld and Nicole: the Logique de Port-Roryl was their work, and no doubt Pascal had eonversed with them on these matters. Now Paseal clid not conmect himself with the Messieurs of Port-Royal until the close of 1654 , after his return to religion. 3d, At the end of the same writing, Pascal speaks of his long experience in all kinds of books and persons."

This fragment was published for t..e tirst time by Father Desinolets, in the eontinuation of the Memoires de Litt'rature et d'Histoire, t. v, part ii.

We follow the text of M. Filugère. 
infinitely superior to nature: God alone can place them in the soul and in such a way as it pleases him. I know that he has desired that they should enter from the heart intc the mind, and not from the mind into the heart, to humiliate that proud power of reasoning that pretends to the right to be the judge of the things that the will chooses; and to cure this infirm will which is wholly corrupted by its filthy attachments. And thence it comes that whilst in speaking of human things, we say that it is necessary to know them before we can love them, which has passed into a proverb,' the saints on the contrary say in speaking of divine things that it is necessary to love them in order to know them, and that we only enter truth through charity, from which they have made one of their most useful maxims.

From which it appears that God has established this supernatural order, which is directly contrary to the order that should be natural to men in natural things. They have nevertheless corrupted this order by making of profane things what they should make of holy things, because in fact we believe scarcely any thing except that which pleases us. And thence comes the aversion which we have to consenting to the truths of the Christian religion that are opposed to our pleasures. "Tell us of pleasant things and we will hearken to you," said the Jews to Moses; as if the agreeableness of a thing should regulate belief! And it is to punish this disorder by an order which is conformed to him, that God only pours out his light into the mind after having subdued the rebellion of the will by an altogether heavenly gentleness which charms and wins it.

I speak therefore only of the truths within our reach; and it is of them that I say that the mind and the heart are as doors by which they are received into the soul, but that very few enter by the mind, whilst they are brought in in crowds by the rash caprizes of the will, without the counsel of the reason. 
These puwers have each their principles and their main. springs of action.

Those of the mind are truths which are natural and known to all the world, as that the whole is greater than its part, besides several particular maxims that are received by some and not by others, but which as soon as they are admitted are as powerful, although false, in carrying away belief, as those the most true.

Those of the will are eertain desires natural and common to all mankind, as the desire of being happy, whieh no one can avoid having, besides several partieular objects which each one follows in order to attain, and which having the power to please us are as powerful, although pernicious in fact, in causing the will to act, as though they made its veritable happiness.

So much for that which regards the powers that lead us to consent.

But as for the qualities of things which should persuade us, they are very different.

Some are drawn, by a necessary consequence, from common principles and admitted truths. These may be infallibly persuasive; for in showing the harmony which they have with acknowledged principles there is an inevitable necessity of conviction, and it is impossible that they shall not be received into the soul as soon as it has been enabled to class them among the principles which it has already admitted.

There are some which have a close connection with the objects of our satisfaction; and these again are received with certainty, for as soon as the soul has been made to perceive that a thing can conduct it to that which it loves supremely, it must inevitably embrace it with joy.

But those which have this double union both with admitter truths and with the desires of the heart, are so sure of their effect that there is $r$ thing that can be more so in nature.

As, on the contrary, that which does not accord either with sur belief or with our pleasures is importunate, false, and ab. solutely alien to us. 
In all these positions, there is no room for doubt. But there are some wherein the things which it is sought to make us believe are well established upon truths which are known, but which are at the same time contrary to the pleasures that interest us most. And these are in great danger of showing, by an experience which is only too common, what I sair? at the beginning-that this imperious soul, which boasted of acting only by reason, follows by a rash and shameful chuice the desires of a corrupt will, whatever resistance may be opposed to it by the too enlightened mind.

Then it is that a doubtful balance is made between truth and pleasure, and that the knowledge of the one and the feeling of the other stir up a combat the success of which is very uneertain, since, in order to judge of it, it would be necessary to know all that passes in the innermost spirit of the man, of which the man himself is scarcely ever conscious.

It appears from this, that whatever it may be of which we wish to persuade men, it is necessary to have regard to the person whom we wish to persuade, of whom we must know the mind and the heart, what principles he acknowledges, what things he loves; and then observe in the thing in question what affinity it has with the acknowledged principles, or with the objects so delightful by the pleasure which they give him.

So that the art of persuasion consists as much in that of pleasing as in that of convineing, so much more are men governed by caprice than by reason!

Now, of these two methods, the cne of convineing, the other of pleasing, I shall only give here the rules of the first; and this in ease we have granted the principles, and remain firm in arowing them: otherwise I do not know whether there could be an art for adapting proofs to the inconstancy of our caprices.

But the manner of pleasing is incomparably more difficult, more subtle, more useful, and more admirable; therefore, if 1 do not treat of it, it is because I am not capable of it; and I feel myself so far disproportionate to the task, that I believe the thing absolutely impossibir. 
Not that I do not believe that there may be as sure rules for pleasing as for demonstrating, and that he who knows perfectly how to comprehend and to practise them will as surely succeed in making himself beloved by princes and by people of all conditions, as in demonstrating the elements of geometry to those who have enough imagination to comprehend its hypotheses. But I consider, and it is, perhaps, my weakness that makes me believe it, that it is impossible to reach this. At least I know that if any are capable of it, they are certain pursons whom I know, and that no others have such clear and such abundant light on this matter.

The reason of this extreme difficulty comes from the fact that the principles of pleasure are not firm and stable. They are different in all mankind, and variable in every particular with such a diversity that there is no man more different from another than from himself at different times. A man has other pleasures than a woman; a rich man and a poor man have different enjoyments; a prince, a warrior, a merchant, a citizen, a peasant, the old, the young, the well, the sick, all vary; the least accidents change them.

Now there is an art, and it is that which I give, for showing the connection of truths with their principles, whether of truth or of pleasure, provided that the principles which have once been avowed remain firm, and without being ever contradicted.

But as there are few principles of this kind, and as, apart from geometry, which deals only with very simple figures, there are hardly any truths upon which we always remain agreed, and still fewer objects of pleasure which we do not change every hour, I do not know whether there is a means of giving fixed rules for adapting discourse to the inconstancy o our caprices.

This art, which I call the art of persuading, and which, properly speaking, is simply the process of perfect methodical proofs, consists of three essential parts: of defining the terms of which we should avail ourselves by clear definitions; of proposing principles or evident axioms to prove the thing in ques 
tion; and of always mentally substituting in the demonstra. tions the definition in the place of the thing defined.

The reason of this method is evident, since it would be useless to propose what it is sought to prove, and to undertake the demonstration of it, if all the terms which are not intelligible had not first been clearly defined; and since it is necessary in the same manner that the demonstration should be preceded by the demand for the evident principles that are necessary to it, for if we do not secure the foundation we cannot secure the edifice; and since, in fine, it is necessary in demonstrating mentally, to substitute the definitions in the place of the things defined, as otherwise there might be an abuse of the different meanings that are encountered in the terms. It is easy to see that, by observing this method, we are sure of convincing, since, the terms all being understood, and perfectly exempt from ambiguity by the definitions, and the principles being granted, if in the demonstration we always mentally substitute the definitions for the things defined, the invincible force of the conclusions cannot fail of having its whole effect.

Thus, never can a demonstration in which these conditions have been observed be subject to the slightest doubt; and never can those have force in which they are wanting.

It is, therefore, of great importance to comprehend and to possess them; and hence, to render the thing easier and more practicable, I shall give them all in a few rules which include all that is necessary for the perfection of the definitions, the axioms, and the demonstrations, and consequently of the entire method of the geometrical proofs of the art of persuading.

\section{Rules for Definitions.}

I. Not to undertake to define any of the things so well known of themselves that clearer terms cannot be had to explain them.

II. Not to leave any terms that are at all obscure or ambig. nous without definition. 
III. Not to employ in the definition of terms any words but such as are perfectly known or already explained.

\section{Rules for .Axioms.}

I. Not to omit any necessary principle without asking whether it is admitted, however clear and evident it may be.

II. Not to demand, in axioms, any but things that are perfectly evident of themselves.

\section{Rules for Demonstrations.}

I. Not to undertake to demonstrate any thing that is so evident of itself that nothing can be given that is clearer to prove it.

II. To prove all propositions at all obscure, and to employ in their proof only very evident maxims or propositions already admitted or demonstrated.

III. To always mentally substitute definitions in the place of things defined, in order not to be misled by the ambiguity of terms which have been restricted by definitions.

These eight rules contain ail the precepts for solid and immutable proofs, three of which are not absolutely necessary and may be neglected without error; while it is difficult and almost impossible to observe them always exactly, although it is more accurate to do so as far as possible; these are the three first of each of the divisions.

For definitions. Not to define any terms that are perfectly known.

For axioms. Not to omit to require any axioms perfectly evident and simple.

For demonstrations. Not to demonstrate any things wellknown of themselves.

For it is unquestionable that it is no great error to define and clearly explain things, although very clear of themselves, nor to omit to require in advance axioms which cannot be refused in the place where they are necessary; nor lastly tc prove propositions that would be admitted without proof.

But the five other rules are of absolute nesessity, and can. 
not be dispensed with without essential defect and olten without error; and for this reason I shall recapitulate them here in detail.

Rules necessary for definitions. Not to leave any terms at all obscure or ambiguous without definition;

Not to employ in definitions any but terms perfectly known or already explained.

Rule necessary for axioms. Not to demand in axioms any but things perfectly evident.

Rules necessary for demonstrations. To prove all propositions, and to employ nothing for their proof but axioms fully evident of themselves, or propositions already demonstrated or admitted;

Never to take advantage of the ambiguity of terms by failing mentally to substitute definitions that restrict and explain them.

These five rules form all that is necessary to render proofs convincing, immutable, and to say all, geometrical; and the eight rules together render them still more perfect.

I pass now to that of the order in which the propositions should be arranged, to be in a complete geometrical series.

After having established ${ }^{1} \ldots \ldots \ldots \ldots \ldots \ldots \ldots \ldots \ldots$

This is in what consists the art of persuading, which is comprised in these two principles: to define all the terms of which we make use; to prove them all by mentally substituting definitions in the place of things defined.

And here it seems to me proper to anticipate three principal objections which may be made:

1 st, that this method has nothing new ; $2 \mathrm{~d}$, that it is very easy to learn, it being unnecessary for this to study the elements of geometry, since it consists in these two words that are known at the first reading; and, $3 \mathrm{~d}$, that it is of little

1 The rest of the phrase is wanting; and all this second part of the com. position, either because it was not redacted by Pascal, or because it has been lost, is found neither in our MS. nor in Father Desmolets.-.-Faugère 
atility, since its use is almost confined to geometrical subjects alone.

It is necessary therefore to show that there is nothing so little known, nothing more difficult to practise, and nothing more useful or more universal.

As to the first objection, that these rules are common in the world, that it is necessary to define every thing and to prove every thing, and that logicians themselves have placed them among the principles of their art, I would that the thing were true and that it were so well known that I should not have the trouble of tracing with so much care the source of all the defects of reasonings which are truly so common. But so little is this the case, that, geometricians alone excepted, who are so few in number that they are single in a whole nation and long periods of time, we see no others who know it. It will be easy to make this understood by those who have perfectly comprehended the little that I have said; but if they have not fully comprehended this, I confess that they will learn nothing from it.

But if they have entered into the spirit of these rules, and if the rules have made sufficient impression on them to become rooted and established in their minds, they will feel how much difference there is between what is said here and what a few logicians may perhaps have written by chance approximating to it in a few passages of their works.

Those who have the spirit of discernment know how much difference there is between two similar words, according to their position, and the circumstances that accompany them. Will it be maintained, indeed, that two persons who have read the same book, and learned it by heart, have a like acquaintance with it, if the one comprehends it in such a manner that he knows all its principles, the force of its conclusions, the .nswers to the objections that may be made to it, and the whole economy of the work; while to the other these are but dead letter's and seeds, which, although like those which have produced such fruitful trees, remain dry and unproductive in the sterile mind that has received them in vain. 
All who say the same things do not possess them in the same manner; and hence the incomparable author of the Airt of Conversation ' pauses with so much eare to make it understood that we must not judge of the capacity of a man by the excellence of a happy remark that we have heard him make; but instead of extending our admiration of a good speech to the speaker, let us penetrate, says he, the mind from which it proeeeds; let us try whether he owes it to his memory, or to a happy chanee; let us reeeive it with coldness and contempt, in order to see whether he will feel that we do not give to what he says the esteem which its value deserves: it will oftenest be seen that he will be made to disavow it on the spot, and will be drawn very far from this better thought in which he does not believe, to plunge himself into another quite base and ridiculous. We must, therefore, sound in what manner this thought is lodged in its author $;^{2}$ how, whence, to what extent he possesses it; otherwise, the hasty judgment will be a rash judge.

I would inquire of reasonable persons whether this principle: Matter is naturally wholly incapable of thought, and this other: I think, therefore $I \mathrm{am}$, are in fact the same in the mind of Descartes, and in that of St. Augustine, who said the same thing twelve hundred years before. ${ }^{3}$

In truth, I am far from affirming that Descartes is not the real author of it, even though he may have learned it only in reading this distinguished saint; for I know how mueh difference there is between writing a word by chance without making a longer and more extended reflection on it, and perceiving in this word an admirable series of conclusions, which prove the distinction between material and spiritual natures, and making of it a firm and sustained principle of a complete metainhysical system, as Deseartes has pretended to

1 Montaigne, Essais, liv. III, chap. viii.--Faugère.

2 Montaigne's expression is: "Feel on all sides how it is lodged in its suthor." Essais, same chapter.-Ibid.

Civ. Dei, l. XI, c. xxvi. 
do. For without examining whether he has effectively succeeded in his pretension, I assume that he has done so, and it is on this supposition that I say that this expression is as different in his writings from the same saying in others who have said it by chance, as is a man full of life and strength from a corpse.

One man will say a thing of himself without eomprehending its excellence, in which another will discern a marvellous series of conclusions, which make us affirm boldly that it is no longer the same expression, and that he is no more indebted for it to the one from whom he has learned it, than a beautiful tree belongs to the one who east the seed, without thinking of it, or knowing it, into the fruitful soil which eaused its growth by its own fertility.

The same thoughts sometimes put forth quite differently in the mind of another than in that of their author: unfruitful in their natural soil, abundant when transplanted. But it much oftener happens that a good mind itself makes its own thoughts produce all the fruit of which they are eapable, and that afterwards others, having heard them admired, borrow them, and adorn themselves with them, but without knowing their exeellenee; and it is then that the difference of the same word in different mouths is the most apparent.

It is in this manner that logic has borrowed, perhaps, the rules of geometry, without comprehending their foree; and thus, in placing them by chance among those hat belorg to it, it does not thence follow that they ' have entered into the spirit of geometry, and I should be greatly averse if they gave no other evidence of it than that of having mentioned it by chance, to placing them on a level with that science that teaches the true method of directing the reason.

But I should be, on the contrary, strongly disposed to exclude them from it, and almost irrevocably. For to have said it by chance, without having taken care that every thing was included within it, and instead of following this light to wan.

1 Doubtless the logicians.--Faugere. 
der blindly in useless researches, pursuing what they promise but never can give, is truly showing that they are not very clear-sighted, and much more than if they had failed to follow the light, because they had not perceived it.

The method of not erring is sought by all the world. The logicians profess to guide to it, the geometricians alone attain it, and apart from their science, and the imitations of it, there are no true demonstrations. The whole art is included in the simple precepts that we have given; they alone are sufficient, they alone afford proofs; all other rules are useless or injurious. This I know by long experience of all kinds of books and persons.

And on this point I pass the same judgment as those who say that geometricians give them nothing new by these rules, because they possessed them in reality, but confounded with a multitude of others, either useless or false, from which they could not discriminate them, as those who seeking a diamove' of great price amidst a number of false ones, but from which they know not how to distinguish it, should boast, in holding them all together, of possessing the true one equally with him who without pausing at this mass of rubbish lays his hand upon the costly stone which they are seeking and for which they do not throw away the rest.

The defect of false reasoning is a malady which is cured by these two remedies. Another has been compounded of an infinity of useless herbs in which the good are enveloped and in which they remain without effect through the ill qualities of the compound.

To discover all the sophistries and equivocations of captious wasonings, they have invented barbarous names that astonish those who hear them; and whilst we can only unravel all the tangles of this perplexing knot by drawing out one of the ends in the way proposed by geometricians, they have indicated a strange number of others in which the former are found included without knowing which is the best.

And thus, in showing us a number of paths which they say conduct us whither we tend, aithough there are but two that 
ead to it, it is necessary to know how to mark them in particular. It will be pretended that geometry which indicates them with certainty gives only what had already been given by others, because they gave. in fact the same thing and inore, without leeding that this boon lost its value by abundance, and was diminished by adding to it.

Nothing is more common than good things: the point in question is only to discriminate them; and it is certain that they are all natural and within our reach and even known to all mankind. But they know not how to distinguish thern. This is universal. It is not among extraordinary and fantastic things that excellence is to be found, of whatever kind it may be. We rise to attain it and become removed from it: it is oftenest necessary to stoop for it. The best books are those, which those who read them believe they themselves could have written. Nature, which alone is good, is wholly familiar and common.

I make no doubt therefore that these rules, being the true ones, are simple, artless, and natural, as in fact they are. It is not Barbara and Baralipton that constitute reasoning. The mind must not be forced; artificial and constrained manners fill it with foolish presumption, through unnatural elevation and vain and ridiculous intlation, instead of solid and vigorous nutriment. And one of the principal reasons that diverts those who are entering upon this knowledge so much from the true path which they should follow, is the fancy that they take at the outset that good things are inaccessible, giving them the name of great, lofty, elevated, sublime. This destroys every thing. I would call them low, common, familiar: these names suit them better; I hate such inflated expressions. 


\section{DISCOURSE}

\section{ON THE PASSION OF LOVE.1}

\section{MaN is born for thought; therefore he is not a moment without it; but the pure thoughts that would render him}

1 This eurious fragment was discovered by M. Cousin in the Bibliothèque Impériale in 1843: it is extracted from a MS. of the Fonds de Saint-Germain-Gesvres, No. 74. The MS. filed under this number is indorsed : Nicole, De la Grâce, autre pièce manuscrite. "On the first page," says M. Cousin, "is the index of the writings contained in this quarto: $1^{\circ}$. Système de M. Nicole sur la Grâce; $2^{\circ}$. Si la dispute sur la Grâce universelle n'est qu'une dispute de nom; $3^{\circ}$. Discours sur les Passions de $l$ 'Amour, by M. Paseal. This discourse is unfinished, and like the MS. of the abbey of Saint-Germain, is only a copy and not an autograph; thero are two or three sentences which are probably wrongly copied, and are defective. It is also probable that this writing was not designed for the puhlie, and that the author had not put the finishing touch to it; but every where in it we recognize the hand of Pascal, the geometrical spirit that never abandors him, the favorite expressions, the characteristic words, the true distinction between reasoning and feeling, and a thousand other things of like nature which are encountered at every step in the Thoughts."

M. Cousin asks, to what epoch of the life of Paseal should be attributed the composition of the Discourse on the Passion of Love, and thinks that it is to the period extending from 1652 to the end of 1654 , a wholly worldly epoch, into which "Pascal must have earried his character, his euriosity, his ardor, the insatiable need of reaching in every thing its ultimate lim1t.."-"This discourse," says M. Cousin, again, "betrays a mystery in the private life of l'ascal, which perhaps will never be cleared up. . . . It is very possible that in the select society where he must have been admitted and sought after, he may have met a person of more exalted rank than his own for whom he felt a lively attraction which he concealed in his heart, expressing it scareely to himself in this veiled and enigmatical discourse."

M. Cousin does not indicate who this person of an exalted rank who inspired Paseal could have been; but M. Faugère thinks that it was Mademoiselle de Roannez. (See in the Revue des Deux Mondes, Sept. 15, 1843 the article entitled: Un fragment inédit de Pascal.-Faugère, Des Pensées de I'assal, introduction, Ixv.)

The Abbé de Maynard, on his side, while recognizing the great literary morit of this fragment, does not think that it can with full eertainty be at tribnted to Pascal, and M. Saint-Beuve says that, without doing injustive to the pages sur l'amour, it is clear that Pascal never set his heart on any created being, and that he loved no one with passion but his Saviour.

Opinions, it is evident, are strangely divided. In the character of an impartial editor, we give them all here. We follow the text of M. Faugère alopting his corrections 
happy, if he could always maintain them, wear $y$ and oppress him. They make a uniform life to which he cannot adapt. himself; he must have excitement and action, that is, it is necessary that he should sometimes be agitated by those passions the deep and vivid sources of which he feels within his heart.

The passions which are the best suited to man and include many others, are love and ambition : they have little conneo tion with each other; nevertheless they are often allied; but they mutually weaken, not to say destroy, each other.

Whatever compass of mind one may have, he is capable of only one great passion; hence, when love and ambition are found together, they are only half as great as they would be if only one of them existed. The time of life determines neither the beginning nor the end of these two passions; they spring up in the earliest years and subsist very often unto the tomb. Nevertheless, as they require much warmth, young persoris are best fitted for them, and it seems that they abate with years: this however is very rare.

The life of man is miserably brief. It is usually computed from his first entrance into the world; for my part, I would only compute it from the birth of reason and from the time that man begins to be influeneed by it, which does not ordinarily happen before twenty years of age. Before this time, we are children, and a child is not a man.

How happy is a life that begins with love and ends with ambition! If I had to choose, this is the one I should take. So long as we have ardor we are amiable; but this ardor dies out, is lost; then what a fine and noble place is left for ambition! A tumultuous life is pleasing to great minds, but those who are mediocre have no pleasure in it; they are machines everywhere. Hence when love and ambition begin and end life, we are in the happiest condition of which human nature is capable.

The more mind we have the greater the passions are, since the passions being only sentiments and thoughts that belong purely to the mind although they are occasioned by the body, 
it is obvious that they are no longer any thing but the mind itself, and that thus they fill up its entire capacity. I speak herc only of the ardent passions, for the others are often min. gled together and cause a very annoying confusion; but this is never the case in those who have mind.

In a great soul every thing is great.

It is asked whether it is necessary to love? This should not be asked, it should be felt. We do not deliberate upon it, we are forced to it, and take pleasure in deceiving ourselves when we discuss it.

Definiteness of mind causes definiteness of passion; this is why a great and definite mind loves with ardor, and sees distinctly what it loves.

There are two kinds of mind : the one geometrical, and the other what may be called the imaginative (de finesse).

The former is slow, rigid, and inflexible in its views, but the latter has a suppleness of thought which fastens at once upon the various pleasing qualities of what it loves. From the eyes it goes to the heart itself, and from the expression without it knows what is passing within.

When we have both kinds of mind combined, how much pleasure is given by love! For we possess at the same time the strength and the flexibility of mind essentially necessary for the eloquence of two persons.

We are born with a disposition to love in our hearts, which is developed in proportion as the mind is perfected, and impels us to love what appears to us beautiful without ever having been told what this is. Who can donbt after this whether we are in the world for any thing else than to love? In fact, we conceal in vain, we always love. In the very things from which love seems to have been separated, it is found secretly and under seal, and man could not live a moment without this.

Man does not like to dwell with himself; nevertheless he loves; it is necessary then that he seek elsewhere something to love. He can find it only in beauty; but as he is himself the most beautiful creature that God has ever formed, he must 
find in himself the model of this beauty which he seeks without. Every one can perceive in himself the first glimmerings of it; and according as we observe that what is without agrees or disagrees with these, we form our ideas of beauty or deformity in all things. Nevertheless, although man seeks wherewith to fill up the great void he makes in going out of himself, he cannot however be satisfied with every kind of object. His heart is too large; it is necessary at least that it should be some. thing that resembles him and approaches him as near as may be. Hence the beauty that can satisfy man consists not only in fitness, but also in resemblance; it is restricted and confined to the difference of sex.

Nature has so well impressed this truth on our souls, that we find a predisposition to all this; neither art nor study is required; it even seems that we have a place to fill in our hearts which is thus filled effectively. But we feel this better than we can express it. It is only those who know how to confuse and contemn their ideas who do not see it.

Although this general idea of beauty may be engraven in the innermost part of our souls with ineffaceable characters, it does not prevent us from being susceptible of great differenees in its individual application; but this is only in the manner of regarding what pleases us. For we do not wish for beauty alone, but desire in connection with it a thonsand circunstances that depend on the disposition in which it is found, and it is in this sense that it may be said that each one possesses the original of his beauty, the copy of which he is secking externally. Nevertheless, women often determine this original. As they have an absolute empire over the minds of men, they paint on them either the qualities of the beauties which they possess o: those which they esteem, and by this means add what pleases them to this radical beanty. Hence there is one epoch for blondes, another for brunettes, and the division there is among women in respect to esteem for the one or the other makes at at the same time the difference among inen in this regard.

Fashion even and country oftun regulate what is called beauty. It is a strange thing that custom should mingle so 
strongly with our passions. This does not hinder each one from having his idea of beauty by which he judges others and with which he compares them; it is on this principle that a lover finds his mistress the most beautiful and proposes her as a model.

Beauty is divided in a thousand different ways. The most proper object to sustain it is a woman. When she has intellect, she enlivens it and sets it off marvellously. If a woman wishes to please, and possess the advantages of beauty or a portion of them at least, she will succeed; and even though men take ever so little heed of it, although she does not strive for it, she will make herself loved. There is an accessible point in their hearts; she will take up her abode there.

Man is born for pleasure; he feels it; no other proof of it is needed. He therefore follows his reason in giving himself to pleasure. But very often he feels passion in his heart without knowing in what it originated.

A true or false pleasure can equally fill the mind. For what matters it that this pleasure is false, if we are persuaded that it is true?

By force of speaking of love we become enamored. 'Thero is nothing so easy. It is the passion most natural to man.

Love has no age; it is always young. So the poets teii us; it is for this that they renresent it to us under the figure of a child. But without asking any thing of it, we feel it.

Love gives intellect and is sustained by intellect. Address is needed in order to love. We daily exhaust the methods of pleasing; nevertheless it is necessary to please and we please.

We have a fountain of self-love which represents us to ourselves as being able to fill several places outside of ourselves; this is what makes us happy to be loved. As we desire it with ardor, we quickly remark it and perceive it in the eyes of the person who loves. For the eyes are the interpreters of the heart; but he alone who is interested in them can anderstand their language.

Man by himself is something imperfect; he must find a weond in order to be happy. He oftenest seeks it in equality 
of condition, because in that the liberty and the opportunity of manifesting his wishes are most easily found. Yet he somewixss rises above this, and feels the kindling flame although he dares not tell it to the one who has caused it.

When we love a woman of unequal condition, ambition may accompany the beginning of the love; but in a little time the latter becomes master. It is a tyrant that will suffer no companion; it wishes to be alone; all the other passions must bend to it and obey it.

An elevated attachment fills the heart of man much brtter than a common and equal one; and little things float in his capacity; none but great ones lodge and dwell therein.

We often write things which we only prove by obliging every one to reflect upon himself, and find the truth of which we are speaking. In this consists the force of the proofs of what I assert.

When a man is fastidious in any quality of his mind, he is so in love. For as he must be moved by every object that is outside of himself, if there is any thing that is repugnant to his ideas, he perceives and shuns it; the rule of this fastidiousness depends on a pure, noble, and sublime reason. Thus we can believe ourselves fastidious without actuaily being so, and others have the right to condemn us; whilst for beauty each one has his rule, sovereign and independent of that of others. Yet between being fastidious and not being so at all, it must be granted that when one desires to be fastidious he is not far from actually being so. Women like to perceive fastidionsness in men, and this is, it seems to me, the most vulnerable point whereby to gain them: we are pleased to see that a thousand others are contemned and that we alone are esteemed.

Quahities of mind are not acquired by habit; they are only perfected. Whence it is easy to see that fastidiousness is a gift of nature and not an acquisition of art.

In proportion as we have more intellect, we find more original beauties; but this is not necessary in order to be in love; for when we love, we find but one. 
Does it not seem that as often as a woman goes out of her self to impress the hearts of others, she makes a place void for others in her own? Yet, I know some who affirm that this is not true. Dare we eall this injustice? It is natural to give back as much as we have taken.

Attachment to the same thought wearies and destroys the mind of man. Honce for the solidity and permanence of the pleasure of love, it is sometimes necessary not to know that we love; and this is not to be guilty of an infidelity, for we do not therefore love another; it is to regain strength in order to love the better. This happens without our thinking of it; the mind is borne hither of itself; nature wills it, commands it. It must however be confessed that this is a miserable consequence of human weakness, and that we should be happier if we were not foreed to change of thought; but there is no remedy.

The pleasure of loving without daring to tell it, has its pains, but it has its joys also. What transport do we not feel in moulding all our actions in view of pleasing the person whom we infinitely esteem! We study each day to find the means of revealing ourselves, and thus empioy as much time as if we were holding converse with the one whom we love. The eyes kindle and grow dim at the same moment, and although we do not see plainly that the one who eauses this disorder takes heed of it, we still have the satisfaction of feeling all these emotions for a person who deserves them so well. We would gladly have a hundred tongues to make it known; for as we cannot make use of words, we are obliged to confine ourselves to the eloquence of action.

Up to this point we have constant delight and sufficient occupation. Thus we are happy ; for the seeret of keeping a passion constantly alive is to suffer no void to spring up in the mind, by obliging it to apply itself without ceasing to what moves it so agreeably. But when it is in the state that ! have just deseribed, it cannot last long, because being sole actor in a passion in which there must necessarily be two, it is difficult to hinder it from soon exhausting all the emotions bj which it is agitated. 
Although the passion may be the same, novelty is needed; the mind takes delight in it, and he who knows how to procure it, knows how to make himself loved.

After having gone thus far, this plenitude sometimes diminshes, and receiving no assistance from the side of its source, we decline miserably, and hostile passions take possession of a beart which they rend into a thousand pieces. Yet a ray of hope, however faint it may be, exalts us as high as we were before. This is sometimes a play in which women delight; but sometimes in feigning to have compassion, they have it in reality. How happy we are when this is the case!

A firm and solid love always begins with the eloquence of action; the eyes have the best share in it. Nevertheless it is necessary to conjecture, but to conjecture rightly.

When two persons are of the same sentiments, they do not conjecture, or at least one conjectures what the other means to say without the other understanding it or daring to undcrstand.

When we love, we appear to ourselves quite different from what we were before. Thus we imagine that every one perceives it; yet nothing is more false. But because the perception of reason is bounded by passion, we cannot assure ourselves and are always suspicious.

When we love, we are persuaded that we shall discover the passion of another: thus we are afraid.

The longer the way is in love, the greater is the pleasure that a sensitive mind feels in it.

There are certain minds to which hopes must long be given, and these are minds of refinement. There are others which cannot long resist difficultics, and these are the grossest. The former love longer and with more enjoyment; the latter love quicker, with more freadom, and sooner end.

The first effect of love is to inspire a profound respect; we have veneration for what we love. It is very just; we see nothing in the world so great as this.

Authors cannot tell us much of the love of their heroes; it w necessary that they should have been the heroes themselves. 
Wandering in love is as monstrous as injustice in the mir.d.

In love, silence is of more avail than speech. It is good to be abashed; there is an eloquence in silence that penetrates more deeply than language can. How well a lover persuades his mistress when he is abashed before her, who elsewhere has so much presence of mind! Whatever vivacity we may have, it is well that in certain junctures it should be extinguished. All this takes place without rule or reflection, and when the mind acts, it is without thinking of it beforehand. This happens through necessity.

We often adore one that is unconscious of it; and do not fail to preserve an inviolable fidelity, although its object knows nothing of it. But this love must be very refined or very pure.

We know the minds of men, and consequently their passions, by the comparison that we make between ourselves and others.

I am of the opinion of him who said that in love one forgets his fortune, his relatives, and his friends; the most elevated attachments go as far as this. What causes us to go so far in love is that we do not think we have need of any thing else than the object of our love: the mind is full; there is no longer any room for care or solicitude. Passion cannot exist without excess; thence it comes that we care no longer for what the world says, as we know already that our conduct ought not to be condemned, since it comes from reason. There is fulness of passion, and can be no beginning of reflection.

It is not an effect of custom, it is an obligation of nature, that men make the advances to gain the attachment of women.

This forgetfulness that is caused by love, and this attachment to the object of our love, make qualities spring up that we had not before. We become magnificent, without ever having becn so.

The miser himself who loves becomes liberal, and does not rumember ever to have had a contrary disposition; we see the reason of this in considering that there are some passions which zontract the soul and render it stagnant, and that there are others which expand it and cause it to overflow.

We have unaptly taken away the name of reason from love 
and have opposed them to each other without good founda. tion, for love and reason are but the same thing. It is a precipitation of thought which is impelied to a side before fully examining every thing, but it is still a reason, and we should not and cannot wish that it were otherwise, for we would then be very disagreeable machines. Let us not therefore exclude reason from love, since they are inseparable. The poets were not right in painting Love blind; we must take off his bandage and restore to him henceforth the enjoyment of his eyes.

Souls fitted for love demand a life of action which becomes brilliant in new events. The external excitement must correspond with the internal, and this manner of living is a marvellous road to passion. Thence it is that courtiers are more successful in love than citizens, since the former are all fire and the latter lead a life in the uniformity of which there is nothing striking: a tempestuous life surprises, strikes, and penetrates.

It seems as though we had quite another soul when we love than when we do not love; we are exalted by this passion and become all greatness; the rest therefore must have proportion, otherwise this does not harmonize and is consequently disagreeable.

The pleasing and the beautiful are only the same thing; every one has his idea of it. It is of a moral beauty that I mean to speak, which consists in external words and actions. We have a rule indeed for becoming agreeable; yet the disposition of the body is necessary to it, but this cannot be acquired.

Men have taken pleasure in forming for themselves so ele. vated a standard of the pleasing that no one can attain it. Let us judge of it better, and say that this is simply nature with surprising facility and vivacity of mind. In love these two qualities are necessary. There must be nothing of force, and yet there must be nothing of slowness: habit gives the rest.

Respect and love should bs so well proportioned as to sus. tain each other without love being stifled by respect.

Great souls are not those that love oftenest; it is a vio. 
lent love of which I speak; an inundation of passion is needed to move them and fill them. But when they begin to love, they love much more strongly.

It is said that there are some nations more amorous than others; this is not speaking rightly, or at least it is not true in every sense.

Love consisting only in an attachment of thought, it is certain that it must be the same over all the earth. It is true that, considering it otherwise than in the thought, the climate may add something, but this is only in the body.

It is with love as with good sense; as one man believes himself to have as much mind as another, he also believes that he loves the same. Yet, they who have the most perception, love even to the most trifling things, which is not possible for others. It is necessary to be very subtle to remark this difference.

One cannot feign to love unless he is very near being a lover, or at least unless he loves in some direction; for the mind and the thoughts of love are requisite for this seeming, and how shall we find means of speaking well without this? The truth of passion is not so easily disguised as serious truth.

We must have ardor, activity, and prompt and natural warmth of mind for the former; the latter we conceal by slowness and pliancy, which it is easier to do.

When we are at a distance from the object of our love, we resolve to do or to say many things; but when we are near, we are irresolute. Whence comes this? It is because when we are at a distance reason is not so much perturbed, but is strangely so in the presence of the object: now for resolution, firmness is needed, which is destroyed by perturbation.

In love we dare not hazard, because we fear to lose every thing; it is necessary, however, to advance, but who can say how far? We tremble constantly until we have found this boint. Prudence does nothing towards maintaining it when it is found.

There is nothing so embarrassing as to be a lover, and to see something in our favor without daring to believe it; we 
are alike opposed by hope and fear. But finally the latter becomes victorious over the other.

When we love ardently, it is always a novelty to see the person beloved. After a moment's absence, he finds a void in ris heart. What happiness is it to find her again! he feels at once a cessation of anxiety.

It is necessary, however, that this love should be already far advanced; for when it is budding, and has made no progress, we feel indeed a cessation of anxiety, but others supervene.

Although troubles thus succeed each other, one is not hindered from desiring the presence of his mistress by the hope of suffering less; yet, when he sees her, he fancies that he suffers more than before. Past troubles no longer move him, the present touch him, and it is of those that touch him that he judges.

Is not a lover in this state worthy of compassion?

\section{OF THE GEOMETRICAL SPIRIT.'}

WE may have three principal objects in the study of truth : one to discover it when it is sought; another to demonstrate it when it is possessed; and a third, to discriminate it from the false when it is examined.

I do not speak of the first; I treat particularly of the second, and it includes the third. For, if we know the method of proving the truth, we shall have, at the same time, that of discriminating it, since, in examining whether the proof that is given of it is in conformity with the rules that are understood, we shall know whether it is exactly demonstrated.

1 A short fragment of this writing was published in 1728 by Desmolets : Condorect gave it in a more eomplete manner, but also with numerous suppressions, under the title: De la manière de prouver la vérité et de l'exposer aux hommes; lastly, Bossut reprinted it in 1779, entitling it: Réflexions sur la Gémétrie en géneral; but it is known by the first diseourse of the Loqique de Port-Reyjal, that Pascal gave it the title under which we reprint it. We follow the text of M. Fangèrs, who has reprodueed the only MS. copy that has been preserved. 
Geometry, which excels in these three methods, has $\mathrm{explained}$ the art of discovering unknown truths; this it is which is ealled analysis, and of which it would be useless to discourse after the many excellent works that have been written on it.

That of demonstrating truths already found, and of elneidating them in such a manner that the proof of them shall be irresistible, is the only one that I wish to give; and for this I have only to explain the method which geometry observes in it; for she teaches it perfectly by her examples, although she may produce no discourse on it. And since this art consists in two principal things, the one in proving each proposition by itself, the other in disposing all the propositions in the best order, I shall make of it two sections, of which the one will contain the rules for the conduct of geometrieal, that is, methodical and perfect demonstrations; and the second will comprehend that of geometrical, that is, methodical and complete order: so that the two together will include all that will be necessary to direct reasoning, in proving and discriminating truths, which I design to give entire.

Section First.-Of the method of geometrical, that is, of methodical and perfect demonstrations.

I cannot better explain the method that should be preserved to render demonstrations convincing, than by explaining that which is observed by geometry.

But it is first necessary that I should give the idea of a method still more eminent and more complete, but which mankind could never attain; for what exceeds geometry surpasses us; and, nevertheless, something must be said of it, although it is impossible to practise it. ${ }^{1}$

1 After this paragraph occur in the MS. the following lines, written in a ther hand, and inclosed in parenthesis :

". . . is mueh more to suceed in the one than the other, and I have ehosen this seience to attain it only because it alone knows the true rules of reasoning, and, without stopping at the rules of syllogisms which are so natural that we eannot be ignorant of them, stops and establishes itsel npon the true method of condueting reasoning in all things, whieh almost every one is ignorant of, and which it is so advantageous to know, that 
This true method, which would form demonstrations in the highest excellence, if it were possible to arrive at it, would consist in two principal things: the one, in employing no term the meaning of which had not first been ciearly explained; the other, in never advancing any proposition which could not be demonstrated by truths already known; that is, in a word, in defining every term, and in proving every proposition. But to follow the same order that I am explaining, it is necessary that I should state what I mean by definition.

The only definitions recognized in geometry are what the logicians call definitions of name, that is, the arbitrary application of names to things which are clearly designated by terms perfectly known; and it is of these alone that I speak.

Their utility and use is to elucidate and abbreviate discourse, in expressing by the single name that has been imposed what could otherwise be only expressed by several terms; so that nevertheless the name imposed remains dirested of all other meaning, if it has any, having no longer any than that for which it is alone designed. Here is an example:

If we are under the necessity of discriminating numbers that are divisible equally by two from those which are not, in order to avoid the frequent repetition of this condition, a name is given to it in this manner: I call every number divisible equally by two, an even number.

This is a geometrical definition; because after having clearly designated a thing, namely, every number divisible equally

we see by experience that among equal minds and like circumstanecs, bo who possesses geometry bears it away, and aequires a new vigor.

"I wish, therefore, to explain what demonstrations are by the examplo of those of geometry, which is almost the only one of the human sciences that produces infalliole ones, because she alone observes the true method, whilst all the others are, through a natural necessity, in a sort of confusion, which the geometricians alone know exceedingly well how to comprebend."

On the margin of this fragment is in the MS. the following note: "That which is in small sharacters was hidden under a paper, the edges of which were glued, and upon which was wrtten the article beginning: I cannot better explain, etc."-Faugère. 
by two, we ggive it a name divested of every other meaning, it it has any, in order to give it that of the thing designated.

Hence it appears that definitions are very arbitrary, anc. that they are never subject to contradiction; for nothing is more permissible than to give to a thing which has been clearly designated, whatever name we choose. It is only necessary to take care not to abuse the liberty that we possess of imposing names, by giving the same to two different things.

Not that this may not be permissible, provided we do not confound the consequences, and do not extend them from the one to the other.

But if we fall into this error, we can oppose to it a sure and infallible remedy: that of mentally substituting the definition in the place of the thing defined, and of having the definition always so present, that every time we speak, for example, of an even number, we mean precisely that which is divisible into two equal parts, and that these two things should be in such a degree joined and inseparable in thought, that as soon as the discourse expresses the one, the mind attaches it immediately to the other. For geometricians, and all those who proceed methodically, only impose names on things to abbreviate discourse, and not to diminish or change the idea of the things of which they are discoursing. And they pretend that the mind always supplies the full definition to the concise terms, which they only employ to avoid the confusion occasioned by the multitude of words.

Nothing more promptly and more effectually removes the captious cavils of sophists than this method, which it is necessary to have always present, and which alone suffices to banish all kinds of difficulties and equivocations.

These things being well understood, I return to the explanation of the true order, which consists, as I have said, in defining every thing and in proving every thing.

This method would certainly be beautiful, but it is absolute.y impossible; for it is evident that the first terms that we wished to define would imply precedents to serve for their explanation, and that in the same manner, the first proposition 
that we wished to prove would imply others which had pre. ceded them; and thus it is clear that we should never reach the first.

Thus, in pushing our researches further and further, we arruve necessarily at primitive words which ean no longer be defined, and at principles so clear that we can find no others that can serve as a proof of them.

Hence it appears that men are naturally and immutably impotent to treat of any science so that it may be in an absolutely complete order.

But it does not thence follow that we should abandon every kind of order.

For there is one, and it is that of geometry, which is in truth inferior in that it is less convineing, but not in that it is less certain. It does not define every thing and does not prove every thing, and it is in this that it is inferior; but it assumes nothing but things clear and constant by natural enlightenment, and this is why it is perfectly true, nature sustaining it in default of discourse.

This order, the most perfect of any among men, consists not at all in defining every thing or in demonstrating every thing, nor in defining nothing or in demonstrating nothing, but in adhering to this middle course of not defining things clear and understood by all mankind, and of defining the rest; of not proving all the things known to mankind, and of proving all the rest. Against this order those sin alike who undertake to define every thing and to prove every thing, and who neglect to do it in those things which are not evident of themselves.

This is what is perfectly taught by geometry. She does not define any of these things, space, time, motion, number, equality, and similar things which exist in great number, because these terms so naturally designate the things that they mean, to those who understand the language, that their elucidation would afford more obscurity than instruction.

For there is nothing more feeble than the discourse of those who wish to define these primitive words. What necessity is there, for example, of explaining what is understood by the 
word man? Do we not know well enough what the thing is that we wish to designate by this term? And what advantage did Plato think to procure us in saying that he was a twolegged animal without feathers? As though the idea that I have of him naturally, and which I cannot express, were not clearer and surer than that which he gives me by his useless and even ridiculous explanation; since a man does not lose humanity by losing the two legs, nor does a capon acquire it by losing his feathers.

There are those who are absurd enough to explain a word by the word itself. I know some who have defined light in this wise: Light is a luminary movement of luminous bodies,' as though we could understand the words luminary and luminous without the word light. ${ }^{2}$

We cannot undertake to define being without falling into the same absurdity : for we cannot define a word without beginning with the word it is, either expressed or understood. To define being therefore, it is necessary to say it is, and thus to employ the word defined in the definition.

We see clearly enough from this that there are some words incapable of being defined; and, if nature had not supplied this defect by a corresponding idea which she has given to all mankind, all our expressions would be confused; whilst we use them with the same assurance and the same certainty as though they were explained in a manner perfectly exempt from ambiguities; because nature herself has given us, with-

' Precisely the same grammatical crror is in the original. We have translated the good Father Noël's definition of light, blunder and all. $-E d$.

2 Pascal alludes here to Father Noël, a Jesuit, with whorn he had had a warm diseussion on the subject of his Experiences touchant le vide. In a Ictter that he wrote to Father Noël in 1647, he said: "The sentence which precedes your closing compliments defines light in these terms: Light is a luminous motion of rays composed of lucid, that is, luminous bodies; upon which, I have to tell you that it seems to me that you ought first to have defined what luminous is, and what a lucid or luminous body is, for till then, I cannot understand what light is. And as we never make use in definitions of the term of the thing defined, I should have diftieulty in conijrming to yours which says: Light is a luminary motion of a luminou body."-Faugère. 
cut words, a clearer knowledge of them than art could acquire by our explanations.

It is not because all men have the same idca of the essence of the things that I say that it is impossible and useless to define.

For, for example, time is of this sort. Who can define it? And why undertake it, since all men conceive what is meant in speaking of time, without any further definition? Nevertheless there are many different opinions touching the essence of time. Some say that it is the movement of a created thing; others, the measure of the movement, etc. Thus it is not the nature of these things that I say is known to all; it is simply the relation between the name and the thing; so that at the expression time, all direct their thoughts towards the same object; which suffices to cause this term to have no need of being defined, though afterwards, in examining what time is, we come to differ in sentiment after having been led to think of it; for definitions are only made to designate the things, that are named, and not to show the nature of them.

It is not because it is not permissible to call by the name of time the movement of a created thing; for, as I have just said, nothing is more arbitrary than definitions.

But after this definition there will be two things that will be called by the name of time: the one is what the whole world understands naturally by this word and what all those who speak our language call by this term; the other will be the movement of a created thing, for this will also be called by this name, according to this new definition.

It is necessary therefore to shun ambiguities and not to confound consequences. For it will not follow from this that the thing that is naturally understood by the word time is in fact the movement of a created thing. It has been allowable to name these two things the same; but it will not be to make them agree in nature as well as in name.

Thus, if we adrance this proposition-time is the movement of a created thing, it is necessary to ask what is meant by this word time, that is, whether the usual and generally received meaning 
is left to it, or whether it is divested of this meaning in order to give to it on this occasion that of the movement of a created thing. For if it be stripped of all other meaning, it cannot be contradicted, and it will become an arbitrary definition, in con sequence of which, as I have said, there will be two things that will have the same name. But if its ordinary meaning be left to it, and it be pretended nevertheless that what is meant by this word is the movement of a created thing, it can be contradicted. It is no longer an arbitrary definition, but a proposition that must be proved, if it is not evident of itself; and this will then be a principle or an axiom, but never a definition, since in this enunciation it is not understood that the word time signifies the same thing as the movement of a created thing, but it is understood that what is conceived by the term time is this supposed movement.

If I did not know how necessary it is to understand this perfectly, and how continually occasions like this, of which I give the example, happen both in familiar and scientific discourses, I should not dwell upon it. But it seems to me, by the experience that I have had from the confusion of controversies, that we cannot too fully enter into this spirit of precision, for the sake of which I write this treatise rather than the subject of which I treat in it.

For how many persons are there who fancy that they have defined time, when they have said that it is the measure of movement, leaving it, however, its ordinary meaning! And nevertheless they have made a proposition and not a definition. How many are there, in the like manner, who fancy that they have defined movement, when they have said: Motus nec simpliciter motus, non mera potentia est, sed actus entis in potentia! And nevertheloss, if they leave to the word movement its ordinary meaning as they do, it is not a definition but a proposition; and confounding thus the definitions which they call definitions of name, which are the true arbitrary definitions, permissible and geonetrical, with thos, which they call defininitions of thing, which, properly speaking, are not at all arbitrary definitions, but are subject to contradiction, they hold 
themselves at liberty to make these as well as others: and each defining the same things in his own way, by a liberty which is as unjustifiable in this kind of definitions as it is permissible in the former, they perplex every thing, and losing all order and all light, become lost themselves and wander into inextricable embarrassments.

We shall never fall into such in following the order of geometry. This judicious science is far from defining such primitive words as space, time, motion, equality, majority, diminution, whole, and others which every one understands. But apart from these, the rest of the terms that this science employs are to such a degree elucidated and defined that we have ao need of a dictionary to understand any of them; so that in a word all these terms are porfectly intelligible, either by nataral enlightenment or by the definitions that it gives of them.

This is the manner in which it avoids all the errors that may be encountered upon the first point, which consists in deGining only the things that have need of it. It makes use of it in the same manner in respect to the other point, which consists in proving the propositions that are not evident.

For, when it has arrived at the first known truths, it pauses there and asks whether they are admitted, having nothing clearer whereby to prove them; so that all that is proposed by geometry is perfectly demonstrated, either by natural enlightenment or by proofs.

Hence it comes that if this science does not define and demonstrate every thing, it is for the simple reason that this is .mpossible.'

It will perhaps be found strange that geometry does not Jefine any of the things that it has for its principal objects: tor it can neither define motion, numbers, nor space; and aevertheless these three things are those of which it treats in

- Here the MS. adds in parenthesis: "(But as nature punishes all that scienee does not bestow, its order ill truth does not give a superhuman perfection, but it has all that ma can attain. It has seemed to me proper to give from the beginning of this discourse this, ete.)." -Faugère. 
particular, and according to the investigation of which it takes the three different names of mechanics, arithmetic, and geom. etry, this last name belonging to the genus and species.

But this will not surprise us if we remark that, this admirable science only attaching itself to the simplest things, this same quality which renders them worthy of being its objects renders them incapable of being defined; so that the lack of definition is a perfection rather than a defect, since it does not come from their obscurity, but on the contrary from their extreme obviousness, which is such that though it may not have the conviction of demonstrations, it has all their certainty. It supposes therefore that we know what is the thing that is understood by the words motion, number, space; and without stopping to define them to no purpose, it penetrates their nature and discovers their marvellous properties.

These three things which comprehend the whole universe, according to the words: Deus fecit omnia in pondere, in numero, et mensura, ${ }^{1}$ have a reciprocal and necessary connection. For we cannot imagine motion without something that moves; and this thing being one, this unity is the origin of all numbers; and lastly, motion not being able to exist without space, we see these three things included within the first.

Time even is also comprehended in it; for motion and time are relative to each other; speed and slowness, which are the differences of motion, having a necessary relation to time.

Thus there are properties common to all these things, the knowledge of which opens the mind to the greatest marvels of nature.

The chief of these comprehends the two infinitudes which are combined in every thing: the one of greatness the other of littleness.

For however quick a movement may bc, we can conceive of one still more so; and so on ad infinitum, without ever reaching one that would be swifi to such a degree that nothing more could be added to it. And, on the sontrary, however

'Sap., xi, 21. Omnia in mensura, et numero, et pondere, disposuisti. 
Blow a movement may be, it can be retarded still more; and thus ad infinitum, without ever reaching such a degree of slowness that we could not thence descend into an infinite number of others, without falling into rest.

In the same manner, however great a number may be, wo can conceive of a greater; and thus ad infinitum, without ever reaching one that can no longer be increased. And on the contrary, however small a number may be, as the hundredth or ten thousandth part, we can still conceive of a less; and so on ad infinitum, without ever arriving at zero or nothingness.

However great a space may be, we can conceive of a greater; and thus ad infinitum, without ever arriving at one which ean no longer be inereased. And, on the contrary, however small a space may be, we can still imagine a smaller; and so on ad infinitum, without ever arrivine at one indivisible, which has no longer any extent.

It is the same with time. We can always conceive of a greater without an ultimate, and of a less without arriving at a point and a pure nothingness of duration.

That is, in a word, whatever movement, whatever number, whatever space, whatever time there may be, there is always a greater and a less than these: so that they all stand betwixt nothingness and the infinite, being always infinitely distant from these extremes.

All these truths cannot be demonstrated; and yet they are the foundations and principles of geometry. But as the cause that renders them incapable of demonstration is not their obcurity, but on the contrary their extreme obviousness, this lack of proof is not a defect, but rather a perfection.

From which we see that geometry can neither define objects 2.or prove principles; but for this single and advantageous icason that both are in an extreme riatural clearness, which convinces reason more powerfully than discourse.

For what is more evident than this truth, that a number whatever it may be, can be increased-can be doubled? Again, may not the speed of a movement be doubled, and may not a epace be doubled in the same manner? 
And who too can doubt that a number, whatever it may be, may not be divided into a half, and its half again into another half? For would this half be a nothingness? And would these two halves, which would be two zeros, compose a number?

In the same manner, may not a movement, however slow it may be, be reduced in speed by a half, so that it will pass over the same space in double the time, and this last movement again? For would this be a perfect rest? And would these two halves of velocity, which would be two rests, compose again the first velocity?

Lastly, may not a space, however small it may be, be divided into two, and these halves again? And how could these two halves become indivisible without extent, which joined together made the former extent?

There is no natural knowledge in mankind that precedes this, and surpasses it in clearness. Nevertheless, in order that there may be examples for every thing, we find minds, excellent in all things else, that are shocked by these infinities and can in no wise assent to them.

I have never known any person who thought that a space could not be increased. But I have seen some, very capable in other respects, who affirmed that a space could be divided into two indivisible parts, howerer absurd the idea may seem.

I have applied myself to investigating what could be the tause of this olscurity, and have found that it chiefly consisted in this, that they could not conceive of a continuity divisible ad infinitum, whence they concluded that it was not divisible.

It is an infirmity natural to man to believe that he possesses tiuth directly; and thence it comes that he is always disposed to deny every thing that is incomprehensible to him; whilst in fact he knows naturally nothing but falsehood, and whilst ne ought to receive as true only those things the contrary of which appear to him as false.

And hence, whenever a proposition is inconceivable, it is necessary to suspend the judgment on it and not to deny it from this indication, but to examine its opposite; and if this 
is found to be manifestly false, we can boldly affirm the former, however incomprehensible it may be. Let us apply this rule to our subject.

There is no geometrician that does not believe space divisible ad infinitum. He can no more be such without this principle than man can exist without a soul. And nevertheless there is none who comprehends an infinite division; and he only assures himself of this truth by this one, but certainly sufficient reason, that he perfectly comprehends that it is false that by dividing a space we can reach an indivisible part, that is, one that has no extent.

For what is there more absurd than to pretend that by continually dividing a space, we shall finally arrive at such a di vision that on dividing it into two, each of the halves shall remain indivisible and without any extent, and that thus these two negations of extensions will together compose an extent? For I would ask those who hold this idea, whether they conceive clearly two indivisibles being brought into contact; if this is throughout, they are only the same thing, and consequently the two together are indivisible; and if it is not throughout, it is then but in a part; then they have parts, therefore they are not indivisible.

If they confess, as in fact they admit when pressed, that their proposition is as inconceivable as the other, they acknowledge that it is not by our capacity for conceiving these things that we should judge of their truth, since these two contraries being both inconceivable, it is nevertheless necessarily certain that one of the two is true.

But as to these chimerical difficulties, which have relation only to our weakness, they oppose this natural clearness and these solid truths: if it were true that space was composed of a certain finite number of indivisibles, it would follow that two spaces, each of which should be square, that is, equal and similar on every side, being the one the double of the other, che one would contain a number of these indivisibles double the number of the indivisibles of the other. Let them bear this consequence well in mind, and let them then apply them. 
selves to ranging points in squares until they shall have formed two, the one of which shall have double the points of the other; and then I will make every geometrician in the world yield to them. But if the thing is naturally impossible, that is, if it is an insuperable impossibility to range squares of points, the one of which shall have double the number of the other, as I would demonstrate on the spot did the thing merit that we should dwell on it, let them draw therefrom the consequence.

And to console them for the trouble they would have in certain junctures, as in conceiving that a space may have an infinity of divisibles, seeing that these are run over in so little time during which this infinity of divisibles would be run over, we must admonish them that they should not compare things so disproportionate as is the infinity of divisibles with the little time in which they are run over: but let them compare the entire space with the entire time, and the infinite divisibles of the space with the infinite moments of the time; and thus they will find that we pass over an infinity of divisibles in an infinity of moments, and a little space in a little time; in which there is no longer the disproportion that astonished them.

Lastly, if they find it surprising that a small space has as many parts as a great one, let them understand also that they are smaller in measure, and let them look at the firmament through a diminishing glass, to familiarize themselves with this knowledge, by seeing every part of the sky in every part of the glass.

But if they cannot comprehend that parts so small that to us they are imperceptible, can be divided as often as the firmament, there is no better remedy than to make them look through glasses that magnify this delicate point to a prodigious mass; whence they will easily conceive that by the aid of another glass still more artistically cut, they could be mag. nified so as to equal that firmament the extent of which they admire. And thus these objects appearing to them now easily divisible, let them remember that nature can do infinitely more than art.

For, in fine, who has assured them that these glasses change 
the natural magnitude of these objects, insteaci of re-establishing, on the contrary, the true magnitude which the shape of our eye may change and contract like glasses that diminish ?

It is annoying to dwell upon such trifles; but there are times for trifling.

It suffices to say to minds elear on this matter that two negations of extension cannot make an extension. But as there are some who pretend to elude this light by this marvellous answer, that two negations of extension can as well make an extension as two units, neither of which is a number, can make a number by their combination; it is necessary to reply to them that they might in the same manner deny that twenty thousand men make an army, although no single one of them is an army; that a thousand houses make a town, although no single one is a town; or that the parts make the whole, although no single one is the whole; or, to remain in the comparison of numbers, that two binaries make a quaternary, and ten tens a hundred, although no single one is such.

But it is not to have an accurate mind to confound by such unequal comparisons the immutable nature of things with their arbitrary and voluntary names, names dependent upon the eaprice of the men who invented them. For it is clear that to facilitate discourse the name of army has been given to twenty thousand men, that of town to several houses, that of ten to ten units; and that from this liberty spring the names of unity, binary, quaternary, ten, lundred, different through our eaprices, although these things may be in fact of the same kind by their unchangeable nature, and are all proportionate to each other and differ only in being greater or less, and although, as a result of these names, binary may not be a quaternary, nor the house a town, any more than the town is a house. But again, although a house is not a town, it is not however a negation of a town; there is a great difference between not being a thing, and being a negation of it.

For, in order to understand the thing to the bottom, it is necessary to know that the only reason why unity is not in the rank of numbers, is that Euclid and the ear'iest authors 
who treated of arithmetic, having several properties to give that were applicable to all the numbers except unity, in order to avoid often repeating that in all numbers except unity this condition is found, have excluded unity from the signification of the word number, by the liberty which we have already said can be taken at will with definitions. Thus, if they had wished, they could in the same manner have excluded the binary and ternary, and all else that it pleased them; for we are master of these terms, provided we give notice of it; as on the contrary we may place unity when we like in the rank of numbers, and fractions in the same manner. And, in fact, we are obliged to do it in general propositions, to avoid saying constantly, that in all numbers, as well us in unity and in fractions, such a property is found; and it is in this indefinite sense that I have taken it in all that I have written on it.

But the same Euclid who has taken away from unity the name of number, which it was permissible for him to do, in order to make it understood nevertheless that it is not a negation, but is on the contrary of the same species, thus defines homogeneous magnitudes: Magnitudes are said to be of the same kind, when one being multiplied several times may exceed the other; and consequently, since unity can, being multiplied several times, exceed any number whatsoever, it is precisely of the same kind with numbers through its essence and its immutable nature, in the meaning of the same Euclid who would not have it called a number.

It is not the same thing with an indivisible in respect to an extension. For it not only differs in name, which is voluntary, but it differs in kind, by the same definition; since an indivisible, muitiplied as many times as we like, is so far from being able .0 exceed an extension, that it can never form any thing else than a single and exclusive indivisible; which is natural and necessary, as has been already shown. And as this last proof is founded upon the definition of these two things, ndivisible and extension, we will proceed to finish and perfect the demon stration. 
An indivisible is that which has no part, and extension is that which has divers separate parts.

According to these definitions, I affirm that two indivisibles united do not make an extension.

For when they are united, they touch each other in some part; and thus the parts whereby they come in contact are not separate, since otherwise they would not touch each other. Now, by their definition, they have no other parts; therefore they have no separate parts; therefore they are not an extension by the definition of extension which involves the separation of parts.

The same thing will bo shown of all the other indivisibles that may be brought into junction, for the same reason. And consequently an indivisible, multiplied as many times as we like, will not make an extension. Therefore it is not of the same kind as extension, by the definition of things of the same kind.

It is in this manner that we demonstrate that indivisibles are not of the same species as numbers. Henee it arises that two units may indeed make a number, because they are of the same kind; and that two indivisibles do not make an extension, because they are not of the same kind.

Hence we see how little reason there is in comparing the relation that exists between unity and numbers with that which exists between indivisibles and extension.

But if we wish to take in numbers a comparison that represents with accuracy what we are considering in extension, this must be the relation of zero to numbers; for zero is not of the same kind as numbers, since, being multiplied, it cannot exceed them: so that it is the true indivisibility of number, as indivisibility is the true zero of extension. And a like one will be found between rest and motion, and betwcen an in. stant and time; for all these things are heterogeneous in their magnitudes, since being infinitely multiplied, they can never make any thing else than indivisibles, any more than the indivisibles of extension, and for the same reason. And then we shall find a perfect correspondence between these things; for 
- all these magnitudes are divisible ad infinitum, without ever falling into their indivisibles, so that they all hold a middle place between infinity and nothingness.

Such is the admirable relation that nature has established between these things, and the two marvellous infinities which she has proposed to mankind, not to comprehend, but to admire; and to finish the consideration of this by a last remark, I will add that these two infinites, although infinitely different, are notwithstanding relative to each other, in such a manner that the knowledge of the one leads necessarily to the knowl. edge of the other.

For in numbers, inasmuch as they can be continually augmented, it absolutely follows that they can be continually diminished, and this clearly; for if a number can be multiplied to 100,000, for example, 100,000th part can also be taken from it, by dividing it by the same number by which it is multiplied; and thus every term of augmentation will become a term of division, by changing the whole into a fraction. So that infinite augmentation also includes necessarily infinite division.

And in space the same relation is seen between these two contrary infinites; that is, that inasmuch as a space can be infinitely prolonged, it follows that it may be infinitely diminished, as appears in this example: If we look through a glass at a vessel that recedes continually in a straight line, it is evident that any point of the vessel observed will continually advance by a perpetual flow in proportion as the ship recedes. Therefore if the course of the vessel is extended ad infinitum, this point will continually recede; and yet it will never reach that point in which the horizontal ray carried from the eye to the glass shall fall, so that it will constantly approach it without ever reaching it, unceasingly dividing the space which will remain under this horizontal point without ever arriving at it. From which is seen the necessary conclusion that is drawn from the infinity of the extension of the course of the vessel to the infinite and infinitely minute division of this little space remainitig beneath this horizontal point. 
Those who will not be satisfied with these reasons, and will persist in the belief that space is not divisible ad infinitum, can make no pretensions to geometrical demonstrations, and although they may be enlightened in other things, they will be very little in this; for one can easily be a very capable man and a bad geometrician.

But those who clearly perceive these truths will be able to admire the grandeur and power of nature in this double infinity that surrounds us on all sides, and to learn by this marvellous consideration to know themselves, in regarding themselves thus placed between infinitude and a negation of extension, between an infinitude and a negation of number, between an infinitude and a negation of movement, between an infinitude and a negation of time. From which we may learn to estimate ourselves at our true value, and to form reflections which will be worth more than all the rest of geometry itself.

I have thought myself obliged to enter into this long discussion for the benefit of those who, not comprehending at first this double infinity, are capable of being persuaded of it. And although there may be many who have suffieient enlightenment to dispense with it, it may nevertheless happen that this discourse which will be necessary to the one will not be entirely useless to the other.

\section{PREFACE TO THE TREATISE ON VACUUM.'}

THE respect that we bear to antiquity is at the present day carried to such a point on subjects in which it ought to have

1 Published for the first time by Bossut, who entitled it, we know not why: De l'autorité en matière de philosophie. This piece, says M. Cousin, seems a fragment of the Discours de ha Héthode, so deeply is it penetrated with the spirit of Descartes. It turns on the essential Cartesian distinetion between philosophy and theology, in the one of which authority is admissible, sinee it admits of no innovations; in the other of which authority is a misconecption, sinee it sees perpetual discoveries. . . . Later, and in the 
less weight, that oracles are made of all its thoughts and mysteries, even of its obscurities; that novelties can no longer be advanced without peril, and that the text of an author suffices to destroy the strongest reasons $1 . \ldots \ldots \ldots \ldots \ldots \ldots .$.

Not that it is my intention to correct one error by another, and not to esteem the ancients at all because others have esteemed them too much.

I do not pretend to banish their authority in order to exalt reasoning alone, although others have sought to establish their authority alone to the prejudice of reasoning ${ }^{2} \ldots \ldots \ldots \ldots$.

Thoughts, Pascal treats neither Descartes nor philosophy with this respect. I suspect that this fragment belongs to that epoch in which Pascal was wholly occupied with the sciences, about the time of the letter to M. le Pailleur, sur le vide, of that to M. Ribeyre, letters which are of the years 1647 and 1651. These are the same prineiples and the same tone, at once grave and animated. This little treatise therefore is not in onr manuscript. It was published first by Bossut, who does not say from what he had taken it.

Bossut had subjected the text to numerous alterations, necessitated in some sort by the arbitrary title that he had adopted, and, besides, had not mdicated the manuscript from which he had made the publication. M. Fangère has restored the text and title in conformity with the manuscript of Father Guerrier.

"It is nothing less," says M. Faugère, "than a preface to a Treatise on Vacuum. It appears that this latter work exists no longer; at least it has not been discovered, and Pascal may never have put the finishing touch to it. M. Périer thus refers to it in the notice preceding the narrative republished by him in 1663 of the celebrated experiment of the Puy-de-Dôme: 'The treatise that is mentioned in several passages of this relation is a great treatise composed by M. Paseal respecting Vacnum, which has been lost, and of which only the few fragments here produced have been discovered.' The fragments mentioned by $\mathrm{M}$. Périer are printed at the end of the 'Traité sur l'Equilibre des liqueurs et la pesanteur de l'air. We havo found another very short fragment in the MS. antograph of the Thoights. $\Lambda$ s to the epoch in which the Treatise on Vacuum was composed, we see in two letters of Pascal, the one to M. Périer concerning the experiment of the Puy-de-Dome, and the other to M. de Ribeyre, that he had already corrmeneed the work is 1647 , and was engaged in its completion in 1851. The preface must have been written in this interval, and probably towards 1651."

We republish here the excellent text of $M$. Fangère.

2 There is a blank here of about ten lines.-Note by Father Guerrier.

2 Break of two limes.-1bia. 
To make this important distinction with care, it is necessary to consider that the former depend solely on memory and are purely historical, having nothing for their object except to know what the authors have written; the latter depend solely on reasoning and are entirely dogmatic, having for their object to seek and discover concealed truths.

Those of the former kind are limited, inasmuch as the books in which they are contained ${ }^{1} \ldots \ldots \ldots \ldots \ldots \ldots \ldots \ldots$

It is according to this distinction that we must regulate differently the extent of this respect. The respect that we shonld

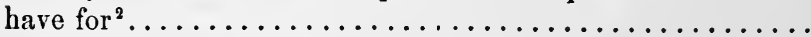

In matters in which we only seek to know what the authors have written, as in history, geography, jurisprudence, languages, ${ }^{3}$ and especially in theology ; and in fine in all those which have for their principle either simple facts or divine or human institutions, we must necessarily have reconrse to their books, since all that we can know of them is therein contained; hence it is evident that we can have full knowledge of them, and that it is not possible to add any thing thereto.

If it is in question to know who was the first king of the French; in what spot geographers place the first meridian; what words are used in a dead language, and all things of this nature; what other means than books can guide us to them? And who can add any thing new to what they teach us, since we wish only to know what they contain?

Authority alone can enlighten us on these. But the subject in which authority has the principal weight is theology, because there she is inseparable from truth, and we know it only through her: so that to give full certainty to matters incomprehensible to reason, it suffices to show them in the sacred books; as to show the uncertainty of the most probable things, it is only necessary to show that they are not included

1 A break.-Faugère.

2 Two lines.--Note by Father Guerrier.

- After the word languages, there is a break of a word or two.-Faugena 
therein; since its principles are superior to nature and reason, and since, the mind of man being too weak to attain them by its own eflorts, he cannot reach these lofty conceptions if he be not carried thither by an omnipotent and superhuman power.

It is not the same with subjects that fall under the senses and under reasoning; authority here is useless; it belongs to reason alone to know them. They have their separate rights : there the one has all the advantage, here the other reigns in turn. But as subjects of this kind are proportioned to the grasp of the mind, it finds full liberty to extend them; its inexhaustible fertility produces continually, and its inventions may be multiplied altogether without limit and without inter-

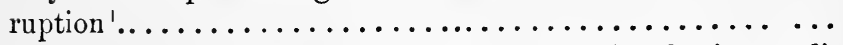

It is thus that geometry, arithmetic,-music, physics, medieine, architecture, and all the sciences that are subject to experiment and reasoning, should be augmented in order to become perfect. The ancients found them merely outlined by those who preceded them; and we shall leave them to those who will come after us in a more finished state than we received them.

As their perfection depends on time and pains, it is evident that although our pains and time may have acquired less than their labors separate from ours, both joined together must nevertheless have more effect than each one alone.

The clearing up of this difference should make us pity the blindness of those who bring authority alone as proof in physical matters, instead of reasoning or experiments; and inspire us with horror for the wickedness of others who make use of reasoning alone in theology, instead of the authority of the Scripture and the Fathers. We must raise the courage ot those timid people who dare invent nothing in physics, and confound the insolence of those rash persons who produce novelties in theology. Nevertheless the misfortune of the age is such, that we see many new opinions in theology, unknown

1 A break. 
to all antiquity, maintained with obstinacy and received with ap. plause; whilst those that are produced in physies, though small in number, should, it seems, be convicted of falsehood as soon as they shock already received opinions in the slightest degree; as if the respect that we have for the ancient philosophers were a duty, and that which we bear to the most ancient of the Fathers solely a matter of courtesy! I leave it to judi. cious persons to remark the importance of this abuse which perverts the order of the sciences with so much injustice; and I think that there will be few who will not wish that this liberty' might be applied to other matters, since new inventions are infallible errors in the matters ${ }^{2}$ which we profane with impunity; and since they are absolutely necessary for the perfection of so many other subjects incomparably lower, which nevertheless we dare not approach.

Let us divide our credulity and suspicion with more justice, and limit this respect we have for the ancients. As reason gives it birth, she ought also to measure it; and let us consider that if they had continued in this restraint of not daring to add any thing to the knowledge which they had received, or if those of their times had made the like difficulty in receiving the novelties which they offered them, they would have deprived themselves and their posterity of the fruit of their inventions.

As they only made use of that which had been bequeathed to them as a means whereby to gain more, and as this happy daring opened to them the way to great things, we should take that which they acquired in the same manner, and by their example, make of it the means and not the end of our study, and thus strive while imitating to surpass them.

For what is more unjust than to treat our ancestors with more deference than they showed to those who preceded them, and to have for them that inviolable respect which

1 The word here underlined, which we restore by conjecture, is blant is the MS.-Fungère.

2 Utere seems to be needed theological matters.-13id. 
they have only merited from us because they had not the like for those who possessed the same advantage over them ${ }^{1}{ }^{1} . .$.

The secrets of nature are concealed; although she is continually working, we do not always discover her effects: time reveals them from age to age, and although always alike in herself she is not always alike known.

The experiments that give us the knowledge of these secrets are multiplied continually; and as they are the sole principles of physies, the consequences are multiplied in proportion.

It is in this manner that we may at the present day adopt different sentiments and new opinions, without despising the ancients and ${ }^{2}$ without ingratitude, since the first knowledge which they have given us has served as a stepping-stone to our own, and since in these advantages we are indebted to them for our ascendency over them; because being raised by their aid to a certain degree, the slightest effort causes us to mount still higher, and with less pains and less glory we find ourselves above them. Thence it is that we are enabled to discover things which it was impossible for them to perceive. Our view is more extended, and although they knew as well as we all that they could observe in nature, they did not, nevertheless, know it so well, and we see more than they.

Yet it is marvellous in what manner their sentiments are revered. It is made a crime to contradict them and an act of treason to add to them, as though they had left no more truths to be known.

Is not this to treat unworthily the reason of man and to put it on a level with the instinct of animals, since we take away the principal difference between them, which is that the effects of reason accumulate without ceasing, whilst instinct remains always in the same state? The cells of the bees were as correctly measured a thousand years ago as to-day, and each formed a hexagon as exactly the first time as the last. It is

1 Break of five or six lines.-Note by Father Guerrier.

2 Rreak of two or three words in the MS. We supply them by the words underlined. - Faugère. 
the same with all that the animals produce by this occult impulse. Nature instructs them in proportion as necessity impels them; but this fragile science is lost with the wants which give it birth : as they received it without study, they have not the happiness of preserving it; and every time it is given them it is new to them, since the ${ }^{1} \ldots$ nature having for her object nothing but the maintenance of animals in a limited order of perfection, she inspires them with this necessary science ${ }^{2}$.... always the same, lest they may fall into decay, and does not permit them to add to it, lest they should exceed the limits that she has prescribed to them. It is not the same with man, who is formed only for infinity. He is ignorant at the earliest age of his life; but he is instructed unceasingly in his progress; for he derives advantage, not only from his own experience, but also from that of his predecessors; since he always retains in his memory the knowledge which he himself has once acquired, and since he has that of the ancients ever present in the books which they have bequeathed to him. And as he preserves this knowledge, he can also add to it easily; so that men are at the present day in some sort in the same condition in which those ancient philosophers would have been found, could they have survived till the present time, adding to the knowledge which they possessed that which their studies would have acquired by the aid of so many centuries. Thence it is that by an especial prerogative, not only does each man advance from day to day in the sciences, but all mankind together make continual progress in proportion as the world grows older, since the same thing happens in the succession of men as in the different ages of single individuals. So that the whole succession of men, during the course of many ages, should be considered as a single man who subsists forever and learns continually, whence we see with what injustice we respect antiquity in philosophers; for as old age is that period of life most remote from infancy, who does not see that old age in this universal

1 Here is a word omitted.-Faugìre.

I Ibid. 
man ought not to be sought in the times nearest his birth, but in those the most remote from it? Those whom we eall ancient were really new in all things, and properly constitute.l the infancy of mankind; and as we have joined to their knowledge the experience of the centuries which have followed them, it is in ourselves that we should find this antiquity that we revere in others.

They should be admired for the results which they derived from the very few principles they possessed, and they should be excused for those in which they failed rather from the lack of the advantage of experience than the strength of reasoning.

For were they not excusable in the idea that they entertained of the milky way, when, the weakness of their vision not having yet received the assistance of art, they attributed this color to a greater density in that part of the heavens which reflected the light more strongly? But would we not be inexcusable ior remaining in the same opinion, now that, by the aid of the advantages procured us by the telescope, we have discovered in it an infinite number of small stars, whose more abundant splendor has revealed to us the true cause of this whiteness?

Had they not also eause for saying that all corruptible bodies were inclosed within the orbit of the moon, when, during the course of so many ages they had not yet remarked either corruption or generation outside of this space?

But ought we not to be assured of the contrary, when the whole world has manifestly beheld comets kindle ${ }^{\prime}$ and disapi ear far beyond the limits of that sphere?

In the same way, in respect to vacuum, they had a right to say that nature would not suffer it, since all their experiments had always made them remark that she abhorred, and could not suffer it.

But if the modern experiments had been known to them, perhaps they would have found cause for affirming what they found cause for denying, for the reason that racuum had not

1 The true nature of comets was still unknown in the time of Pascal.-. Nots in Bossut's edition. 
yet appeared. Thus, in the judgment they formed that nature would not suffer vacuum, they only heard nature spoken of in the condition in which they knew her; since, to speak in general terms, it would not have been sufficient to have seen it constantly in a hundred cases, a thousand, or any other number, however great it may have been; since, if a singre case remained unexamined, this alone would suffice to prevent the general definition, and if a single one was contrary, this

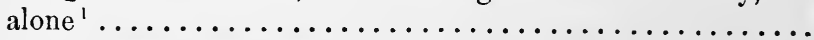

For in all matters the proof of which consists in experiments, and not in demonstrations, we can make no universal assertion, except by the general enumeration of all the parts and all the different cases. Thus it is that when we say that the diamond is the bardest of all bodies, we mean of all the bodies with which we are acquainted, and we neither can nor ought to comprehend in this assertion those with which we are not acquainted; and when we say that gold is the heaviest of all bodies, we should be presumptuous to comprehend in this general proposition those which have not yet come to our knowledge, although it is not impossible that they may exist in nature.

In the same manner, when the ancients affirmed that nature would not suffer a vacuum, they meant that she would not suffer it in any of the experiments they had seen, and they could not, without temerity, comprehend in it those which had not come to their knowledge. Had they done so, they would doubtless have drawn from them the same conclusions, and would, by their acknowledgment, have sanctioned them by this antiquity which it is sought at present to make the sole principle of the sciences.

Thus it is that, without contradicting them, we can affirm the contrary of what they say; and, whatever authority, in ine, this antiquity may have, truth should always have more, although newly discovered, since she is always older than all the opinions that we have had of her, and it would be show-

1 Two lines.-Note by Father Guerrier. 
ing ourselves ignorant of her nature to imagine that she may have begun to be at the time when she began to be known.

\section{NEW FRAGMENT OF THE TREATISE ON VACUUM.}

WIIAT is there more absurd than to say that inanimate bodies have passions, fears, horrors; that insensible bodies, without life, and even incapable of it, may have passions which presuppose a soul at least sensitive to experience them? Besides, if the object of this horror were a vacuum, what is there in a vacuum that could make them afraid? What is there meaner and more ridiculous?

This is not all; if they have in themselves a principle of motion to shun a vacuum, have they arms, legs, muscles, nerves? 





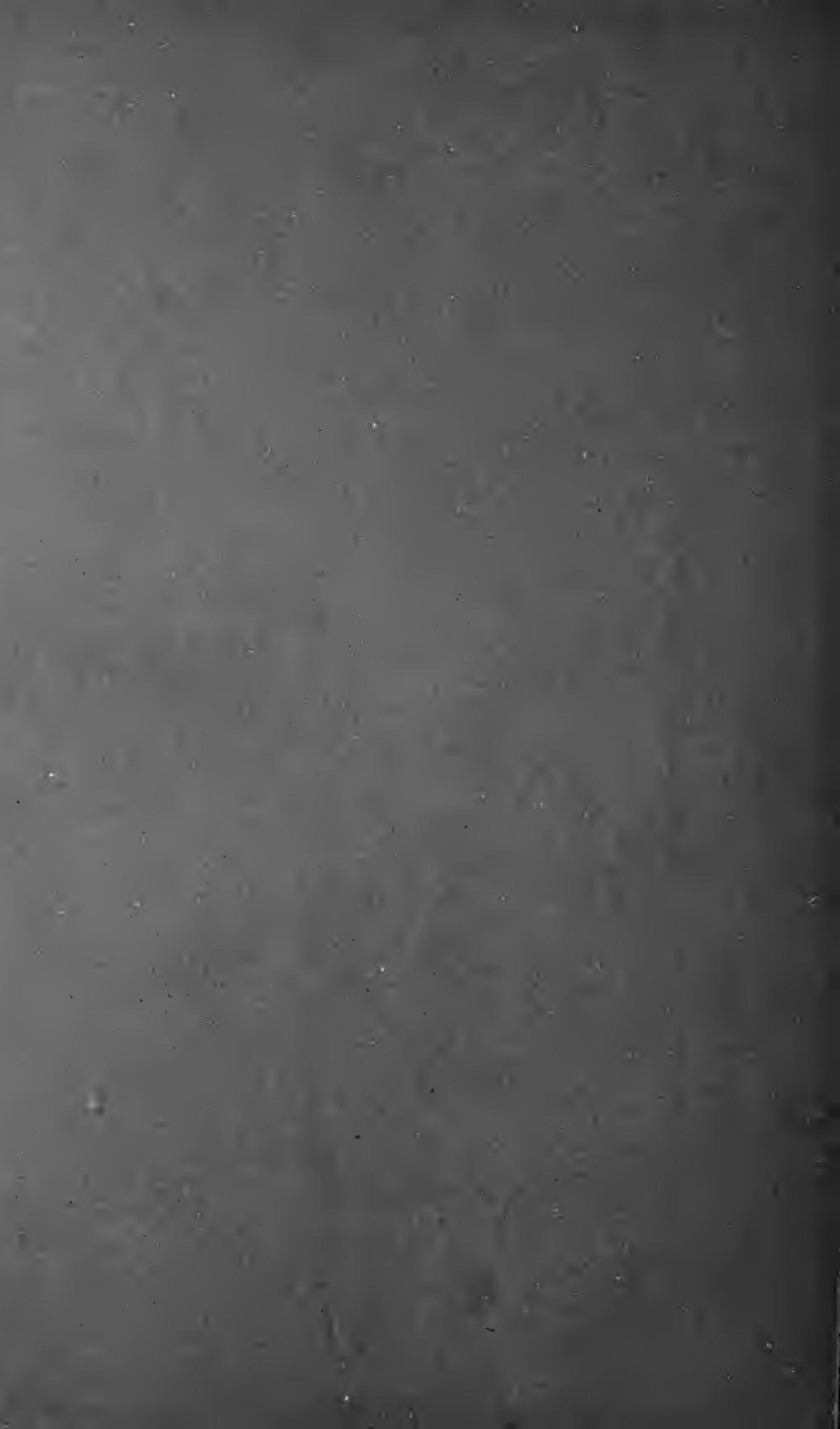


f

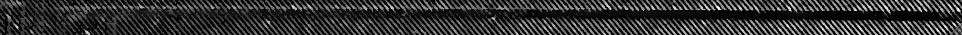

